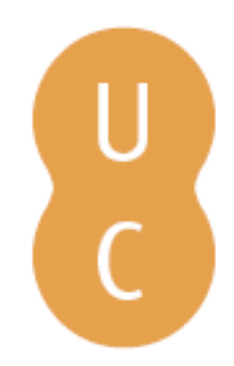

\title{
pompalina
}

\section{The lyric metres of euripidean drama}

Autor(es): Lourenço, Frederico

Publicado por: Centro de Estudos Clássicos e Humanísticos; Imprensa da Universidade de Coimbra

URL

persistente: URI:http://hdl.handle.net/10316.2/2358

DOI: $\quad$ DOI:http://dx.doi.org/10.14195/978-989-721-002-0

Accessed : $\quad$ 26-Apr-2023 16:35:30

A navegação consulta e descarregamento dos títulos inseridos nas Bibliotecas Digitais UC Digitalis, UC Pombalina e UC Impactum, pressupõem a aceitação plena e sem reservas dos Termos e Condições de Uso destas Bibliotecas Digitais, disponíveis em https://digitalis.uc.pt/pt-pt/termos.

Conforme exposto nos referidos Termos e Condições de Uso, o descarregamento de títulos de acesso restrito requer uma licença válida de autorização devendo o utilizador aceder ao(s) documento(s) a partir de um endereço de IP da instituição detentora da supramencionada licença.

Ao utilizador é apenas permitido o descarregamento para uso pessoal, pelo que o emprego do(s) título(s) descarregado(s) para outro fim, designadamente comercial, carece de autorização do respetivo autor ou editor da obra.

Na medida em que todas as obras da UC Digitalis se encontram protegidas pelo Código do Direito de Autor e Direitos Conexos e demais legislação aplicável, toda a cópia, parcial ou total, deste documento, nos casos em que é legalmente admitida, deverá conter ou fazer-se acompanhar por este aviso.

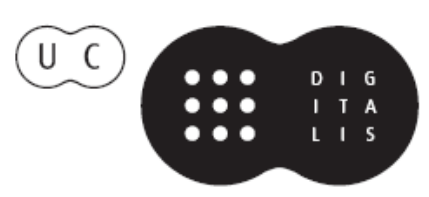




\title{
The Lyric Metres of Euripidean Drama
}

\author{
Frederico Lourenço
}




\section{The Lyric Metres of Euripidean Drama}

Frederico Lourenço 
Each volume in this series is first submitted to a panel of independent referees.

\section{Author}

Frederico Lourenço

Tithe

The Lyric Metres of Euripidean Drama

Publisher

Centro de Estudos Clássicos e Humanísticos da Universidade de Coimbra (1 $\left.1^{\text {st ed. }} / 2011\right)$

Academic Co-ordinator

Maria do Céu Fialho

EDITORIAL BOARD

José Ribeiro Ferreira, Maria de Fátima Silva, Francisco de Oliveira and Nair Castro Soares

Technical Director of the Collection

Delfim F. Leão

DESIGN

Rodolfo Lopes, Nelson Ferreira

\section{PRINTED BY}

Simões \& Linhares, Lda. Av. Fernando Namora, n. ${ }^{o} 83$ Loja 4. 3000 Coimbra

ISBN: 978-989-721-001-3

Digital ISBN: 978-989-721-002-0

DOI: http://dx.doi.org/10.14195/978-989-721-002-0

Legal Deposit: $337871 / 11$

๑ IMPRENSA DA UNIVERISDADE DE COIMBRA

CCentro de Estudos Clássicos e Humanísticos da Universidade de Coimbra

(C) Classica Digitalia Vniversitatis Conimbrigensis (http://classicadigitalia.uc.pt)

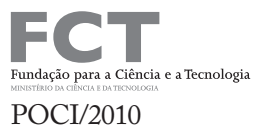

All rights reserved. No part of this publication may be reproduced, stored in a retrieval system, or transmitted, in any form or by any means, electronic, photocopying, or otherwise, without the written permission of the publisher, except for educational purposes, namely e-learning environments. 


\section{Contents}

$\begin{array}{ll}\text { PrefaCe } & 9\end{array}$

Metrical Symbols

Abbreviations and References 16

Part I. Euripides' Use of Lyric Metre 17

$\begin{array}{ll}\text { 1. Introduction } & 19\end{array}$

1.1. Phrasing 20

$\begin{array}{ll}\text { 1.2. Lyric metre and dramatic effect } & 30\end{array}$

1.3. Note on Rhesus and Iphigenia at Aulis $\quad 33$

2. Trochaic $\quad 35$

2.1. Trochaic dimeter $\quad 36$

$\begin{array}{ll}\text { 2.2. Syncopated dimeters } & 38\end{array}$

$\begin{array}{ll}\text { 2.3. Lecythion } & 40\end{array}$

2.4. Longer trochaic cola 43

3. Anapaestic 45

3.1. Anapaestic monometer 48

3.2. Anapaestic dimeter $\quad 49$

3.3. Paroemiac $\quad 50$

4. Dochmiac 53

4.1. Brevis in longo and hiatus 58

4.2. Split resolution $\quad 58$

4.3. Word-end after long anceps $\quad 58$

$\begin{array}{ll}\text { 4.4. Admixture of iambic metra } & 59\end{array}$

$\begin{array}{lr}\text { 4.5. Syncopation } & 59\end{array}$

4.6. Repertory of Euripidean dochmiacs $\quad 60$

4.6.1. With short ancipitia $\quad 60$

$\begin{array}{ll}\text { 4.6.2. With long first anceps } & 61\end{array}$

4.6.3. With long ancipitia $\quad 62$

4.6.4. With long second anceps $\quad 63$

4.6.5. Hypodochmiac $\quad 63$

4.6.6. Kaibelianus $\quad 64$

5. Dactylic $\quad 65$

5.1. Hexameter $\quad 66$

5.2. Pentameter $\quad 66$

$\begin{array}{ll}\text { 5.3. Tetrameter } & 67\end{array}$

$\begin{array}{lr}\text { 5.4. Dimeter } & 69\end{array}$

5.5. Andromache's elegiacs $\quad 69$

6. Enoplian 71

6.1.'D' 71

6.1.1. 'Dx' $\quad 72$

6.1.2. 'xD' 
6.1.3. ' $\mathrm{xDx}$ ' (erasmonidean) $\quad 73$

6.1.4. 'sp + D' 73

6.1.5. ' $-\mathrm{D}+\mathrm{ba} \quad 73$

6.1.6. 'D + ba' $\quad 73$

6.1.7. 'ba + D $\cup>73$

6.1.8. 'D + cr' $\quad 73$

6.1.9. 'x D + sp' $\quad 74$

6.2. Praxillean $\quad 74$

6.3. Cyrenaic $\quad 74$

6.4. Diomedean $\quad 75$

6.5. Alcaic decasyllable $\quad 75$

6.6. 'T'

6.7. 'A' 76

6.8. Enoplian paroemiac $\quad 77$

6.9. Ibycean $\quad 77$

6.10. Hagesichorean 78

6.11. Rarer enoplian cola $\quad 78$

$\begin{array}{ll}\text { 6.11.1. Cola beginning with double short } & 78\end{array}$

6.11.2. Cola beginning with single short 78

6.11.3. Cola beginning in dactylic movement 79

6.11.4. Cola beginning ' $-\smile \cup \cup-\ldots$ '

6.12. Enoplian dicola $\quad 79$

7. Dactylo-epitrite 81

7.1. Phrases beginning with 'D...'

7.2. Phrases beginning with 'x D'

$\begin{array}{ll}\text { 7.3. Phrases beginning with 'e...' } & 83\end{array}$

$\begin{array}{ll}\text { 7.4. Phrases beginning with ' } \mathrm{x} \text { e...' } & 84\end{array}$

7.5. Phrases beginning with '- d...' 85

7.6. Cola with iambic constituent elements $\quad 85$

7.7. Cola with enoplian constituent elements $\quad 85$

8. Ionic $\quad 87$

8.1. Lengths consisting of full ionic metra $\quad 87$

$\begin{array}{lr}\text { 8.2. Syncopated lengths } & 88\end{array}$

$\begin{array}{lr}\text { 8.3. Anacreontic } & 88\end{array}$

8.4. Lengths with 'iambic' prefixes $\quad 89$

9. Aeolic 91

9.1. Glyconic $\quad 91$

9.2. Pherecratean $\quad 95$

9.3. Telesillean $\quad 96$

9.4. Hipponactean 98

9.5. Hagesichorean 100

9.6. Pendent aeolic octosyllable 102

$\begin{array}{ll}\text { 9.7. Ibycean } & 102\end{array}$

$\begin{array}{ll}\text { 9.8. Dodrans } & 104\end{array}$

9.9. Aristophanean 105

$\begin{array}{ll}\text { 9.10. Reizianum } & 107\end{array}$

9.11. Adonean 108

9.12. Wilamowitzian 108 
9.13. Heptasyllable $\quad 110$

9.14. Hexasyllable 111

9.15. Aeolic compounds 111

$\begin{array}{ll}\text { 9.16. Choriambic cola } & 114\end{array}$

9.17. Iambo-choriambic phrases $\quad 115$

10. Repertory of Iambic Cola 117

$\begin{array}{ll}\text { 10.1. Iambic monometers } & 117\end{array}$

10.2. Iambic Dimeters $\quad 118$

10.3. Lyric Trimeters 123

10.4. Longer cola 128

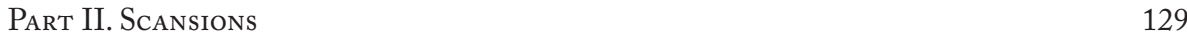

Cyclops 133

$\begin{array}{ll}\text { Alcestis } & 137\end{array}$

$\begin{array}{lr}\text { Medea } & 147\end{array}$

$\begin{array}{lr}\text { Heraclidae } & 155\end{array}$

Hippolytus 161

Andromache $\quad 173$

$\begin{array}{lr}\text { Hecuba } & 183\end{array}$

Supplices 193

Electra 203

Heracles $\quad 215$

$\begin{array}{lr}\text { Troades } & 229\end{array}$

$\begin{array}{ll}\text { Iphigenia in Tauris } & 247\end{array}$

$\begin{array}{ll}\text { Ion } & 259\end{array}$

$\begin{array}{ll}\text { Helena } & 275\end{array}$

$\begin{array}{ll}\text { Phoenissae } & 289\end{array}$

$\begin{array}{ll}\text { Orestes } & 307\end{array}$

Bacchae $\quad 321$

Iphigenia in Aulide $\quad 335$

$\begin{array}{ll}\text { Rhesus } & 349\end{array}$

$\begin{array}{ll}\text { Phaethon } & 357\end{array}$

$\begin{array}{ll}\text { Hypsipyle } & 361\end{array}$

Cresphontes $\quad 365$

Erechtheus 366

$\begin{array}{ll}\text { Telephus } & 367\end{array}$

$\begin{array}{ll}\text { BiBLIOGRAPHY } & 369\end{array}$

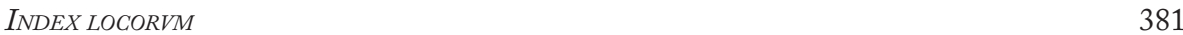

$\begin{array}{ll}\text { INDEX RERVM } & 447\end{array}$ 


\section{Preface}

This book is the first complete survey to appear in print in more than a hundred years and the first ever to be published in English (or any modern language, for that matter) of Euripides' metrical practice in the songs of all his extant plays and longer lyric fragments. Schroeder's Euripidis Cantica was long overdue for an update, not least because Euripidean (and indeed metrical) studies have changed beyond all recognition since 1910. The following names speak for themselves: Barrett, Dale, Diggle, Itsumi, Kannicht, Kovacs, Mastronarde, Matthiessen, Parker, West and Willink. The aim of the present book is to build on these scholars' contributions to Euripidean studies and offer students of Greek tragedy a handy Nachschlagewerk based on what will unquestionably remain, for a long time to come, the standard edition of Euripides: James Diggle’s Oxford Classical Text.

In attempting to understand the metre of Greek tragic lyric we are immediately faced with a number of difficult problems. On p. 1 of her enduringly valuable Lyric Metres of Greek Drama, A. M. Dale wrote that 'choral lyric was so elaborate and delicate a structure that even among the Greeks comprehension waned simultaneously with the art of composition.' Perhaps the main problem presented by the lyrics of Greek drama - other than the fact that the text is garbled in so many places - is that the work of dividing into cola what had previously been written out as prose was undertaken during the Hellenistic period, at a time when the decline in comprehension had already set in. Today's supreme authority on Greek metre puts it very clearly: 'the study of traditional colometries has so far failed to support the idea that because the Alexandrians were so much closer in time to the date of composition they 
necessarily possessed crucial knowledge that we do not. The evidence points rather in the opposite direction' (Parker 1997: 95; see further Parker 2001, Itsumi 2007 and Battezzato's ideally balanced account of the problems in Battezzato 2008 and 2009b: 14-18).

This leaves us with a dilemma. On the one hand, every Greek scholar today would agree (I hope) that it would be pointless to return to the original pre-Hellenistic format and simply print the lyrics of tragedy or comedy as prose: for 'colometry' (whatever its faults) does help the reader understand the rhythm of what (s)he is reading. Parker herself, in her edition of Alcestis (2007), neither prints the lyrics as prose nor in Boeckh-style Pindaric periods, but continues to divide them into cola. Finglass's innovative colometry in his brilliant Cambridge editions of Sophocles' Electra (2007) and Ajax (2011) is colometry none the less. But on the other hand, acceptance that the stasima and other lyrics of tragedy are best read $\kappa \varepsilon \kappa \omega \lambda \iota c \mu \varepsilon ́ v \alpha$ raises the uexata quaestio: 'what is a colon?'

For the purpose of this book, 'colon' is defined quite simply as anything that is printed as a lyric line in West's Aeschylus, Lloyd-Jones and Wilson's Sophocles, Diggle's Euripides and Wilson's Aristophanes, because the basic rule of my study was to observe, describe and interpret (uncoloured by any axe-grinding of my own) the very same phenomena that present themselves to any other reader of the standard editions of Greek drama. But that, of course, does not answer the question. What is a colon?

Admittedly, an answer that would allow consensus of opinion is difficult to find. But some things seem certain. For instance a 'glyconic' (whatever Euripides himself might have named it) is indoubtedly a real colon, because even when there is a sequence of two or three of them and even when one or more of them overlap into the following line it is a clearly defined length: oo $-\cup \cup-\cup-$. The same applies to several other cola, which (apart from the issue of how best to name or classify them) are indisputably real lengths. But in identifying and labelling cola in strings of repeated metra (anapaests, dochmiacs, etc.), there is good reason to be sceptical of 'cola' created by the traditional divisions. If we must carry on using labels such as ' $2 \delta$ ' or ' 2 an', it is best to make it clear at the outset that they are only shorthand for ' $\delta \delta$ ' or 'an an': there is probably no such thing as dochmiac or anapaestic 'dimeters' (see West 1977).

With regard to notation and terminology, in notating nameless cola I have refrained from introducing coinages of my own and have instead culled what seemed most useful from Maas' 'D/e' and Dale's 'ds'. Generally, I have been happy to call cola by their familiar names, taking comfort in Dale's words: 'with all the defects of the received terminology, it is both practical and desirable to use it...' (1969: 45). Past attempts to ban traditional nomenclature have not 
really advanced the subject, perhaps because the names we use to distinguish individual cola, being merely agreed labels attached to certain lines for the sake of convenience, are not in themselves 'the problem'. When all is said and done, whether we call 'oo $-\mathrm{x}-\cup \cup-$ ' a 'wilamowitzian', a 'polyschematist' or an 'anaclastic glyconic' is immaterial (although we can and should decline to follow Wilamowitz himself in calling it a 'choriambic dimeter', for the simple reason that it is not a dimeter consisting of two choriambs). The only thing we can be sure of is that Euripides would have called it something quite different - if, indeed, anything at all.

I have also tried my best not to appear overly assertive in presenting my views and have engaged as little as possible in refutation, 'correction' and overtrumping of other writers on Greek metre, because I have come to find the habit increasingly annoying in reading the work of others. Greek lyric metre is too uncertain a field of study for any scholar to presume to 'know best'; for my part, after grappling with the problems of Euripidean lyric metre for almost twenty years, I can honestly say that the greatest pleasure I have found in studying this endlessly fascinating subject is learning from others.

Books on Greek metre tend not to be very long - Snell's Griechische Metrik needed only 76 pages to change the course of metrical studies - but they do take a long time to write. During the drawn-out process of writing this one, I am honoured to have benefited enormously from the advice and criticism of three formidable metricians. Professor James Diggle, Dr L. P. E. Parker and the late C. W. Willink were kind enough to take an interest in my work, read earlier drafts and comment on them. Sir Charles Willink regularly kept me abreast of his thought-provoking opinions (and startling recantations of former opinions) on the text and metre of tragic lyric; although my own approach to the metrical problems of Euripidean lyric was perhaps too cautious for his taste, he was always happy to provide feedback and helpful suggestions. I am most particularly grateful to Dr Laetitia Parker (whose superlative publications on Greek metre have been my guiding light all along) for having taken the trouble to read my work at an earlier stage and for sending me several pages filled with corrections and proposals for improvement. I cannot thank her enough for her time and generosity. It would be equally difficult to find the right words to thank James Diggle. All this really began because his book Euripidea was sent to me by mistake by Blackwell's Bookshop in 1994; its razor-sharp scholarship made such an impression on me that I abandoned the doctoral thesis I was then preparing on pleasure in Plato and devoted myself to the pleasure of studying tragic lyric instead. James has since given me the benefit of his incomparable knowledge of all things metrical and all things Euripidean (all things Greek, really - not to mention Latin), for which 
I will always thank him; but I also thank him for his immense kindness and hospitality: both he and his wife Sedwell made every visit to Cambridge uniquely memorable.

I wish to make it absolutely clear, however, that my lists, scansions and interpretations are not to be taken as having been 'endorsed' by any of these scholars. Although what good points this book might possess are almost certainly due to their suggested improvements, all shortcomings and errors are mine alone.

At the University of Lisbon (where I taught Greek for twenty years and where part of the material presented here began life as a doctoral thesis), friends and colleagues too numerous to mention one by one helped and encouraged me in many ways. That said, I particularly wish to single out the late Professor Victor Jabouille, whose unstinting support I shall always remember.

In my new academic home, the University of Coimbra (which had already celebrated its seven-hundredth anniversary when I first started making lists of lyric cola), my new colleagues have proved generous providers of excellent advice. Professors Maria de Fátima Sousa e Silva, Maria do Céu Fialho and Delfim Leão did their utmost to turn the idea of this book into tangible reality. For the welcoming friendliness with which I was received in Coimbra, I also wish to thank Professor Maria Helena da Rocha Pereira (doyenne of Greek scholarship in Portugal) and Professors José Ribeiro Ferreira, Francisco de Oliveira, Nair Castro Soares, Carlos André, Carmen Soares, António Rebelo, Margarida Miranda, José Luís Brandão, Carlota Urbano, Luísa de Nazaré Ferreira, Paula Dias, Teresa Schiappa, Susana Pereira, Paulo Sérgio Ferreira, Cláudia Cravo and Carla Gonçalves. I am also very grateful to Sofia Frade and Nuno Jerónimo for the uncomplaining promptness with which they photocopied bibliography in various libraries (in Portugal and in the UK). Finally, a special word of thanks is due to Elisabete Cação and Nelson Ferreira, whose help was invaluable in transmogrifying a thing of the past (piles of printouts from long defunct computers and countless pages of handwritten material) into this wonder of the future: a swish-looking hardback that is at the same time a fully and freely downloadable book. 


\section{Metrical Symbols}

SYMвоLS

\begin{tabular}{|c|c|}
\hline$\cup$ & short syllable \\
\hline — & long syllable \\
\hline $\mathrm{x}$ & anceps \\
\hline$\cup$ & resolved long \\
\hline $\mathrm{oo}$ & aeolic base $(--,-\cup, \cup-, \cup \cup \cup)$ \\
\hline$\cap$ & (syllaba) breuis in (elemento) longo \\
\hline & marks some form of syncopation \\
\hline & colon-end \\
\hline & period-end \\
\hline 1 & period-end marked by hiatus \\
\hline & (hiatus in strophe); $\|^{\mathrm{Ha}}$ (hiatus in antistrophe) \\
\hline$\|^{\mathrm{D}}$ & period-end marked by breuis in longo \\
\hline Bs & (breuis in strophe); $\|\left.\right|^{\mathrm{Ba}}$ (breuis in antistrophe) \\
\hline & end of stanza or lyric sequence \\
\hline & significant word-end \\
\hline & indicates overlap \\
\hline & in responsion with \\
\hline$::$ & change of singer/ speaker \\
\hline e. $\mathrm{m}$. & extra metrum \\
\hline$\otimes$ & beginning of stanza or lyric sequence \\
\hline
\end{tabular}

TYPES OF RHYTHMIC VARLATION

catalexis (cat)

cholosis $(\chi \omega \dot{\lambda} \omega \omega \mathrm{clc}){ }^{\text {(chol) }}$

contraction (contr)

resolution (resol)

syncopation (sync)

\section{TYPES OF METRON}

$\begin{array}{ll}\text { an } & \text { anapaest: } \cup \cup-\cup \cup- \\ \text { ba } & \text { bacchiac: } \cup-- \\ \text { cr } & \text { cretic: }-\cup- \\ \text { ch } & \text { choriamb: }-\cup \cup-\end{array}$




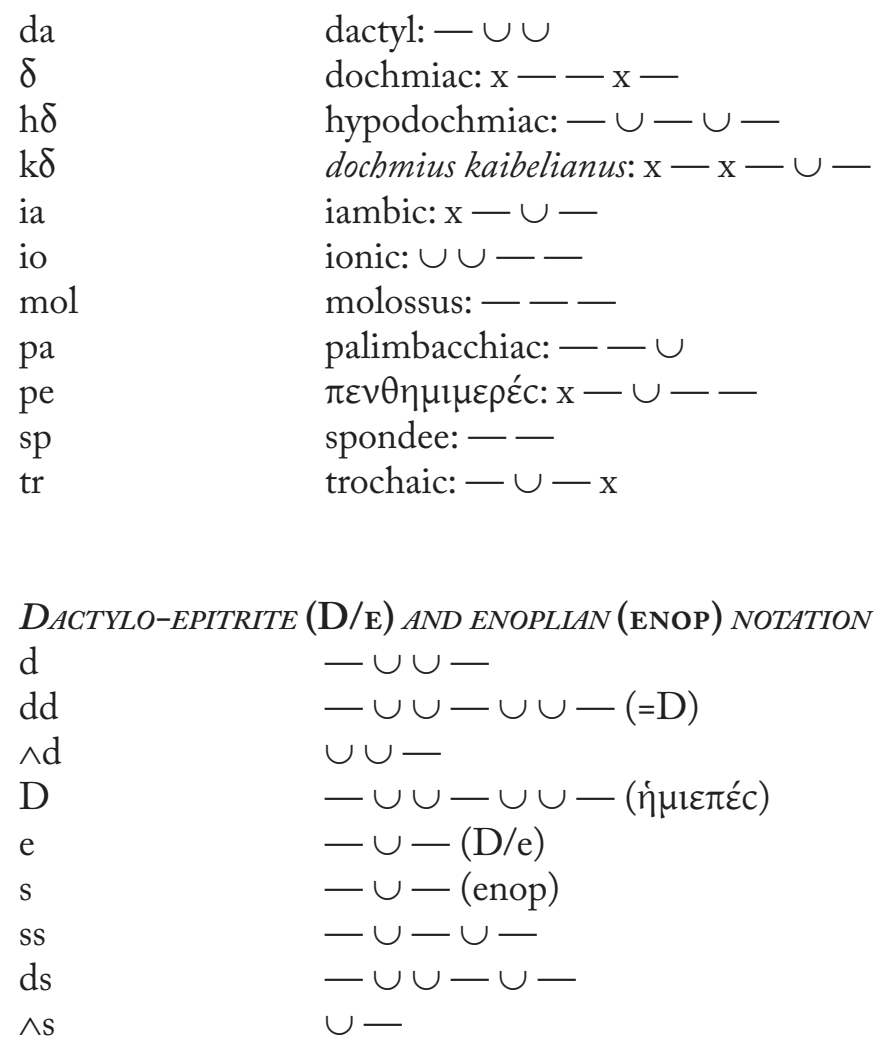

\section{TYPES OF COLON}

$\mathrm{ad}$

anacr

ar

cyren

decasyll

dod

diom

A (enop) enop prm

$\mathrm{T}$ (enop)

erasm

g1

hag

hept

hex

adonean: $-\cup \cup-\longrightarrow$

anacreontic: $\cup \cup-\cup-\cup--$

aristophanean: $-\cup \cup-\cup--$

cyrenaic: $\cup \cup-\cup \cup-\cup-\cup-$

alcaic decasyllable: $-\cup \cup-\cup \cup-\cup--$

dodrans: $-\cup \cup-\cup-$

diomedean: $\cup \cup-\cup \cup-\cup-\mathrm{x}$

$\cup \cup-\cup \cup-\cup \cup-\cup \cup-$ (^dddd)

enoplian paroemiac: $\cup \cup-\cup \cup-\cup \cup-\mathrm{x}$

$\cup \cup-\cup \cup-\cup-(\wedge \mathrm{dds})$

erasmonidean: $\mathrm{x}-\cup \cup-\cup \cup-\mathrm{x}(\mathrm{x}$ D $\mathrm{x})$

glyconic: oo $-\cup \cup-\cup-$

hagesichorean: $\mathrm{x}-\cup \cup-\cup--$

aeolic heptasyllable: $\mathrm{x}-\mathrm{x}-\cup \cup-$

aeolic hexasyllable: oo $-\cup \cup-$ 
hipp

ibyc

ith

$1 \mathrm{k}$

oct

phal

ph

prax

prm

reiz

tel

wil hipponactean: oo $-\cup \cup-\cup--$

ibycean: $-\cup \cup-\cup \cup-\cup-$

ithyphallic: $-\cup-\cup--$

lecythion: $-\cup-\mathrm{x}-\cup-$

pendent aeolic octosyllable: $\mathrm{x}-\mathrm{x}-\cup \cup-$

phalaecian hendecasyllable: oo $-\cup \cup-\cup-\cup--$ pherecratean: oo $-\cup \cup--$

praxillean: $-\cup \cup-\cup \cup-\cup \cup-\cup--$

paroemiac: $\cup \cup-\cup \cup-\cup \cup--$

reizianum: $x-\cup \cup-\longrightarrow$

telesillean: $\mathrm{x}-\cup \cup-\cup-$

wilamowitzian: oo $-\mathrm{x}-\cup \cup-$ 


\section{Abbreviations and References}

$C A=\mathrm{J}$. Powell, Collectanea Alexandrina, Oxford, 1925.

LSJ = H. G. Liddell and R. Scott, A Greek-English Lexicon, revised by Sir Henry Stuart Jones, with a revised supplement, Oxford, 1996.

OCT $=$ Oxford Classical Text(s)

$P C G=$ Poetae Comici Graeci, ed. R. Kassel \& C. Austin, Berlin \& New York, 1983-.

PLF $=$ Poetarum Lesbiorum Fragmenta, ed. E. Lobel \& D. L. Page, Oxford, 1955.

$P M G=$ Poetae Melici Graeci, ed. D. L. Page, Oxford, 1962.

PMGF $=$ Poetarum Melicorum Graecorum Fragmenta, ed. M. Davies, Oxford, 1991.

S. I. G. $^{3}=$ W. Dittenberger, Sylloge Inscriptionum Graecarum, Leipzig, ${ }^{31915-24 .}$

$\operatorname{Tr} G F=$ Tragicorum Graecorum Fragmenta, ed. B. Snell, S. Radt, R. Kannicht, Göttingen, 1971-2004.

TrGFS = Tragicorum Graecorum Fragmenta Selecta, ed. J. Diggle, Oxford, 1998. 
PART I

Euripides' use of LYRIC METRE 


\section{INTRODUCTION}

With its sophistication, dazzling imagery and inexhaustible poetic inventiveness, Euripidean song is arguably the most interesting corpus of lyric poetry that has come down to us written in ancient Greek. Significantly, its beauty was not lost on the poet's ancient readers, who held his songs in the highest regard (even Aristophanes' parodies can be seen as indicative of implicit admiration ${ }^{1}$. There is that famous story, related in Plutarch's Life of Nicias, how knowledge of Euripidean lyric was instrumental in effecting the release from slavery of Greek prisoners in Sicily; how starving soldiers received food and drink in exchange for singing what songs of his they knew; how the Caunians allowed a ship pursued by pirates to harbour in their port after finding out that the men on board were well versed in Euripidean ó'c $\mu \alpha \tau \alpha$ (cf. Plut. Nic. 29.2-3). Whether or not all this is true it would be impossible to say. But the popular appeal of his songs is unquestionably confirmed by papyri containing the remains of Hellenistic anthologies of Euripidean lyrics and references to 'concert performances' of his songs in non-theatrical contexts. ${ }^{2}$ And despite the varying response it may have elicited from classical scholars in the past (disparagement of Euripides' lyrics was at least something the arch-enemies Nietzsche and Wilamowitz could agree $\mathrm{on}^{3}$ ), the fact remains that Euripidean lyric constitutes, after Pindar, our largest extant corpus of ancient Greek lyric poetry. The luxury of being able to cull data from so many plays makes the observation of metrical phenomena in Euripides' lyrics especially rewarding. This alone makes the

\footnotetext{
${ }^{1}$ See Wycherley (1946: 107).
}

${ }^{2}$ Examples of Hellenistic lyric anthologies are the Strasburg papyrus (P. Stras. WG 307, saec. III a. C.), the Leiden papyrus (P. Leid. inv. 510, saec. III a. C.) and the Berlin papyrus which preserves part of the parodos of Phaethon (P. Berol. 9771, saec. III a. C.). As for "concert

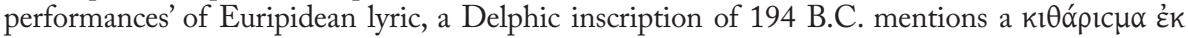

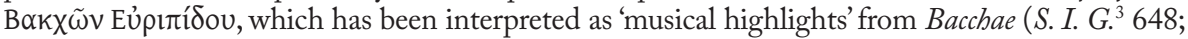
cf. $\operatorname{Tr} G F$, vol. I, p. 19; Pickard-Cambridge ${ }^{2}$ 1968: 287, n. 1; Sifakis 1967: 96). Also, an isthmic inscription of the second century A. D. mentions an actor who won a victory for his rendering of songs from Euripides, Sophocles and Timotheus (in that order: cf. TrGFI DID B 12). The Leiden papyrus referred to above, containing $I A$ 1500-8, 784-93 (in that order), is judged by Comotti (1977: 69-84) to have been the musical score used by a virtuoso singer in concerts of Euripidean lyric; for an invaluable discussion of these papyri, see Prauscello (2006: 123-83).

${ }^{3}$ For Nietzsche, Euripidean lyric was simply 'liederlich' (Die Geburt der Tragödie, § 17). To Wilamowitz, it sometimes seemed 'verkünstelt': see his remarks on Euripidean songs in his edition of Ion (pp. 15, 128). 
corpus a worthwhile field of study, the more so since an added bonus (and advantage in relation to Pindar) is that we are tolerably well informed about the relative dates of his plays; this enables us to observe, albeit in blurred outline, the chronological development of his lyric technique, from Alcestis (438 BC) to Bacchae and Iphigenia at Aulis (his last extant plays).

Metrically speaking, the lyrics of earlier plays such as Alcestis or Andromache are quite different from those of later plays - for instance Helen and Orestes - and even from 'middle period' plays (say Electra or Heracles). Euripides' preference for certain rhythmic patterns changed throughout his career: in his last period, for example, he appears to have lost interest in the complex dactylo-epitrite and enoplian sequences which had played such an important part in earlier plays, whereas aeolo-choriambic and iambic lyric play an ever larger and more sophisticated rôle in his later songs. Late plays such as Helen and Phoenissae also show a new fascination with the lyric possibilities of trochaic composition, a style almost completely absent from the tragedies we know from the period 438-415. The existence of 'early' and 'late' rhythmic features notwithstanding, we should be wary of ascribing too much importance to Euripides' supposed metrical development. The best we can do is take note of a few curious facts: Heraclidae and Andromache contain no anapaests, ${ }^{4}$ Troades practically no aeolo-choriambic and Supplices no dochmiac to speak of; the lyrics of Medea are almost exclusively dactylo-epitrite; Bacchae has the highest incidence of ionic (in keeping with its Dionysiac character and the chorus' oriental identity) and Heracles, a superlative melodrama of great musical sophistication, of 'enoplian dochmiacs'; and, although longer dactylic sequences are a rarity anywhere in Euripides, unexpected examples appear in plays as widely divergent chronologically as Heraclidae and Phoenissae.

\subsection{Phrasing}

An important key to understanding the art of Euripidean lyric is the observation of how large units such as stanzas are divided into periods. This is often a frustratingly difficult endeavour, because tragic stanzas are only

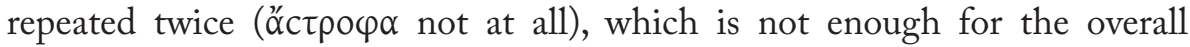
structure to emerge clearly from indications such as hiatus (word ending in vowel or diphthong in contiguous position with word beginning with a vowel or diphthong) and breuis in longo. ${ }^{5}$

\footnotetext{
${ }^{4}$ Hcld. 775 782 is enoplian (see below, p. 77).

${ }^{5}$ We may contrast the many repetitions of the same metrical scheme in Pindar, a fact that enabled Boeckh in the early nineteenth century (Pindari Carmina quae Supersunt [Leipzig, 1811-21]) to lay out Pindar's lyrics in periods, rather than in cola or dicola, as is the case with dramatic lyric. For instance, the very first line of Pindar's first Olympian ode ópictov $\mu \varepsilon \dot{v} v$ ǔ $\delta \omega \rho$,
} 
(Syllaba) breuis in (elemento) longo is a regular feature of Greek lyric poetry: when a position which the metrical scheme requires to be long is occupied by a short syllable at period-end, this short syllable is described as breuis in longo. Some metricians (e.g. West, Willink) have maintained that only an open short syllable at period-end can be named breuis in longo, because 'closed syllables such as -ov at period-end are long by definition'. ${ }^{6}$ Barrett's posthumous Collected Papers (2007: 175-6) show him as also having come to this conclusion sometime after 1982 (since he refers elsewhere in the same paper to West's Greek Metre); however, in his 1965 commentary on Hippolytus he had been

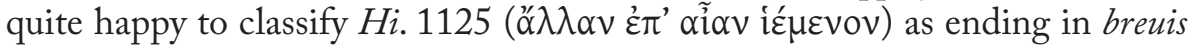
in longo (comm. Hi., p. 369) and on p. 370 to speak of 'relatively mild breuis in

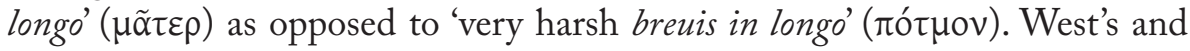
Barrett's (later) position, mainly concerning Pindar, was followed by Finglass in his commentary on Pythian 11 (2007: $47 \mathrm{ff}$.), but not, it seems, by Itsumi in his book on Pindaric metre (2009: 441-2), who lists instances of breuis in longo which, on closer inspection, turn out to contain periods ending in short-vowel closed syllables followed by a word beginning with a vowel or a diphthong in

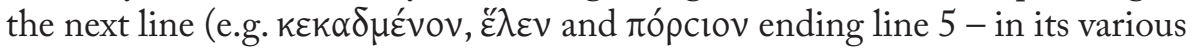
repetitions - of the epode in Olympian 1).

Barrett's main argument for maintaining that syllables containing short vowels ending in $-v$ were felt by Pindar to be long and not short rests on the observation that Pindar studiously avoids the phenomenon 'short open vowel at verse end'. Finglass also draws attention to the fact that, twice in Pindar $(\mathrm{Ol}$. 6. 77; P. 3. 6), a 'short-vowel final-word syllable, ending in sigma and followed by a word beginning in a vowel, is scanned as long within a period' (2007: 49). ${ }^{7}$

However, what is valid for Pindar does not necessarily have to be valid for Euripides. On the one hand, I have been unable to find an example in Euripides of a short-vowel final syllable ending in a consonant and followed by a word beginning with a vowel or diphthong that is to be scanned as long

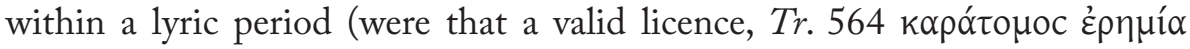
might be scanned $\cup-\cup-\cup-\cup-$ instead of $\cup-\cup \cup \cup-\cup-$, thus avoiding the freak bacchiac with resolved long, for which there is no

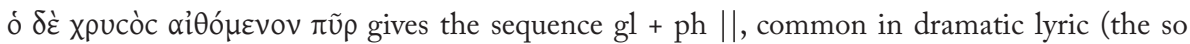
called 'priapean'). But it is only at its seventh repetition (str. 4) that the occurrence of breuis in

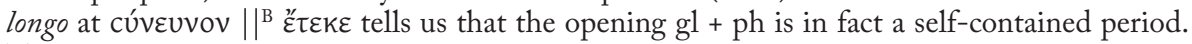
This shows that, when working with the at best two repetitions of dramatic lyric, understanding of the phrasing has often to rely more on the flair and intuition of the metrician than on proof.

${ }^{6}$ So Willink (ed. Or., p. xxi), who appeals to West (1982: 8; cf. 61). The opposite view had already been expressed by Dale (1969: 191 n. 1) and Hill (1974). Hill's intelligent and illuminating article deserves to be better known.

${ }^{7}$ For short vowels both open and closed scanned long within a period in Bacchylides, see Hutchinson (2001: 348) and Maehler's Leiden comm. (Vol. I/1), p. 14. 
other secure parallel in Euripides - but even here Dale, Stinton, Parker and

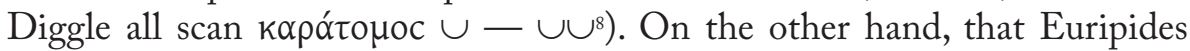
(or Aeschylus for that matter: cf. Dover, Frogs p. 362) did not avoid open short-vowel syllables at period-end can be seen from the following list of all instances of breuis in longo that I find in the extant corpus (lines that feature blunt endings are highlighted in bold type):

\section{A. 'Open' breuis in longo:}

Alc. 219 ( 231 closed breuis), 874 891, 970 ( 981 closed breuis), Med. 147, 860, 1288, Hcld. 90, 101, Hi. 58, 60, 368, 775 (|||), 1388b (|||), Andr. 115, 299 307, 512 534, 1219, 1223, 1225 (|||), Hec. 922 (|||), 1094, 1095, Su. 62 (|||), 366 ( 379 closed breuis), 376 (|||), 607 (|||), 625 (|||), 804, 808, 810 (|||), 827, 924 (|||), 992 1014, 1002 1025, 1030 (|||), 1125, El.113 128, 189 (|||), 465, 480, $1205(|| \mid), 1226$ (|||), Herc. 358 (|||), 383 ( 397 closed breuis), 764, $780(|| \mid), 789$ (|||), 791, 881, 894, 1017, 1069, 1075, Tr. 193a, 816, 844, 1235, 1305 1320, IT 647, 843, 884, 899, †1132†, 1142, 1264 ( 1239 closed breuis), Ion 763a, 1476, 1507, Hel.369b, 644, 664b, Ph. 148, 213 (|||), 238 (|||), $\dagger 301 \dagger, 313,315$, 338a, 1052, 1053, 1293, 1756, 1757, Or. 167 188, 169 ( 190 closed breuis), 200 ( 179 closed breuis), 984a, 1359, 1371, 1379, 1499, Ba. 143, 1161, 1175, 1182, 1198, LA 282 (?), 285, 300, †589†, Rh. 462 (?), 528, 697, 909, Cycl. 73 (?).

\section{B. 'Closed' breuis in longo}

Final word ending in $-v$

Alc. 231, 981, Med. 133, 427, Hcld. 376, 608, Hi. 572, 581, 757 769 (? cf. below, p. 75, n. 157), 1125 1136, 1146, 1377, Andr. 105, 111, 485 (|||), 781, 835, Hec. 72, 83, 684, 705, 947, 952 (|||), 1097, Su. 821, 834, 970 (|||), 1003, 1148, El. 124 (|||), 475 (|||), 1162, 1164 (|||), 1207, 1232 (|||), Herc. 354, 393 (|||), 397, 663, 684, 689, 887b, 1025, 1036, 1084, 1086, 1201, 1213, Tr. 133, 158, 167, 175 (|||), 279, 325, 340b (|||), 577, 1105, 1117 (|||), IT 147, 231, 406 (|||), 899, 1112, 1239, Ion 140, 213a 231b (?), 213b, 458 478, 765, 901, Hel. 183, 210 (|||), 252 (|||), 516, 1109b 1124b, Ph. 152, 158, 168, 230, †303†, 677, 1028, 1532, Or. 179, 1358, 1396, 1464b, 1488b, Ba. 88 (|||), 413, 588, 987, 1153, 1172, LA 209, 214, 251, 794 (?), 1066, 1084, 1091, 1311, 1330, 1480, Rh. 49, 260, Cycl. 72, 662 (|||), Phaeth. 240, Hyps. 39, 46 (?), 271, 274, Teleph. II.5.

${ }^{8}$ Cf. Dale (21968: 74), Stinton (1990: 124), Diggle (1981: 19; 1994: 259 n. 30, 376 n. 37), Parker (1997: 413). See below, p. 235 (n. 89). 
Final word ending in - $\mathrm{C}$

Alc. 415 (|||), 579, 892, Andr. 108, 278, Hec. 164, 686, 699, 1033, 1090, Su. 72, 78 (|||), 368b (|||), 370, 1133, El.1197, Herc. 111, 134, 359, 435 (|||), 660, $\mathbf{8 0 9}, \mathbf{8 8 0}, 1054, \operatorname{Tr} .518,841, \mathbf{1 0 8 5}, 1236,1238$, IT 426, 867, 1234, Ion 167, 684, Hel. 230, 243b, 1131, 1316, 1341, 1479, Ph. 128 (?), 191 (if $4 \mathrm{da}$, as advocated by Mastronarde), 250, 317, 676, 821, 1485, 1518, Or. 190, 1479, 1495, 1542, Ba. 522 541, 603 (|||), 1191, LA 243, 279, 280, 1284, Rh. 249, 355.

Final word ending in $-\rho$

Alc. 411b, Hi. 1144, Andr. 490, Or. 1454a, Rh. 827 (?).

Furthermore, there are several places in Euripidean lyric where a short open vowel at period-end responds with a short closed vowel. At Alc. 970 981, for example, responding period-closing aristophaneans end in a short syllable

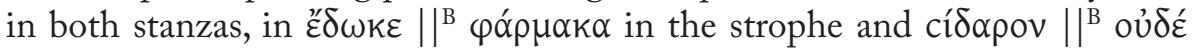
$\tau \mathrm{\tau lC}$ in the antistrophe. The same phenomenon is found at Alc. 219 231, Su. 366 379, Herc. 383 397, IT 1239 1264, Or. 169 190, 179 200. Thus, it could be asked whether to postulate an 'open' short category for $-\varepsilon$ and a 'closed' short category for -ov might not seem needlessly artificial: is not the poet telling us that, to all intents and purposes, he feels them to be the same?

Other than hiatus and breuis in longo, there is a more controversial and altogether less reliable criterion for understanding the underlying structure to the phrasing of dramatic lyric: the 'sense-pause' implied by a syntactic or semantic break. The reason why this criterion is controversial is that not everyone will agree as to what, exactly, may constitute a 'sense-break'; on the other hand, the dramatists (and indeed Pindar) sometimes end a period in a manner which suddenly reigns in the flow of the sentence. As Dale wrote: 'sometimes sense and metrical phrasing move parallel for the whole or part of a stanza. But in other cases, as so often in Pindar's poetic technique, the two may each go their independent ways' (21968: 203).

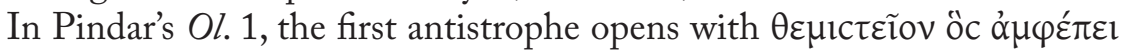

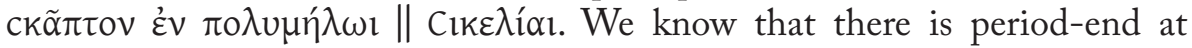
$\pi \circ \lambda u \mu \eta \dot{\gamma} \lambda \omega \mathrm{l}$ because there is a breuis in longo later, at the beginning of the

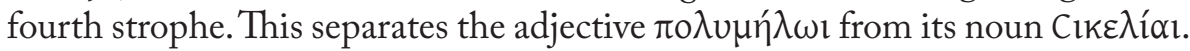
In Aeschylus, breaks of this kind are quite commonplace; they appear to be less frequent, though, in Sophocles and Euripides, who strive for greater smoothness in coupling sense with rhythm. ${ }^{9}$ We must be wary, however, that

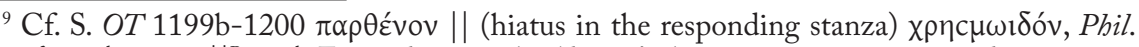

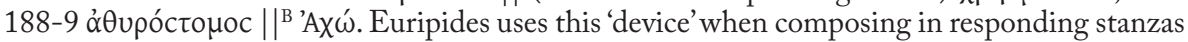

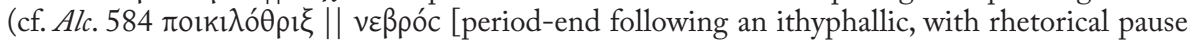


in identifying 'ungainly' instances of period-end we are not being misled by

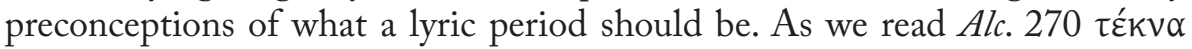

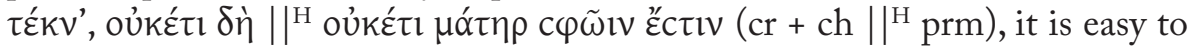
sympathise with the note 'hiatus suspicionem mouet' in Diggle's apparatus;

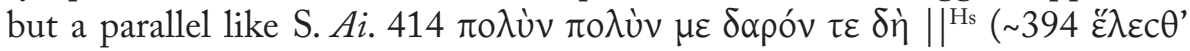

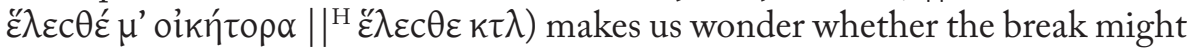
not have sounded perfectly natural to fifth-century Attic ears.

Euripidean periods vary considerably in length. Long, elaborate periods tend to appear more in aeolic contexts, where the characteristic dovetailing of cola produces phrases of great breadth and beauty, such as e. g. Ion 184-7 ( 194-7):

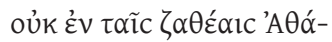

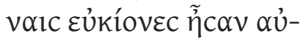

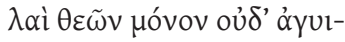

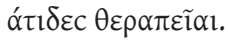

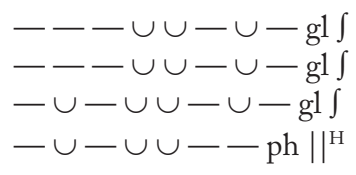

Long periods are a distinctive feature of Heraclidae, where the following examples are to be found in aeolic contexts:

$$
\begin{aligned}
& \text { Hcld. 358-61 367-9: g1 } \int \mathrm{gl} \int \mathrm{g} 1 \int \text { ar }|| \mid \\
& \text { 377-80: tel } \int \mathrm{gl} \int \mathrm{gl} \int \mathrm{ar}|| \mid \\
& \text { 910-14 919-23: ch + ia } \int \mathrm{gl} \int \mathrm{g} 1 \int \mathrm{g} 1 \mid \text { hag } \|
\end{aligned}
$$

An equally effective example in a dactylic context is Hcld. 615-7 626-8 (4 da $\int 4$ da $\left.\int \mathrm{D}-|| \mid\right)$.

As a foil to the spacious unfolding of images in aurally opulent longer periods, Euripides often uses short periods with great expressive power. It is

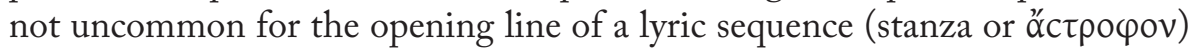
to end (seemingly abruptly) in breuis in longo (Alc. 579, Hcld. 608, Herc. 359, Tr. 279, 325, 577, IT 1234, Ph. 1485, Ba. 1153, IA 1284, $\left.{ }^{10} \mathrm{Rh} .528^{11}\right)$ or hiatus (Hi. 362a, 1121, Andr. 841, Hec. 444, Or. 1537a and Cycl. 49). Catalectic opening cola often turn the first line of a lyric sequence into a self-contained metrical

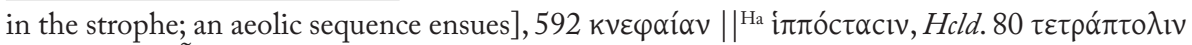

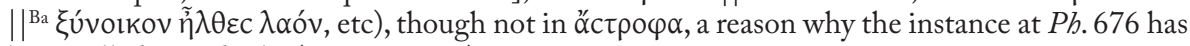
been called into doubt (see next note).

10 'For the breuis in longo, see Hel. 221, Ph. 250, 676' (Diggle 1994: 424 n. 18). But there is

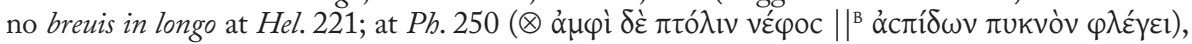

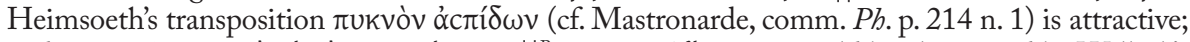

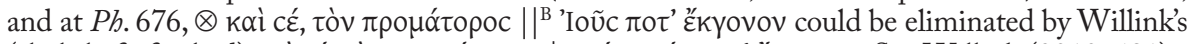

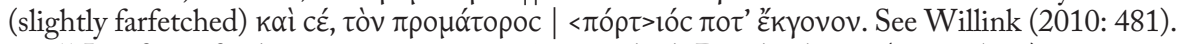

${ }^{11} \mathrm{~L}$ offers a further instance at Herc. 678, to which Diggle objects (1981: 52-4). 
period: see especially the mesodes in the first stasimon of Heracles, ${ }^{12}$ or the opening of the first stasimon of Bacchae. ${ }^{13}$ At Alc. 455-461b ( 466-71b), there is reason to assume that each line is a self-contained period; note, among other features, the insistence on pendent close:

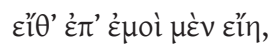

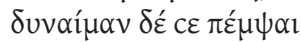

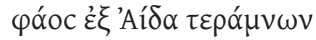

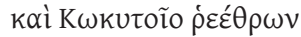

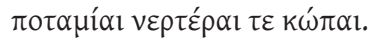

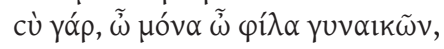

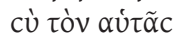

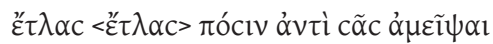

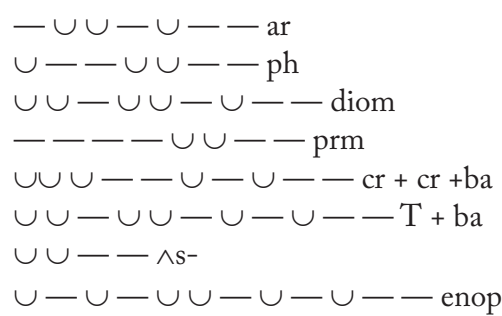

It is not possible to determine period-end in this lyric sequence by means of breuis in longo or hiatus. Nevertheless, the structure is perfectly clear. Although for the last two lines (where another colometry might be possible) we have only the pendent close to go by, each of the other lines contains a significant syntactic pointer revealing how the phrases are articulated: the disjunctions $\mu \varepsilon \dot{v} v$ and $\delta \dot{\varepsilon}$ in the two opening lines fit neatly into separate, complementary periods, as do the copulatives kaí and $\tau \varepsilon(458,459)$. As for the vocative utterance at 460, not only is it 'housed' by an essentially clausular colon, 'T + ba' (on which see below, p. 76), but it responds with a phrase in the antistrophe that ends in full stop. Moreover, it can be observed that invocations, as a class of lyric utterance, tend to fall naturally into small, self-contained periods..$^{14}$

${ }^{12}$ Cf. Herc. 359-63 375-79 389-93 403-7 419-24 436-41: ph || ${ }^{\mathrm{B}} \mathrm{ph}\|\mathrm{ph}\| \mathrm{gl} \int \mathrm{ph}|| \mid$.

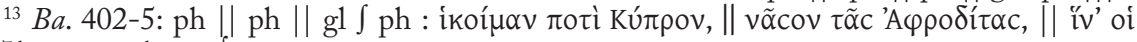

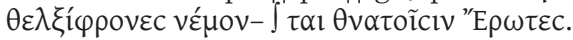

${ }^{14}$ Here is a list of all the examples where the period-end following the invocation is

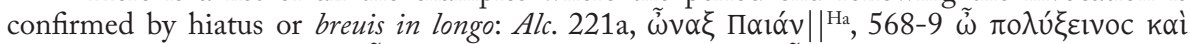

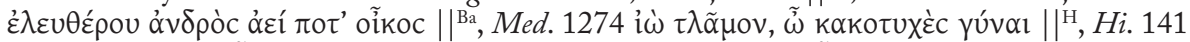

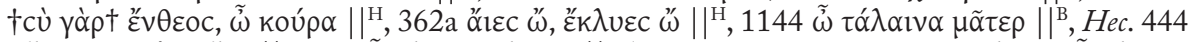

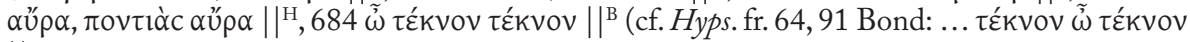
$\|^{\mathrm{B}}=\operatorname{Tr}$ GFS Hyps. 276-7, where the effect is lost with Diggle's colometry = Hyps. Fr. 759a, 1612

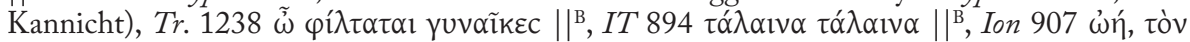

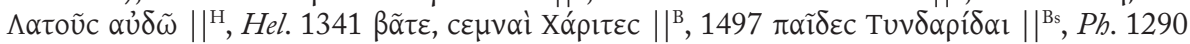

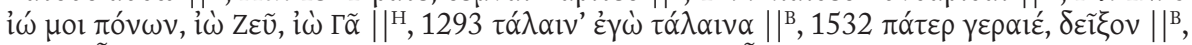

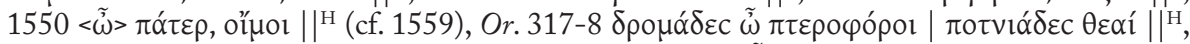

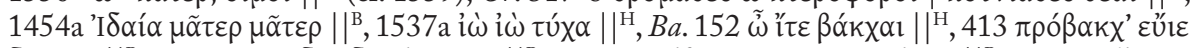

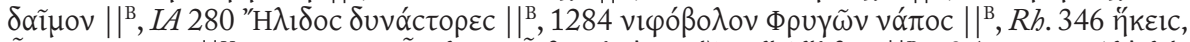

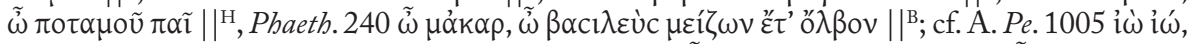

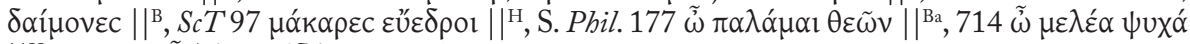

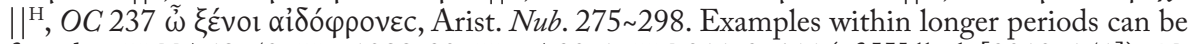
found at Hcld. 748-50, Hec. 1088-90, Herc. 790-1, Hel. 211-2, 644 (cf. Willink [2010: 151]), Ph. 226-8, 801-2 and Ba. 120-2. 
Indeed, the fact that some kind of pause is felt to follow a vocative may even

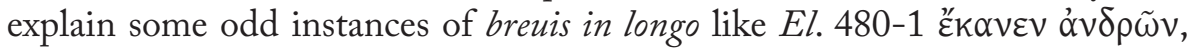

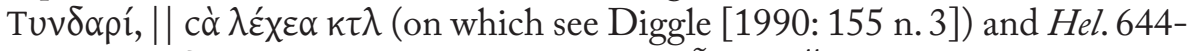

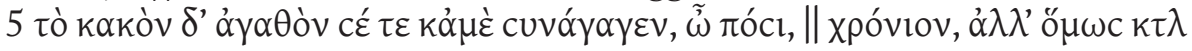
(on which see Willink [2010: 150-152]). ${ }^{15}$

An important question relevant to the understanding of lyric phrasing

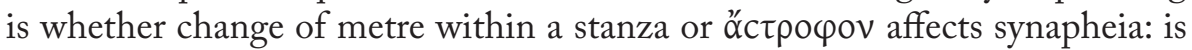
every rhythmic modulation neatly ensconced within the watertight confines of a metrical period, or is 'generic overlap' permissible? Consider the following examples:

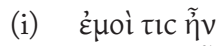

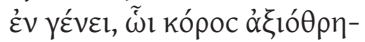

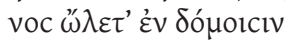

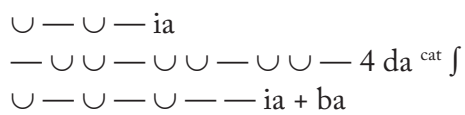

$(\text { Alc. 903-5 })^{16}$

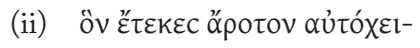

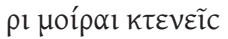

(Med.1281a-b)

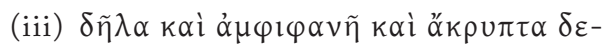

Although it would be natural to view a change of metre as automatically implying period-end, these examples where the metre changes within sequences in synartesis demonstrate that this is not necessarily so. ${ }^{18}$ But, generally speaking, as Stinton (1990: 336) observed, period-end does occur at change of metre 'more often than not'.

When change of metre coincides with an obvious sense-pause, the probability of period-end is that much higher. This being the case, a perplexing question arises when change of metre, clear sense-pause and elision all coincide at once: is elision permissible at period-end? The question might seem in itself odd, because the very notion of period-end implies as necessary prerequisite full word-end without elision. ${ }^{19}$ Nevertheless, there

15 Cf. also $P h .168,317,667$, Or. 167. Cf. Mastronarde's analysis of $P h .191-2$

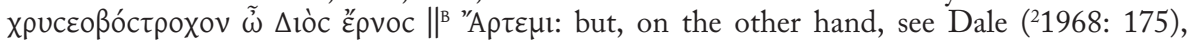
whose analysis precludes breuis in longo.

${ }^{16}$ Cf. Diggle (1994: 206 n. 22).

${ }^{17}$ This example from Andromache is described by Diggle (1994: 259) as a cretic at the end of a colon 'of whatever shape' after an apparent run of dactyls.

${ }^{18}$ Cf. further Hcld. 782-3 (2 an $\int$ ia + ith), 901-2 (3 ia $\int$ ar; dovetailing in the strophe), $H i$. $1385 \mathrm{a}-\mathrm{b}\left(2 \mathrm{ba} \int \mathrm{dod}\right)$, etc.

19 'Elision at period-end is a contradiction in terms' (Willink 2010: 144 n. 37). Snell, however, was not so peremptory $\left({ }^{4} 1982\right.$ : 7, appealing to Maas $\left.§ 139\right)$. 
is that well-known example in Sophoclean spoken trimeters (OT 332, line ending in $\left.\tau \alpha \tilde{v} \tau^{\prime}\right)$. More instances of the so-called $\varepsilon \tilde{i} \delta \circ$ Co $^{\prime}$ ók $\lambda \varepsilon 10 v$ are listed by Zuntz (1965: 232-4); the elided word is either $\delta$ ' or $\tau$ ', attached to the following line. ${ }^{20}$

Turning to Euripidean lyric, in Murray's OCT there was an instance of elision at period-end in the Phrygian's aria in Orestes (1489-90 3 ia || 2 dochmiacs, with strong sense-pause after हैkElv $\left.\tau^{\prime}\right)$, but this is avoided in Diggle's OCT by a clever rearrangement of lines thereabouts. Do any examples remain in Diggle's text? No absolutely certain examples, where (for instance) a colon ending in elision would correspond with a colon ending with hiatus (at $A n d r$. $512 \sim 534$ the phenomenon is rightly avoided by different editors by different means: cf. Willink 2010: 646), breuis in longo or featuring indisputable anceps iuxta anceps. But I should like to draw attention to the following perplexing instances of elision in places where period-end would be expected: Alc. 413 (ia + sp with strong sense pause punctuated by colon || enoplian 'blunt praxillean'), Med. 648 (diomedean + ithyphallic, ${ }^{21}$ with sense pause punctuated by comma |l odd colon, labelled 'trochaic' by Page, comm. Medea p. 185; possibly hס), ${ }^{22}$ $R h .911$ (where the period-closing ' $\mathrm{T}+$ ba' ends in elision ${ }^{23}$ ).

A fascinating question raised by the choral songs of Greek drama concerns the presence of asymmetrical phrasing in responding stanzas, something which tempts us to speculate on the poet's method of composition. Consider, for instance, Alc. 112-21 122-31 (second strophic pair of the parodos):

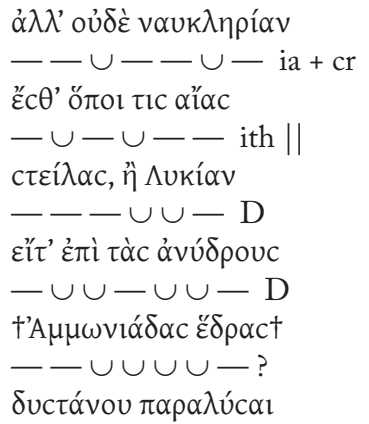

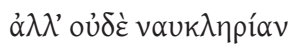

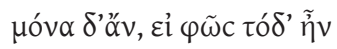

$\cup-\cup--\cup-\mathrm{ia}+\mathrm{cr}$

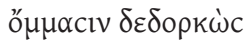

$-\cup-\cup-$ ith ||

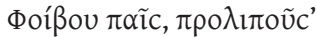

$---\cup \cup-\mathrm{D}$

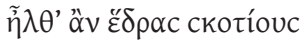

$-\cup \cup-\cup \cup-\mathrm{D}$

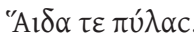

$--\cup \cup-$ an $\|$

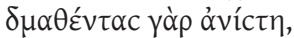

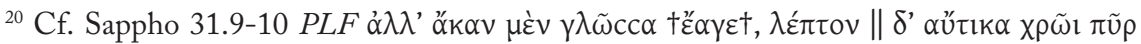

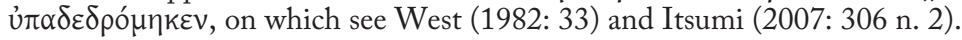

${ }^{21}$ Cf. Diggle (1994: 206).

${ }^{22}$ But at Med. 648, $\alpha i \tilde{\omega} v$ ' could be avoided with Stinton's $\alpha i \tilde{\omega}$, printed by Kovacs in his Loeb text. Mastronarde prints $\propto i \tilde{\omega} v$ ', but admits 'one would expect period-end at 648' (comm. Med., p. 274). For a different approach, see Parker (1976: 20).

${ }^{23}$ Kovacs radically disposes of the elision with his $\pi \lambda \varepsilon$ ćouc' $\varepsilon \pi \lambda \alpha \theta^{\theta} \eta$ for the transmitted

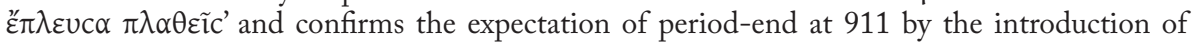
hiatus between 911 and 912 , but Liapis (comm. Rh., p. 312) is right to diagnose nothing more serious than 'superficial textual corruption.' 
Part I - Euripides' use of lyric metre

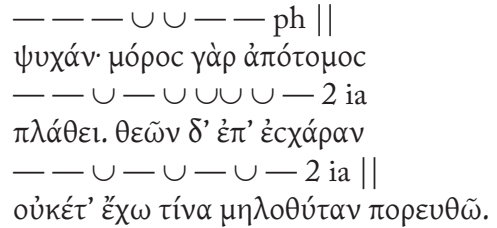

$---\cup \cup--p h||$

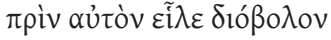

$\cup-\cup-\cup \cup \cup \cup-2$ ia

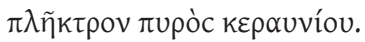

$--\cup-\cup-\cup-2$ ia $\|$

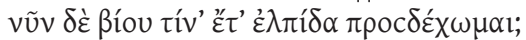

In this curiously ill-matched stanza pair, the manner in which the poetry fits into the metrical scheme is noticeably less successful in the strophe than in the antistrophe, where sentence pattern, rhythm and meaning form a much

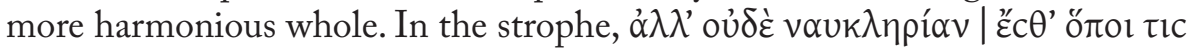

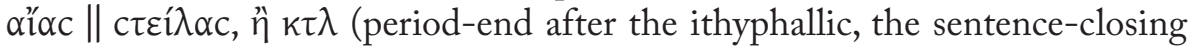

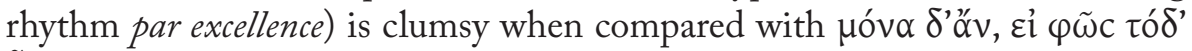

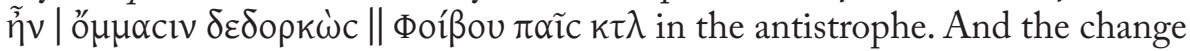
of rhythm at $117-8 \sim 127-8$ (ph || 2 ia), ${ }^{24}$ while working beautifully in the

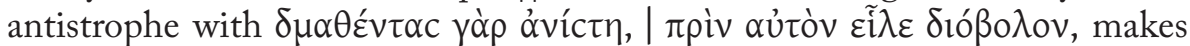

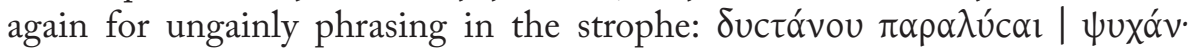

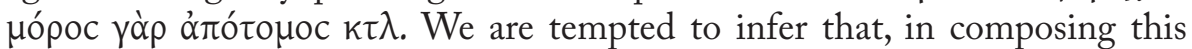
stanza pair, Euripides began by working out the musical and poetic structure in the antistrophe, for which he then composed a matching strophe; however, the need to use the same rhythm for both strophe and antistrophe imposed (in this case) too great a constraint on the phrasing: although it worked well in what I take to be the original stanza (the antistrophe), the same structure produced a

${ }^{24}$ The presence of a pherecratean is surprising in this non-aeolic context, so it is easy to understand why Dale preferred to call 117 127 a 'contracted hemiepes pendent'('Dx'); the anceps iuxta anceps this entails (the next line is an iambic dimeter) is perfectly in order, since periodend is assumed (Dx $\|$ 2ia). Nevertheless, it is probably preferable to analyse as 'pherecratean', although there is some element of artificiality in the use of these terms: as Itsumi notes, 'there may not be so substantial a difference between $-\cup \cup-\cup \cup-$ (hem) and oo $-\cup \cup--$ (pher) as their names indicate' (cf. 1984: 73). Indeed, in his last trilogy, Euripides seems to have been especially interested in exploiting the ambiguity of the colon oo $-\cup \cup-\longrightarrow$ as a means of creating 'transitional' rhythmic effects. In the parodos of Bacchae, it appears as part of the priapean clausula that rounds off the second strophic pair (119 134) and again in the complex epode, where at 146-7, following ionics, its affinity with a (hypothetical) catalectic ionic dimeter

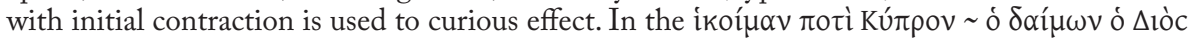
$\pi \alpha \tilde{i} c$ section of the first stasimon (where it appears six times), it opens the stanza, once again modulating from ionics (the first strophic pair). A few lines later (412-6 †427†-33), it features in an interesting example of rhythmic criss-crossing between iambic and aeolic: ' 2 ia $|\mathrm{ph} \||^{\mathrm{B}}$ 3 ia $\int$ ar |l|'. At 575, it appears as part of a 'wil | ph' clausula; and, appropriately enough, it is

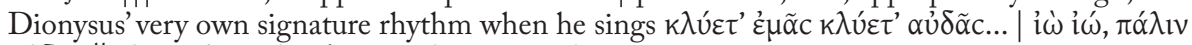

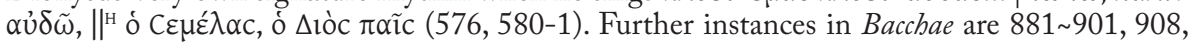
$909,910,912$. In the parodos of $L A$, we encounter it as part of a priapean dicolon at $167 \sim 188$, 181 202 and 184 205; following what, to all intents and purposes, looks like an ibycean at 170 191; after ionics (as in Ba.) at 175 196; and, most notably, in the epode, where it frames a momentary drift into 'anapaests' (209-15: 'ph $\left|{ }^{\mathrm{B}} \mathrm{A}\right| \mathrm{ph}|\mathrm{gl}|$ reiz $\|^{\mathrm{B}} \mathrm{ph}||$ '). 
less felicitous effect in the strophe. This phenomenon of asymmetrical phrasing in responding stanzas is a standard feature of practically every Aeschylean and Euripidean song; ${ }^{25}$ in Sophocles, on the other hand, it is seldom found.

Another interesting feature of Euripides' technique of lyric phrasing is the repetition of identical or similar sounds in the same metrical position in responding stanzas, so as to give a sort of 'mirror' effect — as at Alc. 253 260,

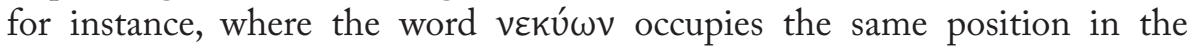
hagesichorean in both stanzas. ${ }^{26}$ This is more readily found in Euripides' earlier plays, where we also encounter occasional responding 'rhyming' effects,

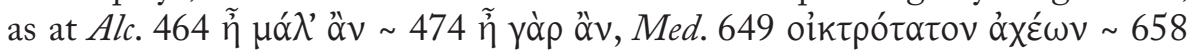
$\delta \varepsilon เ v o ́ \tau \alpha \tau \alpha \pi \alpha \theta \varepsilon ́ \omega v$, etc. ${ }^{27}$

Finally, we may refer to another typical Euripidean mannerism: the use of patterning word-length. Euripides had a marked penchant for grouping together two or more tribrach shaped words $(\cup \cup \cup)$ in iambo-trochaic and dochmiac lyric, often with anadiplosis or paregmenon. Among the types of word most often found are negations in which a privative alpha is grafted on

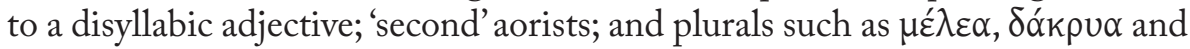
$\pi \alpha \dot{\theta} \varepsilon \alpha$. In the parodos of Helen, for example, we notice that in the antistrophe tribrach shaped words are piled on in typical late Euripidean abundance: 180

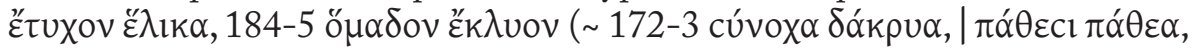

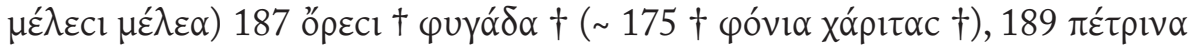

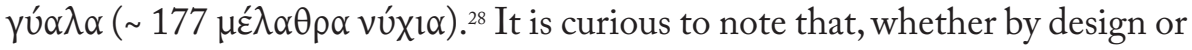

${ }^{25}$ Since it would be foolish to dogmatize on a subject as inimical to dogmatism as Greek lyric metre, the possibility that asymmetrical phrasing in responding stanzas was used for an expressive effect now lost on us ought perhaps not to be ruled out; but we lack the aesthetic criteria that would enable us to analyse it objectively and, in any case, Sophocles' avoidance of it tells against its potential as a deliberately 'beautifying' device.

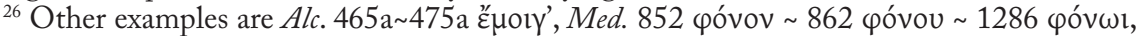

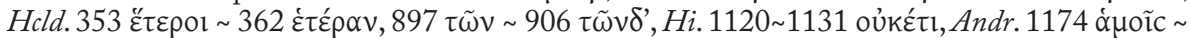

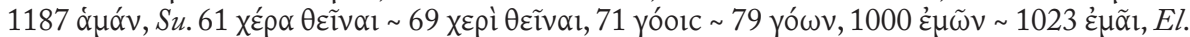

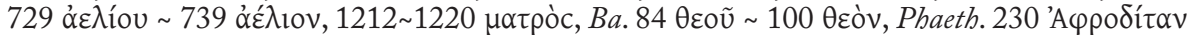

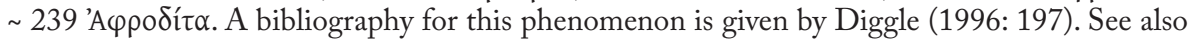
Bond, comm. Herc., pp. 265-6; and Parker, comm. Alc., pp. 102-3.

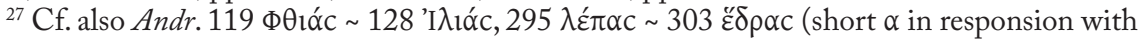

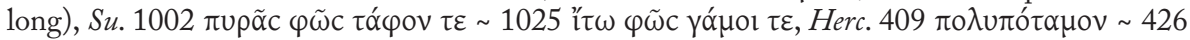

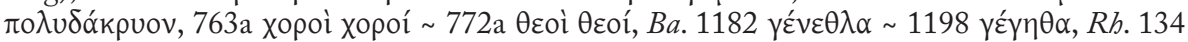

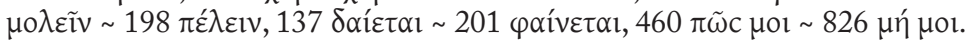

${ }^{28}$ Other Euripidean passages featuring sequences of two or more tribrach shaped words are

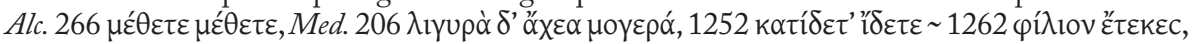

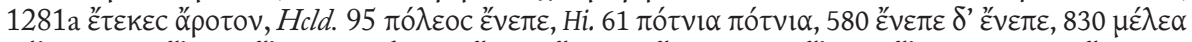

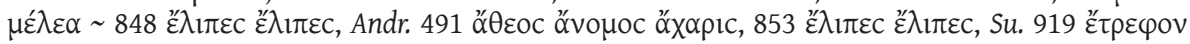

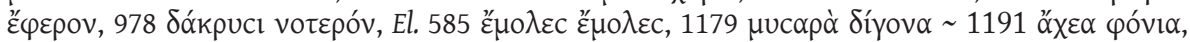

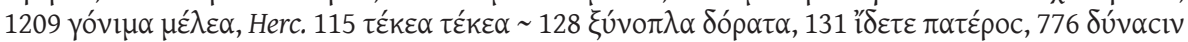

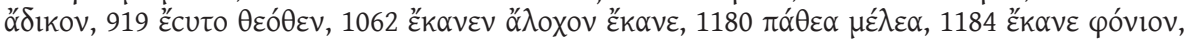

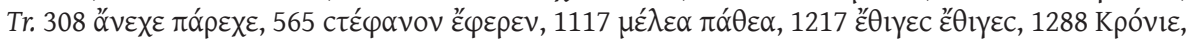




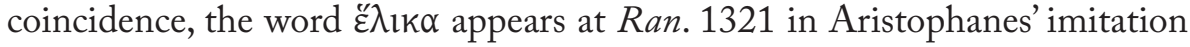

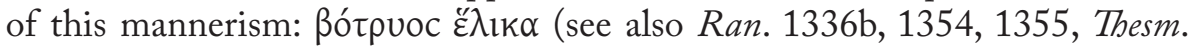
1029, 1039a).

\subsection{Lyric Metre and Dramatic Effect}

The extent to which the choice of a certain metre adds to the dramatic effect of a lyric sequence is something that is not always easy to determine, with the possible exception of dochmiac rhythm, which invariably denotes a heightening of emotional tension. ${ }^{29}$ In Medea, the chorus sings for most of the play in dactylo-epitrite rhythm; but when the events of the tragedy lead inexorably to the murder of Medea's children, they change to dochmiacs. ${ }^{30}$ Similarly, the lyrics which follow upon the terrible carnage of the hero's family in Heracles are also dochmiac, blended with a characteristically Euripidean admixture of anapaestic and dactylic phrases known as 'enoplian'. ${ }^{31}$ Indeed,

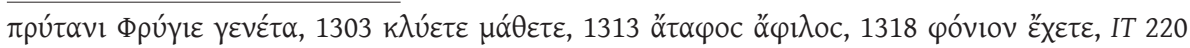

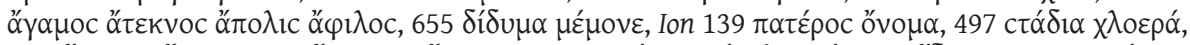
690 öं

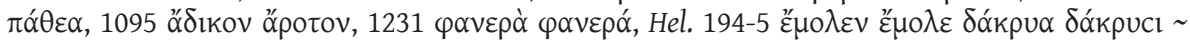

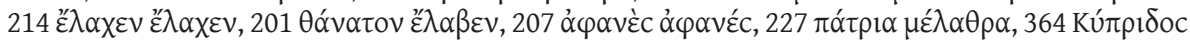

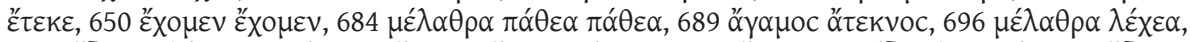

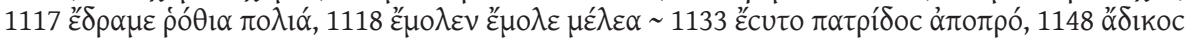

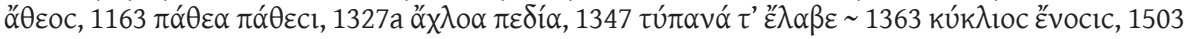

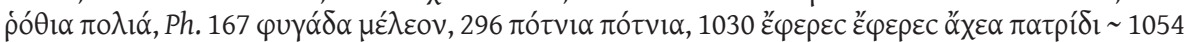

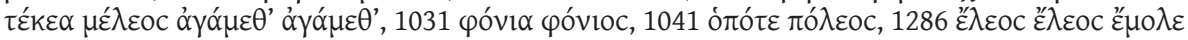

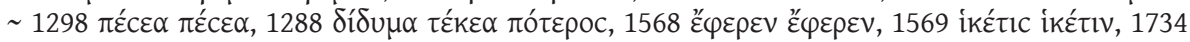

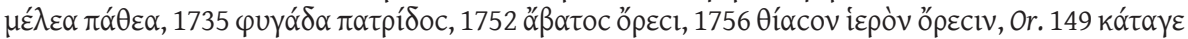

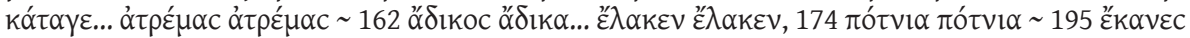

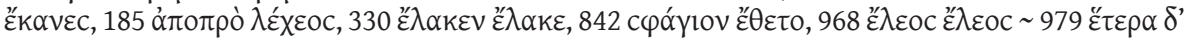

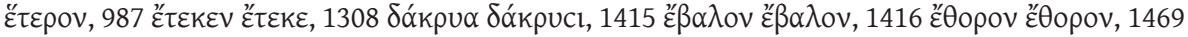

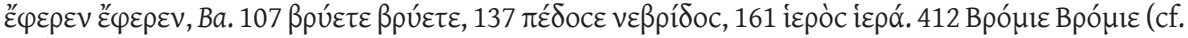

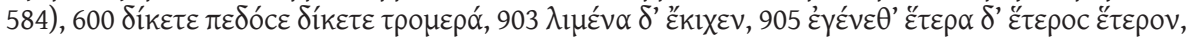

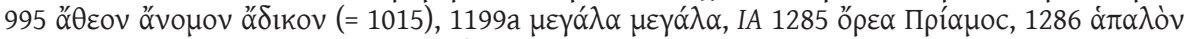

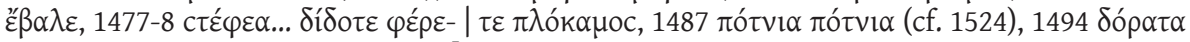

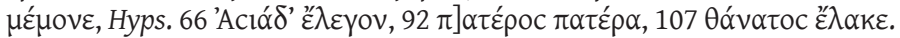

${ }_{29}$ This can be sensed even when dochmiac does little more than ripple fleetingly over the surface of a different rhythmic context, as in Alcestis' farewell aria, where the mention of approaching death (the image of darkening night stealing over the eyes) is accompanied by a brief dochmiac modulation (in the shape of the colon ' $\delta+$ ba', Alc. 269; on this colon see Stinton 1990: 114-19; Diggle 1994: 395), all the more effective because this is a lyric sequence where dochmiacs are otherwise absent.

${ }^{30}$ Cf. Med.1251-60 1261-70, 1273-81b 1282-92b.

${ }^{31}$ There are three extended sequences of enoplian dochmiacs in Heracles: 875-921, 1016-88, 1178-1213. The term 'enoplian dochmiacs' appears to have been coined by Wilamowitz (cf. ed. Herakles, vol. II. p. 146 f.); it is also often used by Willink in his commentary on Orestes and even by Barrett to describe the fourth stasimon of Hippolytus (comm. Hi. p. 392). An early example of this technique in Euripides is the child's monody in Alcestis (393-403 406-15: cf. Willink, comm. Or.p. 112). 
as with dochmiac, enoplian can be said to have been used by Euripides to pull tighter, as it were, at the heart-strings of his audience, to cause lumps to well up more readily in the listener's throat. Interestingly, in his later tragedies enoplian dochmiacs are put to an equivalent use at the other end of the emotional spectrum, as in the reunion duo between Helen and Menelaus, where the heroine's dochmiac phrases, interspersed with enoplian, express the sudden and unexpected joy of being reunited with a loved husband only recently thought dead. ${ }^{32}$

Other rhythmic genres are less easily pinned down as to their aesthetic and emotional overtones. Ionic, for instance, is not really used often enough for us to glean much information as to its specific dramatic resonance: in Bacchae it is used as the 'liturgical' rhythm of Dionysiac $\mu \alpha \kappa \alpha \rho i ́ \alpha,{ }^{33}$ perhaps with oriental overtones (compare the use of ionic in Aeschylus' Persians), but in the parodos of Supplices (42-62 48-70) it seems merely to add decorative colouring to the lyrics sung by the chorus of Argive women. Dactylic and dactylo-epitrite are generally dignified metres, best suited to lyric moments where elevated diction and 'high' poetry call the tune. Iambic, described by Aristotle as $\mu \alpha{ }^{\prime} \lambda_{\imath} c \tau \alpha . .$.

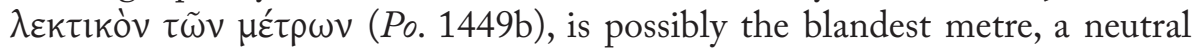
rhythmic vessel into which the poet could pour what mixture of lyric feelings he wished. It suits the chorus' mood of bleak despair in Troades as well as the absurd 'stream of consciousness' ramblings of the Phrygian in Orestes. Trochaic, on the other hand, is sparingly used in the lyrics of tragedy (see next chapter), but the use to which it is put by Euripides evokes its threnetic, rather than its 'fast and undignified', qualities. ${ }^{34}$ Lyric anapaests too are mainly linked with lamentation (as in the anapaestic monodies of Hecuba and Creusa; cf. Tr. 122-52, Ion 859-922) and profound emotional distress. ${ }^{35}$ It is tempting to view the insistent use of anapaestic phrases consisting mainly or entirely of long syllables (cf. below, p. 50) as somehow indicative of a more contained level of grief than that expressed in dochmiac and iambo-trochaic, where the at times incontinent use of resolution lends the suffering of the solo singer an almost comic air of uncontrolled garrulity - something Aristophanes was quick to parody in Birds, where heavily resolved passages in the Euripidean manner are used to mimic meaningless twittering. The most noteworthy instance of this

${ }^{32}$ Cf. Hel. 625-97 and Willink (2010: 132-168).

${ }^{33}$ Compare the anacreontic song in Cyclops (495-518) which, although breezily demotic,

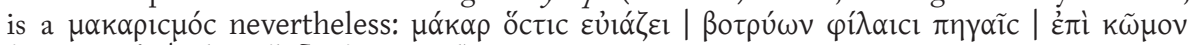

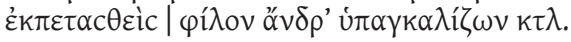

${ }^{34}$ See below, p. 36, n. 48.

${ }^{35}$ See for instance Medea's opening anapaests (Med.96-7, 111-4, 144-7, 160-7) or Phaedra's wilting, half-expressed longings (Hi. 208-11) or her unbridled ravings (Hi. 215-22, 228-31):

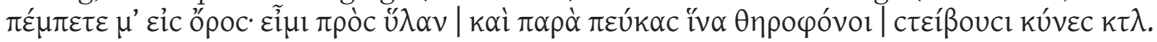


type of chatterbox resolution occurs in a play (later than Birds, however) often described as a tragi-comedy and in a lyric sequence which is almost a send up (cf. Parker 1997: 429) of the traditional tragic ơvaүvẃpıcıc:

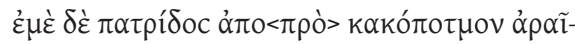

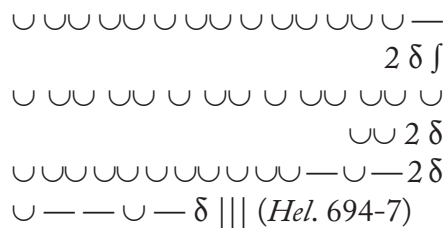

Aristophanes' parody of this in Thesm. $914-15$ is almost tame by comparison:

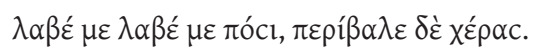

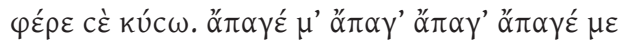

$\cup \cup \cup \cup \cup \cup \cup \cup \cup \cup \cup \cup \cup$

$\cup \cup \cup \cup \cup \cup \cup \cup \cup \cup \cup$

As for aeolic, there are interesting indications we may tentatively take as illuminating why Euripides might have favoured this rhythm for a certain type of lyric. In later Antiquity, the theoretician 'Demetrius' made the disarmingly obvious observation that one of the reasons why Sappho's poetry is so beautiful is quite simply that she beautified it with beautiful words (ovó $\mu \alpha \tau \alpha$ $\kappa \alpha \lambda \alpha$ ). ${ }^{36}$ Similarly, it can be observed that a striking feature of Euripidean aeolo-choriambic lyric is its decorative use of beautifying words and imagery. Consider the halcyon song (IT 1089 1106 ff.), the dawn song in Phaethon, Ion's laurel-broom song (Ion 112 128 ff.), the song of the amazed servant-girls describing the temple of Apollo at Delphi (Ion 141-194 ff.), the Mountain Mother ode (Hel.1301 1319 ff.) or the Phoenician oar song (Hel. 1451 1455 ff.) with its 'Anmut' and 'Heiterkeit'. ${ }^{37}$ Is it mere coincidence that Euripides composed these, his 'prettiest' odes, in aeolic rhythm? The possibility that aeolic was perceived as being the most appropriate metre in which to compose songs in the Lesbian tradition of 'beautiful words' might explain why it was chosen by Sophocles for his most famous (extant) essay in stringing together óvó $\mu \alpha \tau \alpha$

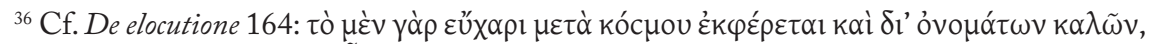

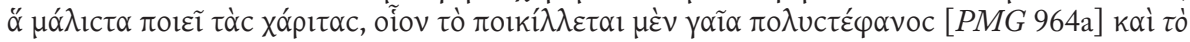

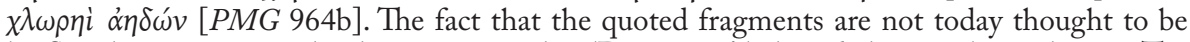
by Sappho is immaterial; what counts is that 'Demetrius' believed them to be authentic. The

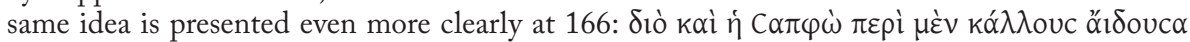

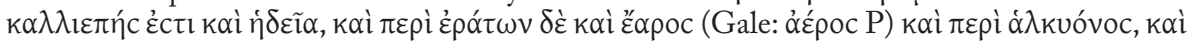

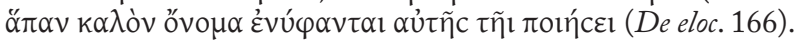

${ }^{37}$ Kannicht, comm. Hel., vol. II, p. 374. 
к $\alpha \lambda$ ó: the Colonus song (OC 668-80 681-93). Even Demetrius' beautifying nightingale bursts into song at 670-3.

The parodos of Phoenissae and the first stasimon of Bacchae also offer significant information on the aesthetic of aeolo-choriambic in Euripides' later lyric style. At Ph. 202 214 ff., we sense a marked difference in poetic tone when we pass from beautifying imagery of the first strophic pair - the exotic Phoenician island in the eastern Aegean; Parnassus covered in snow; the Sicilian zephyr's kó $\lambda \lambda_{\mathfrak{l} c \tau o v} \kappa \varepsilon \lambda \alpha$ á $\delta \mu \alpha$; the fountain of Castalia; the typically Euripidean lyric wish to be elsewhere, ${ }^{38}$ etc. - to the urgent, doom-

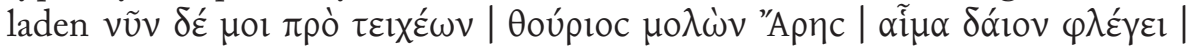

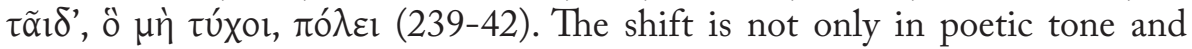
content. In metrical terms, the transition is equally sharp: the opulent lyric imagery of the first strophic pair and epode is aeolo-choriambic at its most 'hypnotic' (cf. West 1982: 115); the anguished description of the besieged city is in syncopated trochaic. In the first stasimon of Bacchae, the first strophic pair - where the chorus has dramatically and even theologically relevant things

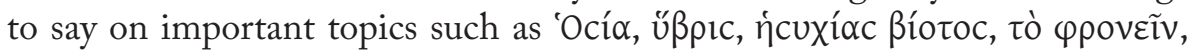

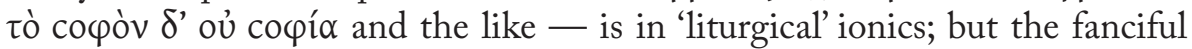

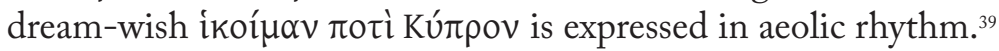

\subsection{Note on Rhesus and Iphigenia at Aulis}

Fraenkel's magisterial review of Ritchie's Authenticity of the Rhesus of Euripides, more than anything else written in the past on the play, succeeded in the opinion of most scholars in settling the 'Rhesus question' and it has since been generally accepted that the play was written (probably in the 4th century) by someone whose spoken trimeters oddly evoke Euripides' restraint with regard to resolution in the 430's and at the same time his much later tolerance of interlinear hiatus, features that are mutually exclusive if they are to be taken as genuinely Euripidean. ${ }^{40}$ The play does seem, on all accounts, too derivative to be by Euripides. Fries puts it in a nutshell: 'the greatest stylistic difference between Rhesus and the rest of surviving tragedy lies in the manner and degree to which it relies on other drama, epic and lyric poetry, ranging from more or less obvious adaptations of scenes to scattered echoes of unusual words and phrases' (2010: 346).

${ }^{38}$ On which see Padel (1974) 227-41.

${ }^{39}$ Seen in this light, Cassandra's 'hymeneal' glyconics in Troades (cf. 314 331, 322 338, 323 339) - a play otherwise practically devoid of aeolic - take on an unexpectedly poignant, bitter-sweet quality.

${ }^{40}$ Mastronarde (2010: 26 n. 69) and Liapis (comm. Rh., pp. lxxi ff.) also agree that the play was written in the 4 th century. 
Confusingly enough, the cantica would seem to present a somewhat different picture. Willink, for one, considered the songs of Rhesus 'fully consistent with attribution to Euripides (influenced indeed by Sophocles); and there are no sufficient grounds for questioning the traditional assignation to an early period of his career, in line with the recognized "early" style of the trimeters. Those who adhere to the "4th century" hypothesis will need to explain how the (disparaged) fourth century tragedian came to deploy with such expertise and consistency a mid 5th century style in the lyrics, despite intervening developments in musical composition and changes of taste. ${ }^{41}$

Fraenkel, however, had already disposed of these objections in his review (see particularly pp. 236-7; see also Liapis, comm. Rh., pp. lxiv-lxvii). For my part, while siding with Fraenkel and Liapis against Willink, I nevertheless include Rhesus in my survey, in the belief that to omit Rhesus altogether would detract considerably from the usefulness of this book.

The fascinating patchwork-play Iphigenia at Aulis - always a favourite with readers and critics ${ }^{42}$ - raises a different kind of problem, because here at least some of the lyrics must have been composed by Euripides. Which? Faced with the bewildering shades of inauthenticity the text of $L A$ evinces today as we read it in Diggle's edition, ${ }^{43}$ we cannot but wonder. Precisely what parts of his last tragedy had the poet actually composed when he died? How much was added, reworked and/or padded out by the younger Euripides (or whoever completed the play in time for its first performance)? These are questions for which a host of scholars, from Musgrave to Kovacs, have proposed ingenious, though far from certain, answers.

${ }^{41}$ Willink (2010: 582).

${ }^{42} \mathrm{I} A$ was a favourite play with none other than Lessing. There is a little known rave review of $I A$ by Patin ( $\left.{ }^{4} 1873: 1-2\right)$ : 'c'est, à la fois, et l'un des chefs-d'oeuvre de la scène grecque, et la pièce la plus parfaite de son auteur: elle offre, avec la beauté achevée que possédait déjà la tragédie, presque sans aucune trace de recherché et de décadence, quelques-uns des traits nouveaux dont Euripide cherchait à l'animer'.

${ }_{43}$ Diggle differentiates four degrees of (in)authenticity: (A) <uu.> fortasse Euripidei: 164230, 302-65, 376-403, 442-64, 471-507, 511-19, 522-35, 631-2, 638-51, 653-64, 666-73, 67580, 695-719, 727-38, 819-98, 900-8, 917-8, 1036-79, 1120-3, 1127-9, 1134-69, 1173-84, 11861240, 1253-69, 1271-75, 1338-1403, 1421-3, 1426-9, 1433-4, 1440-7, 1450-7, 1462-74; (B) <uu> fortasse non Euripidei: 440-1, 465-70, 536-42, 543-89, 674-5, 681-93, 720-2, 739, 899, 909-14, 1080-97, 1124-6, 1130-3, 1170-2, 1185, 1241-52, 1270, 1283-1337, 1404-6, 1410-20, 1424, 1435-49, 1448-9, 1458-61, 1475-1509; (C) <uu.> uix Euripidei: 1-48, 49-114, 115-63, 231-302, 366-75, 404-12, 508-10, 520-1, 590-7, 607-30, 633-4, 694, 723-6, 740-50, 751-800, 801-18, 915-6, 919-1035, 1098-1119, 1276-82,1425,1430-2,1510-31, 1532-77; (D) <uu.> non Euripidei: 413-39, 598-606, 635-7, 652, 665, 1407-9, 1578-1629. 


\section{Trochaic}

In extant tragedy, the extended use of trochaic lyric is practically confined to Euripides' later plays. Pure lyric trochees are infrequent in Aeschylus and never constitute more than a fleeting modulation in an alien context. ${ }^{44}$ Sophocles was not averse to an occasional sprinkling of lyric trochees, but only in Oedipus at Colonus do we find anything approaching an extensive use of the rhythm in the later Euripidean manner..$^{45}$ Trochaic cola are also rare in our earliest Euripidean plays. But from Supplices on, we find trochaic metres making occasional appearances (as in Sophocles) in contexts not primarily trochaic; then, all of a sudden (as it were), in Helen and Phoenissae we encounter an unprecedented, highly concentrated use of trochaic dimeters, imaginatively varied by syncopation, resolution and catalexis. ${ }^{46}$

Entirely or predominantly trochaic songs in Greek tragedy are:

(a) Hel. 167-78 179-90, 191-210 211-28, 229-252, 330-74: this remarkable string of trochaic songs at the beginning of Helen is quite unparalleled; West and Willink have drawn attention to the presumed novelty of the technique here. ${ }^{47}$

(b) Ph. 239-49 250-60: the second strophic pair of the parodos (first strophic pair is aeolo-choriambic).

(c) $\mathrm{Ph}$. 638-56 657-75, 676-89: first stasimon; the only wholly trochaic choral song in tragedy.

(d) IA 231-41 242-52, 253-64 265-76, 277-302: second and third

${ }^{44}$ Cf. A. Pe. 638 645 (tr: see Parker 1990: 338-339), ScT 351 363 (tr + 1k), 352 364 (2 tr), 355 367 (tr + lk), 832-3 840-1 (4 tr), 975 987 (4 tr), Eum. 496 505 (2 tr). At PV 414$17 \sim 420-22$, there is a surprising sequence of three trochaic dimeters, on which see Griffith (1977: 37-39).

${ }^{45}$ Cf. Ai. 606 620 (2 tr), 607 621 (tr + sp? cr + ba ?), 902 948 (tr + cr), El.1284 (tr + cr + tr), 1285 ( 2 tr), 1286 (2 tr), OT 883 897 (2 tr), 894 907 (2 tr), 895 908 ( $2 \mathrm{tr}+\mathrm{cr}$ ), Trach. 826b 836b (tr), 827 837 (tr + sp), 828 838 (tr + sp), 879 (2 tr), Ant. 360 370 (2 tr + cr), 880 (2 tr), 881 (2 tr), Phil. 864 (2 tr), OC 1080 1091 (2 tr), 1081 1092 (2 tr), 1220 1235 (3 tr), 1221 1236 (2 tr), 1222 1237 (2 tr), 1680 1707 (2 tr), 1681 1708 (2 tr), 1684 1711 (2 tr), 1688 1715 (2 tr), $1730 \sim 1743$ (2 tr), 1731 1744 (2 tr), 1732 1745 (2 tr), 1733 1746 (2 tr), 1734a 1747 (mol + tr), 1734b 1748 (sp + tr), 1735 1749 (sp + 2 tr), 1736 1750 (pa + tr).

${ }^{46}$ The catalectic trochaic dimeter $(-\cup-x-\cup-: \operatorname{tr}+\mathrm{cr})$, known as lecythion, also appears ubiquitously in tragedy as a syncopated iambic colon $(-\cup-\mathrm{x}-\cup-: \mathrm{cr}+\mathrm{ia})$ : see below, p. 40.

${ }^{47}$ Cf. West (1982: 102-3); Willink (2010: 169 n. 4, 176 n. 22). 
strophic pairs of the parodos and ensuing epode. It is doubtful, however, that Euripides composed this sequence. A notable feature here is the use of trochaic lengths one metron longer than in the other songs (e.g. 'sp + lk' 19 times).

(e) IA 1283-1335: Iphigenia's monody (perhaps not Euripidean?). Syncopated trochaics (very much in the manner of Helen) appear in the first part of the song (1283-1318); the rest is anapaestic and dactylic, with a final return to trochaic at $1334-5$.

(f) $O C$ 1724-36 1737-50: duet between Antigone and Ismene; it is impossible to resist the temptation of seeing the influence of Euripides in this, our last song from 5 th century Greek tragedy. No other song in Sophocles uses trochaic dimeters as pervasively.

The fact that the number of predominantly trochaic songs in extant tragedy is so limited makes it difficult to reach any definite conclusion as to the dramatic effect intended by the use of trochaic rhythm. ${ }^{48}$ In $(a),(e)$ and $(f)$, the rhythm is used for threnetic purposes ${ }^{49}$ much in the same way that 'Klaganapäste' are used in Hecuba, Troades or Ion. ${ }^{50}$ In (b), trochaic is again

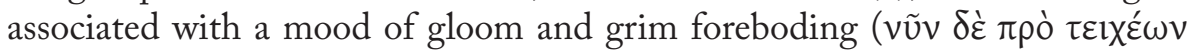

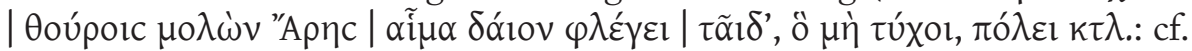
above, p. 33). Deliberate intentions (if any) pertaining to the use of trochaic rhythm in the other songs are more difficult to pin down. In $(c)$, we have a

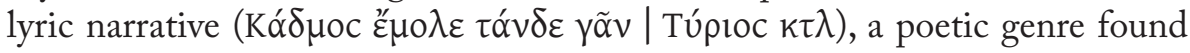
elsewhere in enoplian and aeolo-choriambic rhythm (cf. IT 1234-58 125983; Hel. 1301-18 1319-36, 1337-52 1353-68); however, in marked contrast to the narrative songs in Iphigenia in Tauris and Helen, the lyric narrative in Phoenissae leads into an epode with dirge-like overtones (cf. the significant

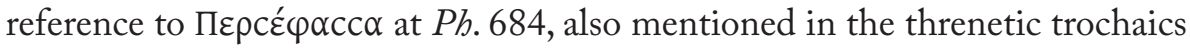

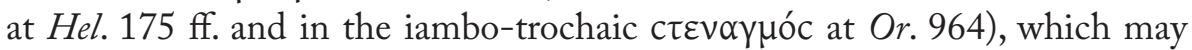
account for the choice of trochaic rhythm. As for the hotch-potch (d), there is no discernible reason for the choice of metre.

\section{1. Trochaic dimeter $(-\cup-x-\cup-x)$}

The most frequent trochaic length to be encountered in Euripidean lyric is the dimeter..$^{51}$ Although the variety of patterns is considerable, the 'standard'

${ }^{48}$ The 'fast and undignified' aspect of trochaic, mentioned by Aristotle (Rhet. 3. 8. 1408b; Po. 1449a), does not apply, as far as we can tell, to the use of the rhythm in lyric contexts.

${ }^{49}$ Compare Anacreon's use of trochaics for lamentation at $P M G$ 419: $\alpha \lambda \lambda^{\prime} \mu \omega \nu$ c' $\tilde{\omega}$

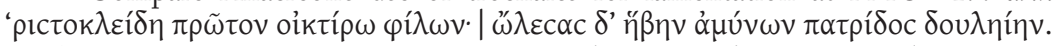

${ }^{50} \mathrm{Cf}$. the anapaestic monodies of Hecuba (Tr. 122-52) and Creusa (Ion 859-922) and the anapaestic duet between Hecuba and Polyxena at Hec. 170-96.

${ }_{51}$ Trochaic monometers are found only at Su. 368b 372b, Or. $967 \sim 978$ (long anceps); and Ph. 1567b, IA 587: these last two examples are of the shape $\cup \cup \cup \cup \cup \cup$. 
form, with short ancipitia $(-\cup-\cup-\cup-\cup)$, is the only shape which can be termed well attested, with just under twenty examples; ${ }^{52}$ all the other shapes occur only a few times each (sometimes only once). Long anceps is generally eschewed in the purely trochaic contexts of the songs listed above - with the notable exception of Iphigenia's monody, where the long ancipitia, found at IA 1307 and 1314, may be an indication that the song was not composed by Euripides..$^{53}$

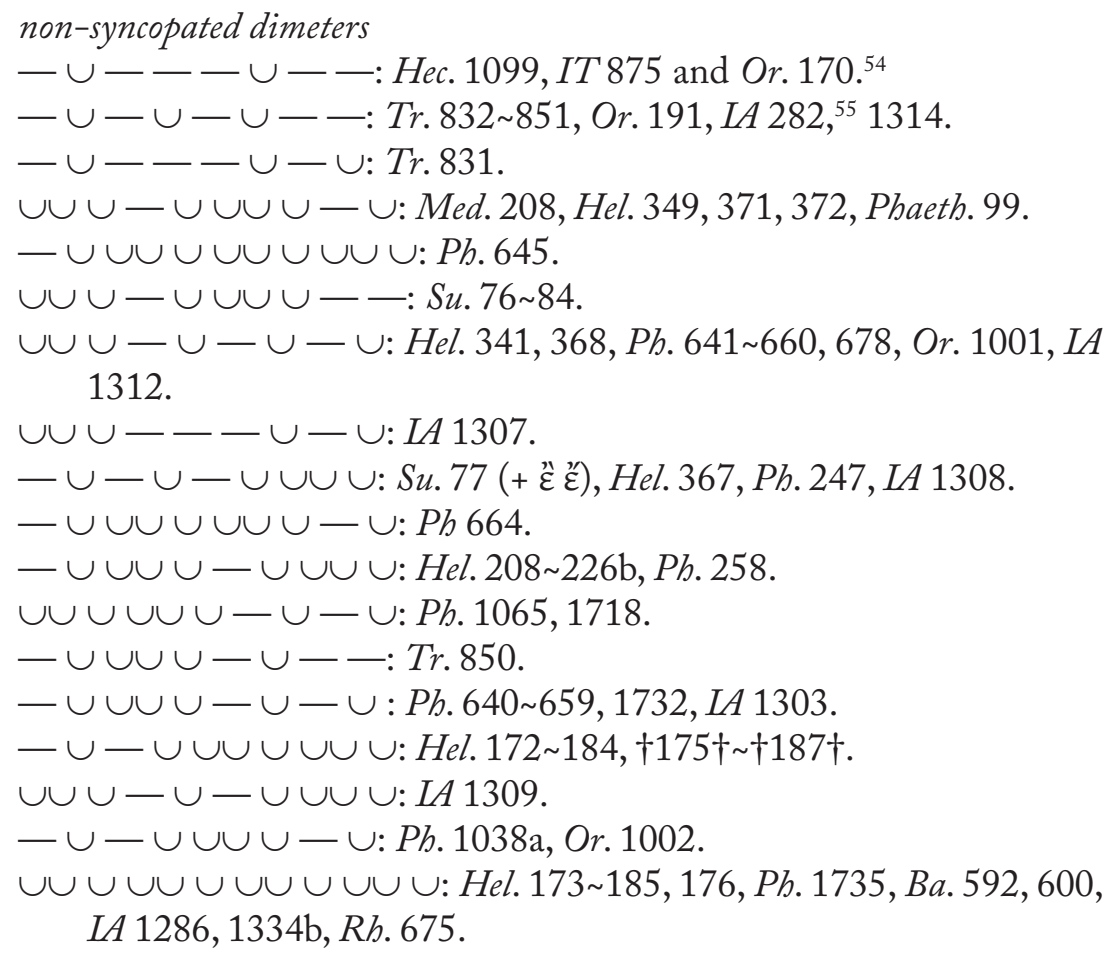

${ }^{52}$ The dimeter $-\cup-\cup-\cup-\cup$ is found at Su. 85 (+ घี है), Herc. 384 398, Tr. 1308 1323, Hel. 205 224, 354, 357a, Ph. 668, 655a 674a, 1019b 1043b, 1062a, Or. 1003, IA 1291, 1292, Cycl. 363.

${ }^{53}$ Diggle's text and colometry smooth away a further instance at 1301, printed by Günther

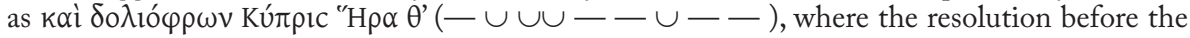
long anceps would be unique. On the question of long anceps in Euripides' late trochaics, cf. Dale (21968: 98); Willink (2010: 178); Mastronarde, comm. Ph., p. 333 n. 1.

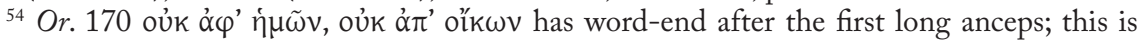
something that tends to be avoided in Greek lyric, as Parker (1966: 1-16) has shown. On p. 16 of this article, however, she accepts this instance on the ground that 'the bisecting of the dimeter produces a metrical parallelism which reinforces the anaphora'. The same explanation applies to

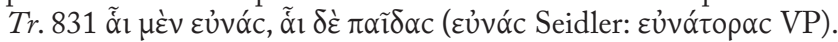

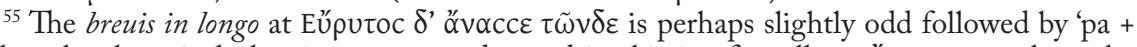

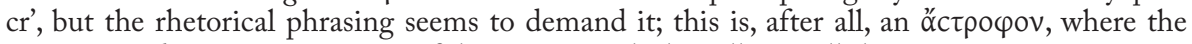
syntactic and semantic structure of the poetry ought literally to call the tune. 
$\cup \cup-\cup \cup \cup \cup \cup \cup \cup$ : Hel. 364, 365, Ph. 1568.

$\cup \cup \cup \cup \cup \cup \cup-\cup:$ Ph. 1041.

$\cup \cup \cup \cup \cup-\cup \cup \cup \cup$ : Hel. 206 225, 207 226a.

\section{2. Syncopated dimeters}

trochaic metron + spondee

$-\cup \cup \cup \cup-\longrightarrow$ : Hel.369b.

$\cup \cup \cup-\cup-\longrightarrow:$ Hel. 209.

$\cup \cup \cup \cup \cup \cup-\longrightarrow$ : Herc. 131, Hel. 201 220, 227.

spondee + trochaic metron

- — $\cup-\cup:$ Hel. 350, Ph. 1039 1063, 1040 1064..$^{56}$

$-\longrightarrow \cup \cup \cup \cup \cup \cup: I A 1285$.

cretic + spondee

$-\cup--\longrightarrow:$ Herc. 132b.

spondee + cretic

$---\cup-:$ Ph. 685.

trochaic metron + palimbacchiac

$-\cup-\cup-\longrightarrow \cup:$ Hel. 174b 186b.

$\cup \cup \cup \cup \cup \cup-\longrightarrow \cup:$ Hel. 177 189.

palimbacchiac + trochaic metron

$-ー \cup \cup \cup \cup-\cup:$ Hel. 351.

$-\multimap \cup \cup \cup \cup-\cup:$ IA 1305.

palimbacchiac + cretic

- $\cup-\cup$ : Hel. 192 212, 200 219, 355, Ph. 677, IA 283, 1293, 1522.

- $\cup \cup \cup \cup-:$ IA 1306.

2 palimbacchiacs

$-\_\cup-\longrightarrow \cup$ : Hel. 353a.

molossus + cretic

$-\leftarrow-\leftarrow \cup-$ : Cycl. 361 .

${ }^{56}$ So Mastronarde, comm.Ph.p. 436; the alternative is ' $m o l+$ ba' (cf.Ion 201), which is not preferable. 


\section{cretic + trochaic metron}

Euripidean trochaic presents a perplexing parallel to the colon 'ba + ia' (discussed by Stinton 1990: 119-28): 'cr + tr', on which see Liapis (comm. $R h .$, pp. 255-6) and Diggle (1994: 424 n. 19), who gives a list of possible Euripidean examples, ${ }^{57}$ on which I offer the following comments:

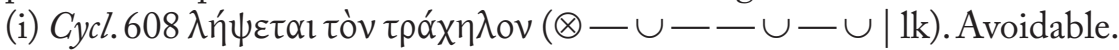
See Willink (2010: 328).

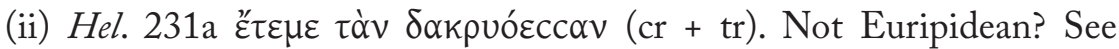
Lourenço (2000: 132-138).

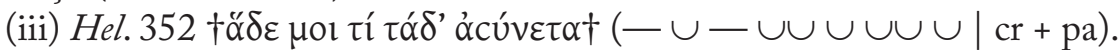
This is part of a curious sequence of trochaic dimeters, where a syncopated first metron is followed by a full trochee:

$$
\begin{aligned}
& ---\cup-\cup \operatorname{sptr} \\
& --\cup \cup \cup \cup-\cup \text { pa tr } \\
& \dagger-\cup-\cup \cup \cup \cup \cup \cup \dagger \text { cr tr }
\end{aligned}
$$

This passage is analysed differently by Dale ${ }^{58}$ and Kannicht $t^{59}$; neither divides so as to give a cr $+\operatorname{tr}$ colon. Since the line is corrupt, for our present purpose it need not be taken into account.

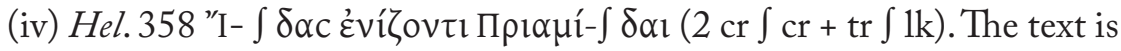

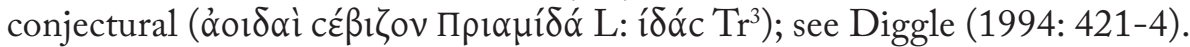

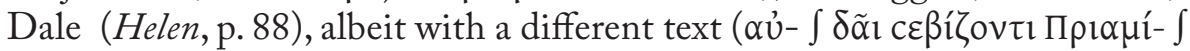
$\delta \alpha \mathrm{l})$, was prepared to accept $\mathrm{cr}+\operatorname{tr}$. Kannicht obelizes $\tau \tilde{\omega} \mathrm{\imath} \tau \varepsilon \dagger c u ́ p \alpha \gamma \gamma^{\prime} \alpha \mathrm{\alpha l}^{-} \int$

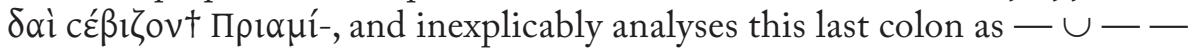

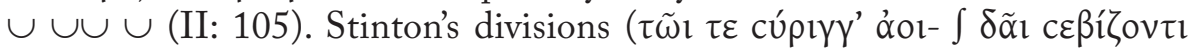

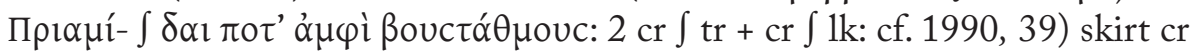
+ tr, but do not solve the problem, as they give a trochaic metron with long anceps, a suspicious phenomenon in late Euripidean iambo-trochaic lyric.

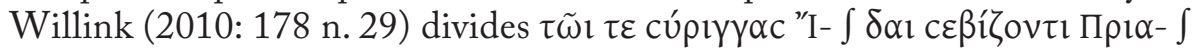
$\mu i ́ \delta \alpha \_\kappa \tau \lambda$, giving cretics ending in an iambic dimeter, against which Diggle makes the valid objection that it would be better to close with a lecythion, the phrase used by Euripides to close each stanza in the parodos as well as Helen's contributions in this lyrical exchange (cf. 1994: 424 n. 20). In view of the insoluble nature of the textual problems (no colometric course is

\footnotetext{
${ }^{57}$ There is a further instance, in Günther's text and colometry, at $I A 1300$.

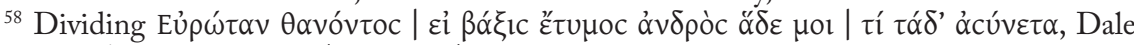
(Helen, p. 88) analyses $\mathrm{sp}+\operatorname{tr}|\mathrm{sp}+2 \operatorname{tr}| 2 \operatorname{tr}$.

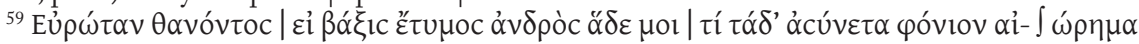
$\kappa \tau \lambda: \mathrm{sp}+\operatorname{tr}|\mathrm{pa}+\operatorname{tr}+\mathrm{cr}| \mid \mathrm{lk} \int \mathrm{pa}+\operatorname{tr}+\mathrm{cr} \|$ (Kannicht, vol. II: 105). However, as we shall see presently, a lecythion in synartesis with the following colon is a sequence Euripides appears to have avoided (cf. below, p. 41 with n. 64).
} 
possible that does not rest heavily on conjecture), I elect to follow Kannicht's conclusion that 'eine sichere Entscheidung... ist nicht möglich' (vol. II: 114).

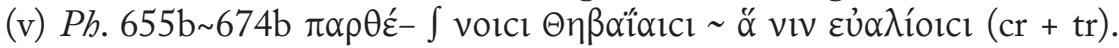
Problems lurk beneath the surface here (see Mastronarde, comm. Ph., p. 334, $339,342-3)$ : the diaeresis of $\alpha \mathrm{l}$ in $655 \mathrm{~b}$ is anomalous. A possible solution

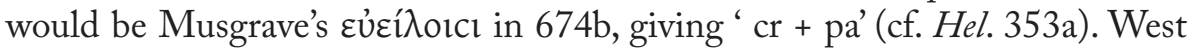

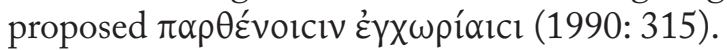

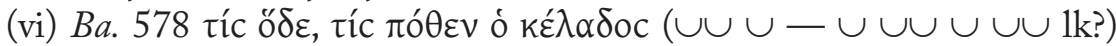
Cf. the lecythion at 589 ò $\Delta$ lóvucoc àvò $\mu \varepsilon \lambda_{\lambda \alpha \theta \rho \alpha}(\cup \cup \cup-\cup \cup \cup \cup \cup \cup)$.

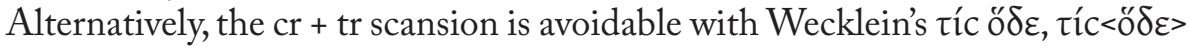
$\kappa \tau \lambda$.

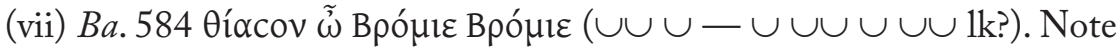
that the following line (585) begins with a lacuna.

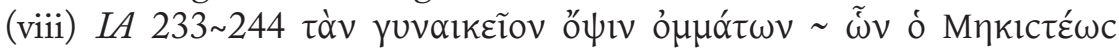

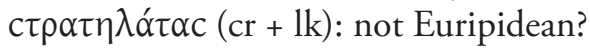

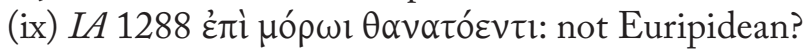

(x) $L A 1304$ Kúr pic, ó $\delta \dot{\varepsilon} \delta o p i ̀ ~ \Pi \alpha \lambda \lambda \alpha ́ c(-\cup-\cup \cup \cup-\cup \|)$ Avoidable

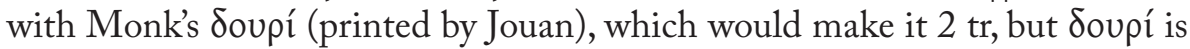
epic and 'a spelling not found in tragedy' (Stinton 1990: 74).

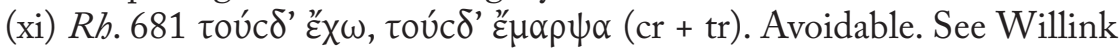
(2010: 578-9).

Differently, then, from ' $\mathrm{ba}+\mathrm{ia}$ ', of which (inter alia) there are eight examples in the Phrygian's monody in Orestes, ${ }^{60}$ ' $\mathrm{cr}+$ tr' is not securely attested in Euripides (or Sophocles). The certain examples are (ii) and (ix), both of which have been suspected of being non-Euripidean. (A. Eum. 324 337, cited by Liapis, is not strictly speaking comparable, given the context and metrical style.)

\subsection{Lecythion}

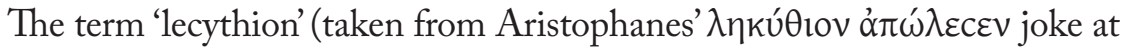
Ran. $1208 \mathrm{ff}$.) is used to describe a dimeter which, because of the frequency with which it appears in iambic lyric contexts, naturally lends itself to the analysis:

$-\cup-\mathrm{x}-\cup-(\mathrm{cr}+\mathrm{ia}=$ syncopated iambic dimeter $)$.

From its occurrence in trochaic contexts, we may equally admit the analysis:

$-\cup-\mathrm{x}-\cup-(\operatorname{tr}+\mathrm{cr}=$ catalectic trochaic dimeter $)$.

Some metricians distinguish between iambic and trochaic lecythia (according to the predominance of either iambs or trochees in the context where the colon occurs); others appear to regard the lecythion as essentially

${ }^{60}$ The references for ba + ia in Diggle's OCT can be found below in chapter 10 ('Repertory of Iambic Cola', p. 122). 
iambic. ${ }^{61}$ Theoretically, it would be possible to distinguish between 'iambic' (acatalectic) and 'trochaic' (catalectic) lecythia. But there is possibly little tangible gain in such a distinction. Euripides and Sophocles often use the 'iambic'lecythion with a clausular effect to mark the end of a metrical period; ${ }^{22}$ this would suggest that, even in otherwise non-trochaic contexts, it sounded somehow intrinsically catalectic (cf. its repeated clausular use in a polymetric - admittedly partly trochaic - lyric context at $B a .579,584,588,589,593$, 603). Another important fact which further reinforces its catalectic status is the avoidance of word overlap between a lecythion and the following colon. This is a striking feature in Euripides and Sophocles, ${ }^{63}$ though (interestingly enough) not in Aeschylus. ${ }^{64}$ A lecythion ending with an elided word is also rare: I have found only three instances in Euripides (Andr. 142, Tr. 830, Rh. 825 ) and none in Sophocles (Aeschylean practice is irrelevant here, since he uses lecythia in synartesis).

It would seem, then, that the trochaic label has the stronger theoretical claim, even in iambic contexts where the lecythion would be the only ostensibly trochaic element. But perhaps it would be preferable to view the lecythion as a genuinely ambiguous rhythm, poised half way between iambic and trochaic, and the ideal gleitender Übergang, therefore, for effecting a transition from one rhythm to the other. Owing to the scarcity of lyric trochees in extant tragedy, however, we find that instances of the lecythion as a transitional phrase from iambic to trochaic are rare: see Su. 368a 372a, Tr. 830 849, Hel. 235-7 and IA 1481-2. Trochaic to iambic: Herc. 386 400, Ph. 1719-21, LA 1315, Phaeth. $100 .{ }^{65}$ A lecythion follows a run of cretics at $P h .317$.

Occasionally, the lecythion provides the means for modulating into iambic (or trochaic) from another rhythm and vice versa:

${ }^{61}$ For lecythia as iambic, see Korzeniewski (21989: 4). Fraenkel, it would seem, viewed lecythia as essentially trochaic (comm. $A g$., vol. II, pp. 59 and 327).

${ }^{62}$ Cf. Alc. 214b 227b, Hi. 1386, Andr. 276 286, 1210 1223, Hec. 706, Su. 366 370, El. 153, 480, Herc. 412, Tr. 1093 1111, IT 867, Ion 1476, Ph. 317, 1750, S. Ai. 868, 871 (||B), El. 208 $\left(||^{\mathrm{B}}\right) 228\left(||^{\mathrm{H}}\right), 855 \sim 866$, OT 199 212, 884 898, 886 900, 888 902, $1338\left(||^{\mathrm{B}}\right) \sim 1358$, Trach. 222, Ant.1139 1148 (|| $\left.{ }^{\mathrm{B}}\right)$, Phil. 1171, $1212\left(\left.\right|^{\mathrm{B}}\right)$, OC 209, $1563\left({ }^{\mathrm{B}}\right) \sim 1575\left(||^{\mathrm{H}}\right)$.

${ }^{63}$ There is a Sophoclean exception at Trach. 133 with the divisions favoured by Dawe as well as Lloyd-Jones and Wilson, but I would sooner follow Jebb in diving 'ia $+\mathrm{cr}|2 \mathrm{tr}| \mathrm{lk}$ '.

${ }^{64}$ There are two doubtful instances in Diggle's OCT: Andr. 484 492, avoidable with Willink's alternative colometry (cf. 2010: 227 n. 17; and n. 70 below); Or. 1370, also avoidable (see Willink's comm. ad loc.). There appear to be no lecythia in synartesis with the following colon in Sophocles, who seems to have regarded it as a 'sentence-ending' rhythm. In Aeschylus, however, we find dovetailed lecythia at Su. 1062-3 1068-9; Ag. 442-4 461-3, 681-3 699-701; Ch. 607 617; Eum. 494 503, 497 506, 515 524, 782 812.

${ }^{65}$ Parker (1990: 331 n. 1) offers a shorter list of examples from Euripides. She rightly draws attention to the fact that the lecythion as a transitional phrase is an important metrical feature of the Frogs' Boating Song (cf. also 1997: 456-67). See also Morais (1995). 
(i) dactylic to iambic: Andr. 294 302, Hel. 1485 1502 ${ }^{66}$.

(ii) iambic to dactylic: $\operatorname{Tr}$. 1093 1111, Ph. 1561, LA $1492\left(2\right.$ ia | lk | D? || $\left.{ }^{\mathrm{B}}\right)$.

(iii) trochaic to dactylic: Ph.1569, Cycl. 609.

(iv) dactylic to trochaic: Cycl. 612.

(v) iambic to choriambic: Alc. 267.

(vi) iambic to dochmiac: $\operatorname{Tr} .1227$ (ia | lk | ho||), Or.1361 1545 (3 ia | $1 \mathrm{k}|\delta| \mid)$.

(vii) enoplian to iambic: $P h .147$ (enop prm | 1k | 3 ia).

Sometimes Euripides uses it independently, almost as an autonomous, not specifically iambo-trochaic, colon: at Hi.67 and El. 153 it appears sandwiched between two glyconics (cf. Hi. 530-4 540-4, where Barrett analyses ph + lk || hept $+1 \mathrm{k} \mid$ reiz || $\mid) ; 67$ at Andr. 136 142, between a dactylic hexameter and a hemiepes; at $P$ h. 1288 1300, a fully resolved lecythion is found between two dochmiacs. Other unusual sequences featuring lecythia are Hi. 1148-50 (D $\cup$ $\mathrm{D}-|\mathrm{lk}|$ ar || $\mid)$, 1385a-6 (2 ba $\left.\int \mathrm{dod}|\mathrm{lk}| \mid\right)$, Ion $1476(2 \delta \mid$ an $|\mathrm{lk}| \mid)$. In the teichoscopia duet in Phoenissae, it is used twice as a transitional phrase to effect a change from enoplian to dactylo-epitrite: cf. 119-121-2 ( $\cup \mathrm{D}|\mathrm{lk}|-$ $\mathrm{e} \cup \mathrm{D}$ sp) and 128-130 (enop | lk $\mid \cup \mathrm{e} \cup \mathrm{D}$ sp); here the lecythion sounds an ambiguous note by lending the epitritic phrase $\mathrm{x}-\cup-\mathrm{x}$ a seemingly iambic lilt. Cf. also $R h .459 \sim 825$ where a lecythion forms the link in the sequence 'cyren ||$^{\mathrm{H}} \mathrm{lk} \mid-\mathrm{D}-\mathrm{e}^{\text {chol'. }}$

There are twelve different shapes of lecythion in Euripides (since the lecythion is properly an iambo-trochaic colon, there seems little point in listing 'iambic' and 'trochaic' lecythia separately; but I add a superscript 'tr' to the unambiguously trochaic instances); although resolution is common, ${ }^{68} \mathrm{a}$ fully resolved lecythion is something of a rarity (cf. Parker 1997: 390):

$-\cup-\cup-\cup-:$ Alc. 214b, 267, Hi. 67, Andr. 136 142, 276 286, 294 302, 1209 1222, 1210 1223, Hec. 706, Su. 780 788, 784 792, 799 812, 1128 1135, El. 1195, 1222 1228, Herc. 132a $\mathrm{a}^{\mathrm{tr}}, 134^{\mathrm{tr}}$, 386 400, 431, Tr. 830, IT 867, Hel. 168 ${ }^{\text {tr }}$ Ph. 129, 147, 317, 338b, 1038b 1062 $\mathrm{b}^{\text {tr }}, 1720^{\text {tr }}, 1740,1741$, Or. 969 980, 997, †1004a†?, 1370 (?), 1372, 1402a, 1408, 1457a, 1460, Ba. 588 232 243, 236, 240 251, 257 269, 259 271, 260 272, 261 273, 276, 278, 280, 296, 298, 299, 1476, 1481, 1482, 1506, 1511, 1520, 1521, Rh. 459 825, Cycl.609, 612, Teleph. II. 5.

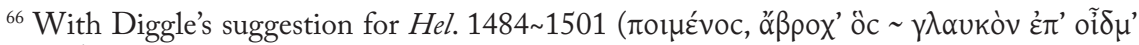

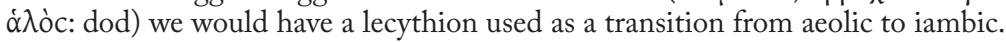

${ }^{67}$ For a lecythion in an aeolic context, cf. also Teleph. II. 5 and Cresph. III 9 (with Diggle's

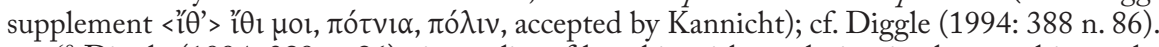

${ }^{68}$ Diggle (1994: 389 n. 86) gives a list of lecythia with resolution in the penultimate long (add Andr. 484 492, Su. 366 370, 623 631, Hel. 178, 1485, Ph. 1567b, 1569, Ba. 578, 584, 589).
} 
$-\cup---\cup-:$ Alc. 227b, Hi. 1149, 1386, IT 865, Hel. †171a †tr, IA 294, 1526.

$\cup \cup \cup-\cup-\cup-:$ Su. 624 632, El. 153, Herc. 412 429, Tr. 849, 1227, Ion 1476, Hel. 167 179 ${ }^{\text {tr }}$, Ph. 314, 1748, 1750, Or. 1361, IA 247, 264, 1490, 1492, 1515, Phaeth. 100.

$\cup \cup \cup--\longrightarrow \cup-:$ El. 480, Ph. 120, ${ }^{69}$ Or. 1545.

$\cup \cup \cup-\cup \cup \cup \cup-:$ Hel. 1485, Ph. 1567b, Cresph. III. 9.

$\cup \cup \cup \cup \cup \cup \cup \cup \cup-:$ Su. 366 370, Hel. $178^{\text {tr }}, 180^{\text {tr }}, P h .1569^{\text {tr }} .70$

$-\cup \cup \cup \cup-\cup-:$ Su. 368a 372a, 1127 1134, Tr. 1093 1111, Hel. $183^{\text {tr }}, 190^{\text {tr }}, 360, P h .1561,1719^{\text {tr }}$.

$-\cup-\cup \cup \cup \cup-: P h .1721^{\text {tr. }}$.

$\cup \cup \cup \cup \cup \cup-\cup-:$ Hel. 1502, Ba. 579, 603 ${ }^{\text {tr }}$, IA 1495.

$-\cup-\cup \cup \cup \cup \cup \cup:$ Su. 623.

$\cup \cup \cup-\cup \cup \cup \cup \cup \cup:$ Su. 631, Ba. 578, 584, 589.

$\cup \cup \cup \cup \cup \cup \cup \cup \cup \cup \cup:$ Ph. 1288 1300, IA 1494.

\subsection{Longer trochaic cola}

As can be seen from the following list, trochaic lengths of more that two metra are a feature that is particularly characteristic of Iphigenia at Aulis:

\section{trochaic trimeter}

$\cup \cup \cup-\cup-\cup-\cup-\cup-\cup: B a .602$

\section{trochaic metron + lecythion}

$-\cup-\cup-\cup-\cup-\cup-$ : Hel. 342-3, IA 293, 1483-4.

$-\cup--\cup \cup \cup-\cup-:$ IA $281 .^{71}$

$\cup \cup \cup-\cup-\cup-\cup-\cup-:$ IA 1335 .

$\cup \cup \cup \cup \cup \cup-\cup-\cup-\cup-:$ Or. 1469.

${ }^{69}$ A further example would be Hyps. fr. 64, 104 in Bond's text and colometry ( $\varepsilon \mu[o ́ \lambda] \varepsilon \tau$ '

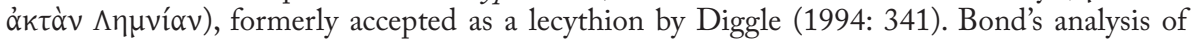
$103-4$ as ' 3 ' ' Hypsipyle, p. 127) was criticised by Parker (1966: 16 n. 1); but since iambic interpretation of this and the preceding line gives word-end after long anceps in both, Diggle is probably right to divide (differently from Bond) as dochmiacs in $\operatorname{Tr} G F S$ (Hyps. 288-9 $+\delta \mathrm{r}^{\prime}$

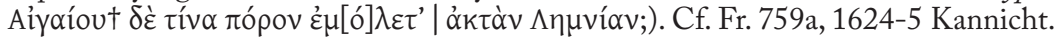

${ }^{70}$ There is a further instance of this shape in the dovetailed lecythia at Andr. 484 492, where Stevens (p. 152) analyses as ia + ba; but a bacchiac with a resolved second syllable is suspicious (see Dale ${ }^{2}$ 1968: 74; Diggle 1981: 49; 1994: 314) and in any case his analysis gives one split resolution at 492 and two at 484 . But a dovetailed lecythion is best avoided in Euripides (see above, n. 64), so Willink's division of the Andromache passage as 'cr + ia $\int 2 \mathrm{ia} \int \mathrm{ith}$ ' is possibly the best solution (cf. 2010: 227 n. 17).

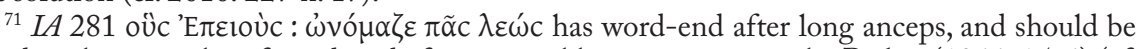
added to the examples of word-end after internal long anceps given by Parker (1966: 15-6) (cf. above, p. 37, n. 54). 
$\cup \cup \cup \cup \cup \cup \cup \cup \cup \cup-\cup-$ : Hel. 194-5 214.

$-\cup \cup \cup \cup \cup \cup \cup-\cup-\cup-$ : IA 1290 .

trochaic metron + ithyphallic ${ }^{72}$

$-\cup-\cup-\cup-\cup-\longrightarrow:$ Ph. 1042 1066.

$\cup \cup \cup \cup \cup-\cup-\cup-—: P h .1733,1757$ (not Euripidean?).

$\cup \cup \cup \cup \cup \cup \cup \cup \cup \cup \cup \cup-—: P h .1756$ (not Euripidean?).

cretic + lecythion

$-\cup--\cup-\cup-\cup-:$ IA 233 244, 253 265, 277.

cretic + trochaic metron + molossus

$\cup \cup \cup-\backsim \cup-\cup--\longrightarrow:$ IA 301 (not Euripidean).

spondee + lecythion

$-\longrightarrow-\cup-\cup-\cup-:$ Hel.191 211, LA 231 242, 237 248, 238 249, 241 252, 254 266, 255, 263 275, 279, 287, 302, Cycl. 613-4, 622.

$-ー \cup \cup \cup-\cup-\cup-:$ IA 245, 267, 288.

lecythion + bacchic

Ph. 248 259.

lecythion + cretic

$-\cup-\cup-\cup--\cup-:$ Cycl. 617.

$-\cup \cup \cup \cup-\cup \cup \cup-\cup-:$ IA 1300.

${ }^{72}$ This is probably best interpreted as a 'trochaeo-iambic' colon; all the instances have

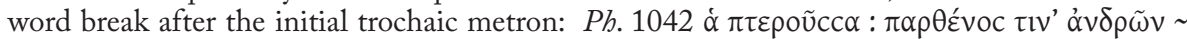

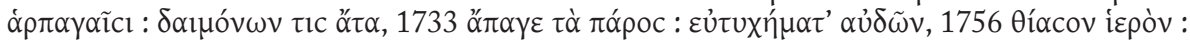

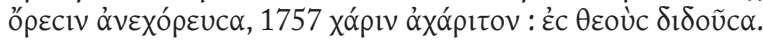




\section{AnApaestic}

The traditional layout of anapaests in the standard editions of Greek tragedy gives the appearance of there being two basic cola in lyric, as in recitative, anapaests: the dimeter and its catalectic version, the paroemiac. Dale, it may be remembered, argued in favour of considering the dimeter the normal anapaestic phrase-length (21968: 48). Nonetheless, that both 'cola' might be nothing more than a figment of the Hellenistic (and, later, Byzantine) imagination - in other words, a meaningless convention adopted down the centuries by generations of copyists - is a probability we must bear in mind (see West 1977: 89-94). However, even West (his disagreement with Dale on this issue notwithstanding) did not go as far as to advocate a change in the way anapaests are printed in our texts, "because any gain would be outweighed by the inconvenience of disturbing standard line-numeration' (p. 94). So anapaestic dimeters will in all likelihood be with us a good while longer.

The one thing we can say with some confidence about anapaests is that the lyric variety is subject to fewer constraints than its recitative counterpart. Take the paroemiac, for instance. Although it is frequently found in lyric as a period-closing phrase and clausula, sometimes with breuis in longo, ${ }^{73}$ it is not exclusively used (as in recitative) to mark the end of a 'system', but can actually constitute the opening line of a run of lyric anapaests (cf. Ion 144, 859), or even be used, as it were, katà ctíxov (cf. Ion 171-5, a run of five paroemiacs). Similarly, period-end can occur independently of catalexis, ${ }^{74}$ as at Ion 167

$$
\lambda \text { í́ }
$$

or at Hi.230-1, where Phaedra closes her anapaestic delirium with

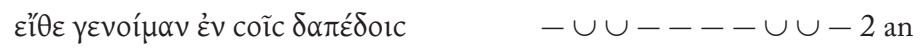

${ }^{73}$ Cf. Diggle (1981: 96-7; add Or. 1454a); for a paroemiac ending in hiatus, see Diggle (1981: 95-6) and (1994: 121; add IT 169, Ph. 827, Phaeth. 82).

${ }^{74}$ Anapaestic dimeters ending in breuis in longo are founded at Med.133 (colometry and text are contentious here: see Diggle 1994: 279-81), El.113=128, IT 125, 193 (but the ensuing text is corrupt), 231, Ion 167; hiatus is found at Med. 132 (although the phenomenon may not be exactly the same, since here we have correption), El. 112=127, 113=128, IT 146, Ion 153, Cycl. 51, Phaeth. 82. This list differs slightly from the one offered by Diggle (1981: 96-7). 


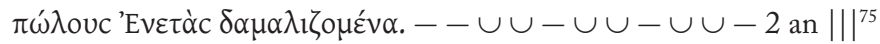

A third, not infrequent, length is the anapaestic monometer, which can be used to close a period in much the same way the paroemiac is used in recitative (e.g. IT 202), or else merely as an alternative to the dimeter, as at Tr. 168-72:

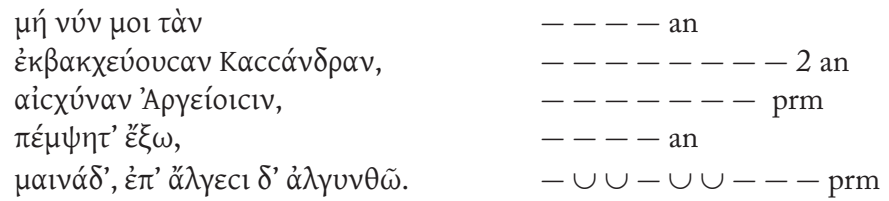

The characteristic metron-pattern in anapaests $(\cup \cup-\cup \cup-)$ is often varied by the used of $-\cup \cup$ or -- in place of the 'foot' $\cup \cup-$. This means that it is not infrequent to come across anapaestic dimeters that look remarkably like dactylic lengths - so much so that at $P h .1546-59$, for instance, it is uncertain whether dactylic or anapaestic scansion is preferable. ${ }^{76}$ It will be noticed that, particularly in Euripides' later lyric, shapes consisting mostly or even entirely of long syllables predominate.

A typical feature of anapaestic versification is the observance of metrondiaeresis (which I indicate ':'). Lyric anapaests are less rigid in this respect than recitative (where, in any case, over-run of one short syllable is permissible), particularly in lengths that are wholly or partly spondaic; ${ }^{77}$ nevertheless, erstrebte Wortgrenze between metra does exert a certain influence on the mode of utterance used in anapaestic lyric: the phrases tend to be short and concentrated, sometimes balancing each other by means of anaphora. ${ }^{78}$ This

${ }^{75}$ There are other full dimeters at change of speaker in this sequence (cf. Diggle 1994: 315).

${ }^{76} \mathrm{I}$ would be inclined to prefer anapaests, in view of the paroemiacs at $\mathrm{Ph} .1547-8$ and the

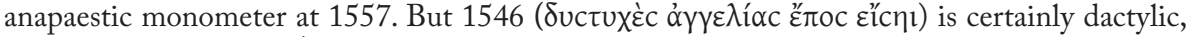
as is the sequence ' $6 \mathrm{da} \mid 2$ da' at $1549-50$ and 1558-9.

${ }_{77}$ Metron-diaeresis in lyric dimeters is absent at Hi. $\nmid 1374 \dagger$, Hec. 156, 170, 178, 194, 195 , 203, 206a, Tr. 127, 143a, 166, 169 191, 182, 195, 203 220, 204 221, 210, 215, IT 125, 133-4, $140,148,149$ (over-run of single short), 158, 160, 161, 162, 181, 186, 187, 198-9, 201, 205, 227, 228, 230, Ion 158, 159, 164, 165, 180, 181, 182, 881, 883, 893, 910, 917, 919, Ph. 826, IA 1320, Phaeth. 79 87 (over-run of single short), 80 88, 81 89 (over-run of single short), Hyps. 69, 72, 261. Metron-diaeresis in lyric paroemiacs is absent at Alc. 97, 105, Hec. 69, 72, 89, 179, 184, 188, Tr. 126, 137, 142, 152, 158 181, 160 183, 163 186, 167 171, 200 217, 224, 229, IT 129, 131, 132, 136, 152, 155, 156, 163-4, 165, 166, 191, 210, 212, 235, Ion 146, 151, 155, 156, 157, 169, 172, 173, 174, 887, 892, 897, 898, 903, 907, 922, Or. 1427, 1454a, LA 116, 122, 132, Phaeth. 83.

${ }^{78}$ Dale (21968: 49) makes this point in her account of recitative anapaests, citing $\operatorname{Tr} .102$

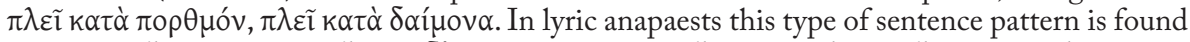

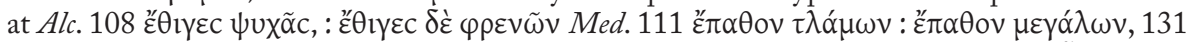

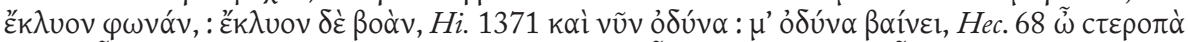

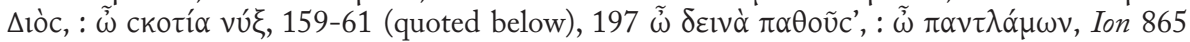

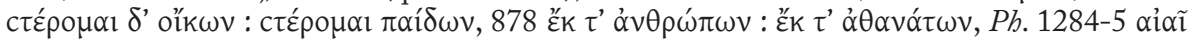


concentration of phrases that are self-contained syntactic and semantic cells, marked off from each other by metron-diaeresis, is particularly noticeable in so called Klaganapäste, where we sense a deliberately halting, 'unflowing' mode of lyric utterance. ${ }^{79}$ Consider, for instance, Hecuba's anapaestic lament at Hec.

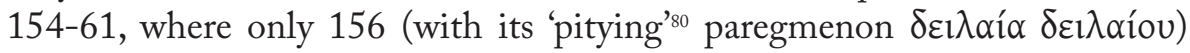
lacks metron-diaeresis:

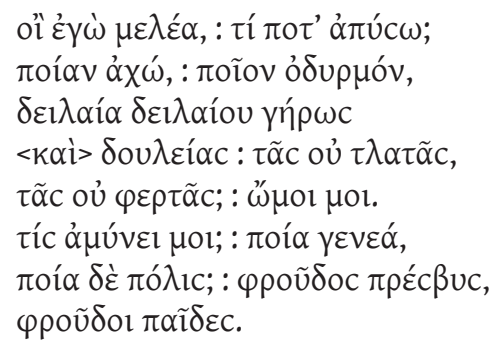

In other monodies - the lyric genre where anapaests are most often used by Euripides -, this intrinsic lack of fluidity does not always suit the overflowing intensity of feeling that usually prompts song in the first place; so it is not surprising that Hippolytus, overburdened with choking emotions, should shift into iambic after an opening run of anapaests (Hi. 1370-8), the better to pour out his feelings in an unrestrained gush of syncopation, resolution and word-overlap (1379-88).

Coincidentally, Hippolytus' monody presents a bizarre instance of two anapaestic dimeters in synartesis (Hi. 1374-5):

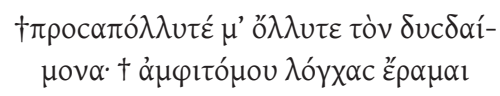

Barrett's claim (comm. Hi. p. 405) that 'such overruns are admissible in lyric anapaests' slightly overstates the case since, other than Or. 1434-5, there is only one other (doubtful) instance in Euripides. ${ }^{81}$ Dale (21968: 68) considers

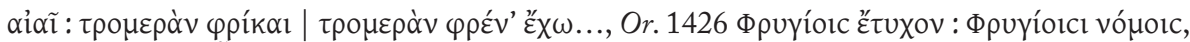

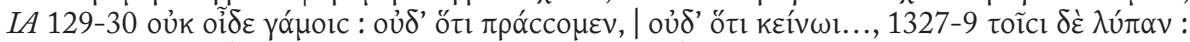

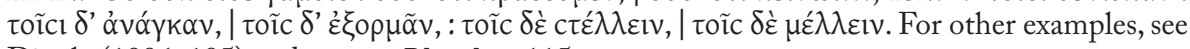
Diggle (1996: 195) and comm. Phaeth.p. 115.

${ }_{79}$ West (1982: 122) prefers to link up the 'halting' quality of anapaestic lyric with catalexis, rather than with metron diaeresis.

${ }^{80} \mathrm{Cf}$. Willink (2010: 163 n. 78). As it happens, the two other dimeters in this sequence also

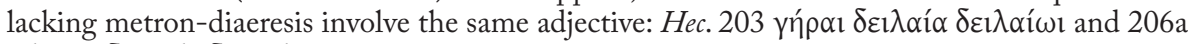

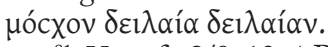

${ }^{81}$ Hyps. fr. 8/9. 13-4 Bond (2 an $\int$ an) = Fr. 753c, 19-20 Kannicht. But we can alternatively divide 'an $\mid 2$ an'; so the example is far from decisive. 


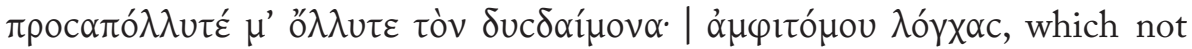
only 'strikingly presents an uncompromising hiatus after the resolved close', but gives a length that, apart from the oddity of the shape, is unparalleled. In view of all this, the OCT's obeli are the only acceptable course.

Another rare phenomenon in anapaestic contexts is resolution. The known examples are Hi. 1372, IT 231, Or. 1397, 1485, 1486.

A problematic case which has been the object of anapaestic interpretation

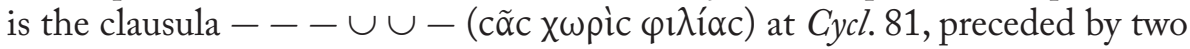
anapaestic dimeters. Parker (1997: 58) associates it with alleged examples of 'a sort of hybrid colon which is typically found in conjunction with dochmiacs in anapaestic contexts'. On the other hand, the fact that this óctpopov is otherwise predominantly aeolic led Diggle (1994: 37) to prefer 'dodrans' (i.e. aeolic hexasyllable). The colon also occurs in an unmistakably anapaestic context at Phaeth. 84 92, where Diggle again prefers aeolic scansion on the ground that 'aeolic cola do occasionally appear among anapaests'. ${ }^{82}$ It is difficult to choose between either of these contrasting approaches to the problem; perhaps Wilamowitz's merely descriptive, noncommittal 'stumpf ausgehender Kurzvers' (1921: 225) is still preferable.

The following repertory lists all the lyric anapaests in Euripides, except those found among dochmiac or other non-anapaestic cola in enoplian contexts (see pp. 76-7).

\section{1. Anapaestic monometer}

$$
\begin{aligned}
& \cup \cup-\cup \cup-: \text { Hi. 1377, 1381b, Tr. 143b, IT 153, Ion 166, 914, Or. } \\
& \text { 1488a, Hyps. 70, 73, 110. } \\
& --\cup \cup-: \text { Hi. 217, 222, Hec. 83, Tr. 140, 149, Ion 868. } \\
& \cup \cup---: \text { Hec. 187, 193, IT 202, Ion 163, 873, Ph. } 1557 . \\
& -\cup \cup-\cup \cup: \text { Ion 176. } \\
& -\cup \cup--: \text { IT 151, Ion 879, IA 121, 1326, 1329. } \\
& ----: \text { Alc. 110, Med. 150 175, Hi. 1370, Hec. 86, 161 204, 180, } \\
& \text { Tr. 134, 164 187a, }{ }^{83} \text { 168 190, 170 192b, 172b 193b, IT 123, 143, } \\
& \quad 157, \text { Ion 145, 147, 160, 904, Cycl. 49. } \\
& \cup \cup \cup \cup \cup \cup-: \text { Hi. 1372. }{ }^{.4}
\end{aligned}
$$

\footnotetext{
${ }^{82}$ Cf. comm. Phaeth. p. 104-5. Dale (21968: 59), discussing the odd glyconics among anapaests at $T r$. 124-5 with tribrach opening and cholosis in the penultimate element, to whom Diggle appeals, is not very helpful: other than Tr.124-5 and Cycl.41-81, she gives two further examples, Ion 504-8 and El.122 ff. The first example is quite free of anapaests in Diggle's OCT; the second, with two anapaestic dimeters at the head of a wholly aeolic stanza, is not really a case of 'aeolic cola appearing among anapaests'.

${ }^{83}$ See Diggle's discussion of ic̀ íú as an anapaestic monometer (1994: 118-9).

${ }^{84}$ According to Diggle (1994: 315), the only Euripidean instance of an anapaestic metron beginning with four shorts that is 'above suspicion'.
} 


\section{2. Anapaestic dimeter}

$\cup \cup-\cup \cup-\cup \cup-\cup \cup-:$ Tr. 218, IT 130, 137, Ion 900, Ph. 825, 1285, Or. 1398, 1403, 1406, 1455, 1487, Phaeth. 79 87, 81 89, 85 93, Hyps. 69, 71, 72, 108, 109.

$\cup \cup-\cup \cup-\cup \cup \cup \cup \cup \cup-:$ Or. 1486 .

$\cup \cup-\cup \cup-\cup \cup---:$ Hec. 154, Tr. 153, 222, IT171.

$\cup \cup-\cup \cup---\cup \cup-:$ Med. 144, 163, Hi. 218, Tr. 151, Ion 862, 875, Or. $1428,1435$.

$\cup \cup-\cup \cup--\cup \cup--:$ Hi.209, Hec. 71, Tr. 201, Ion 161.

$\cup \cup-\cup \cup--\cup \cup-\cup \cup: I T 176$.

$\cup \cup-\cup \cup-----:$ Tr. 178, IT 158, Ion 882, 883.

$\cup \cup----\cup \cup--:$ Hi. 210, IT 180 .

$\cup \cup----\cup \cup-\cup \cup:$ Hec. 181, IT 138 .

$\cup \cup---\cup \cup---:$ Alc. 95, Hi. 1376, Tr. 156, Ion 865.

$\cup \cup---\cup \cup-\cup \cup-:$ Alc. 108, Med.111,131, Tr. 165, Ph. 1297, IA 128.

$\cup \cup-----\cup \cup-:$ Hec. 159, IT 159, Ion 162, 170, Phaeth. 80.

$\cup \cup-------: \operatorname{Tr} .155,202$.

$-\cup \cup-\cup \cup-\cup \cup-\cup \cup:$ Med.160, Ion 921, Ph. 1555.

$-\cup \cup-\cup \cup-\cup \cup--:$ Med. 166, Hi. 215, Hec. 68, IT 223, Ph. $1554,1556$.

$-\cup \cup-\cup \cup--\cup \cup-:$ Hec. 70, IT 149, Ion 920.

$-\cup \cup-\cup \cup----: \operatorname{Tr} .145$, Ion 177, 918.

$-\cup \cup-\cup \cup \cup \cup-\cup \cup-: \operatorname{Tr} .177$.

$-\cup \cup \cup \cup-\cup \cup-\cup \cup-: T r .194$.

$-\cup \cup \cup \cup \cup \cup \cup \cup-\cup \cup-:$ IT 231.

$-\cup \cup-\cup \cup \cup \cup \cup \cup--:$ Or. 1485.

$-\cup \cup--\cup \cup---:$ Alc. 96, Med.113, 161, Hec. 87, Ion 874.

$-\cup \cup--\cup \cup-\cup \cup-:$ Hi. 216, 221, Tr. 131, 154, IT 170, Ion 863, 864.

$-\cup \cup---\cup \cup--:$ Med.112, Hec. 85, 1070, IT141, 175, IA 1327, Cycl.78-9.

$-\cup \cup---\cup \cup-\cup \cup:$ Hec. 79, IA 130.

$-\cup \cup----\cup \cup-:$ Med. 165, 173, Hi. 230, Hec. 80, 81, 202, Tr. 206, Or. 1404.

$-\cup \cup------:$ Med.148, Hi.220, Tr. 180, 159 182, 166.

$--\cup \cup---\cup \cup-:$ Hi. 229, 1378, Hec. 1065, Tr. 176, Ion 167, 872, Cycl. 50, 80, Phaeth. 88.

$--\cup \cup-\cup \cup-\cup \cup-:$ Alc. 109, Med. 96, 164, Hi. 231, Hec. 84, 1075, Tr. 139, 150, IT 209, Ion 870, 871, 876, Ph. 826, Or. 1434. 
$--\cup \cup-\cup \cup---:$ Med. 146, Hi. 208, 211, 219, 1371, Tr. 184, IT 146, Ion 905, ${ }^{85}$ Or. 1405.

$--\cup \cup--\cup \cup-\cup \cup:$ IA 129.

$--\cup \cup \cup \cup--\cup \cup-:$ Or. 1397.

- - $\cup \cup--\cup \cup--:$ Med.162,167, Hi.228, Tr. 132, Ion 867.

$--\cup \cup-----$ : Hi.1373, Hec. 160, 197, Tr. 161.

$---\cup \cup-\cup \cup--:$ Ion 866.

- - - - $\cup \cup--:$ Med. 97, ${ }^{86}$ Hec. 155, 172, Tr. 162, IT 166, 173-4.

$-----\cup \cup-\cup \cup:$ Med. 132.

$----\cup \cup-\cup \cup-:$ Hec. 177, 1069, 1081-2, Tr. 135, 211, 223, IT 160, 182, 196.

$----\cup \cup--\cup \cup:$ Hec. 88

$----\cup \cup---:$ Hec. 186, 1076, El. 112 127, 113 128, Tr. 212, Ion 153, 877, 912, ${ }^{87}$ Ph. 1284 1296, LA 120.

- - - - $\cup \cup-:$ Hec. 198, Tr. 205, 228, IT 193, 200, 228, Ion 878, Ph. [1575], LA 1319, Cycl. 51.

$-------\cup \cup: \operatorname{Tr} 199$.

- - - - - - : Med. 149 174, Hec. 156 199, 157, 158, 203, 162 205, 163 206a, 170, 178, 189, 194, 195, Tr. 127, 138, 143a, 146, 185, 187b, 188, 169 191, 173, 174 195, 197 214, 198 215, 216, 219, 203 220, 204 221, 210 226, 227, IT 124, 125, 133-4, $139,140,145,148,161,172,178-9,181,183-4,186,187,192,198-$ 9, 201, 205, 208, 217, 218, 221, 222, 224, 227, 229, 230, 234, Ion 154, 158, 159, 164, 165, 181, 182, 881, 884, 893, 910, 917, 919, Ph. 1553, $L A 119,1320,1324,1325,1328$.

\section{3. Paroemiac}

$\cup \cup-\cup \cup-\cup \cup--:$ Med.147, Hec. 69, 72, 192, Tr.193a, Ph.1547, 1548, Or. 1429, Phaeth. 82.

$\cup \cup-\cup \cup----:$ Or. 1427.

$\cup \cup--\cup \cup \cup \cup--:$ IT 215 .

$\cup \cup---\cup \cup--:$ Ph. 827.

$\cup \cup------:$ IT 206, 211.

$-\cup \cup--\cup \cup--:$ Alc.111, Med.114.

$-\cup \cup-\cup \cup---:$ Tr. 172a, Or. 1454b.

$-\cup \cup \cup \cup----: \operatorname{Tr} .123$.

\footnotetext{
${ }^{85}$ With Diggle's <k $\alpha \grave{>}$, printed in the OCT.

${ }^{86}$ Following Page (ed.Med.p. 190) in scanning the first syllable of i $i \omega$ as long; to the parallels adduced by Page, add Ion 912 and the other instances cited by Diggle (1994: 118-9).

${ }^{87}$ Cf. Diggle (1981: 107).
} 
$-\cup \cup-----:$ IT 132, Ion 171.

$--\cup \cup-\cup \cup--:$ Alc. 93, 97, 105, 107, Hec. 82, IT 165, Ion 860, 869, 880, Phaeth. 83 91.

$--\cup \cup----:$ Ion 913.

$---\cup \cup \cup \cup--:$ IA 123.

- - - $\cup \cup--$ : Hec. 89, 164, 196, Tr. 208-9, IT 235, Ion 183, 861, 922, Phaeth. 90.

- - - - - - : Hec. 171, 179, 183, 184, 188, 191, 1071, Tr. 122, 126, 130, 133, 137, 141, 142, 152, 158 181, 160 183, 163 186, 167 189, 171 192a, 175 196, 200 217, 207 224, 213 229, IT $128,129,131,135,136,144,147,152,154,155,156,163-4,167$, $168-9,177,191,203,207,210,212,214,216,219$, Ion 144, 146, $151,152,155,156,157,168,169,172,173,174,175,179,859,885$, 887, 888, 891, 892, 897, 898, 899, 901, 902, 903, 907, 911, 915, Or. 1454a, $L A 115,116,122,131,132,136,137,1323$. 


\section{Dochminc}

Dochmiac rhythm with its strong emotional overtones - expressing agitation, despair and, in later Euripidean tragedy, joy - is the quintessential dramatic lyric metre. Although there are fleeting intimations of a protodochmiac of sorts in Pindar, ${ }^{88}$ it is otherwise absent from extant non-dramatic lyric, with the exception of the Hellenistic Fragmentum Grenfellianum, itself a somewhat debased descendant of Euripides' later monodies. ${ }^{89}$ We owe our present understanding of dochmiac lyric to Seidler's De Versibus Dochmiacis (1811-12). The principles of dochmiac versification seem not to have been grasped by Byzantine scholars, as can be inferred from the tangled scansions which led even a metrical authority (comparatively speaking) like Triclinius to distort dochmiac passages in the metrical notes he jotted down in L. ${ }^{90}$ Manuscript divisions of lyric cola often show that an attempt was being made to cope with the unfamiliar dochmiac rhythm by shaping lines into iambics ${ }^{91}$ generally by the omission or interpolation of monosyllables, ${ }^{92}$ but also, on occasion, by changing the word order. ${ }^{93}$ An interesting example concerning a more ambitious interpolation is found in the text of Orestes, a popular play in Antiquity and throughout the late Byzantine period. At. Or.

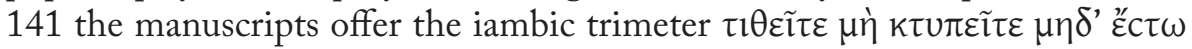

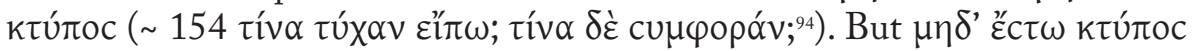
is omitted in a quotation of this sequence by Dionysius of Halicarnassus ( $D e$

${ }^{88}$ In Pyth. 5, the phrase $\cup-\cup \cup-$ appears in line 6 of the strophe marked off from the preceding and the ensuing cola by word-end. Cf. also Pyth. 7 (line 5 of strophe: $\cup \cup \cup-\cup$ -). However, see Dale (1969: 66), who regards 'dochmiac as a misleading notion in Pindar'.

${ }^{89}$ For the text, see $C A$ (pp. 177-9). Powell himself seems to have found this gauche song rather charming: 'sententiarum proprietate, stili concinnitate, numerorum varietate et elegantia, haud ignobile carmen indicatur' (p. 179). For the metre, see Battezzato (2009).

${ }_{90} \mathrm{~A}$ good example of this is the 'recognition duet' in Helen, where Triclinius misguidedly interfered with the division of transmitted dochmiacs at $628,648,664,676,677,696$. Cf. Zuntz (1965: 214, with the note $\dagger$ ).

${ }^{91}$ Cf. Zuntz (1965: 30-1, 37, 214); Willink (2010: 141).

${ }^{92}$ See Mastronarde-Bremer (1982; 158-60); Diggle (1991: 132-4); cf. also Barrett on Hi. 365; Dunbar, comm. Birds p. 49; Parker (1997: 337).

${ }_{93}$ There is a fascinating example at Ar. Ach. 361, revealing that Triclinius was quite at sea when it came to analysing dochmiacs: cf. Parker (1997: 134).

${ }^{94}$ Triclinius tried unsuccessfully to solve the problematic responsion by substituting $\pi$ oí $\alpha \mathrm{v}$ for $\tau$ íva, giving an unsyncopated trimeter corresponding with a syncopated one, a licence Euripides is unlikely to have used (cf. Diggle 1994: 314). 
Compositione Verborum 11.63); more importantly, it is apparently omitted by the Hellenistic papyrus (P. Köln $131=252$ ) which is our oldest witness for this passage. Possible incomprehension of the dochmiac monometers

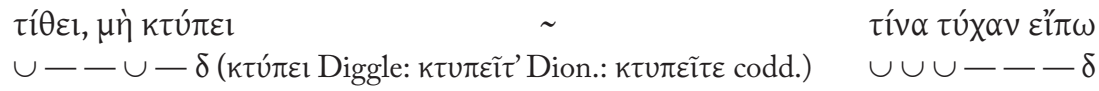

may explain how the interpolation originated..$^{95}$

The fact that our manuscripts of Greek drama were copied during a period when knowledge of lyric metre was so hazy makes it difficult to establish with certainty the standard dochmiac lengths (if any), although editors generally divide runs of dochmiacs in monometers and dimeters. ${ }^{96}$ The same question that West (1977: 89) asked of anapaestic dimeters could, of course, be asked of dochmiac dimeters: did they really exist? Conomis, in a valuable survey of all the dochmiac shapes of Greek tragedy, satyric drama and comedy, ${ }^{97}$ took the metron

$\mathrm{x}-\mathrm{x}-$

and its 32 mathematically possible variations - rather than the dimeter — as the basis of his inquiry. ${ }^{98}$ There is a valid reason for doing this: a significant percentage of the dochmiacs of Greek tragedy are self-contained units, marked off from each other by word-end. ${ }^{99}$ And the difficulties which would arise by postulating dimeter and trimeter lengths (as in iambics, for instance) are obvious. Take the following sequence from Electra (590-5):

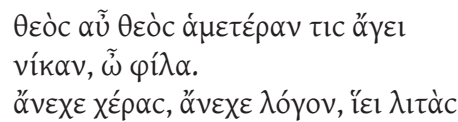

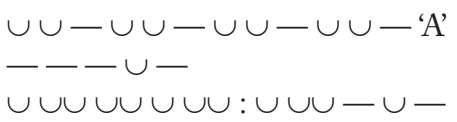

${ }^{95}$ Cf. Barrett, comm. Hi. p. 302 (on responding lyric interpolations); West, comm. Or. p. 132; Diggle (1991: 120,132). Willink does not accept these deletions, but he admits that 'either

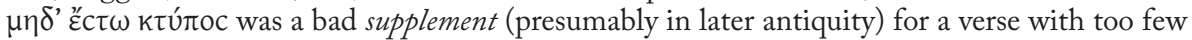
syllables... or an intolerably corrupt line was pruned by some ancient editor' (comm. Or.p. 107).

${ }^{96}$ Willink even championed the dochmiac 'trimeter': ' $3 \delta$ is a common length, which need not be divided (arbitrarily) as $2 \delta \mid \delta$ or $\delta \mid 2 \delta$ or $\delta|\delta| \delta$ ' (2010: 241 n. 3).

${ }^{97}$ Conomis (1964: 23-50). For comedy, see Parker (1997: 65-9).

${ }^{98}$ It is prima facie rather difficult to see how the hypodochmiac $(-\cup-\cup-)$ and the dochmius kaibelianus $(\mathrm{x}-\cup-\cup-$ ) can be variations on $\mathrm{x}--\mathrm{x}-$; but the fact that, in their rare appearances, they are used as dochmiacs tells against a hypothetical (and at any rate equally 'abnormal') iambic identity. West's (1982: 110-11) Euripidean examples of a hypodochmiac responding with a normal dochmiac (Tr. 309 326), or a kaibelianus of the shape $-\cup \cup \cup \cup \cup-$ in responsion with $-\cup \cup-\cup-$ at Ba. 983 1003 are based on a corrupt text.

${ }^{99}$ Cf. Parker (1958: 17; 1997: 65). Her percentages for self-contained dochmiacs marked off by word-end are $72 \%$ for Aeschylus; 66\% for Sophocles; and 60\% for Euripides. 


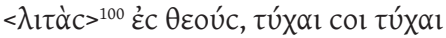

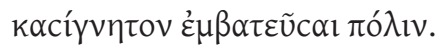

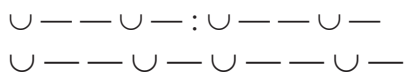

Although these seven dochmiacs are printed as a monometer followed by three dimeters, other (perhaps equally arbitrary) arrangements would be possible; and even if we did reach what we thought was the most satisfactory layout, we still would not be any the wiser as to whether that was what Euripides would have wanted. ${ }^{101}$

Having made this point, I tentatively draw attention to a problem where the hypothetical shape of putative dochmiac 'dimeters' might reinforce a conclusion that had already been reached by other means. IA 1284-90 has nearly always been interpreted as a run of 10 dochmiacs, most recently by Jouan, Günther and Stockert, although this analysis reaches back further. ${ }^{102}$ Here is the text laid out as dochmiacs by Murray in his ${ }^{2} 1913$ OCT (for the sake of convenience, both here and in the repertory below, I use the same numbers used by Conomis to identify each dochmiac shape):

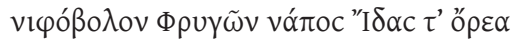

(2) $\cup \cup \cup-\cup-$ : (?) $\cup \cup-\longrightarrow \cup \cup \cup$

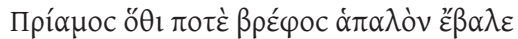

(5) $\cup \cup \cup \cup \cup-:$ (6) $\cup \cup \cup \cup \cup \cup \cup \cup$

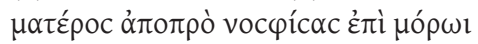

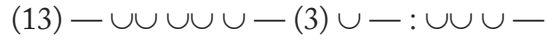

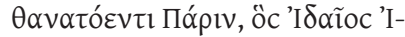

(8) $\cup \cup \cup-\cup \cup \cup:(3) \cup-\longrightarrow \cup-$

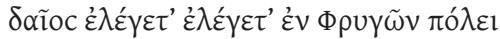

(14) - $\cup \cup \cup \cup \cup:(h \delta)-\cup-\cup-$

As the repertory given below will show, most of these dochmiacs are unexceptionable and securely attested in Euripides, with the exception of $\cup \cup-\_\cup \cup$, a dochmiac with resolved anceps, and (14), a rare form

${ }^{100}$ Matthiae's $<\lambda ı \tau \grave{̀} \mathrm{c}>$ is not actually printed in the text of Diggle's vol. II, but it is necessary to avoid a solitary cretic interposed in the middle of a sequence of dochmiacs, a phenomenon for which there is no secure attestation, as Diggle points out (1994: 375): iambic elements are more likely to appear at the beginning of a sequence of dochmiacs, rather than at the end or in the middle.

${ }^{101}$ An indication that he perhaps did not think in terms of dimeters but monometers is

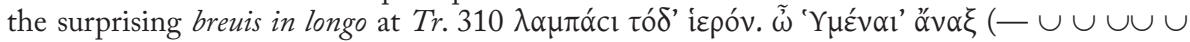
$\cap:-\cup \cup-\cup-$ ); cf. below, p. 57. In iambics, a dimeter such as $x-\cup \cap x-\cup \cup$ would certainly be unthinkable.

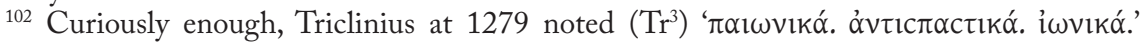
The designation $\alpha \dot{\nu} \tau \iota c \pi \alpha c \tau \iota k \alpha ́$ was one of Triclinius' terms for sequences we now analyse as dochmiac (cf. Zuntz 1965: 37). 
of $\delta$ (unattested, furthermore, in combination with a hypodochmiac ${ }^{103}$ ). On the vexed question of dochmiacs with double short for either anceps, there is nothing to add to the discussions of Conomis, Barrett and Diggle; ${ }^{104}$ it will be enough to remark that its presence here is enough to make dochmiac scansion less than prudent, should a better alternative present itself.

But it might be as well to look into the rare dochmiac shape $-\cup \cup \cup \cup$ $\cup \cup \cup$. Conomis (p. 25) lists four instances in Sophocles (El.1247 1267, OT 661 692) and five in Euripides (Herc. 1084, Tr. 326, IT 870, Ph.1533, LA 1290)

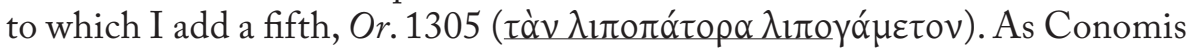
states, the Sophoclean instances and IT 870 are certain examples; and, if allowances are made for the disparity of divergent readings characteristic in a play which formed part of the Byzantine triad, ${ }^{105}$ the same may perhaps be said of the example from Orestes. Of the four remaining Euripidean attestations of this form of dochmiac, two are eliminated in Diggle's text: $\operatorname{Tr} .326$ (= 325 308 Diggle) is printed with Hermann's supplement, which makes it an example of $\cup \cup \cup \cup \cup \cup$-; and $I A 1290$ is printed as trochaic.

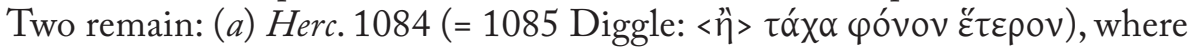
the shape depends on Wilamowitz's supplement $\langle\hat{\eta}\rangle$, since the transmitted text is one syllable short; but other arrangements (giving a wholly resolved $\delta$ ) are possible, if not necessarily more appealing (see Bond ad loc.); and (b) Ph.

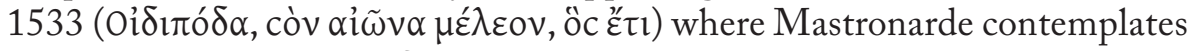
an alternative analysis as $\delta+2$ cretics, with breuis in longo (see comm. Ph., p. 560).

We can now ask after the standing of the combinations given by these dochmiacs when taken as 'dimeters' and if they are otherwise attested in Euripides. (2) $+\cup \cup--\cup \cup \cup$ is immediately suspicious, since the second metron has double short for initial anceps; and (14) $+\mathrm{h} \delta$ is, as noted above, unparalleled. The remaining combinations are:

(i) $\cup \cup \cup \cup \cup \cup-+\cup \cup \cup \cup \cup \cup \cup \cup$ : this combination is found once in Sophocles (OT 1330), but not otherwise in extant tragedy. In any

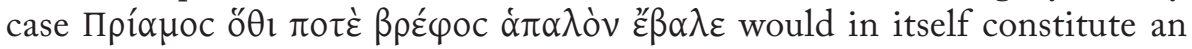
uninspiring second example, since lengthening the second syllable of $\pi 0 \tau \dot{\varepsilon}$

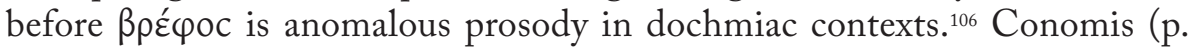
40) suggests

${ }^{103}$ The combination $\delta+h \delta$, although in itself unobjectionable, is quite rare: in tragedy I have only found it at A. ScT 566 629, E. Alc. 393 406, Su. 1078, Ph. 293, Or. 1382.

${ }^{104}$ Cf. Conomis 35-8; Barrett, comm. Hi., p. 434; Diggle (1994: 101 [cf. 1981: 54], 167, 315 and 424 n. 18). It should perhaps be said that West (1982: 111) and Parker (1997: 66) adopt a more tolerant approach.

${ }^{105}$ See Diggle's apparatus; $\lambda$ ıाoүó $\mu \varepsilon \tau o v$ is West's conjecture.

${ }^{106}$ Cf. West (1982: 110); Conomis 38-40. 


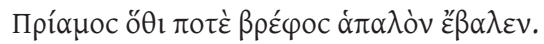

$\cup \cup \cup \cup \cup \cup \cup \cup \cup \cup \cup \cup \cup-$

It may be observed in favour of $\varepsilon \beta \alpha \lambda \varepsilon<v>$ that it gives a combination which is found at Tr. 260, Hel. 684, 694, Or. 185, 1500. ${ }^{107}$

(ii) $\cup \cup \cup-\cup \cup \cup+\cup-\cup \cup \cup-$ : unattested; but there is no good reason to doubt that it is theoretically a possible shape: cf. $\operatorname{Tr} .327-\cup \cup \cup \cup$

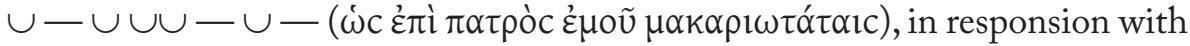
$310-\cup \cup \cup \cup \cup \cap-\cup \cup-\cup-$ (on the surprising brenis in longo see Parker [1997: 445]; cf. above, p. 55 n. 101).

(iii) $\cup \cup \cup-\cup \cup \cup+\cup-\cup \cup \cup-$ : also unattested. But similar patterns are found at:

Hi. $830 \cup \cup \cup-\cup \cup \cup \cup \cup \cup \cup \cup \cup-\sim 848 \cup \cup \cup-\cup \cup \cup \cup \cup \cup$ $-\cup-$

Herc. $1184 \cup \cup \cup-\cup \cup \cup \cup \cup \cup-\cup-$

Ph. $103 \cup \cup \cup-\cup \cup \cup \cup--\cup-$

The upshot of all this is that the putative dochmiac 'dimeters' at the opening of Iphigenia's monody inspire little confidence. And since Diggle further points out that we have an 'abnormal overlap between dochmiacs of

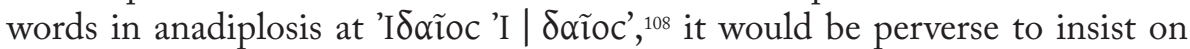
dochmiacs when an alternative (trochaics; cf. OCT) is not only possible but preferable. ${ }^{109}$

\subsection{Breuis in longo and Hiatus}

In his survey of the dochmiacs of Greek drama, Conomis reached the conclusion that, as with other metres, breuis in longo or hiatus are not permissible in dochmiacs without change of speaker, change of metre or pause. A very different picture was later presented by Stinton (1990: $334 \mathrm{ff}$.), who sought to invest dochmiacs with a special status, suggesting that 'the notion of period does not apply to them in the same way as it does to other metres'.

${ }^{107}$ Willink (2010: 153 n. 59) appears not to have noticed that Conomis had already proposed $\varepsilon \beta \beta \lambda \varepsilon<v>$; cf. also Diggle (1994: 424 n. 18).

${ }^{108}$ Cf. Diggle (1994: 424 n. 18); for patterns of dochmiacs in anadiplosis see p. 378. See also 1991: 135 n. 13.

${ }^{109}$ Wilamowitz was the first to propose trochaic scansion (1921: 574), but his divisions are

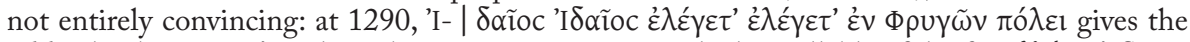
odd colon ' $2 \mathrm{cr}+2$ ia', with iambic scansion starting on the last syllable of the first $\dot{\varepsilon} \lambda \varepsilon \dot{\varepsilon} \gamma \varepsilon \tau$ '. Since these cretics are most naturally taken as syncopated trochees, this would constitute an instance of trochaic running into iambic without intervening word-end, a phenomenon there is reason to reject as unacceptable versification in iambo-trochaics (cf. Parker 1990: 331-48). For a better division, see Diggle's OCT. 
On this issue, my own survey of Euripidean dochmiacs leads me to side with Conomis (whose conclusions remain valid) rather than with Stinton.

\subsection{Split resolution}

Split resolution is more readily admitted in dochmiac than in iambotrochaic and its occurrence in the first biceps of the dochmiac metron may be deemed unexceptionable (cf. Parker 1968: 265). However, the same restrictions to split resolution before long anceps apply. There is only one case in Euripides of split resolution in the final biceps of a dochmiac followed by long anceps in the ensuing metron, $\operatorname{Tr} .253$ :

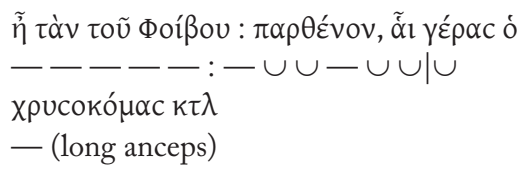

There are a few cases, though, of split resolution in the second biceps of a dochmiac followed by long anceps. Parker (1968: 267) lists the following:

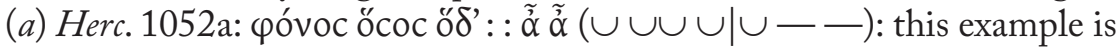
considered 'insignificant' by Parker, 'as the split is followed by a monosyllable, o' $\delta$ ', and the monosyllable by a much stronger division, change of speaker'. Bond (comm. Herc. p. 323) scans 'reiz. (doch.?)', in view of the preceding reiziana. But this would entail resolution in the first long of the choriamb, against which see below (p. 95).

(b) Hel. 694: avoidable with Diggle's text and colometry: See Diggle (1994: 184-6).

(c) IT 827-9: obelized in the Oxford text;

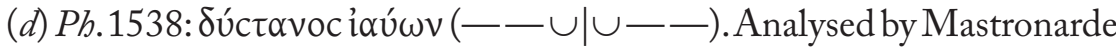
as 'reizianum'. His suggestion (comm. Ph.p. 560) that 1537-8 might be divided

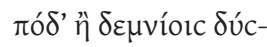

$\tau \alpha v o c i \alpha u ́ \omega v$

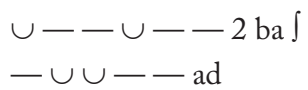

does not fit in with the observation that, as far as we know, in Euripides pendent metra (or cola) only appear in synartesis when an identical metron

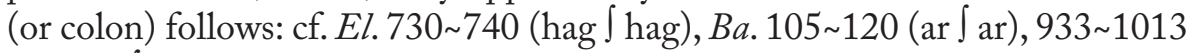
(ia + ba $\left.\int 2 \mathrm{ba}\right)$.

\subsection{Word-end after long anceps}

Word-end after long anceps is rare in dochmiacs. Parker counts fourteen examples of word-end after long initial anceps in Euripides (1966: 11). Since 
she does not tell us where they are to be found, the following list containing the eleven instances in Diggle's text may be helpful (superscript ' $a$ ' and ' $b$ ' indicate whether the metron is to be found in the first or the second half of the line, as printed in the OCT): Med. 1260 a 1270a, Hi. 849 ${ }^{\mathrm{a}}, 1268^{\mathrm{b}}, \mathrm{Hec} .707^{\mathrm{b}}$, $1090^{\mathrm{b}}$, Herc. 1027, Ion 797, 1487, Ph. 309 , Or. 1383a. ${ }^{110}$

Word-end after the second anceps in a dochmiac metron is even rarer. There is only one case in Diggle's OCT, Hec. 1060:111

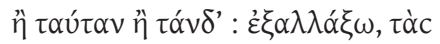

\subsection{Admixture of iambic metra}

Iambic metra are often found among sequences of dochmiacs. The most natural place for them to appear is at the head of a sequence, but they also appear, albeit less frequently, at the end (cf. Diggle 1994: 373-6). Several types of iambic metron are found:

iambic metron: Alc. 873 $\sim 890^{\mathrm{a}}{ }^{112}$ Hi. $866^{\mathrm{b}}, 1092^{\mathrm{a}}, \mathrm{Ph} .127^{\mathrm{a}}$, Hyps. $256^{\mathrm{a}}$;

cretic: Hi. 366 a $\sim 673^{\mathrm{a}}, 367^{\mathrm{a}} \sim 674^{\mathrm{a}}$, Herc. $895^{\mathrm{a}}$, $915^{\mathrm{a}}, 1020^{\mathrm{b}}, 1203$, Hel. $661^{\mathrm{a}}$, $662^{\mathrm{a}}$, Or. $145^{\mathrm{b}},(\sim \mathrm{mol}), 168^{\mathrm{b}} \sim 189^{\mathrm{b}}, 179^{\mathrm{b}} \sim 200^{\mathrm{b}}, B a .1153^{\mathrm{a}}, 1154^{\mathrm{b}}$;

2 cretics: Herc. $742^{a} \sim 757 b^{a}$;

bacchiac: Alc. $894^{\mathrm{b}} \sim 891^{\mathrm{b}}, 877^{\mathrm{b}} \sim 894^{\mathrm{b}}$, Med. $1251^{\mathrm{a}} \sim 1261^{\mathrm{a}}$, Su. $804^{\mathrm{b}} \sim 817^{\mathrm{b}}$, Ion $676^{\mathrm{a}} \sim 695^{\mathrm{a}}$, (if not $\delta+\mathrm{cr} \sim \delta+\mathrm{mol}$ ), Ph. $300^{\mathrm{b}}$, Or. 1011b

2 bacchiacs: Ph. 1290 1302;

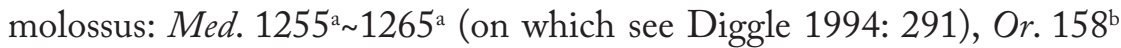
$(\sim \mathrm{cr}), 1415^{\mathrm{b}}$, Hyps. fr. $754.2^{\text {a }}$ N. (p. 34-5 Bond - the line is, however, rejected by Kannicht in $\operatorname{Tr} G F)$, ;

spondee: $I T 651^{\mathrm{b}}, 652^{\mathrm{b}}$.

\subsection{Syncopation}

Syncopation in dochmiacs is a very uncertain licence. A possible instance is Herc. 1024.

${ }^{110}$ In dochmiacs (as elsewhere in other metrical contexts) word-end after long anceps is acceptable when the word 'housed' by the long anceps is a monosyllable: cf. Med.1266, Hi. 369, 870, Andr. 849, 860, Hec. 684, 697, 707, 1056, 1060, 1062, 1079, Herc. 917, 1018, 1026, 1085, 1178, Tr. 310, 327, IT 126, 651, 831, 861, 868, 882, Ion 231, 719, 908, 1460, 1474, Hel. 635, 638, 666, Ph. 104, 156, 349, Or. 338, 1305, Ba. 1162, Rh. 698, Hyps. 257, 258.

${ }^{111} B a .1168$, mentioned by Parker (1966: 12), is printed in the OCT with Scaliger's $\mu \varepsilon$ $\theta$ poeĩc and Jackson's $\langle\gamma u ́ v \alpha l>$, making it an example of the commonest shape $\cup \cup \cup-\cup-$. There is one instance where the long anceps is a monosyllable: Herc. $1052 \mathrm{a}^{\mathrm{a}}:$ póvoc öcoc ő $\delta^{\prime}:$ : $\tilde{\alpha}$ | $\tilde{\alpha}$, but here we have a unique shape of dochmiac. Cf. above, p. 58 .

${ }^{112}$ Cf. Willink (2010) 244 n. 12. 
Part I - Euripides' use of lyric metre

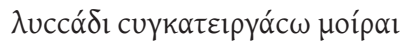
$-\cup \cup-\cup-\cup--\wedge-$

where the second metron can be interpreted either as a syncopated dochmiac (cf. Wilamowitz 1921: 407) or as an 'impure' iambic metron (Denniston 1936: 137, 141-2). ${ }^{113}$

\subsection{Repertory of Euripidean dochmiacs}

\subsubsection{With short ancipitia}

(1) $\cup--\cup-$ : This is the second most frequently attested shape of dochmiac in Euripides. Conomis counted 281 examples; I find only 275 in the Oxford text. ${ }^{114}$

(2) $\cup \cup \cup-\cup$ - Euripides' favourite dochmiac shape, with 395 examples (Conomis counted 403). ${ }^{115}$

\footnotetext{
${ }^{113}$ For other examples of $\cup-\ldots-$, see Diggle (1994: 107).

${ }^{114} \cup-\longrightarrow \cup-$ is found at Alc. 393 $\mathrm{a}, 873^{\mathrm{b}} \sim 890^{\mathrm{b}}, 877^{\mathrm{a}} \sim 894^{\mathrm{a}}$, Med. $_{125} \mathrm{~b} \sim 1261^{\mathrm{b}}, 1253^{\mathrm{b}} \sim 1263^{\mathrm{b}}$, $1254^{\mathrm{a}} \sim 1264^{\mathrm{a}}, 1254^{\mathrm{b}} \sim 1264^{\mathrm{b}}, 1256^{\mathrm{a}} \sim 1266^{\mathrm{a}}, 1259^{\mathrm{b}}, 1269^{\mathrm{b}}, 1273^{\mathrm{a}} \sim 1282^{\mathrm{a}}, 1273^{\mathrm{b}} \sim 1282^{\mathrm{b}}, 1274^{\mathrm{a}} \sim 1283^{\mathrm{a}}$, $1275^{\mathrm{a}} \sim 1286^{\mathrm{a}}, 1275^{\mathrm{b}} \sim 1286^{\mathrm{b}}, 1276 \sim 1287,1279^{\mathrm{a}} \sim 1290^{\mathrm{a}}, 1280 \sim 1291,1281^{\mathrm{b}} \sim 1292^{\mathrm{b}}$, Hcld. 86 $6^{\mathrm{b}} \sim 107^{\mathrm{b}}$, $87 \sim 108,91^{\mathrm{b}}, 104^{\mathrm{b}}, H i .362^{\mathrm{b}} \sim 669^{\mathrm{b}}, 364^{\mathrm{a}} \sim 671^{\mathrm{a}}, 364^{\mathrm{b}} \sim 671^{\mathrm{b}}, 366^{\mathrm{b}} \sim 673^{\mathrm{b}}, 367^{\mathrm{b}} \sim 674^{\mathrm{b}}, 370^{\mathrm{a}} \sim 677^{\mathrm{a}}$, $370^{\mathrm{b}} \sim 677^{\mathrm{b}}, 372^{\mathrm{b}} \sim 679^{\mathrm{b}}, 569,573^{\mathrm{b}}, 578,579,584,585,586,593,670^{\mathrm{a}}, 814^{\mathrm{a}}, 815^{\mathrm{a}}, 816^{\mathrm{b}}, 818^{\mathrm{a}} \sim 837^{\mathrm{a}}$, $818^{\mathrm{b}} \sim 837^{\mathrm{b}}, 822^{\mathrm{a}} \sim 841^{\mathrm{a}}, 827^{\mathrm{b}} \sim 845^{\mathrm{b}}, 849^{\mathrm{a}}, 832^{\mathrm{a}}, 833,850^{\mathrm{a}}, 851,854,855^{\mathrm{b}}, 867^{\mathrm{a}}, 869^{\mathrm{b}}, 870^{\mathrm{b}}, 883^{\mathrm{a}}$, $1268^{\mathrm{a}}, 1272^{\mathrm{a}}, 1279^{\mathrm{b}}, A n d r .833^{\mathrm{a}}, 833^{\mathrm{b}} \sim 837^{\mathrm{b}}, 849^{\mathrm{b}}, 850^{\mathrm{b}}$, Hec. $704^{\mathrm{a}}, 1025^{\mathrm{b}}, 1027,1028,1030^{\mathrm{a}}$, $1030^{\mathrm{b}}, 1033^{\mathrm{b}}, 1034^{\mathrm{b}}, 1063^{\mathrm{a}}, 1063^{\mathrm{b}}, 1074,1077^{\mathrm{b}}, 1090^{\mathrm{a}}, 1092^{\mathrm{b}}, 1106^{\mathrm{a}}, 1106^{\mathrm{b}}$, Su. 804 a ${ }^{\mathrm{a}} 817^{\mathrm{a}}, 1072^{\mathrm{a}}$,

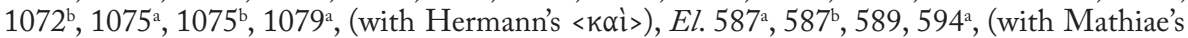
$\left.<\lambda_{\imath} \tau^{\prime} \alpha>\right), 594^{\mathrm{b}}, 595^{\mathrm{a}}, 595^{\mathrm{b}}, 1147^{\mathrm{a}} \sim 1155^{\mathrm{a}}, 1148^{\mathrm{a}}, 1150^{\mathrm{a}} \sim 1158^{\mathrm{a}}, 1150^{\mathrm{b}}, 1151^{\mathrm{a}}, 1152^{\mathrm{b}}, 1163^{\mathrm{a}}, 1163^{\mathrm{b}}$, Herc. 738 753a $739 \sim 753^{\mathrm{b}}, 746 \sim 759,876^{\mathrm{a}}, 877^{\mathrm{b}}, 885^{\mathrm{b}}, 886 \mathrm{~b}^{\mathrm{a}}, 900^{\mathrm{a}}, 921,1042^{\mathrm{b}}, 1044,1045^{\mathrm{b}}, 1046^{\mathrm{b}}$, $1183,1194^{\mathrm{a}}, 1210^{\mathrm{b}}, 1211^{\mathrm{b}}, 1213^{\mathrm{b}}, \operatorname{Tr}_{2} 242^{\mathrm{b}}, 254^{\mathrm{b}}, 276^{\mathrm{b}}, 1217 \mathrm{~b}, 1231^{\mathrm{b}}, 1236^{\mathrm{a}}, I T 644^{\mathrm{b}}, 657,840^{\mathrm{a}}$, $846,854^{\mathrm{a}}, 873,898^{\mathrm{a}}, 898^{\mathrm{b}}, 899^{\mathrm{a}}$, Ion $676^{\mathrm{b}}, 677^{\mathrm{b}} \sim 696^{\mathrm{b}}, 678^{\mathrm{b}}, 681^{\mathrm{a}}, 681^{\mathrm{b}} \sim 700^{\mathrm{b}}, 682,683^{\mathrm{b}} \sim 702^{\mathrm{b}}$, 684 $\sim 704,713,720^{\mathrm{a}}, 724,764 \mathrm{a}^{\mathrm{a}}, 768,791 \mathrm{a}^{\mathrm{b}}, 1455^{\mathrm{b}}, 1461^{\mathrm{b}}, 1467^{\mathrm{b}}, 1471^{\mathrm{a}}, 1496$, Hel. $645^{\mathrm{b}}, 659^{\mathrm{a}}$, $677^{\mathrm{b}}, 685,697, P \mathrm{~h} .103^{\mathrm{b}}, 166^{\mathrm{a}}, 166^{\mathrm{b}}, 169^{\mathrm{a}}, 299^{\mathrm{a}}, 300^{\mathrm{a}}, 318^{\mathrm{a}}, 323^{\mathrm{b}}, 325^{\mathrm{a}}, 325^{\mathrm{b}}, 328^{\mathrm{a}}, 328^{\mathrm{b}}, 329,335^{\mathrm{b}}$, $344^{\mathrm{a}}, 1290^{\mathrm{a}} \sim 1302,1535^{\mathrm{b}}, 1537,1543^{\mathrm{b}}$, Or. 141, 166 $6^{\mathrm{a}} \sim 187^{\mathrm{a}}, 166^{\mathrm{b}} \sim 187^{\mathrm{b}}, 186^{\mathrm{b}} \sim 207^{\mathrm{b}}, 319^{\mathrm{a}} \sim 335^{\mathrm{a}}$, $321^{\mathrm{a}} \sim 337^{\mathrm{a}}, 331^{\mathrm{b}} \sim 347^{\mathrm{b}}, 344,1354^{\mathrm{b}}, 1358^{\mathrm{a}} \sim 1542^{\mathrm{a}}, 1358^{\mathrm{b}}, 1365^{\mathrm{b}} \sim 1549^{\mathrm{b}}, 1402 \mathrm{~b}, 1491 \mathrm{a}^{\mathrm{b}}, B a$. 981 $\sim 1001^{\mathrm{b}}, 984^{\mathrm{a}}, 984^{\mathrm{b}}, 989 \sim 1009^{\mathrm{a}}, 991^{\mathrm{a}} \sim 1010,991^{\mathrm{b}} \sim 1011,996=1016,1019,1020^{\mathrm{a}}, 1021^{\mathrm{a}}, 1023$, $1172^{\mathrm{a}} \sim 1188^{\mathrm{a}}, 1172^{\mathrm{b}} \sim 1188^{\mathrm{b}}, 1183 \mathrm{~b} \sim 1199 \mathrm{~b}$, Rh. 132 ${ }^{\mathrm{b}} \sim 196^{\mathrm{b}}, 134 \sim 198,692 \sim 710$, Phaeth. 277, 278 , Hyps. $245^{\mathrm{b}}$.

${ }^{115}$ For $\cup \cup \cup-\cup-$ see Alc. 395, 399, 406 a 408, 874a $\sim 891^{\mathrm{a}}$, Med. 1253 $\sim 1263^{\mathrm{a}}, 1257 \sim 1267$, $1258^{\mathrm{b}} \sim 1268^{\mathrm{b}}, 1259^{\mathrm{a}}, 1268^{\mathrm{a}},+1269^{\mathrm{a}} \dagger,+1260^{\mathrm{b}} \uparrow \sim 1270^{\mathrm{b}}, 1274^{\mathrm{b}} \sim 1283^{\mathrm{b}}, 1279^{\mathrm{b}} \sim 1290^{\mathrm{b}}$, Hcld. $75^{\mathrm{a}} \sim 95^{\mathrm{a}}$,

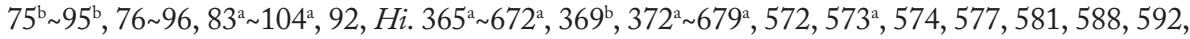
$670^{\mathrm{b}}, 676^{\mathrm{a}}, 811^{\mathrm{a}}, 811^{\mathrm{b}}, 812,814^{\mathrm{b}}, 816^{\mathrm{a}}, 817^{\mathrm{b}} \sim 836^{\mathrm{b}}, 821^{\mathrm{a}}, 821^{\mathrm{b}} \sim 840^{\mathrm{b}}, 822^{\mathrm{b}}, 826^{\mathrm{a}}, 826^{\mathrm{b}}, 827^{\mathrm{a}} \sim 845^{\mathrm{a}}$, $831^{\mathrm{b}}, 836^{\mathrm{a}}, 848^{\mathrm{b}}, 852^{\mathrm{b}}, 853^{\mathrm{b}}, 855^{\mathrm{a}}, 866^{\mathrm{b}}, 869^{\mathrm{a}}, 882^{\mathrm{a}}, 882^{\mathrm{b}}, 884,1276,1278$, Andr. 837 $7^{\mathrm{a}}, 850^{\mathrm{a}}, 854$, $855^{\mathrm{a}}, 859^{\mathrm{a}}, 859^{\mathrm{b}}, 860^{\mathrm{b}}$, Hec. $185,690^{\mathrm{b}}, 691^{\mathrm{b}}, 705,709,711^{\mathrm{a}}, 1025^{\mathrm{a}}, 1026,1029,1033^{\mathrm{a}}, 1034^{\mathrm{a}}, 1057^{\mathrm{a}}$, Su. 1078, El. 585 $, 593,1147^{\mathrm{b}} 1155^{\mathrm{b}}, 1151^{\mathrm{b}}, 1156^{\mathrm{a}}, 1156^{\mathrm{b}}, 1158^{\mathrm{b}}, 1160^{\mathrm{a}}, 1164^{\mathrm{b}}$, Herc. $735^{\mathrm{a}} \sim 750^{\mathrm{a}}$, $735^{\mathrm{b}} 750^{\mathrm{b}}, 736 \sim 751,743,745^{\mathrm{b}}, 875^{\mathrm{a}}, 875^{\mathrm{b}}, 876^{\mathrm{b}}, 877^{\mathrm{a}}, 878^{\mathrm{a}}, 884^{\mathrm{a}}, 885^{\mathrm{a}}, 900^{\mathrm{b}}, 901,902,912,915^{\mathrm{b}}$, $1016^{\mathrm{a}}, 1016^{\mathrm{b}}, 1035^{\mathrm{a}}, 1035^{\mathrm{b}}, 1043^{\mathrm{a}}, 1043^{\mathrm{b}}, 1045^{\mathrm{a}}, 1046^{\mathrm{a}}, 1060^{\mathrm{b}}, 1072,1078^{\mathrm{a}}, 1078^{\mathrm{b}}, 1079^{\mathrm{a}}, 1085^{\mathrm{b}}$, $1180^{\mathrm{b}}, 1182,1184^{\mathrm{b}}, 1203^{\mathrm{b}}, 1210^{\mathrm{a}}, 1210^{\mathrm{b}}, 1211^{\mathrm{a}}, 1212^{\mathrm{b}}, 1213^{\mathrm{a}}, \operatorname{Tr}_{2} 239^{\mathrm{b}}, 244^{\mathrm{b}}, 273^{\mathrm{b}}, 284^{\mathrm{a}}, 284^{\mathrm{b}}$, $288^{\mathrm{b}}, 308^{\mathrm{b}}, 312^{\mathrm{a}} \sim 329^{\mathrm{a}}, 327^{\mathrm{b}}, 1217^{\mathrm{b}}, I T 644^{\mathrm{a}}, 648,649,656,835^{\mathrm{a}}, 835^{\mathrm{b}}, 836,842^{\mathrm{a}}, 842^{\mathrm{b}}, 847^{\mathrm{a}}, 847^{\mathrm{b}}$, $854^{\mathrm{b}}, 856,859,860^{\mathrm{a}}, 860^{\mathrm{b}}, 872,890$, Ion $677^{\mathrm{a}} \sim 66^{\mathrm{a}}, 678^{\mathrm{a}}, 683^{\mathrm{a}} \sim 702^{\mathrm{a}}, 684^{\mathrm{a}} \sim 703,690^{\mathrm{b}} \sim 709,700^{\mathrm{a}}$,
} 


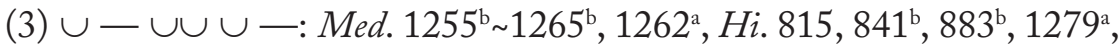
IT 840 , Ion $1487^{\mathrm{a}}, 1503$, Ph. 109, Or. 159 ${ }^{\mathrm{a}}, 1011 \mathrm{~b}^{\mathrm{a}}, 1375^{\mathrm{b}}, 1376$.

(4) $\cup-— \cup \cup \cup:$ Hi. 363a, $831^{\mathrm{a}}$, Herc. 886a, IT 852, Ion 715ª $767^{\mathrm{a}}$, Or. 1502 ${ }^{\mathrm{a}}{ }^{116} \mathrm{Ba}$. 979 999, 990 1009 .

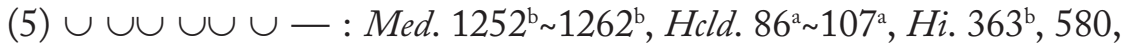
$830^{\mathrm{b}}$, Andr. 853, Hec. 690a, 1058, Su. 1074, El. 585a ${ }^{\mathrm{a}}$ 1152a $, 1153 \sim 1161,1164^{\mathrm{a}}$, Herc. $1019^{\mathrm{a}}, 1022^{\mathrm{b}}, \operatorname{Tr} .260^{\mathrm{b}}, 308^{\mathrm{a}}, 325^{\mathrm{b}},{ }^{117} 1217 \mathrm{a}^{\mathrm{a}}, I T$ 655, 832 $, 871,877$, Ion 690a $, 791 \mathrm{a}^{\mathrm{a}}, 1455^{\mathrm{a}}$, Hel. 654 $, 670^{\mathrm{a}}, 684^{\mathrm{b}}, 689^{\mathrm{a}}, 694^{\mathrm{b}},{ }^{118}$ Ph. 167, 299, Or. 174 195, 185 $, 319^{\mathrm{b}}, 1248^{\mathrm{b}}, 1362,1500^{\mathrm{b}}, B a .161,987,1021^{\mathrm{b}}, 1183 \mathrm{a}^{\mathrm{a}} \sim 1199 \mathrm{a}^{\mathrm{a}}$, Hyps. fr. 7543 N. (p. 34-5 Bond = Fr. 754,1 Kannicht).

$(6) \cup \cup \cup \cup \cup \cup \cup \cup:$ El. 592, Herc. 919 9 , 919 $, 1020^{\mathrm{a}}, 1057,1061^{\mathrm{b}}, 1062^{\mathrm{a}}$, $1190,1191,1192,1204^{\mathrm{a}}, 1212^{\mathrm{a}}, \operatorname{Tr}_{2} 244^{\mathrm{a}}, 248^{\mathrm{a}}, 260^{\mathrm{a}}, 288^{\mathrm{a}}$, Ion $764 \mathrm{a}^{\mathrm{b}}, 790^{\mathrm{b}}$, Hel. $628^{\mathrm{a}}$, $650^{\mathrm{a}}, 650^{\mathrm{b}}, 684^{\mathrm{a}},{ }^{119} 694^{\mathrm{a}}, 695^{\mathrm{a}}, 695^{\mathrm{b}}, 696^{\mathrm{a}}, P h .165^{\mathrm{a}}, 296^{\mathrm{b}}, 1294 \sim 1306$, Or. 149 ${ }^{\mathrm{a}} 162^{\mathrm{a}}$, $149^{\mathrm{b}} \sim 162^{\mathrm{b}}, 150 \sim 163,151 \sim 164,177 \sim 198,185^{\mathrm{a}}, 200^{\mathrm{a}}, 1308,1364^{\mathrm{a}} \sim 1548^{\mathrm{a}}, 1415^{\mathrm{a}}$, $1500^{\mathrm{a}}$, Ba. $986^{\mathrm{a}}, 995^{\mathrm{a}}=1015^{\mathrm{a}}$, Hyps. 244 $4^{\mathrm{a}}, 244^{\mathrm{b}}, 245^{\mathrm{a}}, 258^{\mathrm{a}}, 288^{\mathrm{b}}$.

(7) $\cup-\cup \cup \cup \cup \cup$ : unattested.

(8) $\cup \cup \cup-\cup \cup \cup: H i .587,830^{a} \sim 848^{a}, 853^{a}$, Andr. 842, Herc. $745^{\mathrm{a}}, 1019^{\mathrm{b}}$, $1052 \mathrm{a}^{\mathrm{b}}, 1070^{\mathrm{a}}, 1180^{\mathrm{a}}, 1184^{\mathrm{a}}$, IT $647^{\mathrm{a}}, 654,832^{\mathrm{a}}$, Ion $790^{\mathrm{a}}$, Hel. $634^{\mathrm{a}}$, Ph. $103^{\mathrm{b}}$, $296^{\mathrm{a}}, 1543^{\mathrm{a}}$, Or. $179^{\mathrm{a}}, 335^{\mathrm{b}}, 1501^{\mathrm{b}},{ }^{120}$ Ba. 162, Rh. $131^{\mathrm{a}}, 195^{\mathrm{a}}$, Hyps. $256^{\mathrm{a}}$, fr. 754 2 N. (p. 34-5 Bond - rejected by Kannicht).

\subsubsection{With long first anceps}

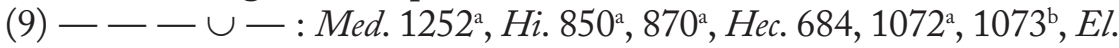
591, Herc. $757 b^{\mathrm{b}}, 917^{\mathrm{a}}, 1026^{\mathrm{b}}, 1042^{\mathrm{a}}, 1071,1086^{\mathrm{b}}, 1193$, Tr. 1231 $1^{\mathrm{a}}$, IT 861 , Ion $714,797,1495$, Or. 322 $2^{\mathrm{b}}, 327^{\mathrm{b}}, 1375^{\mathrm{a}}, 1466^{\mathrm{a}}, 1497^{\mathrm{a}}, \mathrm{Ba} .981^{\mathrm{a}} \sim 1001^{\mathrm{a}}, 982^{\mathrm{a}}, 1034^{\mathrm{a}}$, $1153^{\mathrm{b}}, 1154^{\mathrm{b}}$, Hyps. fr. $754.4^{\mathrm{a}}$ N. (p. 34-5 Bond = Fr. 754, 2 Kannicht), $257^{\mathrm{b}}, 289$.

$701,708,719^{\mathrm{b}}, 720^{\mathrm{b}}, 721^{\mathrm{a}}, 722^{\mathrm{a}}, 763^{\mathrm{b}}, 764^{\mathrm{b}}, 767^{\mathrm{b}}, 777,784,799^{\mathrm{b}}, 894,1452,1453 \mathrm{~b}, 1454 \mathrm{~b}, 1460^{\mathrm{b}}$, $1461^{\mathrm{a}}, 1471^{\mathrm{b}}, 1491,1499^{\mathrm{a}}$, Hel. $_{627^{\mathrm{a}}}, 627^{\mathrm{b}}, 628^{\mathrm{b}}, 629,634^{\mathrm{b}}, 645^{\mathrm{a}}, 649^{\mathrm{a}}, 651^{\mathrm{b}}, 654^{\mathrm{a}}, 655,662^{\mathrm{b}}, 667^{\mathrm{b}}$, $668,673^{\mathrm{a}}, 674^{\mathrm{a}}, 674^{\mathrm{b}}, 678,689^{\mathrm{b}}, 66^{\mathrm{b}}, P \mathrm{Ph} .115^{\mathrm{a}}, 115^{\mathrm{b}}, 127^{\mathrm{b}}, 137,149,165^{\mathrm{b}}, 169^{\mathrm{b}}, 182^{\mathrm{a}}, 293^{\mathrm{a}}, 318^{\mathrm{b}}$, $319^{\mathrm{a}}, 322^{\mathrm{a}}, 322^{\mathrm{b}}, 323^{\mathrm{a}}, 326,335^{\mathrm{a}}, 336,344^{\mathrm{b}}, 345,347^{\mathrm{a}}, 349^{\mathrm{a}}, 354^{\mathrm{a}}, 354^{\mathrm{b}}, 1291^{\mathrm{a}} \sim 1303^{\mathrm{a}}, 1291^{\mathrm{b}}, 1299$, 1301, 1544, Or. 140 $\sim 153^{\mathrm{b}}, 142 \sim 155,144 \sim 157,147^{\mathrm{a}}, 147^{\mathrm{b}}, 152^{\mathrm{a}} \sim 165^{\mathrm{a}}, 152^{\mathrm{b}} \sim 165^{\mathrm{b}}, 154,159^{\mathrm{b}}, 160^{\mathrm{b}}$, 172, 175 196, 176 197, 178 199, 180 201, 181 202, 186 $\sim 207^{\mathrm{a}}, 318 \sim 334,320,321^{\mathrm{b}} \sim 337^{\mathrm{b}}, 322^{\mathrm{a}}$, $323^{\mathrm{a}} \sim 339^{\mathrm{a}}, 323^{\mathrm{b}} \sim 339^{\mathrm{b}}, 324^{\mathrm{a}} \sim 340^{\mathrm{a}}, 324^{\mathrm{b}} \sim 340^{\mathrm{b}}, 325^{\mathrm{a}} \sim 341^{\mathrm{a}}, 325^{\mathrm{b}} \sim 341^{\mathrm{b}}, 331^{\mathrm{a}} \sim 34^{\mathrm{a}}, 1250^{\mathrm{a}} \sim 1270$, $1250^{\mathrm{b}} \sim 1270^{\mathrm{b}}, 1254 \sim 1274,1255^{\mathrm{a}} \sim 1275^{\mathrm{a}}, 1255^{\mathrm{b}} \sim 1275^{\mathrm{b}}, 1261 \sim 1281,1262 \sim 1282,1265,1290,1309$, $1310^{\mathrm{a}}, 1353^{\mathrm{a}} \sim 1537^{\mathrm{a}}, 1353 \mathrm{~b}^{\mathrm{a}} \sim 153 \mathrm{~b}^{\mathrm{a}}, 1357^{\mathrm{a}} \sim 1541^{\mathrm{a}}, 1357^{\mathrm{b}}, 1365^{\mathrm{a}} \sim 1549^{\mathrm{a}}, 1382^{\mathrm{a}}, 1383^{\mathrm{b}}, 1490^{\mathrm{a}}, 1491 \mathrm{a}^{\mathrm{a}}$, $1502^{\mathrm{b}}, 1537 \mathrm{~b}^{\mathrm{b}}, 1542^{\mathrm{b}}, 1546,1548^{\mathrm{b}}, B a \cdot 977^{\mathrm{b}}, 978^{\mathrm{a}}, 978^{\mathrm{b}}, 980^{\mathrm{a}} \sim 1000^{\mathrm{a}}, 980^{\mathrm{b}} \sim 1000^{\mathrm{b}}, 985^{\mathrm{a}}, 995^{\mathrm{b}}=1015^{\mathrm{b}}$, $1034^{\mathrm{b}}, 1038,1168^{\mathrm{b}}, 1169 \sim 1185,1176 \sim 1192,1178,1183 \mathrm{a}^{\mathrm{b}} \sim 1199 \mathrm{a}^{\mathrm{b}}, R h \cdot 131^{\mathrm{b}}, 132^{\mathrm{a}} \sim 196^{\mathrm{a}}, 133^{\mathrm{a}} \sim 197^{\mathrm{a}}$, $133^{\mathrm{b}} \sim 197^{\mathrm{b}}, 136 \sim 200,195^{\mathrm{b}}, 455,694 \sim 712,696 \sim 714,698^{\mathrm{a}} \sim 716^{\mathrm{a}}, 700^{\mathrm{a}} \sim 718^{\mathrm{a}}, 700^{\mathrm{b}} \sim 718^{\mathrm{b}}, 7^{\mathrm{b}} 6^{\mathrm{b}}, 721^{\mathrm{a}}$, $703^{\mathrm{b}} \sim 721^{\mathrm{b}}$, Phaeth. 275, 278 a $279^{\mathrm{a}}, 279^{\mathrm{b}}$, Hyps. 260 $, 260^{\mathrm{b}}, 262,273,281^{\mathrm{b}}, 282$.

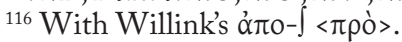

${ }^{117}$ With Hermann's <ä $v \alpha \gamma^{\prime}>$.

${ }^{118}$ With Diggle's áro < $<\rho o ̀>$.

${ }^{119}$ With Hermann's <cò̀ .

${ }^{120}$ With Diggle's <ảvóvatov>. 


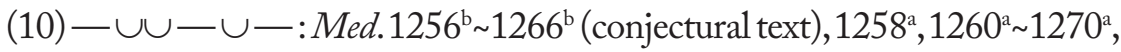
Hi. 591, 817 $, 832^{\mathrm{b}}, 849^{\mathrm{b}}, 880,1268^{\mathrm{b}}, 1271,1275^{\mathrm{a}}, A n d r .849^{\mathrm{a}}$ (with Seidler's <ì>), 858, 865 (if not dod), Hec. 687, 691 ${ }^{\mathrm{a}}, 707^{\mathrm{a}}, 707^{\mathrm{b}}, 710,1057^{\mathrm{b}}, 1062,1066^{\mathrm{a}}, 1077^{\mathrm{a}}$, $1090^{\mathrm{b}}$, Herc. 887a $\mathrm{a}, 1024^{\mathrm{a}}, 1026^{\mathrm{a}}, 1060^{\mathrm{a}}, 1178^{\mathrm{b}}, \operatorname{Tr} .24 \mathrm{a}^{\mathrm{b}}, 245,254^{\mathrm{a}}, 265^{\mathrm{a}}, 273^{\mathrm{a}}, 310^{\mathrm{b}}$, IT 830, 844, 853, 857, 858, 882, 885, 891, Ion $715,719^{\mathrm{a}},{ }^{121} 798,1445^{\mathrm{a}}, 1460^{\mathrm{a}}, 1467^{\mathrm{a}}$, $1474^{\mathrm{a}}, 1474^{\mathrm{b}}$, Hel. 635, 638 a $666^{\mathrm{a}}, 666^{\mathrm{b}}, 682^{\mathrm{a}}$, Ph. 104, 156 ${ }^{\mathrm{a}}, 183^{\mathrm{b}}, 297,309^{\mathrm{a}}, 348^{\mathrm{a}}$,

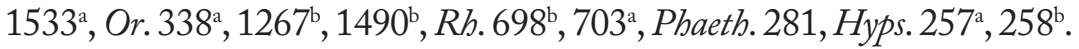

(11) - - $\cup \cup-$ : Hi. 1267 (not mentioned by Conomis, p. 24), Or. $146^{\mathrm{a}}, 343^{\mathrm{b}}, 1387^{\mathrm{a}}$, Ba. $982^{\mathrm{b}}$, Hyps. 264, 281'a .

(12) - - $\cup \cup \cup:$ Hec. $1061^{\mathrm{b}}$, Or. $168^{\mathrm{a}}{ }^{.122}$

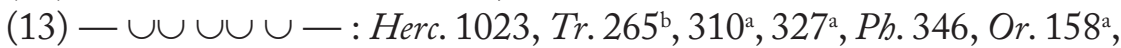
$1383^{\mathrm{a}}, 1501^{\mathrm{a}}$.

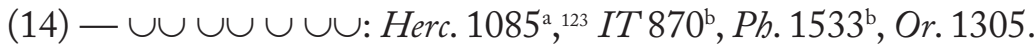

(15) - $\cup \cup \cup \cup \cup$ : unattested.

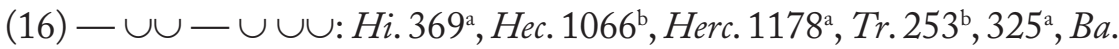
1162, $L A$ 1485, 1489, 1493.

\subsubsection{With long ancipitia}

(17) - - - - : Andr. 860, Hec. 182, 190, 1056 ${ }^{\mathrm{b}}, 1060^{\mathrm{a}}, 1060^{\mathrm{b}}, 1079$, Herc. $917^{\mathrm{b}}, 1061^{\mathrm{a}}$, Tr. 251, 253a, IT 126, 127, ${ }^{124}$ Ion 906, 908, 1497, Hel. 676 ${ }^{\mathrm{b}}$, Ba. $985^{\mathrm{b}}, 1160$.

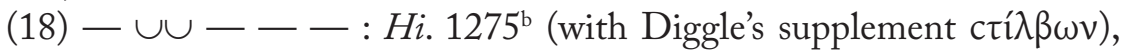
Hec. 165 207, 697, 700, 1056 ${ }^{\mathrm{a}}, 1061^{\mathrm{a}}, 1073^{\mathrm{a}}, 1098$, Herc. 1018, 1027, 1204 ${ }^{\mathrm{b}}$, Tr. $^{2}$.

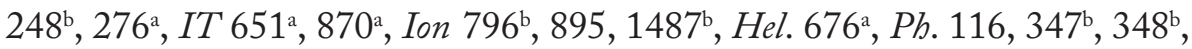
$349^{\mathrm{a}}, 1535^{\mathrm{a}}$, Or. 338 ${ }^{\mathrm{b}}, 1391$, Ba. 1035, $1035^{\mathrm{b}}$, Hyps. fr. $754.4^{\mathrm{b}}$ N. (p. 34-5 Bond = Fr. 754, 2 Kannicht).

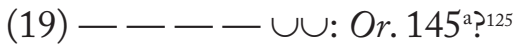

(20) — $\cup \cup \cup-\ldots$ : the only Euripidean instance of this dochmiac

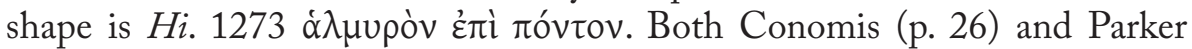
(1968: 260, 265) reject Schroeder's ithyphallic scansion $(-\cup \cup \cup \cup-\longrightarrow)^{126}$ as inappropriate in a predominantly dochmiac context.

${ }^{121}$ With Hermann's < $\tau^{i}>$.

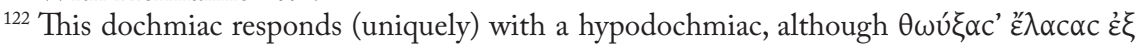
ürvou could alternatively be scanned as molossus $+\cup \cup \cup-\cup-$. On the problems raised by this sequence, see Willink ad loc.

${ }^{123}$ With Wilamowitz's <市.

${ }^{124}$ These two dochmiacs appear at the beginning of a long sequence of lyric anapaests; the colon is described by Dale as a 'dragged dochmiac with the effect of a short paroemiac' ${ }^{2} 1968$ : 60). The same may be said of Ion $906,908$.

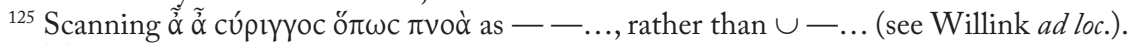

${ }_{126}$ This would be the only example of an ithyphallic of the shape $-\cup \cup \cup \cup-\ldots$ in Euripides (although $\cup \cup \cup-\cup-\longrightarrow$ is common enough: see below, p.120). 
(21) $-\cup \cup \cup \cup-\cup \cup$ : unattested.

(22) - - $\cup-\cup \cup$ : unattested.

(23) $-\cup \cup-\backsim \cup \cup$ : unattested.

(24) $-ー \cup \cup--$ : unattested.

\subsubsection{With long second anceps}

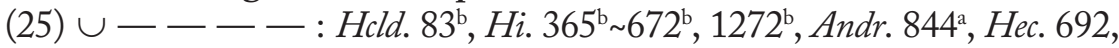

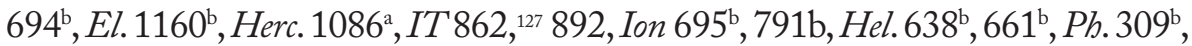
319, 1287, Or. 146 $6^{\mathrm{b}}, 148 \sim 161,326^{\mathrm{a}} \sim 342^{\mathrm{a}}, 327^{\mathrm{a}} \sim 343^{\mathrm{a}}, 328,1310^{\mathrm{b}}, 1466$, Hyps. 266.

(26) $\cup \cup \cup-\longrightarrow-:$ Hi. 571, 676 ${ }^{\mathrm{b}}$, Andr. 843, 844 ${ }^{\mathrm{b}}, 855^{\mathrm{b}}$, Hec. 695, 696, $704^{\mathrm{b}}, 711^{\mathrm{b}}, 1059,1072^{\mathrm{b}}, 1084,1088$, Su. 1079, El. 1148 ${ }^{\mathrm{b}},{ }^{128}$ Herc. 737 752, $878^{\mathrm{b}}, 884^{\mathrm{b}}, 887 \mathrm{a}^{\mathrm{b}}, 895^{\mathrm{b}}, 903,918,1021^{\mathrm{b}}, 1022^{\mathrm{a}}, 1052 \mathrm{~b}, 1058,1062^{\mathrm{b}}, 1063,1070^{\mathrm{b}}$, $1079^{\mathrm{b}}, 1194^{\mathrm{b}}, \operatorname{Tr}_{2}$ 291b, 312b $329^{\mathrm{b}}$, IT $652^{\mathrm{a}}$, ${ }^{129} 878,879,883$, Ion $679,691,721^{\mathrm{b}}$, $796^{\mathrm{a}}, 896,1445^{\mathrm{b}}, 1499^{\mathrm{b}}, 1502,^{130} \mathrm{Hel} .649^{\mathrm{b}}, 651^{\mathrm{a}}, 659^{\mathrm{b}}, 667^{\mathrm{a}}, 670^{\mathrm{b}},{ }^{131} 671,673^{\mathrm{b}}$,

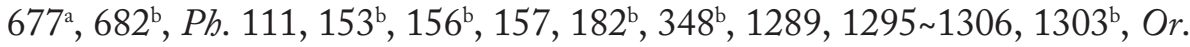
143 156, 160 $, 193,326^{\mathrm{b}} \sim 342^{\mathrm{b}}, 336,1247^{\mathrm{b}}, 1248^{\mathrm{a}}, 1285,1288,1289,1291$, $1305^{\mathrm{b}}, 1306,1364^{\mathrm{a}}, 1387^{\mathrm{b}}, 1491^{\mathrm{b}}, 1541^{\mathrm{b}}, \mathrm{Ba} .9^{2} 7^{\mathrm{a}} \sim 997^{\mathrm{a}}, 997^{\mathrm{b}}, 986^{\mathrm{b}}, 1020^{\mathrm{b}}, 1158$, $1168^{\mathrm{a}} \sim 1184^{\mathrm{a}}, 1184^{\mathrm{b}}, 1171 \sim 1187,1194$.

(27) $\cup-\cup \cup-\longrightarrow$ : unattested.

(28) $\cup--\longrightarrow \cup \cup$ : unattested. ${ }^{132}$

(29) $\cup \cup \cup \cup-\longrightarrow$ : Herc. 1052a

(30) $\cup \cup \cup \cup \cup-\cup \cup:$ Herc. 886b

(31) $\cup-\cup \cup-\cup \cup$ : unattested.

(32) $\cup \cup \cup-\_\cup \cup$ : unattested.

\subsubsection{Hypodochmiac}

$-\cup-\cup-:$ Alc. 393 ${ }^{\mathrm{b}} 406^{\mathrm{b}}$, Hi. 852 2 , 879, $879^{\mathrm{b}}$, Andr. 835, Hec. 694

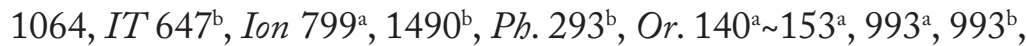
994, 1382 $, 1400^{\mathrm{a}}, 1497 \mathrm{~b}^{\mathrm{a}}, 1497 \mathrm{~b}^{\mathrm{b}}$, Ba. 1175 1191, Hyps. $246^{\mathrm{a}}$.

$-\cup \cup \cup \cup-:$ Med. 649 658, Hec. 1089, Su.1078b, Or. 1417.

$-\cup-\cup \cup \cup:$ Ion $1490^{a}$, Or. 189a.

$\cup \cup \cup \cup \cup \cup-: R h .250$.

$\cup \cup \cup \cup \cup \cup \cup \cup: R h .261$.

— $\cup-$ - Andr. 839 ( 835), Tr.283, 287.

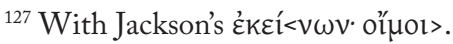

${ }^{128}$ With Seidler's $\langle\dot{\varepsilon} v\rangle$.

${ }^{129}$ With Bothe's $<\delta$ óo $>$.

${ }^{130}$ With Hermann's <i $\left.\dot{\omega}\right\rangle$.

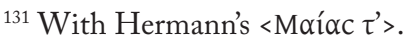

${ }^{132}$ There is one unlikely Sophoclean candidate at $A n t .1289$, avoided (by different means) by Dawe as well as Lloyd-Jones and Wilson. 
Part I - Euripides' use of lyric metre

4.6.6. Kaibelianus $(\mathrm{k} \delta)$

$\cup-\cup-\cup-:$ Hec. 169 210, 1083, Ph. 183, Or. 1459a.

$\cup-\cup \cup \cup \cup-:$ Or. $1247^{\mathrm{a}} \sim 1267^{\mathrm{a}}$.

$\cup-\cup \cup \cup \cup \cup \cup: \operatorname{Tr} .328$.

$\cup \cup \cup \cup \cup \cup \cup-: \operatorname{Tr} .311$. 


\section{DactYlic}

In Greek drama, dactylic is the metre which, with its epic overtones,

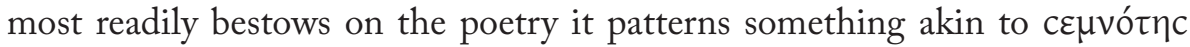
('loftiness': cf. Ar. Nub. 315, with Parker's remarks [1997: 187-8]). Aristotle

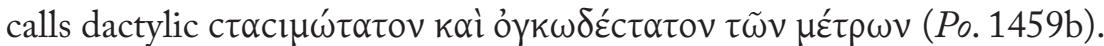

The most frequent dactylic length used by Euripides is the tetrameter, but the hexameter is also quite common. Rarer dactylic cola are the pentameter and the dimeter and there are three curious sequences in Euripides where a run of dactyls is one metron longer than the hexameter: Herc. 382a-b 396 a-b, Hel. $376 \mathrm{a}-\mathrm{b}, P h .793-4 \mathrm{a} \uparrow 810 \dagger-11 \mathrm{a}$. The dactylic trimeter, thought by some to be a legitimate Euripidean colon, is not found in Diggle's OCT. ${ }^{133}$ Generally speaking, we are more likely to encounter a spondee at period-end than a dactyl; however, 'in Attic drama, there are a few passages in which $-\cup \cup$ is followed by hiatus, and so, presumably, by verse-end' (Parker 1997: 53). The only instances of this I have been able to find in Euripides are Alc. 464 474, Med. 137, Hcld. 624 (with correption), Tr. 825-6 (correption) and Ba. 585. ${ }^{134}$

Another disconcerting feature of tragic dactyls is the permissibility of breuis iuxta anceps, which is not a valid licence in other forms of lyric. An example is '5 da | k $\delta$ ' at Hec. 167-9 ( 209-10):

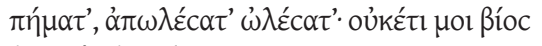

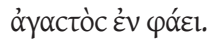

$$
\begin{aligned}
& \begin{array}{l}
-\cup \cup-\cup \cup-\cup \cup-\cup \cup-\cup \cup \\
\cup-\cup-\cup-
\end{array}
\end{aligned}
$$

Parker (1997: 54) gives more Euripidean examples of this, ${ }^{135}$ but most of them are based on passages where the text presents intractable problems; the two examples we might wish to consider are Alc. 464-5 474-5 and Or. 1011a-b.

Resolution in dactyls (i. e. $\cup \cup \cup \cup$ ) is extremely rare. Diggle (1994: 122) cites as possible examples Alc. 120-1 130-1, Andr. 490 and Ph. 796; in his OCT, however, the example from Alcestis is printed as a praxillean with Hartung's emendation, whereas $\mathrm{Ph} . \dagger 796 \dagger$ is given as corrupt.

${ }^{133}$ Cf. Diggle (1994: 316). Lest Herc. 382b 396b be deemed a possible candidate as part of the sequence in synartesis 'ibyc $\int 4 \mathrm{da} \int 3 \mathrm{da}$ ', a run of 7 dactyls ending in - - is not the same as isolated ' $3 \mathrm{da}$ '.

${ }^{134} \mathrm{Cf}$., in an anapaestic context, Med. 132.

${ }^{135}$ For Sophocles, see Stinton (1990: 11). 


\subsection{Hexameter ('6 da')}

Euripidean hexameters come in various shapes. The standard caesura is penthemimeral $(-\cup \cup-\cup \cup-: \ldots)$; the 'trochaic' caesura after the first short of the third biceps $(-\cup \cup-\cup \cup-\cup: \cup \ldots)$ is found five times. ${ }^{136}$ Responding hexameters are almost always perfectly matched pairs; examples of asymmetrical responsion are Hi. 1120-1 1131-2, Andr. 135 141, Tr. 597 603.

$-\cup \cup-\cup \cup-\cup \cup-\cup \cup-\cup \cup--$ : Hcld. 608 619, Hi. 1102-3 1111-2, Andr. 107, 111, 113, 115, 117 126, 119 128, 122 131, 141, 1177-8 †1190-1†, Su. 271, 272, 277, 278-9, 284, El. 475-6, Tr. 595 601, 596 602, 597, 598, 599, 600 606, 803 813-4, Ion 508-9, Hel. 165, Ph. 152, 785 802, 786 803, †792† 809, 819, 1485-6, 1492-3, 1493-4, 1549, 1558, 1566, 1577, 1578, LA 1330.

$-\cup \cup---\cup \cup-\cup \cup-\cup \cup-\longrightarrow:$ Andr. 103, 105, Su. 274, 808 821.

$-\cup \cup-\cup \cup-\cup \cup-—-\cup \cup-\longrightarrow$ : Hel.382, Ph. †789† 806, Ba.167-9.

$-\cup \cup-\cup \cup---\cup \cup-\cup \cup--$ : Hi. 1106-7 1115-6, 1131-2, Andr. 135, Su. 282, 283, 285, Tr. 603, Ph. 787 804, 820, 823.

$-\cup \cup-\cup \cup-----\cup \cup--: P h .821$.

$---\cup \cup-\cup \cup-\cup \cup-\cup \cup-\ldots:$ Andr. 109, Ph. 824.

$----\_\cup \cup-\cup \cup-\cup \cup-\ldots:$ Su. 273.

Although catalexis is not normally a phenomenon associated with dactylic hexameters, there is one candidate for this category at $A n d r$. 274 283-4:

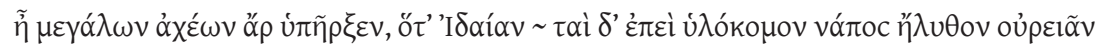
$-\cup \cup-\cup \cup-\cup \cup-\cup \cup-\ldots-\sim-\cup \cup-\cup \cup-\cup \cup-\cup \cup--\longrightarrow$

Alternatively we might analyse as ' $4 \mathrm{da}+$ mol': syncopated iambic follows;

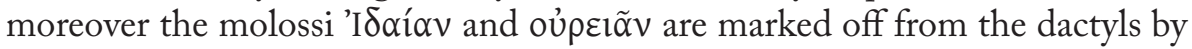
word-end.

\subsection{Pentameter (' $5 \mathrm{da}$ ')}

Lengths consisting of five dactyls are infrequent in Euripides. The instances in the extant corpus are:

$-\cup \cup-\cup \cup-\cup \cup-\cup \cup-\cup \cup$ : Hec. 167 209.

${ }^{136}$ Andr. 274, 278-9, Ph. 1492-3, 1558, 1577. 
$-\cup \cup-\cup \cup-\cup \cup-\cup \cup-\longrightarrow: P h . \dagger 791 \dagger \sim 808$, Cycl.358a 373, Phaeth. 97.137

$-\cup \cup-\cup \cup-\cup \cup----$ : Hel. 384.

$-\_-\cup \cup-\ldots-\ldots-\ldots:$ Ph. 794b-5 811b-12.

There are half a dozen examples of dactylic pentameters with catalexis.

$-\cup \cup-\cup \cup-\cup \cup-\cup \cup-:$ El. 452 464, Ph. 831-2, 1491.

$-\cup \cup-\cup \cup-\cup \cup---$ : Or. 1465.

$---\cup \cup-\cup \cup-\cup \cup-:$ Cycl. 620 .

\section{3. Tetrameter (' $4 \mathrm{da})$}

Lengths of four dactyls are Euripides' favourite dactylic phrase. The colon $-\cup \cup-\cup \cup-\cup \cup-\cup \cup$ appears approximately seventy-five times in the extant corpus. ${ }^{138}$ Other shapes are:

$-\cup \cup-\cup \cup-— \cup \cup: \operatorname{Tr} .806 \sim 817, P h .190,1489$.

$-\cup \cup-\cup \cup-\cup \cup--$ : Hi. 1124 1135, 1126 1137, 1128-

9 1139-40, Andr. 1174 1187, 1182 1195, Su. 281, 890, IT 1237 1262, Ph. 191, 788 805, 790b 807b, 799 †817†, 822, 1506, 1562, 1563, 1564, [1571], Or. 1008, LA 1294;

$-\cup \cup-\cup \cup-\ldots-\ldots$ : Hcld. 611 622, Or. 1395, Ba. 142;

$-\cup \cup--\backsim \cup-\cup \cup:$ Hcld. 613 624, Ph. [1570], Or. 1009, Hyps. 26;

$-\cup \cup-—-\cup \cup-\longrightarrow:$ Hcld. 625, Andr. 1193, Hel. †379†, Ph. 1497a, 1507, [1576], Or. 1006;

$---\cup \cup-\cup \cup-\longrightarrow:$ Ph. 828, 1488, [1578];

$--\backsim \cup \cup-\cup \cup-\cup \cup:$ Andr. 838, 863, Ph. 798, 1490;

$-----\cup \cup-\longrightarrow:$ Hel.380;

$--\longrightarrow \cup \cup-\cup \cup-\cup \cup:$ Ph. 829.

— — — - — — : Alc. 462 472, Or. 1496, Ba. 596.

One of the examples of $-\cup \cup-\cup \cup-\cup \cup--$ listed above presents an interesting problem:

${ }^{137}$ Diggle (1996a: 195) cites also $\operatorname{Tr} .838 \sim 858$ and A. Ag. 165 174. I prefer to analyse the example from Troades as enoplian ending in short anceps (cf. below, p. 79), forming a dicolon with the ensuing ithyphallic. Analysis as a dactylic pentameter would imply two displeasing

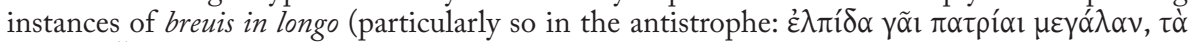

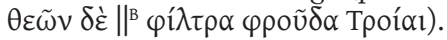

${ }^{138}$ For $-\cup \cup-\cup \cup-\cup \cup-\cup \cup$ cf. Alc. 463 473, 464 474, 591 600, Med. 1345, 136, Hcld. 610 612, 615 626, 616 627, Andr. 293-301, 834, 1173 1186, 1176 †1189†, 1181 1194, El. 140 157, Tr. 825-6 845, Ion 507, Hel. 375, 377, 381, 383, Ph. 135, 151, 351, 352, 784 801, 797a 814, 813, 830, 1487, 1495, 1499, 1500, 1503, 1504, 1565, [1574], 1579, Or. 1005, 1010, 1011a, 1299, Ba. 139, 159, 163-4, 165-6, 585 (conjectural text), 591, 594, 595, IA 225-6, 227-8, 229, 1331-2 (conjectural text), Rh. 26 44, Cycl. 610-11, 615-16, Hyps. 27, $28,29$. 


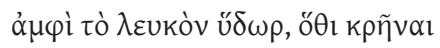

$-\cup \cup-\cup \cup-\cup \cup--4 \mathrm{da}$

Nu$\mu \varphi \tilde{\alpha} v \kappa \varepsilon \tilde{\imath} v \tau \alpha 1$

(IA 1294-5)

gives an awkward (and unparalleled) sequence: 4 da with spondaic fourth foot, followed by $2 \mathrm{sp}$. The 'awkwardness' resides in the fact that, unless a very strong rhetorical pause is felt after the dactylic tetrameter (scarcely the case here), the sequence becomes - at least aurally - a hexameter with an ungainly instance of word-end after the spondaic fourth foot. ${ }^{139}$ The need to avoid the aural suggestion of a less than pleasing hexameter is arguably the reason why Euripides only uses a dactylic tetrameter with final spondee when (a) it is part of a dactylic $\pi v \tilde{i}$ yoc (IT 1237 1262, Hel. 378-80, Ph. 1562-4, Or. $1006,1008)$, where the division of dactyls into tetrameter lengths is possibly artificial; or (b) some from of pause ensues (marked by rhetorical break, breuis in longo, hiatus, change of metre and/or speaker).

Here is the evidence for (b): Hcld. 611 622 (rhetorical break in the antistrophe; followed by 'adonean'), Hi. 1124 1135, 1126 1137, 1128-9 113940, (each of these examples is followed by an iambic colon), Andr. 1016 ( 1025: 4 da with dactylic fourth foot; followed by cretics), 1174 1787 (with strong rhetorical pause, followed by non-dactylic exclamations), 1182 1195 (followed by an enigmatic clausular colon ${ }^{140}$ ), Su. 281 (strong rhetorical pause, followed by four hexameters), Herc. 890 (at period-end, marked by strong rhetorical pause, hiatus, change of speaker and metre), IT 1238-9 1263-4 (period-end marked by breuis in longo, followed by change of metre), $P h .191$ (period-end marked by breuis in longo ${ }^{141}$ ), 788 805 (at period-end, marked by breuis in longo in the strophe, followed by hexameter), 790b 807b (at period end marked by strong rhetorical pause, followed by dactylic pentameter), 793 810 (at period end according to Mastronarde, p. 375, followed by problematic dactylic sequence), 799 †817† (at stanza-end), 822 (marked |l? by Mastronarde, followed by hexameter), 828 (marked ||? Mastronarde, followed by 4 da) 1488 (period-end marked by hiatus), 1497a (period end marked by hiatus), 1506 (|| Mastronarde), 1507 (|| Mastronarde), 1546 (rhetorical pause, followed by change of metre), 1554 (period-end, with hiatus and change of speaker), 1556 (followed by change of metre), [1571] (followed by hemiepes; not Euripidean),

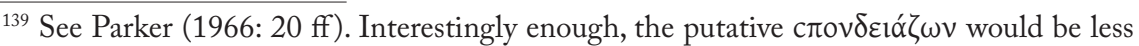
of an anomaly: it is found in late Euripides at $P h .1493$ and, albeit far less plausibly (cf. Willink

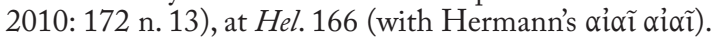

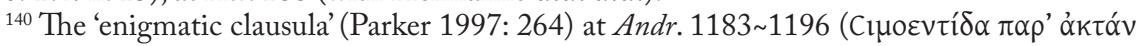

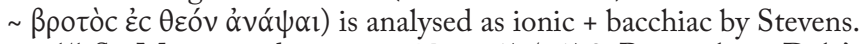

${ }^{141}$ So Mastronarde, comm. Ph., p. 175, 178. But perhaps Dale's enoplian interpretation is preferable (cf. ${ }^{2}$ 1968: 175). 
Or. 1395 (followed by change of metre), Ba. 142 (followed by change of metre), 596 (4 spondees [cf. Ph. 1553], followed by cretics). The exceptions I find are Ph. [1573] (perhaps not Euripidean ${ }^{142}$ ) and the said example $I A 1294$ (probably also not Euripidean).

There are several examples in Euripides of dactylic tetrameters with catalexis:

$-\cup \cup-\cup \cup-\cup \cup-:$ Alc. 904 927, Andr. 482, El. 141 158, Ph. 1580, Or. 831, 1369a, 1431 (conjectural text), Ba. 116 131, LA 588, Cycl. 618, Rh. 244 255, 902 913;

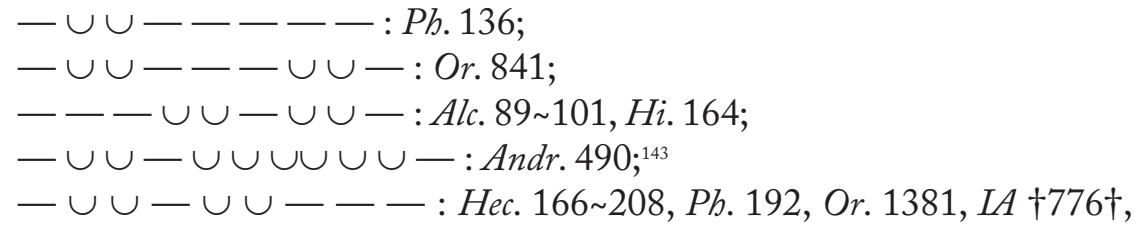
$R h .27 \sim 45$.

\section{4. Dimeter (' $2 \mathrm{da}$ ')}

Dactylic dimeters are not often found in Euripides:

$-\cup \cup-\cup \cup:$ Med.137, Ph. 1496, 1505, Ba.117 132, 601.

$-\cup \cup-—: P h . \dagger 790 \mathrm{a} \uparrow \sim 807 \mathrm{a}, 1497 \mathrm{~b}, 1501,1550$.

————: IA 1295.

Twice in late Euripides we encounter a dactylic dimeter with cretic prefix:

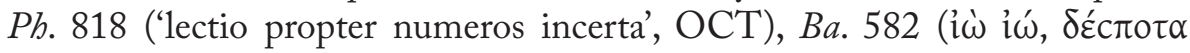
$\delta \varepsilon ́ c \pi о \tau \alpha: \cup \cup \cup-+2$ dactyls, or a dactylic tetrameter of the shape $--—$ $--\cup \cup-\cup \cup)$.

\section{5. Andromache's elegiacs (Andr. 103-16)}

Andromache's elegiac monody was the object of a fascinating essay by D. L. Page, which still makes useful reading today. ${ }^{144}$ The first lines of the elegiac couplet are listed above, with Euripides' other extant hexameters. The second line ('D : D') appears under two forms:

$-\cup \cup-\cup \cup-:-\cup \cup-\cup \cup-:$ Andr. 106, 110,112, 116.

$-\cup \cup---:-\cup \cup-\cup \cup-:$ Andr. 104, 108, 114.

${ }^{142}$ Cropp's defence of $P h .1567-78$ (see 1997: 570-4) does not touch upon the metrical issue.

${ }^{143}$ The sole plausible example of a resolved dactyl in tragedy; see above, p. 65.

${ }^{144}$ See Page (1936: 206-30; the metre is commented upon on p. 221). 


\section{ENOPLian}

The term 'enoplian' became at one point something of a controversial issue among metricians, studiously avoided by West in his Greek Metre, ${ }^{145}$ but, on the other hand, tentatively extended by Willink to include dactylo-epitrites with

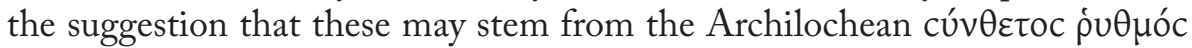
'anciently termed غ̇vó $\pi \lambda$ Ioc' $^{146}$ In turn, Itsumi and Parker have proposed that the term can be meaningfully used, but with certain restrictions. ${ }^{147}$

For my part, I use 'enoplian' generically to designate a group of rhythmic phrases which differ $(a)$ from dactylic in that they admit single or double short opening and the sequence '..$-\mathrm{x}(-)$ ' where dactylic would have '... $-\cup \cup$ $(-) . . ;$; and $(b)$ from dactylo-epitrite in that constituent units are welded together without intervening ancipitia. In other words, a phrase is enoplian if, despite the presence of ostensibly dactylic or anapaestic patterns, it can neither be analysed as a run of dactyls ( $4 \mathrm{da}, 5 \mathrm{da}, 6 \mathrm{da}$ ) nor as a sequence of $\mathrm{D} / \mathrm{e}$ units joined by ' $\mathrm{x}$ '. ${ }^{148}$ Like Willink, I prefer to use the term as an adjective (rather than as a noun) to describe contexts and phrases which share a recognizable set of common features.

\section{1.'D' $(-\cup \cup-\cup \cup-)$}

The hemiepes is, strictly speaking, a dactylic phrase (the first half of the dactylic hexameter marked off from what follows by the penthemimeral caesura); the combination 'D : D' forms the so called 'pentameter' in the elegiac couplet and occurs as an enoplian phrase at IT 1235. In view of this,

${ }^{145}$ West (1982: 195) admits, however, that 'it would be convenient to have a collective name for the group $D, x D, D x, x D x$, and to call them enoplian would not go far beyond ancient usage'. Predictably (as Willink remarked [2010: 97]), West 'is in serious difficulties when he came to Euripides'. Perhaps the best argument in favour of the term 'enoplian' is West's amusing use of periphrasis to avoid it: on p. 113 of Greek Metre, for instance, one marvels at how expressions such as 'felt as part of the dactylic repertory', 'as if in dactylo-epitrite', " anapaestic" cola which end $\cup \cup-\cup-$ ' can be deemed preferable to 'enoplian'.

${ }^{146}$ Cf. Willink (2010: 97); comm. Or., pp. xx-xxi. The term is used at Ar. Nub.651, but it is not very clear what is meant by it (see Dover ad loc., and p. 271 of his Addenda). See Holwerda (1967: 51-58).

${ }^{147}$ Cf. Itsumi (1991-3: 243-61); Parker (1997: 77).

${ }^{148}$ I share Itsumi's doubts (2009: 5 n. 11) with regard to West's writing off of the linksyllable as 'a false concept'. 
' $\mathrm{D}$ ' should perhaps have been listed in the preceding chapter on dactylic, had I not preferred to list there only lengths consisting purely of dactyls and/or spondees. Also, as the typical enoplian phrases are compounds of ' $\mathrm{D}$ ', it seems best to list them together.

The phrase $-\cup \cup-\cup \cup-$ occurs just over seventy times in extant Euripides, most pervasively in Troades. ${ }^{149}$ As the phrase is dactylic, the longs cannot be resolved, but what we do find, occasionally, are contracted hemiepe. Possible examples (also as part of longer dactylo-epitrite lengths) are:

- — $\cup \cup$ - Alc. 114 124, Med. 980-1 987-8, 834 845 (see n. 153), Andr. 774 785-6, Tr. 517-8 537-8, Herc. 380 394, , ${ }^{150}$ Ion 1478, Hel. 1480-1497;

$-\cup \cup-\ldots$ - Med. 840 (in responsion with uncontracted D); ${ }^{151}$

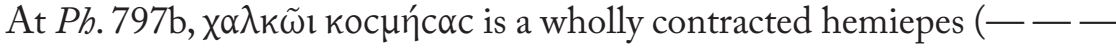
$--)$ in responsion with $-\_\cup \cup-(\dagger 815 \dagger$ : there is corruption in the antistrophe).

There are several enoplian compounds of ' $\mathrm{D}$ ':

\subsection{1. 'D x'}

$-\cup \cup-\cup \cup-\longrightarrow:$ Alc. 439 449, Hcld. 617 628, 774 781, Hi. 60 (ends in breuis in longo), Rh. 245 256, Hyps. $271\left(\left.\right|^{\mathrm{B}}\right)$;

$-\cup \cup-\cup \cup \cup \cup:$ Andr. 1015 1024, Herc. 1076, 1077a, 1199, 1200, Tr. 256, 257, LA 1042 1064, Rh. 464 829.

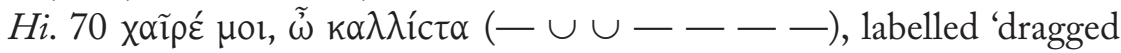
aristophanean' by Dale (21968: 135, 154), could conceivably be interpreted

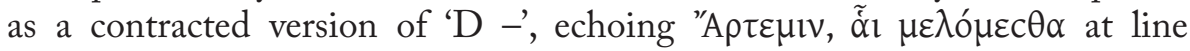
60, particularly since Stinton (1990: 275) and Diggle (1994: 505) express misgivings about taking the phrase $-\cup \cup-\ldots-$ as aeolic.

\subsection{2. 'x D'}

$\cup-\cup \cup-\cup \cup-:$ Alc. 90 †102†, Med. $\$ 856 \dagger, 994 \sim 1000$, Hi.1270, Hel. 1479 1496, Ph. 119, Or. 182 203, 1246 1266, Rh. 28 46, 895 906, 896 907;

$-— \cup \cup-\cup \cup-:$ Alc. 588 597, Med. 846, Andr. 796, El. 483, Rh. 231 240, 348 357.

$149-\cup \cup-\cup \cup-$ is found at Alc. 115 125, 435 445, 440 450, Med. 210, Hi. 59, Andr. 771 782, 790, 1013 1022, Hec. 450 461, 931 941, 945, El. 725, Herc. 1084, 1201, Tr. 511 531, 566, 589 593, 822 842, 827-8 846-7, 834 854, 1082 1100, 1094 1112, 1095 1113, 1096 1114, 1097 1115, 1098 1116, Ion 1479, Hel. 664b, 693, 1146 1160, 1484 1501, Ph. 353, 1512, 1513, [1572], Or. 184 205, 1304, LA 1297, Rh. 32 50, 227 236, 530 549, 533 552, Phaeth. 233 242, Hyps. 30, 67, 269, 275.

${ }^{150}$ The context here $(---\cup \cup-$ followed by ibyc and a run of 7 dactyls) makes a contracted hemiepes more likely than an aeolic hexasyllable.

${ }^{151}$ The context here is dactylo-epitrite (see below, p. 82). Cf. $-\cup \cup---$ in the first half of 'D : D' in Andromache's elegiacs at Andr. 104, 108, 114. 


\title{
6.1.3. 'x D x' ('erasmonidean')
}

The enoplian colon ' $\mathrm{x}$ D x' was named 'erasmonidean' by Snell in his

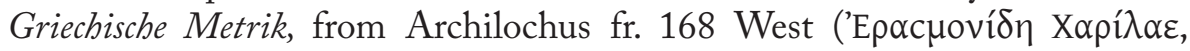

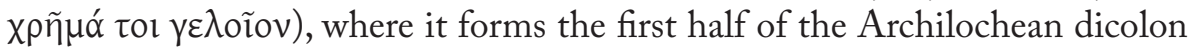
('erasm + ith': cf. below, p. 79). In Euripides, the erasmonidean appears in the following variations:

$-ー \cup \cup-\cup \cup-\longrightarrow:$ Alc. 91, 438-448, Hi. 167, Ph. 833, Rh. 532 551, 534 553, Phaeth. 234 243.

$\cup-\cup \cup-\cup \cup-\cup:$ Herc. 1029, 1032, 1083, Tr. 266, 286, Hel. 664a, Ph. 350, Or. 1256 1276, 1302, IA 585;

$\cup-\cup \cup-\cup \cup-\longrightarrow$ : Herc. 1038, Hel. 1478 1495, Rh. 898 909;

$--\cup \cup-\cup \cup-\cup:$ Andr. 826 830 (in synartesis with an ibycean).

\subsection{4. 'sp + D'}

The only examples of this compound are perhaps $R h .899 \tilde{\eta} \delta u c \delta \alpha i ́ \mu o v \alpha$ k $\alpha \dot{i}$

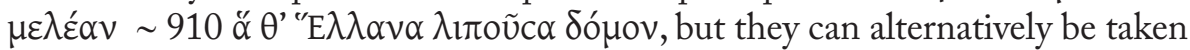
as catalectic dactylic tetrameters ( $-\subset \cup \cup-\cup \cup-)$, as at Alc. 89 101 and $H i .164 .{ }^{152}$

\subsection{5. ' $-\mathrm{D}+\mathrm{ba}$}

This compound is attested thrice in Euripides: Alc. 436 446, Hi. 163.

\subsection{6. 'D + ba'}

Cf. Med. 834 845 (contracted hemiepes)? A possible, but uncertain, instance. ${ }^{153}$

\subsection{7. ' $\mathrm{ba}+\mathrm{D} \cup$ '}

Cf. El. 864 878.

\author{
6.1.8. ' $\mathrm{D}+\mathrm{cr}$ '

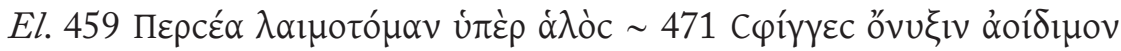 \\ ó $\gamma \rho \alpha v .{ }^{154}$
}

${ }^{152}$ Little help can be derived from considering the context of the Muse's monody in Rhesus, since, although the preceding period is $\cup \mathrm{D}|\cup \mathrm{D}|$ ith, there is a catalectic dactylic tetrameter at 902 913.

${ }_{153}$ Page (ed. Med., p. 186) analyses as hipponactean, probably rightly (as does Mastronarde).

${ }^{154}$ Cf. Diggle (1994: 316), who cites the Sophoclean parallels OC216, 218, (220?) and 222. Line 220 is controversial and is not an example of the colon ' $\mathrm{D}+\mathrm{cr}^{\prime}$ ' in the OCT of Lloyd-Jones and Wilson

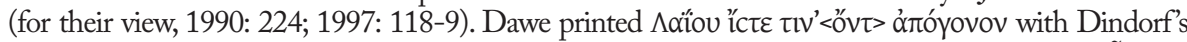
supplement in the second edition of his Teubner text, but in the third edition prefered Elmsley's <oưv $>$. 


\subsection{9. ' $x \mathrm{D}+\mathbf{s p}$ '}

The colon $\cup-\cup \cup-\cup \cup-\longrightarrow$ is found at Andr. 841 and Phaeth. 271 (cf. Diggle, ed. Phaeth., p.167). The same phrase with long initial anceps appears at Tr. 250. Is Alc. 224 236 ( $\cup-\cup \cup-\cup \cup-\cup-$ ) a version of this colon (rather than ' $\mathrm{x}$ ibyc')? But other divisions are possible: see Parker, comm. Alc., p. 95 ..

\subsection{Praxillean $(-\cup \cup-\cup \cup-\cup \cup-\cup--)$}

The praxillean is typically a period-closing colon (cf. Willink on Or. 1369). Diggle (1994: 395) offers a list of its occurrences in Euripides: 'Alc. 568-9 578-9, possibly Su. 599-609, Tr. 1070 1080, Ion 1075 1091, possibly Or. 1369.' For other examples, cf. Alc. 120-1 130-1, Tr. 818-9, Or. 1300, A.

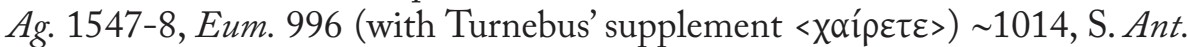
134 148, 135 149. Note that Alc. 568-9 578-9 is actually 'e - prax'; and Or. 1369 is printed as a catalectic dactylic tetrameter followed by an iambic dimeter in Diggle's OCT.

'Blunt praxillean' is probably a contradiction in terms; however, there is a possible candidate:

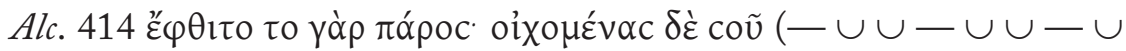
$\cup-\cup-$ ). Cf. S. Phil. 827 843 (first line of 'Ode to Sleep', if not $4 \mathrm{da}$,

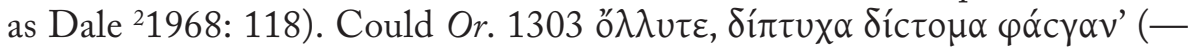
$\cup \cup-\cup \cup-\cup \cup-\cup$ ) be a variation of this colon, shorn of its final syllable?

A 'prolonged' praxillean, with extra dactylic movement, is found at Med. 433-4 440-1 (- $\cup \cup \cup \cup-\cup \cup-\cup \cup-\cup--)$.

\section{3. Cyrenaic $(\cup \cup-\cup \cup-\cup-\cup-)$}

This colon opens with double short, but ends with single short, movement. It is only found in Euripides: El. 586, 588, Herc. 1188, Ion 1448, Rh. 458 824, Phaeth.276, Hyps.276. Two other possible cyrenaics are Alc.228b-9a ( $\dagger 215 \mathrm{~b} \dagger-$ 6), dividing

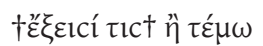

$--\cup \cup-\cup-$ ?

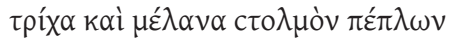

$\cup \cup \cup \cup-\ldots-\cup-$ cyren $^{\text {chol }}$

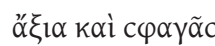

$-\cup \cup-\cup-\operatorname{dod}$

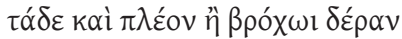
$\cup \cup-\cup \cup-\cup-\cup-$ cyren.

This is perhaps preferable to the OCT's

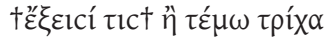

$-\_\cup \cup-\cup-\cap$ ?

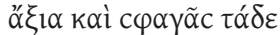

$-\cup \cup-\cup-\cup \cap \mathrm{ch}+$ ia $\|^{\mathrm{B}}$ 


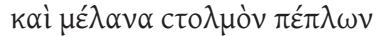

$-\cup \cup--\longrightarrow \cup-\mathrm{ch}+\mathrm{ia}$

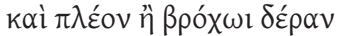

$-\cup \cup-\cup-\cup-c h+$ ia

where the breuis in longo is unconvincing (cf. Diggle 1995: $40 \mathrm{n}$. 5). Other cyrenaics with cholosis are Andr. 857, 862, Hel. 657, 680, 681, Hyps. 279, S. Trach. 647 655. 155 But it should be noted that in these examples cholosis occurs in the ninth, rather than (as here) in the seventh position; also, the responsion is unique.

Cyrenaic + spondee is found once in Euripides at Ion 1509 (cf. 'cyren + ba' at $P V$ 547 555).

\subsection{Diomedean $(\cup \cup-\cup \cup-\cup-x)$}

A length clearly related to the cyrenaic is $\cup \cup-\cup \cup-\cup-\mathrm{x}$. The name 'diomedean' was proposed by Itsumi, from Pi. Nem. $10.7 \Delta$ louń $\delta \varepsilon \alpha \delta$ '

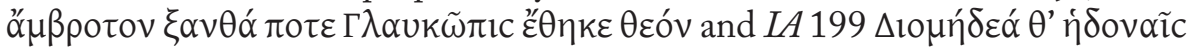

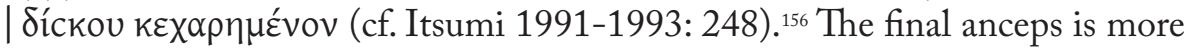
often than not short: Hi. 757 769, ${ }^{157}$ Andr. 1014 1023, Hec. 1067, Tr. 282, 833 852-3, Ion 1078 1094, Or. 183 204, Hyps. 270. There are few examples of final long in Euripides: Alc. 225 237 (|||), 457 468a, El. 168, 733 743, Cycl. 52. Curiously, both Alc. 457 and Cycl. 52 are followed by a paroemiac (there is a lacuna after Alc. 468a).

The compound 'diom $+\mathrm{cr}$ ' is found at IT 1245 1270, 1246-7 1271'158 and Rh. 249 260.

\subsection{Alcaic decasyllable $(-\cup \cup-\cup \cup-\cup--)$}

The clausula to the Alcaic stanza is occasionally used in tragic lyric as an independent, period-closing phrase. Oddly enough, none of the seven Euripidean instances occurs in an aeolic context: ${ }^{159} \mathrm{Hi} .1282$ (|||), Hec. $952(|| \mid)$, El. 486, 1226 1232 (|||), Ion 1049 1062 (as part of 'D - e - $\int$ decasyll'||). ${ }^{160}$

$155 \cup \cup-\cup \cup-\cup--$ at S. Trach. 647 655 is analysed by Dawe as anapaestic metron + anceps + molossus. Some of the other examples are analysed as dochmiac by Wilamowitz (1921: 407).

${ }^{156}$ My presentation of this colon is necessarily divergent from Itsumi's because many examples he includes in the lists on pp. 245-6 can be interpreted differently according to the colometry of Diggle's OCT.

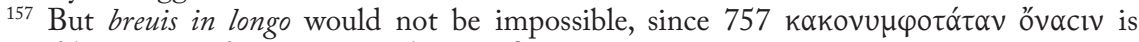
followed by pause and, in any case, change of metre ensues.

${ }^{158}$ The long anceps at IT 1246-7 responds with a short one at 1271.

${ }^{159}$ Six of these examples are listed by Diggle (1994: 394).

${ }^{160}$ The Alcaic decasyllable is otherwise found in tragedy at A. Pe. 651 656, ScT119-20 1401, 860, Su. 662 673, Ag. 1496 1520, Ch. 385 399, PV 167 185, S. El. $1062 \sim 1074,1069 \sim 1081$. 
At IT 392-3 407-8, we find an Alcaic decasyllable with a choriambic prefix; but there the context is not incontrovertibly aeolic either.

\section{6. 'T' $(\cup \cup-\cup \cup-\cup-)$}

As an enoplian unit, $\cup \cup-\cup \cup-\cup-$ has an independent identity from the telesillean: ${ }^{161}$ cf. Hec. 905 914, Su. 778 786, Ion 468 488, 469 489, 1480, 1482, 1486, Hel. 1119 1134, Hyps. fr. 8/9.10 Bond (p. 33) = Fr. 753c, 16 Kannicht (p. 761). Kovacs (1996: 154) toys with the idea of a further instance of 'T' (anapaestic and dactylic context) at Med.135. (For 'T' as an aeolic phrase, cf. below, pp. 97-8).

' $\mathrm{T}$ ' forms the base of compounds such as ' $\mathrm{T}+\mathrm{ba}^{\mathrm{\prime}} 162$ or the longer compound 'T + ith' at Alc. 400 412, Hec. 653-4. Interestingly, the use of $\mathrm{T}$ in the lyric sequence at Ion 1480-6 raises the question of whether it could be viewed as a form of 'headless ibycean' (i.e. a variation on the ibyc at Ion 1484); however, the fact that 'T' occurs so often in synartesis, and the ibycean so seldom (see below, pp. 97-8 n. 209), makes this uncertain.

The colon $\cup \cup-\cup \cup-$ - (often termed 'reizianum'; cf. Dale ${ }^{2} 1968$ : $172)$ is possibly the catalectic, period-closing version of ' $T$ '. It appears as an enoplian phrase at Alc. 909 932, Hec. 909 918 (||), Hyps. fr 8/9.12 Bond (p. 33) = Fr. 753c, 18 Kannicht (but this line is apparently incomplete: see Kannicht's apparatus). At IT 396 411, however, it is doubtful whether breuis in longo suits the phrasing:

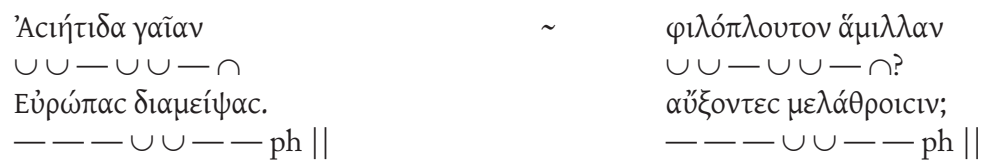

Perhaps some other form of enoplian scansion, with short anceps, is intended.

\section{7.'A' $(\cup \cup-\cup \cup-\cup \cup-\cup \cup-)$}

I take the convenient label ' $A$ ' from Willink to designate a colon 'not always best described as $2 a n$ ' in enoplian contexts (cf. comm. Or., p. xxi). The

${ }^{161}$ See West (1982: 120). I take the label 'T' from Willink (cf. comm. Or., p. xxi).

${ }^{162}$ For the compound $\cup \cup-\cup \cup-\cup-+\cup--$, see Alc. 437 447, 442 452, 460 470, Med. 650 659, Hec. 927 937, Herc. 1080, IT 884, 1251 1275, Ion 1458, Ph. 1581, Rh. 4612 827, 531 550, 900 911, 901, S. Trach. 648 656 (analysed 'anapaestic metron + anceps + trochaic metron' by Dawe), Ar. Au. 1412, 1415 (analysed 'enopl?' by Parker 1997: 343-7). A few of these examples are cited by Ritchie (1964: 318), who calls the colon (impossibly) 'gl + ba'; all of them have, at one time or another, been listed by Diggle (1981: 102, 121; 1994: 112-13, $234,361,505)$. 
following shapes are found:

$\cup \cup-\cup \cup-\cup \cup-\cup \cup-$ : Med. 993 999, Hcld. 775 782, El. 590, Herc. 1207, 1208-9, IT 848, 876, 880, †895†, Ion 470 490, 1508, Hel. 1120 1135, Ph. 1754-5, Or. 1398, LA 210-11, Erechth. III. 5;

$\cup \cup---\cup \cup-\cup \cup-$ : Hi. 165;

$\cup \cup-\cup \cup-\cup \cup-\longrightarrow-$ : Andr. 296 304, 298 306; cf. S. OT 469;

$----\cup \cup-\cup \cup-$ : Hi. 166, Herc. 883a;

$--\cup \cup-\cup \cup-\cup \cup-:$ Ph. 110.

'A' is also the nucleus of several compounds, the most frequent of which is 'A x -', as in Andr. $480 \cup \cup-\cup \cup-\cup \cup-\cup \cup---$ in responsion with 487-8 $\cup \cup-\cup \cup-\cup \cup-\cup \cup-\cup-$. The anceps is usually long (Alc. 396-7 409-10, El. 167 190, Herc. 1205-6, Ion 716, 1442, Ph. 184, IA 177 198); other than Andr. 487-8, short anceps is found only at Hel. 687 and Or. 1392.

Other compounds are:

$\cup \cup-\cup \cup-\cup \cup-\cup \cup-\cup$ ('A $\cup$ '): IT 886-7, Hel. 692, Or. 1363 1547;

$\cup \cup-\cup \cup-\cup \cup-\cup \cup-\cup-\cup-$ ('A + ia'): Herc. 1017, IT12567 1281-2 (the iambic metron has long anceps in the antistrophe), Ion 1466;

$\cup \cup-\cup \cup-\cup \cup-\cup \cup-\cup-\longrightarrow$ ('A + ba' or 'archebulean'): Hcld. 356-7 365-6, Herc. 1197, Erechth. III. 2;163

$\cup \cup-\cup \cup-\cup \cup-\cup \cup-\longrightarrow \cup-\left({ }^{\prime} \mathrm{A}+\mathrm{cr}^{\prime}\right):$ Andr. 279 289.

'A' with a spondaic prefix is found at Erechth. III. 1.

\subsection{Enoplian paroemiac $(\cup \cup-\cup \cup-\cup \cup-x)$}

'Enoplian paroemiac' is Dale's term for $\cup \cup-\cup \cup-\cup \cup-\mathrm{x}$ (cf. ${ }^{2} 1968$ : 175). It is not a frequent colon in Euripidean lyric; and out of the instances listed by Diggle (1994: 206-7), it would perhaps be advisable to retain only

$\cup \cup-\cup \cup-\cup \cup-\cup:$ Andr. 124 133, Ph. 146;

$\cup \cup-\cup \cup-\cup \cup-\ldots$ : Herc. 893, Tr. 516 536, Ion 477 (in an otherwise aeolic context), Rh. 903 914.

\subsection{Ibycean $(-\cup \cup-\cup \cup-\cup-)$}

On this colon, see below, pp. 102-4. It appears as an enoplian phrase at ('chol' indicates cholosis in the penultimate syllable) Andr. 827 831, Herc. 381 395, 1030, 1033 (chol), 1037, Tr. 258 (chol), 267 (chol), 270 (chol), Ion 1484 (chol), Or. 1257 1277 (chol), 1381 (chol).

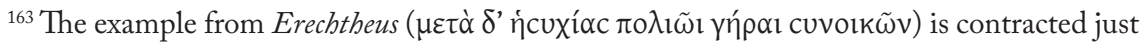
before the bacchiac $(\cup \cup-\cup \cup-\cup \cup---\cup--)$.
} 


\subsection{Hagesichorean $(x-\cup \cup-\cup--)$}

On this colon, see below, pp. 100-2. It is used as an enoplian phrase at Alc. 220 232, 253 260, Med. 151 176, 152 177, 153 178, 157 181, 158 182, 849 859, 850 860, 852 862, 853 863, IT 401 416, Hel. 1110 1125, Phaeth. 230 239, S. Trach. 957 966, 960 969. In Medea it is clearly a rhythmic Leitmotiv.

\subsection{Rarer enoplian cola}

As we have seen, the considerable variety of enoplian lengths made it possible for Euripides to use each particular phrase in a recherché, 'choice' manner; there are really no 'stereotyped' cola such as we find in iambic or aeolic (cf. glyconic, which Euripides uses more than 300 times in the extant corpus). So far, we have surveyed only enoplian phrases for which there is a more or less established label; now, we pass on to a group of nameless cola which appear, at best, two or three times in extant Euripides.

\subsubsection{Cola beginning with double short $(\cup \cup-\ldots)$}

$\cup \cup-\cup-\cup-$ : Hi. 125 135. Cf. S. OT 1209b 1218b, preceded by two hypodochmiacs, whereas the example from $H i$. is followed by two hypodochmiacs.

$\cup \cup-\cup-—-$ Hi. 552 562 (version of above, with cholosis?).

$\cup \cup-\cup \cup-\cup \cup-:$ IT 1240 1265.

$\cup \cup-\cup \cup-\cup \cup-\cup-$ : Hel. 639-40, Ph. 164.

$\cup \cup-\cup \cup-\cup \cup:-\cup-\cup-\longrightarrow$ : Herc. 883b, Or. 1456.

$\cup \cup-\cup \cup-\cup-\cup \cup-\cup \cup-:$ Andr. 1033-4 1043-4.

$\cup \cup-\cup \cup-\cup \cup-\cup \cup-\cup \cup-\cup-$ : Hel. 644.

6.11.2. Cola beginning with single short $(\cup-\ldots)$

$\cup-\cup-\cup \cup-\cup \cup-$ : Alc. 252 259.

$\cup-\cup-\cup \cup-\cup-\cup-\longrightarrow:$ Alc. 461b 471b. ${ }^{164}$

$\cup-\cup-\cup \cup-\cup \cup-\longrightarrow:$ Med.207, Ph. 128 (cf. Ba. 1190). ${ }^{165}$

$\cup-\cup-\cup \cup-$ - Herc. 887b. This colon is sometimes termed 'choriambic enoplian' in aeolic contexts (see below, p. 102); but here the context is enoplian.

${ }^{164}$ With Murray's <हैं $\lambda \alpha c>$ in $461 b$.

165 This is Dale's 'prosodiac-enoplian' no 13 (on the list given in ${ }^{2} 1968: 217$ ). At Ph. 128

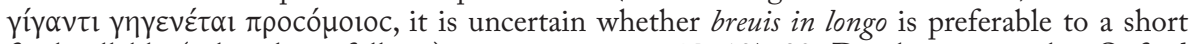
final syllable (a lecythion follows); in any case, on $\mathrm{Ph} .127-30$, Diggle notes in his Oxford apparatus 'nec de uerbis nec de numeris constat'. 
$\cup-\cup \cup-\cup \cup-\cup \cup-\cup \cup-\cup-$ Herc. 1070.

6.11.3. Cola beginning in dactylic movement $(-\cup \cup \ldots)$

$-\cup \cup-\cup \cup-\cup \cup-\cup \cup-\cup$ : Tr. 837-8 857-8 (cf. above, p. 67 n. 137).

6.11.4. Cola beginning $--\cup \cup-\ldots$

$--\cup \cup-\cup-\cup-$ Alc. 443 453

$--\cup \cup-\cup \cup-\cup \cup-\cup \cup-\cup-$ : Herc. 1055-6.

$--\cup \cup-\cup \cup-\cup \cup-\cup \cup-\longrightarrow$ : Erechth. III. 3.

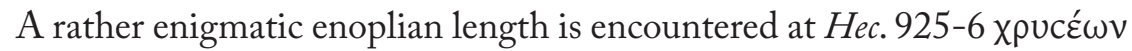

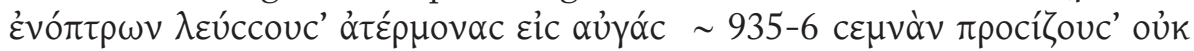

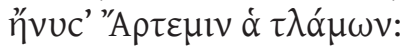

It is followed by ' $T+$ ba' and, a few lines later, we encounter the dactyloepitrite phrase 'e x D' (930 940). The most likely interpretation seems to be 'ia + mol $\cup \mathrm{D}$ ', with contraction in the second biceps of the hemiepes.

\subsection{Enoplian dicola}

The best known enoplian dicolon is 'erasm + ith', the 'Archilochean dicolon'. It is actually quite rare in Euripides: Med. 990-1 996-7, Herc. 136-7 and IT 402-3 417-8 are the known examples. Other dicola are: text) ${ }^{166}$;

diom + ith: Med. 647-8 656-7, Hi. 755-6 767-8, Hec. 655 (conjectural

enop prm + ith: Andr. 124-5 133-4;

$\cup-\cup-\longrightarrow \cup \cup-\cup \cup-$ (ia + D): Hel. 1107 1122, 1137 1151, 1144, Or. 1479, Rh. 224 233, Phaeth. 272.

$-\subset \cup \cup-\cup \cup-----(-\mathrm{D}+2 \mathrm{sp}):$ Rh. 460 826;

$-\cup \cup-\cup \cup-:-\cup-\cup--$ (D + ith): Su. 598 608;

$\cup--\backsim \cup \cup-\cup \cup-\cup(\mathrm{ba}+\mathrm{D} \cup)$ : El. 864 878;

$\cup \cup \cup \cup \cup \cup: \cup-\cup \cup-\cup \cup-\cup$ (ia + erasm): Or. 1468.

$\cup-\cup-\cup-\cup-\cup-\cup \cup-\cup \cup-\cup(2$ ia + erasm): Herc. 896-7, 907-8.

$\cup-\cup--\cup \cup-\cup \cup-\cup-$ (ia + ibyc): Tr. 275. A contracted

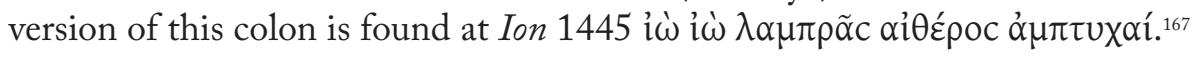

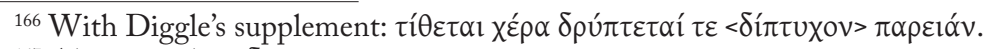

${ }^{167}$ Alternatively, $2 \delta: \cup \cup \cup--\longrightarrow-\cup \cup-\cup-$. 


\section{DACTYLo-epitrite}

Dactylo-epitrite is the rhythmic genre most associated with the great Dorian tradition of lyric composition. Readers of Greek poetry will naturally associate its characteristic rhythm with Pindar. ${ }^{168}$ Absent from the extant plays of Aeschylus (with the exception of Prometheus, which, as far as the lyric metres are concerned, is remarkably un-Aeschylean), dactylo-epitrite is occasionally used by Sophocles and frequently by Euripides (less so, however, in his later plays). Like dactylic, it is a rhythm that immediately implies connotations of dignified diction and 'high' poetry.

Dactylo-epitrite phrases are structures made up of a limited number of units, linked by anceps to form characteristic cola. ${ }^{169}$ The units we encounter in Euripidean dactylo-epitrite are:
D: $-\cup \cup-\cup \cup-$
$\mathrm{d}:-\cup \cup-$
e: $-\cup-$

Less frequently, we may find an enoplian phrase used as a D/e unit (e. g. 'e - praxillean' at Alc. 568-9 576-9, or ' $\cup$ e - enoplian paroemiac' at $H i$. 1104-5 1113-4); cf. below, p. 86. Exceptionally, at Andr. 1033-4 1043-4, the first hemiepes in the length ' $\mathrm{D} \cup \mathrm{D}$ ' is acephalous.

Euripides' preference was for long anceps: there are roughly 280 examples of long and 70 of short anceps in the extant corpus.

At $R h .527$ we find the rather unexpected phenomenon of resolved anceps in responsion with '-' (546):

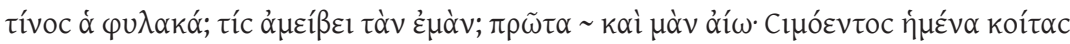

$\cup \cup-\cup \cup-\cup \cup---\cup-\longrightarrow \cap(\cup \cup \mathrm{D}-\mathrm{esp}) \sim \quad--\cup \cup-\cup \cup-\longrightarrow$ $-\cup---(-\mathrm{D}-\mathrm{e} \mathrm{sp})$

Many of Euripides' dactylo-epitrite phrases appear only once in his extant lyric. However, it is possible to single out a few favourite combinations. In the following repertory, I have added, when possible, references to the attestation of these phrases in other poets.

\footnotetext{
${ }^{168}$ On Pindaric D/e, see Itsumi (2009: 409-425).

${ }^{169}$ Cf. West (1982: 70); Korzeniewski (21989: 141).
} 


\subsection{Phrases beginning with 'D...'}

$-\cup \cup-\cup \cup-\cup-\cup \cup-\cup \cup-(\mathrm{D} \cup \mathrm{D}$ : ' choerilean'): Ion 1505-6, Hel. 1139-40 1153-4, 1141-2 1155-6, Rh. 246-7 257-8. Cf. Pi. Ol. 8 (ep.1), Ar. Nub. 466, Pax 775.

$-\cup \cup-\cup \cup-\ldots-\cup \cup-\cup \cup-(\mathrm{D}-\mathrm{D}$ : 'choerilean'): Med. 828-9 840 (cf. above, p. 72, n. 151), Hi. 121 131, Andr. 774 7856, ${ }^{170}, 793-4, \operatorname{Tr} .513-4 \sim 533-4$.

Cf. Pi. Ol. 6 (ep.), 8 (ep. 2, 3, 4), Pyth. 3 (ep.), 9 (str.), Nem. 10 (ep.), 11 (str.), Bacch. 5 (str.), Ar. Nub. 474-5, Pax 795, Ran. 219, 676 708, Eccl. 579.

$-\cup \cup-\cup \cup---\cup \cup-\cup \cup--(\mathrm{D}-\mathrm{D}-)$ : Med.62930 638-9, Tr. 801 811, IT 888-9.

Cf. Pi. Ol. 8 (ep.), Pyth. 9 (str), Nem. 9 (str), 11 (ep), Ar. Nub. 470-1, Vesp. 287, Thesm. 330.

$-\cup \cup-\cup \cup-\cup-\cup \cup-\cup \cup-\longrightarrow(\mathrm{D} \cup \mathrm{D}-)$ : Hi. 1148.

Cf. Ar. Vesp. 279.

$-\cup \cup-\cup \cup-\longrightarrow-\cup-(\mathrm{D}-\mathrm{e}):$ Med. 412-3 424, Phaeth. 237.

Cf. Pi. Ol. 3 (str), 8 (ep. 2, 3, 4), Pyth. 12 (str. 1, 2, 3), Isth. 1 (str).

$-\cup \cup-\cup \cup-\cup-\cup-(\mathrm{D} \cup \mathrm{e})$ : Phaeth. 228.

Cf. Pi. Ol. 8 (antistr. 1, ep. 1), Pyth. 12 (str. 4), Isth. 1 (str. 1, antistr. 3), S. El. 1414 1434.

$-\cup \cup-\cup \cup--\longrightarrow \cup-\longrightarrow$ (D - e -): Med. 832-3 843-4, 980-1 987-8, ${ }^{171}$ Tr. 802 812, Ion $1048 \sim 1061$, Phaeth. 231 240.

Cf. Pi. Ol. 6 (str), 11 (ep), Pyth. 3 (str), Nem. 10 (ep. 1, 2, 3, 4), Isth. 1 (str), 2 (str, ep), 5 (ep), Ar. Nub. 472-3, Pax 784 805.

$--\longrightarrow \cup \cup-\cup-\cup-\longrightarrow(\mathrm{D} \cup \mathrm{e}-)$ : Ion 1478.

Cf. Pi. Isth. 1 (str. 1 ), S. El. 1413.

$-\cup \cup-\cup \cup-\cup-\cup-\cup(\mathrm{D} \cup \mathrm{e} \cup)$ : Ion 1504 .

Cf. S. El. 1433.

$-\cup \cup-\cup \cup---\cup---\cup--(\mathrm{D}-\mathrm{e}-\mathrm{e}-)$ :

Hi. 758-9 770-1, Tr. 823-4 843-4.

\subsection{Phrases beginning with ' $x \mathrm{D} . .$. '}

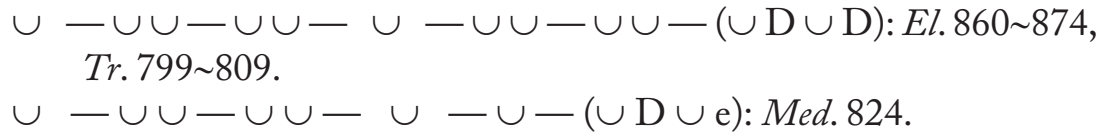


$--\cup \cup-\cup \cup---\cup-(-\mathrm{D}-\mathrm{e}):$ Med. 835, 976-983, Andr. 772-3 783-4, 1011-2 1020-1, Tr. 800 810.

Cf. Pi. Ol. 3 (str, ep), Ol. 8 (ep), Pyth. 1 (ep).

$\cup-\cup \cup-\cup \cup-\cup-\cup--(\cup \mathrm{D} \cup \mathrm{e}-)$ : Alc. 570-1 580-1.

$\cup-\cup \cup-\cup \cup---\cup--(\cup \mathrm{D}-\mathrm{e}-):$ Med. 410 .

$--\cup \cup-\cup \cup---\cup--(-\mathrm{D}-\mathrm{e}-):$ Med. 421-2.

Cf. Bacch. 13 (str), S. Ant. 594, Ar. Nub. 465, Vesp. 278.

$$
\begin{aligned}
& \cup-\cup \cup-\cup \cup---\cup---\cup-(\cup \mathrm{D}-\mathrm{e}-\mathrm{e}): \text { Med. } \\
& -\frac{627-8 .}{636-7 .}
\end{aligned}
$$

Cf. Pi. Ol. 12 (str), Pyth. 12.

$--\cup \cup-\cup \cup---\cup---\cup \cup-\cup \cup-(-\mathrm{D}-\mathrm{e}-$

D): El. 862-3 876-7.

\subsection{Phrases beginning with 'e...'}

$-\cup--(\mathrm{e}-): R h .248 \sim 259$.

$-\cup--\longrightarrow \cup-(\mathrm{e}-\mathrm{e}):$ Andr. 792, 1035 1045.

Cf. Pi. Nem. 1 (str), Ar. Equ. 1267.

$-\cup--\longrightarrow \cup-\longrightarrow(\mathrm{e}-\mathrm{e}-):$ Med. 979 986, Rh. 31 49.

Cf. Pi. Isth. 2 (ep), S. Trach. 97 106, Ar. Vesp. 275 283, ${ }^{172} 277 \sim 285,{ }^{173}$ 279b 289, 284.

$-\cup---\cup--\longrightarrow \cup-(\mathrm{e}-\mathrm{e}-\mathrm{e}):$ Med. 417-8 428-9, Andr. 797, Phaeth. 229 238.

Cf. Pi. Ol. 11 (ep), 12 (str), Pyth. 1 (str), 3 (ep), Nem. 5 (str), 11 (str, ep).

$-\cup---\cup---\cup--(\mathrm{e}-\mathrm{e}-\mathrm{e}-):$ Hi. 760-1 772-3, 762 774.

Cf. Pi. Ol. 3 (str, ep), 7 (ep), Pyth. 12, Isth. 2 (str).

$-\cup--\longrightarrow \cup \cup--(\mathrm{e}-\mathrm{d}-)$ : Alc. 595 604, Erechth, III. 4;

$-\cup--\cup \cup \cup-\cup \cup-(\mathrm{e}-\mathrm{D}):$ Alc. 589 598, 590 599, Med. 411 423, 825 836-7, Hec. 940, Rh. 349 358, 529 548.

Cf. Pi. Ol. 3 (str), 11 (str) 12 (tr), Pyth. 3 (str, ep), 4 (str), 9 (ep), Nem. 10 (str), Isth. 2 (ep), 5 (ep), 6 (ep), [A.] PV 529 539, 892 899, Ar. Equ. 1268 1294, 1296.

$-\cup-\cup-\cup \cup-\cup \cup-(\mathrm{e} \cup \mathrm{D}):$ Hec. 930.

Cf. Pi. Ol.12 (ep), Isth. 5 (ep), Ar. Equ.1270, Eccl.576a.

${ }^{172}$ The line divisions in the parodos of Wasps are slightly confusing in modern editions; the

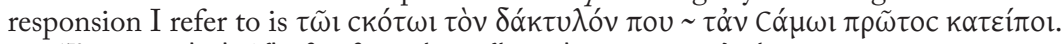

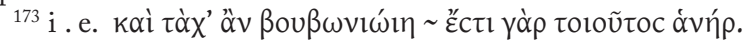


$-\cup---\cup \cup-\cup \cup--(\mathrm{e}-\mathrm{D}-)$. Med. 631-2 6401, 977 985, Andr. 770, 791, Hec. 906-7 915-6, 917, Rh. 29 47, 230 237-8.

Cf. Pi. Ol. 11 (str), 12 (str), Pyth. 1 (ep), 3 (ep), 9 (ep), Isth. 1 (str), 5 (str, ep), 6 (ep), [A.] PV 527-8 537-8, S. Trach. 502 512, Ant. 584 595, Ar. Equ. 1266 1292.

$-\cup-\cup-\cup \cup-\cup \cup-\longrightarrow(\mathrm{e} \cup \mathrm{D}-)$ : Med. 781, Hec. 908, Tr. $820-1 \sim 840-1 .{ }^{174}$

Cf. Pi. Pyth. 3 (ep. 1).

$-\cup---\cup \cup-\cup \cup---\cup--(\mathrm{e}-\mathrm{D}-\mathrm{e}-)$ : Med. 415-6 426-7, 633-4 642-3.

Cf. Pi. Pyth. 3 (ep), Bacch. 14 (str).

$-\cup---\cup \cup-\cup \cup-\cup \cup-\cup \cup-\cup(\mathrm{e}-\mathrm{D}$ prolonged $\cup):$ Hec. 1102-3 (enoplian context). ${ }^{175}$

\subsection{Phrases beginning with ' $\mathrm{x} e . .$. '}

$--\cup---\cup-(-\mathrm{e}-\mathrm{e}): \operatorname{Tr} .805 \sim 816$, Erechth. III. 6.

Cf. Pi. Ol. 8 (ep. 2, 3, 4). Isth. 6 (str), Ar. Equ. 1269, Pax 780.

$\cup-\cup-\cup-\cup \cup-(\cup \mathrm{e} \cup \mathrm{d}):$ Alc. 573 583.

$--\cup---\cup \cup-\cup \cup--(-\mathrm{e}-\mathrm{D}-)$ : Herc. 1075, Hyps. 274.

Cf. Pi. Ol. 8 (str), S. Ai. 175 186.

$--\cup-\cup-\cup \cup-\cup \cup-\cup(-\mathrm{e} \cup \mathrm{D} \cup)$ : Med. 209.

$\cup-\cup--\longrightarrow \cup \cup-\cup \cup-\longrightarrow(\cup \mathrm{e}-\mathrm{D}-)$ : Rh. 226 235.

$--\cup---\cup \cup-\cup \cup---\cup-(-\mathrm{e}-\mathrm{D}-\mathrm{e}):$ Andr. 1010 1019.

$--\cup---\cup \cup-\cup \cup---\cup--(-\mathrm{e}-\mathrm{D}-\mathrm{e}-)$ :

Hec. 943-4.

$--\cup---\cup \cup-\cup \cup-\cup \cup-$ ( - e - D prolonged): Hel. $1111 \sim 1126 .{ }^{176}$

$--\cup---\cup \cup-\cup \cup-(-\mathrm{e}-\mathrm{D}$ : 'iambelegus'): Med. 826-7 838-9, 830-1 841-2, Hi. 1274, 1280-1, Andr. 766-7 7789, 768-9 780, 775-6 787-8, 1029 1038-9, Hec. 948, El. 861 875,

${ }^{174} \operatorname{Tr}$. 820 840 begins with an iambic prefix, clearly marked off by responding word-

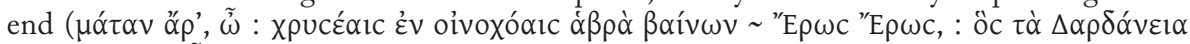

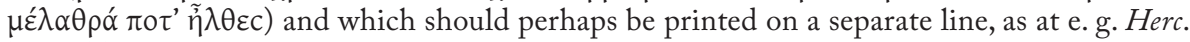
763a 772a. 598.

${ }^{175}$ With synizesis of ' $\Omega \alpha \rho i ́ \omega v$, as at Pi. Nem. 2. 12: Cf. West (1982: 12) and on Hes. Op.

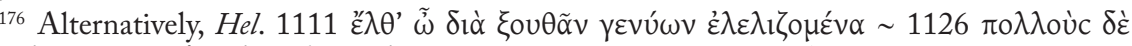

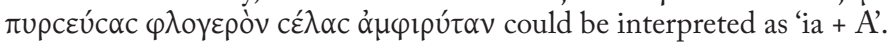


Ion 769, Hel. 686, Ba. 1155, 1195.

Cf. [A.] PV 888-895, 891 898, S. Ai. 178 189, 179 190, 180.

$\cup-\cup-\cup-\cup \cup-\cup \cup \backsim(\cup \mathrm{e} \cup \mathrm{D}$ : 'iambelegus'): Alc. 876 893, Herc. 889, 892, Ba. 1017, 1179. Cf. S. Ai. 191, 911 957.

$\cup-\cup-—-\cup \cup-\cup \cup-(\cup$ e - D: 'iambelegus'): Tr. 804 815 (conjectural text) ${ }^{177}$, Ion 770, 1441, Ba. 1180, 1196.

In the second stasimon of Hecuba (epode), we encounter a form of iambelegus with a spondee tacked on (note the resolution in the 'cretic'):

$\cup \cup \cup \cup-\cup-\cup \cup-\cup \cup-$ - - Hec. 647-8;

$\cup-\cup-\cup-\cup \cup-\cup \cup-$ - - Hec. 649-50.

\section{5. Phrases beginning with ' $-\mathrm{d}$...'}

There is only one dactylo-epitrite phrase in Euripides beginning 'd...':

$--\cup \cup---\cup---(-\mathrm{d}-\mathrm{e}+\mathrm{sp}): \operatorname{Tr} .515 \sim 535$.

\subsection{Cola with iambic constituent elements}

$-\cup \cup-\cup \cup--ー \cup-\cup-\longrightarrow(\mathrm{D}-\mathrm{ith})^{178:}$ Med. 419-20 430-1.

$---\cup \cup-\cup-\cup-\cup \cup \cup-$ ('D contr $\cup$ ith'): Tr. 5178 537-8.

$-\cup \cup-\cup-\cup-\cup-\longrightarrow(\mathrm{d} \cup$ ith $): R h .457 \sim 823$.

$-\cup---\cup-\cup--$ (e - ith): Med. 635 644, Hi. 763 775.

\subsection{Cola with enoplian constituent elements}

An interesting use of dactylo-epitrite is found in emotional exchanges where one of the characters speaks while the other sings (on these duets see Barrett 2007: 386-419). In these cases a favourite technique is to allow the speaking character to begin the phrase with ' $\mathrm{x}$ e $\mathrm{x}$ ' as if the line were an iambic trimeter, only to have the singing character continue the phrase in dactylo-epitrite song. ${ }^{179}$ In Heracles, we find examples of this technique where the enoplian colon 'ibycean' is used instead of a dactylo-epitrite length (such as 'D', say):

(i) Herc. 1187

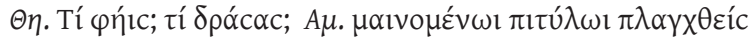

$\cup-\cup---\cup \cup-\cup \cup---(\cup \mathrm{e}-::$ ibyc $)$

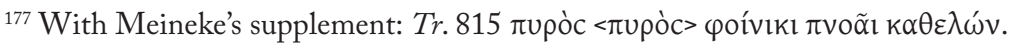

${ }^{178}$ Parker (1976: 18) favours the notation ' $\mathrm{D}-\mathrm{e}+\mathrm{ba}$ '. 1483.

${ }^{179}$ Cf. Hyps. 274. The speaking character can also close the phrase with 'x e x': cf. Ion 1478 , 
(ii) Herc. 1186

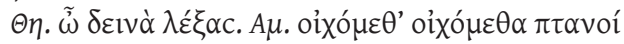

$--\cup---\cup \cup-\cup \cup---(-\mathrm{e}-::$ ibyc $)$

(iii) Herc. 1185

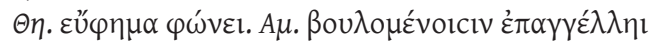

$--\cup---\cup \cup-\cup \cup-\longrightarrow(-\mathrm{e}-::$ ibyc $)$

The sequence ' $\mathrm{x}$ e $\mathrm{x}$ ibyc' is also found without division of speakers:

$-ー \cup--\backsim \cup \cup-\cup \cup--\longrightarrow$ : Ion 685-6, 717-8;

$\cup-\cup-\cup-\cup \cup-\cup \cup-\longrightarrow$ - Ion $705(\sim 685-6)^{180}$, Ph. 130;

$--\cup-\cup-\cup \cup-\cup \cup-\longrightarrow-:$ Ph. 121-2.

Other dactylo-epitrite phrases with enoplian constituent elements are $-\cup---\cup \cup-\cup \cup-\cup \cup-\cup--$ (e - praxillean): Alc. 568-9 578-9;

$\mathrm{x}-\cup--: \cup \cup-\cup \cup-\cup \cup--$ (x e - enoplian paroemiac): Hi. 1104-5 (long initial anceps) 1113-4 (short initial anceps);181

$-\cup---\cup \cup-\cup \cup-\cup--(\mathrm{e}-$ Alcaic decasyllable): $R h$. $536-7 \sim 555$.

${ }^{180}$ Analysed by Owen (ed. Ion, p. 188) as ' 2 ia $+\delta$ '!

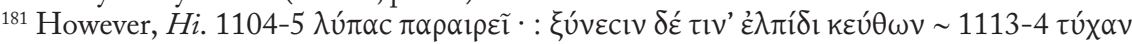

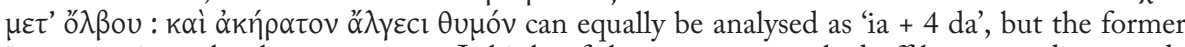
interpretation takes better account, I think, of the segments marked off by responding wordend. 


\section{Ionic}

Ionic is hardly ever encountered in Euripidean lyric, with the exception of Supplices, Bacchae and, rather differently, Cyclops (where there is an ode composed almost exclusively in anacreontics). Although ionic is thought to lend dramatic songs spicy connotations of exoticism and sensuality, ${ }^{182}$ it is unexpectedly absent from the choral lyrics of Phoenissae, where it might have added 'oriental' colour in keeping with the identity of the chorus. We find it blended to interesting effect with aeolic in the famous 'escape ode' in Hippolytus (cf. 732-4b 742-4b) and in the parodos of Iphigenia at Aulis (cf. 171-4 192-5). Indeed, some sort of mysterious affinity with aeolic (another musical genre from the eastern Aegean) may explain why we occasionally find ionic sequences (marked off by word-end) ensconced within aeolic phrases. In the second stasimon of Alcestis (a medley of aeolic and enoplian elements) we find at $471 b^{183}$.

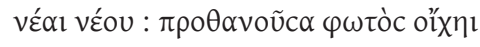

$\cup-\cup-: \cup \cup-\cup-\cup--$

If, on the one hand, the closing $\cup-\cup-\ldots$ is a regular clausula to longer aeolic cola' (Diggle 1994: 505), the phrase as a whole looks, on the other hand, remarkably like an anacreontic preceded by an iambic metron. This phenomenon is found five times in the first stasimon of Hippolytus, where

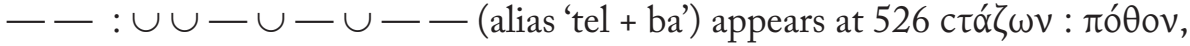

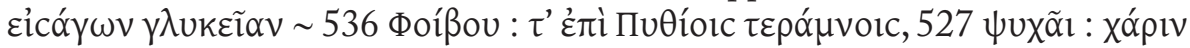

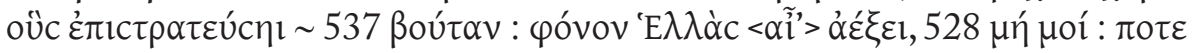

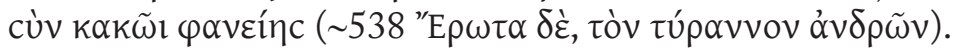

In Euripides, responding ionic cola are almost always perfectly matched pairs. ${ }^{184}$ Resolution is encountered at $B a .79 \sim 95,150,372,398$; contraction at Ba. 81 97, 113 128, 146, 147.

\subsection{Lengths consisting of full ionic metra}

$$
\begin{array}{r}
\cup \cup--\cup \cup-- \text { ('2 io'): Ion 1240, 1241, Ph. 1515, 1517, 1540, } \\
\text { Ba. 67a, 69, 71, 78 94, 80 96, 82 98, 83 99, 84 100, 85 101, }
\end{array}
$$

\footnotetext{
${ }^{182} \mathrm{Cf}$. the salacious comments Agathon's ionic song evokes from the Kinsman in Ar. Thesm. $130 \mathrm{ff}$.

${ }^{183}$ There is corruption in the strophe, where at $461 \mathrm{~b}$ Diggle prints Murray's supplement $\langle\bar{\varepsilon} \tau \lambda \alpha \mathrm{c}\rangle$.

${ }^{184}$ The exceptions are $B a .372-388,382 \sim 398,522 \sim 541,524-5 \sim 543-4$, where in one stanza a colon with resolution responds with an unresolved one in the other stanza.
} 
144, 145, 375 391, 376 392, 377 393, 381 397, 382, 383 399, 384 400, 520 539, 521 540, 528 547, 529 548, 533 522, 534 553, 535 554, 556, 558, 563, 564, 566, 567, 569, 570, IA 173 194, 174 195, Cycl. 501, 509, 517, Hyps. 64.

$\cup \cup \cup \cup-\cup \cup-$ - Ba.79 95.

$\cup \cup-\cup \cup \cup \cup-\longrightarrow: B a .398$.

$-ー-\cup \cup-\longrightarrow: B a .81 \sim 97,146,147$.

$\cup \cup--\cup \cup-\longrightarrow \cup \cup-\longrightarrow$ ('3 io'): Ph. 1516, Ba. 65, 70, 86-

7 102-3, 114 129, 523 542, 543-4, 560, 561-2.

$\cup \cup--\cup \cup-\cup \cup \cup \cup-\longrightarrow: B a .524-5$.

$\cup \cup-\cup \cup \cup \cup-\longrightarrow \cup \cup-\longrightarrow B$ Ba. 150.

$---\cup \cup-\longrightarrow \cup \cup-\ldots$ Ba.113 128.

$\cup \cup--\cup \cup-\longrightarrow \cup \cup-\longrightarrow \cup \cup-\longrightarrow$ ('4 io'): Su. 42 48-9, 55 63, 57-8 65-6, 60 68.

\subsection{Syncopated lengths}

$\cup \cup-\cup \cup-\longrightarrow:$ Ba. 64, 66, 68, 72, 149, Rh. 365 375.

$\cup \cup-\longrightarrow \cup \cup$ : Su. 43 50, 45 52, Herc. 679 693, 680 694, Ba. 67b, 370 386, 371 387, 388, 373 389, 374 390, 379 395, 380 396, 519 538, 541, 557, 559, 565, 568.

$\cup \cup-\cup \cup \cup \cup-$ Ba. 372, 522.

$\cup \cup-\cup-\longrightarrow:$ Hi.734a 744a.

$\cup \cup-—-: H i .734 \mathrm{~b} \sim 744 \mathrm{~b}$.

$\cup-\longrightarrow \cup \cup-$ : Hyps. 63, 148b.

$\cup \cup-\cup-\longrightarrow \cup \cup-$ : Ba. 88 104.

$\cup \cup--\cup \cup--\cup \cup-$ : Su. 56 64, 59 67, 61 69, 62 70, Ba. 378 394.

$\cup \cup--\cup \cup-\longrightarrow \cup \cup-\longrightarrow \cup \cup-$ Su. 46-7 53-4.

$\cup \cup-\cup \cup-\cup-\longrightarrow:$ Ba. 385 401, 536 555.

$\cup \cup-\backsim \cup \cup-\cup-\longrightarrow$ : Cycl. 502, 510, 518.

$\cup \cup-\cup \cup-\longrightarrow \cup \cup-\cup \cup-\longrightarrow: S u .51$.

$-\cup-\cup \cup--\cup \cup-\cup-$ :Ba.571-2 (if not aeolic).

\subsection{Anacreontic $(\cup \cup-\cup-\cup-\longrightarrow)$}

Hi. 733 743, El. 462 474, Herc. 678 692, Ba. 526 545, 527 546, 530 549, 531 550, 532 551, Rh. 364 374, Cycl. 495, 496, 497, 498, †499†, 500, 503, 504, 505, 506, 507, 508, 511, 512, †515†, 516. 


\subsection{Lengths with 'iambic' prefixes}

$$
\begin{aligned}
& -ー \cup-\cup \cup-\longrightarrow \text { ('ia + io'): Hyps. } 65 .{ }^{185} \\
& --\cup-\cup \cup-\longrightarrow \cup \cup-\longrightarrow \text { ('ia }+2 \text { io'): Rh. 363 373. } \\
& -\cup \cup-\cup \cup-\longrightarrow \cup \cup-\text { ('ch }+2 \text { io'): Hi. 732 742. } \\
& \cup--\cup \cup-\longrightarrow \cup \cup-- \text { ('ba }+2 \text { io'): Ph. 1539, LA 171 192, } \\
& \text { 172 193. } \\
& \cup-ー \cup \cup-ー \cup \cup--\cup \cup-\longrightarrow \text { ('ba + } 3 \text { io'): El. 460-1 472-3. }
\end{aligned}
$$

${ }^{185}$ If not aeolic: in the other examples, the 'iambic' prefix starts a series of ionics; here it comes in the middle. 


\section{Aeolic}

'Aeolic' is the generic term used by metricians to describe a large group of closely related rhythmic phrases centred around the choriamb $(-\cup \cup-)$. Practically never used en bloc by Aeschylus (see West 1982: 115), aeolic is one of the main rhythms in the lyrics of Sophocles and Euripides. Sophoclean aeolic, in which stanzas full of subtly interwoven rhythms are often made up of longer ('nameless') cola, generally differs from its Euripidean counterpart by dint of its sheer complexity (cf. Dale ${ }^{2} 1968$ : 151 ; West 1982: 120), although it has to be said that the aeolic lyrics of Oedipus at Colonus, in their comparative simplicity, strike a note curiously reminiscent of Euripides.

Euripides' aeolic stanzas are more often than not made up of variations on the glyconic (oo $-\cup \cup-\cup-$ ), the full colon alternating with its catalectic (pherecratean), headless (telesillean), anaclastic (wilamowitzian) and pendent (hipponactean) versions. ${ }^{186}$ Other frequent cola are the headless wilamowitzian (aeolic heptasyllable), dodrans, aristophanean and reizianum.

\subsection{Glyconic $(o o-\cup \cup-\cup-)^{187}$}

The glyconic is by far the most frequent colon we encounter in Euripidean aeolic. It is often used as the opening phrase of a stanza and thereafter in contrasting alternation with its catalectic and acephalous versions

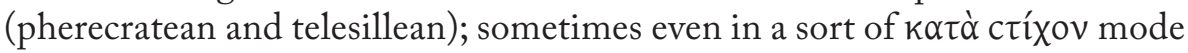

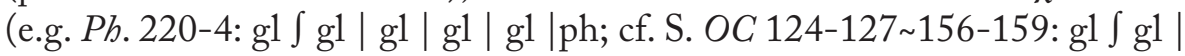
$\mathrm{gl}|\mathrm{gl}| \mathrm{dod})$. A favourite combination in Greek lyric is the priapean dicolon (g1 | ph), a rhythm familiar to generations of Hellenists from the opening

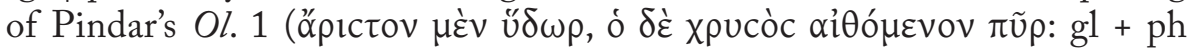
||). ${ }^{188}$ The glyconic appears very frequently in synartesis with other aeolic

${ }^{186}$ What is the nature of the final position in pendent aeolo-choriambic cola (pherecratean, reizianum, aristophanean, hipponactean, hagesichorean, etc.)? Barrett thought it was anceps (comm. Hi., pp. 422-3), but, since he seems not to have found a way to prove this, Parker is surely right to consider it 'far from certain that the poets thought of the final position of pendent aeolo-choriambic cola as anceps, rather than true long' (comm. Alc., p. 245).

${ }^{187}$ On the glyconic in tragedy, see Itsumi's admirable study (1984: 66-82). My survey of the Euripidean glyconic gives results that are somewhat different from his, for the obvious reason that he worked from Murray's text.

${ }^{188}$ The sequence $\otimes \mathrm{gl}+\mathrm{ph} \|$ is actually not very common in Euripides: Su. 971-2, Herc. 348-9 364-5, LA 751-2 762-3 (not Euripidean?), Rh. 23-4 41-2. 
cola; perhaps this explains why it is never used by Aeschylus, and rarely by Euripides, as a period-closing phrase. ${ }^{189}$ Possible instances are: Alc. 988 999 (syntactic break in both strophe and antistrophe, punctuated by full stop), Su. 992 1014 (breuis in longo; but there is corruption in the following line, in both strophe and antistrophe); El. 484 (gl at sentence-end, followed by change of metre), Hel. 1488 1505 (responding sense-pause, but periodend is not entirely certain here, as further glyconics follow), $\mathrm{Ba} .903$ (clear rhetorical break). For Hi. 150 160 and 741 750 (glyconics with cholosis), see below, pp. 93-4.

Euripides uses the glyconic in a considerable variety of shapes (including tribrach base and resolutions in the second long of the choriamb and/or in the last position), but patterns with standard disyllabic base are, on the whole, predominant; contrary to Pindar (cf. Dunbar, comm. Birds p. 524), Euripides definitely favoured the base '- - ':

$$
\begin{aligned}
& ---\cup \cup-\cup-\text { (roughly } 200 \text { attestations); }{ }^{190} \\
& -\cup-\cup \cup-\cup-\text { (c. 70); }{ }^{191} \\
& \cup--\cup \cup-\cup-(30) .{ }^{192}
\end{aligned}
$$

This last shape is, interestingly, less common than the glyconic with

${ }^{189}$ Sophocles, on the other hand, uses the period-closing glyconic comparatively often: cf. Ant. 102 119, Trach. 844 855 $\left(\left.\right|^{\mathrm{H}}\right)$, Phil. 173 184, $1127\left(||^{\mathrm{B}}\right)$ 1150, 1129 1152, OC $132 \sim 164$, $671 \sim 684,675 \sim 688,1218 \sim 1232$. In Pindar's Ol. 10, the clausula to the strophe is a glyconic; and we find glyconics ending in breuis in longo at Pyth. 8.19, Nem. 2.16 and 4.23. In Nem. 6, the glyconic in line 2 of the epode regularly ends in a syntactic break.

${ }^{190}$ The shape $-\ldots-\cup \cup-\cup-$ is found in every extant Euripidean play (most pervasively in Heraclidae), except Orestes: Alc. 964, 974, 977, 988 999, Med. 437a 444a, 444b, Hcld. 358 367, 359 368, 360 369, 371, 372, 374, 375, 379, 748 759, 749 760, 753 764, 755 766, 756 767, 770, 771 778, 772 779, 895 904, 912, 920, 922, Hi. 64-5, 66, 68, 561, 735 745, 737, 748, 752 764, 765, Andr. 504 526, 528, 507 530, 510, 511 533, 513 535, Hec. 448 459, 456, 468 477, 470, 471 480, 911 920, Su. 956, 969 (cf. Diggle 1981: 23-4), 973, 974a, El. 117 132, 123 138, 137, 184, 185, 198, 199, 436 446, 455 467, 484, 707 721, 728 738, Herc. 355 371, 357 373, 362 378, 372, 392 406, 440, 643 661, 668, 651 669, 652 670, 653 671, 676, 781 798, 782 799, 785 802, Tr. 1060 1071, 1061 1072, 1063 1074, 1064, IT 405 420, 422, 1090, Ion 113, 120 136, 121 137, 184, 185 195, 188b 199, 198, 205, $223 \mathrm{~b}$, 223c, 505, 1085 1101, 1088 1104, Hel. 1302, 1365, 1474, 1481, 1487, 1505, 1506, 1510, Ph. 209, 212, 215, 224, 226, 233, 235, Ba. 111 126, 154, 862 882, 870 890, 871 891, 873 893, 888, LA 166 187, 751 762, 760, 1060, 1085, 1086, 1096, Rh. 23 41, 342 351, 343 352 Hyps. 42 85, Cresph. III. 1 10, 2 11, Teleph. II. 9.

${ }^{191}$ The shape $-\cup-\cup \cup-\cup-$ is found at Alc. 575 585, 963, 966, 969 980, 975, Med. 437b, Hcld. 911, 913, 921, Hi. 63, 151, 551, 738, 747, 753, 754, Andr. 501 523, 502 524, 506, 532, Hec. 445, 447 458, 463, 479, 1097, Su. 955 963, 964, 1000, El. 122, 146, 171 194, 175, 176, 186, Herc. 348 364, 356, 423, 650, IT 1089, 1107, 1113, Ion 129, 186 196, 188a, 220, 503b, 1236, Hel. 518, 525, 1488, Ph. 203, Or. 817 829, Ba. 407 422, 867, 868, 907, IA 773, Cycl. 69.

${ }_{192}$ For $\cup--\cup \cup-\cup-$ see Hcld. 378, 752 763, Su. 992 1014, El. 118 133, 160, 706 720, Tr. 314 331, 322 338, 323 339, 1075, IT 1094 1111, Ion. 194, 219, Hel. 524, Ba. 118 133, 404 419, 406 421, IA 213, Hyps. 77. 
tribrach base $(\cup \cup \cup-\cup \cup-\cup-)$, which is arguably the typical feature of 'later' Euripidean aeolic (although there are a couple of examples from plays earlier in his career). ${ }^{193}$

Glyconics with resolution in the second long of the choriamb are perhaps more of a rarity (this is a licence of which neither the Lesbian poets nor Aeschylus availed themselves; used, however, twice by Sophocles). Itsumi counts, as I do, 23 examples in Euripides (1984: 77); since he does not locate the exact references, the following list may be helpful: ${ }^{194}$

$\cup \cup \cup-\cup \cup \cup \cup \cup-:$ El. 445, 458, Hel. 1459, Ph. 206, 227, 234, 237, LA 165 186.

$$
\begin{aligned}
& \cup \cup \cup-\cup \cup \cup \cup \cup \cup \cup: \text { Ba. } 903 \text { (cf. Diggle 1994: 471). } \\
& \cup--\cup \cup \cup \cup \cup-: \text { Hcld.777, Hel. 1301 1319. } \\
& ---\cup \cup \cup \cup \cup-: \text { El. 709 723, IT 1101, Ph. 221, IA 183 204, }
\end{aligned}
$$
771, 1038, Hyps. 34. Cf. S. Ant. 1141 1150 (the only Sophoclean instances).

\section{$-\cup-\cup \cup \cup \cup \cup-:$ Hel. 1489.}

Resolution in the second long of the choriamb also occurs in other aeolic cola: dodrans (Alc. 971 982), hagesichorean (Herc. 794, Hel. 1110 1125), pherecratean (Tr. 1065, LA 795), telesillean (El. 732, Hel. 1119, Hyps. 40), aristophanean (Ba. 123), hipponactean (Herc. 642, IA 1047), reizianum (Cresph. Fr. 71.9 Austin, but Diggle's text in $\operatorname{Tr} G F S=$ Fr. 453 Kannicht is preferable: see above, p. 42 n. 67).

In Euripides' later plays, we sometimes come across a shape of glyconic with tribrach opening and final resolution: $\cup \cup \cup-\cup \cup-\cup \cup \cup(S u$. 971, El. 125, Ion 463, Ph. 208, Ba. 911, IA 180 201, Hyps. 49). ${ }^{195}$ Final resolution with the base '- - ' is found at Hec. 452, IT 1106, Hel.1115 1130, 1348 1364, 1349.

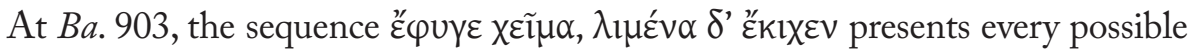
resolution (cf.Diggle 1994: 471; Dale 1983: 141): $\cup \cup \cup \cup \cup \cup \cup \cup \cup \cup$.

Glyconics with cholosis in the penultimate position are, comparatively speaking, something of a rarity in tragedy (for Sophocles, see Dawe on

${ }^{193}$ Cf. Hi. 550 560, Su. 971, El. 115 130, 125, 147 164, 148, 152, 154, 435 445, 440 450, 458 470, Herc. 649 667, Tr. 124, 125, IT 1093 1110 (gl + sp), 1104 1121, 1129, Ion 463 483, 1235, 1238, Hel. 1459, 1461 1475, Ph. 202 214, 206 218, 208 220, 222, 211 223, 227, 232, 234, 237, Ba. 138, 156, 878 898, 903, 911, IA 164 185, 165 186, 180 201, 543 558, 544 559, $548,+573 \dagger, 791,1054 \sim 1076,1087-8,1095$, Hyps. 32 75, 33 76, 49. There are five examples in Sophocles (Trach. 844 855, OC 197, 182 200) and none in Aeschylus (who uses the tribrach opening to an aeolic colon only in the responding pair of pherecrateans at $A g$. 698 716). In Aristophanes, glyconic with tribrach base occurs only three times in Frogs (cf. 1251, 1317, 1327) in parody of Euripides: see Parker (1997: 71, 509).

${ }^{194}$ Diggle's examples of resolution in the choriamb of Euripides' aeolic cola (1994: 123 n. 94) are somewhat confusing in that they include (without warning) doubtful examples of resolution in the first long of the choriamb (against which see Diggle himself, 1994: 470-1; 1995: 39 n. 3). The reason for this is that be was analysing Murray's text, as he clearly states.

${ }^{195} \mathrm{C}$. also IT 425 442 (gl + ia), on which see Platnauer, ed. IT, p. 182 n. 1. In the OCT, this is better analysed as ' $c r+2$ ia'. 
OT 1197; Diggle 1994: 472 n. 146). In Euripides we find the following occurrences:

$$
\begin{aligned}
& -\cup-\cup \cup-- \text { - Hi. }{ } 141 \dagger \sim 151, \text { IT 1123, Ba. 865, 866; } \\
& \cup--\cup \cup-- \text { - Ba. 577; } \\
& \text { - — - } \cup \cup-\ldots \text { - : Hi. 150 160, 741 750 (with Seidler's } \theta \varepsilon o \text { cruv, }
\end{aligned}
$$
advocated by Diggle 1994: 472), Hec. 473 482, El.116 131, IT 1138, Ion 206, Ba. 885, 886, 887 ${ }^{196}$, LA 790, 1056 1078;

\section{$\cup \cup \cup-\cup \cup-\longrightarrow$ - Tr.124,125, Ba. 138 .}

At Hi.150 160 and 741 751, the glyconic - - $-\cup \cup-$ - acts as clausula in a context where the more frequent aeolic clausular rhythms, such as the pherecratean or hipponactean, would normally be expected. This prompts the question of whether the close $. . \cup-\ldots-$ to a glyconic makes it more of a period-closing rhythm than the 'normal' glyconic. The answer to this, as Itsumi has observed (1984: 75), is that examples of dovetailed dragged glyconics can be found in Euripides; and even though the colometry adopted in the current OCT reduces his list of six instances to three (Ion 206, Ba. 866 886), this is nevertheless a valid point. Cholosis, then, does not per se change the glyconic's essentially acatalectic nature and its consequent lack of suitability for providing the rhythm for sentence-closing phrases (see above, p. 92).

Bacchae and Iphigenia at Aulis are notable for presenting the only plausible Euripidean examples of the 'freak glyconic' $\cup \cup \cup-\cup \cup-\cup \cup-$ (cf. 112 127, 115 130; IA 1093). At El.439 449, we find the same phenomenon, with disyllabic base:

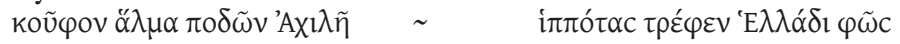

$-\cup-\cup \cup-\cup \cup-\quad-\cup-\cup \cup-\cup \cup-$

Itsumi (1984: 77) calls the labels 'gl' or 'wil' into question. Parker opts for the term 'aeolic dactyls' (1997: 199), whereas Dawe, in his analysis of S. Ai. 231 254 ( $\cup-\cup \cup-\cup \cup-)$, favours the expression 'dodrans longior' (Dale's 'prosodiac' interpretation of Ba.112 127, 115 130 [1983:321] is even more unlikely, given the predominantly aeolic context in which the colon appears). Despite the problem of finding a suitable name for it (see below, ad loc.), the pedigree of oo $-\cup \cup-\cup \cup-$ as a legitimate aeolic phrase is, to a certain extent, vouchsafed by Pindar, who makes repeated use of it ("with ' $U$ -'base) in the epode of Ol.10 (line 2). ${ }^{197}$

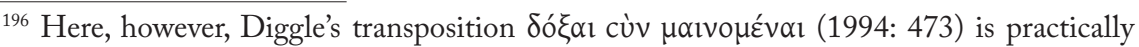
certain, since it avoids responsion between normal glyconic and glyconic with cholosis. This would make the line a wilamowitzian of the shape $-----\cup \cup-$, the commonest pattern in Euripidean lyric.

${ }^{197}$ Cf. Dunbar, ed. Birds p. 526, but the phrase does not so much open a period as close it (breuis in longo in all the repetitions, with hiatus as well in epode 5). 
Finally, it should be observed that resolution in the first long of the choriamb is an unlikely phenomenon anywhere in Euripidean lyric, ${ }^{198}$ it would

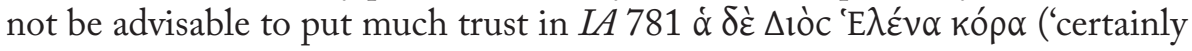
not Euripidean': Diggle 1994: 471).

\subsection{Pherecratean (oo $-\cup \cup--)$}

As the glyconic's catalectic mutation, the pherecratean is typically a period-closing rhythm in Euripidean aeolic. This observation casts suspicion on the colometry printed in the OCT at $I A$ 175-6 196-7:

\begin{tabular}{|c|c|c|}
\hline 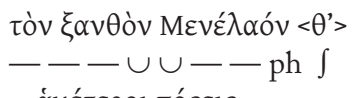 & $\sim$ & 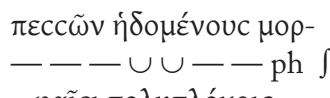 \\
\hline $\begin{array}{c}\alpha \mu \varepsilon \tau \varepsilon \rho \mathrm{ol} \pi \mathrm{oc \varepsilon lc} \\
-\cup \cup-\cup-\mathrm{dod}\end{array}$ & & $\begin{array}{l}\varphi \alpha \overline{i c l} \pi \mathrm{T} \lambda \cup \pi \lambda \text { okolc } \\
-\cup \cup-\cup-\operatorname{dod}\end{array}$ \\
\hline
\end{tabular}

In 175 , the reason for Fritzsche's $\left\langle\theta^{\prime}\right\rangle$ is (like the transmitted $\theta^{\prime}$ at $\mathrm{Hec}$. 476) to avoid breuis in longo in a position where, in the responding antistrophe, there is word-overlap into the next colon. ${ }^{199}$ But, in Euripides, a pherecratean ending in elision is extremely rare (paralleled only by Su. 1004a). ${ }^{200}$ The antistrophe postulates, even more unacceptably, a pherecratean in synartesis with the following colon, an otherwise unattested phenomenon in Sophoclean and Euripidean lyric. ${ }^{201}$ In spite of Stinton's strictures concerning hypothetical redivisions of aeolic cola so as to eliminate pendent cola in synartesis (1990: 360), I venture that the division - - $-\cup \cup \int--\cup \cup-\cup-$ (hex

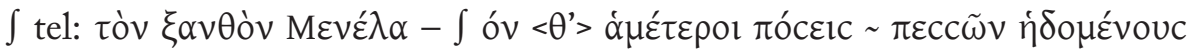
$\int \mu о \rho \varphi \alpha i ̃ c 1 ~ \pi о \lambda u \pi \lambda o_{k o l c)}$ would be preferable. ${ }^{202}$ Although there is no Euripidean parallel for the sequence 'hex | tel', dovetailed hexasyllables are well attested (cf. below, p. 111).

Again, the aeolic base ' - _ is by far most frequent. ${ }^{203}$ But the shapes

${ }^{198}$ Cf. Diggle (1994: 470-1; 1995: 39 n. 3). This may well be a licence in which Sophoclean and Euripidean practice differed sharply: see Parker (1968: 243); Lloyd-Jones \& Wilson (1990: 239). On the problems of scanning $\cup \cup \cup$ at Ar. Au. 1372, see Parker (1997: 344-5).

${ }^{199}$ West is prepared to admit this at Ar. Pax 389 588 (1982: 107-8); cf. Parker's objections (1997: 271-3).

${ }^{200}$ Lloyd-Jones and Wilson print an implausible instance at S. Ai. 199b; the phenomenon is not found in Dawe's text of Sophocles. See Finglass, comm. Ai, p. 202.

${ }^{201}$ The instance in Bond's text of Hypsipyle (fr. I. iii. 4) is satisfactorily eliminated by Diggle's and Kannicht's colometry in TrGFS (Hyps. 61) = Fr. 752g, 4 Kannicht.

${ }^{202}$ Similarly, 'hipp $\int$ dod' contemplated by Parker at Ion 1063-4 (1966: 25) is better divided (as printed in the OCT) 'hex $\int$ hept'.

$203-\_-\cup \cup-\quad$ is found at Alc. 117 127, 577 587, 967 978, 968 979, 976, Med. 212, Hcld. 364, Hi. 143 153, 746, 749, Andr. 525, 801, Hec. 444 455, Su. 979, 1004a, 1008 1030, 
Part I - Euripides' use of lyric metre

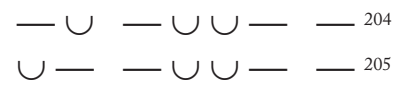

are also quite common.

The tribrach aeolic base is also found in pherecrateans. ${ }^{206}$ Although aeolic cola with tribrach base do not, as a rule, respond with disyllabic base,

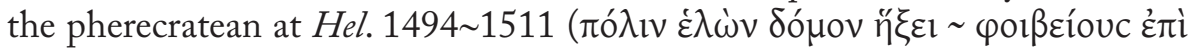
$\pi u ́$ pyouc) is a certain instance. Resolution in the second long of the choriamb is found at $\operatorname{Tr} .1065$ and $L A 795$.

\subsection{Telesillean $(x-\cup \cup-\cup-)$}

The headless glyconic is most often used by Euripides with long half-base. ${ }^{207}$

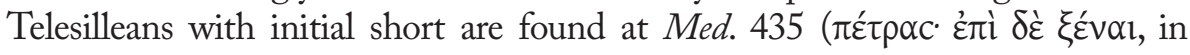
responsion with long half-base; an ambiguous instance), Ion 462, Hel.1114 1129, Hyps. 40, 61, Cresph. III. 4. Cholosis in the penultimate position occurs at Med. 851 861 and Hyps. 61. Instances of resolution in the second long of the choriamb are El.732 and Hyps. 40. The example from Hypsipyle is notable for other reasons:

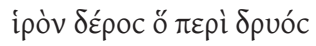

- $-\cup \cup \cup \cup \cup \cup($ Hyps. 40)

For final resolution in a telesillean, cf. $L A$ 1055. The ascription of ipòv is given 'post Buijs Willink' in Diggle's apparatus. The emendation is attractive

El. 119 134, 124 139, 177 200, 179 202, 183 206, 187 210, 189 212, 454 466, Herc. 349 365, 359, 360 376, 361 377, 363 379, 374, 391 405, 393 407, 421 438, 441, 672, 684 698, 686 700, 789 806, Tr. 1062, 1076, IT397 412, 406 421, 438 455, 1095 1112, 1105 1122, Ion 119 135, 124 140, 189, 211 225, 1243, Hel. 522, 527, 1131, 1318 1336b, 1511, Ph. 204 216, 207 219, 213 225, 228, 230, 238, Or. 818 830, Ba. 119 134, 146-7 (if not ionic), 403 418, 405 420, 408 423, 411 426, 575, 912, IA 170 191, 175 196, 181 202, 184 205, 209, 545 560, 557 †572†, 575, 752 763, 787, 1039, 1044 1066, 1094, 1097, Rh. 24 42, 353, 346, 535 554 (if not enoplian), Hyps. 24, 35 78, 38 81, 41 84, 44 87, 48, Teleph. II.2.

$204-\cup-\cup \cup-\quad$ is found at Alc. 965, Med. 438 445, Hcld. 355, 900 909, Hi. 546 556, 736, 739, Andr. 514 536, Su. 996 1019, El. 145 162, Herc. 358, 389 403, 419 436, 424, 654, 681 695, 882, Tr. 324a 340a, 1073, Ion 187 197, Ba. 908, IA 167 188, 581, 774, 786, Hyps. 39 82.

${ }_{205} \cup-\longrightarrow \cup \cup-\ldots$ is found at Alc. 456 467, 962 973, Andr. 503, Su. 1003, 1026b, Herc. 390 404, Ion 200, 454 474, 1080 1096, 1089 1105, Hel. 1116, 1458 †1472†, Ba. 402 417, 413 †429†, 909, 910, IA 215, Rh. 344, 355, Teleph. II. 4.

${ }^{206}$ Cf. Andr. 505 527, 508 531, Su. 972, El. 149 166, 441 451, Herc. 420 437, 422 439, 783 800, IT 1091 1108, Ion 1230, Hel. 519, 1494, Ba. 576, 580, 581, 881 901, IA 212, 1053 1075, Phaeth. 70 78. There is a further example at Hyps. fr. I iii 8 Bond (= TrGFS Hyps. 65 = Fr. 752g, 8 Kannicht), but Diggle's colometry is probably preferable.

$207-\ldots \cup \cup-\cup-$ is found at Alc. 989 1000, Med, 442, 436-443, 854 864, Hcld. 377, 915 924, Hec. 451 462, 466 475, 467 476, El. 120 135, 742, Herc. 685 699, IT 440, 1127 1142, Ion 461 481, 482, IA 179 200, 778, 799, 1077. 
because the papyrus' ípòv gives an unparalleled instance of the colon $\cup \cup$ $-\cup \cup-\cup-$ ('T': see below and next page) in responsion with a normal telesillean. But Diggle's apparatus also notes and ascribes to Willink an alternative, perhaps preferable, division (keeping ípòv):
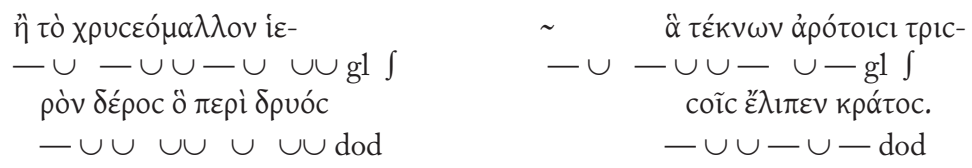

The proposed shape of dodrans with final resolution is unparalleled, but the resolution in the second long of the choriamb is attested for this colon in Euripides (see below, p. 104).

Another passage involving a telesillean, where a different division from that of the Oxford text might fit the sense better, is Hcld.377-8:

$(\mathrm{OCT})$

$\dot{\alpha} \lambda \lambda, \tilde{\omega} \pi 0 \lambda \dot{\varepsilon} \mu \omega \nu \dot{\varepsilon} \rho \alpha-$

$--\cup \cup-\cup-$ tel $\int$

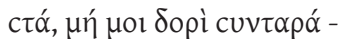

$\cup--\cup \cup-\cup-\mathrm{gl} \int$

$\xi \eta i c k \tau \lambda$ (or alternatively)

$\dot{\alpha} \lambda \lambda^{\prime} \tilde{\omega} \pi 0 \lambda \varepsilon \dot{\varepsilon} \mu \omega v \dot{\varepsilon} \rho \alpha c \tau \alpha \alpha^{\prime}$

$-ー \cup \cup-\cup-\cap$ hag $\|^{\mathrm{B}}$

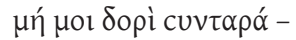

$-\underset{\xi \eta \iota c k \tau}{-\cup-\cup-\text { tel } \int}$

Although the preceding hipponactean ends in breuis in longo, it seems more natural to have the invocation in line 377 as a self-contained period, particularly since Euripidean invocations regularly end in breuis in longo and hiatus (see above, pp. 25-6).

Like the glyconic, the telesillean is a colon often used by Euripides in synartesis: cf. Alc. 989 1000, Med. 436 443, Hcld. 377 (but see above), 915 924, Hec. 451 462, 467 476. Its use as a period-closing phrase is clearly attested at IT 1127 1147 (|| $\left.{ }^{\mathrm{BH}}\right)$. Other less certain examples are El. 120 135, 732 742, Ion 461 481, 462 482, LA 778.

A colon often used by Euripides is $\cup \cup-\cup \cup-\cup-$. It ought not to be termed 'glyconic', ${ }^{208}$ since the 'aeolic base' (oo) can only properly be said to appear under the following mutations in Attic drama: (a) - - ; (b) - $\cup$; (c) $\cup$ - ; (d) $-\cup \cup$; (e) $\cup \cup \cup$ (Dale's reasons are unclear for claiming [21968: 134] that Euripides has 'two or three instances' of $\cup \cup-$ ). Judging from the contexts in which it appears, ${ }^{209} \cup \cup-\cup \cup-\cup-$ belongs to that

${ }^{208}$ Cf. Dale (21968: 133-4); ed. Hel.p. 150; Itsumi (1984: 67). Correspondence justifies using the term 'glyconic' for $\cup \cup-\cup \cup-\cup-$ in the context of Lesbian lyric (for instances of this colon in Sappho, see Page 1955: 80).

${ }^{209}$ In the extant Euripidean corpus, T appears at Hec. 635 644 (T $\int$ wil), 905 914 (T | e - 
ambiguous class of colon (e.g. ibycean, hagesichorean) which can occur as an aeolic or enoplian phrase; for this reason, I have adopted Willink's useful label ' $T$ ' to designate it. ${ }^{210}$ It has been described as 'telesillean with initial resolution' (cf. Parker 1997: 73, 443, 548-9) and the fact that it appears at $L A$ 178 199 in synartesis with a 'normal' telesillean (and elsewhere with other aeolic cola) makes this likely, although there is no plausible instance of the initial $\cup \cup$ in responsion with - ${ }^{211}$ As far as this colon is concerned, resolution in the second long of the choriamb or in the final position are comparatively rare; the known instances are

$$
\begin{aligned}
& \cup \cup-\cup \cup \cup \cup \cup-(\text { Or. 1483) } \\
& \cup \cup-\cup \cup-\cup \cup \cup \text { (Hel. 1332) } \\
& \cup \cup-\cup \cup \cup \cup \cup \cup \cup \text { (Hel. 1119). }
\end{aligned}
$$

The colon $\cup \cup-\cup \cup--$ (often termed 'reizianum'; cf. Dale ${ }^{2} 1968$ : $172)$ is possibly the catalectic, period-closing version of T. Its appearances in aeolic contexts are: Hcld. $373(||), 750 \sim 761\left(||^{\mathrm{H}}\right), 757 \sim 768$, El. $700 \sim 714\left(||^{\text {? }}\right)$, Ion 458 478 (|| $\left.{ }^{\mathrm{B}}\right), 460 \sim 480(||)$, Or. 838 (||), LA 782 (followed by 'normal' reiz; but not Euripidean?), Cresph. fr. 71.9 Austin (||| $)^{212}$.

\section{4. Hipponactean (oo $-\cup \cup-\cup-\longrightarrow)$}

The glyconic's pendent variation gives an essentially period-closing rhythm. Of the forty odd hipponacteans we find in Euripides, twelve are used as clausulas to stanzas; all the others either close longer periods or are themselves a self-contained period, as in e.g. Hec. 631 ( 640):

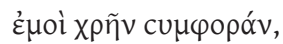

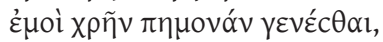

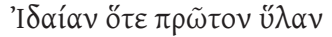

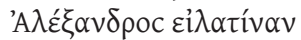

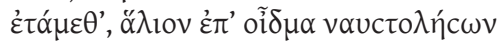

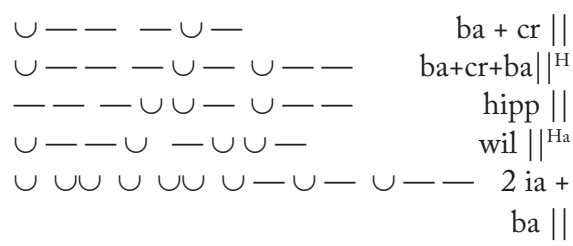

ba $\|$

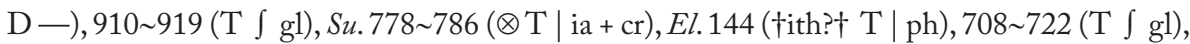

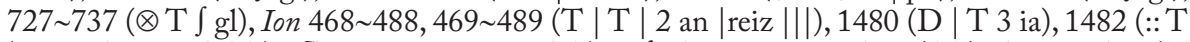
| ia + ba), $1486(:: \mathrm{T} \mid 2 \delta)$, Hel.1113 1128 (T | tel $\left.\int \mathrm{gl}\right), 1119 \sim 1134$ (3 ia | T | A), 1332 (wil |T | wil), 1342 1358 (^ia + ch | T | hept), IA 178 199 (A + sp | T J tel), 582 (T J wil), 1049 1071 (T | hept), 1051 1073 (T $\int$ wil), Hyps. fr 8/9. 10 Bond (p. 33) = Fr. 753c, 16 Kannicht.

${ }^{210}$ Cf. Willink, ed. Or., p. xxi.

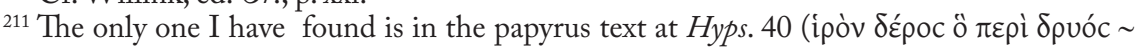

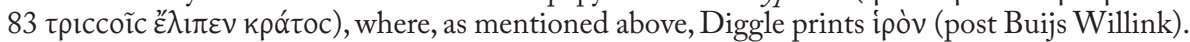

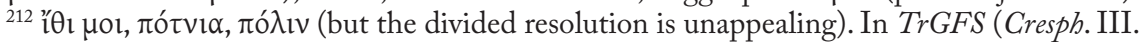

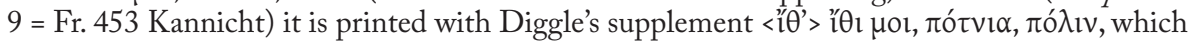
makes it a lecythion (cf. Diggle 1994: 388 n. 86). 
At Hec. 912-3 ( 921-2), two hipponacteans form a 'twin clausula'213 to a partly enoplian, partly dactylo-epitrite, stanza, which, modulating by means of the ambiguous ' $\mathrm{T}$ ', settles into aeolic for the last three lines. But perhaps the most curious use of hipponacteans is in the epode at $B a .902-6$, where the opening ' $\otimes$ hipp' constitutes a rhythmic inception in extant tragedy for which the only parallel is Ai.596 609 (in the OCT, but not in Dawe's text or Finglass's; cf. however, the opening hipp + ia in Pindar, Nem.7):

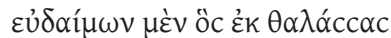
है $\varphi$

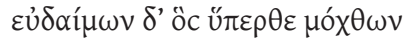

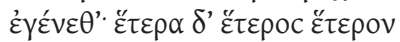

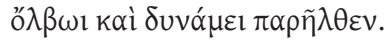

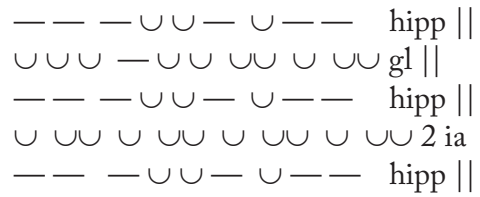

is the only shape of hipponactean which is at all common in Euripides. ${ }^{214}$ The shape $\cup--\cup \cup-\cup-$ - appears only five times (Med. 138, 653 662, Hec. 913, Herc. 660); as for $-\cup-\cup \cup-$ $\cup--$, only Heraclidae of the extant plays presents any examples (Hcld.376, 916 925). The hipponactean is the only aeolic colon other than the glyconic and pherecratean to be found in the Euripidean corpus with tribrach base: $\mathrm{cf}$. Andr. 512 534. For resolution in the second long the choriamb, see Herc. 642 and $L A 1047$.

Finally, mention should be made of the strange colon at $I A 761 \sim 772$, called 'hipp' by Günther in his Teubner edition and, even more unbelievably, 'Alcaic decasyllable' by Stockert (vol. II, p. 418):

${ }^{213}$ Dale's brilliant term (1936: 188). For hipponacteans used in a twin clausula, see A. Ch. 469-70 474-5. Other Aeschylean examples of twin clausula are Pe.556-7 566-7 (ph), ScT73941 747-9 (ia + lk), Ag. 771-2 781-2 (ar), 986-7 999-1000 (1k). The phenomenon is extremely rare in Sophocles: Ai. 199b $\|^{\mathrm{H}_{-}} 200$ (with the transmitted $\beta \alpha \rho v \alpha \lambda^{\prime} \gamma \eta \tau \alpha$, printed by Dawe and Finglass; Lloyd-Jones and Wilson print Nauck's $\beta \alpha \rho v \alpha ́ \lambda \gamma \eta \tau$ ', giving a pherecratean ending in elision, something for which the extant Sophoclean tragedies offer no certain parallel other than Ai.631, although not in Dawe's edition; in any case, with the possible exception of Ant. 946 957, the pherecratean is typically a period-closing and clausular colon in Sophocles), Trach. 223-4, 894-5 (ia + ba). This last example presupposes Dawe's text; Lloyd-Jones and Wilson opt for text and colometry which gives a dochmiac of the shape $\cup \cup \cup \cup \cup \cup-$ (sic! Cf. p. 205 of Davies' commentary) followed by an anacreontic and finally ia + ba (see Lloyd-Jones \& Wilson 1990: 170). That this is not the ideal solution is obvious from the oddities it entails. Twin clausulas are even rarer in Euripides: there are no likely candidates other than Hec. 9123 921-2 referred to above; stanzas that end in a pair of identical cola, but which do not really count as ending in a twin clausula, are found at $S u$. 61-2 69-70 (ionics), Ion 693-4 711-2 (iambic), Hel. 1351-2 ( †1367-8†) (reiz), Ph. 798-9 ( †816-7†) (dactylic).

${ }^{214}$ The references for $--\_\cup \cup-\cup-$ are Alc. 994 1005, Med. 834 845 (if not D/e), Hcld. 918 927, Hi. 69, 123-4 133-4, Hec. 631 640, 912 921, 922, El. 463 475, Herc. 677 691, IT1124 1139, Ba. 902, 904, 906, IA 800, 1069, Rh. 345 354, Cresph, III. 3 12, Teleph. II. 10. 


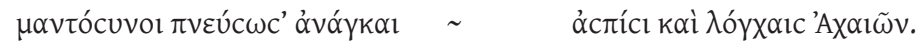

This is the clausula of the second stasimon, a song Diggle does not believe Euripides to have composed (1994: 503-6; this colon is discussed on pp. 5056). The only way this phrase could be labelled 'hipponactean' is by imagining anaclasis between the choriamb and the base; but that would deprive the whole concept of 'aeolic base' of any real meaning. Disconcertingly, the colon looks for all the world like nothing so much as ' $\mathrm{d}$ - e - '; However, a dactylo-epitrite phrase as clausula to an aeolic stanza is strange in Euripides - the nearest we find is 'e - d - at Alc. 595 604; but here we are already clutching at straws. The likelihood that Euripides could have written the second stasimon of $I A$ is in any case remote.

\subsection{Hagesichorean $(x-\cup \cup-\cup-\longrightarrow)$}

The headless hipponactean was felicitously named 'hagesichorean' by West

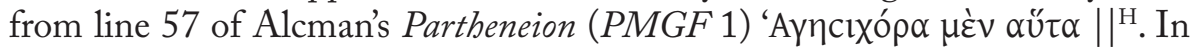
Alcman's poem, it is repeatedly used as the second, clausular element in the dicolon 'lk | hag |l'; Ibycus uses it as the clausula to the stanza '4 da $\int 4$ da | D | hag II' in PMGF S151. Right from its first appearances in Greek poetry, then, its precise 'generic' status seems ambiguous. Is it primarily an aeolo-choriambic phrase, or should it instead be viewed as enoplian? (Understandably, Dale opted to call it a 'choriambic enoplian'.) In tragedy, the hagesichorean can be found in both contexts. ${ }^{215}$ In extant Euripides, its use as an aeolo-choriambic and enoplian phrase is statistically balanced:

enoplian: Alc. 220 232, 253 260, Med. 151 176, 152 177, 153 178, 157 181, 158 182, 849 859, 850 860, 852 862, 853 863, IT 401 416, Hel. 1110 1125, Phaeth. 230 239.

aeolic: Alc. 991 1002, 992 1003, 993 1004, Hcld. 896 905, 914 923, El. 730 740, 731 741, Herc. 354 370, 644 662, 794 811, Ion 191 202, Hyps. 43 86, Cresph. III. 7, 8, Teleph. II. 7.

It should be said, however, that the interwoven rhythms of certain stanzas make it difficult to decide whether, as a whole, enoplian or aeolic predominates. At IT 401 416, a hagesichorean is preceded by iambic and followed by an Archilochean dicolon (a characteristically enoplian sequence); but the ode ends in a priapean. At Hel.1110 1125, the hagesichorean is part

${ }^{215}$ Cf. A. Su. 72 81, Ag. 1483 1507, Ch. 352 370, S. Ai. 196, 598 611, 1206 1218, El. 486 502, OT 885 899, 887 901, Trach. 633 640, 957 966, 960 969, Ant. 783 793, 784 794, 789 799, Phil. 1217, OC 514 526, 515 527, 516 528, 680 693. 
of an extremely complex stanza; the fact that it follows a reizianum and is followed by dactylo-epitrite is eloquent proof of its ambiguous nature; and this, in turn, makes its use as an Übergang in this modulation from aeolic to enoplian ideally gleitend.

As with the aristophanean (see below, p. 105), Euripides uses the hagesichorean as a period-closing colon, with two exceptions (coincidentally, as with the instance of 'ar $\int$ ar' the colon into which the hagesichorean overlaps is again a hagesichorean ${ }^{216}$ ) at El.730 740:

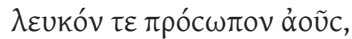

$$
\begin{aligned}
& --\cup \cup-\cup-- \text { hag }
\end{aligned}
$$

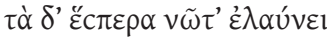

$$
\begin{aligned}
& \cup-\cup \cup-\cup-- \text { hag }
\end{aligned}
$$

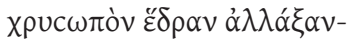

$$
\begin{aligned}
& --\cup \cup---- \text { hag chol } \int
\end{aligned}
$$

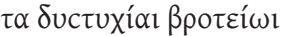

$$
\begin{aligned}
& \cup-\cup \cup-\cup-- \text { hag }
\end{aligned}
$$

Unlike the problematic case with aristophaneans ( $B a .105 \sim 120)$, here an alternative colometry is not possible. It is odd that a rhetorical pause is so clearly indicated in the strophe (comma after ơoṽc and $\delta$ 'in the following line), a fact which suggests that Euripides would have wished to break synapheia in the antistrophe too. The hagesichorean with cholosis in the antepenultimate syllable is also a unique phenomenon; and if the responsion it gives would be held to be objectionable in a glyconic, there is good reason to suspect it here too. All in all, the disturbing feeling that something is amiss can not be dispelled.

Alcestis and Medea are the plays where the hagesichorean is most in evidence as rhythmic Leitmotiv. In the fourth stasimon of Alcestis, there is even an unusual katò ctíxov run consisting of hag| hag | hag | hipp |||. A curious feature of the antistrophe is that the use of the hagesichorean for poetically reporting direct speech in the first person recalls the first-person 'exclaimings', partly in hagesichoreans, in Alcman's Partheneion:

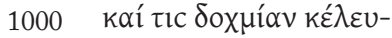

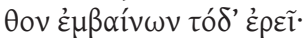

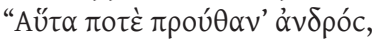

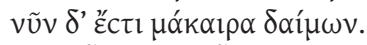

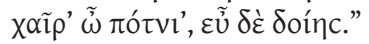

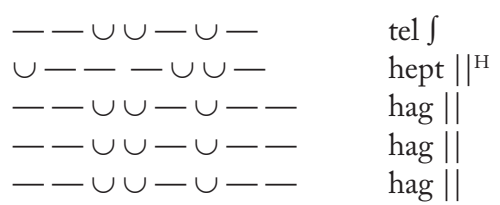

${ }^{216}$ Cf. 'ia + ba $\int 2$ ba' at $B a .933 \sim 1030$. This begs the question of whether synartesis is permissible in an otherwise invariably sentence-and-stanza-closing clausular phrase (' $y$ ', say) if the colon into which ' $y$ ' overlaps is itself ' $y$ '. In other words, ' $y \int y$ ' might be theoretically permissible, whereas ' $y$ f $x$ ' would not. All this is made complicated by the fact that we are primarily discussing Euripidean practice; in Aeschylus, ' $y \int x^{\prime}$ would be perfectly in order; but what we are given to observe of Euripides' lyric technique points to the conclusion that ' $y \int \ldots$ ' is something he tends to avoid. 
Part I - Euripides' use of lyric metre

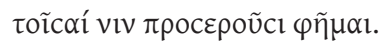

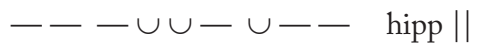

Note also the 'direct' mode of utterance at Med.151-3 ( 176-8):

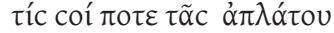

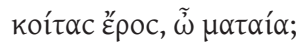

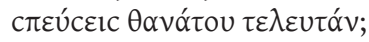

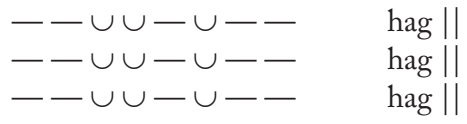

Although the scheme of the hagesichorean is $\mathrm{x}-\cup \cup-\cup--$, examples with short anceps are rare (El.731 741, Herc. 644, Ion 202, Phaeth. 230, Cresph. III. 8, Teleph. II. 7). Resolution in the second long of the choriamb is found at Herc. 794217 and Hel. 1110 1125 (short anceps).

\section{6. 'Pendent aeolic octosyllable' $(x-x-\cup \cup--)$}

This other form of pendent aeolic octosyllable ('choriambic enoplian B' in Dale's nomenclature) responds with $\mathrm{x}-\cup \cup-\cup-$ at S. OC 512 523, so West is perfectly right to call it 'anaclastic hagesichorean'. The label suggested above, inspired by Barrett's 'pendent enhoplion octosyllable c' (comm. Hi. p. 423), is merely descriptive.

The phrase $\mathrm{x}-\mathrm{x}-\cup \cup-$ is found six times in Sophocles (Ai. 1199) 1211 [ [OCT; not Dawe or Finglass], Ant. 336 346, Phil. 1209, OC 523) and twenty-four times in Euripides; strikingly, nine of these examples occur in Heracles.

$-\ldots-\ldots \cup \cup-\ldots:$ Hi. 71-2, 144 154, El. 734 744, Herc. 645, 647 665, IT 431 448, Ion 192 203, 221a.

$-ー \cup-\cup \cup-\longrightarrow:$ Herc. 663, 795 812, Cycl. 65.

$\cup-\cup-\cup \cup-\ldots:$ Herc. 796 813, 887b, Ion 207, Ba. 876 896.

$\cup---\cup \cup-\longrightarrow:$ Hi. 58.

At S. OC 523 it ends in breuis in longo and, in Euripides, it is typically a period-closing colon. ${ }^{218}$ Its only appearances in a non-aeolic context are $\mathrm{Hi}$. 58 (Hippolytus' little solo stanza, followed by 'D | D - |||; but the ensuing stanza is aeolo-choriambic) and Herc. 887b ('enoplian dochmiacs'; see p. 78).

\subsection{Ibycean $(-\cup \cup-\cup \cup-\cup-)$}

Despite its name, the ibycean does not figure largely in the extant fragments of Ibycus. It is repeated three times in the beautiful 'spring song' (PMGF 286, 1-3), followed by dactyls:

217 'Probably corrupt' (Diggle 1994: 123 n. 94); cf. Bond ad loc.

${ }^{218}$ The one exception would be Hi. 58, analysed $\cup---\cup \cup-\cup$ by Barrett (p. 168);

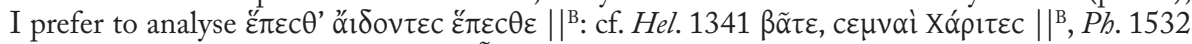

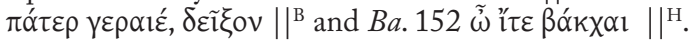




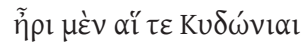

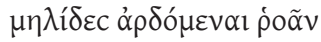

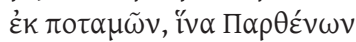

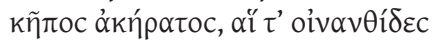

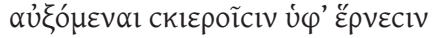

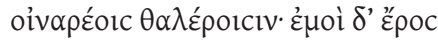

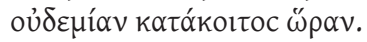

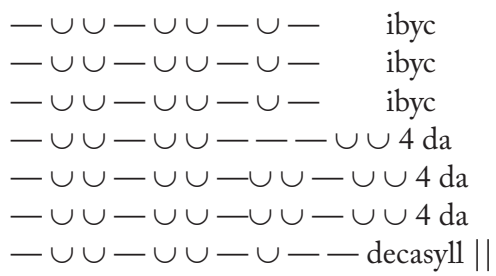

Again, its generic classification is not entirely straightforward. The 'long' / double-short' rhythm naturally links it with dactyls; the 'double-short' / long / short / long' with which it ends is enoplian; and the presence of the clausula to the Alcaic stanza at PMGF 286, 7 suggests that is not averse to mingling with aeolic, something it often does in Attic drama.

Its sole appearance ${ }^{219}$ in Aeschylus is at the head of an aeolic stanza $(C h$. 315 332), but it is immediately followed by the non-aeolic ithyphallic. In Sophocles, ibyceans appear only in Oedipus at Colonus: following dactyls at 252 (in Dawe's text ${ }^{220}$ ); with cholosis in the penultimate position at 239 and 1245 (aeolic); and in the compound ibycean + bacchiac at 119 151 (aeolic). Aristophanes uses it once at Lys. 1288 and, strikingly, seven times in the same song in Thesmophoriazusae $(1136,1137-8,1140,1148,1149,1150,1156)^{221}$, where it is clearly treated as an aeolic colon, alternating with glyconics (see Parker 1997: 448-9).

But it is in Euripides that we find the ibycean put to more extensive use, in both aeolic and enoplian contexts:

aeolic: Alc. 224 248, ${ }^{222}$ El. 151, 155, 701 715, IT 1092, 1098 1115 (in synartesis), $L A$ 169 190, 759 770;

enoplian: Andr. 827 831, Hec. 1068, Herc. 381 395 (in synartesis), 1030,

${ }^{219}$ At ScT 222 229, I would prefer not to follow Dale (21968: 168) and Itsumi (1984: $71 \mathrm{n}$.

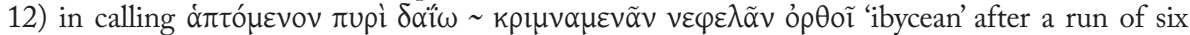
dochmiacs, all but one of the quintessentially Aeschylean shape $-\cup \cup-\cup-$. It is impossible to be absolutely certain here, but (despite the presence of an Alcaic decasyllable earlier at 11920 140-1) it is reasonable to assume that 'enoplian dochmiacs' in the manner of late Euripides are out of place in Septem; thus, it seems more natural to take the clausula as a variation 'prolonging' the preceding dochmiacs than as the wholly unrelated ibycean. Furthermore, since the alleged ibycean at 229 has cholosis in the penultimate position, this would constitute the only instance of a normal ibycean in responsion with an ibycean with cholosis. West's concept of ' $\delta$ d' (dochmiac with dactylic expansion) is attractive here (see 1982: 113).

${ }^{220}$ Cf. Dawe (1978: 65). Lloyd-Jones and Wilson prefer to print a dactylic trimeter (cf. 1990: 225), giving a run of 11 dactyls (250-2).

221 Thesm. 1136 has resolution in the antepenultimate position and 1149 has final resolution; but Parker's suggestion that there may be parody of a late-Euripidean mannerism (1997: 449) should be set against the observation that there seem to be no resolutions in Euripides' ibyceans.

${ }^{222}$ Parker (1997: 518) criticises Dale's 'lavish use of the term enoplian' in the opening of Alcestis' monody as presented in Dale (1981: 72-3). 
1033, 1037, Tr. 258, 267, 270, Ion 1484, Or. 1257 1277, 1381.223

In Iphigenia in Tauris, there is unmistakable proof of the ibycean's aeolic affinities in the responsion 'ibyc-wil' at 1092 1109. The responsion 'gl ibyc' appears at IT 1129 $\dagger 1144 \dagger$, but here the ibycean is part of a sequence where there is considerable textual corruption.

There are thirteen ibyceans in Euripides with cholosis in the penultimate position (Hec. 1068, El. 701 715, Herc. 1033, Tr. 258, 267, 270, Ion 1484, Or. 1257 1277, 1381); accordingly, Itsumi has suggested that the penultimate position in the ibycean is anceps (1984: 71-2), certainly a reasonable notion in view of the two Sophoclean examples and the long penultimate position in enoplian compounds involving an 'ibycean' at Herc. 1187, 1186, 1185, Ion 6556, 717-8, Ph. 121-2, 130 (see above, pp. 85-6).

\section{8. Dodrans $(-\cup \cup-\cup-)$}

The dodrans is arguably the archetypal aeolic phrase (cf. Parker 1997: 70), since it is the basic structure around which most other cola (glyconic, telesillean, etc.) are built. It was used in Lesbian poetry in combination with other units, most notably perhaps in the two opening verses of the Alcaic stanza, where the dodrans is frequently marked off from the preceding penthemimer ( $\mathrm{x}-$ $\cup-\mathrm{x}$ ) by word division, e. $\mathrm{g}$.

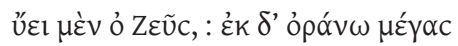

$\cup-\cup--:-\cup \cup-\cup-$ pe $+\operatorname{dod}$ (Alcaeus PLF 338.1)

In tragedy, $-\cup \cup-\cup-$ as an independent aeolic phrase is, given the disparity in number of extant plays, more common in Sophocles than Euripides (in Aeschylus, we find it four times only, at Ch. 345 363, 466 471). Sophocles uses it as a period-closing phrase in Ai. 627 638, Phil. 177 188, 714 725, 1090 1111 (there is hiatus at Phil.714; all the other examples have breuis in longo in one of the stanzas); also, at $O C$ 128 160, there is a clear rhetorical break in both stanzas. But period-end is unlikely in the remaining Sophoclean examples (Ant. 807 824, 842 861).

In Euripides, there are over twenty examples of the phrase $-\cup \cup-\cup$ -. It appears twice with cholosis $(-\cup \cup---)$ at Hec. 637 646 and twice with resolution in the second long of the choriamb (Alc. 971 982). As for its status in the delicate play between lyric metre and lyric utterance, dodrans is used as a clausula at Andr. 865 and Hec. 637 646; also, it closes a period at El. 121 136 and $I A$ 1089. But, as a blunt aeolo-choriambic phrase, it not surprising that we find it nine times in synartesis with other aeolic cola:

${ }^{223}$ Alternatively, 'dactylic tetrameter catalectic': Diggle (1994: 386). 
dod $\int$ ar: Alc. 245a 249a, Ion 1058 1071;

dod S hipp: Hcld. 917 926;

dod J gl: Hec. 469 478, Hel. 517.

The remaining Euripidean instances of this colon are Med. 847 †857†, Hel.1350, 1453 1467, LA 176 197224, Rh. 368 378. A further possible dodrans is Alc. 228b ( $\uparrow 215 \mathrm{~b})$, 'dod | cyren' (see above, p. 74, under 'cyrenaic' and below, p. 116, n. 251).

\subsection{Aristophanean $(-\cup \cup-\cup--)$}

The colon known as 'aristophanean' is something of a misnomer, since it does not exactly abound in extant Aristophanes (see Parker 1997: 82-4); the term is, however, an ancient one (cf. Wilamowitz 1921: 396, and the apparatus of Kassel and Austin on PCG 9), and it is possible that the scholar who coined it had access to more Aristophanic poetry than we do. An inkling that Aristophanes may have used it in an idiosyncratic way in plays now lost is given by an unusual sequence of five aristophaneans from the lost comedy

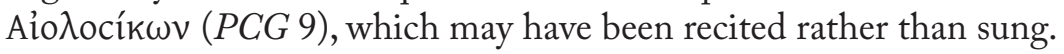

Euripides used the aristophanean comparatively often. The plays where its presence is most pervasive are, on the whole, earlier works such as Alcestis and Heraclidae, where repetition of the clausular phrase $-\cup \cup-\cup-$ should be felt to provide a unifying rhythmic strand linking up the plays' various songs into a satisfying aesthetic whole. 'Middle period' and later tragedies do not, for some inscrutable reason, abound in pendent aeolic cola (the liberal use of the pherecratean in Heracles being an exception); in Bacchae, however, the aristophanean is again used by Euripides in a manner reminiscent of his earliest extant plays. The same is valid for Rhesus (which has no fewer than ten aristophaneans).

There are almost 70 aristophaneans in the extant Euripidean corpus: $67^{225}$ of them are of the shape

\section{$-\cup \cup-\cup-{ }^{226}$}

but, at $B a$. 123, we find a version of the colon with resolution in the second long of the choriamb $(-\cup \cup \cup \cup \cup--)$. A possible headless variation is found at Alc. 911 934.

${ }^{224}$ But with the alternative colometry proposed above (see p. 95), $L A$ 176 197 would be a telesillean.

${ }^{225}$ I include Hcld. $\uparrow 893 \uparrow$, which, with Diggle's emendation, ends suitably in breuis in longo (cf. 1994: 11-4, 54-6) and, with Stinton's (1990: 292), equally so in hiatus.

${ }^{226}$ The references for $-\cup \cup-\cup-$ are Alc. 217 229b, 245b 249b, 256b 263b, 403 415, 444 454, 455 466, 592 601, 970 981, 972 983, Med. 646 655, Hcld. 354 363, 361 370, 380, 902, 897 906, Andr. 864, El. 710 724, Herc. 353b 369b, 638 656, 764 773, 881, IT 426 443, Ion 1059 1072, Or. 843, Ba. 105 120, 106 121, 108, 110 125, 136, 416 432-3, LA 755 766 (not Euripidean?), Rh. 252 263, 350 359, 362 372, 367 377, 369b 379b, Teleph. II. 6. 
Now a striking feature of these seventy odd aristophaneans is that, with two exceptions, they are otherwise used as a sentence-closing phrase to mark off period-end within lyric sequences; ${ }^{227}$ moreover, aristophaneans close Euripidean stanzas 24 times. ${ }^{228}$ This ought to provoke scepticism in relation to Ba. 105 120 (ar $\int$ ar)

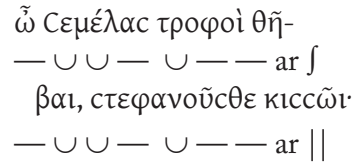

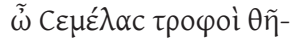

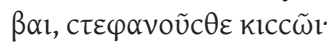

$-\cup \cup-\cup--\operatorname{ar} \mid$

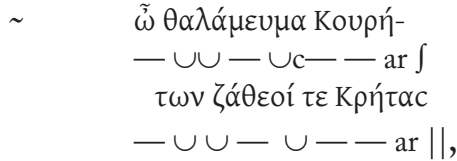

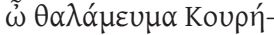

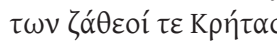

$-\cup \cup-\cup--\operatorname{ar} \|$,

where the temptation is strong to divide

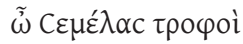

$$
\begin{aligned}
& -\cup \cup-\cup-\operatorname{dod}
\end{aligned}
$$

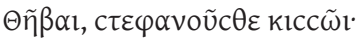

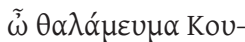

$$
\begin{aligned}
& -\cup \cup-\cup-\operatorname{dod} \int
\end{aligned}
$$

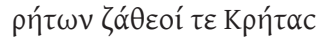

$$
\begin{aligned}
& --\cup \cup-\cup-\text { hag } \| \\
& \text { - - } \cup \cup-\cup-\text { - hag } \|
\end{aligned}
$$

In support of 'dod $\int$ hag', we may note that, of the twenty odd occurences of the dodrans in Euripides, nine are dovetailed (see above, p. 105), and, although there is no precise parallel for the sequence 'dod $\int$ hag', at Hcld. 917-8 926-7 a dodrans overlaps into a hipponactean (the colon of which the hagesichorean is the acephalous variation). ${ }^{229}$ Incidentally, both the type of utterance and the phrasing in the strophe from Heraclidae bear a more than superficial similarity to the passage in Bacchae:

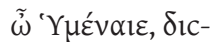

$$
\begin{aligned}
& -\cup \cup-\cup-\operatorname{dod} \int
\end{aligned}
$$

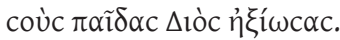

$$
\begin{aligned}
& \text { - - } \cup \cup-\cup-\text { - hipp || (Hcld. 917-8) }
\end{aligned}
$$

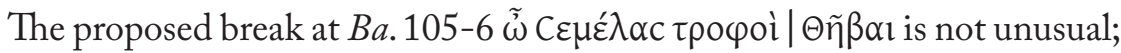
odd colon-splits in the middle of invocations are fairly common: cf. e.g. Med.

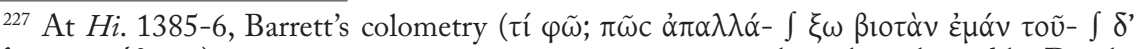

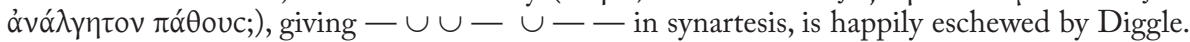
Barrett's claim (p. 405) that $-\cup \cup-\cup-\ldots$ is in this context an iambic colon is immaterial, since $(a) \cup-Z$ is (with the perplexing exception of $B a$. 933 1013) no less sentence-closing in Euripidean iambic than in aeolic; and $(b)$ in any case, the colon 'anaclastic' iambic + bacchiac is otherwise absent from Euripidean iambic.

${ }^{228}$ Cf. Alc. 245b 249b, 256b 263b, 403 415, 444 454, 911 934 (headless ar), 972 983, Hcld. 361 370, 380, Or. 843, Ba. 416 432-3, Rh. 252 263, 350 359, 369b 379b.

${ }^{229}$ There are four examples of a dodrans in synartesis with an aristophanean (also pendent, like 'hag' and 'hipp'): Alc. 245a-b 249a-b; Ion 1058-9 1071-2. 


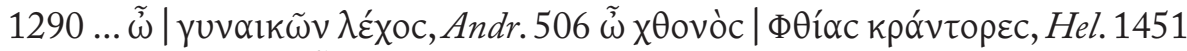

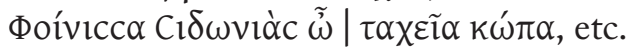

\section{10. Reizianum $(x-\cup \cup--)$}

The reizianum can be described as the acephalous form of the pherecratean. As with the other pendent aeolic cola we have seen, it is intrinsically a periodclosing and clausular phrase. Possible exceptions are:

(i) the strange sequence at Herc. 1049-51, followed by dochmiacs:

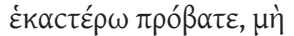

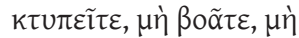

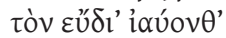

1050 نं

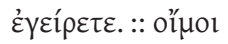

$\cup-\cup-\cup-\cup-2$ ia

$\cup-\cup-\cup-\cup-2$ ia

$\cup-\cup \cup-$ reiz

$\cup-\cup \cup-$ reiz

$\cup-\cup \cup-\ldots$ reiz

Three reiziana in row are unparalleled (the two reiziana at Hel. 13512 are not strictly speaking comparable, see (ii) below); the elision at 1049 is suspicious, since pendent aeolic cola rarely if ever end in elision (see above, p. 95 with n. 200) and this would be the only reizianum to do so. But most perplexing of all is the context, which is certainly not aeolic: here, amid enoplian dochmiacs, Euripides is apparently using 'reiz' as an enoplian phrase;

(ii) the twin clausula at Hel. 1351-2 ( †1367-8†):

1350

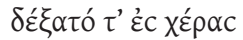

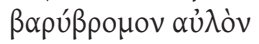

$\tau \varepsilon \rho \varphi \theta \varepsilon \tilde{c} c^{\prime} \dot{\alpha} \lambda \alpha \lambda \alpha \gamma \mu \tilde{\omega} 1$.

$$
\begin{aligned}
& -\cup \cup-\cup-\text { dod } \\
& \cup-\cup \cup-- \text { reiz } \| \\
& --\cup \cup-- \text { reiz } \|
\end{aligned}
$$

The fact that the text in the antistrophe is uncertain makes it difficult to ascertain whether any indication on the period-closing (or otherwise) status of 1351 can be gleaned from the rhetorical phrasing. I would be inclined, however, to assume period-end at 1351 as being likely and that we have here a twin clausula as in Hec. 912-3 921-2 (see above, p. 99).

(iii) Ba. 863 883:

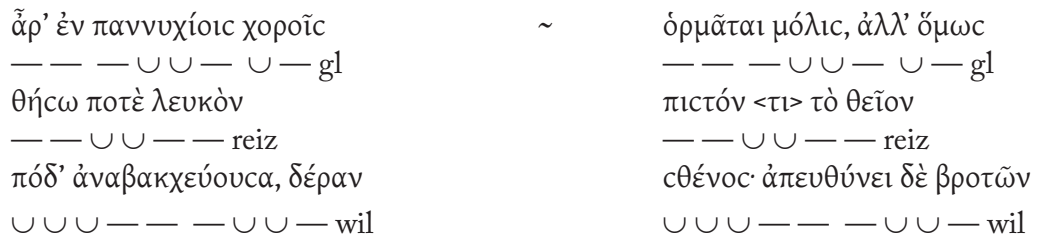

In both strophe and antistrophe (in 883, $<\tau 1>$ is Nauck's supplement),

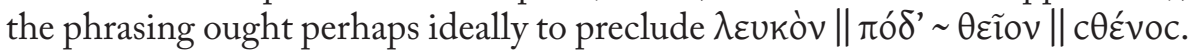


At $I A 789$, the reizianum does not seem to close a period, but then it is part of a lyric sequence that Euripides is hardly likely to have written.

There are approximately 30 reiziana of the shape $--\cup \cup--$ in Euripides; ${ }^{230}$ and 17 with short initial anceps (on responsion between long and short anceps in reiziana, see Diggle 1994: 472). ${ }^{231}$ For the shape $\cup \cup-\cup \cup$ - - often called 'reizianum', see above, p. 98.

Finally, there is a candidate for the label 'catalectic reizianum' at Hi. 62, although the noncommittal ' $-\mathrm{d}$ ' is just as possible:

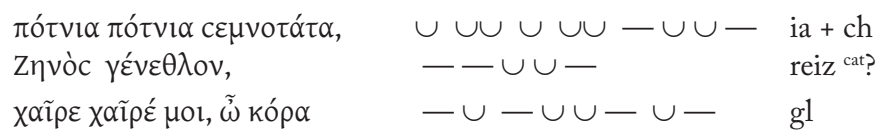

\section{11. Adonean $(-\cup \cup--)$}

This period-closing colarion is not used by Aeschylus and only rarely by Sophocles (Ai. 1210 1222, Ant. 812|| ${ }^{\mathrm{B}} 8229$, OC 1058 1073). It is not often used by Euripides as an aeolic phrase. Certain examples are $M e d .855 \sim 865$ (clausula) and $I A 1082 \mathrm{a}(||)$. It is used as a dactylic phrase at Hcld.609 620 $\left(||^{\mathrm{H}}\right), 612 \sim 623(||$ ?) and Herc. 1077b $(\|)$ and as an enoplian phrase at Andr. 861. At $P h .1528$ it appears between two ionics and a pendent choriambic dimeter ('2 ch -'; cf. Ba. 152-3, where two adoneans again create an Übergang from ionic to a fleeting sojourn in aeolic). At $P h .1545$, it is used as a periodclosing rhythm following a dochmiac (a paroemiac follows).

\subsection{Wilamowitzian $(o o-x-\cup \cup-)^{232}$}

The phrase oo $-\mathrm{x}-\cup \cup$ - was certainly a particular favourite with Euripides, one he used prodigally in almost all his extant plays, the exception being Alcestis, Heraclidae and Troades (and Rhesus). Euripides uses sixteen different shapes of wilamowitzian, but some of these are exceedingly rare and five appear solely in Iphigenia at Aulis, a play where a considerable portion of the aeolic lyric may not be by Euripides. 'Wil' frequently responds with glyconic, ${ }^{233}$ the colon of which there is good reason to suppose 'wil' to be the

${ }^{230}$ For —— $\cup \cup-$ - see Alc. 910 933, Med. 154, Hcld. 754, Hi. 529 539, 544, 554 564, Herc. 797, Ion 115 131, 464 484, 471 491, 494, 1086 1102, Hel. 1109b 1124b, 1352, Ba. 863 883, LA 789, 1079, Cycl. 662, Hyps. 45, 62.

${ }^{231}$ The references for $\cup-\cup \cup-$ - are Med. 179, Hcld. 765, Hi. 534, El. 142 159, Herc. 814, 1049, 1050, 1051, Ion 193 204, Hel.1351, LA 214, 783, 1057, 1091, Hyps. 88.

232 This colon, which is known under a variety of names, was the subject of an invaluable article by Itsumi (1982: 59-74). Again, I draw attention to the fact that Itsumi worked from Murray's text, so my statistics often differ from his.

${ }^{233}$ Diggle (1994: 195, 473 n. 149) gives a list of occurrences of the responsion gl $\sim$ wil, to 
anaclastic form (see Parker 1988: 115). Like the glyconic, it is often used in synartesis; predictably, there are few instances where its use as a sentenceclosing phrase is entirely free from doubt. ${ }^{234}$

By far the most frequent version of the wilamowitzian, with just over one hundred examples in Euripides, is - - - - $\cup \cup-.^{235}$ The other shapes are, by comparison, less common:

(a) - - $\cup-\cup \cup-(35$ examples): Hi.142 152, 146, 149 159, Andr. 449, Hec. 481, 636, El. 201, 729, Herc. 807, 809, IT 1099, 1118, 1125 1140, 1244, 1268, 1269, Ion 209, 479, 496, Hel. 1320, 1333, 1490, 1492, 1498, 1499, Ph. 229, IA 217, 549, 775, Cycl. 46, 61, Hyps. 79;

(b) $\cup \cup \cup —-\cup \cup-(26):$ Herc. 696, 697, Ion 117, 486, 495, Hel. 1473 (with Wilamowitz's $\langle\delta \dot{\varepsilon}>$ ), Ph. 210, Or. 824, 832, 840, Ba. 410 425, 864 884, IA 182 203, 550 †656†, 562, 563, 568, 754, 797, 1081, Cycl. 656, Hyps. 37, 80;

(c) $\cup \cup \cup-\cup-\cup \cup-$ (17): Hel. 1304 1322, 1305 1323, 1507, Or. 807 819, 808 820, 809 821, 812, 825, IA 551 566, 552 567;

(d) $\cup-\longrightarrow \cup-\cup \cup-$ (11): Hec. 632 641, Su. 998, 1024, El. 170 193, IT 444, 1097, 1128, Hel. 1306, IA 788.

(e) $\cup-\longrightarrow-\longrightarrow \cup \cup$ - Ion 459, 465 485:

(f) $-\cup---\cup \cup-(10):$ Med. 651 660, Herc. 790, IT 437, 1126, 1131, 1267, IA 219, 583, 769;

(g) $\cup-\cup-\cup \cup-$ (8): El. 209, 703, Herc. 792, IT 453, Hel. 1460, IA 555, 780, Phaeth. 66;

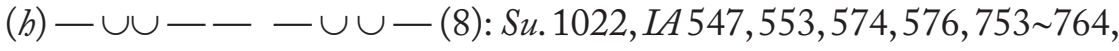
765.

(i) $-\cup \cup-\cup-\cup \cup-$ (1): Su. 999 (cf. Diggle 1994: 506 n. 56; Willink 2010: 395).

Shape (b) appears mainly in Iphigenia at Aulis, a play 'notable for the eccentricity of its aeolo-choriambic' (Parker 1997: 449). Other rare shapes of

which I add IT 1101 1118 and Hel.1481 1498. Note that El. 169 192 is ia + gl ia + wil and that IT 1092 1109 is ibyc wil (on which see Parker 1997: 448). In Diggle's edition of Hypsipyle in $\operatorname{Tr} G F S$, the lines numbered by Bond 'fr. I. ii. 5-6 I. iii. 6-7' (=21, 22, 63, 64, TrGFS) are not regarded as being in responsion (cf. Diggle 1995: 40); Hyps. 63-5 is printed in TrGFS as ionic.

${ }^{234}$ Examples of 'wil' as a sentence-closing phrase are Hec. 472 481, Su. 976, 999 1022, Herc. 351 367 $\|^{\mathrm{Hs}},\left.675 \sim 689\right|^{\mathrm{Ba}}$, 792 809 $\left.\right|^{\mathrm{HsBa}}$, IT 1244 1269, Hel. 1304 1322, 1316 1334|| $\left.\right|^{\mathrm{Bs}}$, 1456 1470, 1490 1507, Ba. 872 892, $880=900$, IA $\left.780\right|^{\mathrm{H}}$, Cycl. 48 62, Phaeth. 64 74|| $\left.\right|^{\mathrm{Ha}}$, 68 76.

${ }^{235}$ Cf. Hi. 156, Andr. 800, Hec. 460, 472, 645, Su. 959 967, 961, 1001, 1006, 1007 1029, El. 172 195, 180 203, 188 211, 207, 208, 433 443, 702 716, 717, 739, Herc. 350 366, 674 688, 675 689, 690, 784 801, IT 436, 439, 454, 1102 1119, 1103, 1116, 1141, 1242, 1243, Ion 114 130, 133, 210, 492, 504, 1229, 1242, Hel.1312 1329, 1315, 1324, 1330, 1331, 1316 1334a, 1317a 1335, 1336a, 1482, 1504, 1509, Ph. 231, Ba. 409 424, 880 900, 892, IA 220, 224, 570, 577, 758, 1052 1074, Cycl. 41 55, 43 57, 45 59, 47, 48 62, 67, 70, 71, 366-7, Phaeth. 64 72, 68 76, 74, Hyps. 36, 47. 
wilamowitzian encountered in this tragedy are $\cup \cup--\cup-\cup \cup-(I A$ 216; cf. S. Phil. 1216), $-\cup \cup-\cup-\cup \cup-($ IA 556), $-\cup \cup \cup \cup \cup-\cup$ $\cup-($ IA 168 189) and - - - $\cup \cup \cup \cup-($ IA 222, where the resolution in the first long of the choriamb is suspect). A few remaining maverick shapes of this colon may be mentioned: $-\cup \cup \cup-\cup \cup \cup-(O r .814 \sim 827,836)$, $\cup \cup-\ldots--\cup \cup-($ IT 1120), $-\cup \cup \cup \cup-\cup \cup-$ (Su. 1021, Hel. 1456 1470), $\cup \cup \cup \cup \cup-\cup \cup-$ (Herc. 682, 683).

\section{13. Heptasyllable $(x-x-\cup \cup-)$}

The 'aeolic heptasyllable' is an acephalous version of the anaclastic glyconic (wilamowitzian). Consequently, it is described by some metricians as an anaclastic telesillean, a notion which is confirmed by the responsion at Phaeth. 69 77

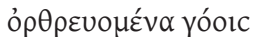

$--\cup \cup-\cup-$ tel

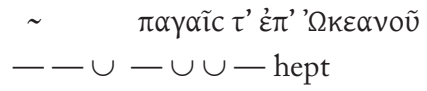

and between the compounds at Herc. 791 808

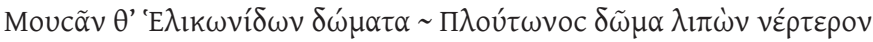

$--\cup \cup-\cup--\cup \cap$ tel + cr $\|^{\mathrm{BH}}----\cup \cup--\cup-$ hept $+\mathrm{cr} \|$

Like the telesillean, the aeolic heptasyllable appears in synartesis and is not primarily a sentence-closing colon. In Cyclops, there is one unique example of a heptasyllable as clausula (Cycl. 54), but the lyrics of that satyric drama are, in some ways, a law unto themselves. Period-closing heptasyllables appear again in Cycl. at 64 (hiatus), 66, 72 (breuis in longo) and 660.236

The most common shape has three longs before the choriamb:

$----\cup \cup-.^{237}$

The shape - $\cup \cup \cup \cup-$ is almost equally well attested. ${ }^{238}$ We also find: $\cup-\cup-\cup \cup-:$ Alc. 990, Ion 112 128, 499, 1057, 1084, IA 208, 569, 767, Cycl.54, 58, 76, Phaeth. 65.

${ }^{236}$ For other examples, see Herc. 646 664, 648 666 (?), Ion 116 132, LA 756 767.

${ }^{237}$ Cf. Hi. 148 158, El. 718, 745, Herc. 646, 648 666, IT 432 449, 445, 446, 447, 451, 1100, Ion 116 132, 473, 1081 1097, †1100† 1103, Hel. 1328, 1339, 1343, 1345, 1346 1362, 1491 1508, Ph. 205, 1753 (?; perhaps iambic, mol + ch) Ba. 869, LA 218, 223, 757, 798, 1072, Cycl. 42 56, 68, 72, Phaeth. 71, 75 .

${ }^{238}$ For $-\cup-\cup \cup-$, cf. Hi. 155, 549 559, Su. 958 966, El. 735, Herc. 664, 788 805, IT 429, 430, 434, 1117, Ion 456 476, 1056 1069, 1070, Hel. 1310, 1311, 1355, 1359, 1361, 1463, 1483 1500, Ph. 217, Ba. 879 899, 889, IA 221, 554, 756, 768, 779, 1050, Cycl. 44, 64, 66, Phaeth. 63, 67, 77 ( 69 tel). 
$\cup--\cup \cup-:$ Alc. 1001, El. 704, Ion 453, 493, 1051 1064, 1087, Hel.523, LA 584, Cycl. 660, Phaeth. 73.

\subsection{Hexasyllable $(\mathrm{x} x-\cup \cup-)$}

The colon aptly named 'aeolic hexasyllable' by Parker has a somewhat enigmatic identity: is it a reversed dodrans, a doubly acephalous wilamowitzian

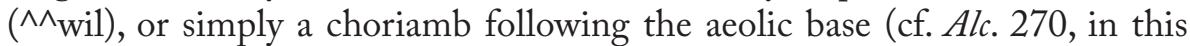
case with Attic resolution $\cup \cup \cup-\cup \cup$-; see Parker ad loc.)? Although it is once used as a clausula (Hec. 474 483), not much importance should be attached to its potential as a sentence-closing phrase, since it is dovetailed at Hi. 122 132, Ion 1063, Hel. 1455 1469 and Rh. 376.

Euripides does not use it quite as frequently as the possibly related heptasyllable; as is his wont with other aeolic cola, he mostly prefers to have the choriamb preceded by two long syllables:

(a) - - $\cup \cup$ - Hi. 122 132, 555, Hec. 474 483, El. 447, IT 441, 433 450, Ion 134, 1050 1063, Hel. 1455 1469, Ba. 874a 894a, Rh. 366 376.

(b) $\cup-\cup \cup-:$ Hi. 545, Hel. 1109a.

(c) $\cup-— \cup \cup-:$ Su. 960, El. 150,239 437, Hel. 1124a, 1303.

\section{15. Aeolic compounds}

Compounds made up of aeolic cola and a suffix or prefix consisting of an iambic metron (syncopated or otherwise) are frequent in Pindar and Sophocles, some of whose compounds are also (sparingly) used by Euripides. Interestingly, the three tragedians appear to have eschewed Pindar's particular favourite, glyconic + cretic (on which see Itsumi 2009: 40-1, 446, under 'gl e'). Longer compounds involving aeolic and iambic elements are especially characteristic of Sophocles; there are a few examples in Euripides' earlier plays.

\section{A. aeolic cola with 'iambic' suffix $x^{240}$}

oo $-\cup \cup-\cup-\cup--(\mathrm{gl}+\mathrm{ba})$ : this aeolic compound, the phalaecian hendecasyllable, is well known outside Attic drama: in Euripides it is found at Hcld. 758 769, Hec. 446 457, 453-4 464-5, Su. 962 970, Ion 1055 1068, 1239, Or. 833.

$-\cup-\cup \cup \cup \cup--\longrightarrow(\mathrm{gl}+\mathrm{mol})$ : this colon (perhaps phalaecian with cholosis, since 'phal' appears two lines later) is found only at Ion 1237.

${ }^{239}$ It seems more natural to scan है हैं, $\delta \rho u ́ \pi \tau \varepsilon$ kó $\rho \alpha$ as $\cup-\longrightarrow \cup \cup-$, rather than as - — — $\cup \cup-\left(\right.$ Dale $\left.{ }^{2} 1968: 165\right)$.

${ }^{240}$ The length ' $\mathrm{gl}+\mathrm{ia}$ ' appears in Pindar, Pyth. 6 (line 5), Isthm. 7 (line 1 of the epode). 
oo $-\cup \cup-\cup--(\mathrm{gl}+\mathrm{sp})$ : a period-closing compound (cf. Itsumi 1984: 79) found at Su. 957 965, IT 1093 1110, Ion 1060 1073.

$---\cup-\cup \cup-\cup-\cup-$ (wil + ia): Hi. 553 563.

oo $-\mathrm{x}-\cup \cup-\cup-($ wil + ba): a comparable compound to the phalaecian hendecasyllable: see El. 432 442, 736 746, Ion 1052-3 1065-6, Hel. 1464 1477, Or. 810 822.

$--\mathrm{x}-\cup \cup--$ - (wil + sp): El. 434 444.

$--\cup \cup-\cup--($ tel $+\mathrm{sp})$ : a headless version of ' $\mathrm{g} 1+\mathrm{sp}$ ' appears at Alc. 576 586 and Hi. 130 140. ${ }^{241}$

$\mathrm{x}-\cup \cup-\cup-\longrightarrow \cup-($ tel $+\mathrm{cr})$ : at Herc. 791 808, 'tel + cr' responds with 'hept + cr' (see above, p. 110).

$\mathrm{x}-\cup \cup-\cup-\cup-($ tel $+\mathrm{ba})$ : the 'headless phalaecian' is a specific feature of the first stasimon in Hippolytus (526 536, 527 537, 528 538).

$\cup-\cup \cup-\cup-\cup \cup-($ tel + ch): Hi. 740 750.

B. aeolic cola with 'iambic' prefix

$\cup \cup \cup \cup \cup \cup-\cup \cup-\cup-($ ia $+\mathrm{gl} \sim$ ia + wil $\cup \cup \cup \cup \cup \cup-\ldots$

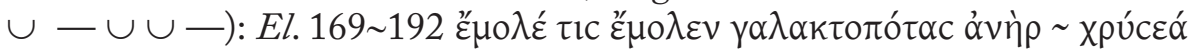

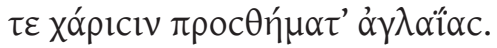

$-\cup-\mathrm{x}-:-\cup \cup-\cup-\left(\mathrm{cr}+\mathrm{gl}\right.$ ? $\left.\int \mathrm{ph}|| \mid\right):$ Hcld. 898-9 907-8

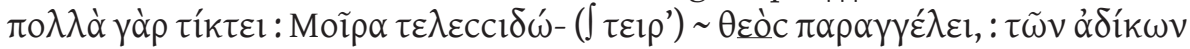
$\pi \alpha \rho \alpha l^{-}\left(\int \rho \tilde{\omega} v\right)$. The responding word-break marks off $-\cup-\mathrm{x}-($ ('h $\delta$ '?) from the ensuing dodrans, but it is difficult to know what conclusion to draw from this fact, if, indeed, any. This length reappears at $I A$ 784-5. ${ }^{42}$

$-\cup-\cup-:-\cup \cup-\cup-\longrightarrow$ (cr + hipp): Med. 155-6 180 घì $\delta \dot{\varepsilon}$

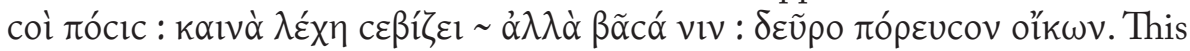
compound is ostensibly a pendent version of ' $\mathrm{cr}+\mathrm{gl}$ ', above. Again, responding word-break marks off $-\cup-\cup-$ ('h $\delta$ '?) from a recognizable aeolic colon (aristophanean). ${ }^{243}$

$\cup-\cup-Z: \cup \cup-\cup-\longrightarrow$ (ia + ar): Med. 432 439 cù $\delta^{\prime} \dot{\varepsilon} \kappa \mu \dot{\varepsilon} v$

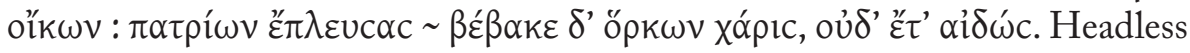
version of $M e d .155-6 \sim 180$ (above)? Other instances are Hi. 128 138 (long anceps), Hel. 1452 1466 and Rh. 347 356 (long anceps).

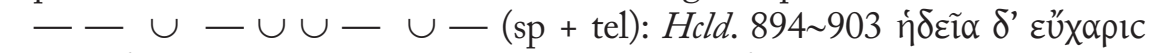

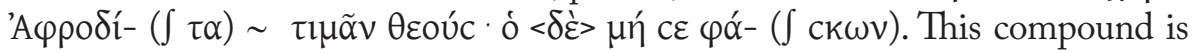

${ }^{241}$ In Pindar, 'tel + sp' is found at Nem. 6 in the sequence ' $2 \mathrm{ch}:$ tel + sp' (lines 6-7 of the strophe); the word-break after the choriambs is bridged in one of the repetitions. Cf. also S. Ai. 1191 1198 and Finglass, comm. Ai., p. 190.

${ }^{242}$ For 'cr + gl', cf. Pindar, Ol.14. 8 20.

${ }^{243}$ The analysis 'tr + hag' (Page, ed. Med.p. 182 - although, needless to say, he does not use the term 'hag') involves anceps iuxta anceps, as Buijs pointed out (1985: 81). 
called spondee + telesillean by Wilkins in his commentary on Heraclidae (p. 169). If, however, as I presume, it is the same colon as Hi. 525 535 "Е $\rho \omega c$ "Е $\rho \omega c$, o $\kappa \alpha \tau$ '

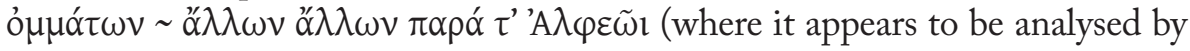
Barrett as 'nameless blunt enneasyllable $c$ ': ed. Hi., p. 423), IT1241 1266 and Or. 816 828, the designation 'anceps + gl' used by Dawe to analyse S. Phil.141 156 in the scansions appended to his Teubner edition is obviously preferable. ${ }^{244}$

$\cup \cup \cup \cup \cup \cup-\cup \cup-\ldots-$ (ia + dod ${ }^{\text {chol }): H i . ~ 147 ~ 157 ~ \alpha ́ v i ́ \varepsilon \rho o c ~}$

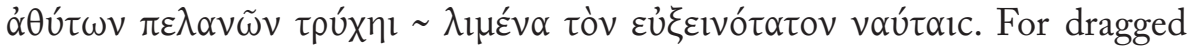
dodrans, cf. Hec. 637 646.

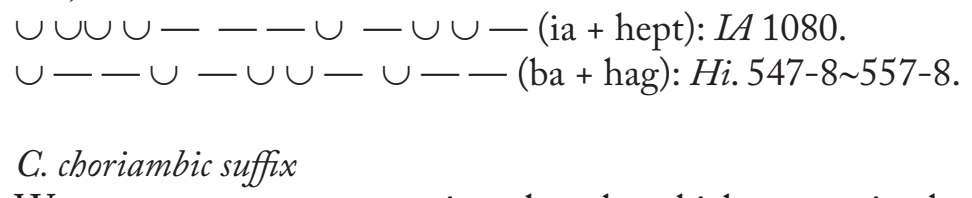

\section{C. choriambic suffix}

We now pass on to two unique lengths which appear in the presumed authentic part of the third stasimon of Iphigenia at Aulis. 1040 1062

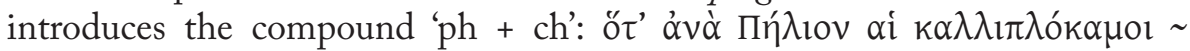

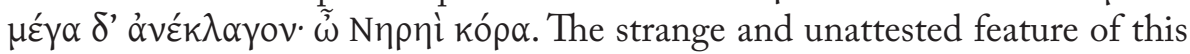
compound is the suffix tacked on to a pherecratean, by nature a catalectic colon. However, Dr L. P. E. Parker has helpfully suggested to me that here we might have two little cola in synartesis:

$\cup \cup \cup-\cup \cup-\operatorname{hex} \int^{\prime}$

$--\cup \cup-+$ aeolic pentasyllable

IA 1045-6 1067-8 appears to be a hexasyllable followed by two choriambs:

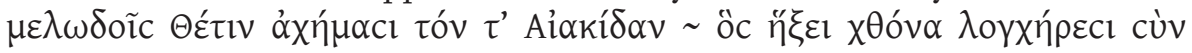

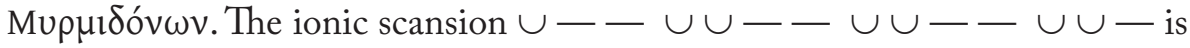
another possibility, although there are no other ionics in this song.

\section{D. choriambic expansion}

This is, again, more a Sophoclean than a Euripidean technique (cf. West 1982: 118); see, however, the colon $\mathrm{x}--\cup \cup--\cup \cup--$ (pherecratean with choriambic expansion or 'asclepiad' ${ }^{245}$ ) at Alc. 256a 263a and 986-7 997-8.

\section{E. longer compounds}

Longer aeolic compounds in the Sophoclean manner are found only in

${ }^{244}$ Cf. Willink's 'x gl' in his commentary on Or. (p. 214). Ba. 877 897 seems unlikely to be a dragged form of this colon, as he suggests. Cf. ' $x$ - gl' in line 2 (strophe) of Pindar's Ol. 10, or 'sp + gl' in Pyth. 5 (lines 7, 8 of the strophe).

${ }_{245}$ Cf. S. Ai. 628 640, El. 472 488, where it is called a catalectic asclepiad by Dawe, a term also used by Parker on Ar. Equ. 599-60 589-90 (1997: 167). Dawe calls the same colon 'ascl. minor cat' at S. Ant. 787 797. 
two of Euripides' earliest extant plays, Medea and Hippolytus.

$-\cup-\cup \cup-:-\longrightarrow \cup-\cup-\cup-$ (hex + 2 ia): Hi. 530-1 540-1

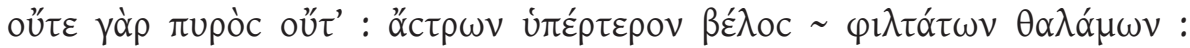

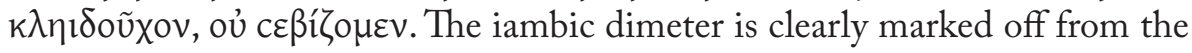
aeolic hexasyllable by responding word-break.

$--\cup-\cup \cup--\cup-\cup-\cup-($ hept $+\mathrm{cr}+\mathrm{ia}=$ hept + lk): Hi. 532-3 542-3.

$-\cup----\cup \cup-\cup-\cup-\sim-\cup----\cup \cup-\cup-$ - (?): Med.159 183. The parodos of Medea presents a notorious problem ${ }^{246}$

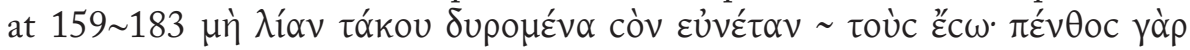

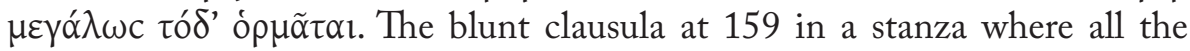
period-closing phrases are pendent is perplexing, as is the case of asymmetrical responsion between the penultimate positions: responsion between elements with and without cholosis is an uncertain licence in Euripidean aeolic. Eủvó $\tau \alpha v$ is found in two manuscripts ( $\mathrm{O}$ and $\mathrm{E}$ ) and was conjectured independently by Tyrwhitt; it was printed by Page in his edition and, more recently, by Kovacs in the Loeb Euripides and by Mastronarde in his Cambridge edition. As Finglass writes, the conjecture certainly 'removes a metrical anomaly at trivial

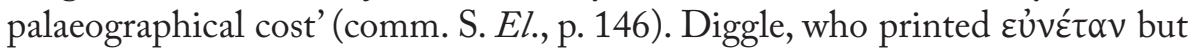

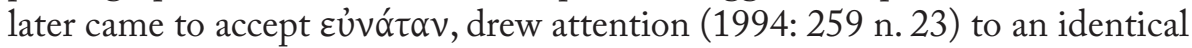
case of asymmetrical responsion in S. El. 123 139, where Lloyd-Jones and Wilson print

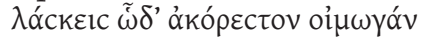

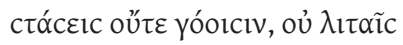

$---\cup \cup-\cup---\quad-\longrightarrow \cup \cup-\cup-\cup-$

Dawe, however, has declined to accept this instance of irregular responsion. ${ }^{247}$

Similarly, at Med. 159 the impression that the blunt and asymmetrically

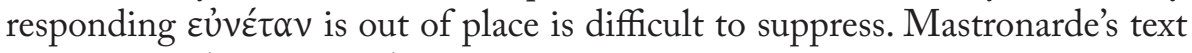
and analysis ('cr $+\mathrm{gl}+\mathrm{sp}$ ') seems the best option.

\section{16. Choriambic cola}

A predictable feature of aeolo-choriambic is the existence of lengths consisting solely of choriambs; less predictable perhaps is the fact that they are hardly ever used. The only reasonably frequent sequence is $-\cup \cup--\cup$

${ }^{246}$ On Med. 159 183 see Stinton (1990: 274, 279); Diggle (1994: 258-60; 1995: 41 n. 8); Lloyd-Jones \& Wilson (1990: 46, 183-4).

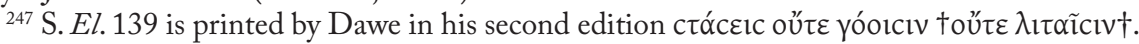

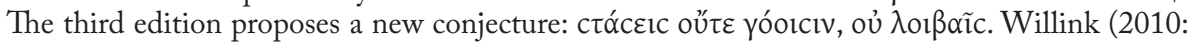

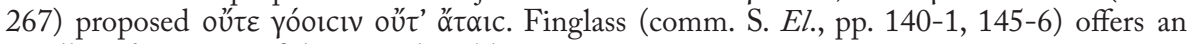
excellent discussion of the textual problems. 
$\cup$-, the choriambic dimeter par excellence. ${ }^{248}$ Otherwise, there is a choriambic monometer at $R h .699 \sim 717$ and a choriambic trimeter at $L A$ 1036 1058; a pendent ' $3 \mathrm{ch}$ - 'appears at Herc. 786-7 803-4. The most spectacular sequence is the $\pi v \tilde{i} y o c$ of nine choriambs in Antigone's monody at Ph. 1519-23.

Compounds consisting of two or more choriambs followed by a syncopated iambic suffix are also few and far between:

$$
\begin{aligned}
& -\cup \cup--\cup \cup-\cup--(2 \mathrm{ch}+\mathrm{ba}) \text { : El. } 726 . \\
& -\cup \cup--\cup \cup--\cup \cup---(3 \mathrm{ch}+\mathrm{sp}) \text { : Alc. 984-5 995-6. }
\end{aligned}
$$

\section{17. Iambo-choriambic phrases $(-\cup \cup-\mathrm{x}-\cup-$ and $\mathrm{x}-\cup$ $--\cup \cup-)$}

The identification of 'iambo-choriambic' as a distinctive genre is a comparatively recent event in the study of Greek lyric metre; Parker's valuable account (1997: 78-84) should be taken as a starting-point. As I see little point in going over the ground already covered by her in relation to the use of this metre by earlier poets, I will here limit my survey to Euripides.

\section{A. $\mathrm{x}-\cup--\cup \cup-$}

This dimeter, often confused with the wilamowitzian, appears quite frequently in Euripides in aeolic contexts.

$\cup-\cup--\cup \cup$ - Su. 977, Herc. 352 368, Ion 1090, Hel.1337, 1338, 1454 1468, 1471, Ph. 236, 1509; ${ }^{249}$

$\cup \cup \cup \cup \cup \cup-\cup \cup$ - Hi. 61, Ion 1054 1067, Hel. 1347 1363, Ba. 874b 894b, IA 1037 1059, 1092;

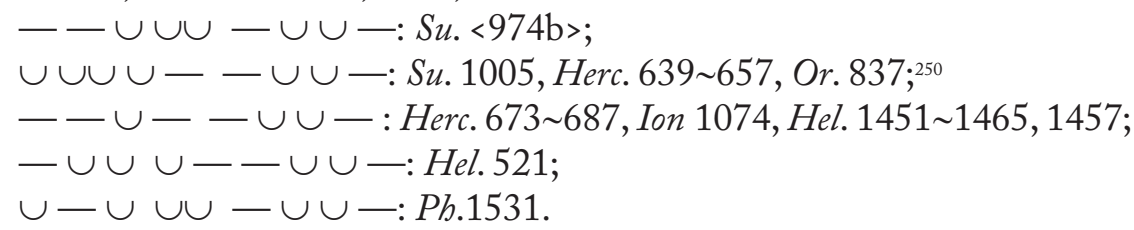

Examples with syncopation in the iambic metron are:

$-\cup-\backsim \cup-(\mathrm{cr}+\mathrm{ch}$ ): Hel. 1340 1356, 1341 1357, Or. 834 (see Willink, comm. Or., p. 221);

$$
-\cup \cup \cup-\cup \cup-(\mathrm{cr}+\mathrm{ch}): \text { Hel. 520, 526; }
$$

${ }^{248}$ The choriambic dimeter $-\cup \cup-\cup \cup \cup-$ is found at Alc. 268, Med.645 654, Hcld. 353 362, Herc. 637 655, IT 435 452, Ph. 1510, 1526, Or. 839, Rh. 251 262, 369a 379a. There is a pendent ' $2 \mathrm{ch}-$ ' at $P$ h. 1529 .

${ }^{249}$ Further instances of $\cup-\cup--\cup \cup-$ in an iambic context are Herc. 765 774, 766 775.

${ }^{250}$ A further instance of $\cup \cup \cup \cup-\smile \cup \cup$ - in an iambic context is El.1193. 


$$
\cup---\cup \cup-(\mathrm{ba}+\mathrm{ch}): \text { Or } 835 \text {. }
$$

B. $-\cup \cup-\mathrm{x}-\cup-$

As Itsumi has remarked, there are 'only a handful of examples' of this colon (1984: 80). Diggle (1995: 40) offers a useful list (Alc. 88 100, Hcld. 910 919, Ion 506, Ba. 109 124, 573 [with Ferrari's conjecture $\pi \alpha \tau \varepsilon$ p', öv, printed by

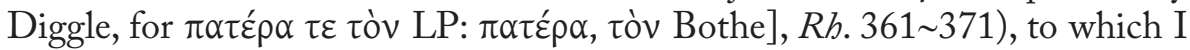

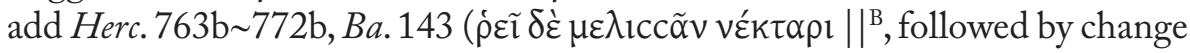
of metre) and $I A 1083$ (with $-\cup \cup-\cup-\cup \cup \cup$, Günther's admittedly

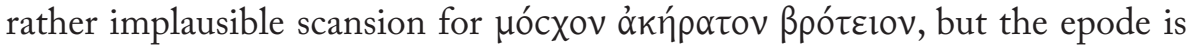
in any case unlikely to have been composed by Euripides). Other examples in the OCT now doubted by Diggle (loc. cit.) are Alc. †215†-6 228-9251 and Hec. 947.252

The shapes contained in these examples are

$-\cup \cup-\cup-\cup-$ : Alc. 88 100, Hcld. 910 919, Hec. 947, Herc. 763b 772b, Ion 506, Rh. 361 371;

$-\cup \cup-\cup \cup \cup \cup \cup \cup: B a .573$;

$-\cup \cup-\cup-\cup \cup \cup:$ Ba.109 124, IA 1083.

$-\cup \cup-\ldots-\cup-$ Ba. 143.

Of these examples, only Alc. 88 100 does not occur in an aeolic context, but in a stanza where there is admixture of iambic and dactylic (or enoplian).

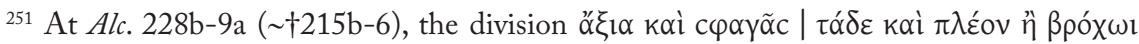
$\delta \dot{\varepsilon} \rho \alpha \nu$ (dod | cyrenaic) is preferable (cf. above, p. 74). Kovacs in his Loeb edition attaches $\alpha \hat{\imath} \alpha \tilde{\imath}$

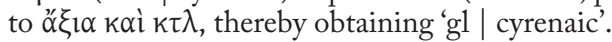

${ }^{252}$ Cf. Collard (1989-1990: 88 n. 6). 


\section{Repertory of Iambic Cola}

The lyric iambics of Greek drama have happily been the object of excellent studies by Denniston, Dale and, particularly, Parker. ${ }^{253}$ There seems little point in going over the same ground and producing, inevitably, a lot of useless repetition on well-known subjects such as split resolution, word-end after long anceps, the permissibility of resolution before syncopation, the improbability of lyric trimeters lacking a caesura, etc. Instead, I offer the following repertory, locating in the Euripidean corpus the different shapes of all the lyric iambic cola used by Euripides. The lecythion is treated above, pp. 40-3.

\section{1. Iambic Monometers}

$\cup-\cup$ - Alc. 903 926, Hi. 813b, 1147 (or extra metrum), Hec. 175, ${ }^{254}$ Su. 1123 1131a, Herc. 763a 772a, 891, 904, Tr. 164 186, ${ }^{255}$ 172b 193b, 241, 309 326, 1226, Ion 766, Hel. 648, Ph. 1019a 1043a, IA 1283.

$-\smile \cup$ - Andr. 846, Tr. 247.256

$\cup \cup \cup \cup$ : Tr. 340b, 1287 1294.

$-\cup \cup \cup-:$ Tr.324b.

1 sp

——: Or. 316 332.

$1 \mathrm{cr}$

$-\cup$ - Ion 1470 .

$\cup \cup \cup$ : Or. 1389b.

$\cup \cup \cup \cup \cup:$ Herc. 744 757a, Tr. 269, IT 881.

${ }^{253}$ Denniston (1936: 121-144); Dale (21968: 69-96); Parker (1966: 1-26; 1968: 241-69; 1976: 14-28; 1990: 331-48; 1997: 27-35). See also Diggle (1981: 18-21, 119; 1990: 76-7, on resolution before syncopation in lyric iambics; on alleged and perhaps real caesura-less trimeters, see 1991: 138 n. 18; 1994: 314, 475-6 n. 158).

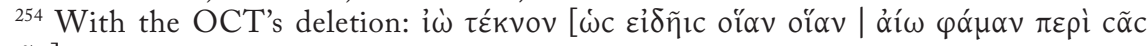
$\psi v \times \tilde{\alpha} c]$.

255 Or anapaestic monometer: see Diggle (1994: 119). The same applies to Tr. 172b 193b.

${ }^{256}$ Alternatively a dochmiac, with Willink's supplement (cf. 2010: 244 n. 12). However, this putative dochmiac would not match any of the standard patterns of anadiplosis in dochmiacs listed by Diggle (1994: 376-8). 


\section{2. Iambic Dimeters ${ }^{257}$}

A. non-syncopated dimeters

$\cup-\cup-\cup-\cup-:$ Alc. 86 98, 214a, 394 407, Hi. 1142, 1379, 1383, Andr. 277, 474, 856, 1207, Hec. 924 934, 1078, 1096, Su. 803 816, 809 822, 815, 827, 1140 1147, El. 1196, 1188 1204, 1201, 1211 1219, 1218, 1225, 1230, Herc. 110, 129, 417 434, Tr. 279, 291a, 313 330, 318 334, 524 544, 527 547, 528 548, 551, 554, 556, 559, 1089, Ion 692, 694, 1507, Hel. 234, 243b, 246b, 330, 334, 339, Ph. 185, 304, 305, 306a, 306b, 307, 310, 332, 333, 337, 339, 340, 341, 342, 653 672, 688, 1022 1046, 1033 1057, 1034 1058, 1036 1060, 1037 1061, 1292 1304, 1711, 1714, 1715, 1739, 1747, 1749, Or. 966b 977b, 990, 991b, 996, 1369b, 1400b, 1409, 1410, 1411, 1413, 1444, 1445, 1450, 1457b, 1461, 1477, 1482, 1488b, 1494a, 1494b, 1499, Ba. 1173 1189, IA 262, 274, 1317, 1491, 1500, 1501, 1503, 1504, 1525, Rh. 720, Phaeth. 270.

$-\longrightarrow \cup-\cup-\cup-:$ Alc. 87 99, 119 129, 227a, 875 892, Andr. 466, 1220, Hec. 685, 686, Su. 802, Herc. 1053, Tr. 1314, Ion 712, Ph. 687, Or. 1449, IA 1514.

$\cup-\cup-—-\cup-:$ Hcld. 81, Andr. 297, Or. 1463, Rh. 702.

$-\ldots \cup-\_\cup-$ : Hcld. 102, Ion 693 711, Hel. 1108a 1123a, 1138 1152, 1143 1157, 1145 1159. ${ }^{258}$

$\cup \cup \cup \cup ー \cup-\cup-:$ El.1181a 1194, 1229, 1231, Herc. 114, 127, Tr.

558, 1298, Ph. 1511, Or. 1446a.

$-\cup \cup \cup-\cup-\cup-:$ El.1223, Tr. 543, 1107, Ion 1076.

$\cup-\cup \cup \cup \cup-\cup-:$ Alc. 261, Su. 371, 1154 1160, El. 1187 1203, 1191, 1210, 1224, Herc. 109, 117, 432, 1074, Tr. 546, 552-3, Ion

${ }^{257}$ Interestingly, the following possible shapes do not occur: (i) $-\cup \cup \cup---\cup-$, (ii) $\cup \cup \cup \cup---\cup-$, (iii) $--\cup \cup \cup--\cup-$, (iv) $\cup \cup \cup \cup \cup \cup--\cup-$, (v) - $\cup-\cup-\cup \cup \cup$, (vi) $-\cup \cup \cup-\backsim \cup \cup$.

${ }^{258}$ It is uncertain whether Hel. 1108a 1123a, 1138 1152, 1143 1157 and 1145 1159 really belong to this group, since dactylo-epitrite interpretation (x e - e) is also possible, as Kannicht notes (vol. II, p. 280). But since Diggle (1991: 138 n. 16) includes Hel.1108 1023 in a list of iambic phrases in which the second metron starts with long anceps, it seems reasonable to assume that, in regard to the other examples, the OCT's 'implicit' scansion is also iambic; note, however, that the inclusion of Hel. $\nmid 171 \dagger$ in this list does not chime in with the statement that 'in all of the trochaic metra of this lyric exchange, and in all those in the parodos which precedes, there is no certain instance of a long anceps' (1994: 424). Also, Hel. $\nmid 171 \dagger$ is possibly not cr + ia, as suggested by Diggle (1994: 341), but tr + cr, since the context is entirely trochaic: catalectic lecythia are to be expected all through $\mathrm{Hel}$. 167-228, and iambic lecythia are, strictly speaking, not catalectic (cf. Parker 1990: $331 \mathrm{n}$. 1; West 1982: 99-100). 
215 233b, Hel. 347, 361, Ph. 308, Or. 983b, 986, 1412b, 1471b, Hyps. 25.

$\cup-\cup \cup \cup-\longrightarrow \cup-$ Alc. 254.259

$\cup \cup \cup \cup \cup \cup \cup-\cup-:$ Med. 211, 1281a 1292a, Hi. 595, Hec. 703, 1031, Su. 621, 1155 1161, El. 1149, 1179 1192, Tr. 526, 545, 836 856, Ion 497, Ph. 1716, 1752, Or. 192, 329 345, 968 979, 1253 1273, Ba. 1022, LA 1478, Rh. 135 199, 693 711, Hyps. 66, 285.

$\cup-\cup-\cup \cup \cup \cup-:$ Alc. 128, Su. 1156, Herc. 126, 416, 1073, Tr. 1315, 1331, Hel. 233, 340, Ph. 652 671, 1728, 1729, Or. 982b, Ba. 992 1012, IA 1316, 1502, 1507.

$\cup-\cup-\cup-\cup \cup \cup:$ Andr. 287, Tr. 539, 557, 855, Ion 212 230, Ph. 294, Or. 966a 977a, 999a, Ba. 875 895.

$-ー \cup-\cup \cup \cup \cup-$ :Alc. 118, El. 479.

$\cup \cup \cup \cup \cup \cup \cup \cup \cup \cup \cup \cup:$ Andr. 483 491, Tr. 1288, 1313 1328-9, IT 220, 232-3, 864, Ion 889, Hel. 348, 1308 1326, Ph. 1030 1054, Or. 1416, 1441, Ba. 905, 1170 1186, LA 1477, Rh. 675b (tr?), Hyps. 107. ${ }^{60}$

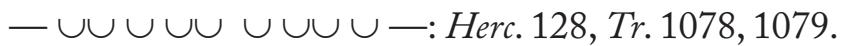

$\cup \cup \cup \cup \cup \cup \cup \cup \cup-:$ Alc. 907-8 930-1, Med. 206, Hi. 1382, Hec. 928 938, Tr. 1067, IT 1250 1274, Ion 1093, Or. 1307, 1414.

$\cup-\cup \cup \cup-\cup \cup \cup$ - Hec. 923 933, Su. 367, Hel. 1309 1327, Ph. 1751, Ba. 137.

$-\cup \cup \cup \cup \cup \cup-\cup$ - Su. 629, Herc. 107, 116, Tr. 523, Ion 1077, 1092.

$ー \cup \cup \cup-ー \cup \cup \cup-:$ Su. 1162.

$\cup-\cup \cup \cup \cup-\cup \cup \cup:$ El. 1178, Tr. 835.

$-ー \cup \cup \cup \cup-\cup \cup \cup:$ Herc. 415, Ph. 1560, IA 1512.

$-\cup \cup \cup \cup \cup \cup \cup \cup \cup \cup \cup:$ Herc. 115, Tr. 540.

$-\_\cup-\cup \cup \cup \cup \cup \cup:$ Herc. 409.

$\cup-\cup-\cup \cup \cup \cup \cup \cup:$ Herc. 426, 433, Tr. 565, 1291, 1312.

$\cup \cup \cup \cup-\cup-\cup \cup \cup: \operatorname{Tr} .519$.

$\cup-\cup \cup \cup \cup \cup \cup \cup \cup \cup: \operatorname{Tr} .520$, Or. 991a, Ba. 412.

$\cup \cup \cup \cup \cup \cup \cup-\cup \cup \cup: T r .525$.

$-\cup \cup \cup-\cup \cup \cup \cup$ - Tr. 1068, Ion 216.

$-\cup \cup \cup-\cup \cup \cup \cup \cup \cup$ : Ion 235a.

$\cup \cup \cup \cup-\cup \cup \cup \cup-$ : Hel. 336.

${ }^{259}$ This and Or. 842 (below, n. 261) are the only instances of resolution before long anceps in Euripidean iambics.

${ }^{260}$ Hyps. 107 (= fr. I. iv. 5 Bond = Fr. 752h, 5 Kannicht) is analysed by Bond (p. 63) as '2 tr', but iambic analysis avoids split resolution. 


$$
\begin{aligned}
& \cup \cup \cup \cup \cup-\cup \cup \cup \text { : Or. 842. } \\
& \cup \cup 1 \\
& \text { (61 }
\end{aligned}
$$

\section{B. Syncopated Iambic Dimeters}

\section{Ithyphallic $(||)$}

$$
\begin{aligned}
& -\cup-\cup-\text { - Alc. 113 123, 441 451, 465b 475b, 572 582, } \\
& \text { 574 584, Med. 848 858, 992 998, Hi. 169, 1143, 1146, Andr. } \\
& \text { 118 127, 120 129, 123 132, 125 134, 485 493, 777 789, } \\
& \text { 1018 1027, 1030 1040, Su. 625 633, 810, El. 1184 1200, 1197, } \\
& \text { 1212 1220, Herc. 137, 418 435, 1054, Tr. 590 594, 839 859, } \\
& \text { 1309 1324, IT 1137, 1258 1283, Ion 502, Ph. 338a, 1020 1044, } \\
& \text { 1032 1056, 1035 1059, Or. 984b, 988, 1373, 1374, 1389a, 1432, } \\
& \text { 1480a, IA 285, 300, 1479, } 1486 . \\
& \cup \cup \cup-\cup-\longrightarrow: \text { Su. 823, Herc. 118 130, 387, Tr. 320 336, 530, } \\
& \text { 581 586, Ion 1079, Hel. 385, Ph. 1028 1052, 1029 1053, LA 1496, } \\
& \text { Hyps. 31, } 111 .
\end{aligned}
$$

$\cup \cup \cup \cup \cup \cup-\longrightarrow:$ Alc. 266, Ion 1095, Hyps. 74.

$-\ldots-\cup-\ldots:$ Alc. 92 104. ${ }^{263}$

\section{Iambic metron + cretic}

$$
\begin{aligned}
& \cup-\cup-\longrightarrow \cup-: \text { Alc. 122, 465a 475a, Hcld. 82 103, Andr. 278 288, } \\
& \text { Su. 73 81, 74 82, 75 83, 779 787, 798, 833, 834, El. 1154 1162, } \\
& \text { Herc. 411 428, 430, Tr. 829 848, IT 1259, Hel. 370, Or. 982a, } \\
& \text { 1448b, 1458, IA 1510b, 1519, Rh. 137 201. } \\
& \text { - } \cup-— \cup-\text { :Alc. 112, Hi.1388a, IT 839, 1234, Phaeth. 96, } 98 . \\
& \cup-\cup-\cup \cup \cup-\text { Tr. } 555 . \\
& \cup \cup \cup \cup-\longrightarrow \cup \text { - Su. 829, 830, Tr. 522 542, IA } 1475 . \\
& \cup-\cup \cup \cup-\cup \longrightarrow: \text { Tr. 319 335264 Hel. 335265. }
\end{aligned}
$$

${ }^{261}$ Cf. note 259, above. Buijs (1986: 52) offers alternative interpretations of this colon.

${ }^{262}$ These freak iambic dimeters respond with $\cup \cup \cup \cup \cup \cup \cup-\cup-$. As Parker observes (1968: 249 n. 1), "impure" iambics are found in dochmiac contexts, as if Euripides were led by the dochmiac rhythm with its double anceps ... momentarily to treat the iambic metron as if it too had two ancipitia'. See also Diggle (1994: 259); Wilamowitz (1921: 410-12); Denniston (1936: 141) and ed. El., p. 224.

${ }^{263}$ I list this as iambic, since 'dragged ithyphallic' is not an implausible analysis for Alc. 92 104, in view of the context.

${ }^{264}$ Stinton's interpretation of this as 'ba + ia' is perhaps not as 'clear' a 'case' as he seems to have thought (1990: 124).

${ }^{265}$ Stinton (loc. cit.) proposes 'ba (with resolved second long) + ia', although he admits that 'the resolved bacchius is not supported by other bacchei'. His opinion that 'the metre is not ambiguous' can be viewed from other angles: see Dale (21968: 92-3); West (1982: 102-3); Parker (1990: 346-7; 1997: 37-8). Alternatively, with Willink's $\tilde{\omega}$ for i $\omega$, we would have two cretics of the shape $-\cup \cup \cup-\cup-($ cf. 2010: 136 n. 13). 
$\cup \cup \cup \cup \cup \cup \cup \cup-:$ El. $485^{266}, P h .1286$.

$\cup \cup \cup \cup \cup \cup-\cup-:$ Su. 811, El. 481267, Ph. 1031 1055, 1298.

$-\cup \cup \cup \cup \cup-\cup-$ : Hec. 1093.

\section{Iambic metron + bacchiac (||)}

$\cup-\cup-\cup-\longrightarrow:$ Alc. 219 231, 262, 905 928, Hi. 1388b, Hec. 942, 946, 949, 1095, Su. 801 814, El. 1202, Herc. 108 120, 113, 397, 913, 1025, 1036, 1064, 1065, 1066, 1067, Tr. 521 541, 529 549, 1229, 1230, 1235, 1238, Ion 213b 231b, 217 235b, Hel. 332, 362, Ph. 312, 315, 343, 1025, 1027 1051, 1293 1305, 1532, Or. 167 188, 190, 992, 1371, 1399, Ba. 993 1013, ${ }^{268}$ IA 1480, Erechth. III. 7, Cresph. III. 5.

$-\smile \cup-\cup-$ - Alc. 255, Hi.1130 1141, Andr. 140 146, 847, 848, Hec. 932, Herc. 810, Ion 1483, Hel. 1112 1127, 1121, Ph. 313, 1049, Or. 169, Rh. 232 241.

$\cup \cup \cup \cup-\cup-\longrightarrow$ : Herc. 125, Tr. 1099.

$\cup-\cup \cup \cup-{ }^{269}$ : Herc. 111, 383, 793, Tr. 567, 1083 1101, Ph. 1518.

$-\multimap \cup \cup \cup \cup-$ Hel.1136, Ph. 1731, IA 207.

$-\cup \cup \cup-\cup-\longrightarrow$ Or. 995.

$\cup \cup \cup \cup \cup \cup-{ }^{270}$ : Herc. 776, Tr. 1117, Ion 1231, Hel. 1486 1503, Ba. 107 122.

\section{Iambic metron + spondee ${ }^{271}$}

$\cup-\cup-$ - $:$ Alc. 401 413, Su. 781 789, IT 400 415, Or. 1401a, 1452, Cycl. 77, Phaeth. 273.272

$\cup \cup \cup \cup-{ }^{273}$ : Ion 149, 150, Or. 1401b..$^{274}$

${ }^{266}$ This could be a lecythion, but if the split resolution it entails $(\cup \mid \cup \cup \ldots)$ can be avoided by analysing 'ia + cr', so much the better.

${ }^{267}$ An alternative analysis as lecythion with two split resolutions is not preferable.

${ }^{268} \mathrm{Ba}$. 993 1013 is a rare example (cf. S. Trach. 842b) of 'ia + ba' (otherwise a period-closing phrase) in synartesis with the following colon $(2 \mathrm{ba})$, but this is probably unremarkable: since it is all one long period, the first bacchiac in a sequence of ' 3 ba' need not be felt as clausular.

${ }^{269}$ Cf. Diggle's list (1981: 49) of Euripidean dimeters with the shape $\mathrm{x}-\cup \cup \cup \cup-\ldots$.

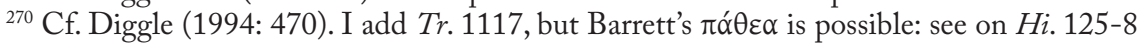
and Diggle again (1994: 458 n. 71).

${ }^{271}$ Cf. OCT's apparatus on Cycl. 77 (I omit Or. $\dagger 1447 \dagger$ ).

${ }^{272}$ This presupposes the colometry in Diggle's Cambridge edition of Phaethon (ia $+\mathrm{D} \int \mathrm{ia}+$ $\mathrm{sp})$, not that printed in $\operatorname{Tr} G F S$ (ia $\int \mathrm{D}+\mathrm{ia}+\mathrm{sp}$ ).

${ }^{273}$ Ion 149 and 150 are not entirely free from controversy, but cf. Diggle (1994: 117 n. 80).

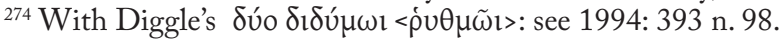




\section{Bacchiac + iambic metron ${ }^{275}$}

$\cup-\backsim \cup \cup$ - Hi.1381a, Herc. 353a 369a, Tr. 560, 561, 562, 563, Ph. 334, Or. 1379, 1407b, 1443, 1451, 1459b, 1464b, 1472b, $1493 \mathrm{~b}$. $\cup-\cup \cup \cup-\cup-:$ Tr. 564.

\section{Bacchiac + cretic}

$\cup-\longrightarrow-\cup-$ : Hec. 629 638, Su. 630a ( 622a: mol + cr), Su. 630b ( 622b: $\mathrm{mol}+\mathrm{cr})$, El. 1208 1216, Tr. $585(\sim 580 ; \mathrm{mol}+\mathrm{cr})$, Ion 214 233a, Ph. 331, 1050 ( 1026: mol + cr), Or. 965 976, 1412a, 1418, 1442, 1448a, 1468a, 1471a, 1492.

$\cup-ー \cup \cup \cup$ - Ba. 1018 .

\section{Bacchiacs}

$\cup-— \cup-$ - Hi. 1380, 1385a, Su. 990 1012, 1002 1025, Herc. 879, Tr. 321, 587 591, 588 592, Ion 190 ( 201: mol + ba), 1465, Hel. 642, Or. 173 194, 1438, Ba. 148a, 994 1014, 1177 1193, 1181 1197, 1182 1198, Rh. 695 713, 706 724, 707 725.

\section{Cretics}

$-\cup-\longrightarrow \cup-$ Andr. 275 285, 1017 1026, Herc. 135, 385, Hel.246a, 357b, Ph. 320, 1525, Or. 1388, 1419, 1420, 1421, 1422, 1423, 1424b, Ba. 988 1008, LA 286, 297, Cycl. 659.

$\cup \cup \cup \cup \cup \cup-:$ Hi 362a 669a, Or. 313 333, Ba. 590.

$-\cup \cup \cup-\cup$ - Su. 921, Or. 1378.

$\cup \cup \cup-\longrightarrow \cup$ - Herc. 399, Ph.1530, LA 1289.

$\cup \cup \cup \cup \cup-\cup-$ : Hi. 1145, Ion 689, 1449.

$-\cup \cup \cup \cup \cup \cup \cup \cup:$ Ion 707.

$-\cup-\cup \cup \cup-$ Or. 1377, 1433.

$-\cup--\cup \cup \cup:$ Or. 1424a.

$-\cup \cup \cup-\cup \cup \cup: B a .135,160$.

\section{Molossi}

- - - - —: Ion 125 141, 126 142, 127 143.

\section{Cretic + molossus}

— $\cup$ - - - Ph. 321, Hyps. Fr. 753c, 21 Kannicht.

$\cup \cup \cup-\ldots$ - Or. 984a (text uncertain). 


\section{Cretic + spondee}

— $\cup$ - —: Herc. 898, 909, Phaeth. 235 244.

\section{Spondee + cretic}

$-\leftarrow-\cup-$ Or. 983a.

\section{Molossus + iambic metron}

$--\backsim \cup-\cup-$ :Andr. 139 145.

\section{Molossus + cretic}

- — - - - Su 622a ( 630a: ba + cr), 622b ( 630b: ba + cr), Tr. 579 584, $580(\sim 585: \mathrm{ba}+\mathrm{cr})$, Ion 687-8 706, Ph. 1021 1045, 1026 ( 1050: ba + cr), Or. 1407a, 1472a.

\section{Molossus + bacchiac}

\section{Spondees}

$$
\text { : Ion } 201(\sim 190: 2 \text { ba). }
$$

— - — - IT 404 419, Ba. 599.

\section{3. Lyric Trimeters}

It is not always easy to determine when trimeters are lyric, particularly if signs such as Doric alpha are not available. My criterion is that a trimeter among lyrics is prima facie lyric, even if dialect is inconclusive, provided it is uttered by the chorus or a singing character.

\section{A. non-syncopated trimeters}

i. unresolved

$\cup-\cup-\cup-\cup-\cup-\cup-$ : Hcld. 892 901, Hi. 368 675, 371 678, 813a, Andr. 299 307, 479 486, 1208 1221, Hec. 689, Su. 71 79, 615, 783 791, 923, 1124 1131b, 1125 1132, El. 1213-4, Herc. 880, IT 843, 845, Hel. 641, Ph. 148, 168, 311, 327, 654 673, Or. 960 971, 1271, 1360, 1475, 1476, 1478, 1489, 1498, LA 1523, Rh. 719, Cycl.357 371, 362.

$-ー \cup-\cup-\cup-\cup-\cup-:$ Hec. 699, IT 827, 837-8, Ph. 138.

$\cup-\cup-\cup-\cup---\cup-:$ El. 1206.

$--\cup-\cup-\cup-\longrightarrow-\cup-$ Ph. 145, Or. 1252, Phaeth. 280.

$--\cup---\cup-\cup-\cup-$ : Hcld. 90, Or. 1355, 1359, Ba. 1161.

$\cup-\cup-—-\cup-\cup-\cup-:$ Hec. 1094, El.1182 1198, Herc. 894, 
Ph. 1717,,276 Or. 1278, 1356, Erechth. IV. 3.

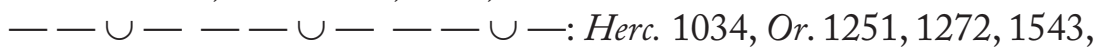
1544.

ii. with resolution in one metron

$\cup \cup \cup \cup-\cup-\cup-\cup-\cup-$ : Andr. 1216, Su. 602 612, 826, El.

1199, Ph. 1745.

$\cup-\cup \cup \cup \cup-\cup-\cup-\cup-:$ El. 1221, Hec. 621-2.

$\cup \cup \cup \cup \cup \cup \cup-\cup-\cup-\cup-$ El. 1183 .

$-ー \cup \cup \cup \cup-\cup-\cup-\cup-$ Tr. 1311.

$\cup-\cup-\cup \cup \cup \cup \cup \cup \cup-\cup-$ :Hi. 878 , Or. 961.

$\cup-\cup-\cup \cup \cup \cup-\cup-\cup-:$ Andr. 481, 1204, 1224, Su. 373 377, 614, 618 626, 831-2, 1129 1136, 1152 1158, 1153, El. 1217, Or. 963 974, Phaeth. 95.

$\cup-\cup-\cup-\cup \cup \cup \cup-\cup-$ : Andr. 1211, Su. 375 379, Herc. 768-9, 1081-2, Tr. 333, 1320.

$\cup-\cup---\cup-\cup \cup \cup \cup-$ Su. 605.

$\cup-\cup-\cup-\cup-\cup \cup \cup \cup-$ Tr. 1305, Or. 1481.

$\cup-\cup--\cup \cup \cup---\cup-$ IT 833

$--\cup-\cup \cup \cup \cup-\cup-\cup-:$ Su. 1143 1150.

$-\cup \cup \cup \cup \cup \cup-\cup-\cup-\cup-:$ Andr. 464-5 †471-2†, LA 1524.

$-\cup \cup \cup-\cup-\cup-\cup-\cup-$ :Andr. 1197-8 1213-4.

$--\cup-\cup-\cup-\cup \cup \cup \cup-$ Andr. 489.

$--\cup-\cup-\cup \cup \cup-\longrightarrow \cup-:$ Ph. 158.

$--\cup--\cup \cup \cup--\longrightarrow \cup-R h .701$.

iii. with resolution in two metra

$\cup-\cup \cup \cup \cup \cup \cup \cup-\cup-\cup-:$ El. 1209, Herc. 778-9, Tr. 10845 1102-3.

$\cup-\cup \cup \cup \cup-\cup \cup \cup \cup-\cup-$ : Herc. 770, Ba. 414-5.

$\cup-\cup-\cup-\cup \cup \cup \cup-\cup \cup \cup: T r .316-7$.

$\cup \cup \cup \cup-\cup \cup \cup \cup \cup \cup-\longrightarrow \cup-: T r .1326$.

$\cup \cup \cup \cup-\cup \cup \cup \cup \cup \cup \cup-\cup-$ : Hel. 1148 .

$\cup-\cup \cup \cup \cup-\cup-\cup \cup \cup \cup-$ IT 398-9, Ion 122-3.

$\cup \cup \cup \cup \cup \cup \cup \cup \cup-\cup-\cup-$ : Hel. 1117 1132, 1118 1133.

$\cup-\cup-\cup-\cup \cup \cup \cup \cup \cup \cup-: P h .1710$.

$\cup-\cup \cup \cup \cup \cup \cup \cup-\cup-\cup-:$ Ph. 1737 .

$\cup-\cup--\cup \cup \cup \cup \cup \cup \cup \cup \cup-$ Or. 972.

$\cup \cup \cup \cup \cup \cup \cup \cup \cup \cup \cup \cup \cup-\cup-$ Or. 987.

${ }^{276} \mathrm{Ph} .1717$ lacks a caesura, but the passage is spurious (cf. Diggle 1991: 138 n. 18). 
$\cup-\cup \cup \cup \cup \cup \cup \cup \cup \cup-:$ IA 1318 .

$-\cup \cup \cup \cup \cup-\cup-\cup \cup \cup \cup-:$ Andr. 798-9, IA 1487-8.

$-\cup \cup \cup-\cup-\cup \cup \cup \cup \cup-$ : Andr. 1200-1.

$-\cup \cup \cup-\cup-\cup \cup \cup \cup \cup \cup$ : Su. 365 369.

$--\cup \cup \cup \cup \cup \cup \cup \cup \cup-\cup$ - Hec. 950-1.

iv. with resolution in all three metra

$-\smile \cup \cup \cup \cup \cup \cup \cup \cup \cup$ - Ion 138-9.

$\cup-\cup \cup \cup \cup-\cup \cup \cup \cup \cup \cup \cup-$ B Ba. 430-1.

B. syncopated trimeters

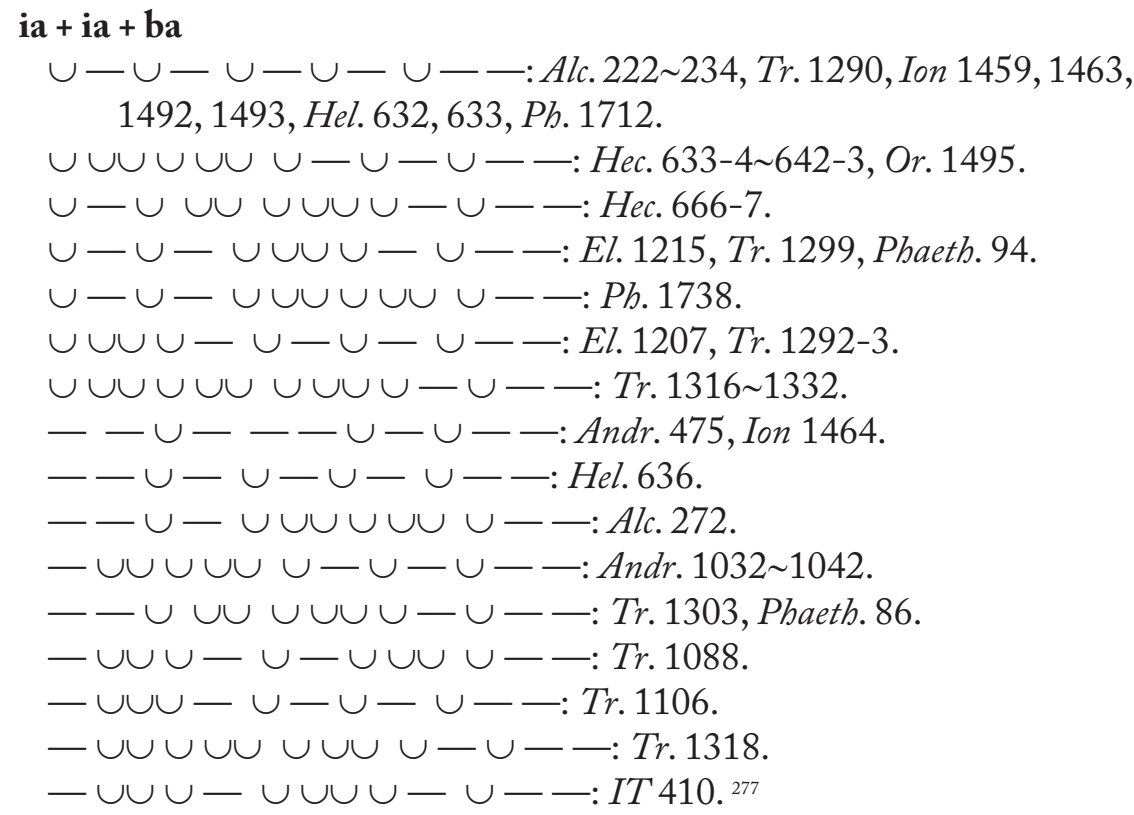

\section{$\mathbf{i a}+\mathbf{b a}+\mathbf{i a}$}

$\cup-\cup-\cup--\cup-\cup-: R h .25$.

$\cup-\cup-\cup----\cup-: R h .43$.

$--\cup-\cup-\leftarrow \cup-\cup-: P h .686$.

\section{$\mathbf{i a}+\mathbf{c r}+\mathbf{b a}$}

$\cup-\cup-\backsim \cup-\cup-\longrightarrow:$ Alc. 872 889, Hcld.773 780, 776 783, Hi. 161, Andr. 1212 1225, Hec. 1091, Su. 78 86, 785 793, 1139 1146,

${ }^{277}$ With Wecklein's supplement <cúv>, printed in the OCT. 
1157 1163, El.1189 1205, Herc. 410 427, 771 780, Tr. 1321, Ph. 1725, Or. 970 981, LA 1513, Phaeth. 101.

$-ー \cup-\backsim \cup-\cup-\longrightarrow: \operatorname{Tr} .578 \sim 583,1306$.

$\cup \cup \cup \cup-\cup \cup \cup-\cup-\longrightarrow:$ Tr. 1307 1322.

$\cup \cup \cup \cup-\longrightarrow \cup \cup \cup \cup-\longrightarrow:$ Or. 1480b. ${ }^{278}$

$$
\begin{aligned}
& \text { ia }+ \text { cr }+ \text { ia } \\
& \cup-\cup--\cup-\cup-\cup-\text { : Andr. 1031 1041, Su. 601 611, } \\
& --\cup--\cup-\cup-\cup-: \text { Su. 800, Tr. } 285 . \\
& \cup \cup \cup \cup-\cup \cup-\cup-\cup-: \text { Su. } 72 . \\
& \cup \cup \cup \cup-\backsim \cup--\longrightarrow \cup-: \text { Su. } 80 . \\
& \cup-\cup-\longrightarrow \cup-\cup \cup \cup \cup \cup \cup: \operatorname{Tr} .332 . \\
& \cup-\cup--\cup-\cup \cup \cup \cup-\text { : Hel. } 363 \text {. } \\
& \cup-\cup-\cup \cup \cup-\cup-\cup-: \text { Ph. } 1744 .
\end{aligned}
$$$$
\text { 782 790, 813, Tr. 1304 1319, Ph. 1723, 1726, Or. } 1470 .
$$

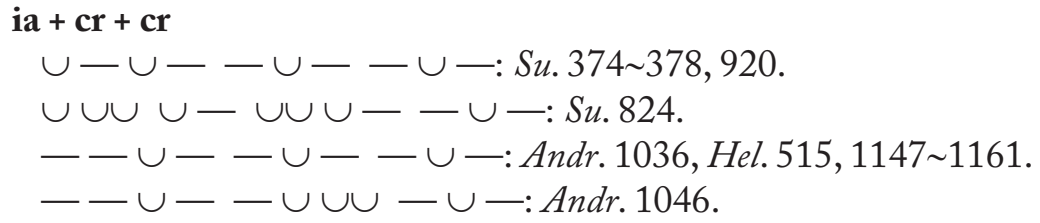

\section{ia + ch $+\mathbf{i a}$}

$\cup-\cup--\cup \cup-\cup-\cup-$ : Hi. 877, Su. 604, Or. 811 823, Rh. 242-3 253-4.

$\cup \cup \cup \cup-\backsim \cup \cup \cup-\cup-:$ El. 181-2 204-5.

\section{$\mathbf{b a}+\mathbf{c r}+\mathbf{i a}$}

$\cup---\cup-\cup-\cup-:$ Andr. 121 130, 295 303, †469† 476, Su. 600 610, 603 613, 620 628, 835, 1149, Herc. 408 425, Ph. 1724, IA 1497-8.

\section{$\mathbf{b a}+\mathbf{c r}+\mathbf{b a}$}

$\cup---\cup-\cup-\longrightarrow:$ Andr. 282 292, 470 477-8, 1199 1215, 1202-3 1217, Hec. 630, 639, Su. 606-7 616-7, 1141 1148, Herc. 388 402, Tr. 577 582, Ion 236, Hel.374, Or. 989, LA 1499.

\section{$\mathbf{b a}+\mathbf{i a}+\mathbf{b a}$}

$$
\cup--\cup-\cup-\cup-\longrightarrow: P h .298 .
$$

${ }^{278}$ With Diggle's supplement $\hat{\eta}<k \alpha \grave{l}>$, printed in the OCT. 

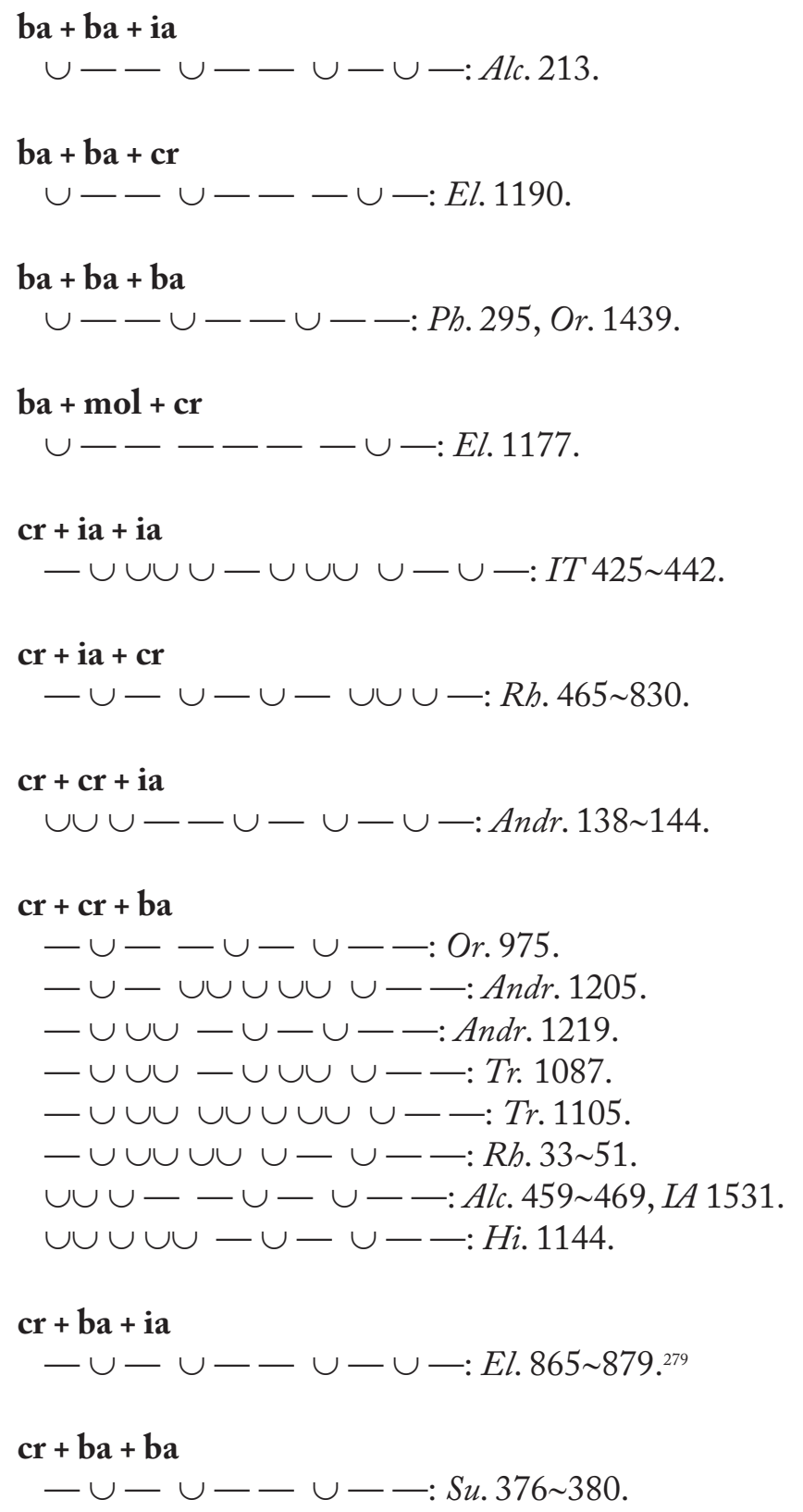

${ }^{279}$ As clausula to dactylo-epitrites, however, the catalectic analysis $-\cup-\cup-\cup \cup-$ $\cup-(\mathrm{tr}+\mathrm{pa}+\mathrm{cr})$ is tempting. 
Part I - Euripides' use of lyric metre

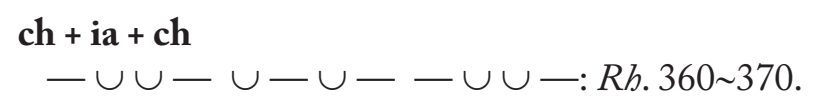

$$
\mathbf{c h}+\mathbf{c r}+\mathbf{b a}
$$

$-\cup \cup--\cup-\cup-\longrightarrow$ : Andr. 300 308, Su. 619 627, 836, 1126 1133, 1130 1137, †1144† 1151.

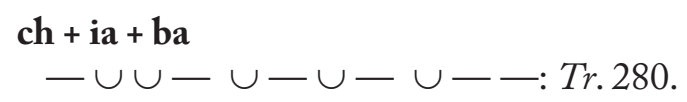

$\mathbf{m o l}+\mathbf{i a}+\mathbf{i a}$

$--\cup-\cup-\cup-\cup-$ :Med. 205.

$\mathbf{m o l}+\mathbf{b a}+\mathbf{i a}$

$-\smile-\cup-\backsim-\cup-$ IT $1255 \sim 1280$.

\section{4. Longer cola}

\section{4 bacchiacs}

$\cup--\cup--\cup--\cup-\longrightarrow$ : Ion 1446-7, Hel. 516, Ph. 1536, Or. $1294-5,1440 .{ }^{280}$

${ }^{280}$ See Parker (1997: 450) for more examples. 
PART II

Scansions 


\section{Introductory Note}

In the interest of clarity and convenience, an individual scansion is offered for each stanza in strophic pairs.

In indicating period-end $(||)$, I have preferred to err on the side of caution and signal it only when certain. 


\section{CYCLOPS}

Parodos (Cycl. 41-81)

Strophe 1

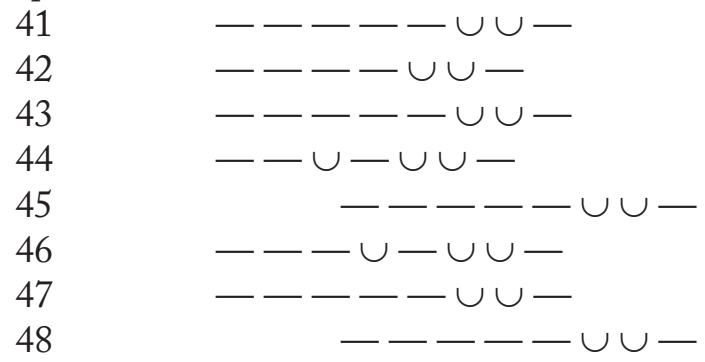

$$
\begin{array}{r}
\text { wil } \\
\text { hept } \\
\text { wil } \\
\text { hept } \int \\
\text { wil } \\
\text { wil } \\
\text { wil } \int \\
\text { wil }
\end{array}
$$

mesode

49

50

51

52

53

54
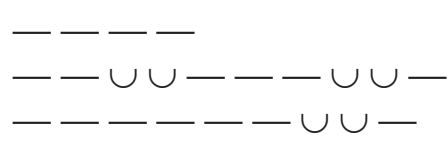

$\cup \cup-\cup \cup-\cup-$

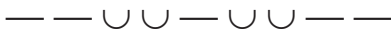

$\cup-\cup-\cup \cup-$ an $\|^{\mathrm{H}}$
2 an
2 an $\|^{\mathrm{H}}$
diom
prm
hept

$\sim$ antistrophe 1

55

56

57

58

59

60

61

62

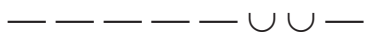

$----\cup \cup-$

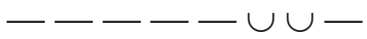

$\cup-\cup-\cup \cup-$
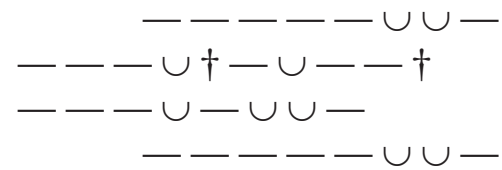

epode

63

64

65

67

66

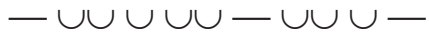

$--\cup-\cup \cup-$

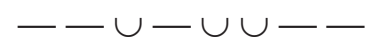

$----\cup \cup \cup-$

$--\cup-\cup \cup-$ wil

hept wil hept $\int$ wil ?

wil wil 

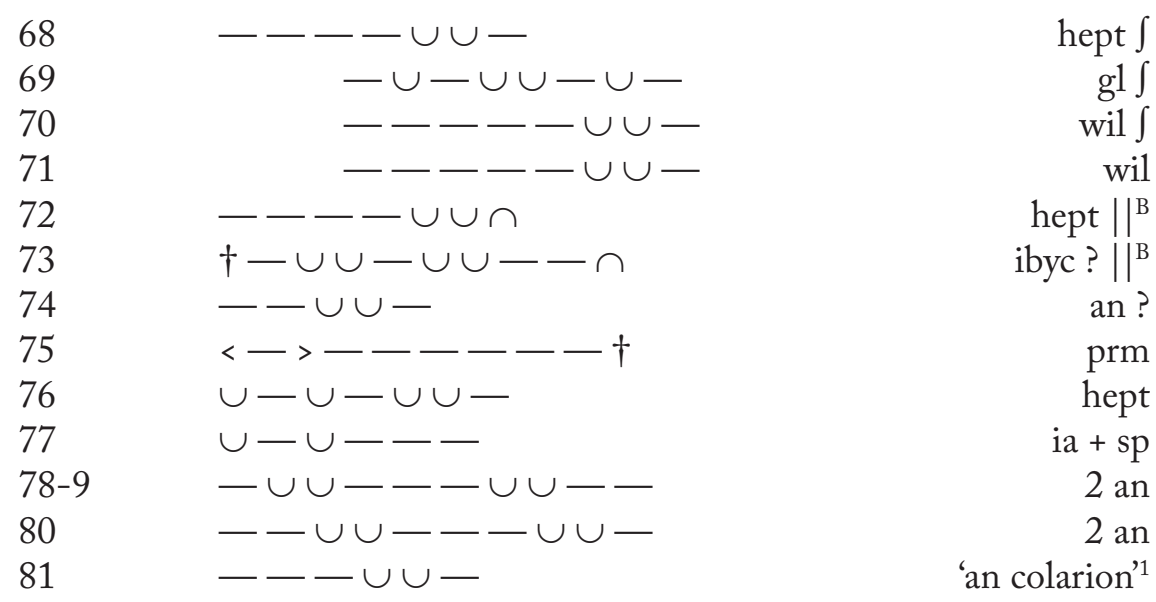

Cycl.356-374

Strophe

356

357

$358 \mathrm{a}$

$358 \mathrm{~b}$

359

360

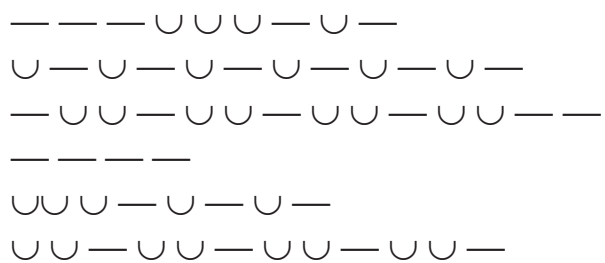

$?^{2}$

3 ia

$5 \mathrm{da}$

$2 \mathrm{sp}$

$1 \mathrm{k}$

2 an

mesode

361

362

363

$---\cup \cup$

$\cup-\cup-\cup-\cup-\cup-\cup-$

$\mathrm{mol}+\mathrm{cr}$

3 ia $\|$

$-\cup-\cup-\cup-\cup$

$2 \operatorname{tr}$

364

365

$-\cup-\cup-\cup-$

366-7

368-9

$\cup \cup-\cup \cup \dagger-\cup-\dagger$

$1 \mathrm{k}$

wil

2 ia

$\sim$ antistrophe

370

371

$\dagger----\cup---\cup-\dagger$

3 ia

373

$\cup-\cup-\cup-\cup-\cup-\cup-$

$5 \mathrm{da}$

${ }^{1}$ Called 'stumpf ausgehender Kurzvers' by Wilamowitz (1921: 225); see Parker (1997: 58). On the metre of 76-81, see Diggle (1994: 37-8). See above, p. 48.

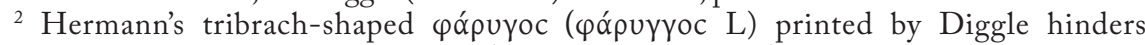
Seaford's attractive trochaic scansion (comm. Cycl., p. 174). Seaford himself proposes

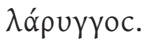




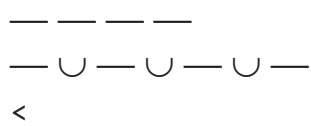

\section{Cycl.495-518}

\section{Strophe 1}

502

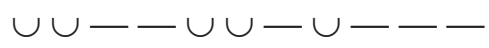

Strophe 2

$\mathrm{Kv}$.

503

$\cup \cup-\cup-\cup-$

anacr

504

$\cup \cup-\cup-\cup-$

anacr

505

$\cup \cup-\cup-\cup-$

anacr

506

$\cup \cup-\cup-\cup-$

anacr

507

$\cup \cup-\cup-\cup-$

anacr

508

$\cup \cup-\cup-\cup--$

anacr

509

$\cup \cup--\cup \cup--$

2 io

510

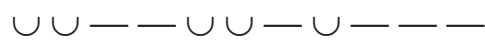

Strophe 3

Xo.

511

512

513

514

515

516

517

518

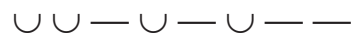

anacr

$\cup \cup-\cup-\cup-$

anacr

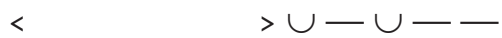

$\cup \cup \dagger-\cup-$

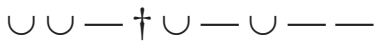

$\cup \cup-\cup-\cup-$

anacr

$\cup \cup--\cup \cup--$

2 io

2 io $^{\text {sync }}+\mathrm{mol}$

${ }^{3}$ Cf. Dale on $510(=502=518)$ : 'the final clausula ends in a molossus instead of the normal “trochaic” metron' (21968: 126). 
Cycl. 608-623

Xo.
608

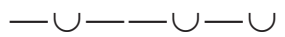
$\mathrm{cr}+\mathrm{tr}$
609
$-\cup-\cup-\cup-$
610-11

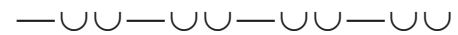
612

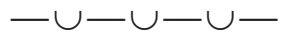
4 da
613-14

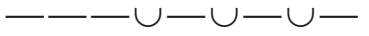
615-16

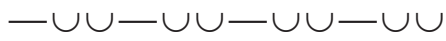
617

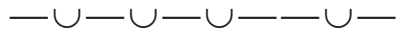
$\mathrm{sp}+\mathrm{lk}$
618
619
$-\cup \cup-\cup \cup-\cup \cup-$
620
$\cup-\cup-\cup-\cup-$
$4 \mathrm{da}$
$\mathrm{lk}+\mathrm{cr}$
$4 \mathrm{da}^{\text {cat }}$
2 ia
621

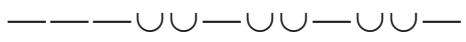
$5 \mathrm{da}^{\text {cat }}$
2 ia
622
$\cup-\cup-\cup-\cup-$
$\mathrm{sp}+\mathrm{lk}$
623

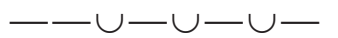
2 ia

\section{Cycl.656-662}

Xo.

656

$\cup \cup \cup---\cup \cup-$

wil $\int$

657

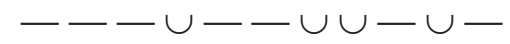

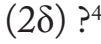

658

$---\cup \cup--$

ph

659

$-\cup--\cup-$

$2 \mathrm{cr}$

660

$\cup---\cup \cup-$

hept

661

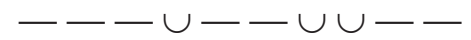

$(\delta+?)^{5}$

662

${ }^{4}$ Diggle's suggested redivisions with slightly altered word-order (cf. apparatus ad loc.) exempt

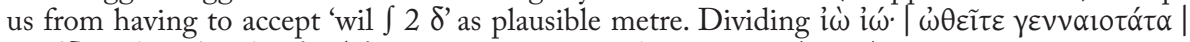

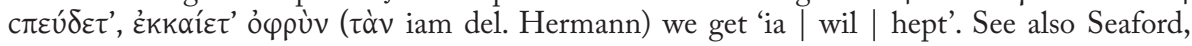
comm. Cycl., pp. 218-9. 59.

${ }^{5}$ For $-\cup \cup-$ interpreted as a 'syncopated dochmiac', see Hutchinson, comm. ScT, p. 


\section{ALCESTIS}

Parker's 2007 edition and commentary of Alcestis is invaluable on all problems concerning text and metre in the lyrics of this play. It should be noted, however, that her divisions differ considerably from Diggle's.

Parodos (Alc. 86-131)

Strophe $1 \sim$

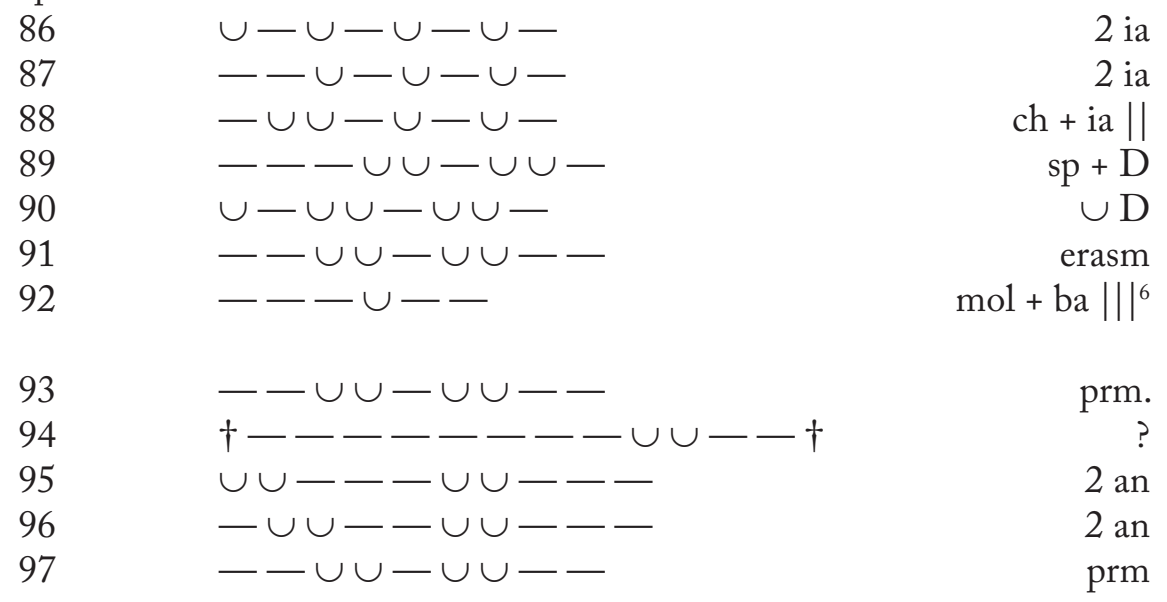

$\sim$ antistrophe 1

98

$\cup-\cup-\cup-\cup-$

99

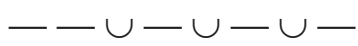

100

$-\cup \cup-\cup-\cup-$

101

102

$--\backsim \cup \cup \cup \cup$

103

$\cup-\cup \dagger \cup-\cup \cup$

2 ia

2 ia

104

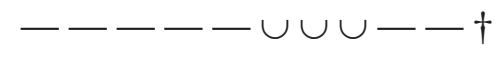

ch + ia ||

$\mathrm{sp}+\mathrm{D}$

$\cup \mathrm{D}$

$\mathrm{mol}+\mathrm{ba} \| \mid$

105

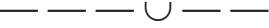

prm

106

$$
\begin{aligned}
& --\cup \cup-\cup \cup-- \\
& \dagger \cup \cup--\dagger
\end{aligned}
$$

${ }^{6}$ See above, p. 120, n. 263. 
Part II - Scansions

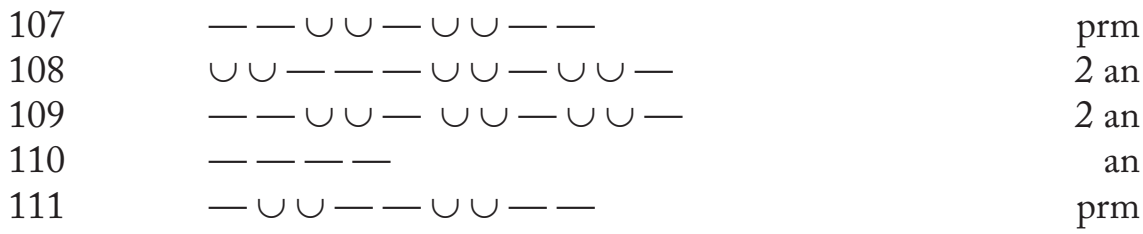

Strophe $2^{7}$

112

113

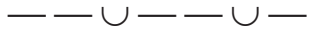

$\mathrm{ia}+\mathrm{cr}$

114

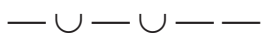

ith

D contr

115

$---\cup \cup-$

D

116

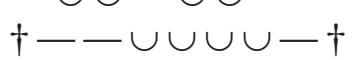

117

118

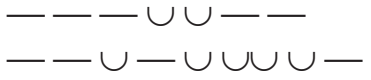

119

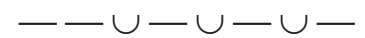

120-1

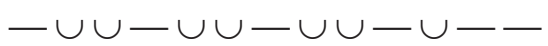

?

ph

2 ia

2 ia

prax

$\sim$ antistrophe 2

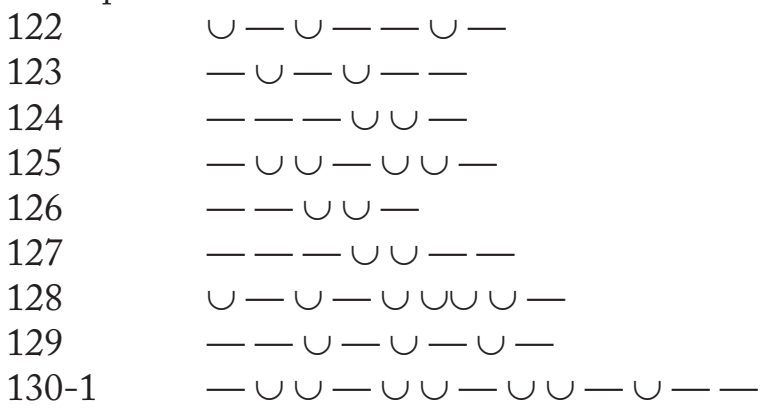
$\mathrm{ia}+\mathrm{cr}$ ith $\mathrm{D}^{\text {contr }}$ D an $\mathrm{ph}$ 2 ia 2 ia prax

First Stasimon (Alc.213-237)

Strophe

$\begin{array}{ll}213 & \cup--\cup--\cup-\cup- \\ 214 \mathrm{a} & \cup-\cup-\cup-\cup- \\ 214 \mathrm{~b} & -\cup-\cup-\cup- \\ 215 \mathrm{a} & <--> \\ 215 \mathrm{~b} & \dagger--\cup \cup \dagger-\cup-\cup \cap \\ 216 & -\cup \cup---\cup- \\ 217 & -\cup \cup-\cup-- \\ 218 & -\cup-\cup--\cup-\cup-\end{array}$

$\delta+h \delta$

2 ia

$1 \mathrm{k}$

ch + ia ar || $h \delta+h \delta$

\footnotetext{
${ }^{7}$ See above, pp. 27-9.
} 
219

220

$221 \mathrm{a}$

$221 \mathrm{~b}$

222

223

224

225 $\cup-\cup-\cup-\cap$

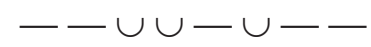

$--\cup-$

$--\cup-\cup-\cup---\cup-$

$\cup-\cup-\cup-\cup-\cup-$

$\dagger-\cup--\dagger--$

$\cup-\cup \cup-\cup \cup-\cup-$

$\cup \cup-\cup \cup-\cup--$ ia + ba $\|^{\text {Bsa }}$

hag $\|^{\text {Hsa }}$

ia ||

3 ia

$2 \mathrm{ia}+\mathrm{ba}$

$\cup$ ibyc $^{8}$

diom

$\sim$ antistrophe

226

$227 \mathrm{a}$

$\cup-<\quad>$

$227 \mathrm{~b}$

$228 \mathrm{a}$

$228 \mathrm{~b}$

$229 \mathrm{a}$

$229 \mathrm{~b}$

230

231

232

$233 \mathrm{a}$

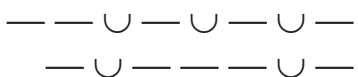

2 ia $\int^{?}$

$1 \mathrm{k}$

ch + ia $\|^{\mathrm{B}}$

$\mathrm{ch}+\mathrm{ia}^{9}$

$-\cup \cup-\cup-\cup \cap$

$-\cup \cup-\cup-\cup-$

$-\cup \cup-\cup--$

ar 1

$\mathrm{h} \delta+\mathrm{h} \delta$

$-\cup-\cup--\cup-\cup-$

$\cup-\cup-\cup-\cap$

$\cup-\cup \cup-\cup-$

$233 \mathrm{~b}$

$\cup-\cup-$

234

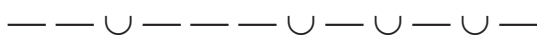

$\cup-\cup-\cup-\cup-\cup--$

235

236

$--\cup--$

$\cup-\cup \cup-\cup \cup-\cup-$

237

$\cup \cup-\cup \cup-\cup--$ $\mathrm{ia}+\mathrm{ba}\|\|^{\mathrm{Bsa}}$ hag $\|$ Hsa ia $\|^{\mathrm{H}}$ 3 ia $2 \mathrm{ia}+\mathrm{ba}$ pe ibyc diom

Alcestis' Monody (Alc. 244-263)

Strophe 1

244

$-\cup \cup-\cup \cup-\cup-$

$245 \mathrm{a}$

$-\cup \cup-\cup-$

ibyc

$245 b$

$-\cup \cup-\cup-$

$\operatorname{dod} \int$

ar

$\sim$ antistrophe 1

248

$-\cup \cup-\cup \cup-\cup-$

249 a

$-\cup \cup-\cup-$

ibyc

$249 \mathrm{~b}$

${ }^{8}$ See above, p. 74.

${ }_{9}^{9}$ See above, pp. 74-5; 116 (n. 251). 
Strophe 2

252

$\cup-\cup-\cup \cup-\cup \cup$

$\wedge$ ssdd

253

$-\backsim \cup \cup-\cup--$
$\cup-\cup \cup ル-\backsim \cup$

hag

254

$2 \mathrm{ia}^{10}$

255

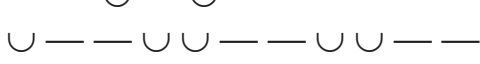

$\mathrm{ia}+\mathrm{ba}$

$256 \mathrm{a}$

$\cup--\cup \cup--\cup \cup-$

$\mathrm{ph}^{\text {+ch }}$

$256 \mathrm{~b}$

$-\cup \cup-\cup--$

ar

$\sim$ antistrophe 2

259

$\cup-\cup-\cup \cup-\cup \cup-$

$\wedge$ ssdd

260

$\cup-\cup \cup-\cup-$

hag ||

261

$\cup-\cup \cup \cup \cup-\cup-$

2 ia

262

$\cup-\cup-\cup--$

ia + ba

$263 \mathrm{a}$

$\cup--\cup \cup--\cup \cup-$

$263 b$

$-\cup \cup-\cup-$

$\mathrm{ph}^{+\mathrm{ch} f}$

ar

epode

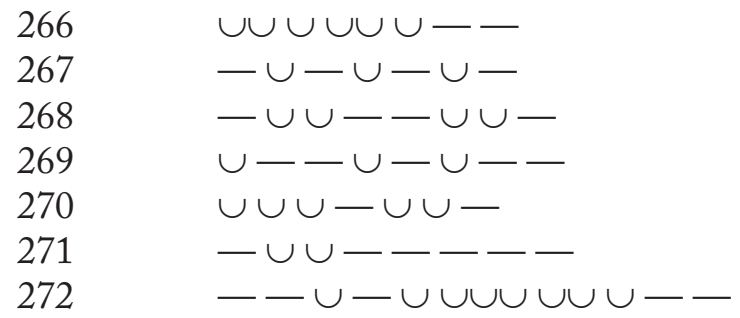

ith ||

$1 \mathrm{k}$

$\mathrm{ch}+\mathrm{ch}$

$\delta+\mathrm{ba}^{11}$

hex? ${ }^{12} \|^{\mathrm{H}}$

prm

2 ia + ba

Child's Monody (Alc. 393-415) $)^{13}$

Strophe

393

394

$\cup--\cup--\cup-\cup-$

$\delta+h \delta$

395

$\cup-\cup-\cup-\cup-$

2 ia

396-7

$\cup \cup \cup-\cup-$

$\delta$

398

$\cup \cup-\cup \cup-\cup \cup-\cup \cup-\cdots$

399

$\dagger \cup \cup \cup \cup \cup \cup \cup \cup-\dagger$

$\mathrm{A}+\mathrm{sp}$

$\cup \cup \cup-\cup-$

400

$\cup \cup-\cup \cup-\cup--\cup-\cup-$

401

$\cup-\cup---$

402

$\dagger \cup--\cup-\cup \cup-\cup-$

\footnotetext{
${ }^{10}$ See above, p. 119 (n. 259).

${ }^{11}$ See above, p. 30 (n. 29).

${ }^{12}$ Or 'reversed dodrans'? See Parker (comm. Alc., p. 105) and above, p. 111.

${ }^{13}$ See above, p. 30 (n. 31).
} 
antistrophe

\begin{tabular}{|c|c|c|}
\hline 406 & $\cup \cup \cup-\cup--\cup-\cup-$ & $\delta+h \delta$ \\
\hline 407 & $\cup-\cup-\cup-\cup-$ & 2 ia \\
\hline 408 & $\cup \cup \cup-\cup-$ & $\delta$ \\
\hline $409-10$ & $\cup \cup-\cup \cup-\cup \cup-\cup \cup---$ & $A+s p$ \\
\hline $411 \mathrm{a}$ & $<$ & \\
\hline $411 b$ & $>-\cup \cap$ & \\
\hline 412 & $\cup \cup-\cup \cup-\cup--\cup-\cup--$ & $\mathrm{T}+\mathrm{ith}$ \\
\hline 413 & $\cup-\cup---$ & $\mathrm{ia}+\mathrm{sp}$ \\
\hline 414 & $-\cup \cup-\cup \cup-\cup \cup-\cup-$ & ddds -14 \\
\hline 45 & $-\cup \cup-\cup-\cap$ & \\
\hline
\end{tabular}

Second Stasimon (Alc. 435-475)

Strophe 1
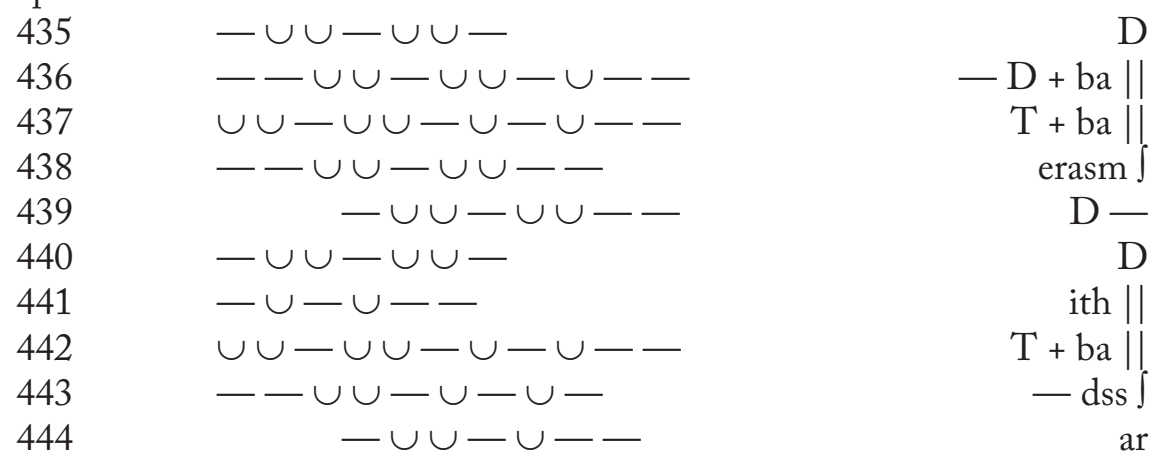

$\sim$ antistrophe 1

445

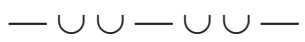

446

447

448

449

450

451

452

453

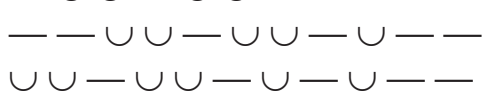

454

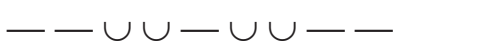

$-\mathrm{D}+\mathrm{ba} \|$
$\mathrm{T}+\mathrm{ba} \|$
erasm

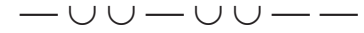

$\mathrm{D}-$ $\mathrm{D}$

ith $\|$
$\mathrm{T}+\mathrm{ba} \|$

$-\mathrm{dss} \int$

${ }^{14}$ See above, p. 74. 
Strophe $2^{15}$

455

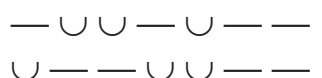

456

$\cup--\cup \cup-$

457

$\cup \cup-\cup \cup-\cup--$

458

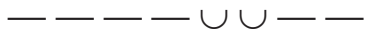

459

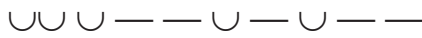

460

$\cup \cup-\cup \cup-\cup-\cup-$

$461 \mathrm{a}$

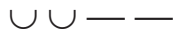

$461 \mathrm{~b}$

$\cup-\cup-\cup \cup-\cup-\cup-$

$\wedge \mathrm{S}$

462

463

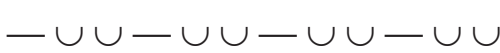

464

$-\cup \cup-\cup \cup-\cup \cup-\cup \cup$

$465 \mathrm{a}$

$\cup-\cup--\cup-$

$465 \mathrm{~b}$

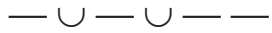

$\sim$ antistrophe 2

466

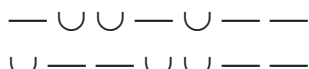

467

$\cup-\backsim \cup \cup-\longrightarrow$

$468 \mathrm{a}$

$\cup \cup-\cup \cup-\cup-$

$\mathrm{ph}$

diom

$468 \mathrm{~b}$

469

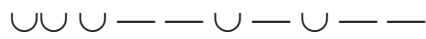

470

$\cup \cup-\cup \cup-\cup-\cup-$

$471 \mathrm{a}$

$\cup \cup--$

$471 b$

$\cup-\cup-\cup \cup-\cup-\cup-$

472

473

$-\cup \cup-\cup \cup-\cup \cup-\cup \cup$

474

$-\cup \cup-\cup \cup-\cup \cup-\cup \cup$

$475 \mathrm{a}$

$\cup-\cup--\cup-$

$475 b$

$-\cup-\cup-$

Third Stasimon (Alc. 568-605)

Strophe 1

568-9

$570-1$

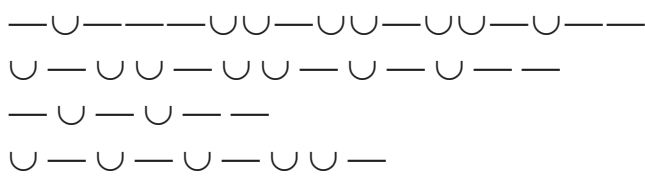

$\mathrm{e}-\operatorname{prax}^{17} \| \mathrm{Ba}$

572

573

$\cup-\cup-\cup-\cup \cup-$

$\cup \mathrm{D} \cup \mathrm{e}-$

ith $\|$

$\cup \mathrm{e} \cup \mathrm{d}$

574

\footnotetext{
${ }^{15}$ See above, p. 25.

${ }^{16}$ See above, p. 87 (with n. 183).

${ }^{17}$ For the label 'praxillean' applied to 568-9 578-9, see Diggle (1994: 395).
} 
$\sim$ antistrophe 1

578-9

$580-1$

582

583

584

585

586

587

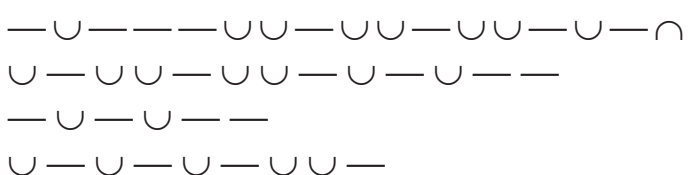

$-\cup-$

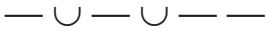

$-\cup-\cup \cup-\cup-$

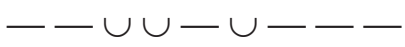

$---\cup \cup--$

Strophe 2

588

589

590

591

592

593

594

595

596

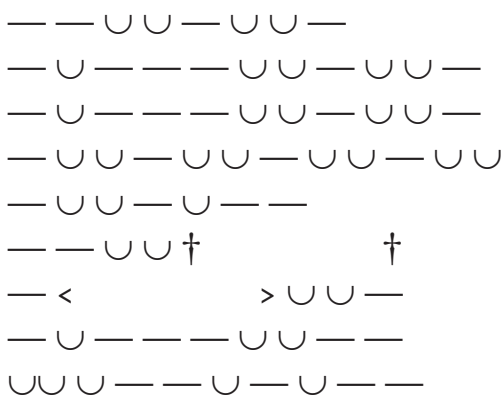

$$
\begin{array}{r}
-\mathrm{D} \\
\mathrm{e}-\mathrm{D} \\
\mathrm{e}-\mathrm{D} \\
4 \mathrm{da} \\
\operatorname{ar} \|^{\mathrm{Ha}} \\
? \\
? \\
\mathrm{e}-\mathrm{d}- \\
\mathrm{cr}+\mathrm{ith}
\end{array}
$$

$\sim$ antistrophe 2

597

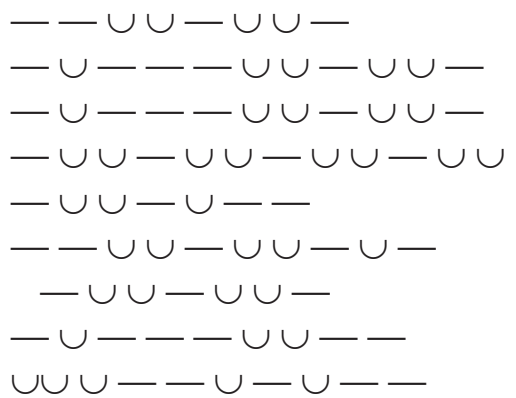

598

599

600

601

602

603

604

605

\footnotetext{
${ }^{18}$ See above, p. 112 (with n. 241).
} 


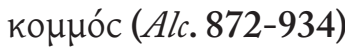

Strophe 1

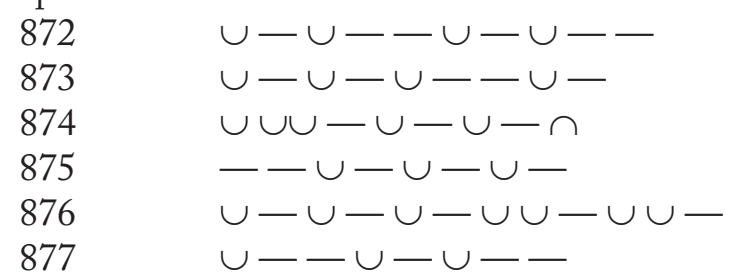

$$
\begin{array}{r}
i a+i t h \\
i a+\delta \\
\delta+b a \\
2 \text { ia } \\
\cup s \cup D \\
\delta+b a
\end{array}
$$

$\sim$ antistrophe 1

889

890

891

892

893

894 $\cup-\cup--\cup-\cup--$

$\cup-\cup-\cup--\cup-$

$\cup \cup \cup-\cup-\cup-\cap$

$--\cup-\cup-\cup \cap$

$\cup-\cup-\cup-\cup \cup-\cup \cup-$

$\cup--\cup-\cup-\cdots$ ia + ith ia $+\delta$

$\delta+\mathrm{ba}$

2 ia

$\cup \mathrm{s} \cup \mathrm{D}$

$\delta+\mathrm{ba}$

Strophe 2

903

$\cup-\cup-$

904

$-\cup \cup-\cup \cup-\cup \cup-$

905

$\cup-\cup-\cup-$

906

907-8

$\cup \cup----$

909

$\cup \cup \cup \cup \cup \cup \cup \cup$

910

$\cup \cup-\cup \cup-$

911

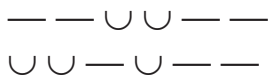

$\sim$ antistrophe 2

926

$\cup-\cup-$

927

928

$-\cup \cup-\cup \cup-\cup \cup-$

$\cup-\cup-\cup-$

929

$\cup \cup---$

930-1

932

$\cup \cup \cup \cup \cup \cup \cup \cup \cup \cup-$

933

934

$\cup \cup-\cup \cup-$

$-\leftarrow \cup \cup--$

$\cup \cup-\cup--$

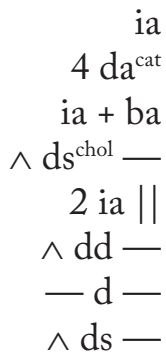
$4 \mathrm{da}^{\text {cat }} \int$ $\mathrm{ia}+\mathrm{ba}$ $\wedge \mathrm{ds}^{\mathrm{chol}}$ 2 ia $\|$ $\wedge \mathrm{dd}-$ $-\mathrm{d}-$ $\wedge \mathrm{ds}-$

Fourth Stasimon (Alc.962-1005)

Strophe 1

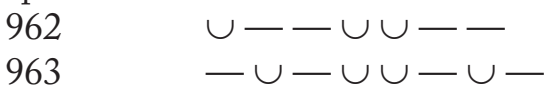


964

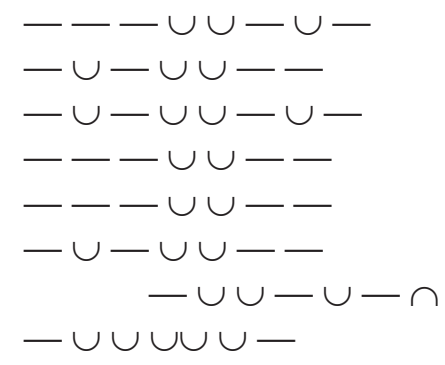

965

966

967

968

969

970

971

$-\cup \cup-\cup--$

$\sim$ antistrophe 1

973

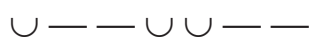

974

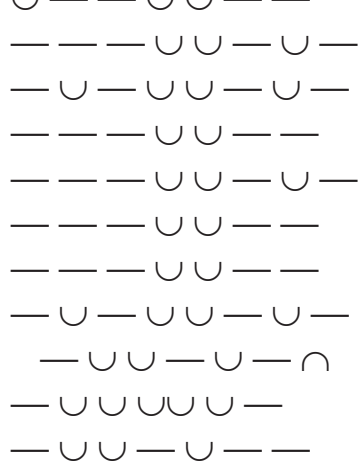

Strophe 2

984-5

$-\cup \cup--\cup \cup--\cup \cup---$

986-7

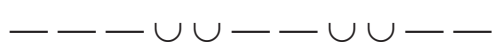

988

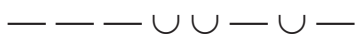

989

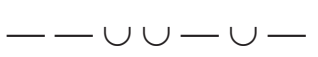

990

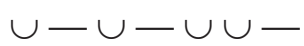

991

992

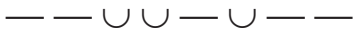

993

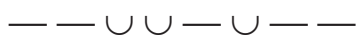

994
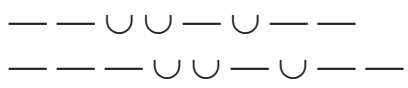

$3 \mathrm{ch}+\mathrm{sp}^{19}$ $\mathrm{ph}^{\text {+ch }}$

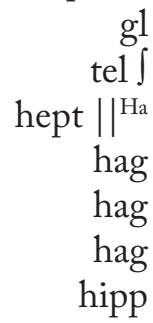

$\sim$ antistrophe 2

995-6

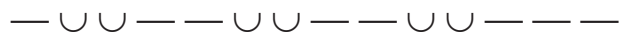

997-8

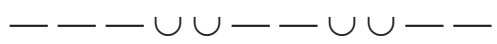

$3 \mathrm{ch}+\mathrm{sp}$

999

1000

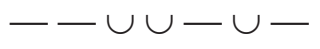

1001

\footnotetext{
${ }^{19}$ See above, p. 115.
} 
Part II - Scansions

1002

$$
\begin{array}{ll}
1002 & --\cup \cup-\cup-- \\
1003 & --\cup \cup-\cup-- \\
1004 & --\cup \cup-\cup-- \\
1005 & ---\cup \cup-\cup--
\end{array}
$$$$
1004-\quad-\cup \cup-\cup-
$$ 
$\mathrm{M \eta}$.

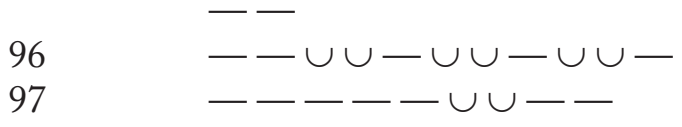

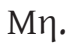

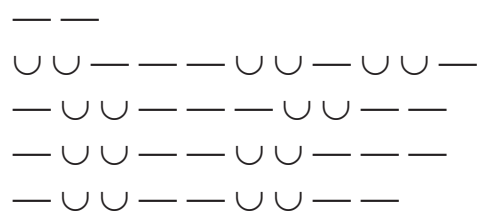

Parodos (Med.131-212)

XOPOC

134-5 $-\cup \cup-\cup \cup-\cup \cup-\cup \cup$

$136-\cup \cup-\cup \cup-\cup \cup-\cup \cup$

137

$-\cup \cup-\cup \cup$ $2 \mathrm{da}$

138

$\cup--\cup \cup-\cup--$

$\mathrm{M \eta}$.

Strophe 

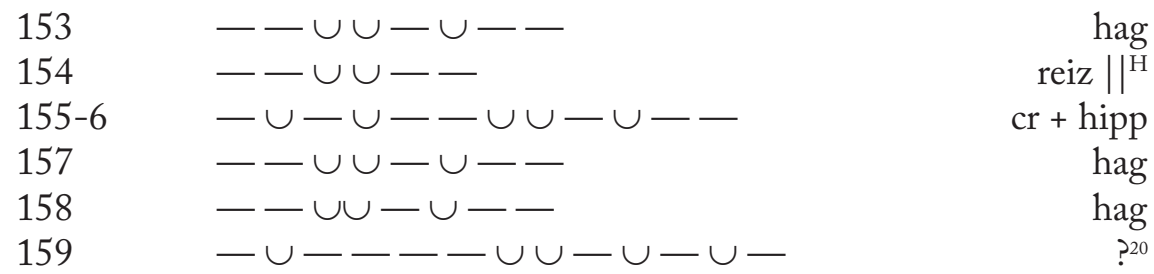

$\mathrm{M \eta}$.

160

$-\cup \cup-\cup \cup-\cup \cup-\cup \cup$

2 an

161

$-\cup \cup-\leftarrow \cup \cup--$

2 an

162

$--\cup \cup--\cup \cup--$

163

$\cup \cup-\cup \cup---\cup \cup-$

2 an

2 an

164

$-\smile \cup \cup-\cup \cup-\cup \cup-$

2 an

165

$-\cup \cup----\cup \cup-$

166

$-\cup \cup-\cup \cup-\cup \cup-$

2 an

2 an

167

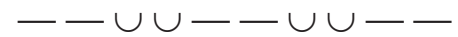

2 an

$\sim$ antistrophe

173

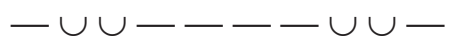

2 an

174

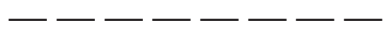

2 an

175

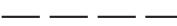

an

176

177

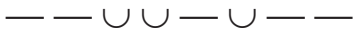

178

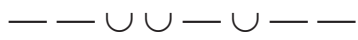

179

$--\cup \cup-\cup-$

180

$\cup-\cup \cup$

181

$-\cup-\cup--\cup \cup-\cup--$

182

$--\cup \cup-\cup--$

183

$--\cup \cup-\cup--$

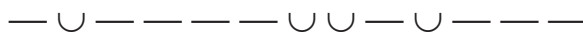

205

206

$--\backsim \cup \cup-\cup-\cup-$

207

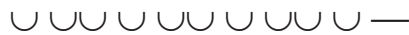

208

$\cup-\cup-\cup \cup-\cup \cup-$

209

210

211

212

$\cup \cup-\cup \cup \cup-\cup$

$-\cup \cup-\cup$

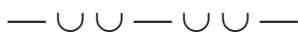

$\cup \cup \cup \cup \cup \cup \cup-\cup-$

2 ia

ph

${ }^{20}$ Cf. above, p. 114. 


\section{First Stasimon (Med.410-445)}

Strophe $1 \sim$

$$
\begin{array}{llr}
410 & \cup-\cup \cup-\cup \cup---\cup- & \cup \mathrm{D}-\mathrm{e}- \\
411 & -\cup---\cup \cup-\cup \cup- & \mathrm{e}-\mathrm{D} \|^{\mathrm{H}} \\
412-3 & -\cup \cup-\cup \cup---\cup- & \mathrm{D}-\mathrm{e} \\
414 & -\cup \cup-\cup \cup-- & \mathrm{D}- \\
415-6 & -\cup---\cup \cup-\cup \cup---\cup & \mathrm{e}-\mathrm{D}-\mathrm{e}-\|^{\mathrm{HBa}} \\
417-8 & -\cup---\cup---\cup- & \mathrm{e}-\mathrm{e}-\mathrm{e} \|^{\mathrm{H}} \\
419-20 & -\cup \cup-\cup \cup---\cup-v- & \mathrm{D}-\mathrm{e}+\mathrm{ba}
\end{array}
$$

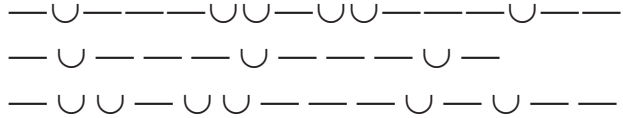

$\sim$ antistrophe 1

421-2

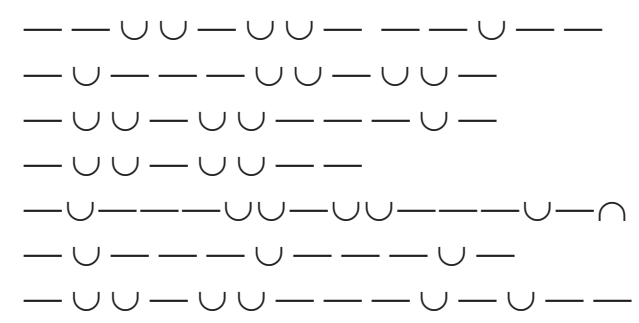

$$
\begin{array}{r}
-\mathrm{D} \mid-\mathrm{e}- \\
\mathrm{e}-\mathrm{D} \|{ }^{\mathrm{Hs}} \\
\mathrm{D}-\mathrm{e} \\
\mathrm{D}-
\end{array}
$$

424

425

426-7

428-9

$430-1$

$-\cup \cup-\cup \cup---\cup-\cup--$

$\mathrm{e}-\mathrm{D}-\mathrm{e}-\|^{\mathrm{HBs}}$ $\mathrm{e}-\mathrm{e}-\mathrm{e} \|{ }^{\mathrm{Hs}}$

$\mathrm{D}-\mathrm{e}+\mathrm{ba}$

Strophe 2

432

$\cup-\cup--\cup \cup-\cup--$

433-4

$-\cup \cup-\cup \cup-\cup \cup-\cup \cup-\cup-$

435

$--\cup \cup-\cup-$

436

$--\cup \cup-\cup-$

$437 \mathrm{a}$

$437 \mathrm{~b}$

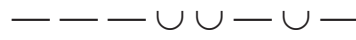$$
-\cup-\cup \cup-\cup-
$$

$\mathrm{ia}+\mathrm{ar}$ $\operatorname{prax} \|^{21}$

438

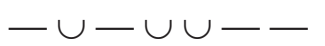

tel

tel $\int$ gl I gl I $\mathrm{ph}$

$\sim$ antistrophe 2

439

$\cup-\cup--\cup \cup-\cup--$

440-1

$-\cup \cup-\cup \cup-\cup \cup-\cup \cup-\cup-$ ia + ar

442

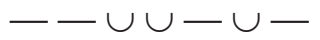

prax ||

443

$--\cup \cup-\cup-$

tel

$444 \mathrm{a}$

$---\cup \cup-\cup-$

$444 \mathrm{~b}$

$---\cup \cup-\cup-$

tel $\int$

gl $\int$

445

${ }^{21}$ See above, p. 74. 
Second Stasimon (Med.627-662)

Strophe 1

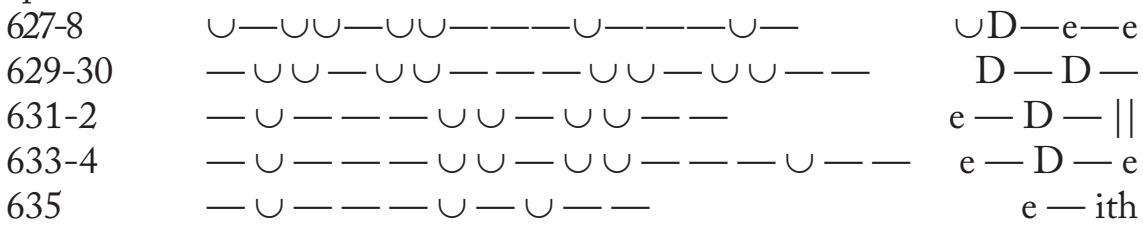

$\sim$ antistrophe 1

636-7

638-9

640-1

642-3

644

Strophe 2

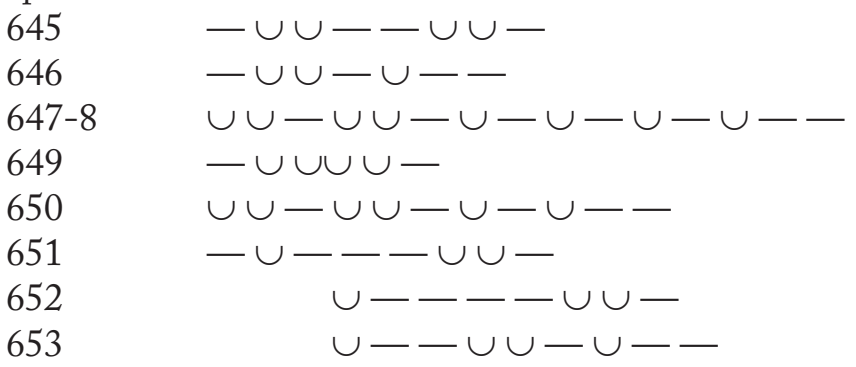

$\sim$ antistrophe 2

654

655

656-7

658

659

660

661

662

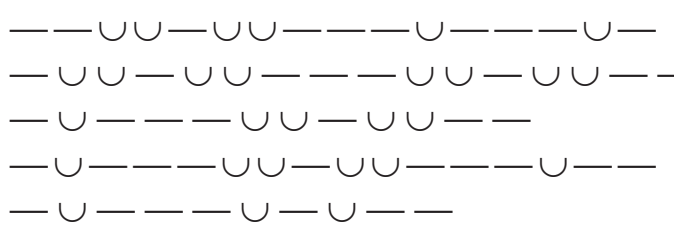

$-\mathrm{D}-\mathrm{e}-\mathrm{e}$

$\mathrm{D}-\mathrm{D}-$

$\mathrm{e}-\mathrm{D}-$

$\mathrm{e}-\mathrm{D}-\mathrm{e}-$ $\mathrm{e}-\mathrm{ith}$

$\mathrm{ch}+\mathrm{ch}$ ar $\|$ diom + ith ho? II $\mathrm{T}+\mathrm{ba}$ wil I wil I hipp $\mathrm{ch}+\mathrm{ch}$ ar diom + ith ho ? II $\mathrm{T}+\mathrm{ba}$ wil wil hipp

\section{Third Stasimon (Med. 824-865)}

Strophe 1

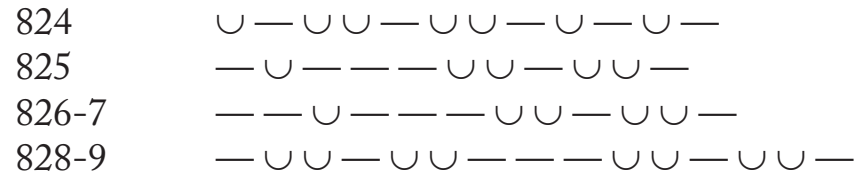

$$
\begin{array}{r}
\cup \mathrm{D} \cup \mathrm{e} \\
\mathrm{e}-\mathrm{D} \\
-\mathrm{e}-\mathrm{D} \\
\mathrm{D}-\mathrm{D}
\end{array}
$$


830-1

832-3

834

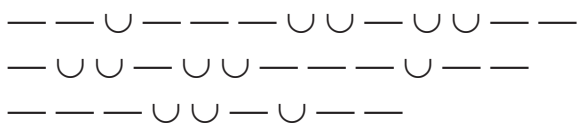

$\sim$ antistrophe 1

835

836-7

838-9

840

841-2

843-4

845

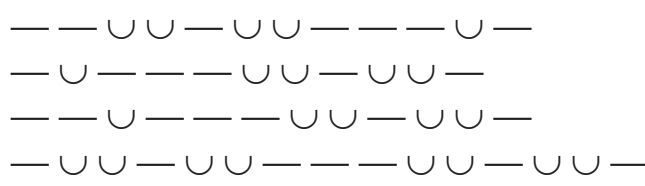

$--\cup--\backsim \cup \cup-\cup \cup$

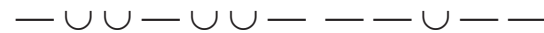

$--\backsim \cup \cup-\cup-$
$-\mathrm{e}-\mathrm{D}-$
$\mathrm{D}-\mathrm{e}-$

$-\mathrm{D}-\mathrm{e}$

$\mathrm{e}-\mathrm{D}$

$-\mathrm{e}-\mathrm{D}$

$D-D$

$-\mathrm{e}-\mathrm{D}$

$\mathrm{D}-\mathrm{e}-$ hipp<smiles>[2H][CH]</smiles>
dod ith hag hag II tel hag hag tel $\mathrm{ad}$

$\cup \mathrm{D}$ dod ith hag hag || tel hag hag tel $\mathrm{ad}$

${ }^{22}$ See above, p. 73 (with n. 153). 
Fourth Stasimon (Med.976-1001)

Strophe 1

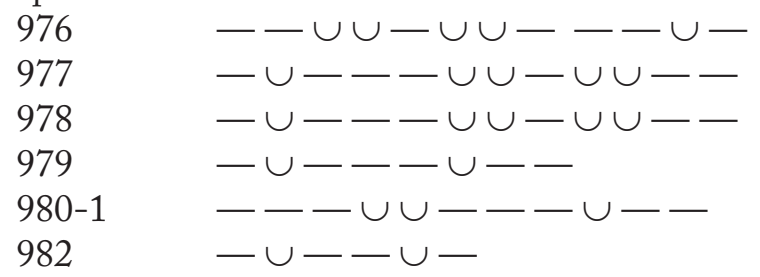

$$
\begin{array}{r}
-\mathrm{D}-\mathrm{e} \\
\mathrm{e}-\mathrm{D}- \\
\mathrm{e}-\mathrm{D}- \\
\mathrm{e}-\mathrm{e}- \\
\mathrm{D}{ }^{\mathrm{contr}}-\mathrm{e}- \\
2 \mathrm{cr}
\end{array}
$$

$\sim$ antistrophe 1

983

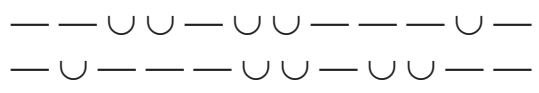

$$
\begin{array}{r}
-\mathrm{D}-\mathrm{e} \\
\mathrm{e}-\mathrm{D}- \\
\mathrm{e}-\mathrm{D}- \\
\mathrm{e}-\mathrm{e}- \\
\mathrm{D}^{\mathrm{contr}}-\mathrm{e}- \\
2 \mathrm{cr}
\end{array}
$$

984

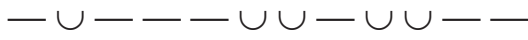

986

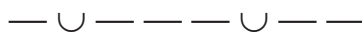

987-8

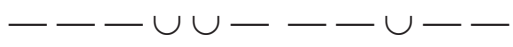

989

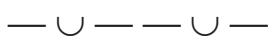

Strophe 2

990-1

$\cup-\cup \cup-\cup \cup-\cup-\cup-\cup-$

992

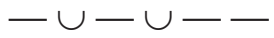

993

$\cup \cup-\cup \cup-\cup \cup-\cup \cup-$

erasm + ith

994

$\cup-\cup \cup-\cup \cup-$

995

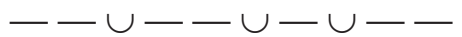
ith

A

ia + ith

$\sim$ antistrophe 2

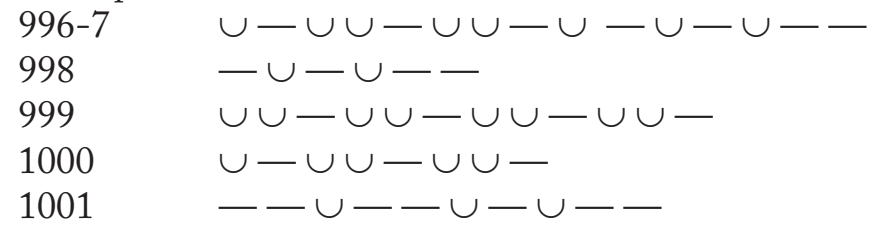
erasm + ith ith A $\cup \mathrm{D}$ ia + ith

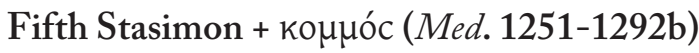

Strophe 1

1251

1252

1253

1254

1255

1256

1257

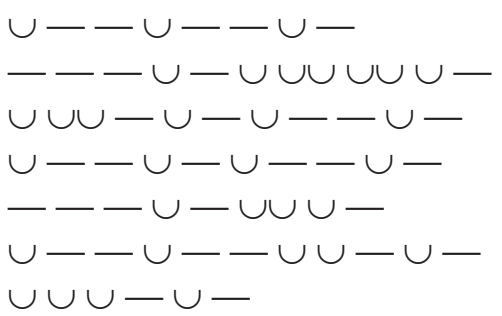

$b a+\delta$

$2 \delta$

$2 \delta$

$2 \delta$

$\mathrm{mol}+\delta$

$2 \delta$ 
1258

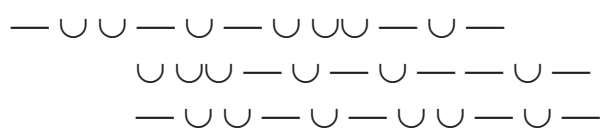

1260

$\sim$ antistrophe 1

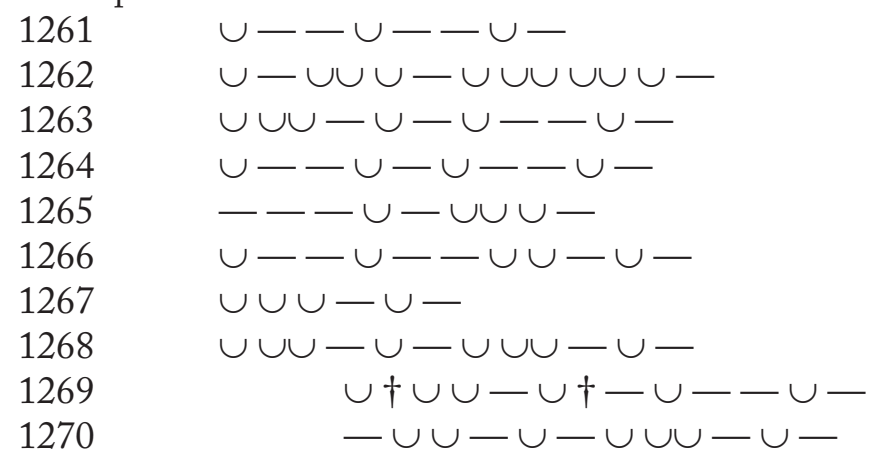

Strophe 2

Xo.

$$
\begin{array}{ll}
1273 & \cup--\cup-\cup--\cup- \\
1274 & \cup--\cup-\cup \cup \cup-\cup-
\end{array}
$$

$\Pi \alpha .^{\alpha}$

1271

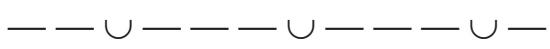

3 ia

$\Pi \alpha .^{\beta}$

1272

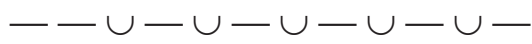

3 ia

Xo.

1275

$\cup--\cup-\cup--\cup-$

1276

$\cup--\cup-$

$\Pi \alpha{ }^{\alpha}$

1277

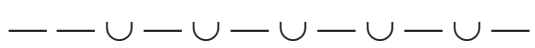

3 ia

$\Pi \alpha .^{\beta}$

1278

$--\cup---\cup-\cup-\cup-$

3 ia

Xo.

1279

$\cup--\cup-\cup \cup \cup-\cup-$

$2 \delta \int$

1280

$\cup--\cup-$

$\delta$

$1281 \mathrm{a}$

$\cup \cup \cup \cup \cup \cup \cup-\cup-$

2 ia

$1281 \mathrm{~b}$

$\cup--\cup-$

$\sim$ antistrophe 2

1282

$\cup--\cup-\cup--\cup-$

$2 \delta$

1283

$\cup--\cup-\cup \cup \cup-\cup-$

$2 \delta$

1284 
Part II - Scansions

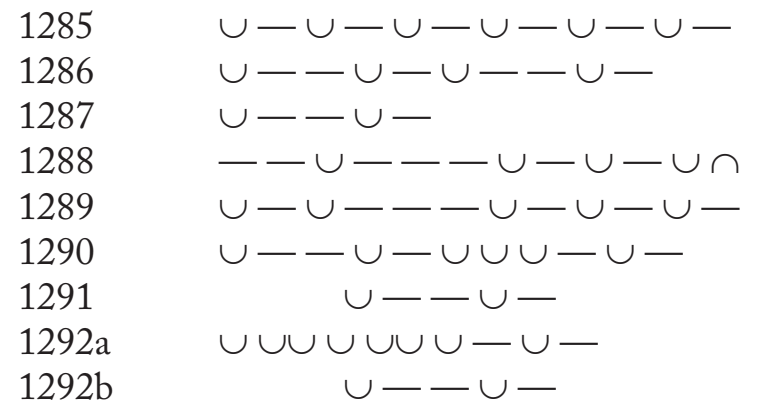

3 ia
$2 \delta$
$\delta \|^{\mathrm{H}}$
$3 \mathrm{ia} \|^{\mathrm{B}}$
3 ia
$2 \delta$
2 ia $\int_{\delta}$
$\delta$




\section{Heraclidae}

Parodos (Hcld. 75-108)

Strophe

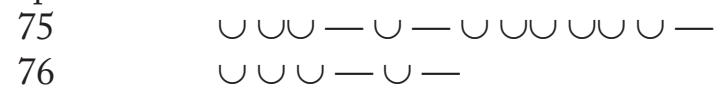

Xo.

80

$\cup-\cup---\cup-\cup-\cup-$

3 ia

81

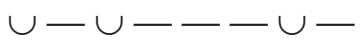

2 ia

82

$\cup-\cup \cup \cup-\cup-$

83

$\cup \cup \cup-\cup-\cup-\cdots-$

Xo.

86

$\cup \cup \cup \cup \cup \cup-\cup--\cup-$

87

$\cup--\cup-$

Xo.

90

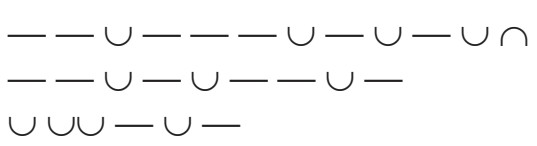

3 ia $\|^{\mathrm{BH}}$ ia $+\delta$

92

$\cup \cup \cup-\cup-$ $\delta$

$\sim$ antistrophe

Xo.

95

$\cup \cup \cup-\cup-\cup \cup \cup \cup \cup \cup-$ $2 \delta$

96

$\cup \cup \cup-\cup-$

Хo.

101

$--\cup---\cup---\cup \cap$

3 ia $\|^{\mathrm{B}}$

102

$--\cup---\cup-$

$\cup-\cup \cup \cup-\cup-$

2 ia $\int$

103

$\cup \cup \cup \cup-\cup--\cup-$

$\mathrm{ia}+\mathrm{cr}$

104

Xo.

107

$\cup \cup \cup \cup \cup \cup-\cup--\cup-$

$2 \delta \int$

108

$\cup--\cup$ 
First Stasimon (Hcld.353-380)

Strophe

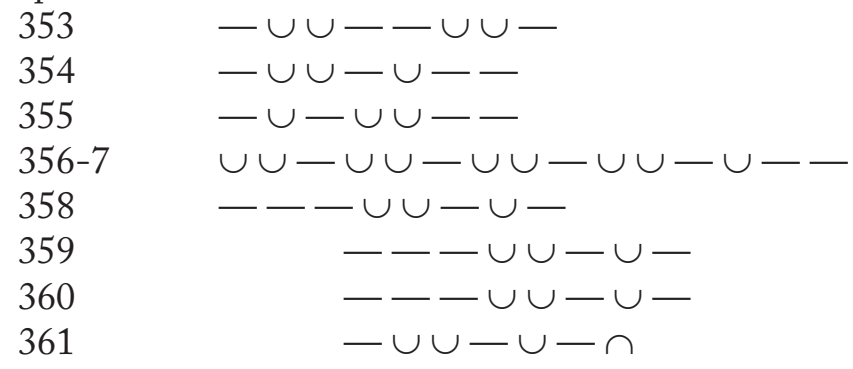

$\mathrm{ch}+\mathrm{ch}$

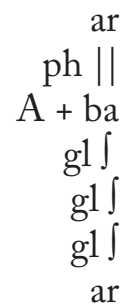

$\sim$ antistrophe

362

363

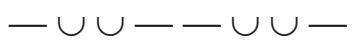

$\mathrm{ch}+\mathrm{ch}$

364

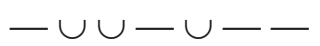

365-6

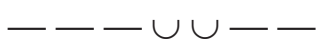

367

$\cup \cup-\cup \cup-\cup \cup-\cup \cup-\cup-$

368

369

370

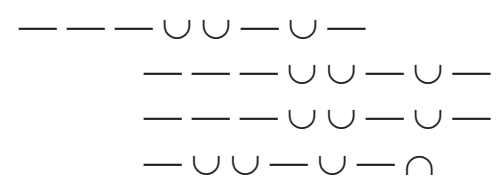

ar

$\mathrm{ph} \|$

$\mathrm{A}+\mathrm{ba}$

gl $\int$

gl $\int$

gl $\int$

ar

epode

371

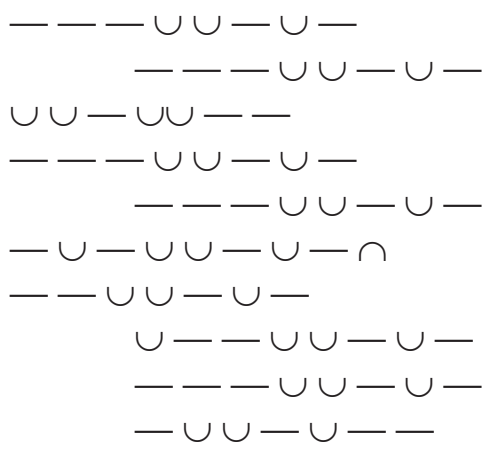

gl $\int$

372

373

374

375

376

377

378

379

380

$-\cup \cup-\cup-$

Second Stasimon (Hcld.608-628)

Strophe
608
$-\cup \cup-\cup \cup-\cup \cup-\cup \cup-\cup \cup-\cap$
$6 \mathrm{da} \|$
609
$-\cup \cup--$
$\operatorname{ad} \| \mathrm{H}$

${ }^{23}$ The same period as 371-3 is found at 748-50, with hiatus in the strophe. See also p. 98.

${ }^{24}$ See above, p. 97. 
$\sim$ antistrophe

619

$-\cup \cup-\cup \cup-\cup \cup-\cup \cup-\cup \cup--$

620

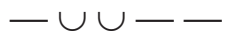

621

622

$-\cup \cup-\cup \cup-\cup \cup-\cup \cup$

623

$-\cup \cup-\cup \cup-\cdots-$

624

$-\cup \cup--$

625

$-\cup \cup---\cup \cup-\cup \cup$

626

627

$-\cup \cup---\cup \cup-$

628

$-\cup \cup-\cup \cup-\cup \cup-\cup \cup$

$-\cup \cup-\cup \cup-\cup \cup-\cup \cup$

$-\cup \cup-\cup \cup-$

$6 \mathrm{da} \|$
$\mathrm{ad} \|{ }^{\mathrm{H}}$
$4 \mathrm{da}$
$4 \mathrm{da}$
$\mathrm{ad}$
$4 \mathrm{da}$
$4 \mathrm{da}$
$4 \mathrm{da} \int$
$4 \mathrm{da} \int$
$\mathrm{D}-$

Third Stasimon (Hcld. 748-783)

Strophe $1 \sim$

748

749

750

751

752

753

754

755

756

757

758
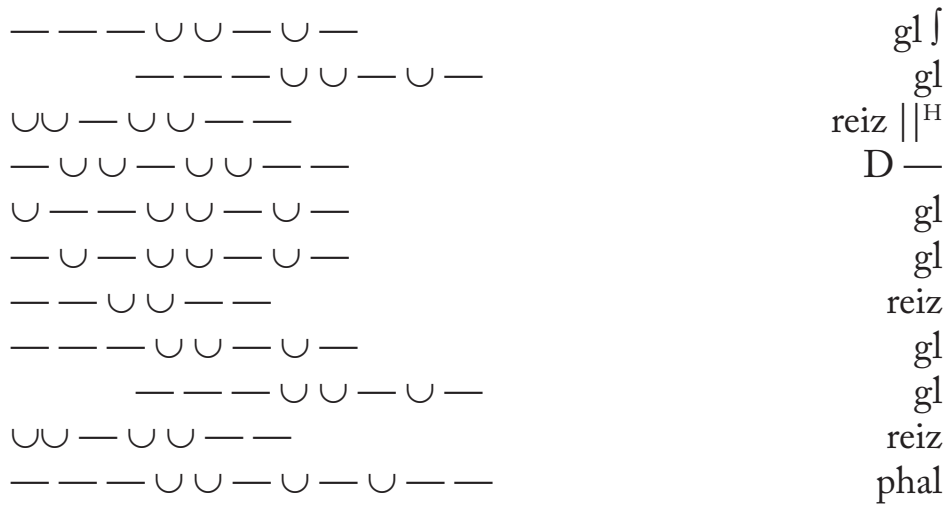

$\sim$ antistrophe 1

759

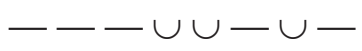

760

761

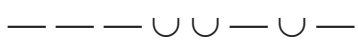

762

$\cup-\cup \cup-$

reiz |

$-\cup \cup-\cup \cup-$

$\mathrm{D}$ -

763

$\cup-\leftarrow \cup \cup-\cup$ 
764

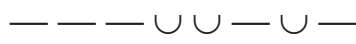

gl

765

$\cup-\cup \cup--$

766

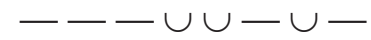

reiz

767

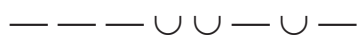

768

Uー Uソ- -

gif

769

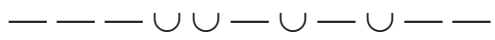

reiz

phal

Strophe 2

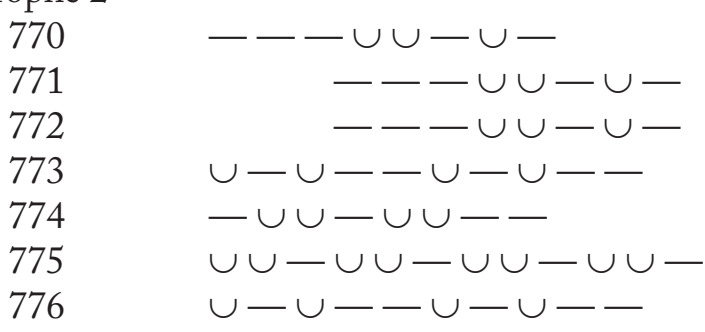

gl $\int$

$\sim$ antistrophe 2

777

778

779

780

781

782

783

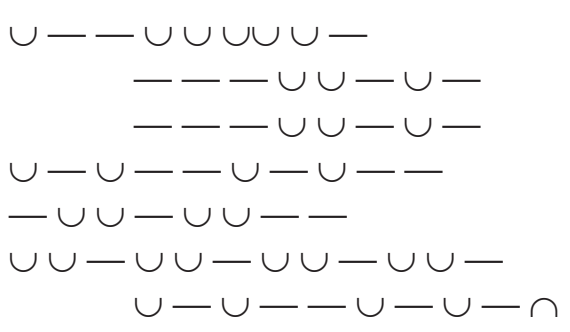

g1 $\int$

gl f

g1 ia + ith $\|{ }^{\mathrm{H}}$

$\mathrm{D}-\|\|^{\mathrm{H}}$

A ia + ith

Fourth Stasimon (Hcld. 892-927)

Strophe 1

892

$u-\cup-\cup-\cup-\cup-\cup-$

893

$-\cup \cup \dagger \cup \cup \dagger$

894

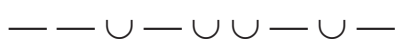

895

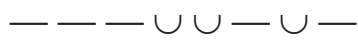

896

897

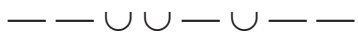

898-9

900
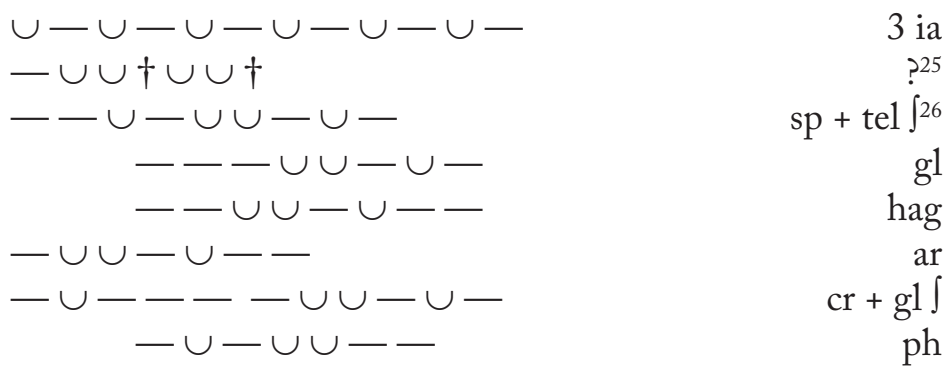

$\sim$ antistrophe 1

901

$\cup-\cup-\cup-\cup-\cup-\cup-$

3 ia

${ }^{25}$ See above, p. 105 (n. 225).

${ }^{26}$ Or 'x' gl. See above, pp. 112-3. 
902<smiles>C=C=[W]=C</smiles>

ar

903

$--\cup-\cup \cup-\cup-$

904

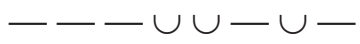

905

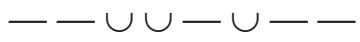

906

$-\cup \cup-\cup--$

907-8

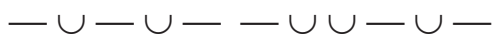

909

Strophe 2

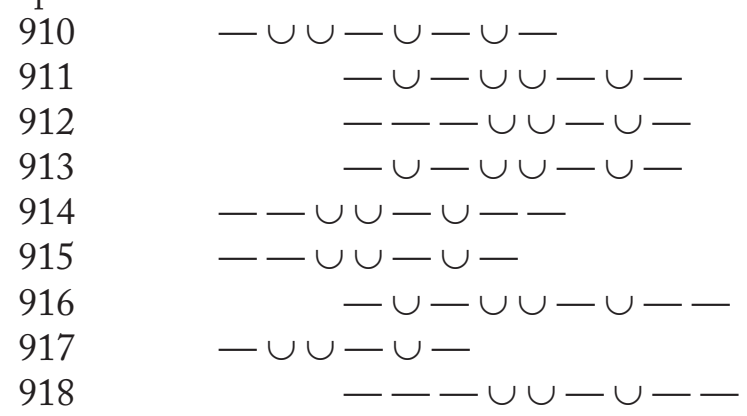

$\sim$ antistrophe 2

919

920

921

922

923

924

925

926

927

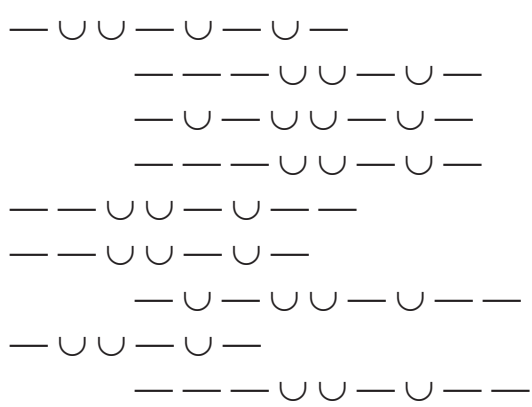

ch + ia $\int$ gl $\int$ gl $\int$ hag tel $\int$ hipp II $\operatorname{dod} \int$ hipp

\section{g1 \\ $\int$ 1

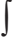 $\int$} ch + ia $\int$ gl $\int$ gl $\int$ g1 hag tel hipp II $\operatorname{dod}$ J hipp 


\section{Hippolytus}

Similarly to Parker's Alcestis, Barrett's Hippolytus is also especially rich in metrical information. Again, his divisions often differ from Diggle's.

$\mathrm{I} \pi$.

$58^{27}$

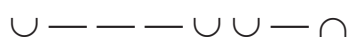

oct $\|^{\mathrm{B}}$

59

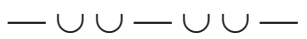

$\mathrm{D}$

60

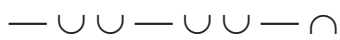

$\mathrm{D}-$

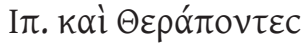

61

$\cup \cup \cup \cup \cup ー \cup \cup-$

$\mathrm{ia}+\mathrm{ch}$

62

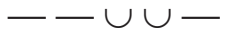

$-\mathrm{d}^{28}$

63

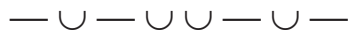

64-5

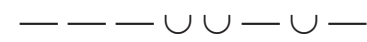

gl

66

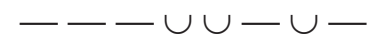

67

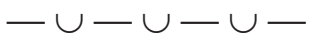

g1

68

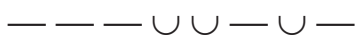

69

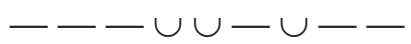

70

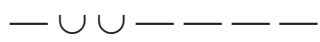

hipp

$71-2$

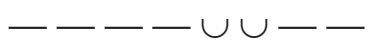

$\mathrm{D}-{ }^{29}$

$1 \mathrm{k}$

gl $\int$

hipp

oct

\section{Parodos (Hi. 121-169)}

Strophe 1
121
$-\cup \cup-\cup \cup---\cup \cup-\cup \cup-$
$\mathrm{D}-\mathrm{D}$
122

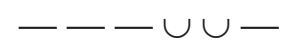
123-4

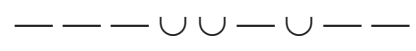
hex $\int$
125
$\cup \cup-\cup-\cup-$
hipp ||
126

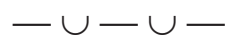
enop
' $h \delta$ '
127
$\cup \cup \cup-\cup-$

${ }^{27}$ See above, p. 102 (n. 218).

${ }^{28}$ See above, p. 108.

${ }^{29}$ On 70, see above p. 72.

${ }^{30}$ So Dale (21968: 170 n. 1), but the inverted commas are mine. Barrett interprets 122-130 as aeolic throughout, but admits that $126-7$ 'are not distinctly aeolic' (comm. Hi., p. 183). 
Part II - Scansions

128

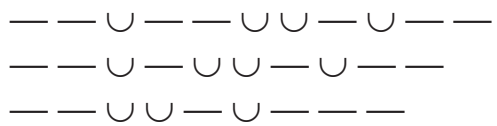

ia + ar

129

$--\cup \cup-\cup--$

$\mathrm{x}$ hipp

130

tel $+\mathrm{sp}$

antistrophe 1

131

132

$-\cup \cup-\cup \cup---\cup \cup-\cup \cup-$

133-4

135

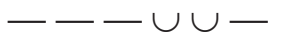

$---\cup \cup-\cup--$

136

$\cup \cup-\cup-\cup-$

137

$-\cup-\cup$

138

$\cup \cup \cup-\cup$

139

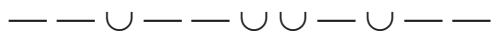

140

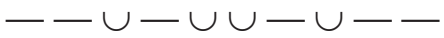

$-\leftarrow \cup \cup-\cup--$

$\mathrm{D}-\mathrm{D}$
hex $\int$
hipp II
enop
'h $\delta$
' $\delta$ '
ia + ar
$\mathrm{x}$ hipp
tel $+\mathrm{sp}$

gl? ||$^{\mathrm{H}}$ wil

$\dagger \cup \cup \dagger-\cup \cup--$
$---\cup-\cup \cup-$
143

144

145

146

147

148

149

150
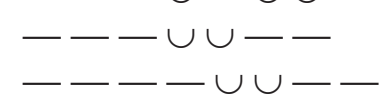

$\dagger \cup \dagger-\cup-\cup \cup-$

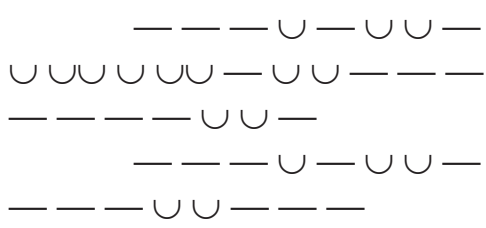

$\sim$ antistrophe 2

151

152

153

154

155

156

157

158

159

160

epode

161

162

163

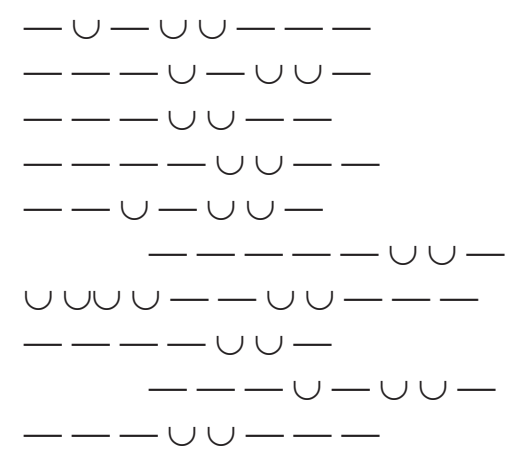

$\cup-\cup-\backsim \cup \cup-$

$-\cup \cup-\cup-$

$-\longleftarrow \cup \cup-\cup \cup-\cup-$ $\mathrm{ph}$
oct $\|$
hept

wil

ia + dod

hept $\int$

wil

gl

gl $\|\left.\right|^{\mathrm{Hs}}$ wil

ph
oct II

wil

ia + dod

hept I

wil

g1

ia + ith dod

$-\mathrm{D}+\mathrm{ba}$ 


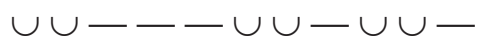

Phaedra's lyric anapaests (Hi. 208-231)

$\Phi \alpha$.

\begin{tabular}{|c|c|c|}
\hline & -- & e. $\mathrm{m}$. \\
\hline 208 & $--\cup \cup-\cup \cup---$ & $2 a$ \\
\hline 209 & $\cup \cup-\cup \cup--\cup \cup--$ & \\
\hline 210 & $\cup \cup----\cup \cup--$ & \\
\hline 211 & $--\cup \cup-\cup \cup---$ & \\
\hline 215 & $-\cup \cup-\cup \cup-\cup \cup--$ & \\
\hline 216 & $-\cup \cup--\cup \cup-\cup \cup-$ & \\
\hline 217 & $--\cup \cup-$ & \\
\hline 218 & $\cup \cup-\cup \cup---\cup \cup-$ & \\
\hline 219 & $--\cup \cup-\cup \cup---$ & \\
\hline 220 & $-\cup \cup-----$ & \\
\hline 221 & $-\cup \cup--\cup \cup-\cup \cup-$ & \\
\hline 222 & $--\cup \cup-$ & \\
\hline 228 & $--\cup \cup--\cup \cup--$ & \\
\hline 229 & $--\cup \cup---\cup \cup--$ & \\
\hline 230 & $-\cup \cup----\cup \cup-$ & \\
\hline 31 & $--\cup \cup-\cup \cup-\cup \cup-$ & \\
\hline
\end{tabular}

Dochmiac Song (Hi.362-72 669-79)

Strophe

Xo.
$362 \mathrm{a}$
$\cup \cup \cup-\cup \cup \cup-$
$362 \mathrm{~b}$
$\cup--\cup-$
$\operatorname{cr}+\operatorname{cr} \|_{\delta}^{\mathrm{H}}$
363
$\cup--\cup \cup \cup \cup \cup \cup \cup \cup \cup-$
$2 \delta$
364
$\cup--\cup-\cup--\cup-$
$2 \delta \|^{\mathrm{Ha}}$
365
$\cup \cup \smile \cup-\cup--\cup$
$2 \delta$

\footnotetext{
${ }^{31}$ So Barrett (p. 183). But 'e - e - e -', which we find later on at 760-2 772-4, is also possible.
} 
Part II - Scansions

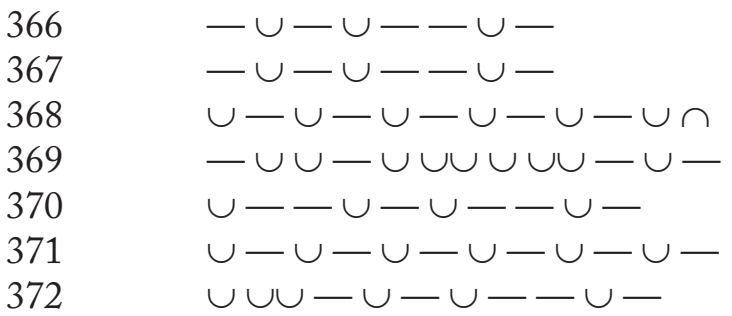

$$
\begin{array}{r}
\mathrm{cr}+\delta \\
\mathrm{cr}+\delta \\
3 \mathrm{ia} \|^{\mathrm{B}} \\
2 \delta \\
2 \delta \\
3 \text { ia } \\
2 \delta
\end{array}
$$

$\sim$ antistrophe

$\Phi \alpha$.

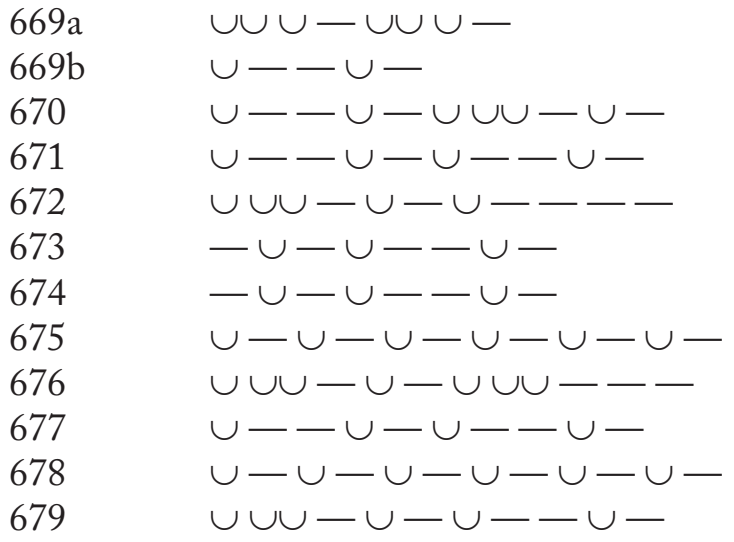

$$
\begin{array}{r}
c r+c r \\
\delta \\
2 \delta \\
2 \delta \| \mathrm{H} \\
2 \delta \\
\mathrm{cr}+\delta \\
\mathrm{cr}+\delta \\
3 \mathrm{ia} \\
2 \delta \\
2 \delta \\
3 \mathrm{ia} \\
2 \delta
\end{array}
$$

First Stasimon (Hi. 525-564)

Strophe 1

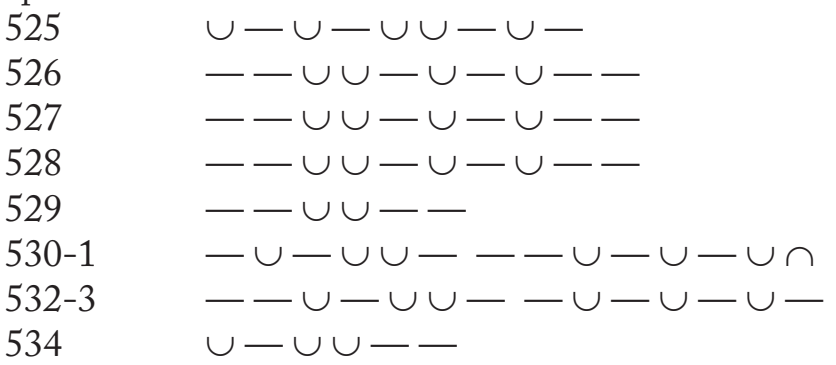

$$
\begin{array}{r}
\mathrm{x} \mathrm{gl}^{32} \\
\text { tel }+\mathrm{ba}^{33} \\
\text { tel }+\mathrm{ba} \|^{\mathrm{Ha}} \\
\text { tel }+\mathrm{ba} \\
\text { reiz } \\
\text { hex }+2 \mathrm{ia} \\
\text { hept }+\mathrm{lk} \\
\text { reiz } \\
\\
\mathrm{x} \mathrm{gl} \\
\text { tel }+\mathrm{ba} \\
\text { tel }+\mathrm{ba} \|^{\mathrm{H}}
\end{array}
$$

$\sim$ antistrophe 1

535

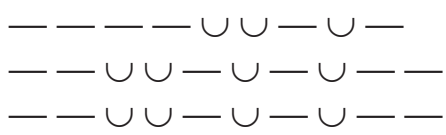

537

\footnotetext{
${ }^{32}$ See above, p. 113.

${ }^{33}$ See above, p. 87.
} 
540-1 $\quad-\cup-\cup \cup--\cup \cup-\cup-\cup-$ hex +2 ia

$542-3$ $--\cup-\cup \cup--\cup-\cup-\cup-$

544

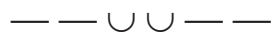

hept $+1 \mathrm{k}$

reiz

Strophe 2

545

$-\cup-\cup \cup-$

hex

546

$-\cup-\cup \cup-$

$547-8$

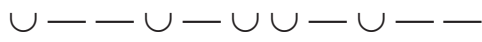

549

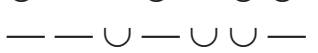

550

$\cup \cup \cup-\cup \cup-\cup-$

551

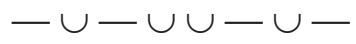

$552^{35}$

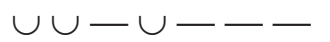

$\wedge \mathrm{dss}^{\text {chol }}$

553

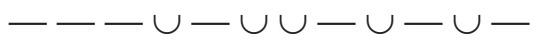

554

wil + 'ia'

reiz

$\sim$ antistrophe 2

555

556

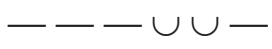

$557-8$

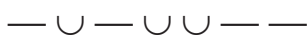

559

$\cup--\cup-\cup \cup-\cup-$

560

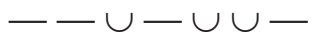

561

$\cup \cup \cup-\cup \cup-\cup-$

562

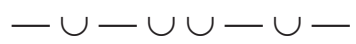

563

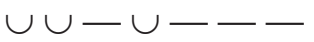

$\wedge \mathrm{dss}^{\text {chol }}$

564

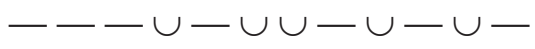

wil + 'ia'

reiz

\section{Dochmiac scene (Hi. 569-595)}

$\Phi \alpha$.

569

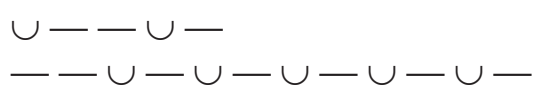

$\delta \|^{\mathrm{H}}$

570

$-\backsim \cup-\cup-\cup-\cup-\cup-$

Xo.

$571-2$

$\cup \cup \cup---\cup \cup \cup-\cup \cap$

$2 \delta \|^{\mathrm{B}}$

573

$\cup \cup \cup-\cup-\cup--\cup-$

$2 \delta$

574

$\cup \cup \cup-\cup \cap$

${ }^{34}$ Barrett (p. 257) suggests 'Sapphic hendecasyllable with "aeolic base", $\cup$ - in place of the initial $-\cup$.'

35 See above, p. 78. 
Part II - Scansions

$\Phi \alpha$.

$\begin{array}{ll}575 & \cup-\cup-\cup-\cup---\cup- \\ 576 & \cup-\cup-\leftarrow \cup \cup \cup-\cup-\cup-\end{array}$

Xo.

577-8

$\cup \cup \cup-\cup-\cup--\cup-$

579

$\cup--\cup-$

580-1

$\cup \cup \cup \cup-\cup \cup \cup \backsim$

$2 \delta$

$\Phi \alpha$.

582

$\cup-\cup---\cup-\cup-\cup-$

583

$-\cup \cup \cup--\cup-\cup-\cup \cap$

3 ia $\|^{\mathrm{H}}$

3 ia $\|$

Xo.

584-5

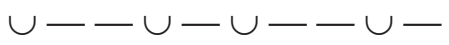

$2 \delta$

$586-7$

$\cup--\cup-\cup \cup \cup-\cup \cup \cup$

588

$\cup \cup \cup \cup-$

$2 \delta$

$\delta$

$\Phi \alpha$.

589

$--\cup-\cup-\cup-\cup-\cup-$

3 ia

590

$--\cup-\cup-\cup---\cup \cap$

3 ia

Xo.

591-2

$-\cup \cup-\cup-\cup \cup \cup-\cup-$ $2 \delta$

593

$\cup--\cup$

594

$\cup-\cup-\cup-\cup \cup \cup-\cup-$

595

$\cup \cup \cup \cup \cup-\cup-$

Second Stasimon (Hi. 732-775)

Strophe 1

732

$-\cup \cup-\cup \cup--\cup \cup--$

733

$\cup \cup-\cup-\cup-\cdots$

ch +2 io

$734 \mathrm{a}$

$\cup \cup-\cup-$

anacr

$734 \mathrm{~b}$

$\cup \cup--$

io $\wedge+\wedge$ io $\int$

735

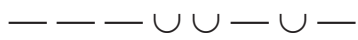

io $\wedge+\wedge \wedge$ io $\| \mathrm{Hs}$

736

737

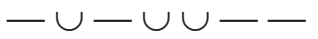

738

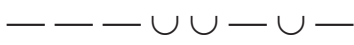

739

$-\cup-\cup \cup-\cup-$

gl

ph

gl|

gl f

740

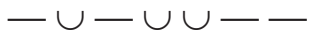

ph

tel + ch

741

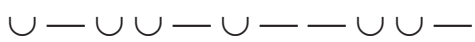

g1

$\sim$ antistrophe 1

742

$-\cup \cup-\cup \cup--\cup \cup--$

ch +2 io 
Strophe 2

752

753

754

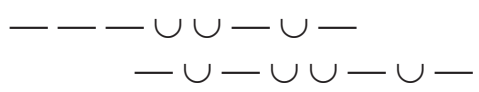

gl

$$
-\cup-\cup \cup-\cup-
$$

755-6

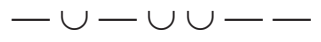

757

$\cup \cup-\cup \cup-\cup-\cup-\cup-\cup--$

ph

$758-9$

$\cup \cup-\cup \cup-\cup-\cup$

diom + ith

$760-1$

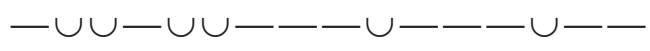

762

763

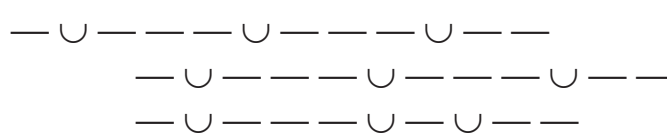
$\operatorname{diom}^{37}$

$\sim$ antistrophe 2

764

765

766

767-8

769

770-1

$772-3$

774

775

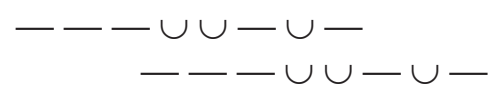

$-\cup-\cup \cup--$

$\cup \cup-\cup \cup-\cup-\cup \mid-\cup-\cup-$

$\cup \cup-\cup \cup-\cup-\cup$

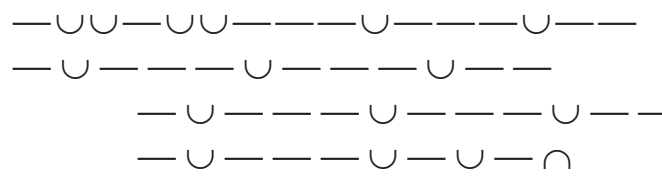

gl $\int$

gl $\int$

$\mathrm{ph}$

diom + ith

diom

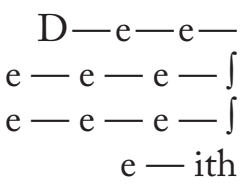

\section{Hi. 811-816}

Xo.

811

812

$\cup \cup \cup-\cup-\cup \cup \cup-\cup-$

$813 \mathrm{a}$

${ }^{37}$ See above, p. 75 (with n. 157). 


\section{Theseus' Monody (Hi. 817-851)}

Strophe 1

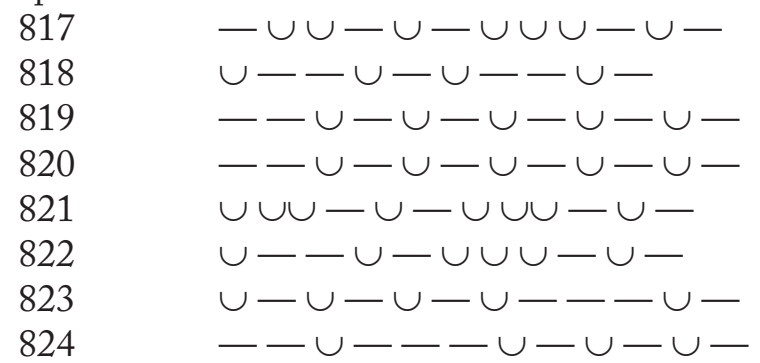

$2 \delta$
$2 \delta \|^{\mathrm{H}}$
$3 \mathrm{ia}$
$3 \mathrm{ia}$
$2 \delta$
$2 \delta$
$3 \mathrm{ia}$
$3 \mathrm{ia}$

$2 \delta$
$2 \delta$
$3 \mathrm{ia}$
$3 \mathrm{ia}$
$2 \delta$
$2 \delta$
$2 \delta$
$\delta$

826

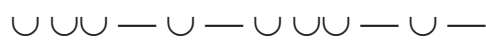

827

$\cup \cup \backsim \cup-\cup-\backsim-$

828

$--\cup-\cup-\cup-\cup-\cup-$

829

830

$--\cup---\cup---\cup$

831

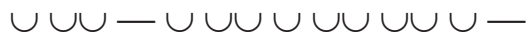

832

$\cup-ー \cup \cup \cup \cup \cup-\cup-$

833

$\cup--\cup--\cup \cup-\cup-$

$\sim$ antistrophe 1

836

837

838

839

840

841

842

843

844

845

846

847

848

849

850 $\cup \cup \cup-\cup-\cup \cup \cup-\cup-$

$\cup--\cup-\cup--\cup$

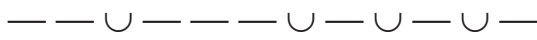

$\cup-\cup---\cup-\cup-\cup \cap$

$\dagger \cup-\cup-\dagger \cup-\cup \cup \cup-\cup-$

$\cup--\cup-\cup-\cup \cup \cup-$

$--\cup-\cup-\cup-\cup-\cup-$

$\cup-\cup---\cup-\cup-\cup-$

$\cup \cup \cup-\cup-\cup--\cup-$

$2 \delta$

3 ia

3 ia

$2 \delta$

$2 \delta$

$2 \delta$ I 
Xo.

852

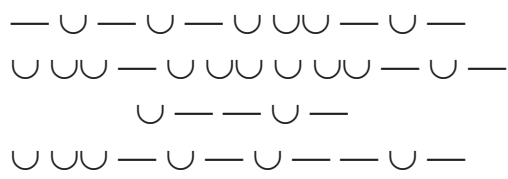

$\mathrm{h} \delta+\delta$

$2 \delta \int$

854

855

$\cup \cup \cup \cup-\cup--\cup$

Xo.

866<smiles>CO[AlH2]OC</smiles>

867

$\cup--\cup-\cup \cup+\cup-$

868

$\cup--\cup-\cup--\cup-\dagger$

ia $+\delta$

869

$\cup \cup \cup-\cup-\cup--\cup-$

$\delta+\cup \cup$ cr?

$2 \delta$ ?

870

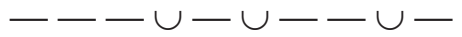

$2 \delta$

$2 \delta$

$\Theta \eta$.

877

$\cup-\cup-\cup-\cup-\cup-\cup-$

3 ia

878

$\cup-\cup-\cup \cup \cup \cup \cup \cup \cup-$

3 ia

879

$-\cup-\cup--\cup-\cup-$

$\mathrm{h} \delta+\mathrm{h} \delta$

880

$-\cup \cup-\cup-$

Xo.

881

$\cup-\cup-\leftarrow-\cup---\cup-$

3 ia

$\Theta \eta$.

882

$\cup \cup \cup-\cup-\cup \cup \cup-\cup-$

$2 \delta$

883

$\cup--\cup-\cup-\cup \cup \cup-$

$2 \delta$

884

$\cup \cup \cup \cup-$

$\delta$

Third Stasimon (Hi.1102-1150)

Strophe 1

$$
\begin{aligned}
& \text { 1102-3 }-\cup \cup-\cup \cup-\cup \cup-\cup \cup-\cup \cup--\quad 6 \mathrm{da} \\
& \text { 1104-5 } \cup-\cup--\cup \cup-\cup \cup-\cup \cup--\quad \text { ia }+4 \mathrm{da}^{38} \\
& \text { 1106-7 }-\cup \cup-\cup \cup--\leftarrow \cup \cup-\cup \cup--\quad 6 \mathrm{da} \\
& \text { 1108-9 }-\cup \cup-\cup \cup-\cup-\cup \cup-\cup \cup-\cup \cup- \\
& 2 \mathrm{da}+\mathrm{ia}+4 \mathrm{da}^{39}
\end{aligned}
$$

antistrophe 1

1111-2

$-\cup \cup-\cup \cup-\cup \cup-\cup \cup-\cup \cup--$

$6 \mathrm{da}$

\footnotetext{
${ }^{38}$ See above, p. 86 (n. 181).

${ }^{39}$ For the sequence $\cup \cup-\cup \cup-\cup \cup-\longrightarrow$ in this song as 'acephalous 4 da' see Parker (1997: 54).
} 


$$
\begin{aligned}
& \text { 1113-4 } \cup-\cup-\backsim \cup \cup-\cup \cup-\cup \cup--\quad \text { ia }+4 \text { da } \\
& \text { 1115-6 }-\cup \cup-\cup \cup---\cup \cup-\cup \cup--\quad 6 \mathrm{da} \\
& \text { 1117-8 }-\cup \cup-\cup \cup \cup-\cup-\cup \cup-\cup \cup-\cup \cup-- \\
& 1119 \cup-\cup-\cup-\leftarrow \quad \text { ia }+ \text { ba }
\end{aligned}
$$

Strophe 2

1120-1

$1122-3$

$-\cup \cup-\cup \cup-\cup \cup-\cup \cup-\cup \cup--\quad 6 \mathrm{da} \|^{\mathrm{H}}$

1124

$\cup-\cup--\cup-: \cup \cup-\cup \cup-\cup \cup-\longrightarrow$ ia + cr : enop prm

1125

$-\cup \cup-\cup \cup-\cup \cup--$

$4 \mathrm{da}$

1126

$--\cup-\cup \cup \cup \cup \cap$

2 ia $\|^{\mathrm{B}}$

$-\cup \cup-\cup \cup-\cup \cup-$

$4 \mathrm{da}$

1127

$-ー \cup \cup \cup \cup \cup \cup-$

2 ia

1128-9

$-\cup \cup-\cup \cup-\cup \cup-$

$4 \mathrm{da}$

1130

$\sim$ antistrophe 2

1131-2

$-\cup \cup-\cup \cup---\cup \cup-\cup \cup-\ldots \quad 6 \mathrm{da}$

$1133-4$

$\cup-\cup--\cup-: \cup \cup-\cup \cup-\cup \cup-\longrightarrow$ ia + cr : enop prm

1135

$-\cup \cup-\cup \cup-\cup \cup-$

$4 \mathrm{da}$

1136

$--\cup-\cup \cup \cup \cup \cap$

1137

$-\cup \cup-\cup \cup-\cup \cup-$

2 ia $\|{ }^{\mathrm{B}}$

1138

$-ー \cup-\cup \cup \cup-$

$4 \mathrm{da}$

$1139-40$

$-\cup \cup-\cup \cup-\cup \cup-$

2 ia

1141

$--\cup-\cup--$

$4 \mathrm{da}$

$\mathrm{ia}+\mathrm{ba}$

epode

1142

$\cup-\cup-\cup-\cup-$

2 ia

1143

$-\cup-\cup--$

1144

$\cup \cup \cup \cup-\cup-\cup-\cap$

1145

$\cup \cup \cup \cup \cup-\cup-$

$\mathrm{cr}+\mathrm{ith} \|^{\mathrm{B}}$

1146

1147

$-\cup-\cup-\cap$

$\mathrm{cr}+\mathrm{cr}$

1148

$\cup-\cup-$

ith $\|^{\mathrm{B}}$

1149

$-\cup \cup-\cup \cup-\cup-\cup \cup-\cup \cup-$

$\mathrm{D} \cup \mathrm{D}-$

1150

$-\cup---\cup-$

$1 \mathrm{k}$

$-\cup \cup-\cup--$

ar

Fourth Stasimon (Hi.1268-1282)

1268

$\cup--\cup--\cup \cup-\cup-$

$2 \delta$

1269

$\cup-\cup \cup-\cup-$

$\mathrm{T} \int$

1270

$\cup-\cup \cup-\cup \cup-$

$\cup \mathrm{D}$

1271

$-\cup \cup-\cup-$ 


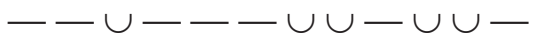

1276-7 $\cup \cup \cup-\cup--ー \cup \cup \cup-$

$1278 \cup \cup \cup-\cup-$

1279

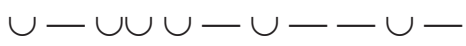

$1280-1$

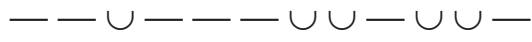

1282

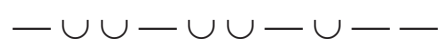

\section{Hi. 1370-1388}

1370

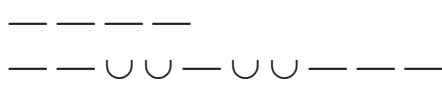

1371

1372

$\cup \cup \cup \cup \cup \cap$

1373

1374

1375

1376

1377

1378

1379

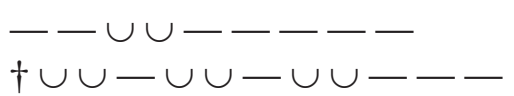

2 an

an ||$^{\mathrm{B}}$

2 an

2 an $\int$

$\cup \cup \dagger-\cup \cup---\cup \cup-$

2 an

2 an $\|$

an $\|^{\mathrm{B}}$

2 an

2 ia

1380

$1381 \mathrm{a}$

$1381 \mathrm{~b}$

1382

1383

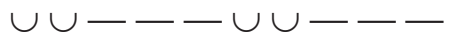

2 ba $\int$

$\mathrm{ba}+\mathrm{ia}$

an $\|{ }^{\mathrm{H}}$

2 ia

2 ia

e. m.?

1384

$1385 \mathrm{a}$

$\cup--$

$2 \mathrm{ba} \int$

$1385 \mathrm{~b}$

1386

$\cup--\cup--$

dod

1k ||

1387

$-\cup---\cup-$

$\mathrm{ch}+\mathrm{ia}$

$1388 \mathrm{a}$

$-\cup \cup-\cup-\cup-$

$\mathrm{ia}+\mathrm{cr} \int$

$1388 b$

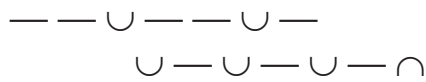

ia + ba

${ }^{40}$ For dochmiac scansion of this line, see Parker (1968: 260). The alternative scansion as ithyphallic $(\mathrm{cr}+\mathrm{ba})$ entails split resolution in the cretic. 


\section{Andromache}

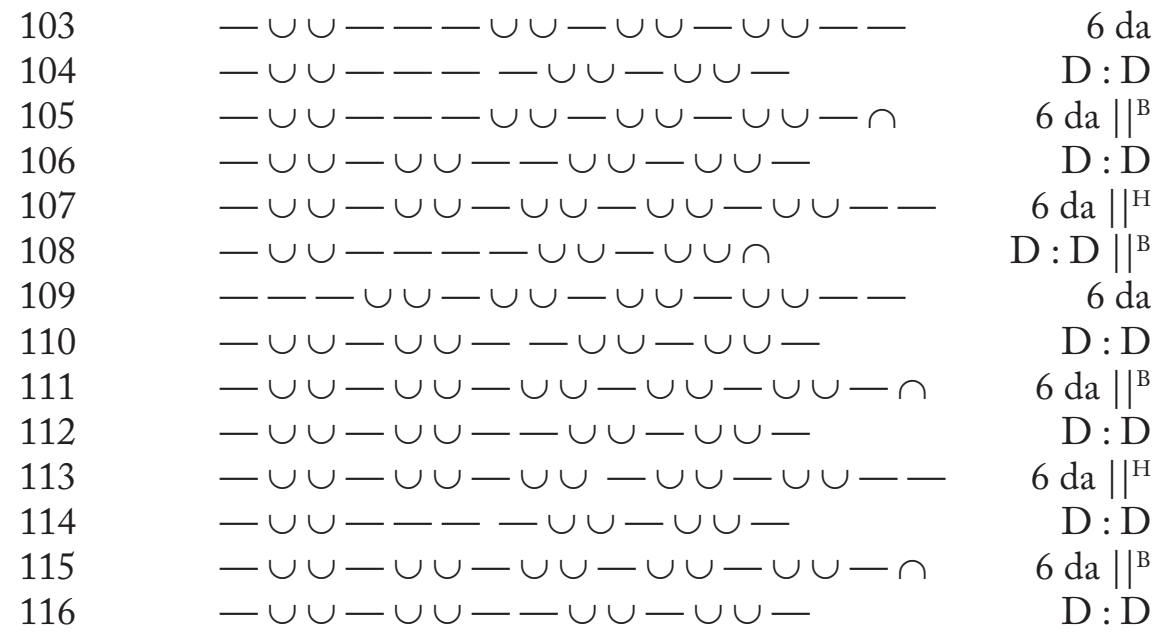

\section{Parodos (Andr. 117-146)}

Strophe 1

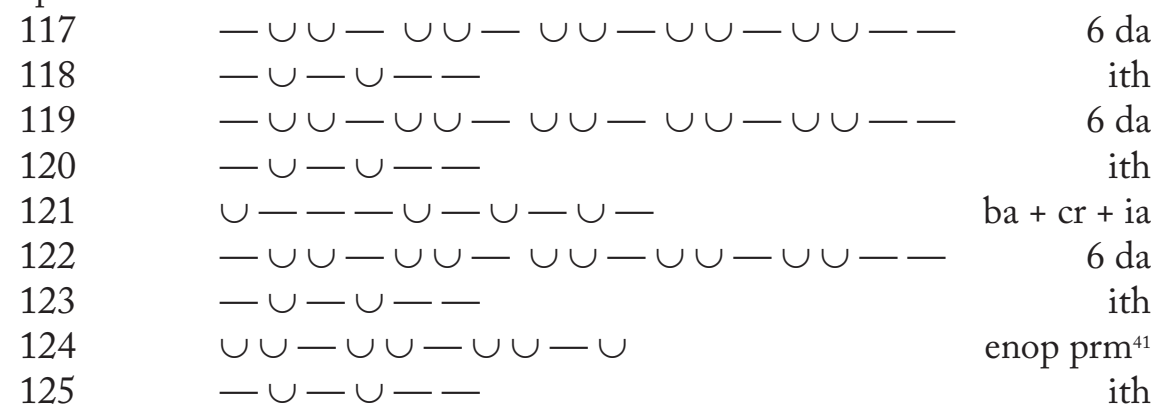

$\sim$ antistrophe 1

126

127

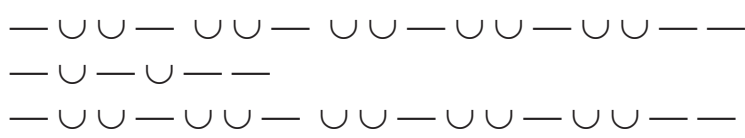

$6 \mathrm{da}$ ith

128 $6 \mathrm{da}$

\footnotetext{
${ }^{41}$ See Diggle (1994: 205).
} 
Part II - Scansions

129

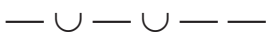

$\mathrm{ba}+\mathrm{cr}+\mathrm{ia}$

130

$\cup---\cup-\cup-\cup-$

ith

131

$-\cup \cup-\cup \cup-\cup \cup-\cup \cup-\cup \cup--$

$6 \mathrm{da}$

132

$-\cup-\cup--$

ith

133

$\cup \cup-\cup \cup-\cup \cup-\cup$

134

$-\cup-\cup--$

enop prm ith

Strophe 2

135

$-\cup \cup-\cup \cup---\cup \cup-\cup \cup-$

$6 \mathrm{da}$

136

$-\cup-\cup-\cup-$

137

$-\cup \cup-\cup \cup$

D

138

$\cup \cup-ー \cup-\cup-\cup-$

$\mathrm{cr}+\mathrm{cr}+\mathrm{ia}$

139

$---\cup-\cup-$

$\mathrm{mol}+$ ia $\|^{\mathrm{H}}$

140

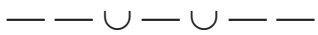

$\mathrm{ia}+\mathrm{ba}$

$\sim$ antistrophe 2

141

142

$-\cup \cup-\cup \cup-\cup \cup-\cup \cup-\cup \cup--$

$6 \mathrm{da}$

143

$-\cup-\cup-\cup-$

$1 \mathrm{k}$

144

$-\cup \cup-\cup \cup-$

$\mathrm{D}$

145

$\cup \cup \cup--\cup-\cup-\cup-$

146

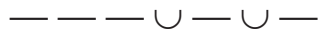

$\mathrm{cr}+\mathrm{cr}+\mathrm{ia}$

$\mathrm{mol}+\mathrm{ia}$

$\mathrm{ia}+\mathrm{ba}$

First Stasimon (Andr. 274-308)

Strophe 1

274

275

$-\cup \cup-\cup \cup-\cup \cup-\cup \cup-\cdots$

$4 \mathrm{da}+\mathrm{mol}^{42}$

276

277

$-\cup--\cup-$

$\mathrm{cr}+\mathrm{cr} \int$

$-\cup-\cup-\cup-$

$1 \mathrm{k}$

2 ia

278

$\cup-\cup-\cup-\cup-$

$\mathrm{ia}+\mathrm{cr} \|^{\mathrm{B}}$

279

$\cup-\cup--\cup \cap$

280

$\cup \cup-\cup \cup-\cup \cup-\cup \cup--\cup-$

$\mathrm{A}+\mathrm{cr}$

reiz

281

$-\backsim \cup--$

3 ia

282

$\cup-\cup-\cup \cup \cup \cup-\cup-\cup-$

$\mathrm{ba}+\mathrm{ith}$

$\sim$ antistrophe 1

283-4

$\cup---\cup-\cup--$

285

$-\cup \cup-\cup \cup-\cup \cup-\cup \cup--$

286

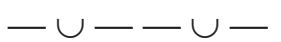

$4 \mathrm{da}+\mathrm{mol}$

$\mathrm{cr}+\mathrm{cr} \int$

$1 \mathrm{k}$

${ }^{42}$ See above, p. 66. 
Strophe 2

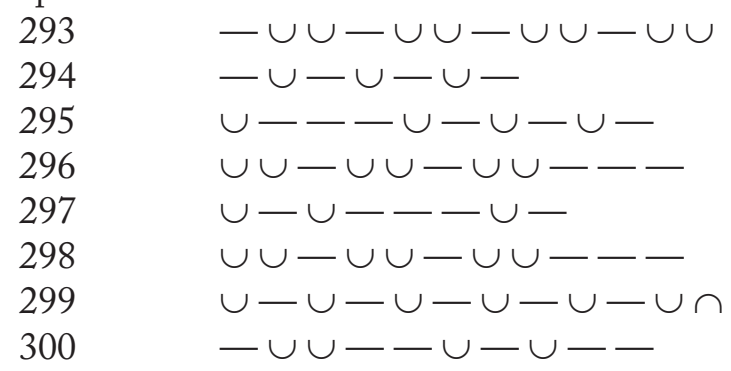

$\sim$ antistrophe 2

301

$-\cup \cup-\cup \cup-\cup \cup-\cup \cup$

$4 \mathrm{da}$

302

$-\cup-\cup-\cup-$

$1 \mathrm{k}$

303

$\cup--ー \cup-\cup-\cup-$

304

$\cup \cup-\cup \cup-\cup \cup--$

$\mathrm{ba}+\mathrm{lk}$

305

$\dagger------\downarrow \dagger$

306

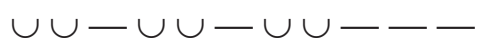

307

$\cup-\cup-\cup-\cup-\cup-\cup \cap$

308

$-\cup \cup-\leftarrow \cup-\cup-$

A

\section{Second Stasimon (Andr. 464-493)}

Strophe $1 \sim$
464-5
$-\cup \cup \cup \cup \cup \cup-\cup-\cup-\cup-$
3 ia
466 $--\cup-\cup-\cup-$
467-8
$\dagger \cup \cup \cup---\cup-\cup--$
469
$\cup---\cup-\cup-\dagger \cup-$
470
$\cup---\cup-\cup-\cdots$
2 ia
$\mathrm{ba}+\mathrm{lk}$ ba + ith
$\sim$ antistrophe 1
471-2
474

$$
\begin{aligned}
& \dagger-\cup \cup \cup \dagger \cup \cup-\cup-\cup-\cup- \\
& \cup-\cup-\cup-\cup-
\end{aligned}
$$
3 ia
2 ia

${ }^{43} 296 \sim 304$ and 298 306 'are not anapaestic dimeters but dragged enoplians' (Dale ${ }^{2} 1968$ : 168-9). 


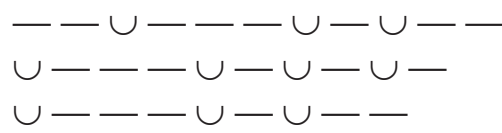

2 ia + ba

476

$\cup--\cup-\cup-$

$\mathrm{ba}+\mathrm{lk}$

$477-8$

$\cup-\cup-\cup-\cup-\cup-\cup-$

ba + ith

Strophe 2

479

$\cup \cup-\cup \cup-\cup \cup-\cup \cup--$

480

$\cup-\cup-\cup \cup \cup \cup-\cup-\cup-$

481

$-\cup \cup-\cup \cup-\cup \cup-$

483

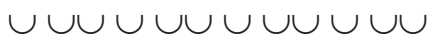

484

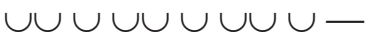

$-\cup-\cup-\cap$

3 ia
$A+s p^{44}$

3 ia $4 \mathrm{da} \wedge \|$ 2 ia $1 \mathrm{k} \int_{45}$

485 ith

$\sim$ antistrophe 2

486

$\cup-\cup-\cup-\cup-\cup-\cup-$

3 ia

$487-8$

$\cup \cup-\cup \cup-\cup \cup-\cup \cup-\cup-$

489

$--\cup-\cup-\cup-\cup \cup \cup \cup-$

3 ia

490

$-\cup \cup-\cup \cup \cup \cup \cup \cap$

491

$\cup \cup \cup \cup \cup \cup \cup \cup$

492

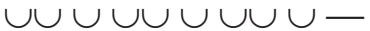

2 ia

$1 \mathrm{k}$

493

\section{Lyric Duet (Andr. 501-536)}

Strophe

Av.

501

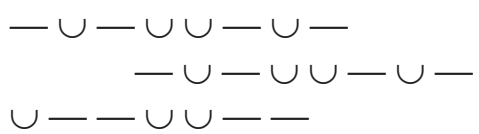

502

$\cup--\cup \cup-$

503

$\Pi \alpha$.

504

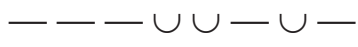

$\mathrm{g} 1$

505

$\cup \cup \backsim \cup \cup-$

ph

Av.

506

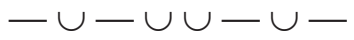

g1

507

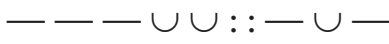

508

${ }^{44}$ See above, p. 77.

${ }^{45}$ The dovetailed lecythion is surprising (however see Dunbar, comm. Birds, p. 689). Willink

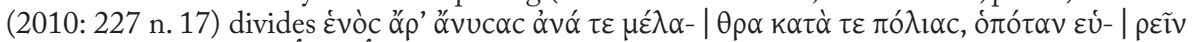
$\theta \varepsilon ́ \lambda \omega c l$ kaıpóv (cr + ia $\int 2$ ia $\int$ ith). See above, p. 43 (n. 70)

${ }^{46}$ For the resolved dactyl see Diggle (1994: 122-3). 
Av.

510

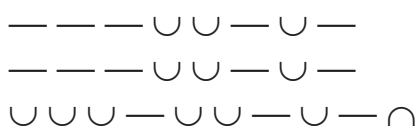

hipp $\left.\right|^{g}$

512

\section{1}

$\Pi \alpha$.

513

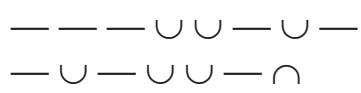

g1

514

$-\cup-\cup \cup-\cap$

ph

$\sim$ antistrophe

Av.

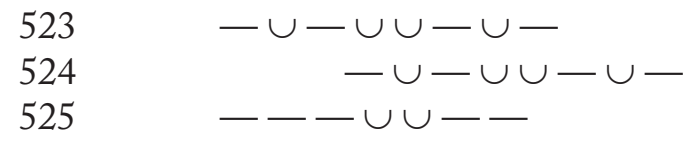

g1

gl

ph

$\Pi \alpha$.

526

$---\cup \cup-\cup-$

gl

527

$\cup \cup \backsim \cup \cup-$

ph

Av.

528

$-\longleftarrow \cup \cup-\cup$

530

$---\cup \cup::-\cup$

531

$\cup \cup \cup-\cup \cup--$

g1

gl

ph

Av.

532

$-\cup-\cup \cup-\cup-$

g1

33

$--\backsim \cup \cup-\cup$

534

$\cup \cup \cup-\cup \cup-\cup-\cap$

hipp $\|^{\mathrm{B}}$

$\Pi \alpha$.

535

$--\backsim \cup \cup-\cup-$

536

$-\cup-\cup \cup-$

g1

ph

\section{Third Stasimon (Andr. 766-801)}

Strophe

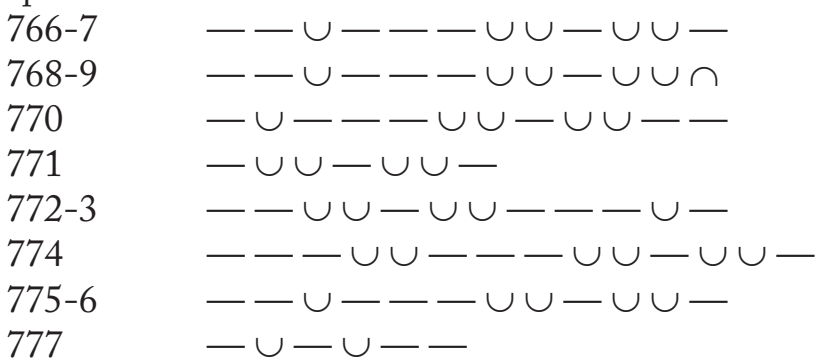

$$
\begin{array}{r}
-\mathrm{e}-\mathrm{D} \\
-\mathrm{e}-\mathrm{D} \|^{\mathrm{B}} \\
\mathrm{e}-\mathrm{D}-\mathrm{D} \\
-\mathrm{D}-\mathrm{e} \\
\mathrm{D}-\mathrm{D} \\
-\mathrm{e}-\mathrm{D} \\
\text { ith }
\end{array}
$$


$\sim$ antistrophe

778-9

780

781

782

783-4

$785-6$

787-8

789

epode

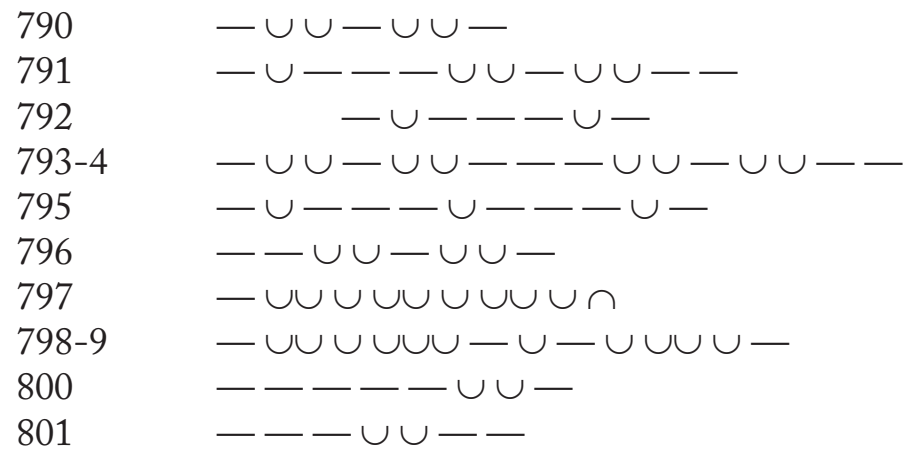

$-e-D$
$-e-D$
$e \cup D-\|^{B}$
$D$
$-D-e$
$D-D$
$-e-D$
$i t h$

$\mathrm{D}$

$e-D-1$

$\mathrm{e}-\mathrm{e}$

$\mathrm{D}-\mathrm{D}$

$\mathrm{e}-\mathrm{e}-\mathrm{e}$

$-\mathrm{D}$

2 ia $\|^{\mathrm{B}}$

3 ia

wil

ph

\section{Hermione's Monody (Andr. 825-865)}

Strophe $1 \sim$

E $\rho$.

825

$\cup---$

e. $m$.

826

$--\cup \cup-\cup \cup-\cup$

827

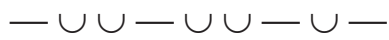

erasm

ibyc

$\mathrm{T} \rho$.

828

$--\cup---\cup-\cup-\cup-$

3 ia

$\sim$ antistrophe 1

E $\rho$.

829

$\cup---$

830

$--\cup \cup-\cup \cup-\cup$

e. $\mathrm{m}$.

831

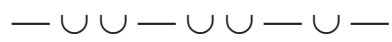

erasm $\int$

ibyc

T $\rho$.

832 
Strophe 2

E $\rho$.

833

$\cup--\cup-\cup--\cup-$ $2 \delta$

834

$-\cup \cup-\cup \cup-\cup \cup-\cup \cup$ $4 \mathrm{da} \int$

835

$-\cup-\cup \cap$ h⿱ \|\|$^{\mathrm{B}}$

$\sim$ antistrophe 2

E $\rho$.

837

$\cup \cup \cup-\cup-\cup--\cup-$

838

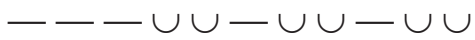

839

E $\rho$.

841

$\cup-\cup \cup-\cup \cup-\cdots$

842-3

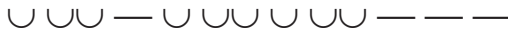

$\cup \mathrm{D}+\mathrm{sp} \mid \|^{\mathrm{H}_{47}}$

844

$\cup----\cup \cup \cup---$ $2 \delta$

$2 \delta$

$\mathrm{T} \rho$.

845

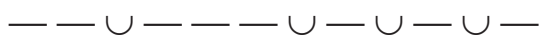

3 ia

E $\rho$.

846

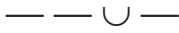

847

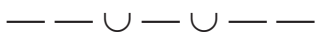

848

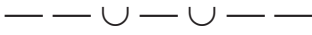

849

$-\cup \cup-\cup-\cup--\cup-$

850

$\cup \cup \cup \cup-\mid \cup--\cup-$

$\mathrm{T} \rho$.

851

$\cup-\cup---\cup-\cup-\cup-$

3 ia

852

$-\cup \cup-\cup-\cup-\cup-\cup \cap$

3 ia

E $\rho$.

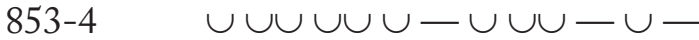
$2 \delta$

855

$\cup \cup \cup-\cup-\cup \cup \cup-\ldots$

856

$\cup-\cup-\cup-\cup-$

$2 \delta$

857

$\cup \cup-\cup \cup-\cup-\cdots$

2 ia

858

$-\cup \cup-\cup-$

859

$\cup \cup \cup-\cup-\cup \cup \cup-\cup-$

860

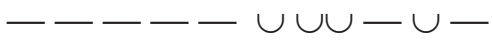

861

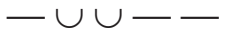

862

$\cup \cup-\cup \cup-\cup--$

863

$--\cup \cup-\cup \cup-\cup \cup$

864

${ }^{47}$ Cf. Diggle. comm. Phaeth., p. 167. 
865

Fourth Stasimon (Andr. 1010-1046)

Strophe 1

$$
\begin{aligned}
& 1010 \\
& --\cup---\cup \cup-\cup \cup-\cdots-\cup- \\
& -\mathrm{e}-\mathrm{D}-\mathrm{e} \\
& \text { 1011-2 } \\
& -\longleftarrow \cup \cup-\cup \cup---\cup \\
& -\mathrm{D}-\mathrm{e} \int \\
& 1013 \\
& -\cup \cup-\cup \cup- \\
& \cup \cup-\cup \cup-\cup-\cup \\
& \text { D II } \\
& -\cup-\cup--
\end{aligned}
$$
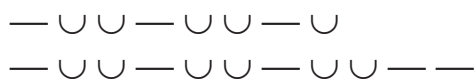

$\sim$ antistrophe 1

1019

1020-1

1022

1023

1024

1025

1026

1027

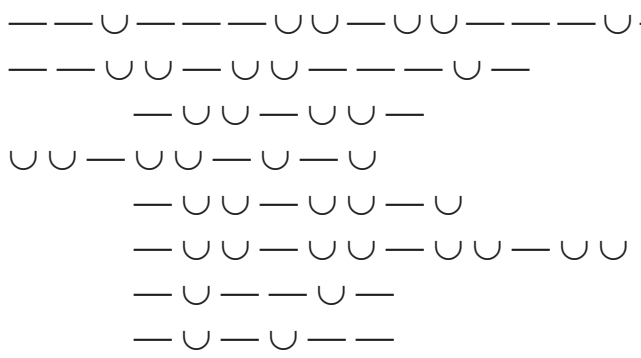
$-\mathrm{e}-\mathrm{D}-\mathrm{e}$ $-\mathrm{D}-\mathrm{e} \int$ D || diom $\mathrm{D} \cup$ $4 \mathrm{da} \int$ $2 \mathrm{cr} \int$ ith

Strophe 2

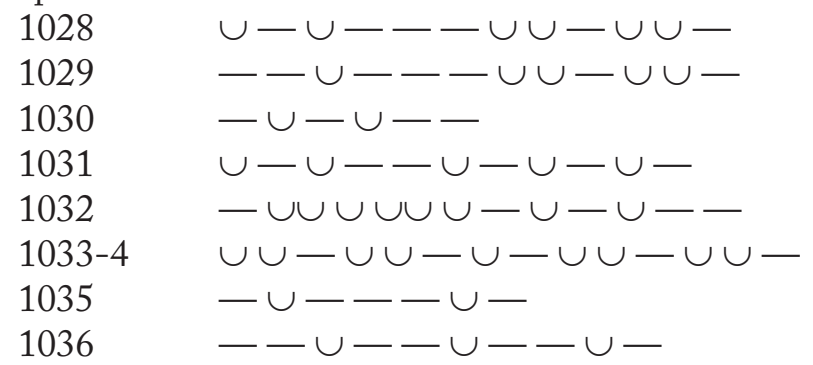

$$
\begin{array}{r}
\cup e-D \\
-e-D \\
i t h \\
i a+c r+i a \\
2 i a+b a \\
\wedge D \cup D \\
e-e \\
i a+2 c r
\end{array}
$$
$\sim$ antistrophe 2

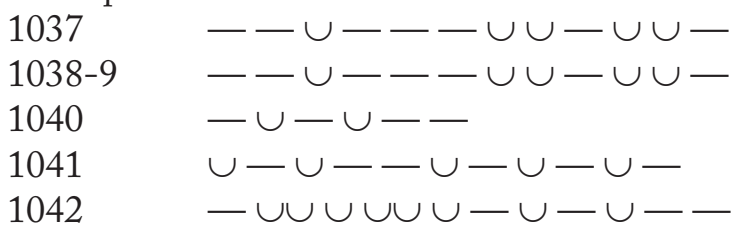

$$
\begin{array}{r}
-\mathrm{e}-\mathrm{D} \\
-\mathrm{e}-\mathrm{D} \\
\mathrm{ith} \\
\mathrm{ia}+\mathrm{cr}+\mathrm{ia} \\
2 \mathrm{ia}+\mathrm{ba}
\end{array}
$$

\footnotetext{
${ }^{48}$ Or dochmiac? See Willink (2010: 649).
} 
1043-4

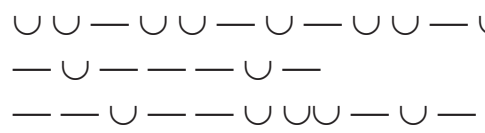
$\wedge \mathrm{D} \cup \mathrm{D}$
$\mathrm{e}-\mathrm{e}$
$\mathrm{ia}+2 \mathrm{cr}$

1045

1046

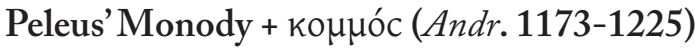

Strophe $1 \sim$

Пү.

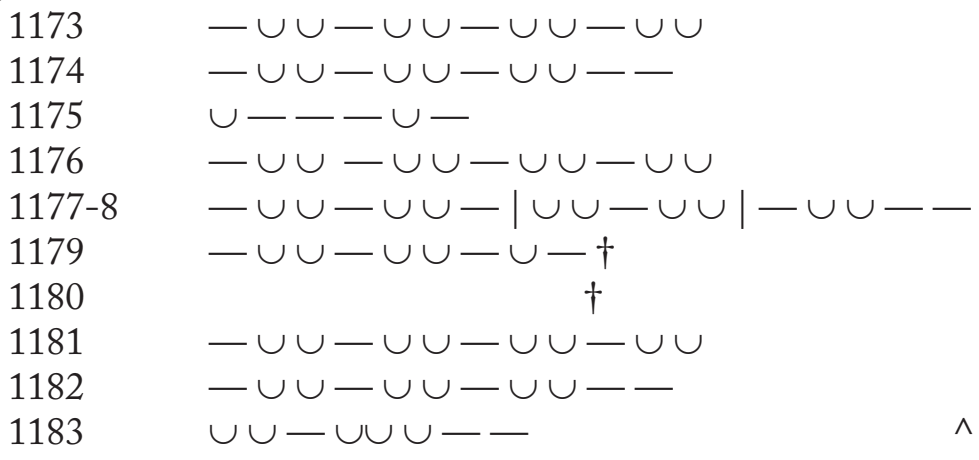

$4 \mathrm{da}$ $4 \mathrm{da}$

e. m. ? $4 \mathrm{da}$ $6 \mathrm{da}$ $1177-8$

$\sim$ antistrophe 1

1186

$$
\begin{aligned}
& -\cup \cup-\cup \cup-\cup \cup-\cup \cup \\
& -\cup \cup-\cup \cup-\cup \cup-- \\
& \cup-\cup \cup--
\end{aligned}
$$

1188

$4 \mathrm{da}$

1188

$4 \mathrm{da}$

1189

$\dagger-\cup \cup-\cup \cup-\cup \cup-\cup \cup$

e. m. ?

1190-1

1192

1193

1194

$-\cup \cup-\cup \cup-\mid \cup \cup-\cup \cup-\cup \cup--$ $\dagger$

1195

1196

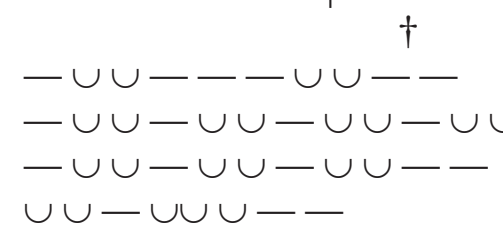

$4 \mathrm{da}$

$4 \mathrm{da}$

$4 \mathrm{da}$

$\wedge 2 \mathrm{da}+\mathrm{ba}$

Strophe 2

Xo.
$1197-8$
$-\cup \cup \cup-\cup-\cup-\cup-\cup-$
3 ia
1199
$\cup---\cup-\cup--$
$\mathrm{ba}+\mathrm{ith}$

Пฤ.

$\begin{array}{llr}1200-1 & -\cup \cup \cup-\cup \cup \cup \cup-\cup-\cup- & 3 \text { ia } \\ 1202-3 & \cup---\cup-\cup-- & \text { ba }+ \text { ith }\end{array}$

${ }^{49}$ See Willink (2010: 660) and above, p. 68 (n. 140). 
Part II - Scansions

Xo.

1204

$\cup-\cup-\cup \cup \cup \cup-\cup-\cup-$

П†.

$1205-\cup-\cup \cup \cup \cup \cup-$

[1206 - - $-ー-\cup \cup \cup$

$1207 \cup-\cup-\cup-\cup-$

$\mathrm{cr}+\mathrm{ith} \| \mathrm{Ba}$
$\mathrm{mol}+\delta$ ?]
$2 \mathrm{ia}$

Xo.

$1208 \cup \cup \cup-\cup-\cup-\cup-\cup-$

3 ia

П†.

$1209-\cup-\cup-\cup-$

$1210 \quad-\cup-\cup-\cup-$

$1211 \cup-\cup-\cup-\cup \cup \cup \cup-\cup-$

$1212 \cup-\cup-\leftarrow \cup-\cup--$

$1 \mathrm{k}$
$\mathrm{lk} \|^{\mathrm{Ba}}$
$3 \mathrm{ia}$

$\sim$ antistrophe 2

Xo.

$\begin{array}{ll}1213-4 & -\cup \cup \cup-\cup-\cup-\cup-\cup- \\ 1215 & \cup-\leftarrow-\cup-\cup--\end{array}$

3 ia $\mathrm{ba}+\mathrm{ith}$

П†.

$1216 \cup \cup \cup \cup \cup \cup \cup-\cup-\cup-$

1217

$\cup---\cup-\cup-$

3 ia

ba + ith

Xo.

$1218 \cup \cup \cup-\cup-\cup-\cup-\cup-$

3 ia

П†.

$1219 \quad-\cup \cup \cup-\cup-\cup-\cap$
$1220 \quad-\cup \cup-\cup-\cup-$

$\mathrm{cr}+\mathrm{ith} \|^{\mathrm{B}}$

2 ia

Xo.

1221

$\cup-\cup-\cup-\cup-\cup-\cup-$

3 ia $\|^{\mathrm{H}}$

П†.

$\begin{array}{ll}1222 & -\cup-\cup-\cup- \\ 1223 & -\cup-\cup-\cup \cap \\ 1224 & \cup-\cup-\cup \cup \cup \cup-\cup-\cup- \\ 1225 & \cup-\cup-\backsim \cup-\cup-\cap\end{array}$

$1 \mathrm{k}$

$1 \mathrm{k}||^{\mathrm{Ba}}$

3 ia

ia + ith 


\section{Hecuba}

Ek.

68

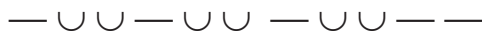

2 an

69

$\cup \cup-\cup \cup-\cup \cup-$

70

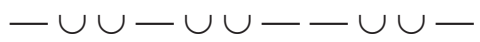

prm

2 an

71

$\cup \cup-\cup \cup--\cup \cup--$

2 an

72

$\cup \cup-\cup \cup-\cup \cup-\cap$

prm $\|^{\mathrm{B}}$

[...]

79

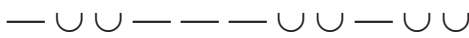

2 an

80

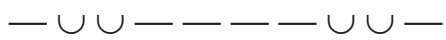

2 an

81

$-\cup \cup----\cup \cup-$

2 an

82

$--\cup \cup-\cup \cup-$

83

$--\cup \cup \cap$

84

$--\cup \cup-\cup \cup-\cup \cup-$

85

$-\cup \cup---\cup \cup--$

86

87

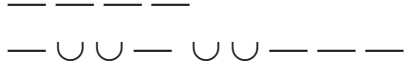

88

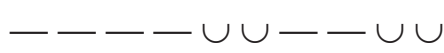

prm

an $\|^{\mathrm{B}}$

2 an

2 an

an

2 an

2 an

89

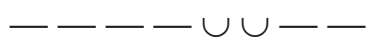

prm

Hecuba Polyxena (Hec. 154-210)

Strophe

EK.

154

155

156

157

158

159

160

161

162

163

164
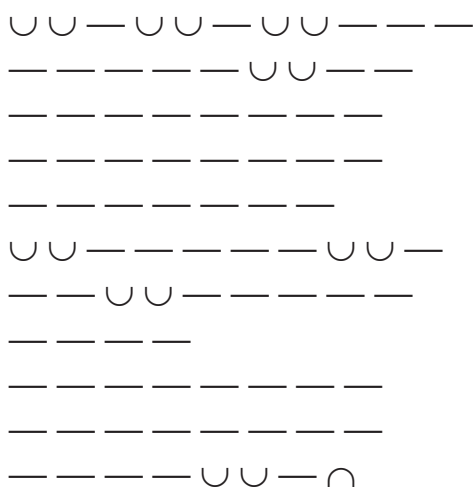

2 an

2 an

2 an

2 an

prm

2 an

2 an

an

2 an

2 an

prm $\|^{\mathrm{B}}$ 
$\sim$ antistrophe $\mathrm{e}^{51}$

По.
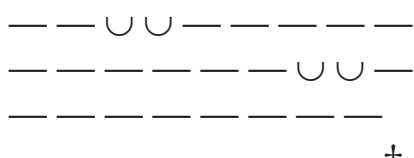

200

201

202

$\dagger$
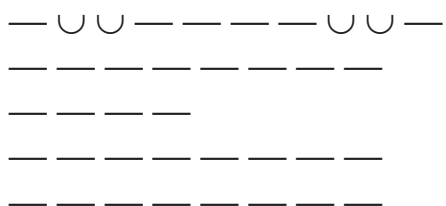

$<$

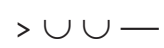

208
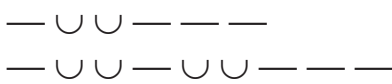

\section{Anapaestic duet (Hec. 177-196)}

По.

EK.

По.

181 $\cup \cup---\cup \cup-\cup \cup$

Eк.

${ }^{50}$ Called 'iambische Tripodie' by Matthiessen (comm. Hec., p. 423). The ' $\delta$ ' at 165 is interpreted anapaestically by West (1982: 123). See above, p. 65 .

${ }^{51}$ Responsion between Polyxena's monody and Hecuba's is declined by Matthiessen (comm. Hec., p. 276) because of the many 'Eingriffe in den überlieferten Text' that it entails. 
По.

183

prm

184

185

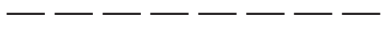

prm

$\delta$

Ek.

186

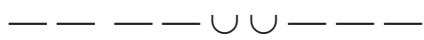

2 an

По.

187

$\cup \cup--$

an

EK.

188

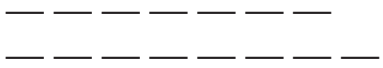

prm

189

2 an

190

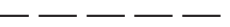

По.

191

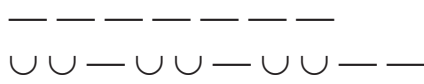

prm $\|^{\mathrm{H}}$

192

$\cup \cup--$

prm

an

EK.

194

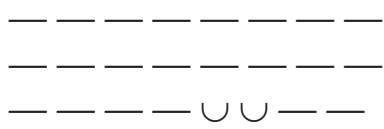

First Stasimon (Hec. 444-483)

Strophe 1

444

445

446

447

448

449

450

451

452

453-4

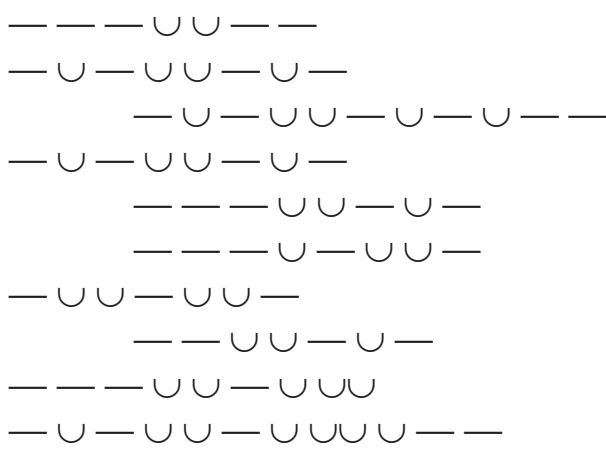

$\sim$ antistrophe 1

455

456

457

458

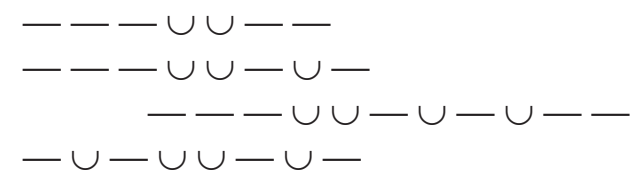

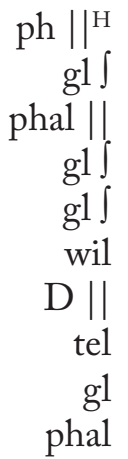

ph $\|$ Hs g1 $\int$ phal || gl f 
Part II - Scansions

459

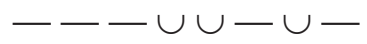

460

461

462

$-\cup \cup-\cup \cup-$

463

$-\leftarrow \cup \cup \cup-$

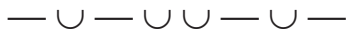

464-5

Strophe 2

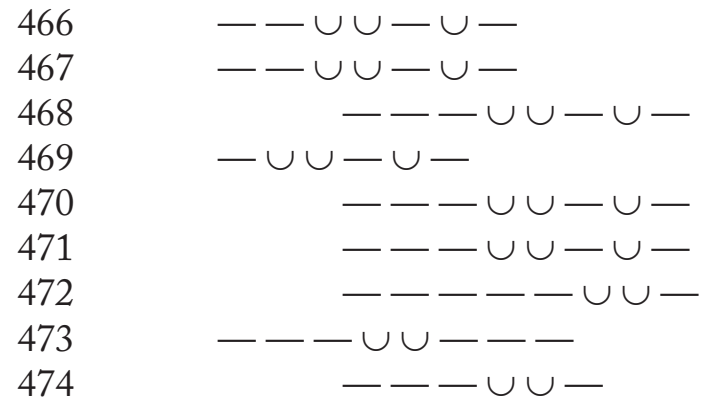

$\sim$ antistrophe 2

475

$--\cup \cup-\cup-$

476

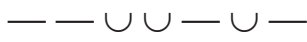

477

478

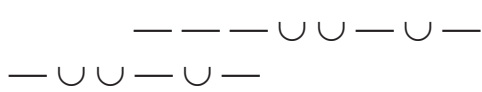

479

480

481

482

483
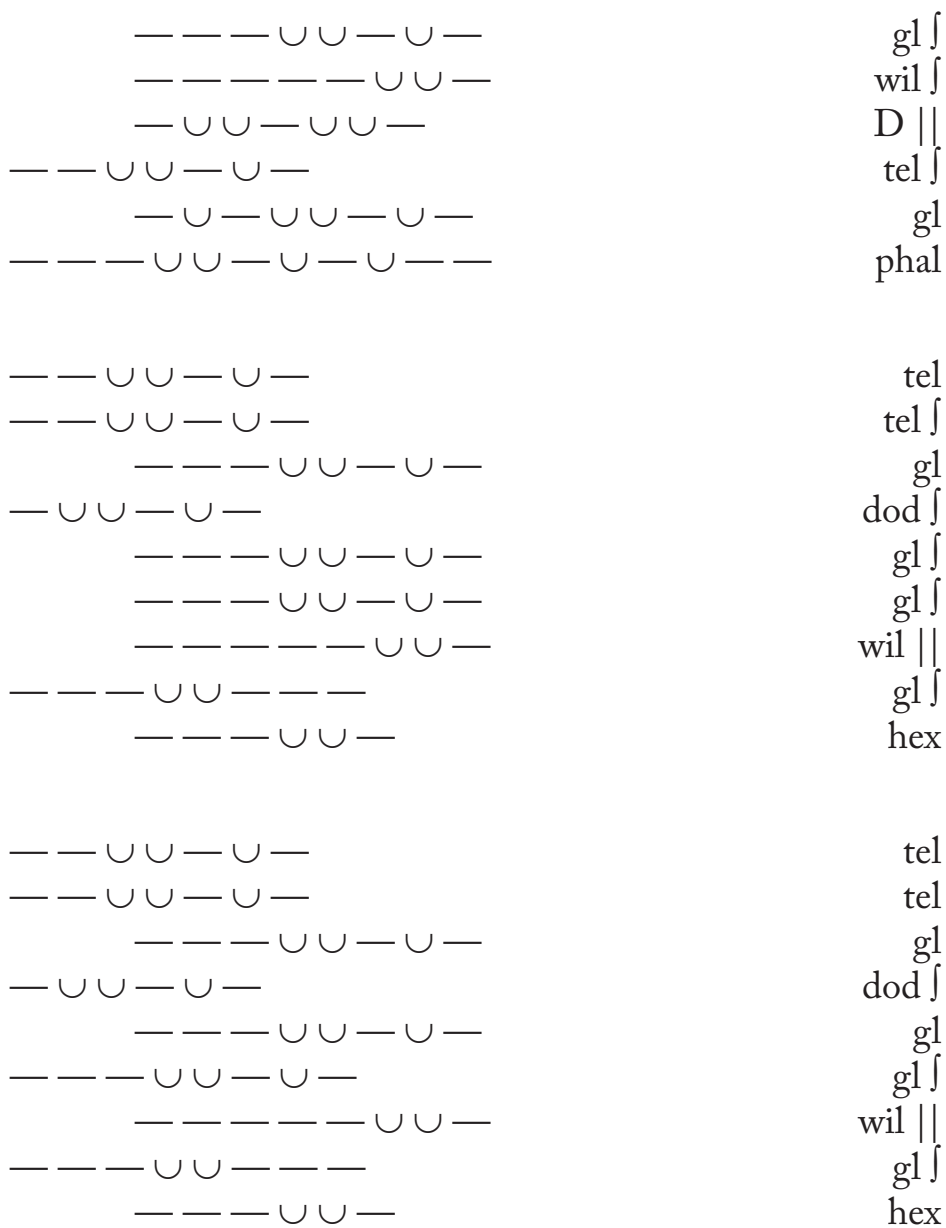

g1

\section{(n)}

phal l

\section{Second Stasimon (Hec. 629-667)}

Strophe

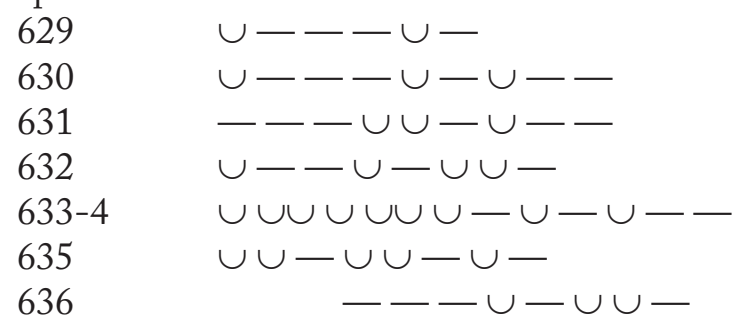

$$
\begin{array}{r}
\mathrm{ba}+\mathrm{cr}\|\|^{52} \\
\mathrm{ba}+\mathrm{cr}+\mathrm{ba} \|^{\mathrm{Hs}} \\
\text { hipp } \| \\
\text { wil } \| \mathrm{Ha} \\
2 \mathrm{ia}+\mathrm{ba} \| \\
\mathrm{T} \\
\text { wil }
\end{array}
$$

\footnotetext{
${ }^{52}$ See above, p. 98.
} 
$\sim$ antistrophe

638

639

640

641

642-3

644

645

646

epode

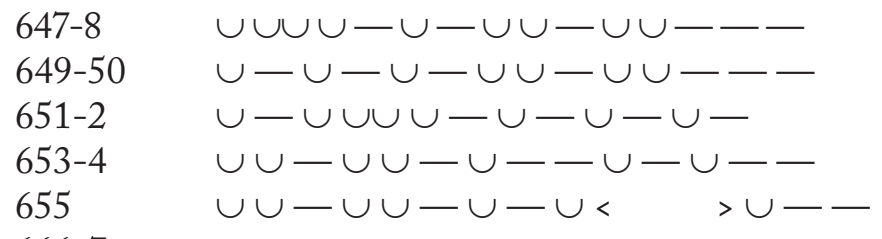

666-7 $\cup--\cup-$

$\cup---\cup-\cup--$

$---\cup \cup-\cup-\cdots$

$\cup--\cup-\cup \cup-$

$\cup \cup \cup \cup \cup \cup \cup-\cup-\cup-$

$\cup \cup-\cup \cup-\cup-$

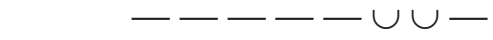

$-\cup \cup--$

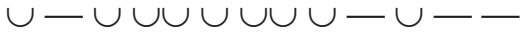

$$
\begin{array}{r}
\mathrm{ba}+\mathrm{cr} \| \\
\mathrm{ba}+\mathrm{cr}+\mathrm{ba} \| \mathrm{Hs} \\
\text { hipp } \| \\
\text { wil } \|\left.\right|^{\mathrm{H}} \\
2 \mathrm{ia}+\mathrm{ba} \| \\
\mathrm{T} \int \\
\text { wil } \\
\text { dod }^{\text {chol }}
\end{array}
$$

iambelegus $+\mathrm{sp}^{54}$ iambelegus $+\mathrm{sp}$ 3 ia $\mathrm{T}+\mathrm{ith}$

$2 \mathrm{ia}+\mathrm{ba}$

\section{Hecuba’s Lament (Hec. 681-711)}

Eк.

684
685
686
687
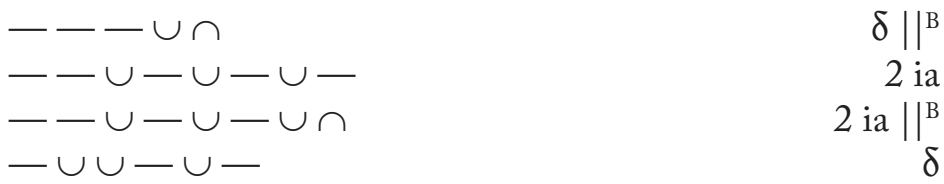

Xo.

688

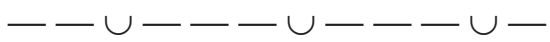

3 ia $\|^{\mathrm{BH}}$

EK.

689

690

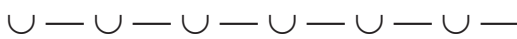

691

$\cup \cup \cup \cup \cup \cup-\cup \cup \cup-\cup-$

$-\cup \cup-\cup-\cup \cup \cup-\cup-$

3 ia $\|^{\mathrm{H}}$

$2 \delta\|\|^{\mathrm{H}}$

$2 \delta$

692

$\cup-\cdots-$

Xo.

693

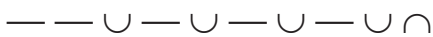

3 ia $\|^{\mathrm{BH}}$

\footnotetext{
${ }^{53}$ On the possibility of a dragged dodrans, see Parker (1997: 71-2).

${ }^{54}$ Cf. above, p. 85.
} 
Part II - Scansions

EK.

694

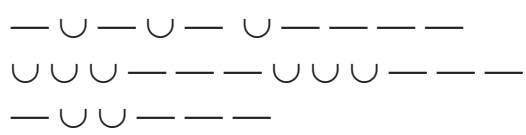

$\mathrm{h} \delta+\delta$

695-6

697

$\Theta \varepsilon(\rho \alpha ́ \pi \alpha \imath v \alpha)$

698

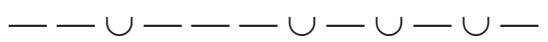

3 ia

EK.

699

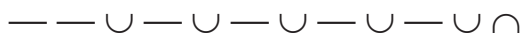

700

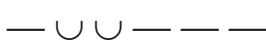

3 ia

$\Theta \varepsilon$.

701

$--\cup---\cup \cup \cup \cup-\cup-$

3 ia

EK.

702

$----$

e. m. ? $\|^{\mathrm{H}}$

703

$\cup--\cup-\cup \cup \cup--$

2 ia

704

$\cup \cup \cup-\cup \cap$

$2 \delta \int$

705

$-\cup-\cup-\cup-$

706

$\delta \|^{\mathrm{B}}$

$1 \mathrm{k} \|^{\mathrm{H}}$

$707 \quad-\cup \cup-\cup-\leftarrow \cup \cup-\cup$

$2 \delta$

Xo.

708

$--\cup---\cup-\cup-\cup-$

3 ia

EK.

709-10

$\cup \cup \cup-\cup--\cup \cup-\cup-$

$2 \delta$

711

$\cup \cup \cup \cup \cup \cup \cup--$

$2 \delta$

Third Stasimon (Hec. 905-952)

Strophe 1

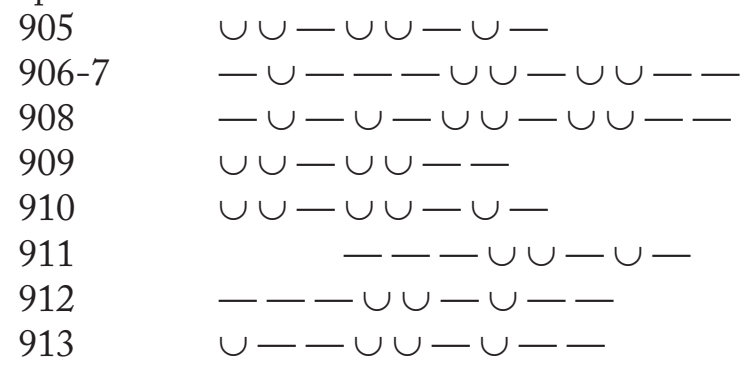

$$
\begin{array}{r}
\mathrm{T} \\
\mathrm{e} \cup \mathrm{D}- \\
\text { reiz } \\
\mathrm{T} \int \\
\mathrm{g} 1 \\
\text { hipp } \\
\text { hipp }
\end{array}
$$

$\sim$ antistrophe 1

914

$\cup \cup-\cup \cup-\cup-$

915-6

$-\cup---\cup \cup-\cup \cup-$

$\mathrm{e}-\mathrm{D}-$ 
Strophe 2

923

$\cup-\cup \cup \cup \cup \cup \cup \cup-$

2 ia

924

$\cup-\cup-\cup-\cup-$

2 ia

925-6

927

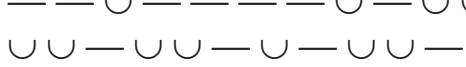

?55

$\mathrm{T}+\mathrm{ba}$

928

$\cup \cup \cup \cup \cup \cup \cup$

2 ia $\|$

929

$\cup-\cup-\cup-\cup-\cdots-$

2 ia + cr

930

$-\cup-\cup-\cup \cup-\cup \cup-$

$\mathrm{e} \cup \mathrm{D}$

931

$-\cup \cup-\cup \cup-$

$\mathrm{D}$

932

$--\cup-\cup--$

$\mathrm{ia}+\mathrm{ba}$

$\sim$ antistrophe 2

933

934

935-6

937

938

939

940

941

942

epode

$$
\cup-\cup \cup \cup \cup \cup \cup \cup-
$$$$
\cup-\cup-\cup-\cup-
$$

2 ia

2 ia

$\mathrm{T}+\mathrm{ba}$

2 ia

2 ia $+\mathrm{cr}$

e $-D$

D

$\mathrm{ia}+\mathrm{ba}$

$$
\begin{aligned}
& --\cup---\cup \cup-\cup \cup---\cup-- \\
& -\mathrm{e}-\mathrm{D}-\mathrm{e}- \\
& 945 \\
& -\cup \cup-\cup \cup- \\
& 946 \\
& \cup-\cup-\cup-- \\
& 947 \\
& -\cup \cup-\cup-\cup \cap \\
& 948 \\
& 949 \\
& --\cup---\cup \cup-\cup \cup- \\
& \text { 950-1 } \\
& \cup-\cup-\cup-- \\
& 952 \\
& --\cup \cup \cup \cup \cup \cup \cup \cup \cup \cup-\cup- \\
& -\cup \cup-\cup \cup-\cup-\cap
\end{aligned}
$$

\footnotetext{
${ }^{55}$ Matthiessen (p. 433) suggests 'ia + sp + gl'. See above, p. 79.
} 
Hec. 1024-1034

Xo.

1024

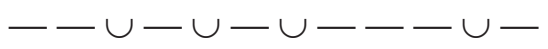

3 ia

1025

$\cup \cup \backsim \cup-\cup--\cup-$

1026-7

$\cup \cup-\cup-\cup--\cup-$

$2 \delta$

$1028-9$

$\cup-ー \cup-\cup \cup U-\cup-$

$2 \delta$

1030

$\cup--\cup-\cup--\cup-$

1031

$\cup \cup \cup \cup \cup \cup \cup-\cup-$

$--\cup---\cup-\cup-\cup-$

3 ia

1033

$\cup \cup \cup-\cup-\cup--\cup-$

$2 \delta$

1034

$\cup \cup ル \cup-\cup--U-$

Polymestor's Monody (Hec. 1056-1106)

По.

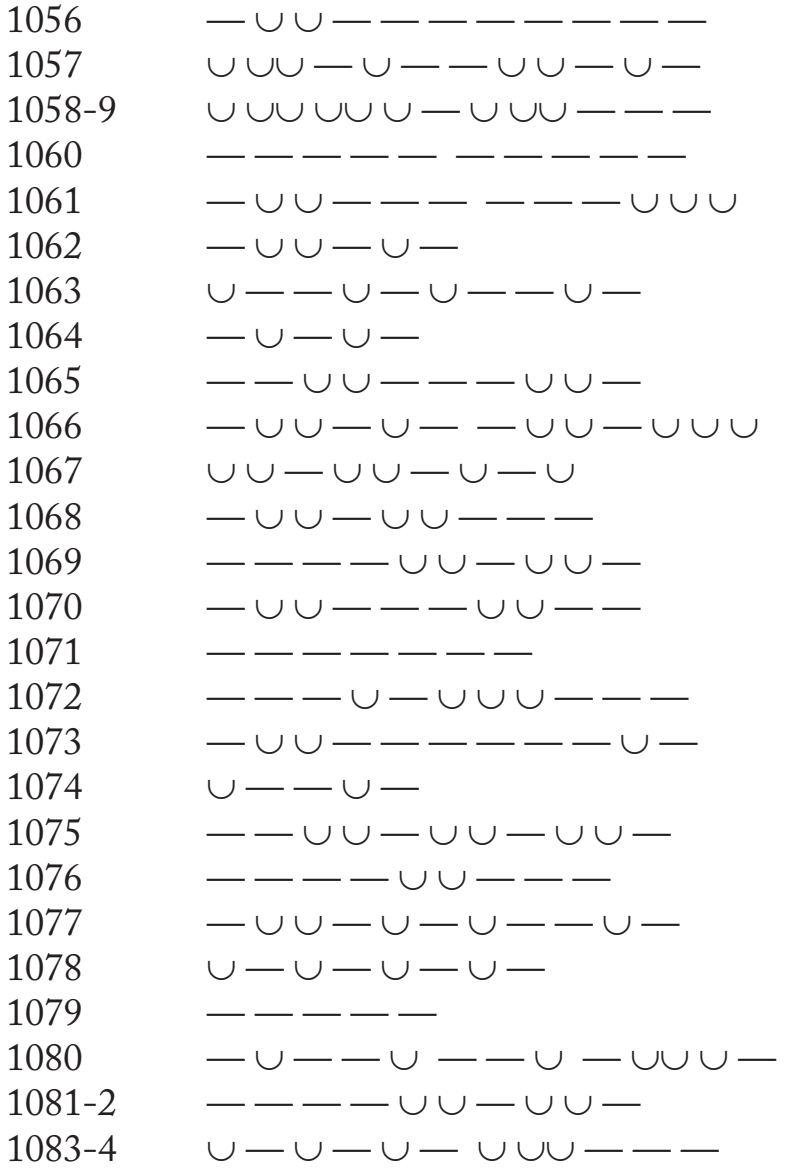


Xo.

1085

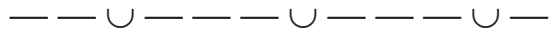

3 ia

1086

$--\cup---\cup-\cup-\cup-$

3 ia

1087

По.

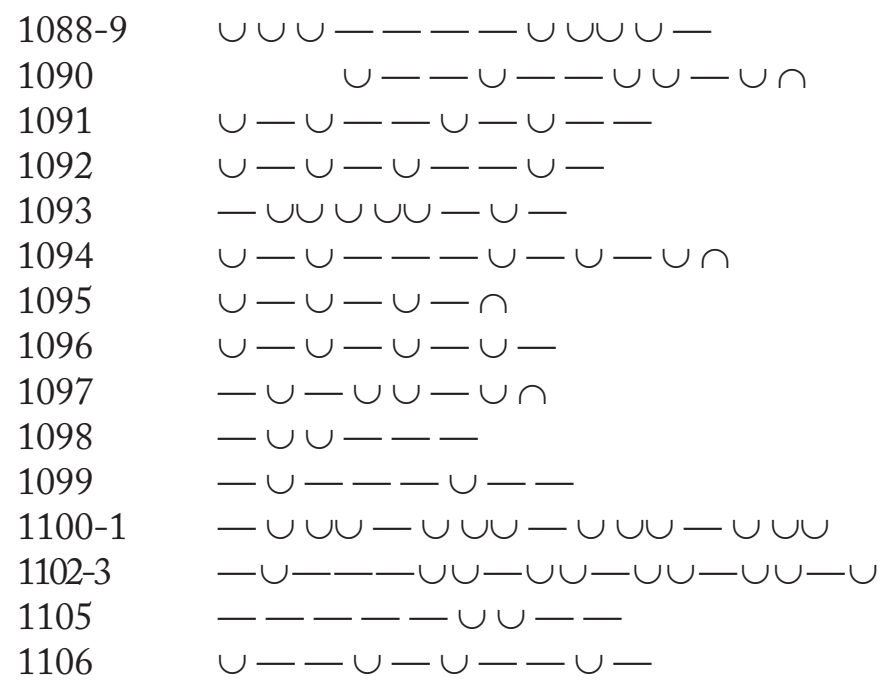

$\delta+\mathrm{h} \delta \int$
$2 \delta \|^{\mathrm{B}}$
$\mathrm{ia}+\mathrm{cr}+\mathrm{ba}$
$\mathrm{ia}+\delta$
$\mathrm{ia}+\mathrm{cr}$
$3 \mathrm{ia} \|^{\mathrm{B}}$
$\mathrm{ia}+\mathrm{ba} \|^{\mathrm{B}}$
2 ia
$\mathrm{gl}$ ? $^{56}$
$\delta$
$2 \mathrm{tr} \|^{\mathrm{H}}$
$4 \mathrm{cr}$
$\mathrm{enop}^{57}$
$\mathrm{~A}$
$2 \delta$

${ }^{56}$ See Parker (1997: 514).

${ }^{57}$ See above, p. 84 (n. 175). 


\section{Supplices}

Parodos (Su. 42-86)

Strophe 1

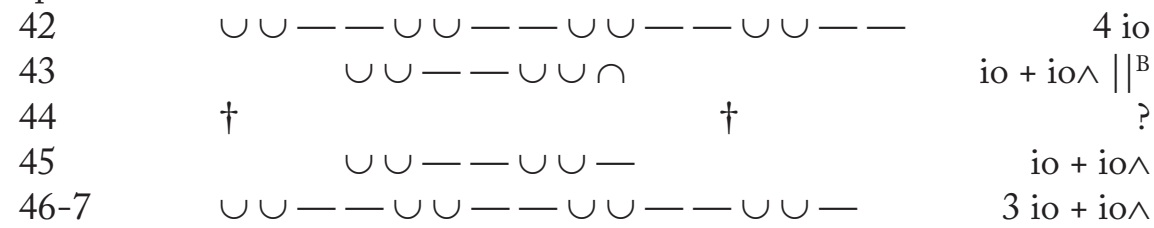

$\sim$ antistrophe 1

48-9

$\cup \cup--\cup \cup--\cup \cup--\cup \cup--$ 4 io $\int$
io + io $\wedge \|^{\text {Bs }}$
2 io $\wedge+$ io $\int^{58}$
io + io $\wedge$
3 io + io $\wedge$

Strophe 2

55

$\cup \cup--\cup \cup--\cup \cup--\cup \cup-$ 4 io $\int$

56

$57-8$

$\cup \cup-\backsim \cup--\cup \cup-$

2 io + io $\wedge$

59

$\cup \cup--\cup \cup--\cup \cup--\cup \cup-$ 4 io

60

$\cup \cup-\leftarrow \cup \cup-$

2 io + io $\wedge$ 4 io $\int$

61

$\cup \cup-\leftarrow \cup \cup--\cup \cup--\cup \cup--$

2 io + io $\wedge$

62

$\cup \cup--\cup \cup--\cup \cup-$

2 io + io $\wedge$

$\sim$ antistrophe 2

63

$\cup \cup-\backsim \cup \cup \backsim$

2 io $+10 \wedge$

64

$\cup \cup--\cup \cup--\cup \cup--\cup \cup-$

4 io

65-6

$\cup \cup--\cup \cup--\cup \cup-$

67

68

$\cup \cup--\cup \cup--\cup \cup--\cup \cup--$

2 io + io $\wedge$

4 io $\int$

2 io + ios

69

$\cup \cup--\cup \cup--\cup \cup-$

4 io $\int$

2 io + io $\wedge \int$

70

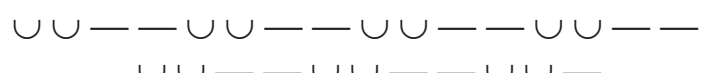

$\cup \cup--\cup \cup--\cup \cup-$

2 io + io $\wedge$

\footnotetext{
${ }^{58}$ See Parker (1997: 62).
} 
Strophe 3

71

72

73

74

75

76

77

78 $\cup-\cup-\cup-\cup-\cup-\cup-$

$\cup \cup \cup \cup--\cup-\cup-\cup \cap$

$\cup-\cup--\cup-$

$\cup-\cup--\cup-$

$\cup-\cup--\cup-$

$\cup \cup \cup-\cup \cup \cup \cup-$

$-\cup-\cup-\cup \cup \cup \cup$

$\cup-\cup--\cup-\cup-\cap$

$$
\begin{array}{r}
3{i a^{59}}^{1}+c r+i a \|^{B} \\
i a+c r \\
i a+c r \\
i a+c r \\
2 \text { tr } \\
2 t r+\stackrel{\varepsilon}{\varepsilon} \varepsilon \\
i a+i t h
\end{array}
$$

$\sim$ antistrophe 3

79

80

81

82

83

84

85

86

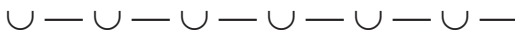

$\cup \cup \cup \cup--\cup---\cup-$

$\cup-\cup--\cup-$

$\cup-\cup--\cup-$

$\cup-\cup--\cup-$

$\cup \cup \cup-\cup \cup \cup \cup-\cup$

$-\cup-\cup-\cup-\cup$

$\cup-\cup--\cup-\cup--$
3 ia $\mathrm{ia}+\mathrm{cr}+\mathrm{ia} \|\left.\right|^{\mathrm{Bs}}$

$\mathrm{ia}+\mathrm{cr}$

$\mathrm{ia}+\mathrm{cr}$

$\mathrm{ia}+\mathrm{cr}$

$2 \operatorname{tr}^{60}$

$2 \operatorname{tr}+\stackrel{\varepsilon}{\varepsilon} \varepsilon$

ia + ith

Su. 271-285

271

272

273

274

[275-6]

277

278-9

280

281

282

283

284

285

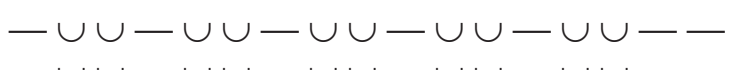

$6 \mathrm{da}$ $6 \mathrm{da}$ $6 \mathrm{da}$ $6 \mathrm{da}$

$6 \mathrm{da}$

$6 \mathrm{da}$

$4 \mathrm{da}$

$6 \mathrm{da}$

$6 \mathrm{da}$

$6 \mathrm{da}$

$6 \mathrm{da}$

\footnotetext{
${ }^{59}$ On 71-86, see Willink (2010: 224-236).

${ }^{60}$ At 84 perhaps the last syllable of yuvaĩkac should be taken as long (breuis in longo), as in the responding position at 76 .
} 
First Stasimon (Su.365-380)

Strophe $1 \sim$

$\begin{array}{llr}365 & -\cup \cup \cup-\cup-\cup \cup \cup \cup ー \cup ー & 3 \mathrm{ia} \\ 366 & \cup \cup \cup \cup \cup \cup \cup \cup \cup \cap & 1 \mathrm{k} \|^{\mathrm{HB}} \\ 367 & \cup-\cup \cup \cup \cup \cup \cup \cup- & 2 \mathrm{ia} \\ 368 \mathrm{a} & -\cup \cup \cup \cup-\cup- & \mathrm{kk} \\ 368 \mathrm{~b} & -\cup-\cap & \text { tr }\end{array}$

$\sim$ antistrophe 1

369

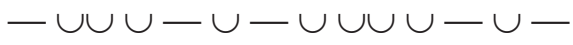

3 ia

370

$\cup \cup \cup \cup \backsim \cup$

$1 \mathrm{k} \mid \|^{\mathrm{B}}$

371

$\cup-\cup \cup \cup-\cup-$

$372 \mathrm{a}$

$-\cup \cup \cup-\cup-$

2 ia

$372 b$

$-\cup--$

$1 \mathrm{k}$

$\operatorname{tr}$

Strophe 2

373

374

$\cup-\cup-\cup \cup \cup \cup-\cup-\cup-$

$3 \mathrm{ia}^{61}$

375

$\cup-\cup--\cup--\cup-$

$\mathrm{ia}+\mathrm{cr}+\mathrm{cr}$

376

$\cup-\cup-\cup-\cup \cup \cup \cup-\cup-$

3 ia

$\mathrm{cr}+\mathrm{ba}+\mathrm{ba}$

$\sim$ antistrophe 2

377

$-\cup-\cup--\cup-\cap$

378

379

$\cup-\cup-\cup \cup \cup \cup-\cup-\cup-$

3 ia $\mathrm{ia}+\mathrm{cr}+\mathrm{cr}$

380

$\cup-\cup--\cup--\cup-$

3 ia

$\mathrm{cr}+\mathrm{ba}+\mathrm{ba}^{62}$

Second Stasimon (Su.598-633)

Strophe 1

598

599

$-\cup \cup-\cup \cup--\cup-\cup--$

$\mathrm{D}+\mathrm{ith}$

600

corrupt

601

$\cup---\cup-\cup-\cup-$

$\mathrm{ba}+\mathrm{cr}+\mathrm{ia}$

$\mathrm{ia}+\mathrm{cr}+\mathrm{ia}$

602

$\cup-\cup--\cup-\cup-\cup-$

3 ia

603

$\cup \cup \cup \cup-\cup-\cup-\cup-\cup-$

$\mathrm{ba}+\mathrm{cr}+\mathrm{ia}$

604

$\cup---\cup-\cup-\cup-$

ia + 'ch' + ia

605

$\cup-\cup--\cup \cup-\cup-\cup-$

$\cup-\cup--ー \cup-\cup \cup U \cup \amalg$

3 ia

${ }^{61}$ On the phrasing of this and the responding stanza, see Stinton (1990: 130-1).

${ }^{62}$ See Diggle (1994: 457). 
606-7<smiles>O[AlH2]O[Hg]</smiles>

$\mathrm{ba}+\mathrm{ith}$

$\sim$ antistrophe 1

608

609

610

611

612

613

614

615

616-7 $-\cup \cup-\cup \cup--\cup-\cup-$

$-\cup \cup-\cup \cup-\cup \cup-\cup-$

$\cup--\cup-\cup-\cup-$

$\cup-\cup-\leftarrow \cup-\cup-$

$\cup \cup \cup-\cup-\cup-\cup-\cup-$

$\cup-\leftarrow-\cup-\cup-\cup-$

$\cup-\cup-\cup \cup \cup \cup \cup-\cup$

$\cup-\cup-\cup-\cup-\cup-\cup-$

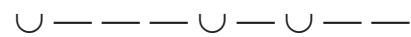

$\mathrm{D}+\mathrm{ith}$ prax $\|$ $\mathrm{ba}+\mathrm{cr}+\mathrm{ia}$ $\mathrm{ia}+\mathrm{cr}+\mathrm{ia}$ 3 ia $\mathrm{ba}+\mathrm{cr}+\mathrm{ia}$ 3 ia 3 ia $\int$ ba + ith

Strophe 2

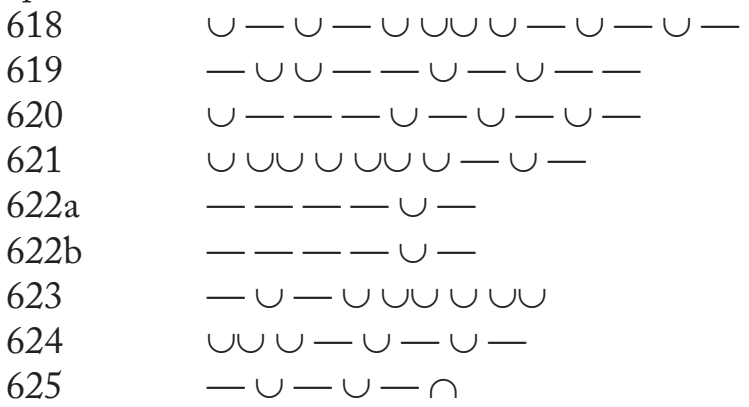

3 ia 'ch' + cr + ba $\|^{\mathrm{Ha}}$ $\mathrm{ba}+\mathrm{cr}+\mathrm{ia}$ 2 ia $\mathrm{mol}+\mathrm{cr}$ $\mathrm{mol}+\mathrm{cr}$ $1 \mathrm{k}$ $1 \mathrm{k}$ ith

$\sim$ antistrophe 2

626

$\cup-\cup-\cup \cup \cup \cup-\cup-\cup-$

3 ia

627

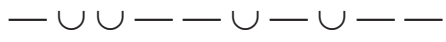

628

$\cup--\backsim \cup \cup \cup-$

629

$-\cup \cup \cup U \cup-\cup$

$630 \mathrm{a}$

$\cup---\cup-$

$630 \mathrm{~b}$

$\cup---\cup-$

631

$\cup \cup-\cup \cup \cup \cup U$

'ch' + cr + ba $\|^{\mathrm{H}}$

$\mathrm{ba}+\mathrm{cr}+\mathrm{ia}$

2 ia

$\mathrm{ba}+\mathrm{cr}$

$\mathrm{ba}+\mathrm{cr}$

632

$\cup \cup \cup-\cup-\cup-$

$1 \mathrm{k}$

$1 \mathrm{k}$

633

$-\cup-\cup--$

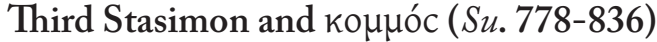

Strophe $1 \sim$

778

779

$\cup \cup-\cup \cup-\cup-$

780

$\cup-\cup--\cup-$

$\mathrm{ia}+\mathrm{cr}$

781

$-\cup-\cup-\cup-$

$1 \mathrm{k}$

$\mathrm{ia}+\mathrm{sp} \|^{\mathrm{H}}$ 
$\mathrm{ia}+\mathrm{cr}+\mathrm{ia}$

$\sim$ antistrophe 1

786

787

788

789

790

791

792

793 $\cup \cup-\cup \cup-\cup-$

$\cup-\cup--\cup-$

$-\cup-\cup-\cup-$

$\cup-\cup-\cdots$

$\cup-\cup--\cup-\cup-\cup-$

$-\cup-\cup-\cup-$

$\cup-\cup--\cup-\cup-\cap$ $\cup-\cup-\cup-\cup-\cup-\cup-$

$$
\begin{array}{r}
\mathrm{T} \\
\mathrm{ia}+\mathrm{cr} \\
\mathrm{lk} \\
\mathrm{ia}+\mathrm{sp} \|\left.\right|^{\mathrm{Hs}} \\
\mathrm{ia}+\mathrm{cr}+\mathrm{ia} \\
3 \mathrm{ia} \\
\mathrm{lk} \\
\mathrm{ia}+\mathrm{ith}
\end{array}
$$

Strophe 2

798

799

$\cup-\cup--\cup-$

$-\cup-\cup-\cup-$

800

801

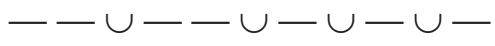

802

$\cup-\cup-\cup--$

803

$-\cup-\cup-\cup-$

$\cup-\cup-\cup-\cup-$

$804^{63}$

$\cup--\cup-\cup-\cap$

805

806

$\cup-\cup--\cup-\cup-\cup-$

lacunose

807

$\cup \cup \cup \cup-\cup-\cup-\cdots \cup-$

808

809

$-\cup \cup---\cup \cup-\cup \cup-\cup \cup-\cap$

$\cup-\cup-\cup-\cup-$

$-\cup-\cup-\cap$ $\mathrm{ia}+\mathrm{cr}$ $1 \mathrm{k}$ $\mathrm{ia}+\mathrm{cr}+\mathrm{ia}$ $\mathrm{ia}+\mathrm{ba}\|\|^{\mathrm{H}}$ 2 ia 2 ia $\delta+$ ba $\|^{\mathrm{HB}}$ $\mathrm{ia}+\mathrm{lk} \|^{\mathrm{HBa}}$

$2 \mathrm{ia}+\mathrm{cr}$ $6 \mathrm{da}$ 2 ia $\int$ ith

$\sim$ antistrophe 2

811

812

813

814

815

816

$\cup \cup \cup \cup \cup \cup-\cup-$ $\mathrm{ia}+\mathrm{cr}$ $1 \mathrm{k}$ $\mathrm{ia}+\mathrm{cr}+\mathrm{ia}$ $\mathrm{ia}+\mathrm{ba}\|\|^{\mathrm{Hs}}$ 2 ia 2 ia

817

818 $-\cup-\cup-\cup-$ $\delta+\mathrm{ba} \| \mathrm{H}$ $\mathrm{ia}+\mathrm{lk} \|{ }^{\mathrm{B}}$ $\mathrm{sp}+\mathrm{lk}$

${ }^{63}$ See Wilamowitz (1921: 250-1), Stinton (1990: 114-9) and Diggle (1994: 395). 


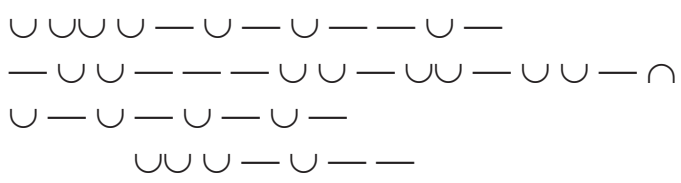

$2 \mathrm{ia}+\mathrm{cr} \|^{\mathrm{H}}$

821

822

823

$\cup \cup-\cup-$ $6 \mathrm{da}$ 2 ia ith

epode

824

825

$\cup \cup \cup \cup-\cup \cup \cup--\cup-$ $\mathrm{ia}+2 \mathrm{cr}$

826

827

$\cup--\cup$ $\delta$

3 ia 2 ia $\|^{\mathrm{HB}}$

828 e. $\mathrm{m}$.

829

$\cup-\cup-\cup-\cup \cap$

$-\cup-\cup-$

830

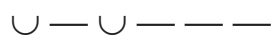

831-2

$\cup \cup \cup--\cup-$

833

$\cup-\cup-\cup \cup \cup \cup-\cup-\cup-$

834

$\cup-\cup--\cup-$

835

$\cup-\cup-\backsim \cap$

836

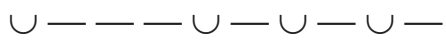

$\mathrm{ia}+\mathrm{cr}\|\|^{\mathrm{B}}$

$\mathrm{ba}+\mathrm{cr}+\mathrm{ia}$ 'ch' $+\mathrm{cr}+\mathrm{ba}$

ö́cтрочоv (Su. 918-924)

918

919

$\cup-\cup--\cup-$

$\cup \cup \cup \cup \cup \cup \cup-\cup-$

920

921

$\cup-\cup--\cup--\cup-$

922

$-\cup \cup \cup-\cup-$

923

$\cup--\cup-\cup-$

924

$\cup-\cup-\cup-\cup-\cup-\cup-$

$-\cup-\cup-\cap$

\section{Fourth Stasimon (Su.955-979)}

Strophe

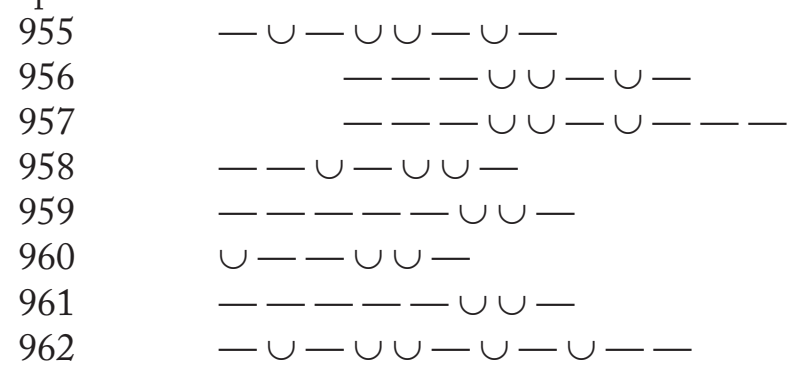

gl $\int$ gl $\int$ $\mathrm{g} 1+\mathrm{sp}$ hept wil hex wil phal

\footnotetext{
${ }^{64}$ Extra metrum?
} 
$\sim$ antistrophe

963

$-\cup-\cup \cup-\cup-$

964

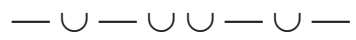

965

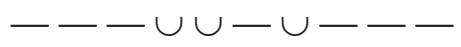

966

$--\cup-\cup \cup-$

967

968

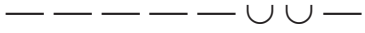

corrupt

969

corrupt $^{65}$

970

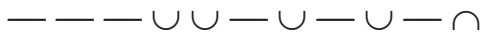

phal

epode

971

$\cup \cup \cup-\cup \cup-\cup \cup \cup$

g1

972

$\cup \cup \cup-\cup \cup--$

ph

973

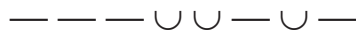

g1

$974 \mathrm{a}$

$--\backsim \cup \cup-\cup$

$974 \mathrm{~b}$

$<--\cup \cup \cup-\cup \cup \rightarrow$

975

$\cup----\cup \cup-$

976

$\cup----\cup \cup-$

977

$\cup-\cup-\backsim \cup \cup$

978

$\cup \cup \cup \cup \cup-\cup$

979

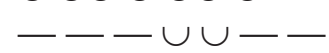

$2 \mathrm{ba}$

$\mathrm{gl} \|^{\mathrm{B}}$

993

994

995

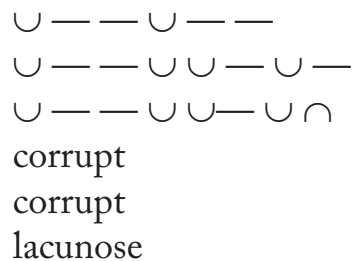

ia + ch

wil

wil ia $+\mathrm{ch}$

$2 \mathrm{ia}^{66}$ $\mathrm{ph}$

Evadne's Monody (Su. 990-1030)

Strophe

990

991

996

997

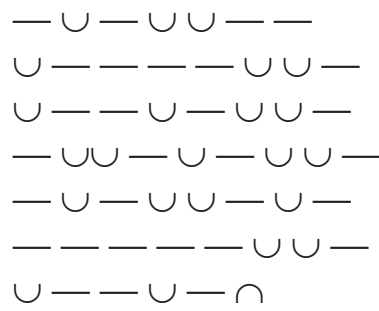

ph

wil

998

999

1000

1001

1002

$\cup-\backsim-\cap$

wil

wil ${ }^{67}$

g1

wil

$2 \mathrm{ba} \| \mathrm{BHa}$

\footnotetext{
${ }^{65}$ On 969 see Diggle (1981: 23-4).

${ }^{66}$ On 978 see Diggle (1994: 123 n. 94); Itsumi (1984: 78).

${ }^{67}$ See Diggle (1994: 506, n. 56); Willink (2010: 395).
} 


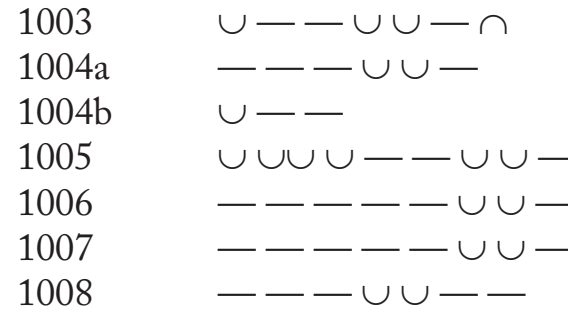

$$
\begin{array}{r}
\text { ph } \\
\text { ph } \\
\text { ba } \\
\mathrm{ia}+\mathrm{cr} \\
\text { wil } \\
\text { wil } \\
\text { ph }
\end{array}
$$

$\sim$ antistrophe

1012

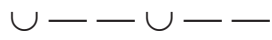

$2 \mathrm{ba}$

1013

$\cup--\cup \cup-\cup$

1014

$\cup--\cup \cup-\cup \cap$

1015

corrupt

1016

corrupt

1018

corrupt

1019

$-\cup-\cup \cup--$

1020

$\cup----\cup \cup-$

ph

wil

1021

$-\cup \cup \cup \cup-\cup \cup-$

wil

1022

$-\cup \cup---\cup \cup-$

wil

1023

$\cup-\cup--\cup \cup-$

wil

1024

$\cup--\cup-\cup \cup-$

wil

1025

$1026 \mathrm{a}$

$\cup--\cup-\cap$

2 ba $\|^{\mathrm{BH}}$

$1026 b$

corrupt

$1027 \mathrm{a}$

$\cup--\cup \cup--$

ph

$1027 \mathrm{~b}$

$\cup-$

ba

1028

corrupt

1029

corrupt

1030

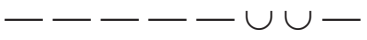

wil

ph

Choral dochmiacs (Su. 1072-1079)

1072

1073

1074

1075

1076

1077

1078

1079 $\cup--\cup-\cup--\cup-$

spoken iambic trimeter

$\cup \cup \cup \cup-$

$\cup--\cup-\cup--\cup-$

spoken iambic trimeter

$\cup-\cup-$

$\cup \cup \cup-\cup--\cup \cup \cup \cup-$

$\cup--\cup-\cup \cup \cup--$
$2 \delta$

$\delta$

$2 \delta$

ia

$\delta+\mathrm{h} \delta$

$2 \delta$ 
Kouнóc (Su. 1123-1163)

Strophe 1
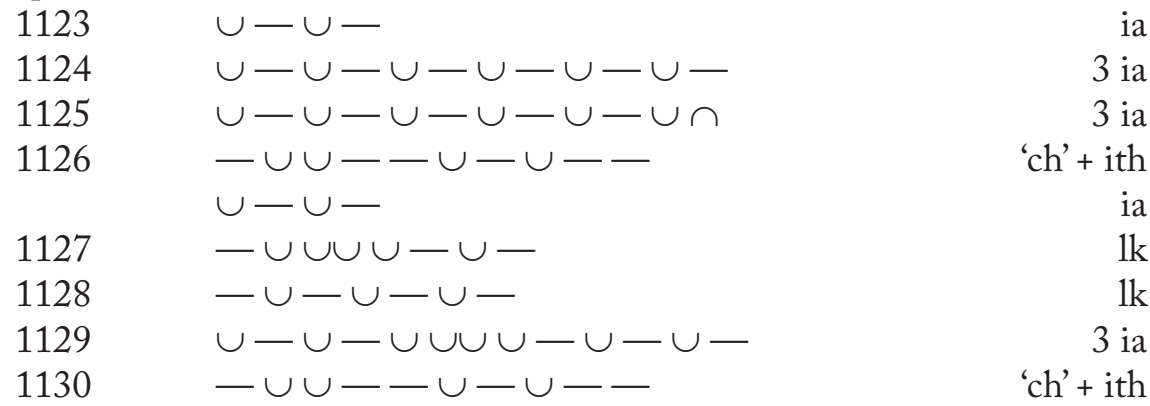

$\sim$ antistrophe 1
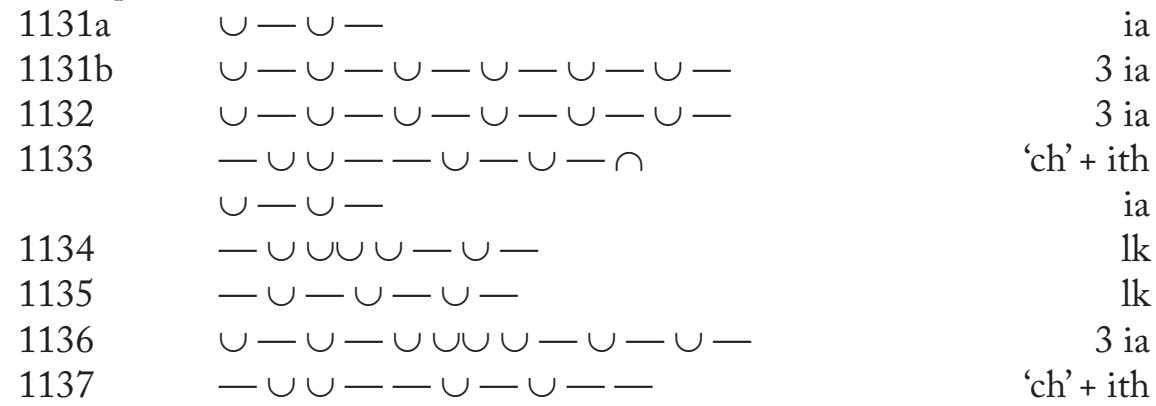

Strophe 2

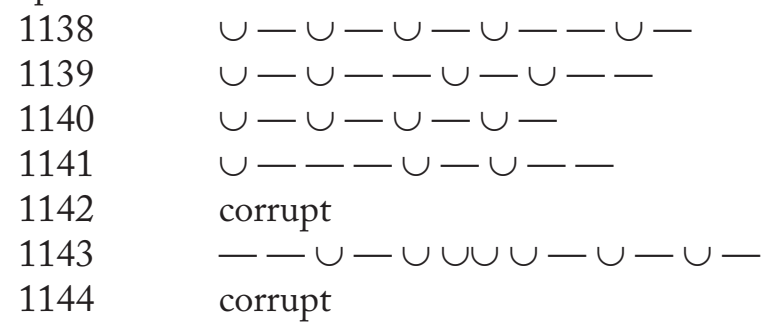

2 ia $+\mathrm{cr}$ ia + ith $\|^{\mathrm{Ha}}$ 2 ia ba + ith 3 ia $\sim$ antistrophe 2

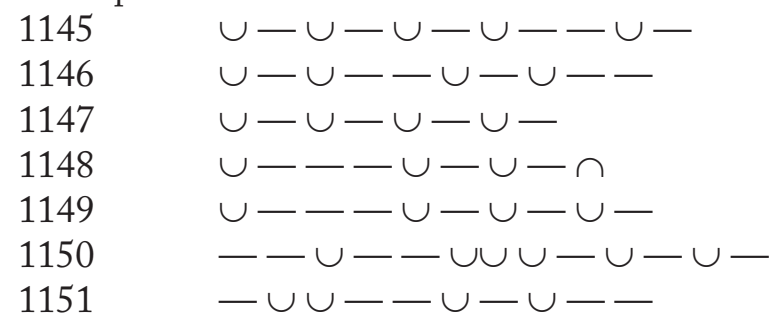


Part II - Scansions

Strophe 3

1152

$\cup-\cup-\cup \cup \cup \cup-\cup-\cup-$

3 ia

1153

$\cup-\cup-\cup \cup \cup \cup-\cup-\cup-$

3 ia

1154

$\cup-\cup \cup \cup \cup-\cup-$

2 ia

1155

$\cup \cup \cup \cup \cup \cup \cup-\cup-$

2 ia

1156

$\cup-\cup--\cup \cup \cup-$

2 ia

1157

$\cup-\cup--\cup-\cup--$

ia + ith

$\sim$ antistrophe 3

1158

1159

$\cup-\cup-\cup \cup \cup \cup-\cup-\cup-$

3 ia

1160

lacunose

1161

$\cup-\cup \cup \cup \cup-\cup-$

2 ia

1162

$\cup \cup \cup \cup \cup \cup \cup-\cup-$

2 ia

1163

$-\cup \cup \cup--\cup \cup \cup-$

2 ia

ia + ith 


\section{Electra}

\section{Monody (El.112-166)}

Strophe 1
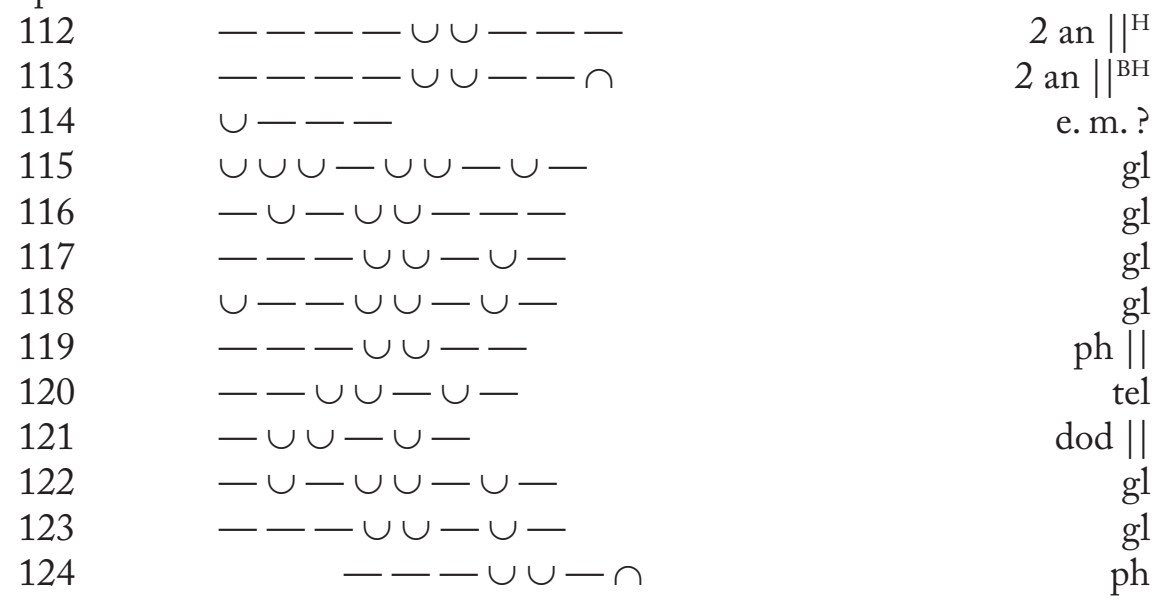

mesode 1

125

$\cup \cup \cup-\cup \cup-\cup \cup$

gl ?

126

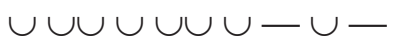

antistrophe 1

127

128

129

130

131

132

133

134

135

136

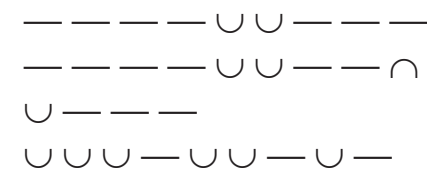

$\cup \cup \cup-\cup \cup-\cup-$
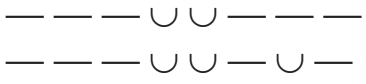

$\cup--\cup \cup-\cup-$

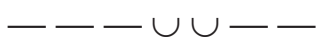

$--\cup \cup-\cup-$

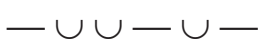

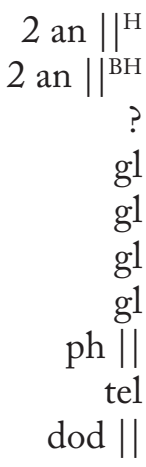

${ }^{68}$ See Diggle (1994: 123, n. 94). 
Part II - Scansions

137

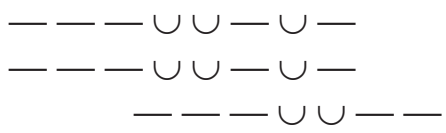

$\mathrm{gl}$

139

Strophe 2

140

141

142

$143 \mathrm{a}$

$143 \mathrm{~b}$

144

145

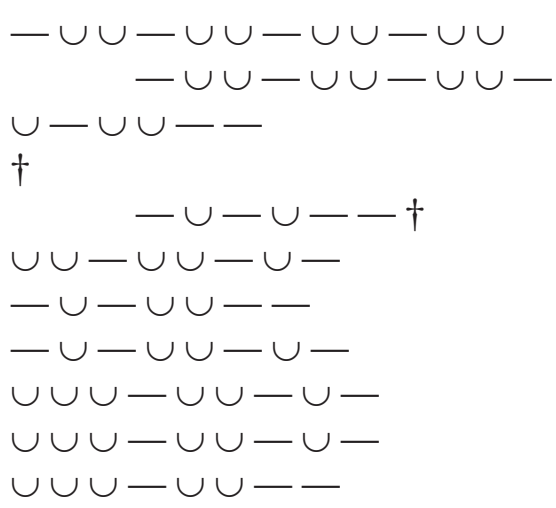

$4 \mathrm{da} \int$ $4 \mathrm{da} \wedge$ reiz $\|^{\mathrm{H}}$ ith ? ph $\begin{array}{r}\mathrm{T} \\ \mathrm{Ba} \\ \mathrm{g} 1 \\ \mathrm{~g} 1 \\ \mathrm{~g} 1 \\ \mathrm{ph}\end{array}$

mesode 2

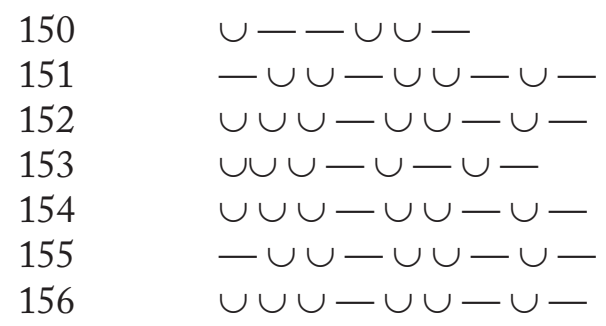

hex $^{69}$ ibyc

146

148

149

$\mathrm{lk} \|^{\mathrm{H}}$ g1 ibyc gl $\sim$ antistrophe 2

157

158

$-\cup \cup-\cup \cup-\cup \cup-\cup \cup$

159 $-\cup \cup-\cup \cup-\cup \cup-$

160

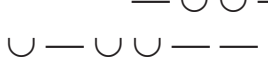

$\cup--\cup \cup-\cup-$

$161 \mathrm{a}$

$-\cup-\cup-\dagger-$

$161 \mathrm{~b}$

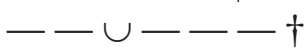

162

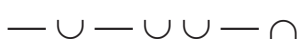

163

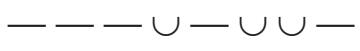

164

$\cup \cup \cup-\cup \cup-\cup$

165

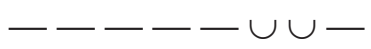

166

$\cup \cup \cup-\cup \cup-$

${ }^{69}$ See Parker (1997: 449). 


\section{Parodos (El.167-212)}

Strophe

Xo.

167

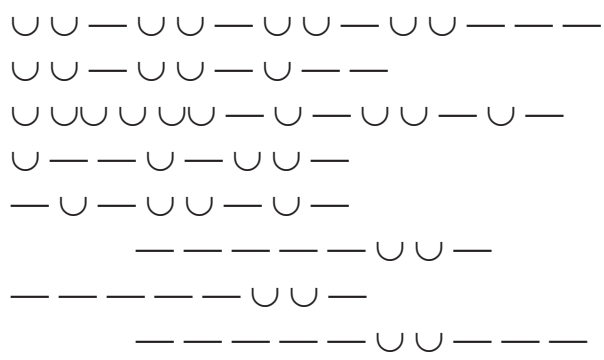

$\mathrm{A}+\mathrm{sp}$

168

169

170

171

172

173

174

$\mathrm{H} \lambda$.

175

176

177

178

179

180

181-2

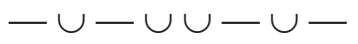

$-\cup-\cup \cup-\cup-$

183

184

185

186

187

188

189
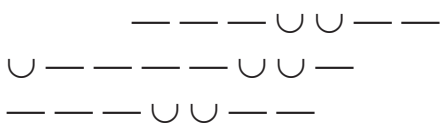

diom

ia $+\mathrm{gl}$ wil

gl I

wil

wil I wil $+\mathrm{sp}$

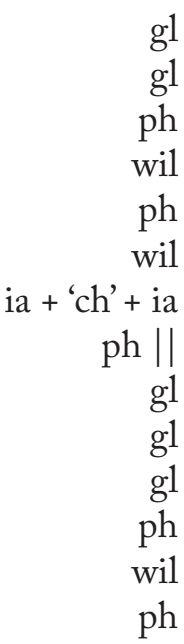

$\sim$ antistrophe

190

191

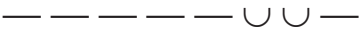

wil

h $\|$

g1

g1

g1

ph

wil

$\mathrm{ph}$

192

193

194

$\cup \cup-\cup \cup-\cup \cup-\cup \cup--$

$A+s p$ 'ch enop B' || ${ }^{70}$ ia + wil wil gl $\int$

195

196

$\cup \cup-\cup-\cup \cup--$

$\cup \cup \cup \cup \cup \cup--\cdots-\cup \cup-$

$\cup--\cup-\cup \cup-$

wil

197

$-\cup-\cup \cup-\cup-$

gl I

wil $+\mathrm{sp}$

$\mathrm{H} \lambda$.

198

${ }^{70}$ On the responsion and 'choriambic enoplian B', see Dale (21968: 137 n. 1; 169 n. 2). 


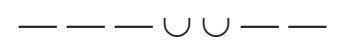

ph

203

wil

204-5

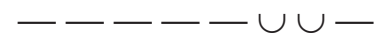

$i a+$ 'ch' + ia

206

207

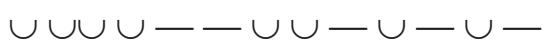

ph $\|$

208

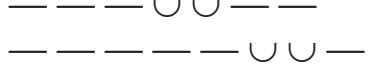

wil

209

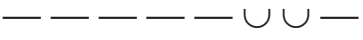

wil

210

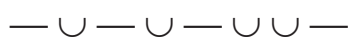

wil

211

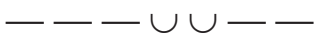

ph

wil

212

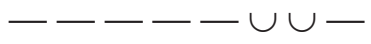

ph

\section{First Stasimon (El.432-486)}

Strophe 1

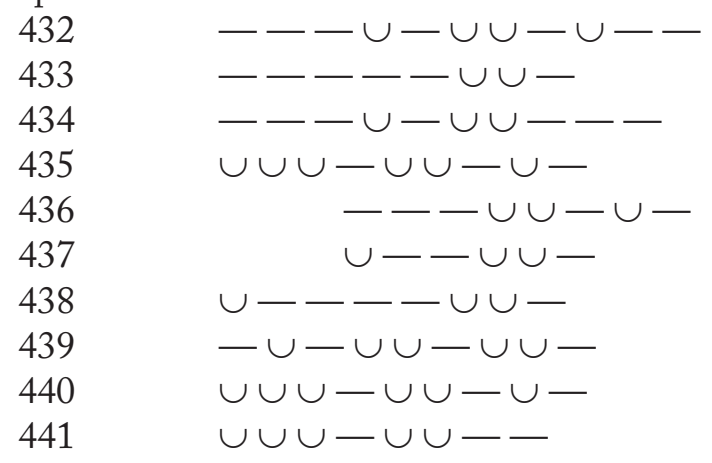

$$
\begin{array}{r}
\text { wil + ba } \\
\text { wil } \\
\text { wil + sp } \\
\text { gl } \int \\
\text { gl } \int \\
\text { hex } \\
\text { wil } \\
\text { sdd }^{71} \\
\text { gl } \\
\text { ph }
\end{array}
$$
antistrophe 1

442

443

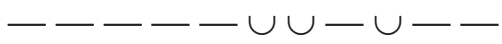

wil + ba

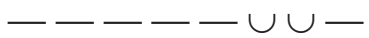
wil

444

445

446

447

448

449

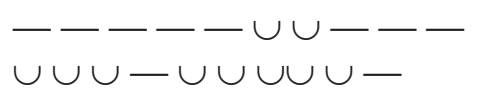

wil + sp g1 $\int$ g1 hex

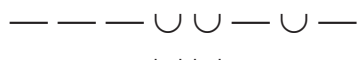
sdd

450

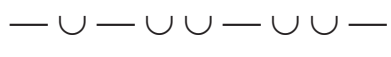

${ }^{71}$ On this colon see Finglass (comm. Ai., p. 208) and above, p. 94. Itsumi's 'reversed ibycean' (2009: xiii) is perhaps the best name for it. 
451

Strophe 2

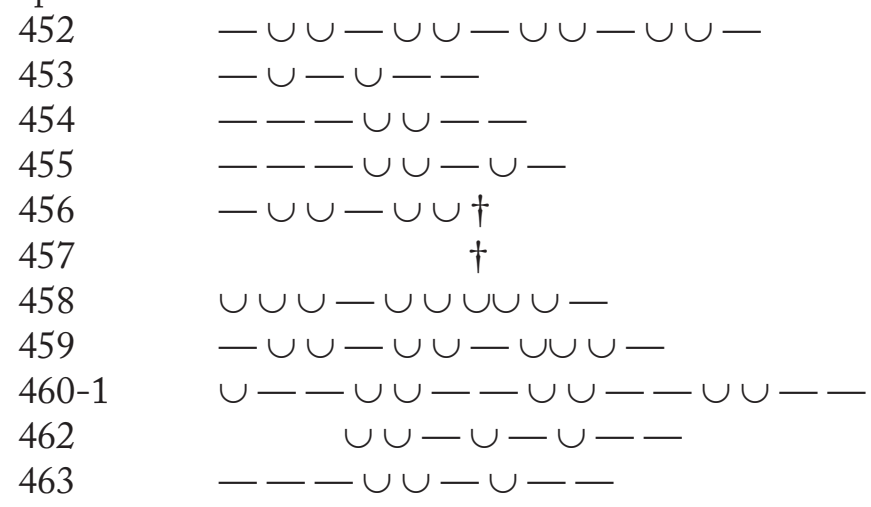

$5 \mathrm{da} \wedge$ ith $\mid{ }^{\mathrm{BaHa}}$ ph $\|$ g1 ? || $\mathrm{Ha}$ gl $\mathrm{D}+\mathrm{cr}^{72}$ $\mathrm{ba}+3$ io anacr hipp

antistrophe 2

464

465

$-\cup \cup-\cup \cup-\cup \cup-\cup \cup-$

466

$-\cup-\cup-\cap$

467

468

469

470

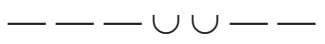

471

472-3

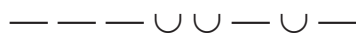

474

475

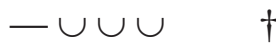

$\dagger$
$\dagger$

$5 \mathrm{da} \wedge$ ith ${ }^{\mathrm{BH}} \|$ ph $\|$ gl ? $\mid \mathrm{H}$

$\cup \cup \cup-\cup \cup-\cup-$ g1

$\mathrm{D}+\mathrm{cr}$ $\mathrm{ba}+3$ io $\int$ anacr hipp

epode

475-6

477-8

$-\cup \cup-\cup \cup-\cup \cup-\cup \cup-\cup \cup-$

479

$\cup---\cup-\cup \cup \cup \cup-$

$6 \mathrm{da}$

480

$-ー \cup-\cup \cup \cup \cup-$ $\mathrm{ba}+1 \mathrm{k} \|$

481

$\cup \cup--\backsim \cap$ 2 ia

$1 \mathrm{k} \|^{\mathrm{B}}$

483

$\cup \cup \cup \cup \cup-\cup-$ $\mathrm{ia}+\mathrm{cr}^{73}$

484

$-\backsim \cup-\cup \cup-$

- D

485

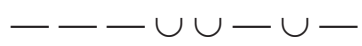

486

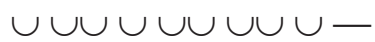

$\mathrm{ia}+\mathrm{cr}^{74}$ decasyll

\footnotetext{
${ }^{72}$ See above, p. 121 (n. 267).

${ }^{73}$ See above, p. 73 (with n. 154).

${ }^{74}$ See above, p. 121 (n. 266).
} 
Part II - Scansions

El. 585-595

Xo.

585

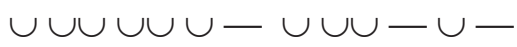

$2 \delta$

586

$\cup \cup-\cup \cup-\cup-\cup-$

cyren

587

$\cup-\backsim \cup-\cup-\cup$

$2 \delta$

588

$\cup \cup-\cup \cup-\cup-\cup-$

589

$\cup-\smile \cup$

590

$\cup \cup-\cup \cup-\cup \cup-\cup \cup-$

591

592-3

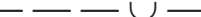

594

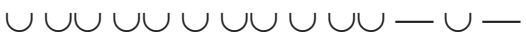
cyren

$\delta$

A

$\delta$

$2 \delta$

$\mathrm{cr}+\delta$

595

$-\cup-\cup--\cup-$

$2 \delta$

Second Stasimon (El.699-746)

Strophe 1

699

700

$\dagger \quad \dagger$

701

$\cup \cup-\cup \cup--$

702

703

$-\cup \cup-\cup \cup---$

reiz

ibyc chol $^{\text {che }}$

704

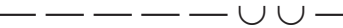

705

$-\cup-\cup-\cup \cup-$

$\cup---\cup \cup$

wi

wil

hept

wil

706

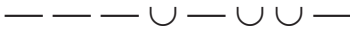

gl $\int$

707

$\cup-\leftarrow \cup \cup-\cup-$

gl

708

$\cup \cup-\cup \cup-\cup-$

709

710

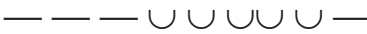

711

$-\cup \cup-\cup-$

712

$-\cup \cup \dagger-\cup \cup$

$\cup-\dagger \cup--\cup \cup-\cup-$

antistrophe 1

713

714

715

716

717

718

719

720

721 $\cup \cup-\cup \cup-\cup--\cup-$

$\cup \cup-\cup \cup--$

$-\cup \cup-\cup \cup--$

$----\cup \cup$

$-----\cup \cup$

$---\cup \cup$

$-\cup--\cup \cup \cup \cup-$

$\cup--\cup \cup-\cup-$ $\mathrm{gl}+\mathrm{cr}$ ? reiz ibyc chol wil wil hept gi j g1 
Strophe 2

727

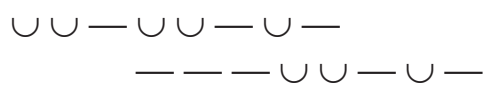

728

729

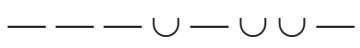

730

731

732

733

734

735

736

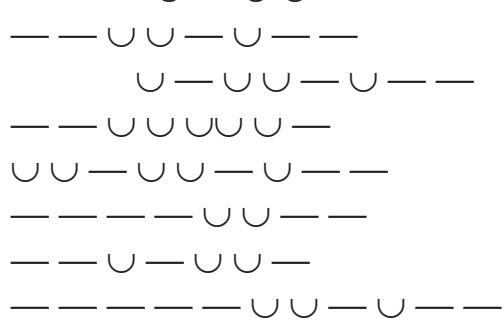

$2 \mathrm{ch}+\mathrm{ba}$

$\sim$ antistrophe 2

737

738

739

740

741

742

743

744

745

746 $\cup \cup-\cup \cup-\cup-$
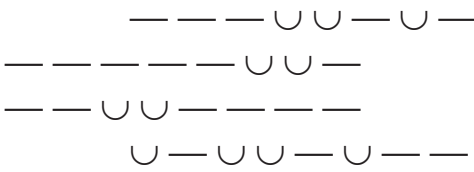

$--\cup \cup-\cup-$
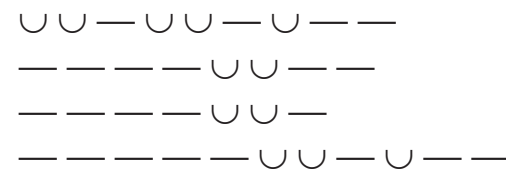

T J

g1

wil

hag hag tel diom oct || hept wil + ba

T $\int$ g1 wil hag $^{\text {chol }} \int 75$ hag tel diom oct II hept wil + ba

\section{El. 860-879}

Strophe

Xo.

860

$\cup-\cup \cup-\cup \cup-\cup-\cup \cup-\cup \cup-$

861

$--\cup---\cup \cup-\cup \cup-$

$862-3$

$--\cup \cup-\cup \cup---\cup---\cup \cup-\cup \cup-$

$-\mathrm{D}-\mathrm{e}-\mathrm{D}$

864

$\cup---\cup \cup-\cup \cup-\cup$ $\mathrm{ba}+\mathrm{D} \cup$

\footnotetext{
${ }^{75}$ See above, p. 101.
} 
Part II - Scansions

865

$\sim$ antistrophe

Xo.

874

$\cup-\cup \cup-\cup \cup-\cup-\cup \cup-\cup \cup-$

$\cup \mathrm{D} \cup \mathrm{D}$

875

$--\cup---\cup \cup-\cup \cup-$

$-\mathrm{e}-\mathrm{D}$

876-7

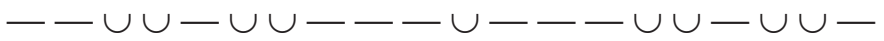

$-\mathrm{D}-\mathrm{e}-\mathrm{D}$

878

$\cup---\cup \cup-\cup \cup-\cup$

$\mathrm{ba}+\mathrm{D} \cup$

879

$-\cup-\cup--\cup-\cup-$

ith + ia

\section{El.1147-1164}

Strophe

Xo.

1147

$\cup--\cup-\cup \cup \cup-\cup-$

1148

$\cup--\cup-\cup \cup \cup--$

$\cup \cup \cup \cup \cup \cup \cup-\cup-$

1150

$\cup--\cup-\cup--\cup-$

$2 \delta$

1151

1152

1153

$\cup-\backsim \cup \cup \cup-$

$2 \delta$

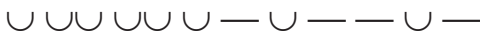

$2 \delta$

1154

$\cup \cup \cup \cup-$

$\delta$

$\mathrm{ia}+\mathrm{cr} \|^{\mathrm{Ba}}$

$\sim$ antistrophe

1155

$\cup-\backsim \cup \cup \cup-$

$2 \delta$

1156

1157

$\cup \cup \cup-\cup-\cup \cup \cup-\cup-$

1158

$\cup \cup \cup \cup \cup---$

$2 \mathrm{ia}^{76}$

$\cup--\cup-\cup \cup \cup-\cup-$

$2 \delta \int$

1159

$\cup--\dagger \cup-\cup \cup \cup \dagger-\cup-$

1160

1161

$\cup \cup \backsim \cup-\backsim---$

$2 \delta$

1162

$\cup \cup \cup \cup \cup \cup-$

$\delta$

1163

$\cup-\cup-\backsim \cup$

$\mathrm{ia}+\mathrm{cr} \|\left.\right|^{\mathrm{Ba}}$

$\cup--\cup-\cup--\cup-$

1164

$\cup \cup \cup \cup \smile \cup \cup \cup-\cup \cap$

${ }^{76}$ On the 'impure' iambic metron, see Wilamowitz (1921: 410-12) and Parker (1968: 246 n. 1), who writes " "impure" iambics are found in dochmiac contexts, as if Euripides were led by the dochmiac rhythm with its double anceps momentarily to treat the iambic metron as if it too had two ancipitia.' See above, p. 120 (n. 262). 


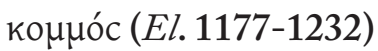

Strophe $1 \sim$

Op.

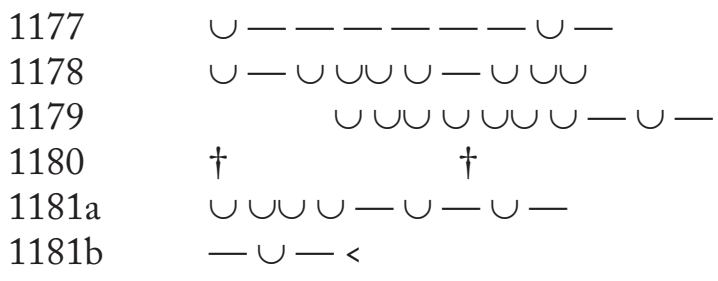

$\mathrm{H} \lambda$.

1182<smiles>CO[Hg]O[Hg]O[Si]</smiles>

3 ia

1183

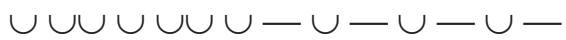

3 ia

1184

$-\cup-\cup--$ ith

<Xo.>

1185

$\cup-\cup--\cup-$

1186

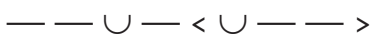

$\mathrm{ia}+\mathrm{cr}$ $\mathrm{ia}+\mathrm{ba}$

1187

$\cup-\cup \cup \cup \cup-\cup-$

2 ia

1188

$\cup-\cup-\cup-\cup-$

2 ia

1189

$\cup-\cup-\leftarrow \cup-\cup-$

ia + ith

$\sim$ antistrophe 1

Op.

1190

1191

$\cup--\cup--\cup-$

1192

1193

$\cup \longleftarrow \cup \cup \cup-\cup-$

$\cup \cup \cup \cup \cup-\cup-$

1194

1195

$\circlearrowleft \cup \cup \cup-$

$\cup \cup \cup-\cup-\cup-$

1196

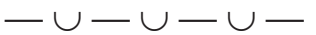

1197

$\cup-\cup-\cup-\cup-$

$2 \mathrm{ba}+\mathrm{cr}$

2 ia $\int$

2 ia ia + 'ch'

2 ia $1 \mathrm{k}$

2 ia ith

$\mathrm{H} \lambda$.

1198

$\cup-\cup---\cup-\cup-\cup-$

3 ia

1199

$\cup \cup \cup \cup-\cup-\cup-\cup-\cup-$

3 ia

1200

77 See Diggle (1994: 168). 
Part II - Scansions

Xo.

1201

$\cup-\cup-\cup-\cup-$

2 ia

1202

$\cup-\cup-\cup--$

$\mathrm{ia}+\mathrm{ba}$

1203

$\cup-\cup \cup \cup \cup-\cup-$

2 ia

1204

$\cup-\cup-\cup-\cup-$

2 ia

1205

$\cup-\cup--\cup-\cup-\cap$

ia + ith

Strophe 2

<Op.>

$\begin{array}{ll}1206 & \cup-\cup-\cup-\cup---\cup- \\ 1207 & \cup \cup \cup \cup-\cup-\cup-\cup-\cap \\ 1208 & \cup---\cup- \\ 1209 & \cup-\cup \cup \cup \cup \cup \cup \cup-\cup-\cup-\end{array}$

3 ia $2 \mathrm{ia}+\mathrm{ba} \|^{\mathrm{B}}$ $\mathrm{ba}+\mathrm{cr}$ 3 ia

Xo.

1210

$\cup-\cup \cup \cup \cup-\cup-$

2 ia

1211

$\cup-\cup-\cup-\cup-$

2 ia

1212

$-\cup-\cup-$ ith

$\sim$ antistrophe 2

Op.
1213-4
$\cup-\cup-\cup-\cup-\cup-\cup-$
1215
$\cup-\cup-\cup \cup \cup \cup-\cup-$
1216
$\cup---\cup-$
1217
$\cup-\cup-\cup \cup \cup \cup-\cup-\cup-$

3 ia

$2 \mathrm{ia}+\mathrm{ba} \|^{\mathrm{Bs}}$

$\mathrm{ba}+\mathrm{cr}$

3 ia

Xo.

$\begin{array}{ll}1218 & \cup-\cup-\cup-\cup- \\ 1219 & \cup-\cup-\cup-\cup- \\ 1220 & -\cup-\cup-\leftarrow\end{array}$

2 ia

2 ia ith

Strophe 3

Op.

$\begin{array}{ll}1221 & \cup-\cup \cup \cup \cup-\cup-\cup-\cup- \\ 1222 & -\cup-\cup-\cup- \\ 1223 & -\cup \cup \cup-\cup-\cup-\end{array}$ $\mathrm{H} \lambda$.

1224

$\cup-\cup \cup \cup \cup-\cup-$

2 ia

1225

$\cup-\cup-\cup-\cup-$

2 ia

1226

$-\cup \cup-\cup \cup-\cup-\cap$

decasyll

$\sim$ antistrophe 3

$<0$. $>$

1227

$\cup-\cup-\cup \cup \cup \cup-\cup-\cup-$

3 ia 
1228

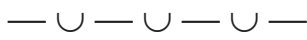

$1 \mathrm{k}$

1229

$-\cup \cup \cup \cup-\cup-$

2 ia $\|^{\mathrm{Ha}}:$ :

$\mathrm{H} \lambda$.

1230

$\cup-\cup-\cup-\cup-$

2 ia

1231

$\cup \cup \cup \cup-\cup-\cup-$

2 ia

1232

$-\cup \cup-\cup \cup-\cup-\cap$

decasyll 


\section{Heracles}

Parodos (Herc. 107-137)

Strophe 1
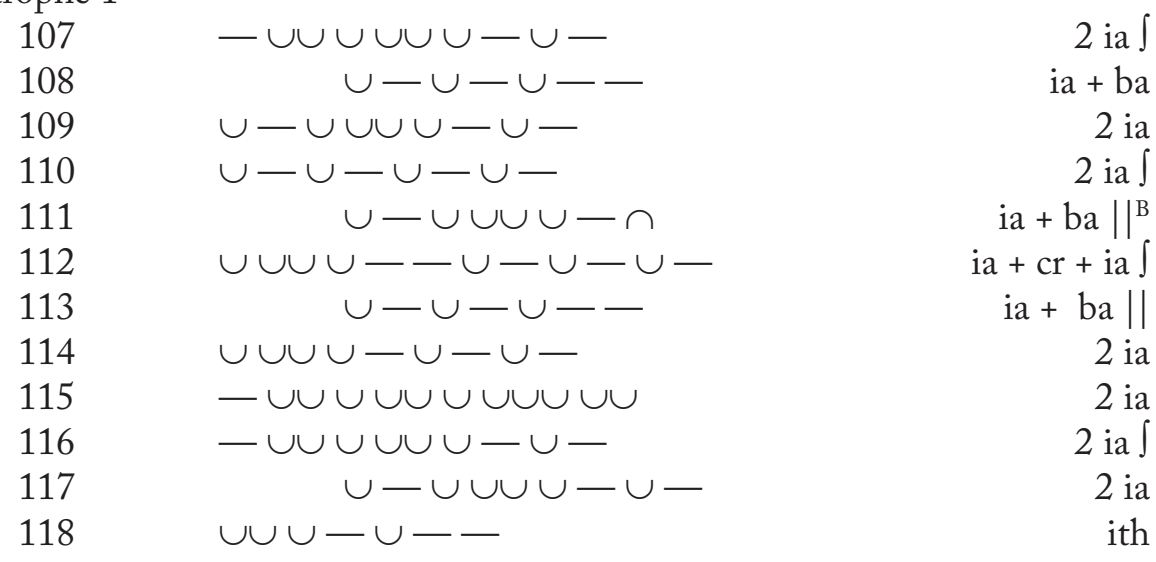

$\sim$ antistrophe 1

119

$\dagger-\cup \cup-\cup \cup \cup \dagger \cup \cup \cup-$

120

$\cup-\cup-\cup--$

121

$u-\dagger$

122

123

124

125

126

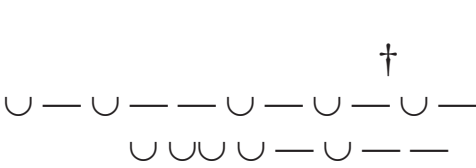

128

127

129

130

$\cup-\cup-\cup \cup \cup \cup-$

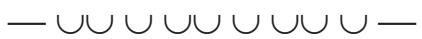

$\cup \cup \cup \cup-\cup-\cup-$

$\cup-\cup-\cup-\cup-$

$\cup \cup-\cup-$

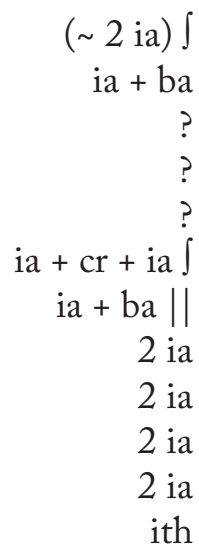

epode

131

$132 \mathrm{a}$

$\cup \cup \cup \cup \cup-$

$\operatorname{tr}+\operatorname{sp} \int$
$\mathrm{lk}$
$\mathrm{cr}+\mathrm{sp}$
$2 \mathrm{tr}+\mathrm{cr}$

$132 \mathrm{~b}$

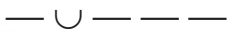

$\cup \cup \cup \cup \cup \cup-\cup-\cup-\cup-$ 
First Stasimon (Herc. 348-441)

Strophe 1

348

349

350

351

352

$353 \mathrm{a}$

$353 \mathrm{~b}$

354

355

356

357

358

mesode 1

359

360

361

62

363
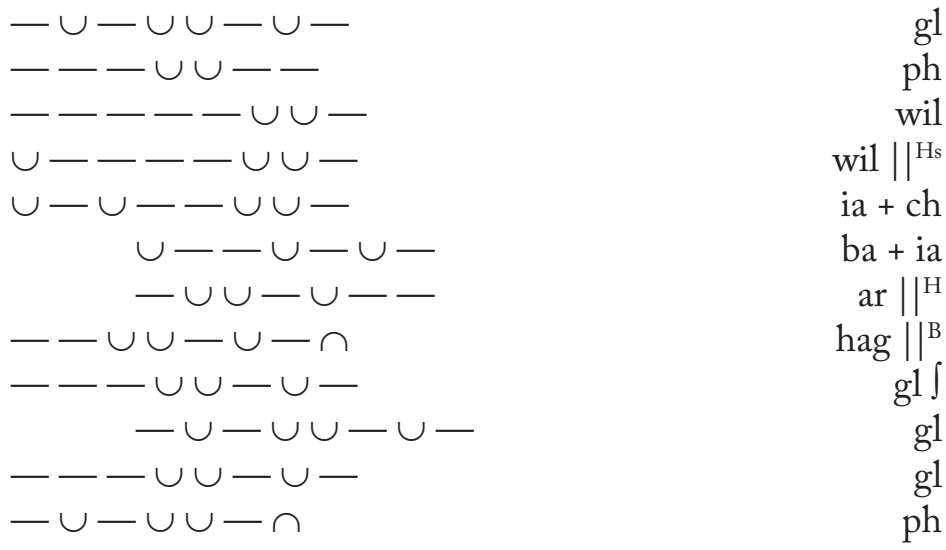
ph $\|^{\text {Bs }}$
ph
ph
g1
ph

$\sim$ antistrophe 1

364

$-\cup-\cup \cup-\cup-$

365

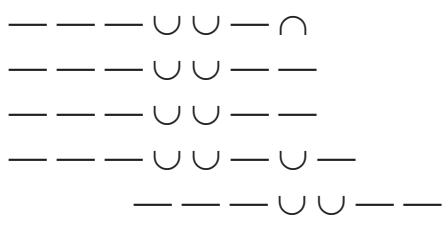

g1

ph

366

367

368

$369 \mathrm{a}$

$369 \mathrm{~b}$

370

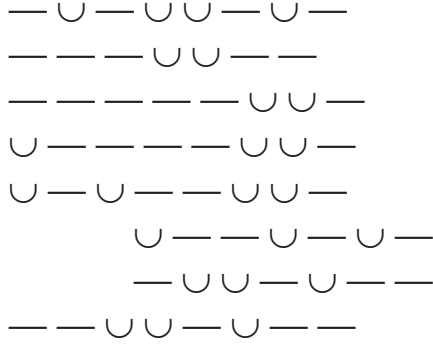

wil wil \|\|$^{\mathrm{Hs}}$ ia + ch $\int$ $\mathrm{ba}+\mathrm{ia} \int$ ar \|\|$^{\mathrm{Hs}}$ hag $\|^{\text {Bs }}$

${ }^{78}$ See West (1982: 104). Or else Barrett's pendent 'enhoplian' c (comm. Hi., p. 423), the last position of which is (in Barrett's view) anceps (cf. S. OC 523). Note that elsewhere in Herc. the phrase $\mathrm{x}-\mathrm{x}-\cup \cup-$ appears ten times (see above, pp. 78, 102). 'Erasm + ith' is, of course, the so-called Archilochean dicolon. 
epode 1

375

376

377

378

379

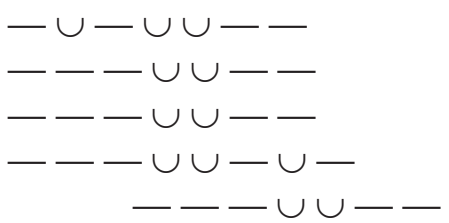

Strophe 2

380

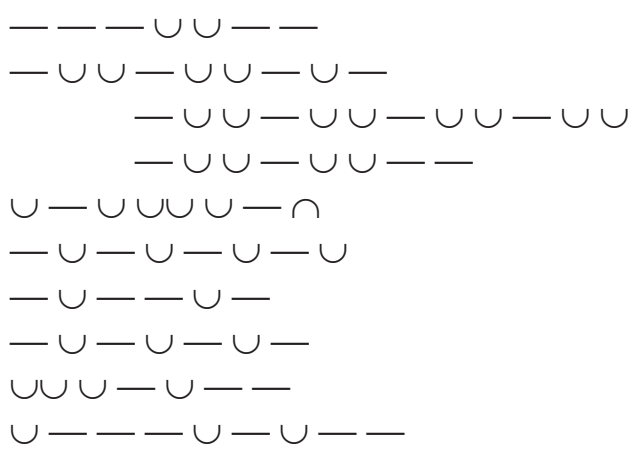

$$
\mathrm{D}^{\text {contr }}
$$

381

$382 \mathrm{a}$

$382 \mathrm{~b}$

383

384

385

386

387

388

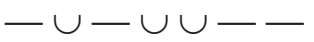

ph || ph

390

$\cup--\cup \cup-$

ph

392

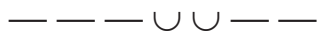

393

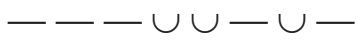

ph

$\sim$ antistrophe 2

394

395

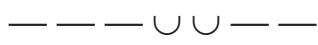

Dentr

$396 a$

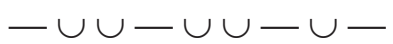

$396 b$

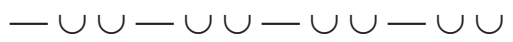

ibyc $\int$

$4 \mathrm{da} \int$

$3 \mathrm{da}$

397

$-\cup \cup-\cup \cup-$

$\mathrm{ia}+\mathrm{ba} \|^{\mathrm{B}}$

398

$\cup-\cup-\cup-\cap$

399

$-\cup-\cup-\cup-\cup$

$2 \operatorname{tr}$

$2 \mathrm{cr}$

${ }^{79}$ The sequence 'ibyc $\int 4 \mathrm{da} \int 3$ da' invites the question whether ' 3 da' is not in fact a 'catalectic ibycean', in the sense that an adonean is a catalectic dodrans (cf. Parker 1997: 321): catalexis would make it pendent, thereby affording contrast with its normal, blunt close. 
Part II - Scansions

400

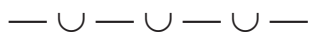

$1 \mathrm{k}$

401

$-\cup-\cup--$

ith

402

$\cup---\cup-\cup-\cdots$

$\mathrm{ba}+\mathrm{cr}+\mathrm{ba}$

epode 2

403

404

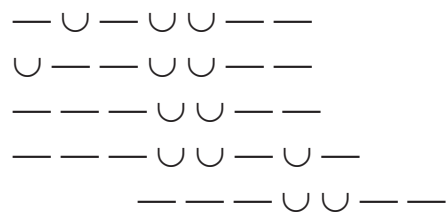

ph ||

405

406

407

$\mathrm{ph}$

ph

g1 $\int$

ph

Strophe 3

408

$\cup---\cup-\cup-\cup-$

$\mathrm{ba}+\mathrm{cr}+\mathrm{ia}$

409

$--\cup-\cup \cup \cup \cup \cup \cup$

410

$\cup-\cup--\cup-\cup-$

411

$\cup-\cup--\cup-$

412

$\cup \cup \cup-\cup-\cup-$

413

$\cup-\cup--\dagger \cup-$

414

415

416

$--\cup \cup \cup \cup-\cup-{ }^{\dagger}$

417

418

$\cup-\cup-\cup \cup \cup \cup-$

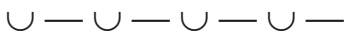

2 ia

$\mathrm{ia}+\mathrm{cr}+\mathrm{ba}$

$\mathrm{ia}+\mathrm{cr}$

$1 \mathrm{k}$

?

2 ia

2 ia $\int$

2 ia

$-\cup-\cup--$

ith

mesode 3

419

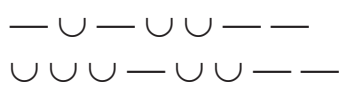

ph || ph

ph

421

422

$---\cup \cup--$

ph

423

$-\cup-\cup \cup-\cup-$

gl I

424

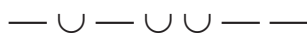

ph

$\sim$ antistrophe 3

425

426

427

428

429

430

431

432

433 $\cup---\cup-\cup-\cup-$

$\cup-\cup-\cup \cup \cup \cup \cup \cup$

$\cup-\cup--\cup-\cup--$

$\cup-\cup--\cup-$

$\cup \cup \cup \cup-\cup-$

$\cup-\cup-\cdots \cup$

$-\cup-\cup-\cup-$

$\cup-\cup \cup \cup \cup-\cup-$

$\cup-\cup-\cup \cup \cup \cup \cup \cup$ $\mathrm{ba}+\mathrm{cr}+\mathrm{ia}$

2 ia

$\mathrm{ia}+\mathrm{cr}+\mathrm{ba}$

$\mathrm{ia}+\mathrm{cr}$

$1 \mathrm{k} \|$

$\mathrm{ia}+\mathrm{cr}$

$1 \mathrm{k}$

2 ia

2 ia $\int$ 
epode 3

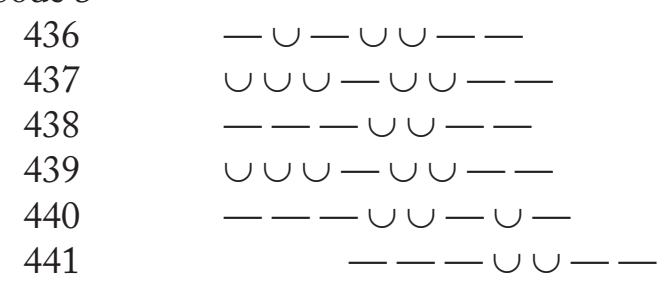
ph ph ph g1 ph

Second Stasimon (Herc. 637-700)

Strophe 1

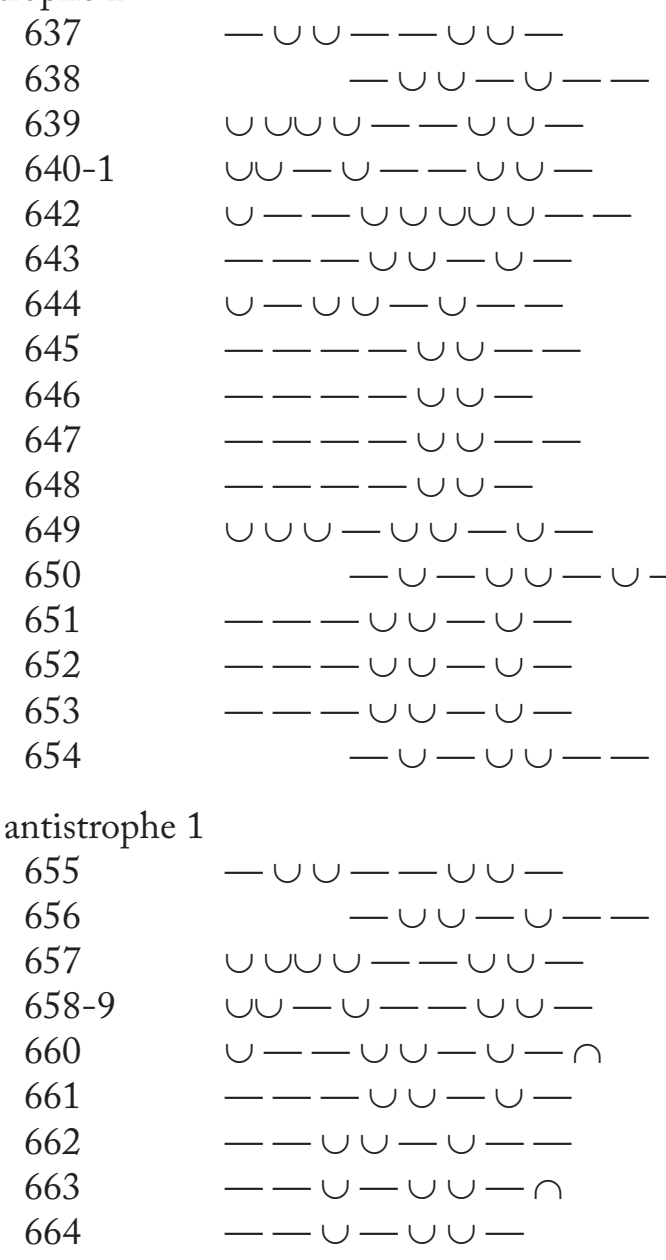

$\sim$ antistrophe 1 

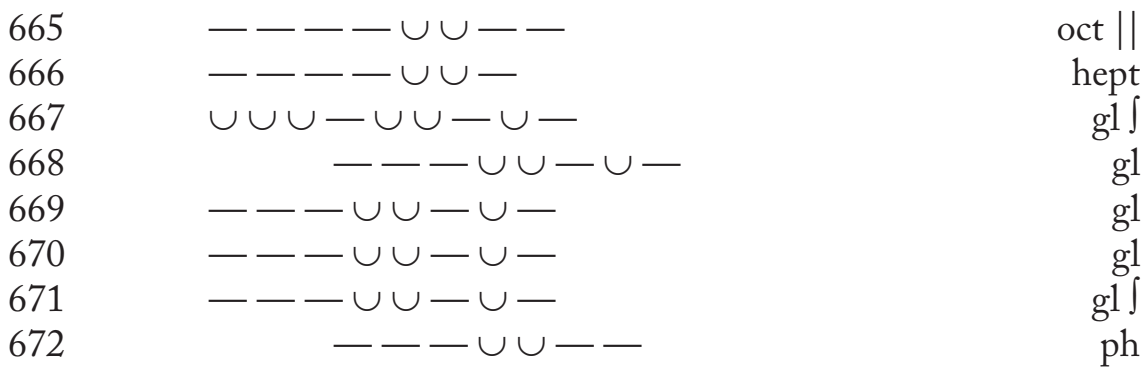

Strophe 2

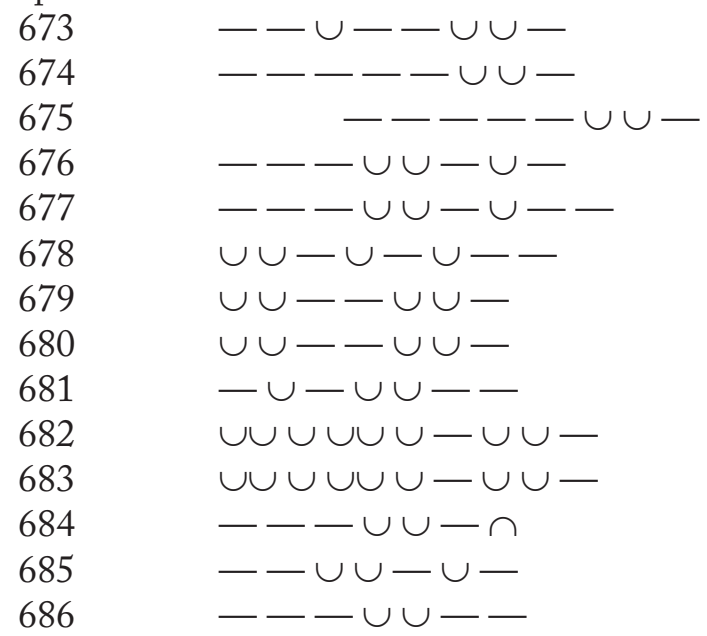

$$
\begin{array}{r}
\text { ia }+ \text { ch } \\
\text { wil } \int^{\text {wal }} \\
\text { wil } \\
\text { hipp } \| \\
\text { anacr } \\
\text { io + io } \wedge \\
\text { io + io } \wedge \\
\text { ph } \| \\
\text { wil } \\
\text { wil } \\
\text { ph } \|{ }^{\mathrm{B}} \\
\text { tel } \\
\text { ph }
\end{array}
$$

$\sim$ antistrophe 2

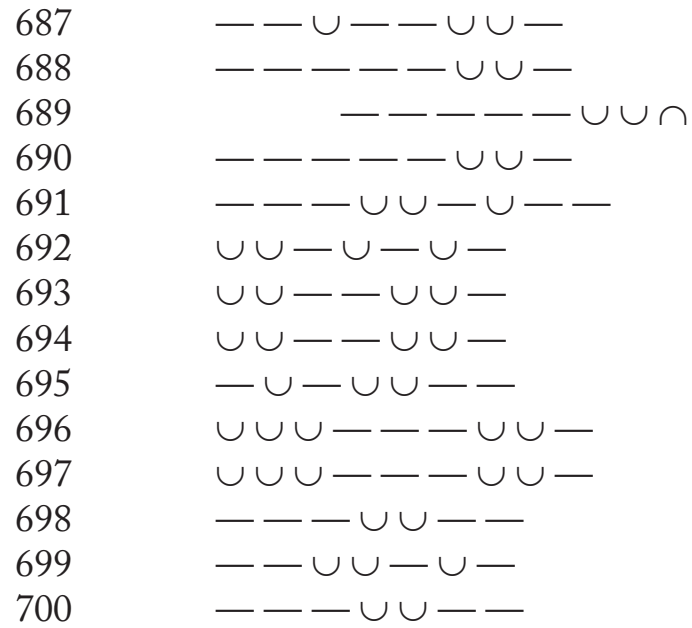


Third Stasimon (Herc. 735-814)

Strophe 1

Xo.

735

$\cup \cup \cup-\cup-\cup \cup \cup-\cup-$

736-7

$\cup \cup \cup-\cup-\cup \cup \cup-\ldots$

738

$\cup-$

e. $\mathrm{m}$.

738-9

$\cup--\cup-\cup--\cup-$

$2 \delta$

740

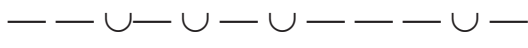

741

$\cup-\cup---\cup-\cup-\cup-$

3 ia spoken

3 ia spoken

$742-3$

744

$-\cup--\cup-\cup \cup \cup-\cup-$

$2 \mathrm{cr}+\delta$

745

$\cup \cup \cup \cup$

$\mathrm{cr}$

$\cup \cup \cup-\cup \cup \cup \cup \cup \cup-\cup-$

$2 \delta$

746

$\cup--\cup-$

747

$--\cup---\cup-\cup-\cup-$

3 ia spoken

748

$\cup-\cup-\leftarrow-\cup-\cup-\cup-$

3 ia spoken

$\Lambda v .\left({ }^{\prime} c \omega \theta \varepsilon v\right)$

749

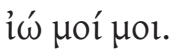

$\sim$ antistrophe 1

Xo.

750

751-2

$\cup \cup \cup-\cup-\cup \cup \cup-\cup-$

$2 \delta$

753

$\cup \cup \cup-\cup-\cup \cup \cup-\ldots$

$2 \delta$

753

$\cup-$

e. $\mathrm{m}$.

$2 \delta$

$\Lambda v .\left({ }^{\prime} c \omega \theta \varepsilon v\right)$

3 ia spoken

Xo.

755

$--\cup-\cup-\cup-\cup-\cup-$

756

$\cup-\cup-\cup-\cup \cup-\cup-$

$757 \mathrm{~b}$

$\cup \cup \cup-\cup \cup \cup---\cdots \cup$

$757 \mathrm{a}$

ひソソ

758

$\dagger$

$\dagger \cup \cup \cup-\cup-$

759

$\cup--\cup-$

760

$\cup-\cup-\cup-\cup-\cup-\cup-$

761

$-\cup-\cup-\cup-\cup-\cup \cap$

Strophe 2

$763 \mathrm{a}$

$\cup-\cup-$

$763 \mathrm{~b}$

$-\cup \cup-\cup-\cup-$

764

3 ia spoken

3 ia spoken $2 \mathrm{cr}+\delta$ cr ?

3 ia spoken

3 ia spoken

$$
\begin{array}{r}
\mathrm{ch}+\mathrm{ia} \int^{\mathrm{ia}} \\
\operatorname{ar} \|^{\mathrm{B}}
\end{array}
$$


Part II - Scansions

765

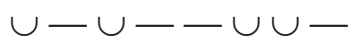

$\mathrm{ia}+\mathrm{ch}$

766

$\cup-\cup--\cup \cup-$

767

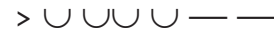

768-9

$<$

$>\cup \cup \cup-$

770

$\cup-\cup-\cup-\cup \cup U \cup-\cup-$

771

$\cup-\cup \cup \cup \cup \cup \cup \cup \cup$

$\mathrm{ia}+\mathrm{ch}$

? II

3 ia

3 ia

ia + ith

$\sim$ antistrophe 2

$772 \mathrm{a}$

$772 \mathrm{~b}$

773

774

775

776

777

778-9

780 $\cup-\cup-$

$-\cup \cup-\cup-\cup-$

$-\cup \cup-\cup-$

$\cup-\cup--\cup \cup-$

$\cup-\cup--\cup \cup-$

$\cup \cup \cup \cup \cup \cup$

$\dagger \cup-\cup-\cup-\cup \cup \cup \cup-\cup$

$\cup-\cup \cup \cup \cup \cup \cup \cup-$

$\cup-\cup--\cup-\cup-\cap$ ia $\mathrm{ch}+\mathrm{ia}$ ar ||$^{\mathrm{Bs}}$ $\mathrm{ia}+\mathrm{ch}$ $\mathrm{ia}+\mathrm{ch}$ $\mathrm{ia}+\mathrm{ba}$

3 ia ia + ith

Strophe 3

781

782

783

784

785

786-7

788

789

790

$791^{80}$

792

793

794

795

796

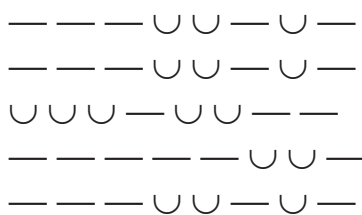

g1

g1

ph

wil

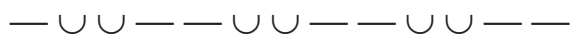

$-\cup-\cup \cup-$

$--\backsim \cup-\cap$

$-\cup---\cup \cup$

tel + cr $\|\left.\right|^{\mathrm{BH}}$

$-\leftarrow \cup \cup-\cup-\backsim \cap$

$-\cup-\cup-\cup \cup$

$\cup-\cup \cup \cup-$

$\mathrm{wil}^{\mathrm{Hs} / \mathrm{Ba}}$

ia + ba hag $\|$ oct oct reiz |

797

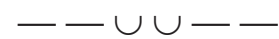

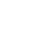

$\sim$ antistrophe 3

798

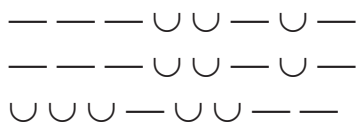

799

800

$\cup \cup \cup-\cup \cup-$

${ }^{80}$ See above, p. 110. 


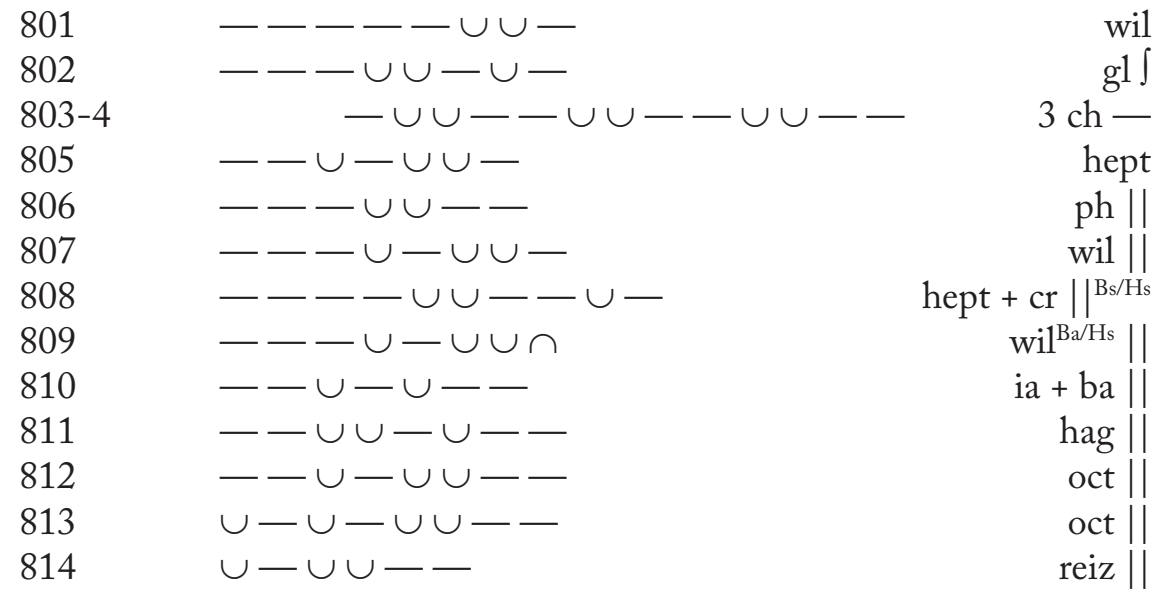

Herc. 875-921

Xo.

875

$\cup \cup \cup-\cup-\cup \cup \cup-\cup-$ $2 \delta$

876

$\cup--\cup-\cup \cup \cup-\cup-$

$2 \delta$

877

$\cup \cup \cup-\cup-\cup--\cup-$

$2 \delta$

878

$\cup \cup \cup-\cup-\cup \cup \cup--$

$2 \delta$

879

$\cup--\cup--$

$\mathrm{ba}+\mathrm{ba}$

880

$\cup-\cup-\cup-\cup-\cup-\cup \cap$

3 ia

881

$-\cup \cup-\cup-\cap$

882

$-\cup-\cup \cup--$

$883 a$

$883 \mathrm{~b}$

$----\cup \cup-\cup \cup$

ar $\|^{\mathrm{B}}$

$\mathrm{ph}$

A

$\wedge$ ddss -

884

$\cup \cup-\cup \cup-\cup \cup-\cup-\cup-$

$2 \delta$

885

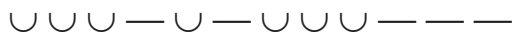

$2 \delta$

$<A \mu .>(\stackrel{\prime}{\varepsilon} c \omega \theta \varepsilon v)$

$886 a$

$\cup--\cup \cup \cup$

$\delta$

Xo.

$886 \mathrm{~b}$

$\cup--\cup-\cup \cup \cup \cup \cup-\cup \cup$

$2 \delta$

$887 \mathrm{a}$

$-\cup \cup-\cup-\cup \cup \cup-\ldots$

$2 \delta$

$887 \mathrm{~b}$

$\cup-\cup-\cup \cup-\cap$

$\cup \mathrm{sd}-\| \mathrm{B}$

$\mathrm{A} \mu$.

888

$\cup-\cup-$

ia

Xo.

$\cup-\cup-\cup-\cup \cup-\cup \cup-$

ia $\cup \mathrm{D}$

890

$-\cup \cup-\cup \cup-\cup \cup--$

$4 \mathrm{da}$ 
Part II - Scansions

$\mathrm{A} \mu$.

$891 \cup-\cup-$

Xo.

892

$\cup-\cup-\cup-\cup \cup-\cup \cup-$

ia $\cup \mathrm{D}$

893

$\cup \cup-\cup \cup-\cup \cup-$

enop prm

$<\mathrm{A \mu} .>$

894

$\cup-\cup--\longrightarrow \cup::-\cup-\cup \cap$

3 ia $\|^{\mathrm{B}}$

895

$-\cup-\cup \cup \cup--$

896-7

$\cup-\cup-\cup-\cup-\cup-\cup \cup-\cup \cup-\cup$

$2 \mathrm{ia}+$ erasm

898

$-\cup---$

$\mathrm{cr}+\mathrm{sp} \|^{\mathrm{H}}$

$\mathrm{A} \mu$.

899

$\cup-\cup-$

ia

Xo.

900

$\cup--\cup-\cup \cup \cup-\cup-$

$2 \delta$

901-2

$\cup \cup \cup-\cup-\cup \cup \cup-\cup-$

903

$\cup \cup \cup---$

$2 \delta$

904

$\cup-\cup-$

905

$\cup-\cup---\cup---\cup-$

ia

3 ia

$\mathrm{A \mu}$.

906

$--\cup--\cup--\cup--$

$\mathrm{sp}+3 \mathrm{ba}$

907-8

$\cup-\cup-\cup-\cup-\cup-\cup \cup-\cup \cup-\cup$

$2 \mathrm{ia}+$ erasm

909

$-\cup---$

$\mathrm{cr}+\mathrm{sp}$

ЕЕАГГЕ $О \mathrm{OC}$

910

$--\cup---\cup:: \cup \cup \cup-\cup \cup \cup$

3 ia

911

$\cup-:: \cup-\cup-\cup-\cup-\cup-$

3 ia

912

$\cup \cup \cup-\cup-$

$\mathrm{E} \xi$.

913

$\cup-\cup-\cup::-\longrightarrow$

$\mathrm{ia}+\mathrm{ba}$

$<\mathrm{E} \xi$.>

914

$\cup-\cup-\cup-\cup::-\cup-\cup-$

3 ia

915

$-\cup-\cup \cup \cup-\cup-$

$\mathrm{cr}+\delta$

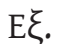

916

$--\cup---\cup-\cup-\cup-$

3 ia

Xo.

917

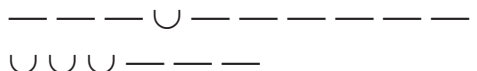

$2 \delta$

918

$\circlearrowleft \cup--$

919

$\cup \cup \cup \cup \cup \cup \cup \cup \cup \cup \cup \cup \cup \cup \cup \cup$

$2 \delta$

920

$\cup \cup \cup \cup \cup<$

$>-\cup-$

? 
Herc. 1016-1088

Xo.

1016

$\cup \cup \cup-\cup-\cup \cup \cup-\cup-$

1017

$\cup \cup-\cup \cup-\cup \cup-\cup \cup-\cup-\cup \cap^{81}$

$2 \delta$
$\mathrm{A}+\mathrm{ia} \|^{\mathrm{B}}$
$\delta$
$2 \delta$
$\delta+\mathrm{cr}$
$2 \delta$
$2 \delta$
$\delta$
$\delta+\delta \wedge\|\|^{\mathrm{H}}$
$\mathrm{ia}+\mathrm{ba} \|^{\mathrm{B}}$
$2 \delta \int$
$\delta$

1018

$-\cup \cup---$

1019

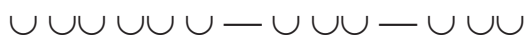

1020

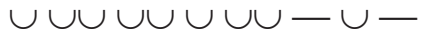

1021

1022

$\cup \cup \cup---\cup \cup \cup---$

1023

$\cup \cup \cup---\cup \cup \cup \cup \cup-$

$1024^{82}$

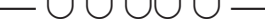

1025

$-\cup \cup-\cup-\cup-\cdots$

1026

1027

1028

1029

1030

1031

1032

1033

1034

1035

1036

1037

1038

1039

1040

1041

$\cup-\cup-\cup-\cap$
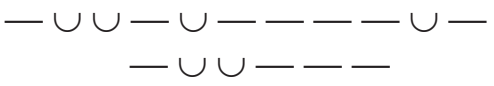

e. $m$.

erasm

ibyc

e. $\mathrm{m}$.

erasm

ibyc $^{\text {chol }} \|^{\mathrm{H}}$

$-\cup \cup-\cup \cup--$

3 ia

$2 \delta$

ia + ba $\|^{\mathrm{B}}$

ibyc

erasm

3 ia spoken

3 ia spoken

3 ia spoken

$\mathrm{A} \mu$.

1042

1043

1044

$\cup-\cup \cup-\cup \cup--$

$\cup-\cup-\cup-\cup-\cup-\cup-$

$--\cup---\cup-\cup-\cup \cap$

$\cup-\cup-\leftarrow-\cup-\cup-\cup \cap$

$2 \delta \int$

$2 \delta \int$

$\delta$

Xo.

1045

$\cup \cup \cup-\cup-\cup--\cup-$

$2 \delta \|^{2 \delta}$

1046

$\cup \cup \cup-\cup-\cup--\cup-$

\section{$\delta$}

\footnotetext{
${ }^{81}$ For the breuis in longo see Diggle (1994: 104).
}

82 See Diggle (1994: 107). 
Part II - Scansions

$\mathrm{A} \mu$.
1047
$\cup-\cup-\cup-\cup-$
2 ia
1048
$\cup-\cup-\cup-\cup-$
2 ia
1049
$\cup-\cup \cup--$
reiz ${ }^{83}$
1050
$\cup-\cup \cup--$
reiz
1051
$\cup-\cup \cup--$
reiz
$1052 \mathrm{a}$
$\cup \cup \cup \cup-\backsim \cup \cup-\cup:: \cup \cup$
$2 \delta \int$
$1052 \mathrm{~b}$
$\cup \cup \cup---$
$\delta \| \mathrm{H}$

$<\mathrm{A \mu}$. $>$

1053

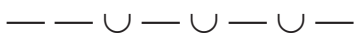

2 ia $\int$

1054<smiles>CO[Hg]O</smiles>

1055-6 - $\cup \cup-\cup \cup-\cup \cup-\cup \cup-\cup \cap$ - dddds $\|^{\mathrm{B}}$

1057-8

$\cup \cup \cup \cup \cup \cup \cup \cup--$

$2 \delta \|^{H}$

Xo.

$1059 \cup \cup \cup \cup \cup \cup \cup-{ }^{84}$

$\mathrm{A} \mu$.

1060

$-\cup \cup-\cup-\cup \cup \cup-\cup-$

$2 \delta \|^{\mathrm{H}}$

Xo.

1061

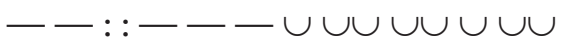

1062

$\cup \cup \cup \cup \cup \cup \cup \cup-\ldots$

1063

$\cup \cup \cup--$

Xo.

1064

$\cup-\cup-:: \cup--$

$\mathrm{ia}+\mathrm{ba}$

$<$ Xo. $>$

1065

$\cup-\cup-\cup::--$

$\mathrm{ia}+\mathrm{ba}$

$<$ Xo $>$

1066

$\cup-\cup-\cup::--$

$\mathrm{ia}+\mathrm{ba}$

Xo.

1067

$--\cup::-\cup-\cap$

1068-9

$\cup-\cup \cup-\cup \cup-\cup \cup-\cup \cup-\cup \cap$

1070

$\cup \cup \cup-\cup \cup \cup \cup \cup--$

$\mathrm{a}+\mathrm{ba} \|^{\mathrm{B}}$
$\cup$ dddds $\|^{\mathrm{HB}}$

$2 \delta$

Xo.

$1071-2$

$--\cup-\cup \cup \cup-\cup-$

$2 \delta \|^{H}$

\footnotetext{
${ }^{83}$ See above, p. 107.

${ }^{84}$ Dale analyses as 'iambic tripody' ('1968: 115; see also Barrett, comm. Hi., p. 267). Diggle's

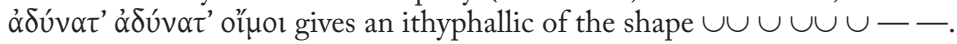


$\mathrm{A} \mu$.

$$
\begin{aligned}
& 1073 \quad \cup-\cup-\cup \cup \cup \cup-\quad 2 \text { ia } \\
& 1074 \quad \cup-\cup \cup \cup \cup-\cup-\quad 2 \text { ia } \\
& 1075-\leftarrow \cup--\leftarrow \cup \cup-\cup \cup-\cap-\mathrm{e}-\mathrm{D}-\|^{\mathrm{B}} \\
& 1076-\cup \cup-\cup \cup-\cup \quad \mathrm{D} \cup \mathrm{J} \\
& \text { 1077a } \quad-\cup \cup-\cup \cup-\cup \quad \mathrm{D} \cup \\
& 1077 \mathrm{~b}-\cup \cup-\longrightarrow
\end{aligned}
$$

Xo.

$1078 \cup \cup \cup-\cup-\cup \cup \cup-\cup-$

$\mathrm{A} \mu$.

$1079 \cup \cup \cup-\cup-\cup \cup \cup--$

$1080 \cup \cup-\cup \cup-\cup-\cup-$

3 ia
erasm
$\mathrm{D}$
$2 \delta$
$2 \delta \|^{\mathrm{B}}$

Xo.

1081-2 $\cup-\cup-\cup-\cup \cup \cup \cup \cup-$

$1083 \cup \cup \cup \cup-\cup \cup-\cup$

$1084-\cup \cup-\cup \cup \cap$

D

$1085-\cup \cup \cup \cup \cup \cup \cup \cup \cup \cup-\cup-$

$1086 \cup-\ldots---\leftarrow \cup \cap$

3 ia spoken

1087

$--\cup---\cup-\cup-\cup-$

$1088-\leftarrow \cup-\cup \cup \cup \cup \cup-\cup$

3 ia spoken

Herc. 1178-1213

$\mathrm{A} \mu$.

$1178-\cup \cup-\cup \cup \cup-\cup \cup-\cup-$

$\Theta \eta$.

$1179-\because \cup-\leftarrow \cup \cup \cup \cup-\cup-$

3 ia

$\mathrm{A} \mu$.

$1180 \cup \cup \cup-\cup \cup \cup \cup \cup-\cup$

$\Theta \eta$.

$1181-\because \cup-\cup \cup \cup \cup \cup-\cup-\quad 3$ ia

$\mathrm{A} \mu$.

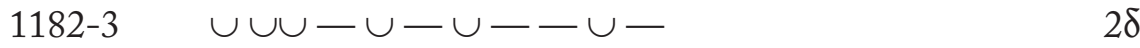

$1184 \cup \cup \cup \cup \cup \cup \cup \cup-\cup-\quad 2 \delta$

$\Theta \eta$.

$1187 \quad \cup-\cup-\leftarrow::-\cup \cup-\cup \cup---\quad$ ia - ibyc ${ }^{\text {chol }}$

$1188 \cup \cup-\cup \cup-\cup-\cup-\quad$ cyren

$\Theta \eta$.

1186

$-\leftarrow \cup-\leftarrow::-\cup \cup-\cup \cup---\quad$ ia - ibyc $c^{\text {chol }}$ 
Part II - Scansions

$\Theta \eta$.

1185

$--\cup--::-\cup \cup-\cup \cup---$

ia - ibyc chol

$\Theta \eta$.

1189

$--\cup---\cup-\cup-\cup-$

3 ia

$\mathrm{A} \mu$.

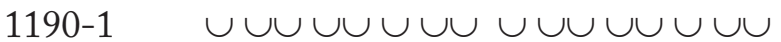

1192-3 $\cup \cup \cup-\cup \cup \cup--ー \cup-$ $2 \delta$

$2 \delta \int$

1194

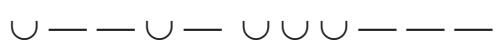

$2 \delta$

$\Theta \eta$.

1195

$--\cup---\cup---\cup-$

3 ia

$\mathrm{A} \mu$.

1196

$-\cup---\cup \cup-$

1197

$\cup \cup-\cup \cup-\cup \cup-\cup \cup-\cup-$

$\mathrm{s}-\mathrm{d}$

$\wedge$ dddds-

$\Theta \eta$.

1198

$\cup-\cup-\cup-\cup-\cup-\cup-$

3 ia

$\mathrm{A} \mu$.

1199

$-\cup \cup-\cup \cup-\cup$

$\mathrm{D} \cup$

1200

$-\cup \cup-\cup \cup-\cup$

$\mathrm{D} \cup$

1201

$-\cup \cup-\cup \cup \cap$

$\mathrm{D} \|{ }^{\mathrm{B}}$

$\Theta \eta$.

1202

$--\cup---\cup---\cup \cap$

3 ia

$\mathrm{A} \mu$.

1203

$-\cup-\cup \cup \cup-\cup-$

1204

$\cup \cup \cup \cup \cup \cup \cup \cup-\cup \cup-\ldots$

1205-6

$\cup \cup-\cup \cup-\cup \cup-\cup \cup-\cdots$

1207

$\cup \cup-\cup \cup-\cup \cup-\cup \cup-$

A

1208-9

$\cup \cup-\cup \cup-\cup \cup-\cup \cup-$

1210

$\cup \cup \cup-\cup-\cup--\cup-$

1211

$\cup \cup \cup-\cup-\cup-\cdots-$

1212

$\cup \cup \cup \cup \cup \cup \cup \cup \cup \cup \cup \cup-$

$\mathrm{cr}+\delta$

1213

$\cup \cup \cup-\cup-\cup--\cup \cap$

$\mathrm{cr}+\delta$
$2 \delta$
$\mathrm{A}+\mathrm{sp} \|^{\mathrm{H}}$
$\mathrm{A}$
$\mathrm{A}$
$2 \delta \int$
$2 \delta$
$2 \delta$
$2 \delta$




\section{Troades}

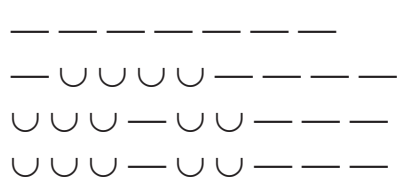

125

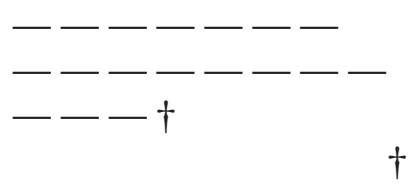

129

130

131

132

133

134

135

136

137

138

139

140

141

142

$143 a$

$143 b$

144

145

146

147

148

149

150

151

152
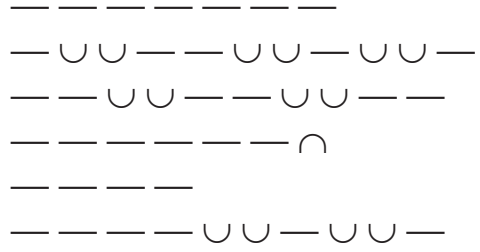

$\dagger \cup \cup \cup \cup \cup \cup \cup \cup-\cup \cup-\dagger$
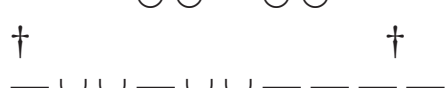

2 an

2 an

$\dagger$

$$
\dagger
$$

${ }^{85}$ See Dale (21968: 51); Parker (1976: 20). 
Parodos (Tr. 153-229)

Strophe $1 \sim$

HMIXOPION A'
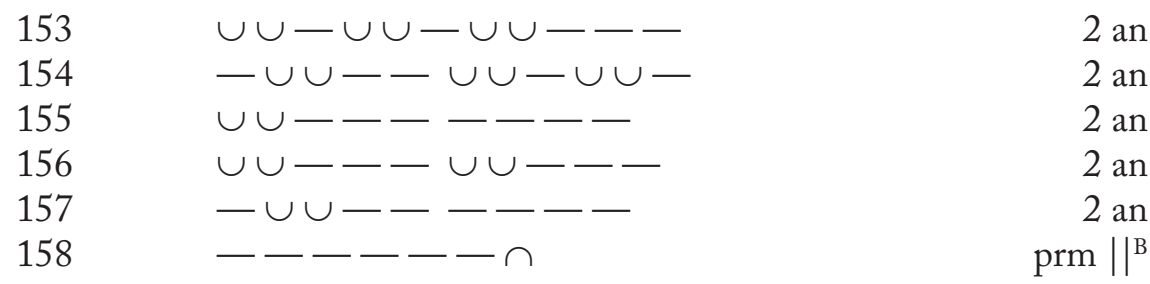

EK.

159

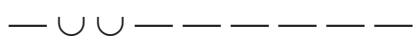

2 an

160

prm

$\mathrm{H \mu}$.

161

162

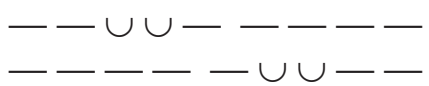

2 an

2 an

EK.

163

prm

$\mathrm{H \mu}$.

164

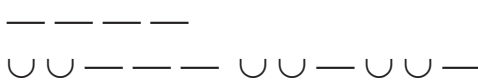

an

165

$\cup \cup---\cup \cup-\cup \cup-$

2 an

166

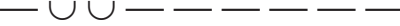

2 an

167

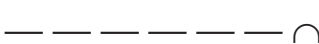

prm $\|^{\mathrm{B}}$

Ek.

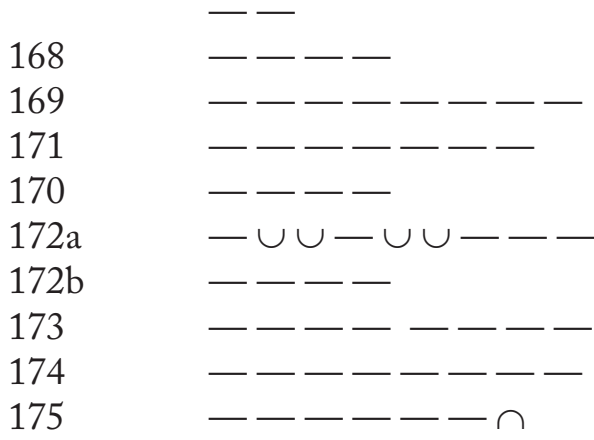

e. $m$. an 2 an prm an prm an 2 an 2 an prm $\|^{\mathrm{B}}$

$\sim$ antistrophe 1

HMIXOPION B'

176

$--\cup \cup---\cup \cup-$

2 an

177

$-\cup \cup-\cup \cup \cup \cup-\cup \cup-$

2 an 
EK.

182

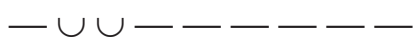

2 an

183

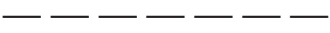

prm

$\mathrm{H} \mu$.

184

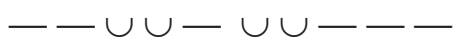
2 an

185

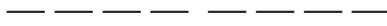

2 an

EK.

186

prm

$\mathrm{H \mu}$.

$187 \mathrm{a}$

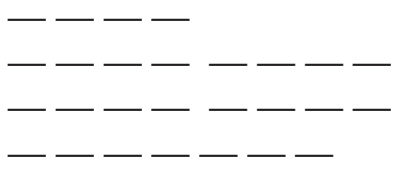

an

2 an

$187 \mathrm{~b}$

2 an

189

prm

EK.

\section{0}

e. $m$. an 2 an

191

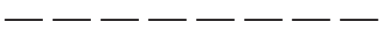
prm

$192 \mathrm{~b}$

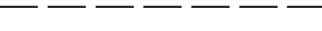

an

$193 \mathrm{a}$

$\cup \cup-\cup \cup-\cup \cup-\cap$

$193 \mathrm{~b}$

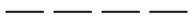

prm $\|^{\mathrm{B}}$

194

$-\cup \cup \cup \cup-\cup \cup-\cup \cup-$ an

2 an

195

2 an

196

prm

Strophe 2

Xo.

197

198

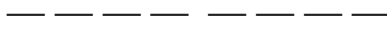

2 an

2 an

199

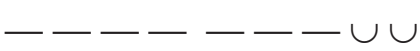

2 an

200

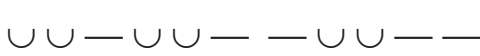

prm

201

202

$\cup \cup-\cdots--\cdots$

2 an

2 an

203

2 an

204

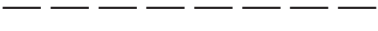

2 an

2 an 
Part II - Scansions

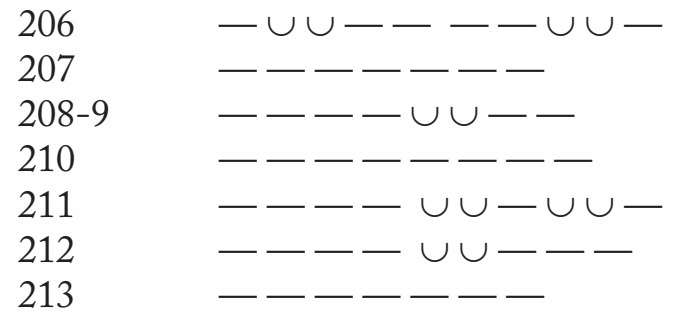

2 an

prm

prm

2 an

2 an

2 an

prm

$\sim$ antistrophe 2

214

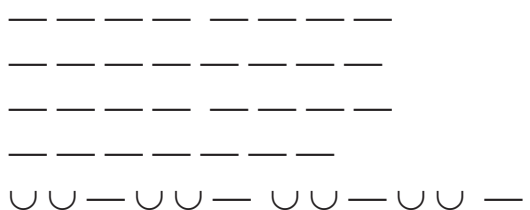

2 an

215

2 an

216

2 an

217

218

219

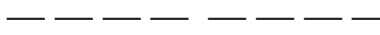

prm

2 an

2 an

220

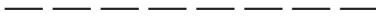

2 an

2 an

222

$\sim \cup-\cup \cup-\cup \cup--$

2 an

2 an

223

$---\cup \cup-\cup \cup-$

prm

225

226

$\dagger$

$\dagger$

227

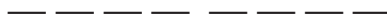

2 an

2 an

228

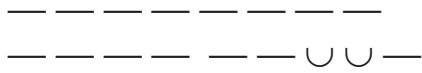

2 an

229

$-\div----$

prm

Duet (Tr. 235-291)

TA $\triangle \Theta$ YBIOC

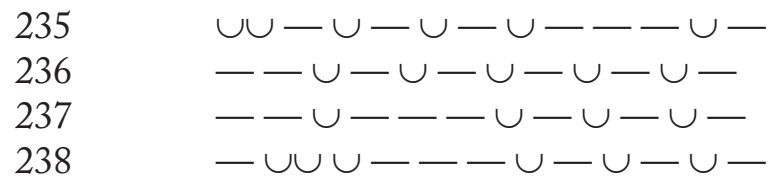

3 ia

3 ia

3 ia

EK.

239

$\dagger \cup \cup \cup \cup \cup-\cup-\cup \dagger \cup \cup \cup-\cup-$

$?+\delta ?$

To.

240

$--\cup---\cup-\cup-\cup-$

3 ia

EK. 
$\mathrm{T \alpha}$.

243

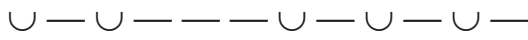

EK.

$\cup \cup \cup \cup \cup \cup \cup \cup \cup-\cup-$ $2 \delta$

245

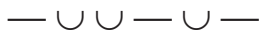

$\delta \| \mathrm{H}:$

$\mathrm{T} \alpha$.

246

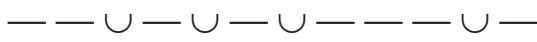

EK.

$\mathrm{T} \alpha$.

249

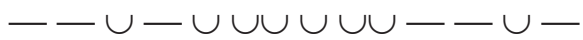

3 ia

EK.

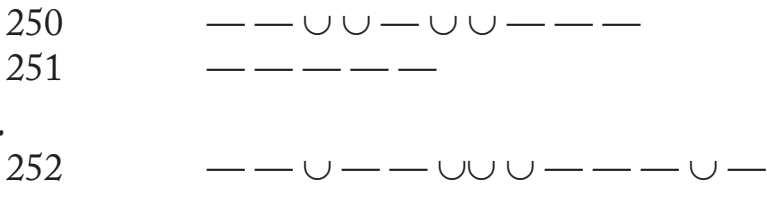

$\mathrm{T} \alpha$.

EK.

253

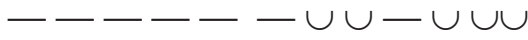

$2 \delta^{86}$

254

$-\cup \cup-\cup-\cup--\cup-$

$\mathrm{T} \alpha$.

255

$\cup-\cup---\cup-\cup-\cup-$

3 ia

EK.

256

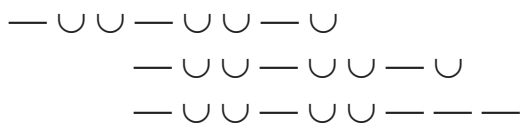

$\mathrm{D} \cup \int$

257

258

$-\cup \cup-\cup \cup--$

$\mathrm{D} \cup \int$ ibyc $^{\text {chol }}$

$\mathrm{T} \alpha$.

259<smiles>C=IONOC</smiles>

EK.

260

$\cup \cup \cup \cup \cup \cup \cup \cup \cup \cup \cup \cup \cup-$ $2 \delta$

261 $+$ $\dagger$

262<smiles>O=[V]=[V]=[Hg]</smiles>

prm?

263

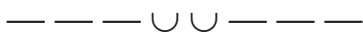

\footnotetext{
${ }^{86}$ On the split resolution, see above, p. 58.
} 
Part II - Scansions

$\mathrm{T} \alpha$.

264

$--\cup---\cup-\cup-\cup-$

3 ia

EK.

265

$-\cup \cup-\cup--\cup \cup \cup \cup \cup-$

$2 \delta$

266

$\cup-\cup \cup-\cup \cup-\cup$

erasm

267

$-\cup \cup-\cup \cup--$

ibyc $^{\text {chol }}$

$\mathrm{T} \alpha$.

268

$--\cup-\cup-\cup-\cup-\cup-$

3 ia

EK.

269

$\cup \cup \cup \cup$

$\mathrm{Cr}$

270

$-\cup \cup-\cup \cup--$

ibyc chol $^{\text {cr }}$

$\mathrm{T} \alpha$.

271

$\cup-\cup-\cup-\cup---\cup-$

3 ia

Ek.

272

$\cup---\cup \cup-\cup \cup-\cup \cup--$

$\mathrm{ba}+$ enop

273

$-\cup \cup-\cup-\cup \cup \cup-\cup-$

$2 \delta$

$\mathrm{T} \alpha$.

274

$--\cup--\cup \cup \cup---\cup-$

3 ia

EK.

$\begin{array}{ll}275 & \cup-\cup-:-\cup \cup-\cup \cup-\cup- \\ 276 & -\cup \cup---\cup--\cup \cap\end{array}$

ia + ibyc

$2 \delta \|^{\mathrm{B}}$

$\mathrm{T} \alpha$.

277

$\cup-\cup--\cup \cup \cup---\cup-$

3 ia

EK.

278

e. $\mathrm{m}$.

279

$\cup-\cup-\cup-\cup \cap$

280

$-\cup \cup-\cup-\cup-\cup-$

2 ia $\|^{B}$

281

$\cup---$

282

$\cup \cup-\cup \cup-\cup-\cup$

diom

283

$-\cup---$

$\mathrm{h} \delta$

284

$\cup \cup \cup \cup-\cup \cup \cup-\cup-$

$2 \delta$

285

$--\cup--\cup-\cup-\cup-$

$\mathrm{ia}+\mathrm{cr}+\mathrm{ia}$

286

$\cup-\cup \cup-\cup \cup-\cup$

erasm

287

$-\cup--$

$\mathrm{h} \delta$

288

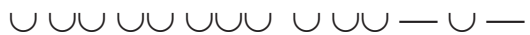

$2 \delta$

289

$\dagger \cup---\cup-\cup$

?87

${ }^{87}$ See Stinton (1990: 130 n. 31). 
291a $\cup-\cup-\cup-\cup-$

\section{Cassandra's Monody (Tr. 308-340)}

\begin{tabular}{|c|c|c|}
\hline \multicolumn{3}{|l|}{ Strophe } \\
\hline 308 & $\cup \cup \cup \cup \cup-\cup \cup \cup-\cup-$ & $2 \delta$ \\
\hline 309 & $\cup-\cup-$ & ia \\
\hline 310 & $-\cup \cup \cup \cup \cup \cap^{88}-\cup \cup-\cup-$ & $2 \delta$ \\
\hline 311 & $\cup \cup \cup \cup \cup \cup \cup-$ & $\mathrm{k} \delta$ \\
\hline 312 & $\cup \cup \cup-\cup-\cup \cup \cup---$ & $2 \delta$ \\
\hline 313 & $\cup-\cup-\cup-\cup-$ & 2 ia $\|^{H}$ \\
\hline 314 & $\cup--\cup \cup-\cup-$ & gl \\
\hline 315 & $\cup-\cup-\cup \dagger$ & ? \\
\hline $316-7$ & $\cup-\cup-\cup-\cup \cup \cup \cup-\cup \cup \cup$ & 3 ia \\
\hline 318 & $\cup-\cup-\cup-\cup-$ & 2 ia $\|$ \\
\hline 319 & $\cup-\cup \cup \cup-\cup-$ & $\mathrm{ia}+\mathrm{cr}^{89}$ \\
\hline 320 & $\cup \cup ー \cup ー-$ & ith \\
\hline 321 & $\cup--\cup--$ & $\mathrm{ba}+\mathrm{ba} \|$ \\
\hline 322 & $\cup--\cup \cup-\cup-$ & g1 \\
\hline 323 & $\cup--\cup \cup-\cup-$ & gl \\
\hline $324 a$ & $-\cup-\cup \cup--$ & $\mathrm{ph}$ \\
\hline $324 b$ & $-\cup \cup \cup$ & ia? \\
\hline$\sim$ antistrop & & \\
\hline 325 & $-\cup \cup-\cup \cup \cup \cup \cup \cup \cup \cup \cap$ & $2 \delta \|^{\mathrm{B}}$ \\
\hline 326 & $\cup-\cup-$ & ia \\
\hline 327 & $-\cup \cup \cup \cup \cup-\cup \cup \cup-\cup-$ & $2 \delta$ \\
\hline 328 & $\cup-\cup \cup \cup \cup \cup$ & $\mathrm{k} \delta$ \\
\hline 329 & $\cup \cup \cup-\cup-\cup \cup \cup---$ & $2 \delta$ \\
\hline
\end{tabular}

${ }^{88}$ See Parker (1997: 445).

${ }^{89} \operatorname{Tr}$. 319 335 raises the question whether the second long of a bacchiac may be resolved (resolution of the first long is unthinkable, as it goes against the principle formulated by Dale that the penultimate long of pendent cola is 'inviolable': $\left.{ }^{2} 1968: 74\right) . T r .319 ~ 335$ can be analysed either as 'ia + cr' $(\cup-\cup \cup \mid \cup-\cup-\sim \cup-\cup \cup \cup-\cup-)$ or 'ba + ia' $(\cup-\cup \cup \cup-\cup-$ $\sim \cup-\cup \mid \cup \cup-\cup-$ ). Since split resolution is unavoidable either way, I prefer to analyse 'ia + cr', as resolved bacchiacs in Euripides are an absolute rarity, the only plausible example being

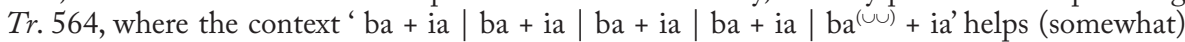
to suspend disbelief (cf. Diggle 1981: 19; Parker 1997: 413). Note that Hel. 335 (analysed by Stinton 1990: 125 as 'ba + ia') can also be analysed as ' $i a+c r$ ', although neither is likely to be right (see Willink 2010: 136 n. 13). 


$$
\cup-\cup-\cup-\cup-
$$

$\cup-\cup--\cup-\cup \cup \cup \cup \cup \cup$

\section{First Stasimon (Tr. 511-567)}

Strophe

511

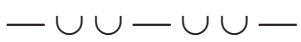

512

513-4

515

516

$517-8$

519

520

521

522

523

524

525

526

527

528

529

530

$\cup-\cup-\cup-$

$\cup \cup-\cup-$
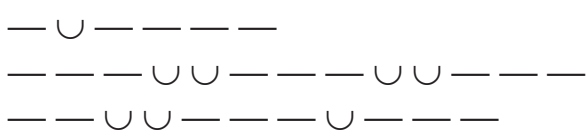

$\cup \cup-\cup \cup-\cup \cup-$

$---\cup \cup-\cup-\cup \cup \cup \cup-\cap$

$\cup \cup \cup-\cup-\cup \cup$

$\cup \longleftarrow \cup \cup \cup \cup \cup$

$$
\cup-\cup-\cup--
$$

$\cup \cup \cup--\cup-$

$-\cup \cup \cup \cup-\cup$

$\cup-\cup-\cup-\cup-$

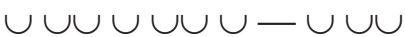

$\cup \cup \cup \cup \cup-\cup-$

$\cup-\cup-\cup-\cup-$

$\cup-\cup-\cup-\cup-$

\section{D}

$\mathrm{e}-\mathrm{sp}^{90}$
$\mathrm{D}^{\text {contr }}-\mathrm{D}^{\text {contr }}$

- d - e sp enop prm $D^{\text {contr }} \cup$ ith $\|\left.\right|^{\mathrm{B}}$ 2 ia 2 ia $\int$ $\mathrm{ia}+\mathrm{ba} \|^{\mathrm{H}}$ $\mathrm{ia}+\mathrm{cr}$ 2 ia 2 ia 2 ia 2 ia $\mid$ ? 2 ia 2 ia $\mathrm{ia}+\mathrm{ba}$ ith

$\sim$ antistrophe

531

$-\cup \cup-\cup \cup$

532

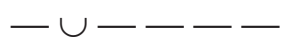

$\mathrm{D}^{\mathrm{contr}}-\mathrm{D}^{\mathrm{contr}} \|^{\mathrm{sp}}$

533-4

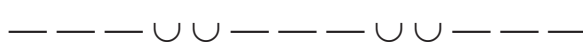

\footnotetext{
${ }^{90}$ On this colon, see Diggle, comm. Phaeth., p. 148 (cf. 1996a: 197).
} 


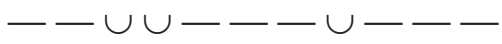

- d - e sp

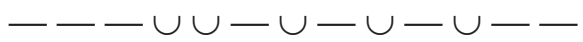

539

$\cup-\cup-\cup-\cup \cup U$

$\mathrm{D}^{\text {contr }} \cup$ ith ||$^{\mathrm{Bs}}$

540

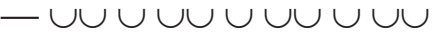$$
\cup-\cup \cup \cup \cup-\cup-
$$

epode

551

552-3

$$
\cup-\cup-\cup-\cup-
$$

2 ia

554

$\cup-\cup \cup \cup-\cup-$

2 ia

555

$\cup-\cup-\cup-\cup-$

2 ia

556

$\cup-\cup-\cup \cup \cup-$ $\mathrm{ia}+\mathrm{cr}$

557

$\cup-\cup-\cup-\cup-$

2 ia $\int$

2 ia $\int$

558

559

$\cup-\cup-\cup-\cup \cup U$

2 ia

560

$\cup \cup \cup \cup-\cup-\cup-$

2 ia $\|^{?}$ $\mathrm{ba}+\mathrm{ia}$

561

$\cup--\cup-\cup-$

$\mathrm{ba}+\mathrm{ia}$

562

$\cup--\cup-\cup-$

$\mathrm{ba}+\mathrm{ia}$

563

$\cup--\cup-\cup-$

$\mathrm{ba}+\mathrm{ia}$

564

$\cup--\cup-\cup-$

$\mathrm{ba}+\mathrm{ia}^{91}$

565

$\cup-\cup \cup \cup-\cup-$

$2 \mathrm{ia}^{92}$

566

$\cup-\cup-\cup \cup \cup \cup$

D

567

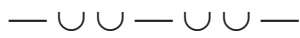

$\mathrm{ia}+\mathrm{ba}$

${ }^{91}$ See above, on $T r .319 \sim 335$.

${ }^{92}$ For the resolution before change of metre, see Diggle (1994: 398 n. 122). 
Part II - Scansions

Duet (Tr. 577-606)

Strophe 1

Av.

577

$\cup---\cup-\cup-\cap$

$b a+i t h$

Eк.

578

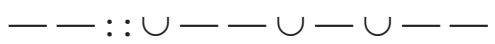

$i a+i t h$

Eк.

579

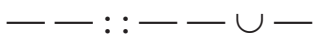

$\mathrm{mol}+\mathrm{cr}$

Ek.

580

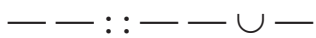

$\mathrm{mol}+\mathrm{cr}$

EK.

581

$\cup \cup \cup::-\cup-\longrightarrow$

ith

$\sim$ antistrophe 1

EK.

582

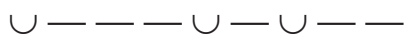

ba + ith

Av.

583

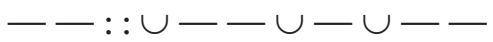

ia + ith

Av.

584

$--::--\cup-$

$\mathrm{mol}+\mathrm{cr}$

Av.

585

$\cup-::--\cup-$

$\mathrm{ba}+\mathrm{cr}$

Av.

586

$\cup \cup \cup::-\cup--$

ith

Strophe 2

Av.

587

$\cup--\cup--$

$2 \mathrm{ba}$

EK.

588

$\cup--\cup-$ 2 ba

589

$-\cup \cup-\cup \cup-$

D

Av.

590

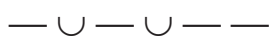

ith

$\sim$ antistrophe 2

Av.

591

$\dagger u \dagger--u--$

$2 \mathrm{ba}$

EK.

592

$\cup--\cup-\cdots$

2 ba 
Av.

594

Strophe 3

Av.

595

$-\cup \cup-\cup \cup-:: \cup \cup-\cup \cup-\cup \cup--$

$6 \mathrm{da}$

Av.

596

$-\cup \cup-\cup \cup-:: \cup \cup-\cup \cup-\cup \cup--$

$6 \mathrm{da}$

Av.

597

$-\cup \cup-\cup \cup-\cup \cup-\cup \cup-\cup \cup--$

$6 \mathrm{da}$

598

$-\cup \cup-\cup \cup-\cup \cup-\cup \cup-\cup \cup--$

$6 \mathrm{da}$

599

$-\cup \cup-\cup \cup-\cup \cup-\cup \cup-\cup \cup-$ $6 \mathrm{da}$

600

$-\cup \cup-\cup \cup-\cup \cup-\cup \cup-\cup \cup-$

$6 \mathrm{da}$

$\sim$ antistrophe 3

EK.

$601-\cup \cup-\cup \cup-:: \cup \cup-\cup \cup-\cup \cup--\quad 6 \mathrm{da}$

Eк.

602

$-\cup \cup-\cup \cup-:: \cup \cup-\cup \cup-\cup \cup--$

$6 \mathrm{da}$

EK.

603

$-\cup \cup-\cup \cup-\cup \cup-\cup \cup-\cup \cup--$

$6 \mathrm{da}$

604

$\dagger-\cup \cup-\cup \cup-\cup \cup--\dagger$

605

$-\cup \cup-\cup \cup-\cup \cup-\cup \cup<$

606

$-\cup \cup-\cup \cup-\cup \cup-\cup \cup-\cup \cup-$

Second Stasimon (Tr.799-859)

Strophe 1

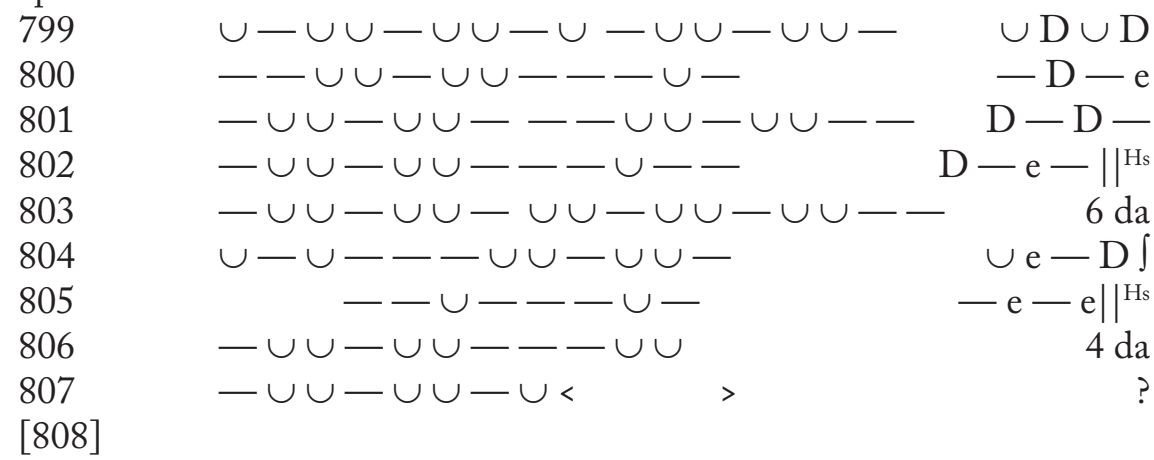


$\sim$ antistrophe 1

809

810

811

812

813-4

815

816

817

818-9 $\cup-\cup \cup-\cup \cup-\cup-\cup \cup-\cup \cup-\quad \cup \mathrm{D} \cup \mathrm{D}$ $--\cup \cup-\cup \cup---\cup-\quad-\mathrm{D}-\mathrm{e}$ $-\cup \cup-\cup \cup---\cup \cup-\cup \cup--$

$-\cup \cup-\cup \cup---\cup--$ $\mathrm{D}-\mathrm{e}-\|^{\mathrm{Hs}}$ $-\cup \cup-\cup \cup-\cup \cup-\cup \cup-\cup \cup--$ $\cup-\cup---\cup \cup-\cup \cup-$ $6 \mathrm{da}$ $\cup \mathrm{e}-\mathrm{D}$ $-\mathrm{e}-\mathrm{e} \|{ }^{\mathrm{Hs} / \mathrm{Ba}}$ $4 \mathrm{da}$ prax

Strophe 2

820-1

822

$\cup-\cup-:-\cup-\cup-\cup \cup-\cup \cup--$

$-\cup \cup-\cup \cup-$

ia $: \mathrm{e} \cup \mathrm{D}-\|^{93}$

$823-4$

$-\cup \cup-\cup \cup---\cup---\cup-\cdots$

$825-6$

$-\cup \cup-\cup \cup-\cup \cup-\cup \cup$

$827-8$

$-\cup \cup-\cup \cup-$

829

$\cup-\cup-\leftarrow \cup$

830

$-\cup-\cup-\cup-$

831

832

833

834

835

836

$837-8$

839

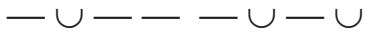

$-\cup-\cup-\cup--$

$\cup \cup-\cup \cup-\cup-\cup$

$\mathrm{D}-\mathrm{e}-\mathrm{e}-\|$ $4 \mathrm{da} \|^{\mathrm{Hs}}$

$\mathrm{D} \| \mathrm{Hs}$ $\mathrm{ia}+\mathrm{cr} \int$

$-\cup \cup-\cup \cup-$

$\cup-\cup \cup \cup \cup-\cup \cup \cup$

$1 \mathrm{k}$

$2 \operatorname{tr}$

$2 \operatorname{tr} \|$

diom

$\mathrm{D}$

2 ia $\int$

$\cup \cup \cup \cup \cup-\cup-$

2 ia

$\mathrm{D} \wedge \mathrm{D} \cup^{94}$

$-\cup \cup-\cup \cup-\cup \cup-\cup \cup-\cup$

ith

$\sim$ antistrophe 2

840-1

842

$-\cup-\cup--$

843-4

845

$\cup-\cup-:-\cup-\cup-\cup \cup-\cup \cup-\cap$

ia $: e \cup D-\|^{B}$

$-\cup \cup-\cup \cup-$

$\mathrm{D}$

846-7

$-\cup \cup-\cup \cup--\cup \cup-\backsim \cup \cap$

$\mathrm{D}-\mathrm{e}-\mathrm{e}-\|^{\mathrm{Ba}}$

848

$-\cup \cup-\cup \cup-\cup \cup-\cup \cup$

849

$-\cup \cup-\cup \cup-$

$\mathrm{D} \|{ }^{\mathrm{Hs}}$

$\cup-\cup--\cup-$

$\mathrm{ia}+\mathrm{cr}$

$\cup \cup \cup \cup-\cup-$

850

$-\cup \cup \cup \cup-\cup--$

851

$-\cup-\cup-\cup-$

2 tr

$2 \operatorname{tr} \|$

\footnotetext{
${ }^{93}$ See above, p. 84 (n. 174).

${ }^{94}$ Cf. West's notation of PV 547 555 at the end of his Teubner Aeschylus. See above, p. 67 (n.137).
} 
852-3

$\cup \cup-\cup \cup-\cup-\cup$

diom

854

$-\cup \cup-\cup \cup-$

D

855

$\cup-\cup-\cup-\cup \cup \cup$

2 ia $\int$

856

$\cup \cup \cup \cup \cup \backsim \cup-$

2 ia

$857-8$

$-\cup \cup-\cup \cup-\cup \cup-\cup \cup-\cup$

$\mathrm{D}^{\wedge} \mathrm{D} \cup$

859

$-\cup-\cup-$

ith

\section{Third Stasimon (Tr. 1060-1117)}

Strophe 1
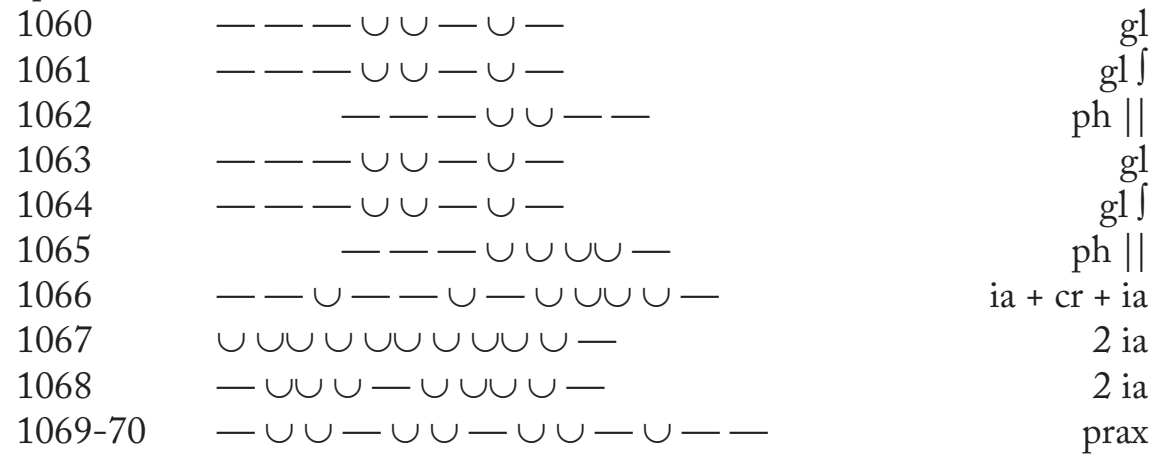

$\sim$ antistrophe 1

1071

1072

1073

1074

1075

1076

1077

1078

1079

1080-1
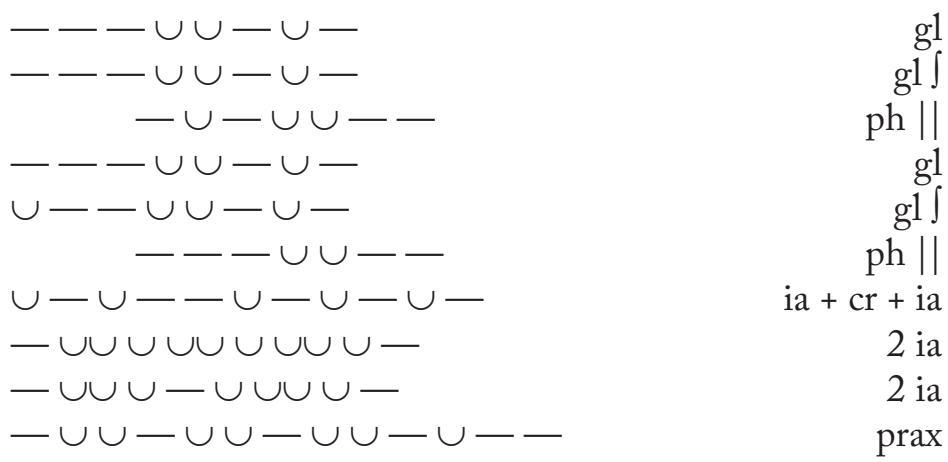

Strophe 2

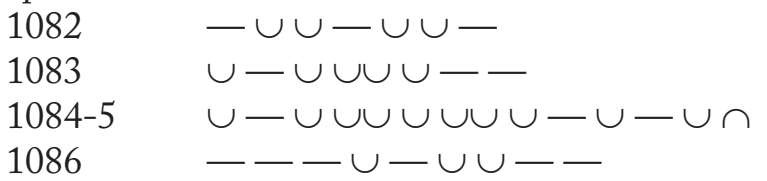

$\mathrm{D}$

$\mathrm{ia}+\mathrm{ba}$

3 ia $\underset{? 95}{\| B}$

95 For two different approaches to the problems of 1086 1104, see Wilamowitz (1921: 171) and Diggle (1981: 71-2). Metrically, Wilamowitz's solution (a pendent octosyllable) might

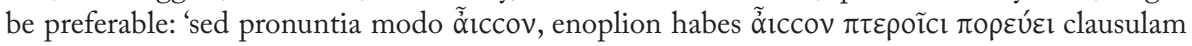



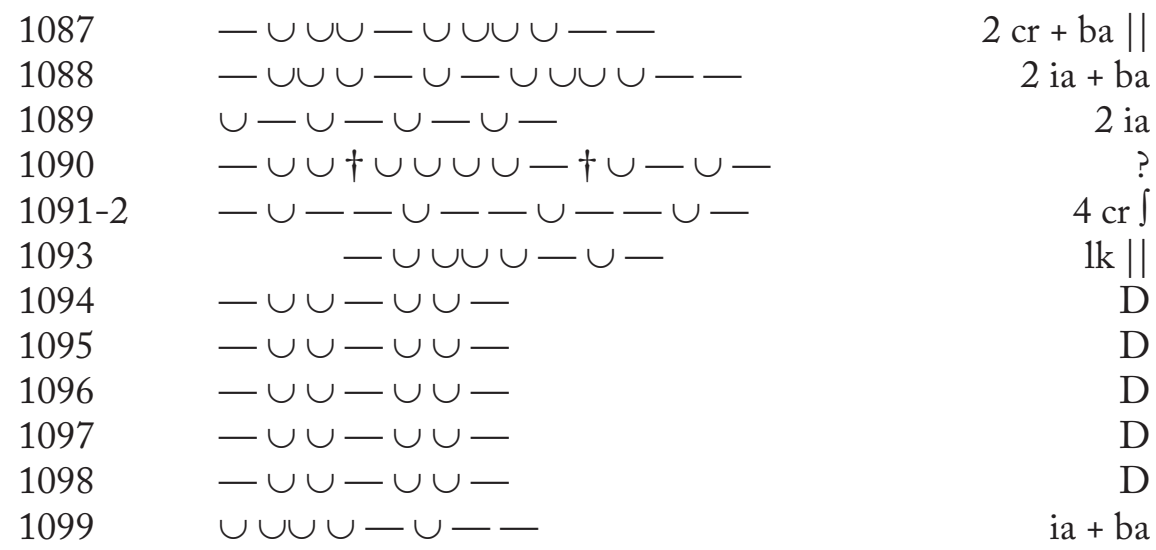

$\sim$ antistrophe 2

1100

$-\cup \cup-\cup \cup$

1101

$\cup-\cup \cup \cup-$

1102-3 $\cup-\cup \cup \cup \cup \cup \cup \cup-\cup-\cup-$

1104

$\dagger$

$\dagger \cup-\cup \cup$

$1105-\cup \cup \cup \cup \cup \cup \cup \cup \cup-\cap$

1106

$-\cup \cup \cup-\cup-\cup-\cup-$

1107

$-\cup \cup-\cup-\cup$

1108

$\cup \cup \cup-\cup-\cup-\cup-\cup-$

1109-10 $-\cup--\cup--\cup--\cup-$

1111

1112

$-\cup \cup \cup-\cup-$

1113

$-\cup \cup-\cup \cup-$

1114

1115

1116

1117

$-\cup \cup-\cup \cup-$

D

$-\cup \cup-\cup \cup-$

$\mathrm{D}$

$-\cup \cup-\cup \cup-$

$\mathrm{D}$

D

$\mathrm{ia}+\mathrm{ba}$

$\operatorname{Tr}$.1216-1245

Xo.

1216

$\cup-\cup-$

ia

$1217 \mathrm{a}$

$\cup \cup \cup \cup \cup \cup-\cup \cup \cup-\cup-$

$2 \delta$

$1217 \mathrm{~b}$

$\cup--\cup-$

$\delta$

periodi optimam'. With Diggle's conjecture at 1104, we would have $---\cup-\cup \cup--$ ('e $\mathrm{e}^{\text {chol }} \cup \mathrm{d}-$ ') corresponding with $-\cup-\cup-\cup \cup--$ ('e $\cup \mathrm{d}-$ '), although elsewhere in Euripides 'e' $(-\cup-)$ does not seem to respond with '- - - '. 
Xo.

1226

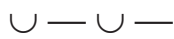

$1227 \cup \cup \cup-\cup-\cup-$

$1 \mathrm{k}$

1228

$-\cup-\cup-$

$\mathrm{h} \delta$

1229

$\cup-\cup-\cup::--$

ia + ba

Xo.

1230

$\cup-\cup-\cup::--$

$\mathrm{ia}+\mathrm{ba} \|^{\mathrm{H}}$

Xo.

1231

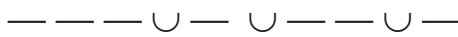

EK.

1232

$\cup-\cup--\cup \cup \cup-\cup-\cup-$

3 ia

1233

$--\cup-\cup \cup \cup \cup-\cup-\cup-$

3 ia

1234

$\cup-\cup-\cup-\cup-\cup-\cup \cap$

Xo.

$\begin{array}{ll}1235 & \cup-\cup-\cup-\cap \\ 1236 & \cup--\cup-\cup-\cap \\ 1237 & \cup--\leftarrow\end{array}$

$\mathrm{ia}+\mathrm{ba} \|^{\mathrm{B}}$

$\delta+$ ba $\|^{\mathrm{B}}$

e. $\mathrm{m}$.

EK.

1238

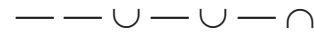

$\mathrm{ia}+\mathrm{ba} \|^{\mathrm{B}}$

Xo.

1239

$\dagger \cup \cup--\dagger \cup \cup \cup \cup \cup \cup---$ ?

коциóc (Tr. 1287-1332)

Strophe 1

EK.
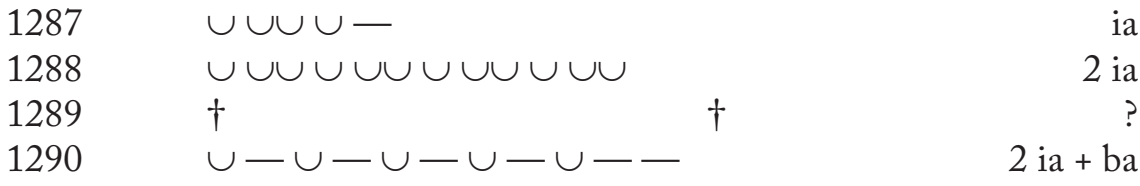

Xo.

$1291 \cup \cup \cup-\cup \cup \cup \cup \cup \cup$

2 ia

$1292-3$

$\cup \cup \cup \cup-\cup-\cup-\cup-$

$2 \mathrm{ia}+\mathrm{ba}$

$\sim$ antistrophe 1

EK. 
Part II - Scansions

Xo.

1298

$\cup \cup \cup-\cup-\cup-$

2 ia

1299

$\cup-\cup-\cup \cup \cup \cup-\cup-$

$2 \mathrm{ia}+\mathrm{ba}$

Strophe 2

EK.

1302

$\cup-\smile \cup \cup-\cup-\cup-$

$\mathrm{ba}+\mathrm{cr}+\mathrm{ia}$

Xo.

e. $m$.

EK.

1303

$--\cup \cup \cup \cup \cup \cup \cup \cup-$

$2 \mathrm{ia}+\mathrm{ba}$

Xo.

1304

$\cup-\cup--\cup-\cup-\cup-$

$\mathrm{ia}+\mathrm{cr}+\mathrm{ia}$

EK.

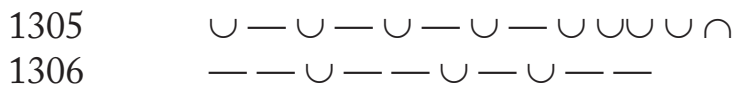

3 ia $\|^{\mathrm{B} / \mathrm{Ha}}$ $\mathrm{ia}+\mathrm{ith} \|^{\mathrm{Ha}}$

Xo.

1307

$\cup \cup \cup-\cup \cup \cup-\cup-$

ia + ith

1308

$-\cup-\cup-\cup-\cup$

$2 \mathrm{tr}$

1309

$-\cup-\cup-\leftarrow$

ith $\| \mathrm{Ha}$

EK.

1310

$\cup \cup \cup \cup \cup::-\cup--\cup-$

$2 \mathrm{ia}+\mathrm{cr}$

EK.

1311

$-ー \cup \cup \cup \cup-\cup::-\cup-\cup-$

3 ia $\|$

EK.

1312

$\cup-\cup-\cup \cup \cup \cup \cup$

2 ia

1313

$\cup \cup \cup \cup \cup \cup \cup \cup \cup \cup \cup$

2 ia

1314

$--\cup-\cup-\cup-$

2 ia $\|^{\mathrm{Ha}}$

Xo.

1315

$\cup-\cup-\cup \cup \cup \cup-$

$\cup \cup \cup \cup \cup \cup \cup \cup \cup-\cup-\cap$

2 ia $\int$

1316

$\sim$ antistrophe 2

EK.

1317

$\cup--\cup \cup \cup \cup-\cup-$

$\mathrm{ba}+\mathrm{cr}+\mathrm{ia}$

Xo.

e. $m$.

EK. 
Xo.

1319

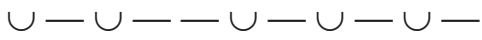

$\mathrm{ia}+\mathrm{cr}+\mathrm{ia}$

EK.

1320

$\cup-\cup-\cup-\cup \cup \cup \cup-\cup \cap$

3 ia $\|{ }^{\mathrm{B} / \mathrm{H}}$

1321

$\cup-\cup--\cup-\cup-$ $\mathrm{ia}+\mathrm{ith} \|^{\mathrm{H}}$

Xo.

1322

$\cup \cup \cup \cup-\cup \cup \cup-\cup-$

ia + ith

$1323-\cup-\cup-\cup-\cup$

$2 \mathrm{tr}$

1324

$-\cup-\cup--$

ith $\| \mathrm{Ha}$

Ek.

1325

$\cup \cup \cup \cup \cup \cup::-\cup-\longrightarrow \cup \cap$

$2 \mathrm{ia}+\mathrm{cr}$

EK.

1326

$\cup \cup \cup-\cup \cup \cup \cup:: \cup--\cup \cap$

3 ia $\|^{B}$

EK.

1327

$\cup-\cup-\cup \cup \cup \cup \cup$

2 ia

1328-9

$\cup \cup \cup \cup \cup \cup \cup \cup \cup \cup \cup$

2 ia

1330

$--\cup-\cup-\cup-$

2 ia $\|^{\mathrm{Ha}}$

Xo.

1331

$\cup-\cup-\cup \cup \cup \cup$

2 ia

1332

$\cup \cup \cup \cup \cup \cup \cup \cup \cup \cup-\cup-$

2 ia + ba 


\section{IPHIGENIA IN TAURIS}

\section{Parodos (IT123-235)}

I $\Phi$.

123

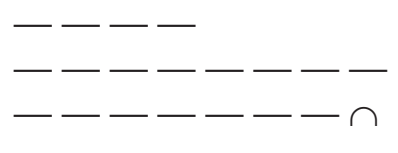

2 an
2 an $\|^{\text {B }}$

125

124

XOPOC

126

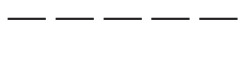

$\delta^{96}$

127

128

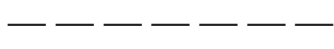

prm

129

130

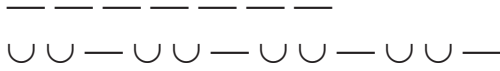

131

132

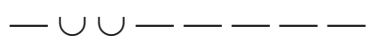

133-4

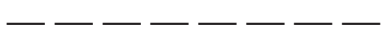

135

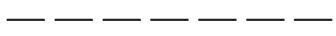

136

137

138

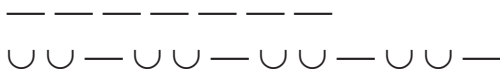

prm

2 an

139

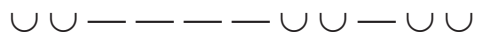

prm $\|^{\mathrm{H}}$

prm

2 an

prm

prm

2 an

2 an

2 an

140

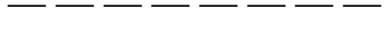

2 an

141

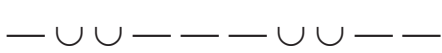

142

$\dagger \cup---+$

2 an

IФ.

143

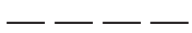

an

144

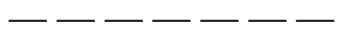

145

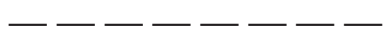

prm 2 an

146

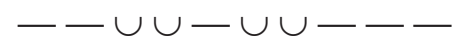

147

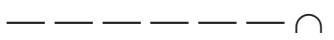

2 an $\|^{\mathrm{H}}$ prm $\|^{\mathrm{B}}$

148

149

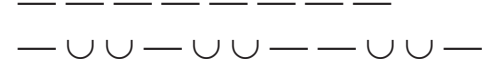

2 an

2 an

150

$\dagger----\cup \cup-\dagger$

151

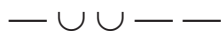

an

152

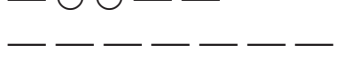

prm $\|^{\mathrm{H}}$

96 'Dragged dochmiac with the effect of a short paroemiac' (Dale $\left.{ }^{2} 1968: 60\right)$. 
Part II - Scansions
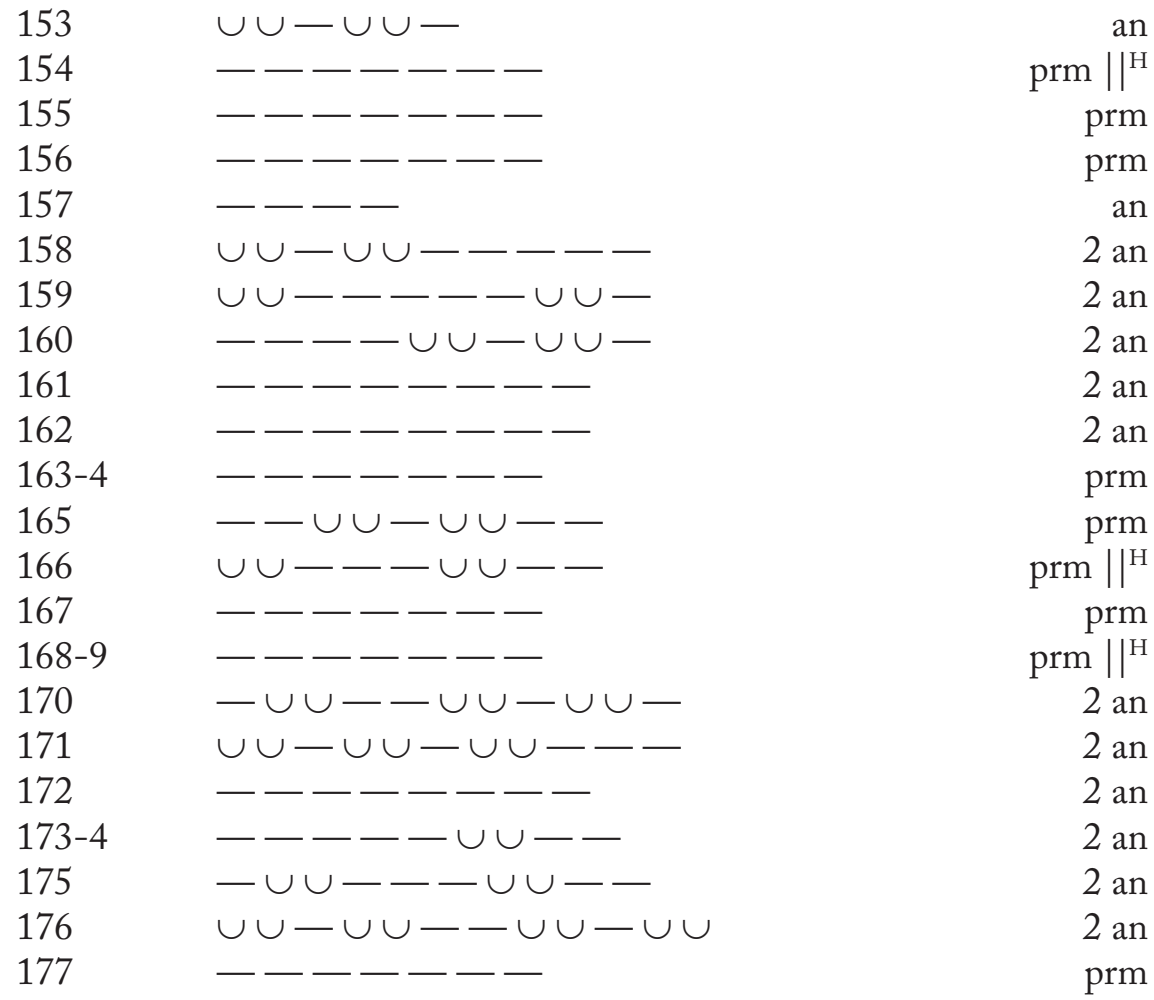

Xo.

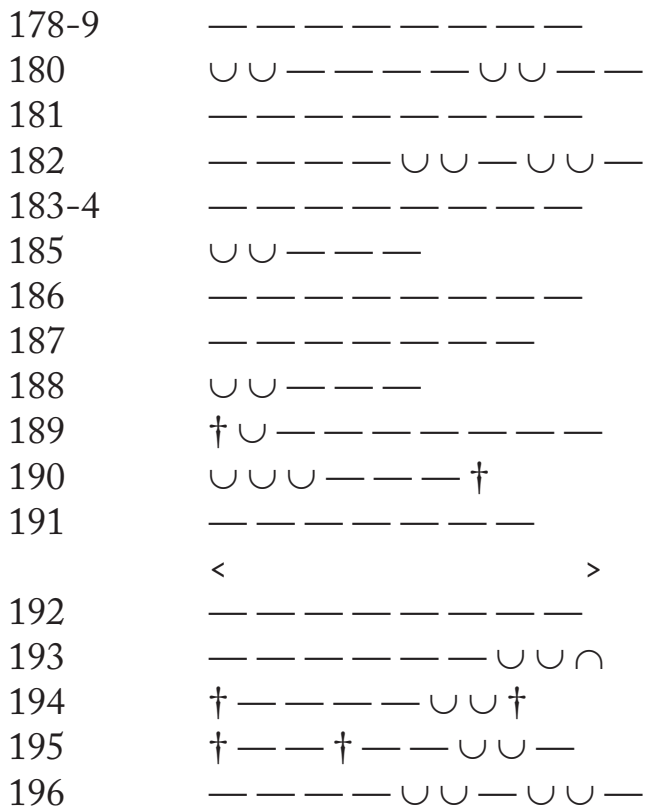

2 an 2 an 2 an 2 an 2 an an 2 an prm an ? ?

prm 2 an 2 an $\|^{1}$ 2 an 
$197 \quad \dagger \cup \cup \cup \cup \cup-\cup \cup \cup \cup \cup \cup \dagger$

198-9

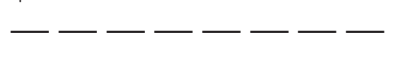

$200 \quad-----\cup \cup \cup$

201

202

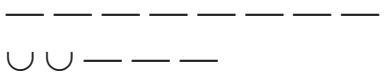

2 an

2 an

2 an

an

IФ.

203

204

205

206

207

209

210

211

212

213

214

215

216

217

218

219

220

208

221

222

223

224

225

226

227

228

229

230

231

232-3

234
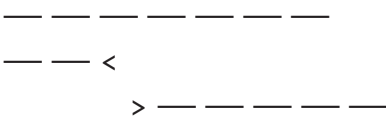

prm

2 an

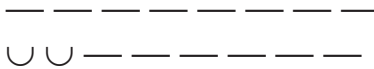

prm

prm $\|{ }^{\mathrm{H}}$

2 an

prm

prm

prm

$\dagger \cup \cup \cup \cup \cup \cup-\cdots+\dagger$

?

prm

prm

prm

2 an

2 an

prm $\|^{\mathrm{H}}$

2 ia $^{97}$

2 an

2 an

2 an

2 an

2 an

2 an?

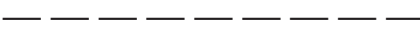

2 an

2 an

2 an

2 an

2 an $\|^{\mathrm{B}}$

2 an

2 an

235

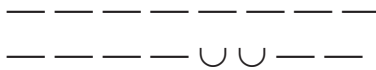

\footnotetext{
${ }^{97}$ Cf. Diggle (1981: 96).
} 
First Stasimon (IT392-455)

Strophe 1

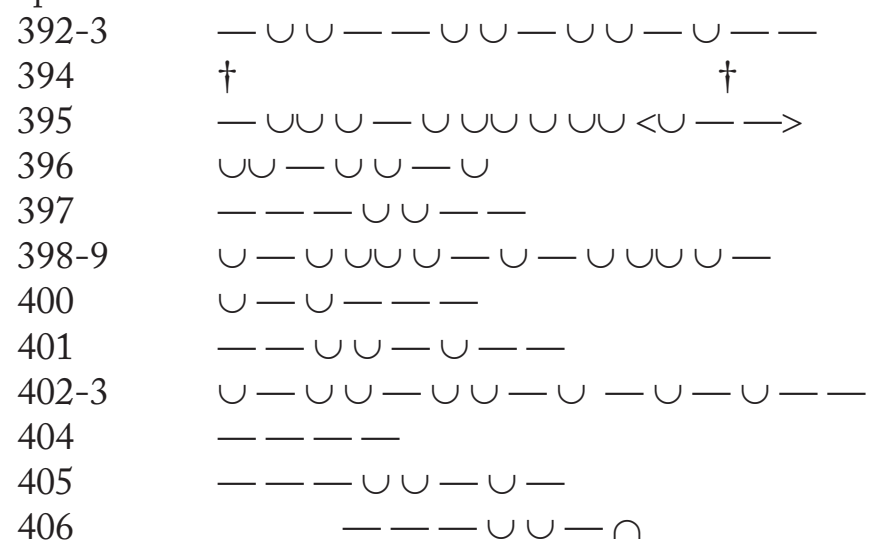

$$
\begin{array}{r}
\mathrm{ch}+\text { decasyll } \\
? \\
2 \mathrm{ia}+\mathrm{ba} \\
\text { reiz }{ }^{98} \\
\mathrm{ph} / \mid \\
3 \mathrm{ia} \\
\mathrm{ia}+\mathrm{sp} \\
\text { hag } \\
\text { erasm }+\mathrm{ith}^{99} \\
2 \mathrm{sp} \\
\text { gl } \\
\text { ph }
\end{array}
$$

$\sim$ antistrophe 1
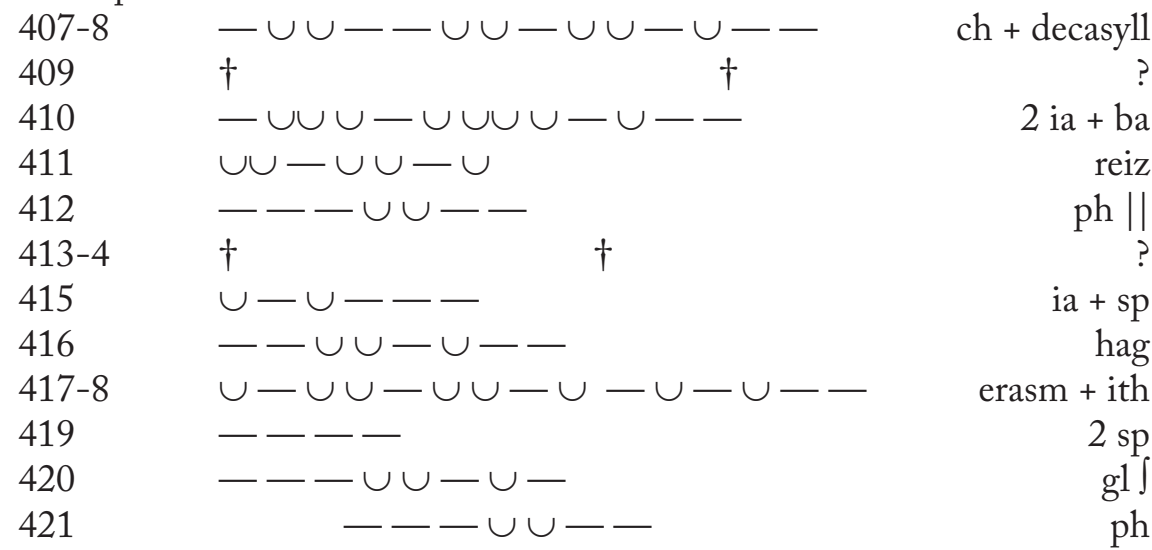

Strophe 2
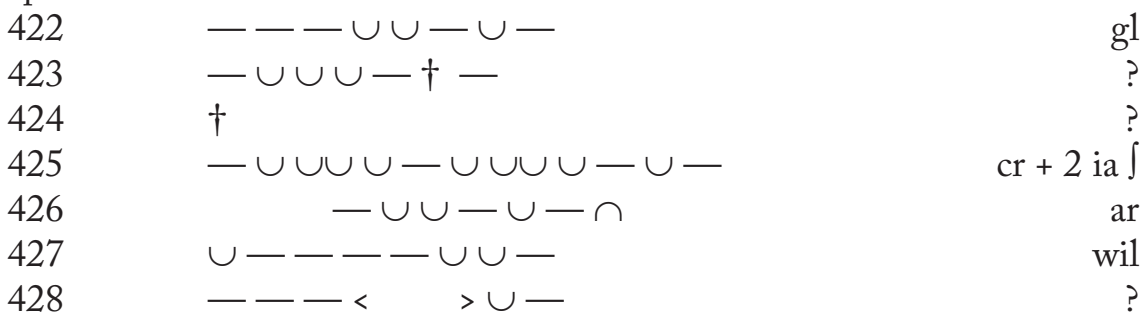

\footnotetext{
${ }^{98}$ See above, p. 76.

${ }^{99}$ See above, p. 79.
} 


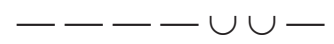

433

434

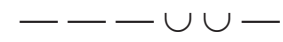

435

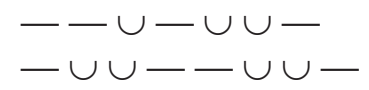

436

437

438

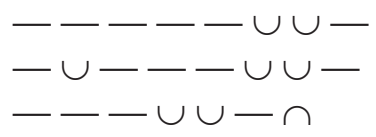

hept

hept

oct

hept

hex

hept II.

$2 \mathrm{ch} \int$

wil I

wil

ph

$\sim$ antistrophe 2

439

$----\cup \cup-$

440

$--\cup \cup-\cup-$

441

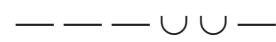

442

443

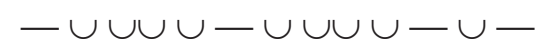
$-\cup \cup-\cup-$

444

445

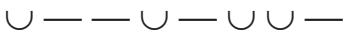

446

447

448

449

450

451

452

453

454

455

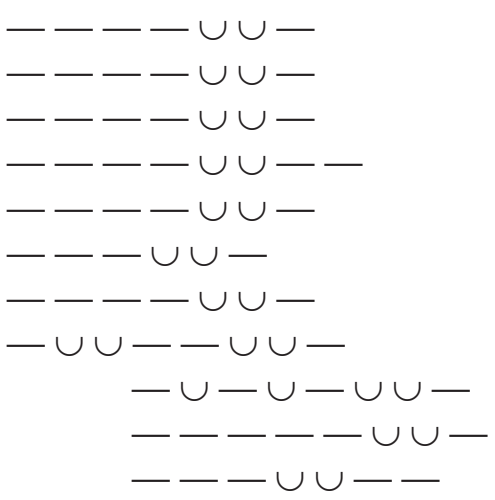

wil tel hex $\mathrm{cr}+2$ ia $\int$

$$
\begin{array}{r}
\text { ar } \\
\text { wil } \\
\text { hept } \\
\text { hept } \\
\text { hept } \\
\text { oct } \\
\text { hept } \\
\text { hex } \\
\text { hept II } \\
2 \text { ch } \int \\
\text { wil } \\
\text { wil } \int \\
\text { ph }
\end{array}
$$

\section{IT 644-655}

Xo.

644

$$
\cup \cup \cup-\cup-\cup--\cup-
$$

Op.

646

$$
--\cup---\cup-\cup-\cup-
$$

3 ia

Xo. 
Part II - Scansions

648-9 $\cup \cup \cup-\cup-\cup \cup \cup-\cup-$

$\Pi v$.

650

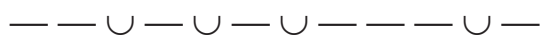

3 ia

Xo.

651

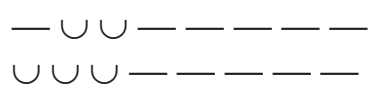

652

$\dagger \cup \cup \cup \cup--\dagger$

$\delta+\mathrm{sp}$

653

$\cup \cup \cup-\cup \cup \cup \cup \cup \cup \cup \cup-$

$\delta+\mathrm{sp}$

654

$\cup \cup \cup \cup-\cup--\cup-$

$2 \delta$

655

\section{Duet (IT 827-899)}

I $\Phi$.

827

830

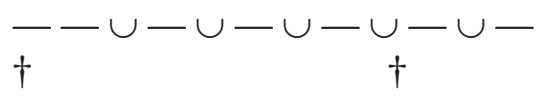

Op.

831

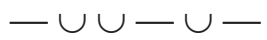

3 ia

?

3 ia

IФ.

832

833

$\cup \cup \cup-\cup \cup \cup \cup \cup \cup \cup$

$2 \delta$

3 ia

834

835

$\cup-\cup--\cup \cup \cup--\cup$

836

$\cup \cup \cup-\cup-\cup \cup \cup-\cup-$

837-8

$\cup \cup \cup-\cup-$

839

$--\cup-\cup-\cup-\cup-\cup-$

840

$--\cup--\cup-$

$\cup--\cup-\cup-\cup \cup \cup-$

?

$2 \delta$

$\delta$

3 ia

$\mathrm{ia}+\mathrm{cr}$

$2 \delta$

Op.

841

$\cup-\cup-\cup-\cup---\cup \cap$

3 ia

IФ.

842

$\cup \cup \cup-\cup-\cup \cup \cup-\cup-$

843

$\cup-\cup-\cup-\cup-\cup-\cup \cap$

844

$-\cup \cup-\cup-$

845

$\cup-\cup-\cup-\cup-\cup-\cup-$

846

$\cup-\backsim-$

847

$\cup \cup \cup \cup \cup \cup-\cup-$

848

$\cup \cup-\cup \cup-\cup \cup-\cup \cup-$

849

$-\cup--\cup-$

$2 \delta$

3 ia $\|^{\mathrm{H}}$

$\delta \| \mathrm{H}$

3 ia

$\delta$

$2 \delta$

A

$2 \mathrm{cr}$

$0 \rho$.

850

$\cup-\cup-\cup-\cup-\cup-\cup-$

3 ia 
851 $--\cup---\cup-\cup-\cup \cap$

3 ia

IФ.

852-3 $\cup-ー \cup \cup \cup-\cup \cup-\cup-$ $2 \delta$

$854 \cup-\backsim \cup-\cup \cup \cup-\cup-$ $2 \delta$

Op.

855

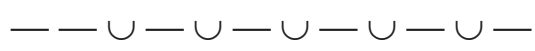

IФ.

856-7 $\cup \cup \cup-\cup--\cup \cup-\cup-$ $2 \delta$

858-9

$-\cup \cup-\cup-\cup \cup \cup-\cup-$

$2 \delta$

$860 \cup \cup \cup-\cup-\cup \cup \cup-\cup-$

$2 \delta$

861-2 - - $\cup-\cup----$

$2 \delta^{\mathrm{H}}$

Op.

863

$--\cup---\cup---\cup-$

3 ia

IФ.

$864 \cup \cup \cup \cup \cup \cup \cup \cup$

2 ia

865

$-\cup---\cup-$

$1 \mathrm{k}$

867

$-\cup-\cup-\cup \cap$

$1 \mathrm{k}$

Op.

866

$--\cup-\cup-\cup-\cup-\cup \cap$

3 ia

IФ.

868-9

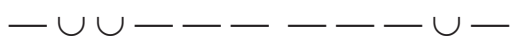
$2 \delta$

870

$\cup-----\cup \cup \cup \cup \cup \cup$ $2 \delta$

$871-2$

$\cup \cup \cup \cup \cup \cup \cup \cup \cup \cup-\cup-$

873

$\cup--\cup-$

874

875

$-\cup \dagger--\cup \dagger-\cup-$

876

$-\cup---\cup--$

877-8

$\cup \cup-\cup \cup-\cup \cup-\cup \cup-$

879

$\cup \cup \cup \cup \cup-\cup \cup \cup--$

$2 \delta$

$\delta$

?

$2 \mathrm{tr}$

A

$2 \delta$

880

$\cup \cup \cup---$

$\delta$

881

$\cup \cup-\cup \cup-\cup \cup-\cup \cup-$

A

882-3

$\cup \cup \cup \cup$

$\mathrm{cr}$

$2 \delta$

884

$-\cup \cup-\cup-\cup \cup \cup--$

885

$\cup \cup-\cup \cup-\cup-\cup-\cap$

886-7

$-\cup \cup-\cup$

$\mathrm{T}+\mathrm{ba} \|^{\mathrm{BH}}$

888-9

$\cup \cup-\cup \cup-\cup \cup-\cup \cup-\cup$

$A \cup($ cf. Hel. 692)

890-1

$-\cup \cup-\cup \cup---\cup \cup-\cup \cup-$

892

$\cup \cup \cup-\cup--\cup \cup-\cup-$

$\mathrm{D}-\mathrm{D}-$

894

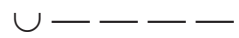

$2 \delta \int$

895

$\cup-\cup \cup-\cap$

$\dagger \cup \cup-\cup \cup-\cup \cup-\cup \cup-$

reiz

A ? 
Part II - Scansions

896

897

$\cup-\cup \cup-$

898

$\cup \cup \cup \cup \cup-\cdots+$

899

$\cup--\cup-\cup--\cup-$

$\cup--\cup \cap$

$2 \delta$

Second Stasimon (IT 1089-1152)

Strophe 1
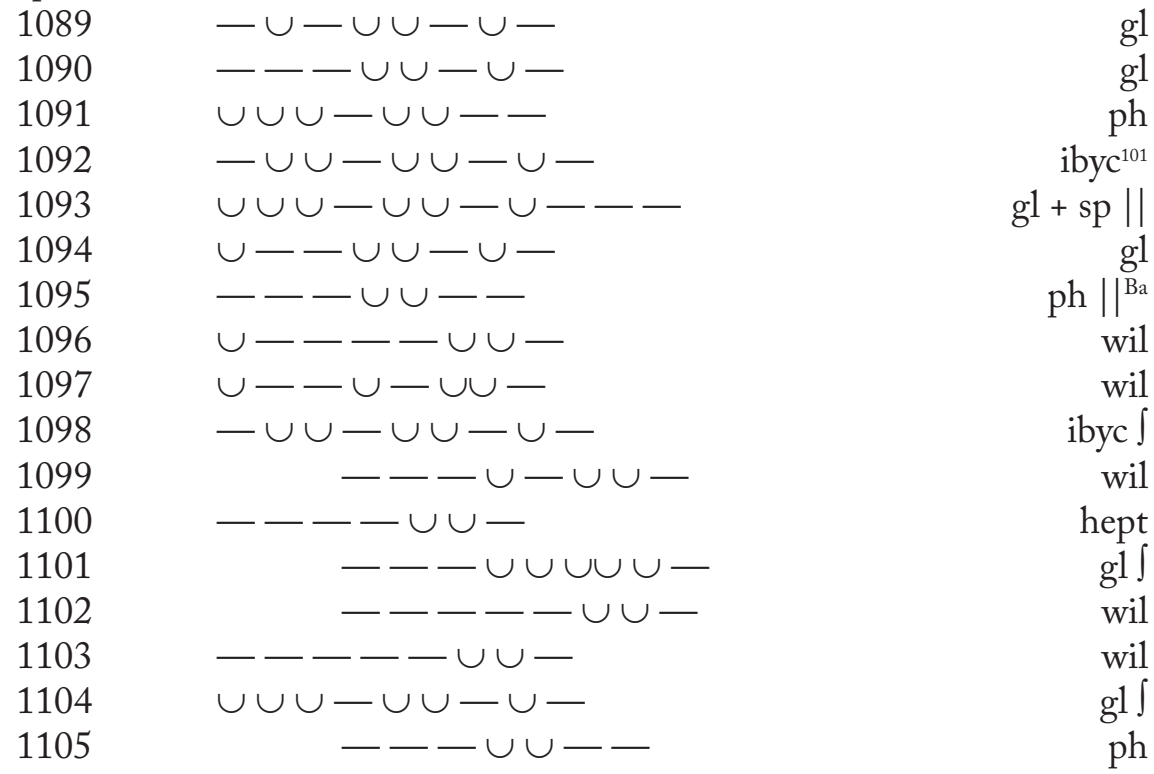

$\sim$ antistrophe 1

1106

1107

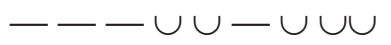

1108

$-\cup-\cup \cup-\cup-$

1109

$\cup \cup \cup-\cup \cup-$

1110

$\cup \cup \cup---\cup \cup-$

1111

$\cup \cup \cup-\cup \cup-\cup---$

1112

$\cup--\cup \cup-\cup-$

1113

1114

1115

1116

$---\cup \cup-\cap$

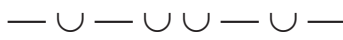

$\cup--\cup \cup-\cup-$

$-\cup \cup-\cup \cup-\cup-$

ibyc $\int$

gl

g1

ph

wil

$\mathrm{gl}+\mathrm{sp} \|$

g1

ph || ${ }^{\mathrm{Ba}}$

g1

gl

wil

hept I

1117

${ }^{101}$ For the responsion 'ibyc wil', see Parker (1997: 448). 
${ }^{102}$ Are the textual problems of 1129-37 1144-52 quite as desperate as they seem in the OCT (when Sansone prints the whole sequence without a single dagger in his Teubner edition)? By picking and choosing in Kovacs' apparatus, a solution can certainly be found for every problem (though whether Euripides would recognize the following poetry as his own is another matter):

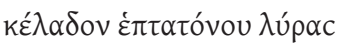

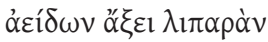

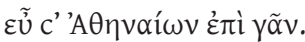

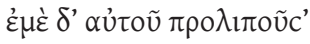

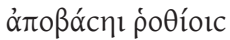

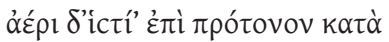

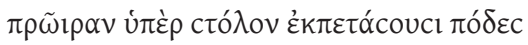

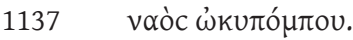

1144

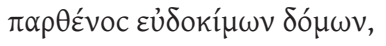

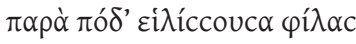

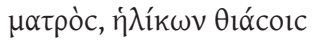

$\varepsilon \dot{\varepsilon} \alpha \dot{\alpha} \mu \hat{\imath} \lambda \lambda \alpha c \chi \alpha \rho i ́ \tau \omega \nu$

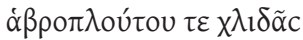

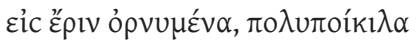

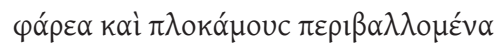

The text I have put together above (more daring even than Kovacs'...) entails almost a dozen

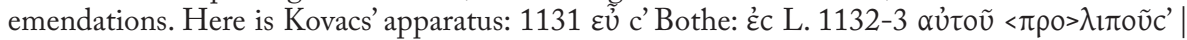

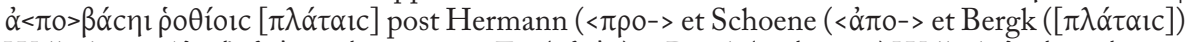

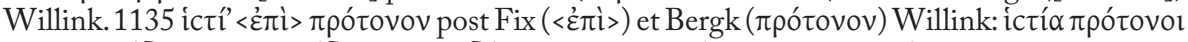

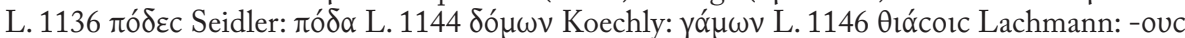

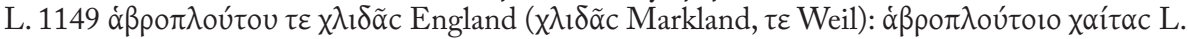

1129

$$
\begin{aligned}
& \cup \cup \cup-\cup \cup-\cup-\text { gl } \\
& \cup---\cup \cup \cup \text { wil } \\
& \cup \cup---\cup \cup-\text { wil } \\
& \cup \cup--\cup \cup-\text { hept } \\
& -\cup \cup-\cup \cup-\cup \cup-\cup \cup 4 \text { da } \\
& -\cup \cup-\cup \cup-\cup \cup-\cup \cup-5 \text { das }
\end{aligned}
$$
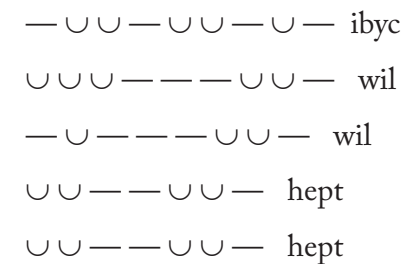

$-\cup \cup-\cup \cup-\cup \cup-\cup \cup 4$ da $-\cup \cup-\cup \cup-\cup \cup-\cup \cup-5 \mathrm{da}$

$\cup \cup-\cup-\longrightarrow$ ith

$1137-\cup-\cup-\longrightarrow$ ith

1152

The responsion ' $\mathrm{g} 1 \sim$ ibyc' is unique, but in view of 'ibyc wil' at 1092 1109 it can be accepted. The shape of the 'aeolic heptasyllables' are otherwise unparalleled in Euripides. 1135:

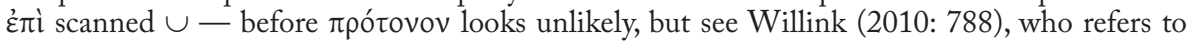
Barrett on Hi. 760. 


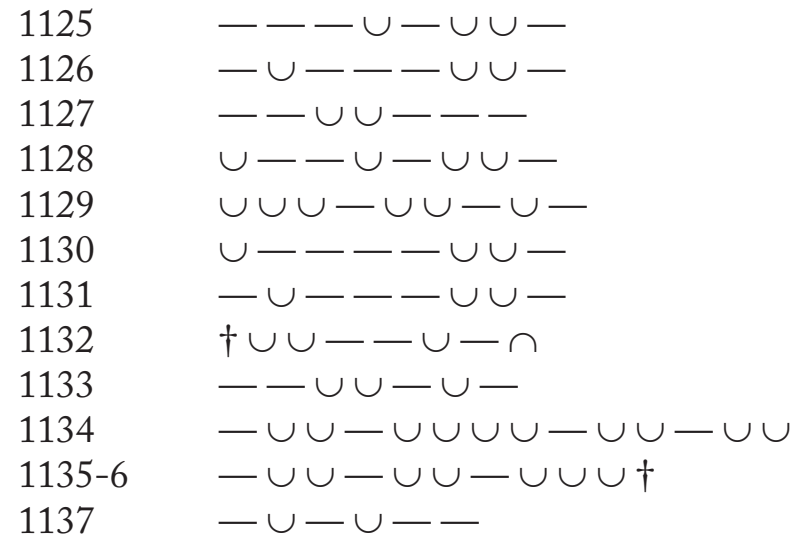

$\sim$ antistrophe 2

1138

1139

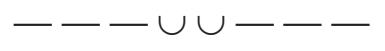

1140

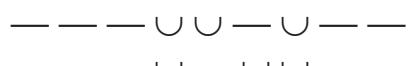

1141

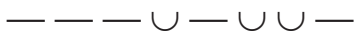

1142

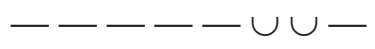

1143

$--\cup \cup--\cap$

1144

$\cup---\cup \cup$

1145

$\dagger-\cup \cup-\cup \cup-\cup-$

1146

$\cup \cup \cup-\cup-\cup \cup-$

1147

$\cup \cup \cup-\cup-\cup \cup-$

1148-9

$\cup \cup--\cup \cup-$

1150

$\cup \cup--\cup---\cup-$

1151

$-\cup \cup-\cup \cup-\cup \cup-\cup \cup$

1152

$-\cup \cup-\cup \cup-\cup \cup-$

$\cup \cup \cup-\cup-\cdots \dagger$

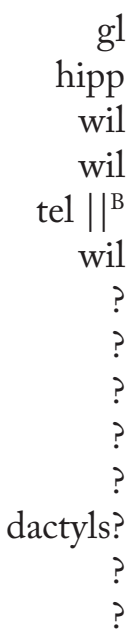

Third Stasimon (IT1234-1283)

Strophe

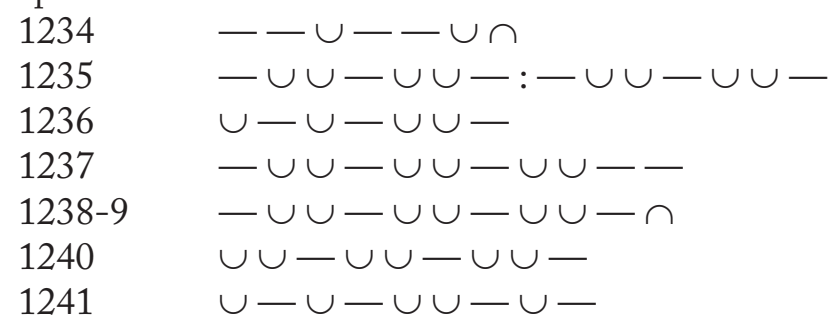

$\mathrm{ia}+\mathrm{cr} \|^{\mathrm{Bs}}$

$\mathrm{D}+\mathrm{D}$

hept $4 \mathrm{da}$ $4 \mathrm{da} \|^{\mathrm{Ba}}$ $\wedge$ ddd $\mathrm{x}$ gl $\int^{103}$

${ }^{103}$ See above, p. 113. 
1246-7 $\cup \cup-\cup \cup-\cup---\cup-$

1248-9 $-\cup-\cup-\cup-\dagger-\cup----\cup \cup \cap \dagger$ ?

1250

1251

1252-3

1254

$\cup \cup \cup \cup \cup \cup \cup$ diom + cr ||

1255

1256-7

$$
\cup \cup-\cup \cup-\cup-\cup--
$$

2 ia $\mathrm{T}+\mathrm{ba} \|$ $\mathrm{cr}+\mathrm{cr}-\mathrm{D}$ $\operatorname{dod}+2$ ia $\mathrm{mol}+\mathrm{ba}+\mathrm{ia}$ $A+i a$ antistrophe

1259

1260

$\cup-\cup--\cup-$

1261

$-\cup \cup-\cup \cup<$

1262

$$
--\cup-\cup \cup-
$$

1263-4

$-\cup \cup-\cup \cup-\cup \cup-$

1265

1266

1267

1268

1269

1270

1271

$$
-\cup \cup-\cup \cup-\cup \cup-\cap
$$

1272-3

1274

$\cup \cup-\cup \cup-\cup \cup$

1275

$-ー \cup-\cup \cup-\cup-$

1276-7

1278-9

1280

1281-2

1283
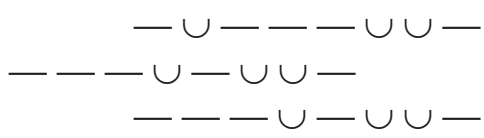

$\cup \cup-\cup \cup-\cup---\cup$

$\cup \cup-\cup \cup-\cup-\cup-\cup-$

$-\cup-\cup-\cup \cup-\cup \cup---\cup$

$\cup \cup \cup \cup \cup \cup \cup$

$\cup \cup-\cup \cup-\cup-\cup--$

$\cup \cup-\longleftarrow \cup--\cup \cup-\cup$

$\cup \cup \cup-\cup \cup---\cup---\cup-$

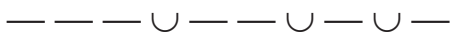

$\cup \cup-\cup \cup-\cup \cup-\cup \cup---\cup-$

$\mathrm{ia}+\mathrm{cr} \|$ Bs

hept $4 \mathrm{da}$ $4 \mathrm{da} \|\left.\right|^{\mathrm{Ba}}$ $\wedge$ ddd $\mathrm{x} \mathrm{gl}$ wil wil f wil diom $+\mathrm{cr}$ diom + cr $\|$ $\mathrm{e} \cup \mathrm{D}-\mathrm{e}$ 2 ia $\mathrm{T}+\mathrm{ba} \|$ $\mathrm{cr}+\mathrm{cr}-\mathrm{D}$ $\operatorname{dod}+2$ ia $\mathrm{mol}+\mathrm{ba}+\mathrm{ia}$ $A+i a$ ith 


\section{IoN}

\section{Ion's Monody (Ion 112-183)}

Strophe

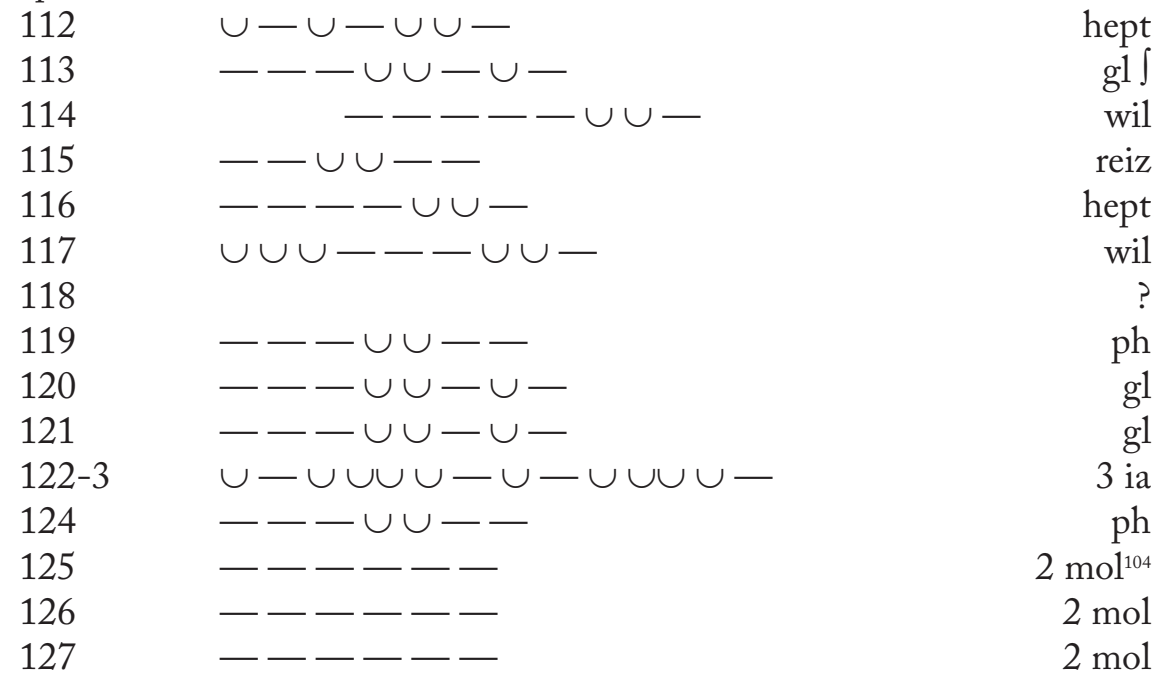

$\sim$ antistrophe

128

$\cup-\cup-\cup \cup-$

129

$-\cup-\cup \cup-\cup-$

hept

130

131

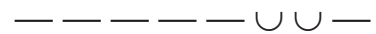

132

133

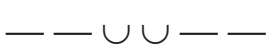

wil

reiz

hept

134

$----\cup \cup-$

wil

hex

135

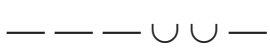

ph

136

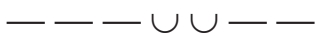

137

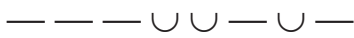

gl

138-9

${ }^{104}$ See Parker (1997: 471).

105 Probably the only believable caesura-less trimeter in Euripides (cf. Diggle 1994: $476 \mathrm{n}$. 158). 


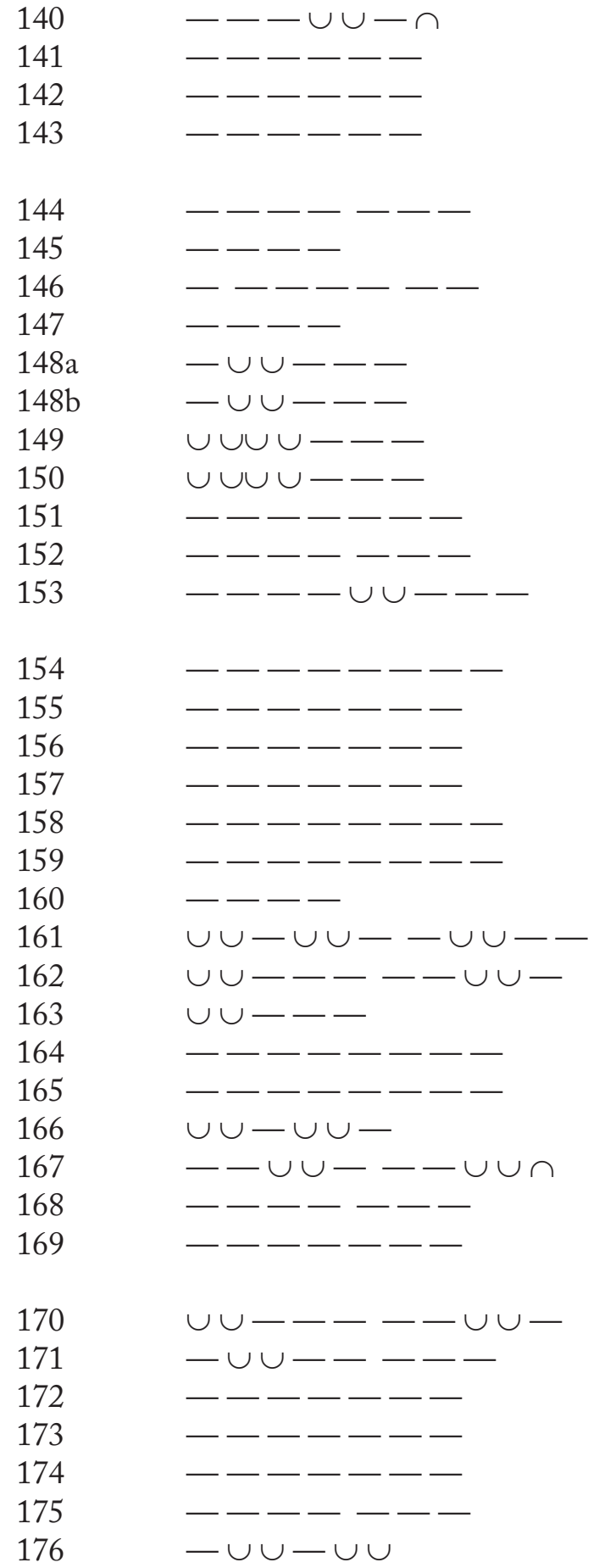

$\mathrm{ph}$
$2 \mathrm{~mol}$
$2 \mathrm{~mol}$
$2 \mathrm{~mol}$

prm

an

prm

an

$\delta$

$\delta$

$\mathrm{ia}+\mathrm{sp}$

ia $+\mathrm{sp}$

prm

prm

2 an $\|^{\mathrm{H}}$

e. m.?

2 an

prm

prm

prm

2 an

2 an

an

2 an

2 an

an

2 an

2 an

2 an $\|^{\text {an }}$

prm

prm

e. m. ?

2 an

prm

prm

prm

prm

prm $\|^{\mathrm{H}}$

an 

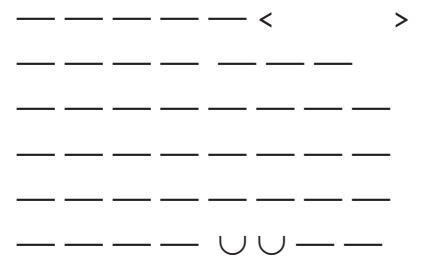

\section{Parodos (Ion 184-236)}

Strophe 1
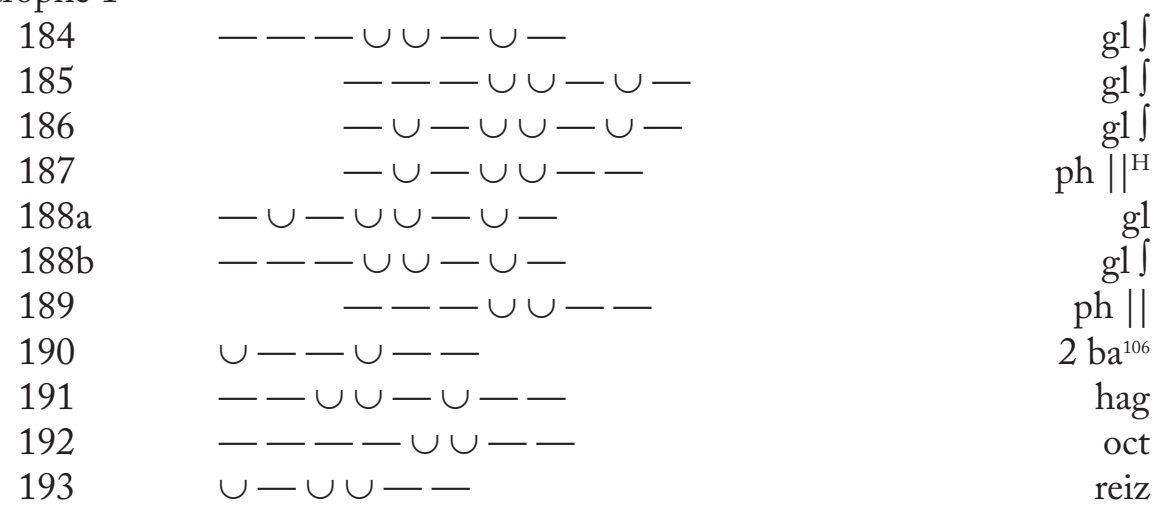

$\sim$ antistrophe 1

194

195

196

197

198

199

200

201

202

203

204 $\cup--\cup \cup-\cup-$
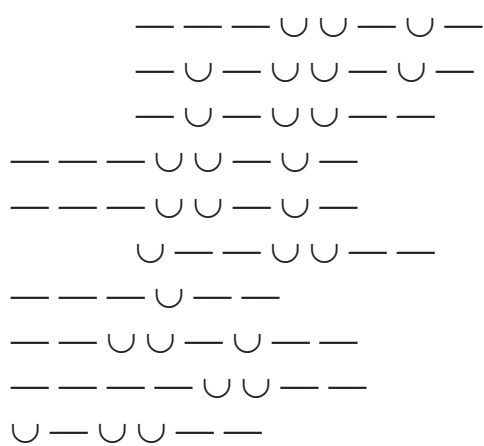

$\cup-\cup \cup-$

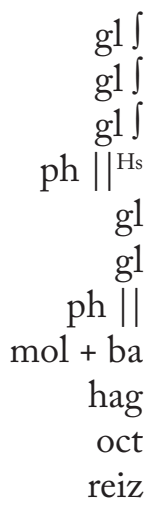

gl $\int$

g1 $\int$ oct

${ }^{106}$ On the responsion 'ba mol', see Diggle (1994: 201). 
Part II - Scansions

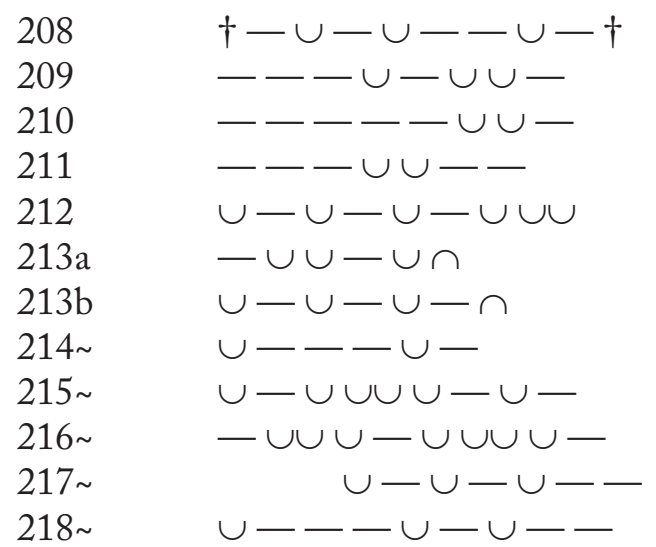

$\sim$ antistrophe 2

219

220

$221 \mathrm{a}$

$221 \mathrm{~b}$

222

$223 \mathrm{a}$

$223 \mathrm{~b}$

$223 \mathrm{c}$

224

225

226

227

228

229

230

$231 \mathrm{a}$

$231 \mathrm{~b}$

232

$233 \mathrm{a}$

$233 \mathrm{~b}$

234

$235 \mathrm{a}$

$235 \mathrm{~b}$

236 $\cup-\leftarrow \cup \cup-\cup-$

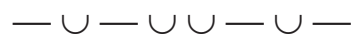$$
---\backsim \cup \cup
$$

$-\cup \cup-\cup \cup$

$\cup \cup-\cup \cup$
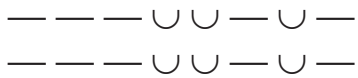

$-\cup \cup-\cup \cup-\cup \cup-\cup \cup$

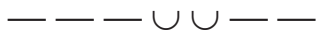

$-\cup \cup-\cup \cup \cup \cup-\cup \cup-$

$-\cup \cup---\cup \cup-$

$\cup \cup-\cup \cup-\cup \cup--$

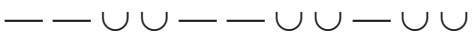

$\cup-\cup-\cup-\cup \cup$

$-\cup \cup-\cup \cap$

$\cup-\cup-\cup-$

$-\cup \cup-\cup \cup-\cup \cup-\cup \cup$

$\cup---\cup-$

$\cup-\cup \cup \cup-\cup-$

$--\cup \cup---\cup \cup-$

$-\cup \cup \cup \cup \cup$

$\cup-\cup-\cup-$

$\cup--\backsim \cup-\cup-$

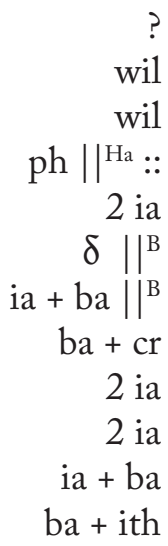

?

wil

wil

2 ia

$\delta \|^{\mathrm{B}}$

$\mathrm{ba}+\mathrm{cr}$

2 ia

2 ia

ba + ith

gl $\int$
gl $\int$
oct $\|$

an

?

an

g1

2 an

ph $\|^{\mathrm{Ha}}::$

2 an

2 an

2 an

2 an

2 ia

$\delta \|^{\mathrm{B}}$

ia + ba

2 an

$\mathrm{ba}+\mathrm{cr}$

2 ia

2 an

2 ia $\int$

$\mathrm{ia}+\mathrm{ba}$

ba + ith 
First Stasimon (Ion 452-509)

Strophe

452

453

454

$\cup----\cup \cup-$

wil

hept

455

$\cup---\cup \cup-$

ph

456

$\cup--\cup \cup-$

wil J

457

458

459

460

461

462

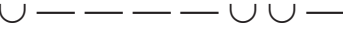

hept

$\cup \cup-\cup \cup-\dagger \cup-\cup \dagger--$

$\cup \cup \cup \cup-\cap$

reiz $\|^{\mathrm{B}}$

$\cup----\cup \cup-$

wil

reiz

$\cup-\cup \cup--$

tel

463

$\cup-\cup \cup-\cup-$

tel

464

$\cup \cup \cup-\cup \cup-\cup \cup U$

465

$--\cup \cup--$

466

$\cup---\cup \cup$

reiz

wil

gl

467

468

$\cup \cup-\cup \cup-\cup-$

$\mathrm{T}$

469

$\cup \cup-\cup \cup-\cup-$

470

$\cup \cup-\cup \cup-\cup \cup-\cup \cup-$

471

$--\cup \cup-$

reiz

$\sim$ antistrophe

472

473

474

475

476

477

478

479

480

481

482

483

484

485

$\cup----\cup \cup-$

wil

hept

ph

wil

hept prm

$\cup \cup-\cup \cup-\cup \cup-$

reiz ||

wil

reiz

tel

$--\cup \cup-\cup-$

tel

reiz |

gl

486

$-\cup \cup-\cup-$

wil

487

488

$\cup \cup \cup-\cup \cup-\cup$

$\cup---\cup \cup$

? 
Part II - Scansions

489

480

$\cup \cup-\cup \cup-\cup-$

481

$\cup \cup-\cup \cup-\cup \cup-\cup \cup-$

A

reiz

epode

492

493

494

495

496

497

498

499

$--\cup \cup--$

500

501

502

$503 \mathrm{a}$

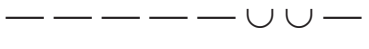

wil

hept reiz ||

wil

wil

2 ia

$\delta$ ?

hept

$\cup-\cup-\cup \cup-$

tel?

$\delta$ ?

ith $\|$

$\mathrm{h} \delta$ ?

$503 \mathrm{~b}$

$-\cup-\cup \cup-\cup-$

504

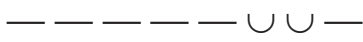

505

506

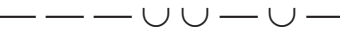

507

$-\cup \cup-\cup-\cup-$

508-9

$-\cup \cup-\cup \cup-\cup \cup-\cup \cup$

$4 \mathrm{da}$

$6 \mathrm{da}$

Second Stasimon (Ion 676-724)

Strophe

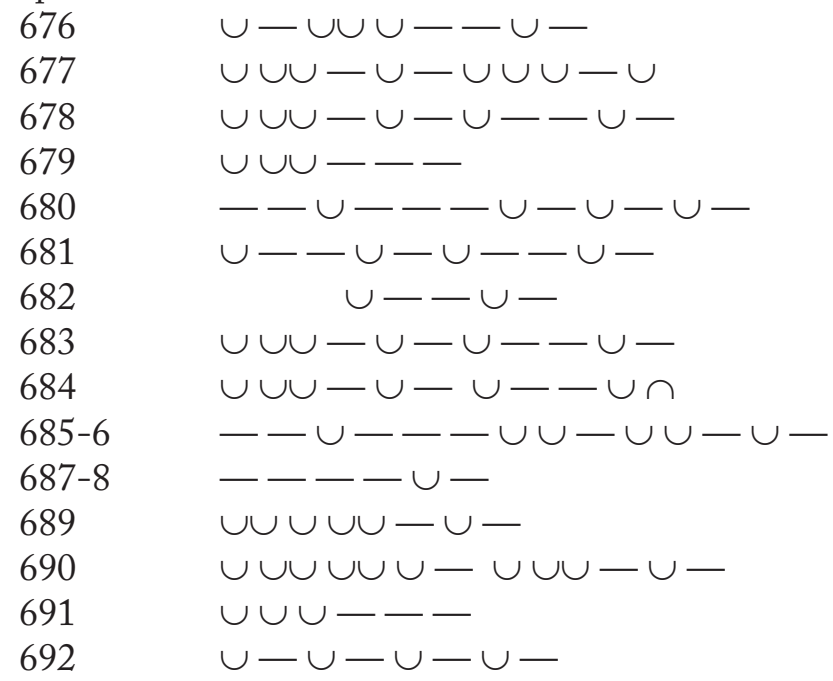

$\delta+\mathrm{cr}$

$2 \delta$

$2 \delta$

$\delta \|$ Hs

3 ia

$2 \delta \int$

$\delta$

$2 \delta$

$2 \delta \|$

- e - ibyc

$\mathrm{mol}+\mathrm{cr}$

2 cr? $\|^{\mathrm{Hs}}$

$2 \delta$

2 ia $\|$ 
693

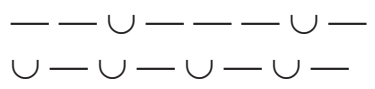

2 ia

694

$\cup-\cup-\cup-\cup-$

$\sim$ antistrophe

695

$\cup-\cup \cup \cup-\cdots-$

$\delta+\operatorname{mol}$

696

$\cup \cup \cup-\cup-\cup--\cup-$

697

$\dagger$

698

699

700

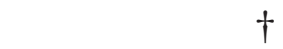

$\dagger$

$--\cup---\cup-\cup-\cup-$

3 ia

701

$\cup \cup-\cup-$

702

$\cup \cup-\cup-\cup--\cup-$

$2 \delta$

$\delta$ $2 \delta$

703-4

$\cup \cup-\cup-\cup-\cup-$

$2 \delta \|$

705

$\cup \cup \cup-\cup-\cup--\cup-$

$\cup$ e $\cup$ ibyc

706

707

708-9

$\cup-\cup-\cup-\cup \cup-\cup \cup-\cup-$

$---\cup-$

$-\cup \cup \cup \cup \cup \cup \cup \cup$

$\mathrm{mol}+\mathrm{cr}$

$2 \mathrm{cr}$ ? $\|^{\mathrm{Hs}}$

$2 \delta$

710

$\cup \cup-\cup-\cup \cup-\cup-$

$\mid{ }^{\mathrm{H}}$

2 ia

711

712

$--\cup--\cup-$

2 ia

epode

713-4

715

$\cup--\cup---\cup-$

$2 \delta$

$\cup--\cup \cup \cup-\cup \cup-\cup-$

$2 \delta$

716

$\cup \cup-\cup \cup-\cup \cup-\cup \cup---$

$\mathrm{A}+\mathrm{sp}$

$717-8$

$--\cup---\cup \cup-\cup \cup--$

- e - ibyc chol

719

720

$-\cup \cup-\cup-\cup \cup \cup-\cup-$

$2 \delta$

$\cup-\backsim \cup-\cup \cup \cup \cup-$

$2 \delta$

721

$\cup \cup \cup-\cup-\cup \cup \cup---$

$2 \delta$

$722 \mathrm{a}$

$\cup \cup \cup-\cup-<$

$2 \delta$

$722 \mathrm{~b}$

723

724

$\dagger \quad \dagger \cup \cup \cup--\cup-$

$\delta$

$?$

$\delta$

Ion $752-799$

Xo.

752

$\cup---$

$\mathrm{K} \rho$.

753

$\cup-\cup-\cup-\cup-\cdots-\cup-$

3 ia 
Part II - Scansions

Xo.

754

$\cup---$

K $\rho$.

755<smiles></smiles>

3 ia

Xo.

756

$--\cup--\cup \cup \cup---\cup \cap$

3 ia

$\mathrm{K} \rho$.

757

$\cup-\cup-\cup-\cup-\cup-\cup \cap$

3 ia

Xo.

758

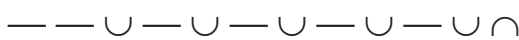

$\mathrm{K} \rho$.

759

$--\cup-\cup-\cup-\cup-\cup \cap$

3 ia $\|^{\mathrm{BH}}$

Xo.

760

$--\cup---\cup---\cup-$ 3 ia

761

$--\cup---\cup---\cup-$

762

$--\cup---\cup-\cup-\cup \cap$

3 ia

3 ia $\|^{\mathrm{BH}}$

$\mathrm{K} \rho$.

763a $\quad-\cup-\cap$

$\mathrm{pe}^{107}$

$<\prod \rho .>$

$763 \mathrm{~b}$

$\cup \cup \cup K \rho .>-\cup-$

$764 \mathrm{a}$

$\cup--\cup-\cup \cup \cup \cup \cup \cup \cup$

$764 \mathrm{~b}$

$\cup \cup \cup-\cup-$

765

$\cup-\cup-\cup-\cap$

$\mathrm{a}+\mathrm{ba} \|$

$\mathrm{K} \rho$.

766

$\cup-\cup-$

767

$\cup-\leftarrow \cup \cup \cup \cup \cup-\cup-$

768

$\cup-\leftarrow \cup-$

ia

$2 \delta \int$

$\delta$

Пр.

769

770

$--\cup--::-\cup \cup-\cup \cup-$

$-\mathrm{e}-\mathrm{D}$

771

$\cup-\cup-\cup::-\cup \cup-\cup \cup-$

$\cup$ e $\cup \mathrm{D}$

772-3

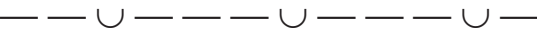

3 ia

3 ia

Xo.

774

$--\cup-\cup-\cup-\cup-\cup-$

3 ia

775

$\cup-\cup \cup \cup--\cup---\cup$

${ }^{107}$ Cf. Diggle (1994: 314). 
$\mathrm{K} \rho$.

$776 \cup \cup \cup \cup \cup \cup \cup \cup \cup \cup$ $2 \delta$

777

$\cup \cup \cup-\cup-$

$\Pi \rho$.

778

$\cup \cup \cup--\backsim-\cup-\cup-$

3 ia

779

$\cup-\cup-\cup-\cup-\cup-\cup \cap$

3 ia

Xo.

780

$--\cup-\cup-\cup-\cup-\cup-$
$\cup-\cup---\cup-\cup-\cup-$

3 ia

781

3 ia

$\mathrm{K} \rho$.

$782-3$

$--\dagger$

$\dagger---$

784

$\cup \cup \cup-\cup-$

$\stackrel{?}{\delta}$

$\Pi \rho$.

785

$--\cup-\cup-\cup-\cup-\cup-$

3 ia

786

$\cup-\cup---\cup-\cup-\cup-$

3 ia

Xo.

787

$\cup-\cup---\cup-\cup-\cup-$

3 ia

788-9

$--\cup---\cup---\cup \cap$

3 ia

$\mathrm{K} \rho$.

$790 \cup \cup \cup \cup \cup \cup \cup \cup \cup \cup$ $2 \delta$

$791 \mathrm{a}$

$\cup \cup \cup \cup \cup \cup \cup--\cup-$

$2 \delta$

$791 \mathrm{~b}$

$\cup---$

$\delta$

Пр.

792

$\cup-\cup---\cup---\cup-$

3 ia

793

$\cup-\cup---\cup-\cup-\cup-$

3 ia

Xo.

794

$--\cup---\cup-\cup-\cup-$

3 ia

795

$--\cup-\cup-\cup-\cup-\cup-$

3 ia

K $\rho$.

796

$\cup \cup \cup----\cup \cup--$

$2 \delta \int$

797-8

$---\cup--\cup \cup-\cup-$

799

$-\cup-\cup-\cup \cup \cup-\cup-$

$2 \delta$

$\mathrm{h} \delta+\delta$

Creusa's Monody (Ion 859-922)

$\mathrm{K} \rho$.

859

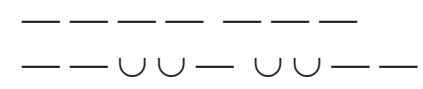

860

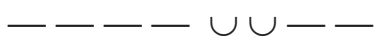

prm
prm $\|^{H}$
prm 


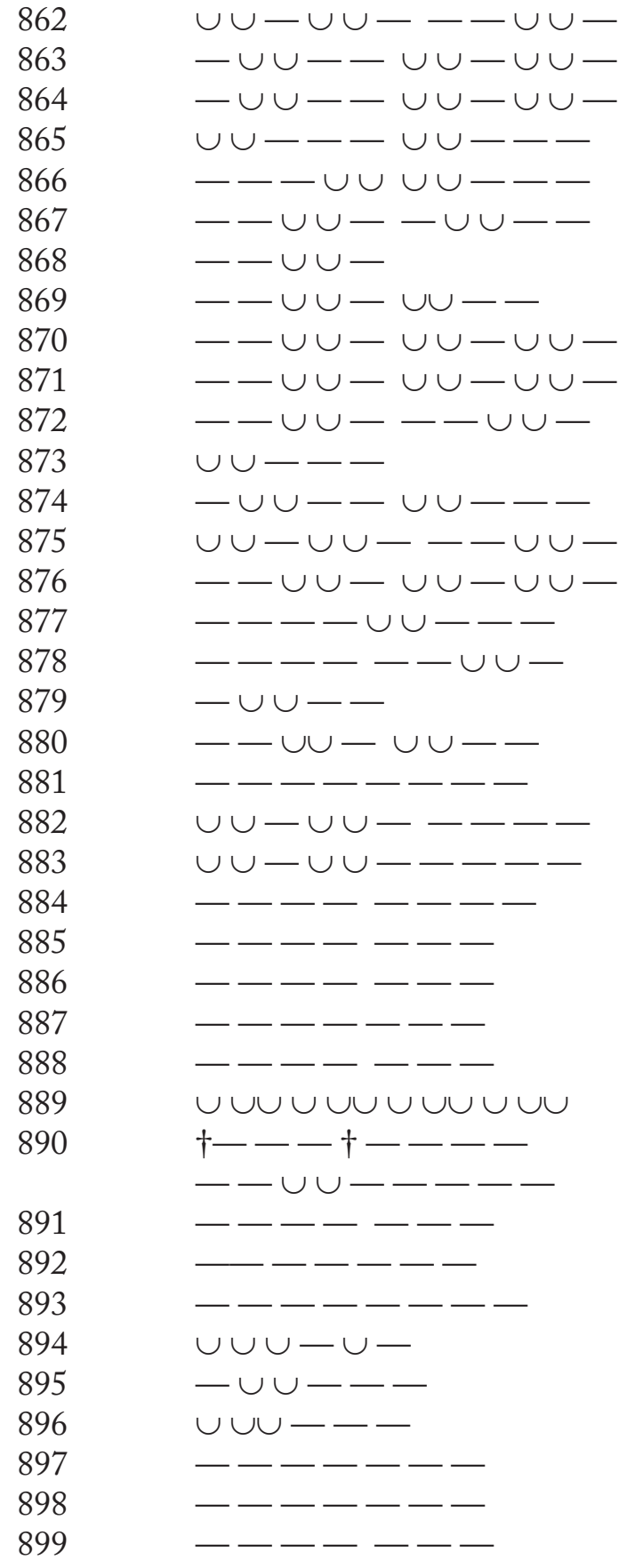

2 an
2 an
2 an
2 an
2 an
2 an
an
prm
2 an
2 an
2 an
an
2 an
2 an
2 an
2 an
2 an
an
prm
2 an
2 an
2 an
2 an
prm
prm $\mid{ }^{\mathrm{H}}$
prm
prm
2 ia
prm?
prm
prm
2 an
$\delta$
$\delta$
prm
prm

${ }^{108}$ Cf. Diggle (1981: 96; 1994: 117 n. 81, 316). 


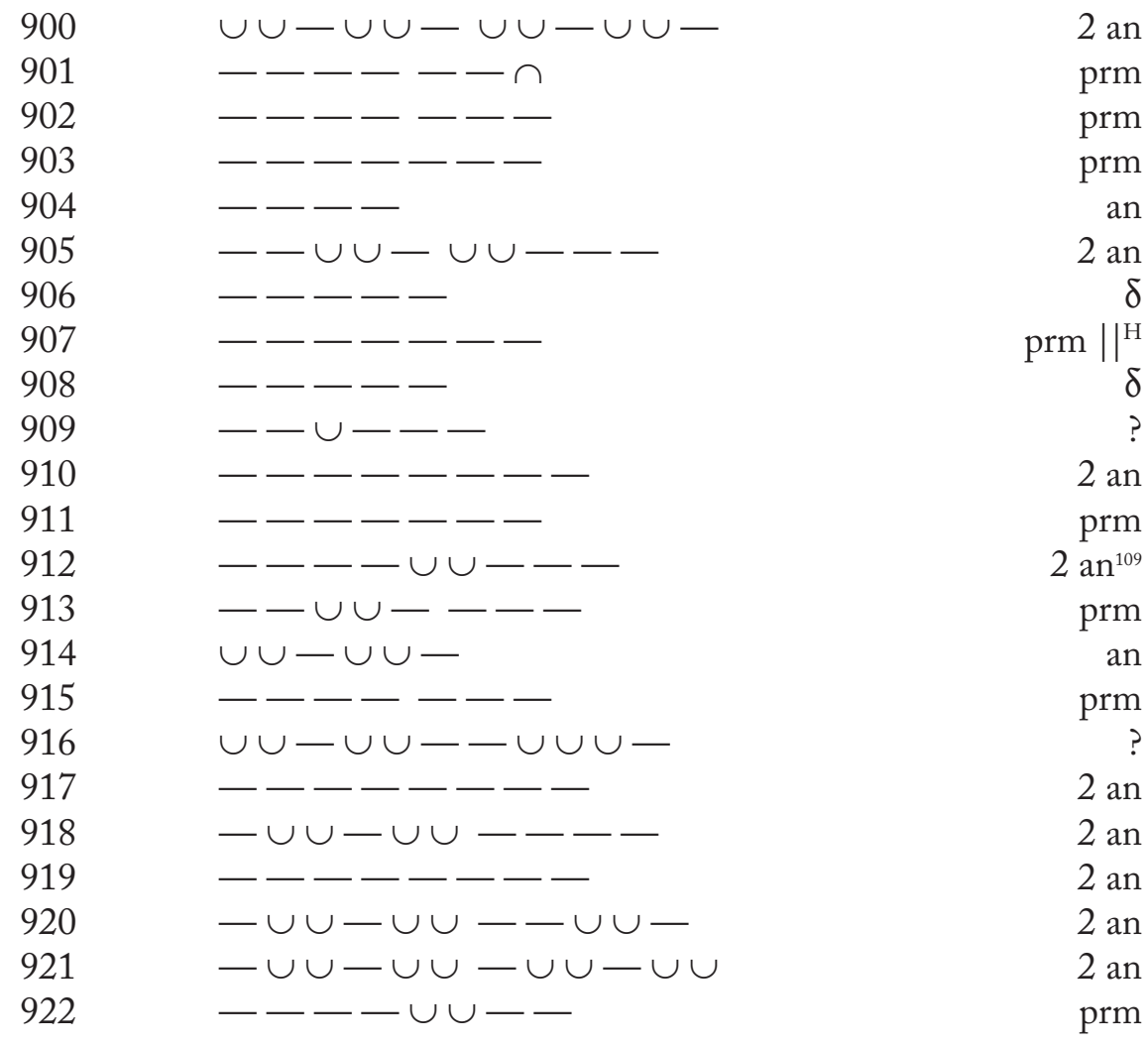

Third Stasimon (Ion 1048-1105)

Strophe 1

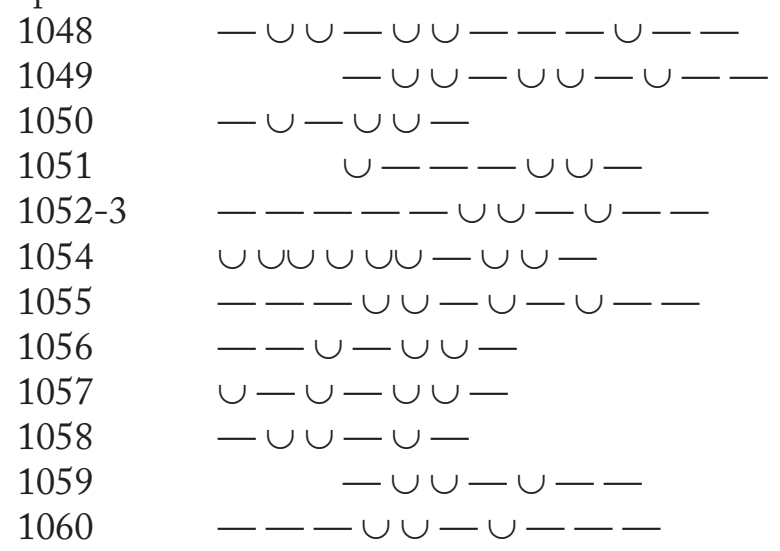
$\mathrm{D}-\mathrm{e}-$ decasyll hex hept wil + ba $\|$ ia + ch phal hept hept $\operatorname{dod} \int$ ar $\mathrm{gl}+\mathrm{sp}$

${ }^{109}$ Cf. Diggle (1981: 107). Cf. Med. 97. 
antistrophe 1
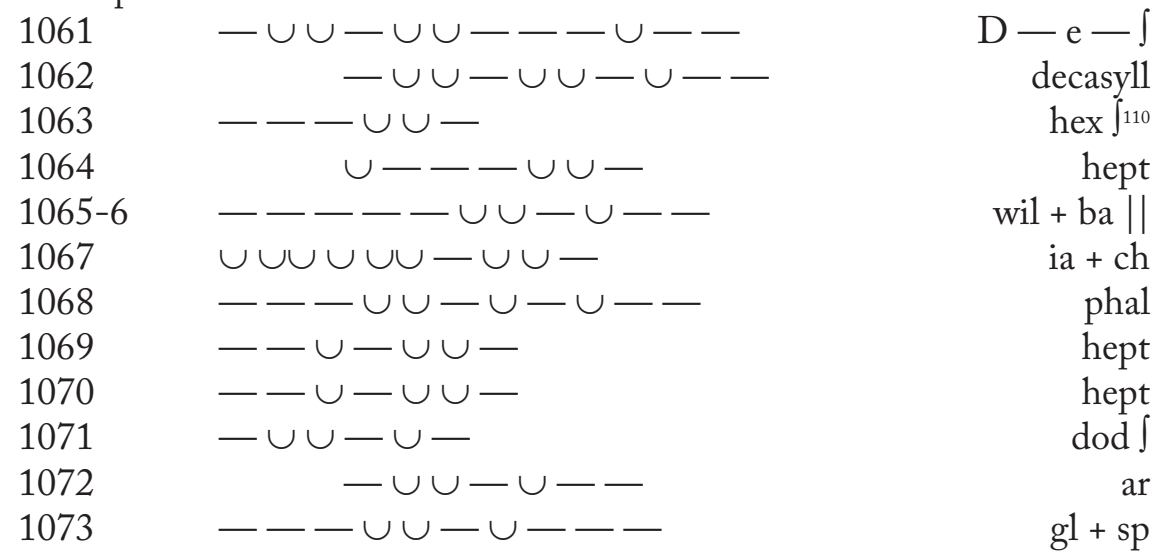

Strophe 2

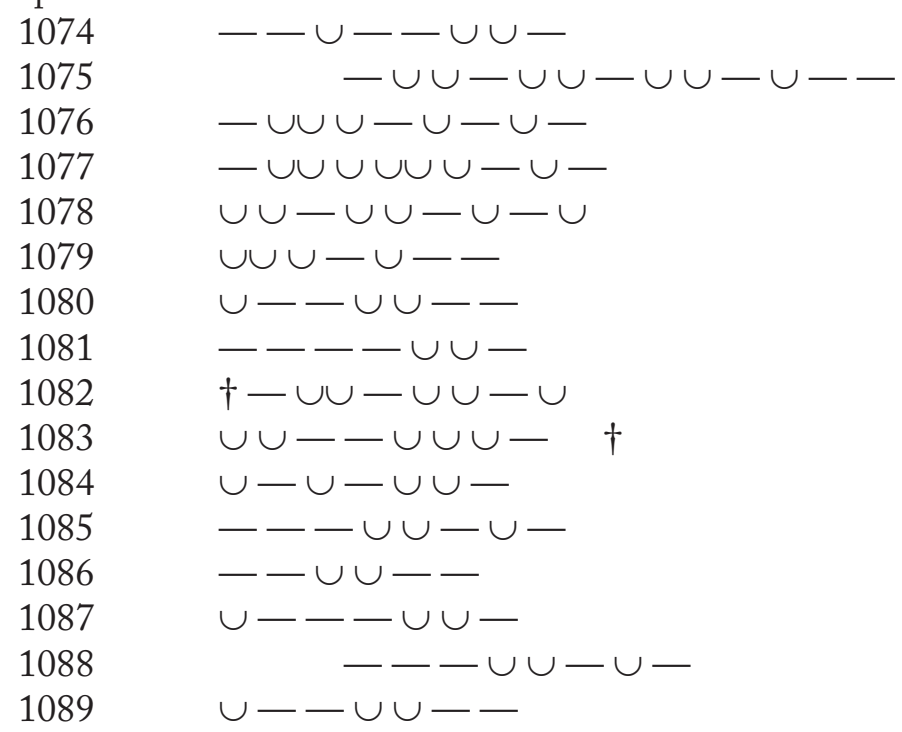

$\sim$ antistrophe 2

1090

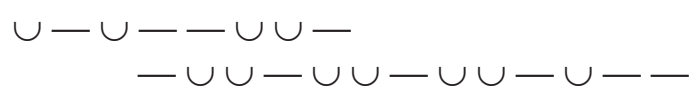

1091

1092

1093

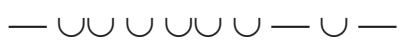

1094

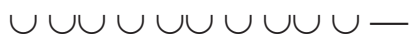

1095

$\cup \cup-\cup \cup-\cup-\cup$

1096

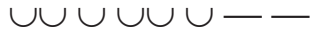

$\cup-\leftarrow \cup \cup-$

${ }^{110}$ See above, p. 95 (n. 202). 

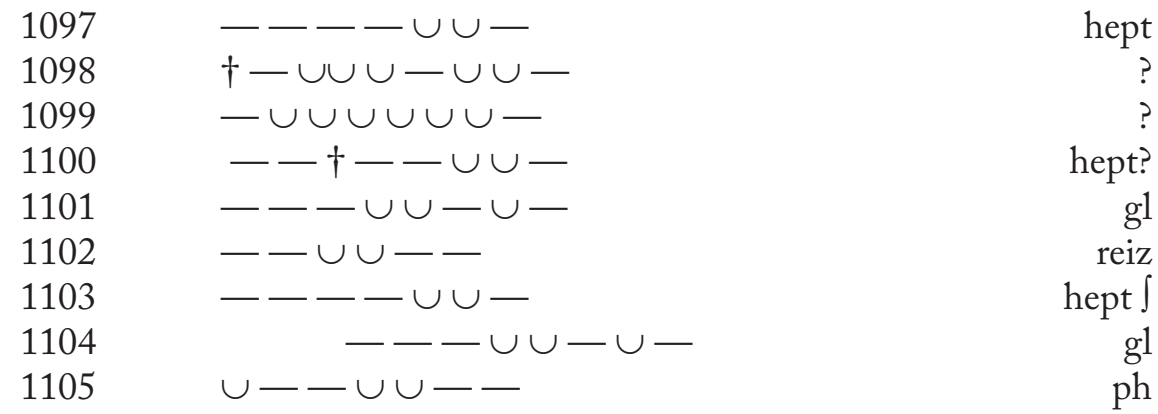

Fourth Stasimon (Ion 1229-1243)
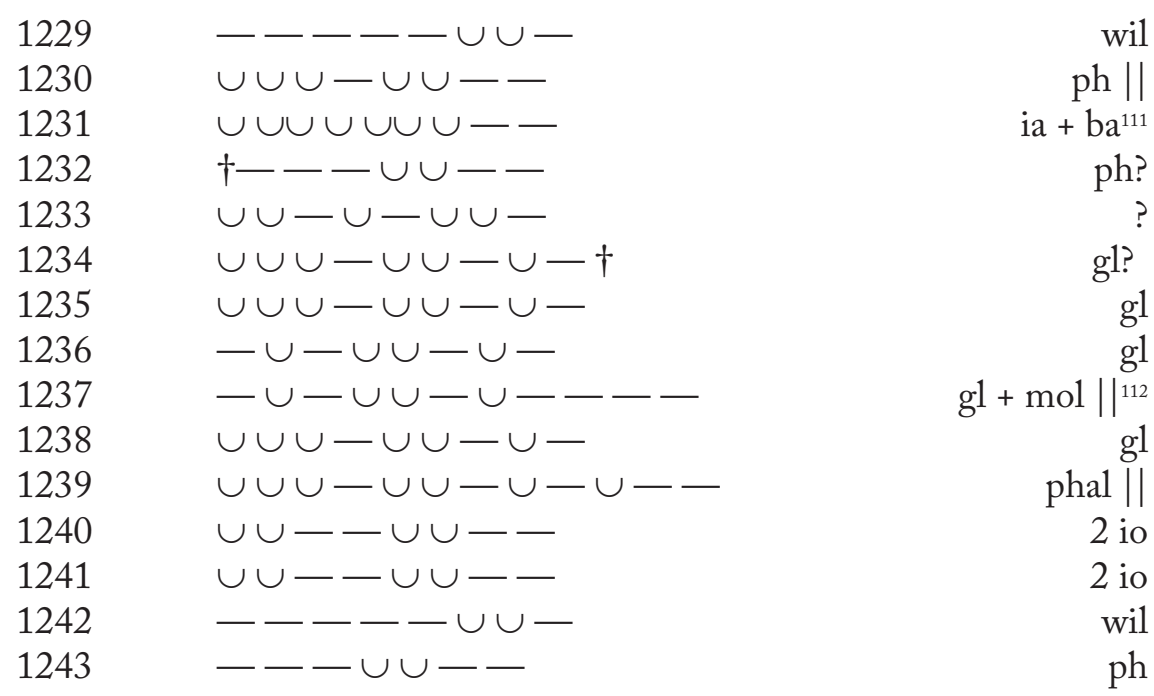

\section{Duet (Ion 1439-1509)}

$\mathrm{K} \rho$.

1439

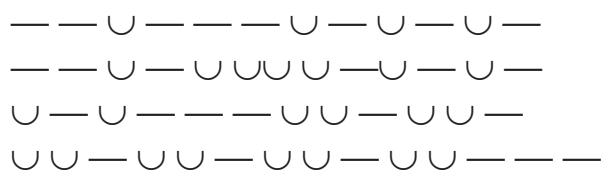

3 ia

1440

1441

1442

3 ia $\cup \mathrm{e}-\mathrm{D}$

$A+\mathrm{sp}$

I $\omega \mathrm{V}$

1443

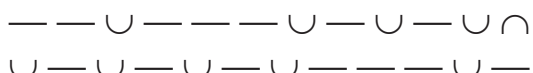

3 ia

1444

$\cup-\cup-\cup-\cup---\cup-$

${ }^{111}$ See Diggle (1994: 470).

112 See above, p. 111. 
K $\rho$.

1445

$\cup \cup \cup----\cup \cup-\cup-$

1446-7

$\cup--\cup--\cup--\cup--$

4 ba

1448

$\cup \cup-\cup \cup-\cup-\cup-$

cyren

1449

$\cup \cup \cup \cup-\cup-$

$2 \mathrm{cr}^{114}$

$\mathrm{I} \omega \mathrm{V}$

1450

$\cup-\cup---\cup-\cup-\cup \cap$

3 ia

1451

$--\cup---\cup-\cup-\cup-$

3 ia

$\mathrm{K} \rho$.

1452

$\cup \cup \cup-\cup-$

$\mathrm{I} \omega \mathrm{V}$

$1453 \mathrm{a}$

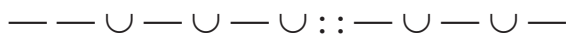

3 ia

$1453 \mathrm{~b}$

$\cup \cup \cup-\cup-$

$\delta$

1454a $\cup-\cup-\cup-\cup \cup \cup \cup \cup \cup-$

$1454 \mathrm{~b}$

$\cup \cup \cup-\cup-$

1455

$\cup \cup \cup \cup \cup-\cup--\cup-$

$2 \mathrm{ia}+\mathrm{cr}^{115}$

$\mathrm{I} \omega \mathrm{V}$

$1456-\because \cup-\cup-\cup-\cup-\cup-$

3 ia

$1457--\cup-\cup-\cup-\cup-\cup-$

3 ia

K $\rho$.

1458

$\cup \cup-\cup \cup-\cup-\cup-$

$\mathrm{T}+\mathrm{ba}$

1459

$\cup-\cup-\cup-\cup-\cup--$

$1460-\cup \cup-\cup-\cup \cup \cup-\cup-$

$2 \mathrm{ia}+\mathrm{ba}$

$2 \delta$

$1461 \cup \cup \cup-\cup-\cup-\leftarrow \cup-$

$2 \delta$

$\mathrm{I} \omega \mathrm{v}$

1462

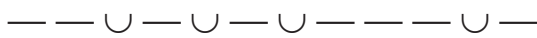

3 ia

K $\rho$.

1463

$\cup-\cup-\cup-\cup-\cup-$

$2 \mathrm{ia}+\mathrm{ba}$

1464

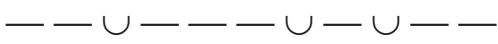

$2 \mathrm{ia}+\mathrm{ba}$

1465

$\cup--\cup-$

2 ba

1466

$\cup \cup-\cup \cup-\cup \cup-\cup \cup-\cup-\cup-$

1467

$-\cup \cup-\cup-\cup--\cup-$

$\mathrm{A}+\mathrm{ia} \| \mathrm{H}$

${ }^{113}$ For ì̀ ì̀ scanned $\cup \cup \cup$ 一, see Willink (2010: 377, with n. 96).

${ }^{114}$ See Diggle (1981: 18).

115 See Diggle (1994: 377). 
$\mathrm{I} \omega \mathrm{V}$

$1468 \quad--\cup---\cup-\cup-\cup-\quad 3$ ia

$1469-\leftarrow \cup--\leftarrow \cup-\cup-\cup-\quad 3$ ia

K $\rho$.

$1470 \quad-\cup-\quad$ cr

$1471 \cup-\leftarrow \cup-\cup \cup \cup-\cup-$

$\mathrm{I} \omega \mathrm{V}$

$1472--\cup::-\cup-\cup \cup \cup-\cup \cap$

$2 \mathrm{ia}+\mathrm{cr}^{116}$

$1473--\cup-\cup-\cup-\cup-\cup \cap$

3 ia

$\mathrm{K} \rho$.

1474

$-\cup \cup-\cup--\cup \cup-\cup-$

$2 \delta$

1475

$\cup \cup-\cup \cup-$

an

1476

$\cup \cup-\cup-\cup \cap$

$1 \mathrm{k} \| \mathrm{BH}:$

$\mathrm{I} \omega \mathrm{V}$

1477

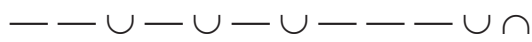

3 ia

K $\rho$.

1478

$-\leftarrow-\cup \cup-:: \cup-\cup--$

$\mathrm{D}^{\text {contr }} \cup \mathrm{e}-$

1479

$-\cup \cup-\cup \cup-$

D

1480

$\cup \cup-\cup \cup-\cup-$

$\mathrm{T}^{117}$

1481

1482

$--:: \cup--\cup \cup \cup-\cup-\cup \cap$

3 ia

1483

$\cup \cup-\cup \cup-\cup-$

$\mathrm{T}$

1484

$--:: \cup-\cup-$

ia + ba

1484

$-\cup \cup-\cup \cup--$

ibyc $^{\text {chol }}$

$\mathrm{I} \omega \mathrm{V}$

1485

$\cup-\cup-\cup-\cup-\cup-\cup-$

3 ia

K $\rho$.

1486

$\cup \cup-\cup \cup-\cup-$

T

1487

$\cup-\cup \cup \cup-\leftarrow \cup \cup--$

$2 \delta$

$\mathrm{I} \omega \mathrm{v}$

1488

$--\cup---\cup-\cup-\cup \cap$

3 ia

$\mathrm{K} \rho$.

1489

$-\cup \cup \cup \dagger \cup--\cup-\dagger$

1490

$-\cup-\cup \cup \cup-\cup-\cup-$

1491

$\cup \cup \cup-\cup-$

$2 \mathrm{~h} \delta \int$

1492

$\cup-\cup-\cup-\cup-\cup-$

$\delta$

1493

$\cup-\cup-\cup-\cup-\cup--$

$2 \mathrm{ia}+\mathrm{ba}$

$2 \mathrm{ia}+\mathrm{ba}$

116 See Diggle (1981: 20).

${ }^{117}$ See above, p. 76. 
Part II - Scansions

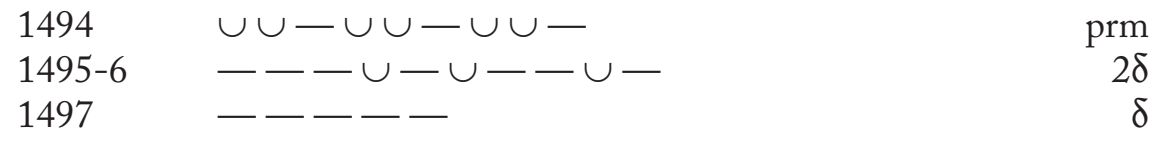

$\mathrm{I} \omega \mathrm{V}$

$1498 \quad--\cup-\cup-\cup-\cup-\cup-\quad 3$ ia

$1499 \cup \cup \cup-\cup-\cup \cup \cup---$

1500-1 - - : : - $-\leftarrow \cup \cup+$ ?

K $\rho$.

1502-3 $\cup \cup \cup--ー \cup-\cup \cup \cup-$

$1504-\cup \cup-\cup \cup-\cup-\cup-\cup$

$2 \delta^{118}$

1505-6 $-\cup \cup-\cup \cup-\cup-\cup \cup-\cup \cup-$

$\mathrm{D} \cup \mathrm{e} \cup$

1507

$\cup-\cup-\cup-\cup \cap$

$\mathrm{D} \cup \mathrm{D}$

1508

$\cup \cup-\cup \cup-\cup \cup-\cup \cup-$

2 ia $\|^{\mathrm{B}}$

1509

$\cup \cup-\cup \cup-\cup-\cup--$

A

cyren $+s p^{119}$

118 See Diggle (1994: 375).

${ }^{119}$ Cf. above, p. 75. 


\section{Helena}

\section{Parodos (Hel. 167-252)}

Strophe 1

167

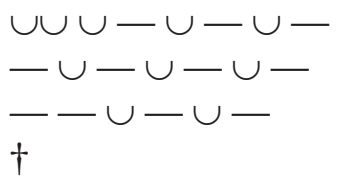

$1 \mathrm{k}$

168

169

170

$$
\dagger
$$

$171 \mathrm{a}$

$171 \mathrm{~b}$

172

173

$\dagger$

$-\cup-\cup \cup \cup \cup \cup \cup \cup$

$\cup \cup \cup \cup \cup \cup \cup \cup \cup \cup$

$174 \mathrm{a}$

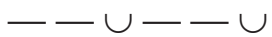

$174 \mathrm{~b}$

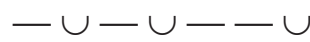

175

176

177

$-\cup-\cup \cup \cup \cup \cup \cup \cup$

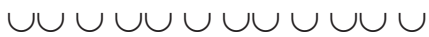

178

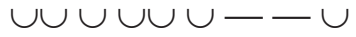

$\cup \cup \cup \cup-\cup-$

? $\left(\mathrm{k} \|\left.\right|^{\mathrm{Ba}}\right)$

$2 \operatorname{tr}$

$2 \operatorname{tr}$ pa + pa

$\operatorname{tr}+\mathrm{pa}$

$2 \operatorname{tr}$

$2 \operatorname{tr}$

$\operatorname{tr}+\mathrm{pa}$

$1 \mathrm{k}$

$\sim$ antistrophe 1

179

$\cup \cup-\cup-\cup-$

$1 \mathrm{k}$

180

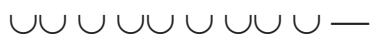

$\mathrm{lk}$

181

$182 \mathrm{a}$

$+$

$\mathrm{pa}+\mathrm{cr}$

$182 \mathrm{~b}$

$+$

183

$-\cup \cup \cup-\cup \cap$

184

$-\cup-\cup \cup \cup \cup \cup$

185

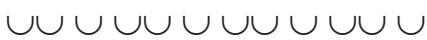

$186 a$

$<--\cup>120--\cup$

$186 \mathrm{~b}$

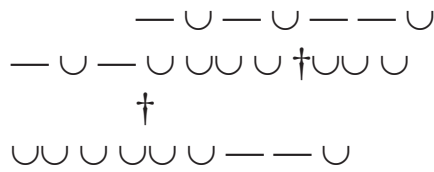

187

188

189

${ }^{120}$ My supplement for this lacuna (Lourenço 2000a: 601) has since found a place in the apparatus of Kovacs' Loeb edition and of Allan's Cambridge commentary. 
Strophe 2

191

192

193

194-5

196

197

198

199

200

201

202

203

204

205

206

207

208

209

210
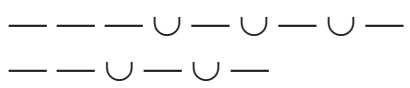

$--\cup-\cup$

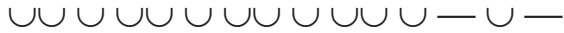

$-\cup-\cup-\cup-$

$\cup \cup-\cup-\cup-$

$\cup \cup-\cup-\cup-$

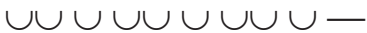

$-\smile \cup-\cup-$

$\cup \cup \cup \cup-\longrightarrow$

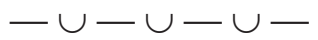

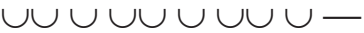

$\cup \cup \cup \cup-\cup-$

$-\cup-\cup-\cup-\cup$

$\cup \cup \cup \cup \smile \cup \cup$

$\cup \cup \cup \cup-\cup \cup U$

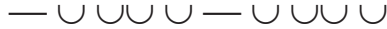

$\cup \cup-\cup-$

$-\cup-\cup-\cup \cap$

$$
\begin{array}{r}
\mathrm{sp}+1 \mathrm{k} \\
\mathrm{pa}+\mathrm{cr} \|\left.\right|^{\mathrm{Ha}} \\
\mathrm{pa}+\mathrm{pa} \\
2 \mathrm{tr}+\mathrm{cr} \\
1 \mathrm{k} \\
\mathrm{lk} \\
1 \mathrm{k} \\
\mathrm{lk} \\
\mathrm{pa}+\mathrm{cr} \\
\mathrm{tr}+\mathrm{sp} \int \\
1 \mathrm{k} \\
1 \mathrm{k} \\
1 \mathrm{k} \\
2 \mathrm{tr} \\
2 \mathrm{tr} \\
2 \mathrm{tr} \int \\
2 \mathrm{tr} \\
\operatorname{tr}+\mathrm{sp} \int \\
1 \mathrm{k}
\end{array}
$$

$$
\begin{array}{r}
\mathrm{sp}+1 \mathrm{k} \\
\mathrm{pa}+\mathrm{cr} \|^{\mathrm{H}} \\
\mathrm{pa}+\mathrm{pa} \\
2 \mathrm{tr}+\mathrm{cr} \\
1 \mathrm{k} \\
1 \mathrm{k} \\
1 \mathrm{k} \\
1 \mathrm{k} \\
\mathrm{pa}+\mathrm{cr} \\
\mathrm{tr}+\mathrm{sp} \int \\
1 \mathrm{k} \\
1 \mathrm{k} \\
1 \mathrm{k} \\
2 \mathrm{tr} \\
2 \mathrm{tr} \\
2 \mathrm{tr} \int \\
2 \mathrm{tr} \\
\operatorname{tr}+\mathrm{sp}
\end{array}
$$


epode $^{121}$

229

230

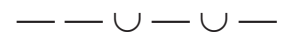

231a

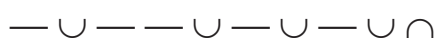

$231 \mathrm{~b}$

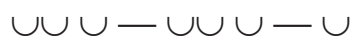

$2 \mathrm{cr}+\mathrm{ia} \|^{\mathrm{B}}$

232

$-\cup---$

233

$-\cup \cup \cup-\cup-$

234

$\cup-\cup ー \cup \cup \cup-$

$\mathrm{cr}+\mathrm{tr}$

$\mathrm{cr}+\mathrm{sp}$

$1 \mathrm{k}$

235

$\cup-\cup-\cup-\cup-$

2 ia

2 ia

[236

$-\cup-\cup-\cup-$

$1 \mathrm{k}$

237

$\cup \cup-\cup-\cup-$

$1 \mathrm{k}$

238

$-\cup-\cup-\cup-$

$1 \mathrm{k}]$

239

$-\cup \cup \cup \cup \cup-\cup-$

240

$\cup \cup-\cup-\cup \cup \cup$

$2 \mathrm{tr}+\mathrm{cr}$

2 tr

$1 \mathrm{k}$

241

242

$-\cup-\cup-\cup-$

$-\cup-\cup-\cup-\cup$

2 tr

2 tr

$243 \mathrm{a}$

$\cup \cup-\cup-\cup-\cup$

$\mathrm{pa}+\mathrm{cr}$

$243 \mathrm{~b}$

$\cup-\cup-\cup-\cup \cap$

244

245

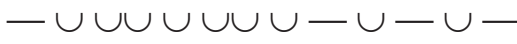

2 ia $\|^{\mathrm{B}}$

$2 \mathrm{tr}+\mathrm{cr}$

$246 \mathrm{a}$

$\cup \cup \cup \cup \cup \cup-\cup$

$2 \operatorname{tr}$

$2 \mathrm{cr}$

$246 \mathrm{~b}$

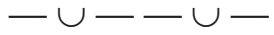

2 ia

247

248

$\cup-\cup-\cup-\cup-$

$2 \operatorname{tr}$

$2 \mathrm{tr}$

249

$ル \cup-\cup-\cup \cup \cup$

$1 \mathrm{k}$

250-1

$\cup \cup-\cup-\cup-$

3 tr

252

$\cup \cup \cup \cup \cup \cup \cup \cup-\cup-\cup$

$-\cup \cup \cup-\cup \cap$

$1 \mathrm{k}$

Lyric scene (Hel.330-385)

E入.

330

$$
\cup-\cup-\cup-\cup-
$$

331

$-\cup-\cup-\cup-$

332

$\cup-\cup-\cup--$

333

$-\cup-\cup-\cup-$

2 ia

$1 \mathrm{k}$ ia + ba

lk $\|$

Xo.

334

$\cup-\cup-\cup-\cup-$

2 ia $\|$

${ }^{121}$ See Lourenço (2000). 
$E \lambda$.

Xo.

338

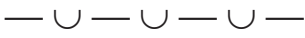

339

$\cup-\cup-\cup-\cup$

$1 \mathrm{k}$

E入.

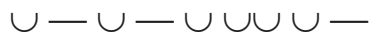

Xo.

E入.

$\cup \cup \cup \cup \cup \cup \cup \cup \cup \cup \cup$

2 ia

349

$\cup \cup-\cup \cup \cup \cup-\cup$

$2 \mathrm{tr}$

350

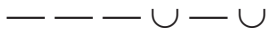

$\mathrm{sp}+\mathrm{tr}$

351

352

$353 \mathrm{a}$

$-ー \cup \cup \cup \cup-\cup$

$\mathrm{pa}+\operatorname{tr}$

$\dagger \quad t$

$353 \mathrm{~b}$

$\cup \cup---\cup$

? 123

$\mathrm{cr}+\mathrm{pa}$

$\cup \cup-\cup-\cup-$

354

$-\cup-\cup-\cup-\cup$

355

356

$357 \mathrm{a}$

$357 \mathrm{~b}$

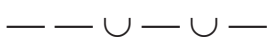

358

$-\cup \cup-\cup \cup-\cup \cup-\cup \cup-\cup \cup-$

$1 \mathrm{k} \| \mathrm{H}$

$2 \mathrm{tr}$ $\mathrm{pa}+\mathrm{cr} \|$

Xo.

360

$-\cup \cup \cup-\cup-$

$1 \mathrm{k}$

361

$\cup-\cup \cup \cup \cup \cup$

$\mathrm{E} \lambda$.

${ }^{122}$ Analysed by Stinton (1990: 125) as 'ba + ia'. See above, p. 120 (n. 265).

${ }^{123}$ See above, p. 39.

${ }^{124}$ For invocations as self-contained periods, see above, p. 25 (n. 14). 


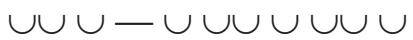

$2 \operatorname{tr}$

365

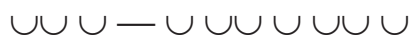

366

367

$\dagger$

$\dagger$

$2 \operatorname{tr}$

$-\cup-\cup-\cup \cup \cup \cup$

368

$\cup \cup-\cup-\cup-\cup$

$2 \operatorname{tr}$

$2 \operatorname{tr} \int$

369a $\quad-\cup-\cup-\cup-$

$369 \mathrm{~b}$

370

$-\cup-\cup-\cap$

371

372

$\cup-\cup--\cup-$

373

$\cup \cup-\cup \cup \cup \cup-\cup$

$\cup \cup-\cup \cup \cup-\cup$

374

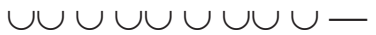

375

$\cup-\leftarrow-\cup-$

$376 \mathrm{a}$

$-\cup \cup-\cup \cup-\cup \cup-\cup \cup$

$376 \mathrm{~b}$

377

378

379

380

381

382

383

384

385

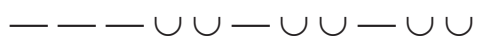

$-\cup \cup-\cup \cup-\cup \cup$

$-\cup \cup-\cup \cup-\cup \cup-\cup \cup$

$\operatorname{tr}+\mathrm{sp} \|^{\mathrm{B}}$

$\mathrm{ia}+\mathrm{cr}$

$2 \operatorname{tr}$

2 tr

$1 \mathrm{k}^{125}$

ba + ith $\|$

$4 \mathrm{da}$

$4 \mathrm{da} \int$

$3 \mathrm{da}$

$4 \mathrm{da}$

$4 \mathrm{da}$

$4 \mathrm{da}$

$4 \mathrm{da}$

$4 \mathrm{da}$

$6 \mathrm{da}$

$4 \mathrm{da}$

$5 \mathrm{da}$

ith

\section{Epiparodos (Hel.515-527)}

Xo.

515

516

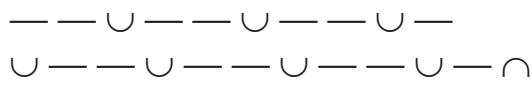

517

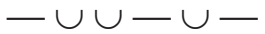

$\mathrm{ia}+2 \mathrm{cr}$

4 ba $\|^{B_{126}}$

$\operatorname{dod} \int$

518

$-\cup-\cup \cup-\cup-$

519

$\cup \cup \cup-\cup \cup-$

gl

ph

520

$-\cup \cup \cup-\cup \cup-$

521

$-\cup \cup \cup--\cup \cup-$

522

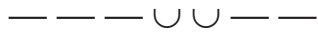

$\mathrm{cr}+\mathrm{ch}^{127}$

ia + ch

523

$\cup---\cup \cup-$

ph

hept

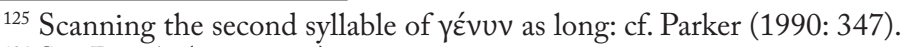

${ }^{126}$ See Diggle (1994: 426).

${ }^{127}$ See below, on Hel. 1340. 
Part II - Scansions

524

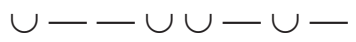

$\mathrm{g} 1$
$\mathrm{~g} 1$
$\mathrm{cr}+\mathrm{ch}$
$\mathrm{ph}$

525

$-\cup-\cup \cup-\cup-$

526

$-\cup \cup \cup-\cup \cup-$

527

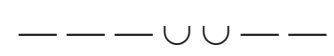

3 ia
3 ia $\|^{\text {BH }}$
$2 \delta$
$2 \delta$
$\delta$

$\mathrm{M \varepsilon .}$

630

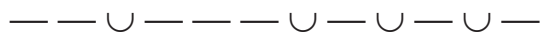

3 ia

$631--\cup-\leftarrow-\cup---\cup-$

3 ia

E入.

$\begin{array}{ll}632 & \cup-\cup-\cup-\cup-\cup-- \\ 633 & \cup-\cup-\cup-\cup-\cup-- \\ 634 & \cup \cup \cup-\cup \cup \cup \cup \cup \cup-\cup- \\ 635 & -\cup \cup-\cup-\end{array}$

2 ia + ba

2 ia + ba

$2 \delta$

$\delta$

Me.

636

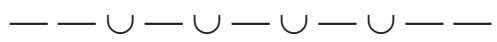

$2 \mathrm{ia}+\mathrm{ba}$

637

$\dagger \cup-\cup-\cup-\cup \cup--\cap^{\mathrm{H} \dagger}$

$\mathrm{E} \lambda$.

638
$639-40 \quad \cup \cup-\cup-\cup----$

$\mathrm{M \varepsilon}$.

641

$\cup-\cup-\cup-\cup-\cup-\cup-$

3 ia

642

$\cup--\cup-\cdots$

$2 \mathrm{ba}$

643

$\cup--\cup--\cup-\cdots$

$3 \mathrm{ba}$

$\mathrm{E} \lambda$.

644

645

$\cup \cup-\cup \cup-\cup \cup-\cup \cup-\cup \cup-\cup \cap$

$\cup \cup \cup-\cup-\cup--\cup-$

enop || 129 $2 \delta$

$\mathrm{M \varepsilon .}$

646

$\cup-\cup-\cup-\cup-\cup-\cup-$

3 ia

${ }^{128}$ See above, p. 31 and Barrett (2007: 402-5); Willink (2010: 132-68; 767-77).

${ }^{129}$ See Willink (2010: 150-1). 
647

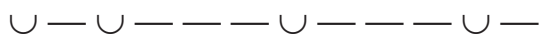

3 ia

$\mathrm{E} \lambda$.

648

$\cup-\cup-$

ia

649

$\cup \cup \cup-\cup-\cup \cup \cup---$

$2 \delta$

650

$\cup \cup \cup \cup \cup \cup \cup \cup \cup \cup \cup \cup \cup \cup$

$2 \delta$

651

$\cup \cup \cup---\cup \cup \cup-\cup-$

$2 \delta$

$\mathrm{M \varepsilon .}$

652

$\cup-\cup-\cup-\cup-\cup-\cup-$

3 ia

653

$\cup-\cup---\cup-\cup-\cup-$

3 ia

$\mathrm{E} \lambda$.

$654 \cup \cup \cup-\cup-\cup \cup \cup \cup \cup$ $2 \delta$

655

$\cup \cup \cup-\cup-$

$\mathrm{M \varepsilon .}$

656

$\cup-\cup-\cup-\cup-\cup-\cup \cap^{\mathrm{H}}$

3 ia

E入.

657

$\cup \cup-\cup \cup-\cup--$

cyren $^{\text {chol }}$

$\mathrm{M \varepsilon}$.

658

$--\cup-\cup-\cup---\cup-$

3 ia

659

$\cup--\cup-\cup \cup \cup---$

$2 \delta$

$660--\cup--\backsim \cup-\cup-\cup-$

3 ia

$\mathrm{E} \lambda$.

661

$\cup \cup-\cup---$

662

$\cup \cup-\cup--\cup-$

$\mathrm{cr}+\delta^{130}$

$\mathrm{cr}+\delta$

$\mathrm{M \varepsilon .}$

663

$\cup-\cup-\cup-\cup-\cup-\cup-$

3 ia

E入.

664a $\cup-\cup \cup-\cup \cup-\cup$

664b $-\cup \cup-\cup \cup \cap^{\mathrm{H}}$

erasm

$\mathrm{D} \|$

$\mathrm{M \varepsilon .}$

665

$\cup-\cup-\cup-\cup---\cup-$

3 ia

$\mathrm{E} \lambda$.

666

$-\cup \cup-\cup--\cup \cup-\cup-$ $2 \delta$

667

$\cup \cup \cup---\cup \cup \cup-\cup-$

668

$\cup \cup \cup-\cup-$

$2 \delta \int$

$\delta$

$\mathrm{M \varepsilon .}$

669

$\cup-\cup---\cup---\cup-$

3 ia

${ }^{130}$ See Diggle (1994: 374). Cf. Willink (2010: 244 n. 12). 
Part II - Scansions

$\mathrm{E} \lambda$.

$670 \cup \cup \cup \cup \cup \backsim \cup \cup \cup--$

671

$\cup \cup \cup---$

$\mathrm{M \varepsilon .}$

672

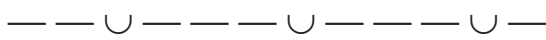

3 ia

$\mathrm{E} \lambda$.

673

$\cup \cup \cup-\cup-\cup \cup \cup--$

$2 \delta$

674

$\cup \cup \cup-\cup-\cup \cup \cup-\cup-$

$2 \delta$

$\mathrm{M \varepsilon}$.

675

$--\cup---\cup---\cup \cap$

3 ia

E久.

676

$-\cup \cup-------$

$2 \delta$

677

$\cup \cup \cup---\cup--\cup-$

$2 \delta$

678

$\cup \cup \cup-\cup-$

$\delta$

$\mathrm{M \varepsilon .}$

679

$\dagger$

$\dagger$

?

$\mathrm{E} \lambda$.

680

$\cup \cup-\cup \cup-\cup::--$

cyren $^{\text {chol }}$

681

$\cup \cup-\cup \cup-\cup::--\longrightarrow$

682

$-\cup \cup-\cup-\cup \cup \cup--$

cyren $^{\text {chol }}$

$2 \delta \|^{\mathrm{H}}$

$\mathrm{M \varepsilon}$.

683

$--\cup---\cup-\cup-\cup-$

3 ia

$\mathrm{E} \lambda$.

684

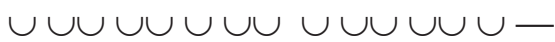

$2 \delta \int$

685

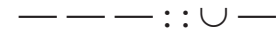

$\delta$

686

$--\cup---\cup \cup-\cup \cup-$

687

$\cup \cup-\cup \cup-\cup \cup-\cup \cup-\cup-$

enop

$\mathrm{M \varepsilon}$.

688

$--\cup--\cup---\cup \cap$

3 ia

$\mathrm{E} \lambda$.

689

$\cup \cup \cup \cup \cup-\cup \cup \cup-\cup-$

$2 \delta$

690

$\cup \cup \cup \cup \cup \dagger-\cup-\dagger$

$\mathrm{M \varepsilon .}$

691

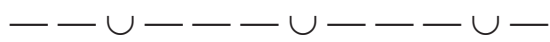

3 ia

$\mathrm{E} \lambda$.

692

$\cup \cup-\cup \cup-\cup \cup-\cup \cup-\cup$

$\mathrm{A} \cup(\mathrm{cf.}$ IT 886-7)

693

$-\cup \cup-\cup \cup-$

694

$\cup \cup \cup \cup \cup \cup \cup \cup \cup$

695

$\cup \cup \cup \cup \cup U \cup \cup \cup U \cup \cup \cup$ 


\section{First Stasimon (Hel.1107-1164)}

Strophe 1
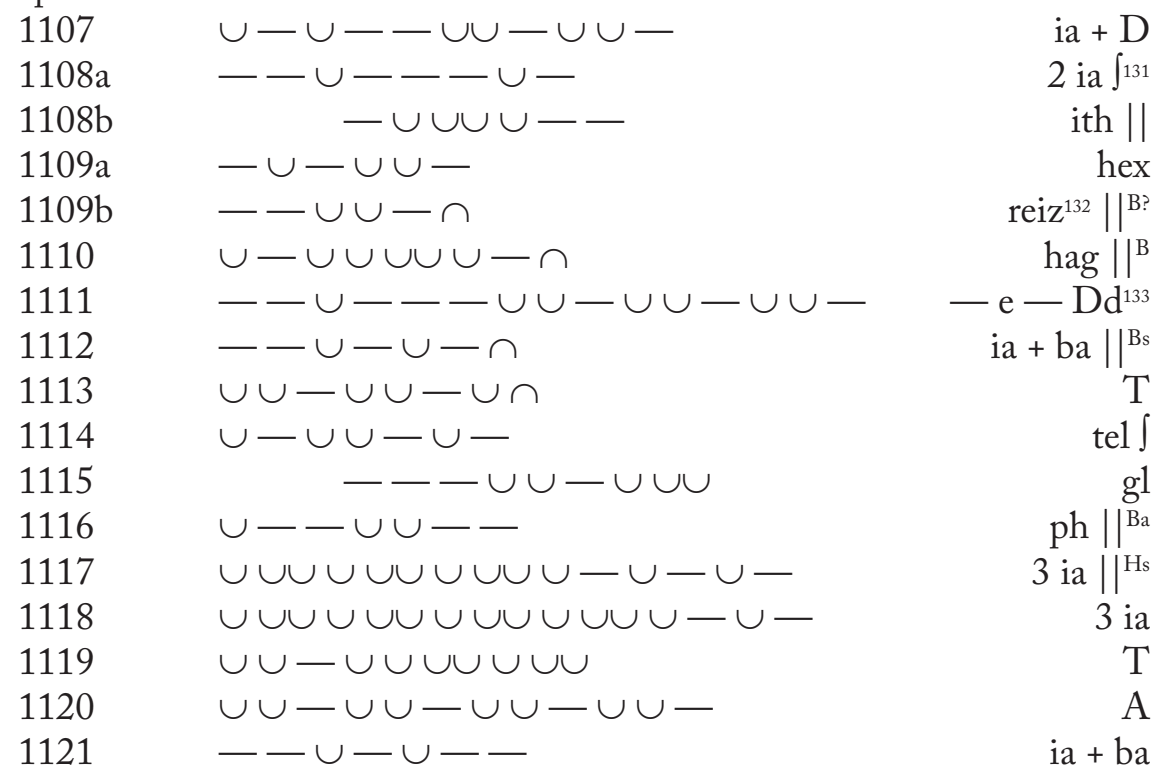

$\sim$ antistrophe 1

1122

$1123 \mathrm{a}$

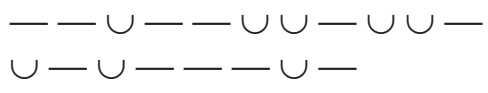

$1123 b$

$1124 \mathrm{a}$ $-\cup \cup \cup-$

$1124 \mathrm{~b}$

1125

1126

1127

1128

1129

1130

1131
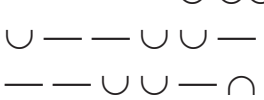

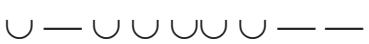

reiz $\|^{\mathrm{B}}$ ?

hag $\|^{\text {Bs }}$

$-\mathrm{e}-\mathrm{Dd}$ ia + ba $\|^{\text {Bs }}$

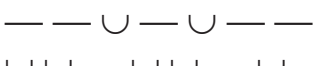

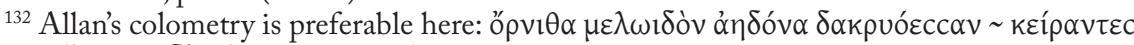

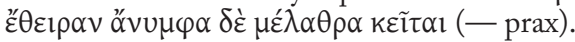

${ }^{133}$ Less fussily analysed as 'ia +2 an' by Kannicht (Vol. II: p. 277). See above, p. 84, n. 176. 


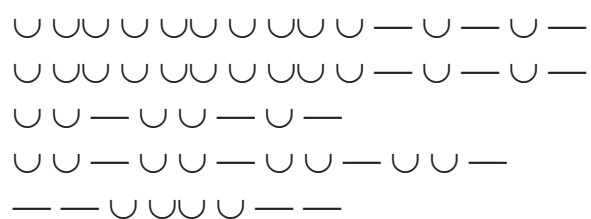

3 ia $\|^{\mathrm{Hs}}$

1133

1134

1135

1136

$--\cup \cup \cup \cup-$

3 ia

$\mathrm{T}$

A

$\mathrm{ia}+\mathrm{ba}$

Strophe 2

1137

$\cup \cup \cup \cup--\cup \cup-\cup \cup-$

$\mathrm{ia}+\mathrm{D}$

1138

$\cup-\cup---\cup-$

2 ia

1139-40

$-\cup \cup-\cup \cup-\cup-\cup \cup-\cup \cup-$

$1141-2$

$-\cup \cup-\cup \cup-\cup-\cup \cup-\cup \cup-$

1143

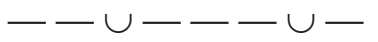

1144

$\cup \cup \cup-\backsim \cup \cup \cup$

1145

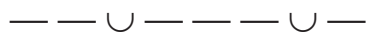

1146

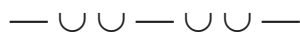

1147

1148

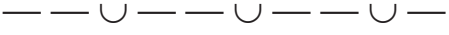

1149

1150

$\dagger$

$\cup \cup-\cup-\cap \dagger$

$\mathrm{D} \cup \mathrm{D}\|\|^{\mathrm{Ha}}$

$\mathrm{D} \cup \mathrm{D}$

2 ia $\|$ $\mathrm{ia}+\mathrm{D}$

2 ia

$\mathrm{D} \|$

$\mathrm{ia}+2 \mathrm{cr}$

3 ia

ith?

$\sim$ antistrophe 2

1151

$\cup \cup \cup \cup--\cup \cup-\cup \cup-$

ia $+D$

1152

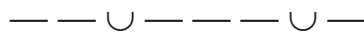

2 ia

1153-4

$-\cup \cup-\cup \cup-\cup-\cup \cup-\cup \cup-$

$1155-6$

$-\cup \cup-\cup \cup-\cup-\cup \cup-\cup \cup-$

1157

1158

$+$

1159

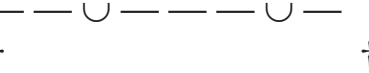

$\dagger$

$\mathrm{D} \cup \mathrm{D} \|^{\mathrm{H}}$

$\mathrm{D} \cup \mathrm{D}$

2 ia

1160

$--\cup---\cup-$

2 ia

1161

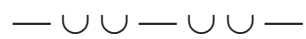

$\mathrm{D} \|$

1162

1163

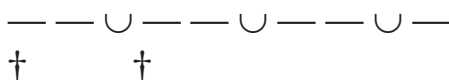

$\mathrm{ia}+2 \mathrm{cr}$

1164

$\cup \cup \cup \cup \cup \cup \cup \cup \cup \cup-\dagger-\cup-$

?

?

Second Stasimon (Hel. 1301-1368)

Strophe 1

1301

$\cup--\cup \cup \cup \cup \cup-$

gl $\int$

1302 $---\cup \cup-\cup-$

1303

$\cup--\cup \cup-$

hex

1304

$\cup \cup \cup-\cup-\cup \cup-$

wil ||?

1305

$\cup \cup \cup-\cup-\cup \cup-$

wil 
$1306 \quad \cup-\leftarrow \cup-\cup \cup-$

wil

1307

$1308 \cup \cup \cup \cup \cup \cup \cup \cup \cup \cup$

$1309 \cup \cup \cup \cup \cup \cup \cup \cup \cup$ -

$1310-\because \cup-\cup \cup-$

$1311-\because \cup-\cup \cup-$

$1312 \quad--\div-\longrightarrow \cup \cup-$

$1313 \cup---\leftarrow \cup \cup-$

$1314 \mathrm{a}+\dagger \quad+$

$1314 \mathrm{~b} \quad<\cup \cup-\cup>\cup-\cup \cup \cup$

$1315----\longrightarrow \cup \cup-$

$1316-----\cup \cup \cap$

1317a $\quad----\cup \cup$

$1317 \mathrm{~b}<-\mathrm{x}-\mathrm{x}-\cup \cup->$

$1318---\cup \cup-$

pentamakron

2 ia

2 ia

hept

hept

wil

wil

T (cf. Hel. 1119)

wil

wil ||

wil

<wil>

ph

antistrophe 1

1319

$\cup-\leftarrow \cup \cup \cup \cup-$

g1 $\int$

1320

$---\cup-\cup \cup-$

wil

1321

1322

$--\cup \dagger \cup-\dagger$

1323

$\cup \cup \cup-\cup-\cup \cup-$

1324

$\cup \cup \cup-\cup-\cup \cup-$

wil ||?

wil

wil

1325

$----\cup \cup-$

1326

$\cup \cup \cup \cup \cup \cup \cup \cup \cup \cup$

1327a $\cup-\cup \cup \cup \cup \cup \cup \cup$ -

$1327 \mathrm{~b}<\mathrm{x}-\mathrm{x}-\cup \cup->$

1328

$----\cup \cup-$

1329

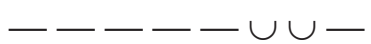

1330

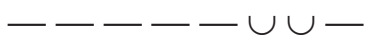

1331

1332

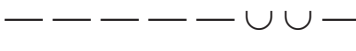

1333

$\cup \cup-\cup \cup-\cup \cup \cup$

1334

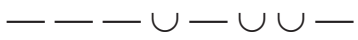

1335

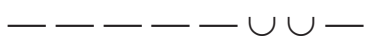

$1336 a$

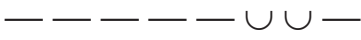

$1336 b$

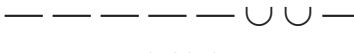

$---\cup \cup--$

pentamakron

2 ia

2 ia

hept

hept

wil

wil

wil

T

wil

wil ||

wil

wil

ph

Strophe 2

1337

$\cup-\cup--\cup \cup-$

ia $+\mathrm{ch}$

1338

$\cup-\cup--\cup \cup-$

ia $+\mathrm{ch}$

1339

hept 


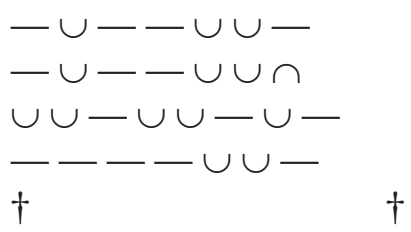

$$
\begin{array}{r}
\mathrm{cr}+\mathrm{ch}^{134} \\
\mathrm{cr}+\mathrm{ch} \| \\
\mathrm{T} \\
\text { hept } \\
? \\
\text { hept } \\
\text { hept } \\
\mathrm{ia}+\mathrm{ch} \\
\mathrm{gl} \int \\
\mathrm{gl} \\
\text { dod } \\
\text { reiz } \\
\text { reiz }
\end{array}
$$

1342

1343

1344

1345

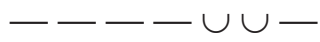

$\dagger$

1346

1347

$\cup \cup \cup \cup \backsim \cup \cup$

1348

1349

1350

1351

$-\cup \cup-\cup-$

$\cup \cup \cup$

1352

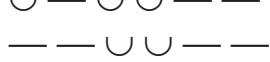

$\sim$ antistrophe 2

1353

1354

$\dagger--\cup \cup-\cup \cup \cup$

1355

$\cup---\cup \cup-\dagger$

1356

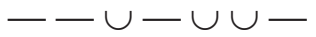

hept

1357

1358

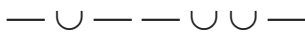

$\mathrm{cr}+\mathrm{ch}$

$\mathrm{cr}+\mathrm{ch}$

1359

$\cup \cup-\cup \cup-\cup$

$\mathrm{T}$

1360

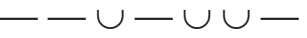

hept

1361

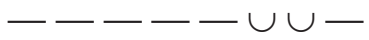

1362

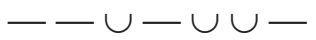

wil

hept

hept

1363

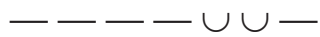

ia + ch

1364

$\cup \cup \cup \cup \backsim \cup \cup-$

gl $\int$

1365

$--\backsim \cup \cup-\cup \cup$

$\mathrm{gl}$

1366

1367

$\dagger$

1368

Third Stasimon (Hel.1451-1511)

Strophe 1

1451

1452

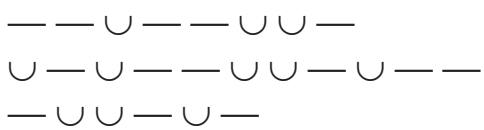

ia + ch

ia + ar

1453

$-\cup \cup-\cup-$

dod

${ }^{134}$ Rather than 'hept' (= $\wedge$ wil), which Euripides seems to have felt as ' $\mathrm{x}-\mathrm{x}-\cup \cup-$ '. Cf. Hel. 520, 526, Or. 834 (see Willink, comm. Or., p. 221), and above, p. 115.

135 See above, p. 107. 
1454

1455

1456

1457

1458

1459

1460

1461

1462

1463

1464

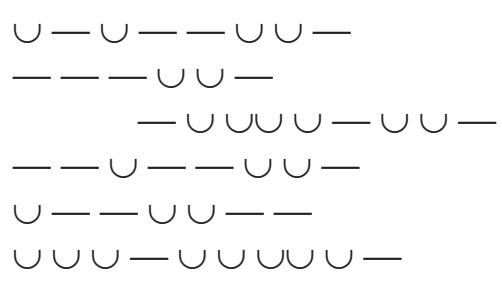

$-\cup-\cup-\cup \cup$

$\cup \cup \cup-\cup \cup-\cup-$

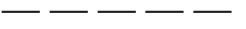

$--\cup-\cup \cup-$

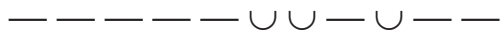

$\sim$ antistrophe 1

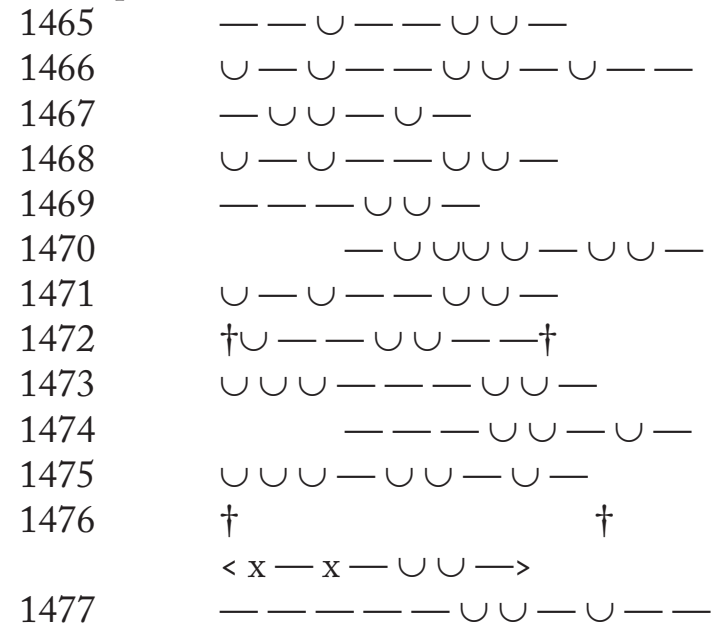

Strophe 2

1478

1479

1480

1481

1482

1483

1484

1485

1486

1487

1488

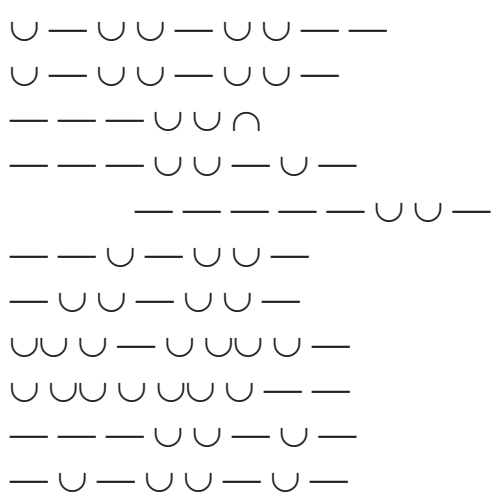

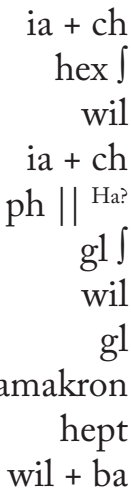

$\mathrm{ia}+\mathrm{ch}$

$\mathrm{ia}+\mathrm{ar}$ dod ia + ch hex $\int$ wil ia + ch $\mathrm{ph} \|{ }^{\mathrm{H}}$ ? wil f gl g1 pentamakron? (hept) wil + ba

${ }^{136}$ Period-end at 1478-9 1495-6 ('erasm $\| \cup \mathrm{D}$ ') is confirmed by anceps iuxta anceps. 
Part II - Scansions
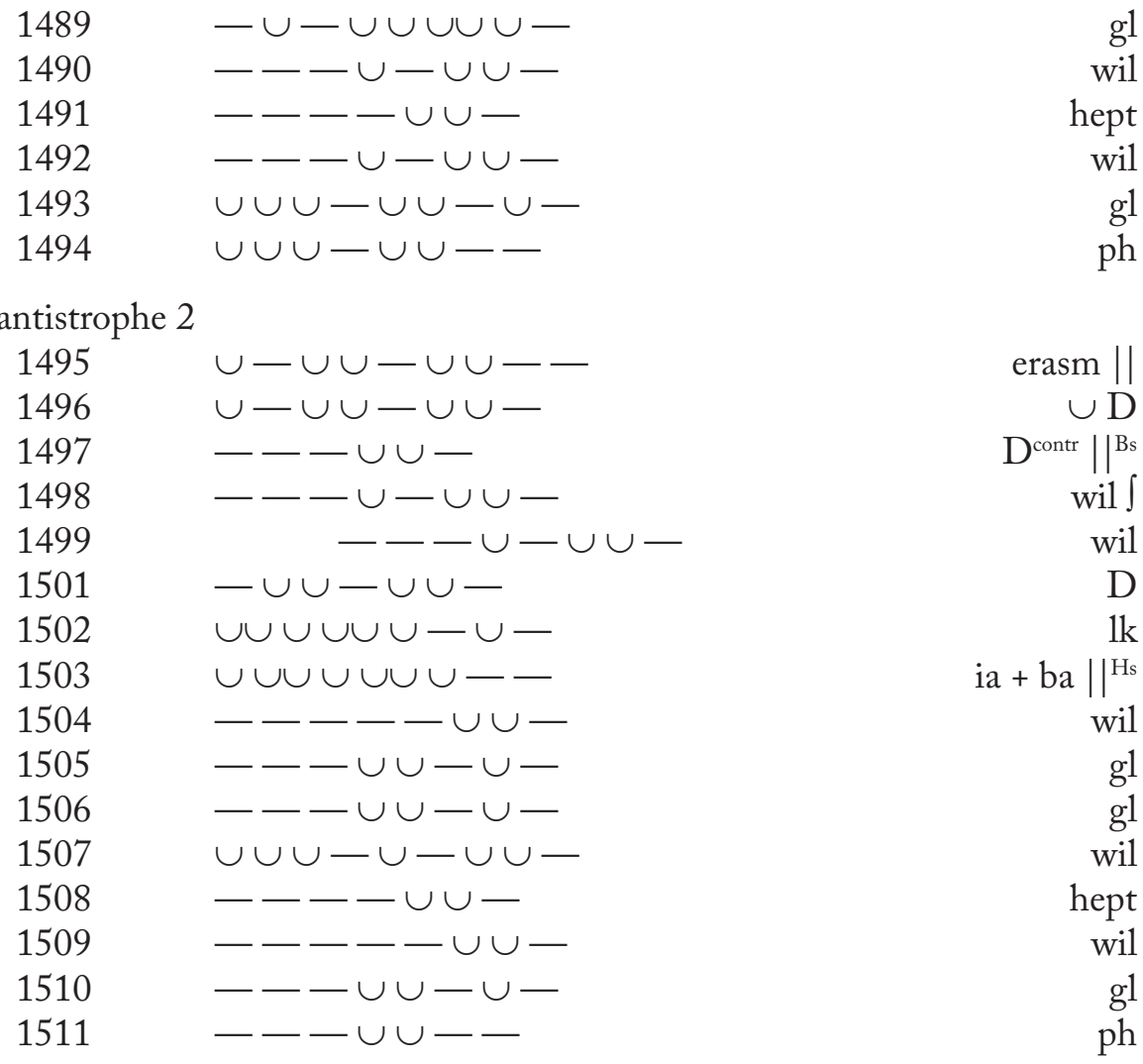


\section{Phoenissae}

Teıхоскоті́a (Ph.103-192)

Av.

$103 \cup \cup \cup \cup \cup \cup \cup \cup-\longrightarrow \cup-$

$104-\cup \cup-\cup-$

$2 \delta$

$105 \quad \cup \cup-\cup \cup--$

$\mathrm{T}$ chol

$\Theta \varepsilon$.

$106 \quad \cup-\cup---\cup-\cdots \cup \cup-$

3 ia spoken

107

$\cup-\cup---\cup-\cdots \cup-$

3 ia spoken

108

$\cup-\cup---\cup---\cup-$

3 ia spoken

Av.

109

$\cup-\cup \cup \cup-$

110

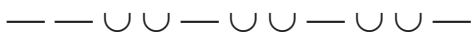

$\delta$

111

$\cup \cup \cup--$

$\Theta \varepsilon$.

112

3 ia

113

3 ia

Av.

114

115

$\dagger+\dagger$

? 137

$2 \delta$

116

$\cup \cup \cup-\cup-\cup \cup \cup-\cup-$

$\delta$

$\Theta \varepsilon$.

117

3 ia

118

3 ia

Av.

119

$\cup-\cup \cup-\cup \cup-$

$\cup \mathrm{D}$

120

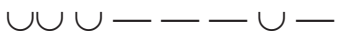

$1 \mathrm{k}^{138}$

121-2

$--\cup-\cup-\cup \cup-\cup \cup-\cdots$

$-\mathrm{e} \cup$ ibyc ${ }^{\text {chol }}$

$\Theta \varepsilon$.

123

$:$ :

3 ia

${ }^{137}$ See Diggle (1994: 342-4).

${ }^{138}$ See above, p. 42. 
Part II - Scansions

124

3 ia

125

3 ia

126

3 ia

Av.

127

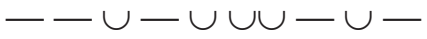

128

$\cup-\cup-\cup \cup-\cup \cup-\cap$ ?

e. $m$.

ia $+\delta$

129

$-\cup-\cup-\cup-$

enop ||? ${ }^{139}$

130

$\cup-\cup-\cup-\cup \cup-\cup \cup--$

$1 \mathrm{k}$

$\Theta \varepsilon$.

131

3 ia

132

3 ia

Av.

133

$--\cup-\cup-\cup-\cup-\cup-$

3 ia

134

$\cup-\cup-\leftarrow-\cup-\cup-$

3 ia

Av.

135

$-\cup \cup-\cup \cup-\cup \cup-\cup \cup$

136

137

$-\cup \cup-----$

138

$\cup \cup \cup-\cup-$

$--\cup-\cup-\cup-\cup-\cup-$

$4 \mathrm{da}$ $4 \mathrm{da} \wedge$ $\delta \|^{\mathrm{H}}$ 3 ia

Av.

145<smiles>CO[Hg]O[Hg]OC</smiles>

3 ia

146

$\cup \cup-\cup \cup-\cup \cup-\cup$

enop prm ${ }^{140}$

147

$-\cup-\cup-\cup-$

$1 \mathrm{k}$

148

$\cup-\cup-\cup-\cup-\cup-\cup \cap$

$3 \mathrm{ia}^{141}$

149

$\cup \cup \cup-\cup-$

$\delta \|\left.\right|^{\mathrm{H}}:$ :

$\Theta \varepsilon$.

150

3 ia

Av.

151

$-\cup \cup-\cup \cup-\cup \cup-\cup \cup$

152

$-\cup \cup-\cup \cup---\cup \cup-\cup \cup-\cap$

153

$\cup \cup \cup \cup \cup \cup-\cdots$

$4 \mathrm{da}$
$6 \mathrm{da} \|^{\mathrm{B}}$
$\mathrm{cr}+\delta$

$\Theta \varepsilon$.

154

3 ia

155

3 ia

${ }^{139}$ See above, p. 78 n. 165.

${ }^{140}$ See Diggle (1994: 206).

${ }^{141}$ See Diggle (1994: 398). 
Av.

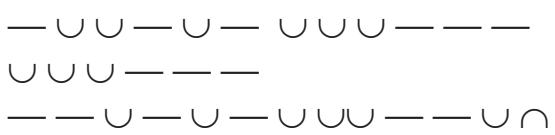

$\Theta \varepsilon$.

$161 \cup-:: \cup---\cup-\cup-\cup-$ 3 ia

162

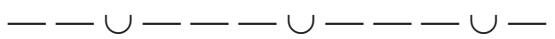

3 ia

163

$\cup \cup-\cup \cup-\cup \cup-\cup \cup-$

2 an

164

$\cup \cup-\cup \cup-\cup \cup-\cup-$

165

$\cup \cup \cup \cup \cup \cup \cup \cup \cup \cup-\cup-$

enop

166

$\cup--\cup-\cup--\cup-$

$2 \delta$

$2 \delta^{142}$

167

$\cup \cup \cup \cup \cup \cup$

168

$\cup-\cup-\cup-\cup-\cup-\cup \cap$

$\delta$

169

$\cup-\backsim \cup \cup \cup \cup-\cup-$

3 ia

$2 \delta$

$\Theta \varepsilon$.

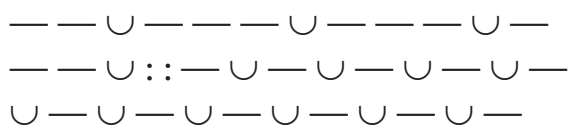

3 ia

171

172

$\cup-\cup-\cup-\cup-\cup-\cup-$

3 ia

3 ia

$\Theta \varepsilon$.

173

3 ia

174

3 ia

Av.

175

$-\cup \cup---\cup \cup \cup \dagger-\cup \cup-$

176

177

178

179

180

181

$-\cup \cup-\cup-\cup \dagger--\cup \cap$

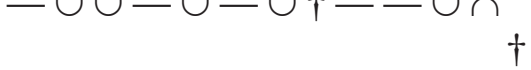

$\dagger$

$-\backsim-\cup-\cup---\cup-$

$\cup \cup-:: \cup---\cup---\cup-$

3 ia

3 ia

Av.

182

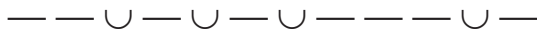

e. $\mathrm{m}$.

183

$\cup \cup \cup-\cup-\cup \cup \cup--$

$2 \delta$

$\mathrm{k} \delta+\delta$

184

$\cup-\cup-\cup--\cup \cup-\cup-$

$\mathrm{A}+\mathrm{sp}$

185

$\cup \cup-\cup \cup-\cup \cup-\cup \cup--$

186

$\cup-\cup-\cup-\cup-$

2 ia

$\delta$ ?

187

$-\cup \cup---\dagger \cup--\cup$

$\delta$ ?

${ }^{142}$ See Diggle (1994: 344-5). 
Part II - Scansions

$\begin{array}{llr}188 & \cup \cup \cup--\cup- & \delta \text { ? } \\ 189 & \cup \cup \cup---\cup \cup \cup- \\ 190 & -\cup \cup-\cup \cup---\cup \cup \\ 191 & -\cup \cup-\cup \cup-\cup \cup-\cap & \delta \text { ? } \\ 192 & -\cup \cup-\cup \cup--- & 4 \mathrm{da} \\ & & 4 \mathrm{da} \\ 4 \mathrm{da}^{\text {cat }} \wedge\end{array}$

Parodos (Ph. 202-238)

Strophe 1

202

$\cup \cup \cup-\cup \cup-\cup-$

203

$-\cup-\cup \cup-\cup-$

204

$---\cup \cup--$

205

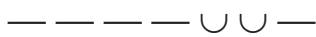

206

$\cup \cup \cup-\cup \cup \cup \cup \cup-$

207

208

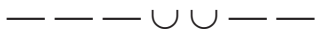

209

$\cup \cup \cup-\cup \cup-\cup \cup \cup$

210

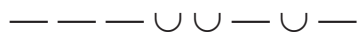

211

212

$\cup \cup \cup \cup-$

213

$---\cup \cup-\cup-$

$---\cup \cup-\cap$

$\sim$ antistrophe 1

214

215

216

217

218

219

220

221

222

223

224

225

epode

226

227

228

229

230 $\cup \cup \cup-\cup \cup-\cup-$
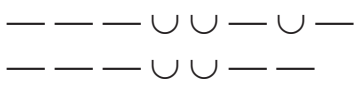

$-\backsim \cup \cup \cup-$

$\cup \cup \cup-\cup \cup-\cup$

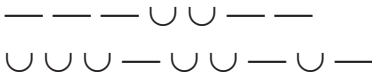

$--\backsim \cup \cup \cup \cup$

$\cup \cup \cup-\cup \cup-\cup-$

$\cup \cup \cup-\cup \cup-\cup$

$---\cup \cup-\cup-$

$---\cup \cup-$ 


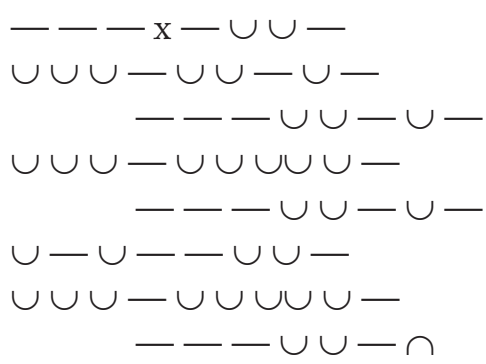

Strophe 2

239

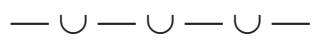

240

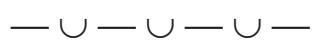

$1 \mathrm{k} \mid{ }^{\mathrm{Ba}}$

241

$-\cup-\cup-\cup-$

242

$-\cup-\cup-\cup-$

243

$-\cup-\cup-\cup-$

244

245

$-\cup-\cup-\cup-$

246

247

$-\cup-\cup-\cup-$

$1 \mathrm{k} \|$

$1 \mathrm{k}$

248

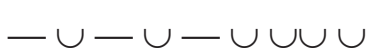

$\mathrm{mol}+2 \mathrm{sp}^{144}$

$2 \mathrm{tr}$

249

$-\cup-\cup-\cup-\cup-$

$\mathrm{lk}+\mathrm{ba}$

$-\cup-\cup-\cup-$

$1 \mathrm{k}$

$\sim$ antistrophe 2

250

251

$-\cup-\cup-\cup \cap$

252

$-\cup---\cup-$

$1 \mathrm{k} \|{ }^{\mathrm{B}}$

$1 \mathrm{k}$

253

$-\cup-\cup-\cup-$

$1 \mathrm{k}$

254

$-\cup-\cup-\cup-$

$1 \mathrm{k}$

255

$-\cup-\cup-\cup-$

$1 \mathrm{k}$

256

$-\cup-\cup-\cup-$

$1 \mathrm{k}$

$-\cup-\cup-\cup-$

$1 \mathrm{k}$

257

258

$-\cup \cup \cup \cup-\cup \cup \cup \cup$

$\mathrm{mol}+2 \mathrm{sp}$

$2 \mathrm{tr}$

259

$-\cup-\cup-\cup-\cup-$

$\mathrm{lk}+\mathrm{ba}$

260

$-\cup-\cup-\cup-$

$1 \mathrm{k}$

\section{Ph. 293-300}

Xo.

293

$\cup \cup \cup-\cup--\cup-\cup-$

$\delta+h \delta$

${ }^{143}$ On the indeterminate quantity of the iota of icĩco see Mastronarde, comm. Ph., p. 214.

144 'Heptamakron'? 
Part II - Scansions
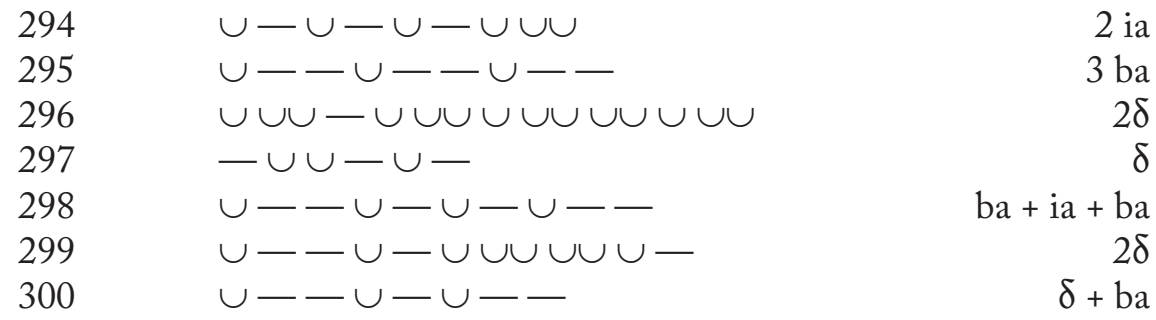

Jocasta's Monody (Ph. 301-354)

Io.

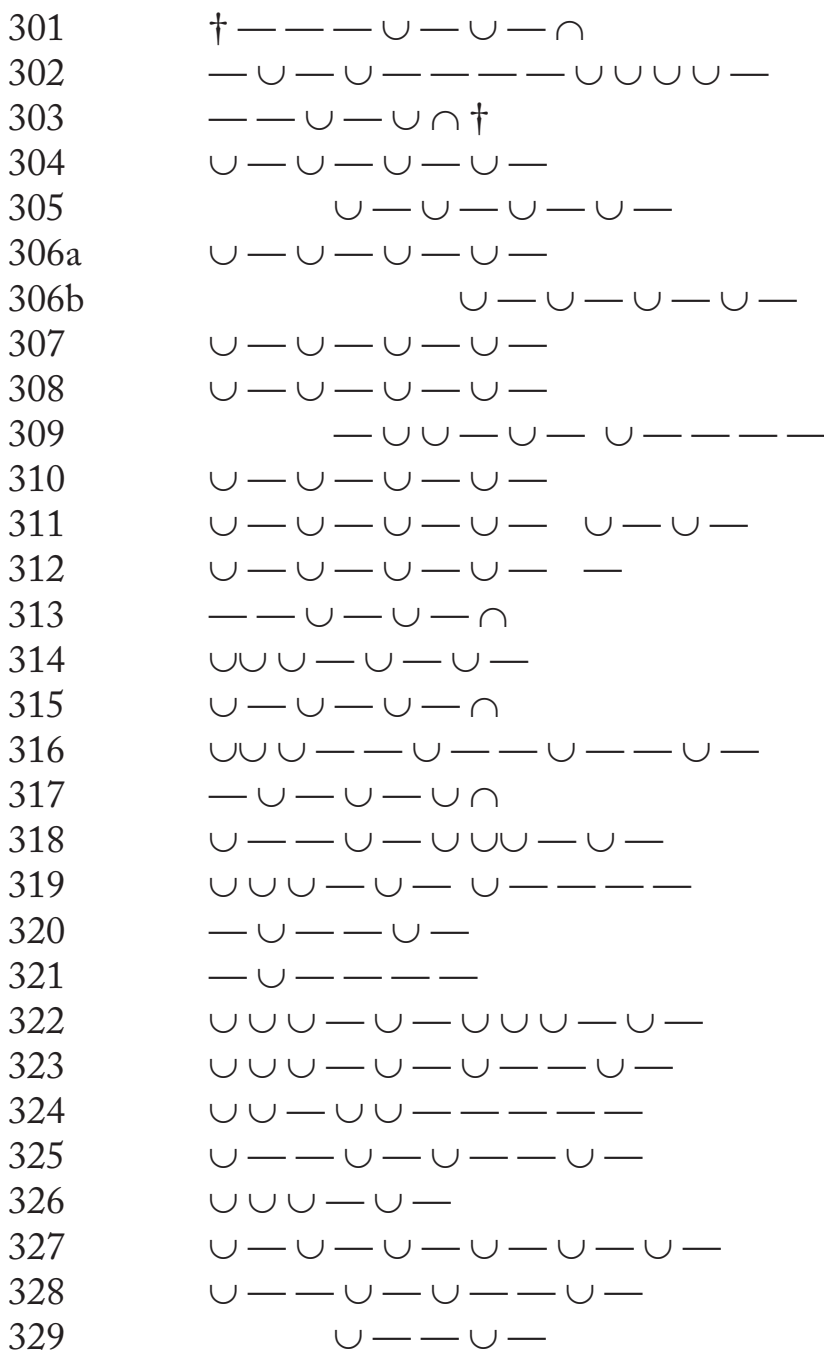


First Stasimon (Ph. 638-689)

Strophe

$\begin{array}{ll}638 & -\cup \cup \cup \cup-\cup- \\ 639 & \cup \cup \cup-\cup-\cup- \\ 640 & -\cup \cup \cup \cup-\cup-\cup \\ 641 & \cup \cup \cup-\cup-\cup-\cup \\ 642 & -\cup-\cup-\cup- \\ 643 & \cup \cup \cup-\cup-\cup- \\ 644 & \cup \cup \cup \cup \dagger \\ 645 & -\cup \cup \cup \cup \cup \cup \cup \cup \cup \\ 646 & \cup \cup \cup-\cup-\dagger-- \\ 647 & --\cup-\cup- \\ 648 & \\ 649 & \cup \cup \cup-\cup \cup \cup \cup \dagger-\end{array}$

$1 \mathrm{k}$

$1 \mathrm{k}$

$2 \operatorname{tr}$

$2 \operatorname{tr}$

$1 \mathrm{k}$

$1 \mathrm{k}$

$2 \operatorname{tr}$

? 
650
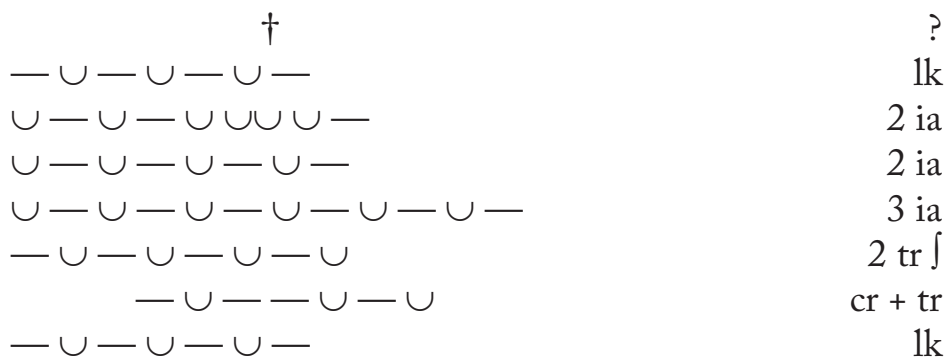

$\sim$ antistrophe

657

658

$-\cup \cup \cup \cup-\cup-$

$1 \mathrm{k}$

659

$\cup \cup-\cup-\cup-$

660

$-\cup \cup \cup \cup \cup$

661

$\cup \cup-\cup-\cup-\cup$

662

$\cup \cup-\cup-\cup-$

$\cup \cup-\cup-\cup-$

663

$-\cup \cup \cup-\cup-$

664

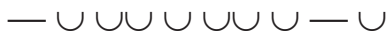

665

$-\cup-\dagger \cup-\dagger \cup-$

666

667

668

669

670

671

672

673

$674 \mathrm{a}$
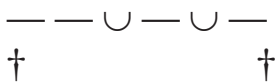

$-\cup-\cup-\cup-\cup$

$2 \operatorname{tr}$

$-\cup-\cup-\cup-$

$-\cup-\cup-\cup-$

$\cup-\cup-\cup \cup \cup \cup-$

$\cup-\cup-\cup-\cup-$

$\cup-\cup-\cup-\cup-\cup-\cup-$

$674 \mathrm{~b}$

675

$-\cup-\cup-\cup-\cup$

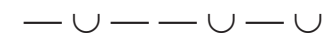

$-\cup-\cup-\cup-$

$1 \mathrm{k}$

$2 \operatorname{tr}$

$2 \operatorname{tr}$

$1 \mathrm{k}$

$1 \mathrm{k}$

$1 \mathrm{k}$

$2 \operatorname{tr}$

$1 \mathrm{k}$ ?

$\mathrm{pa}+\mathrm{cr}$

?

$1 \mathrm{k}$

$1 \mathrm{k}$

2 ia

2 ia

3 ia

$2 \operatorname{tr}$

$\mathrm{cr}+\operatorname{tr}$

$1 \mathrm{k}$

epode

676

677

678

679

680

681

682

$-\cup-\cup-\cup \cap$

$1 \mathrm{k} \|{ }^{\mathrm{B}}$

$\mathrm{pa}+\mathrm{cr}$

$--\cup-\cup \cap$

$2 \operatorname{tr}$

$\dagger \cup \cup \cup \cup \cup \cup \cup-\cup-\cup-$

$\cup--\cup-\cup-\dagger$

ia + cr?

$1 \mathrm{k}$

$1 \mathrm{k}$

683

$-\cup-\cup-\cup-$

$1 \mathrm{k}$

684

$-\cup-\cup-\cup-$

$1 \mathrm{k}$

685

$-\cup-\cup-\cup-$

$\mathrm{sp}+\mathrm{cr}$ 


\section{Second Stasimon $(P h .784-833)$}

Strophe

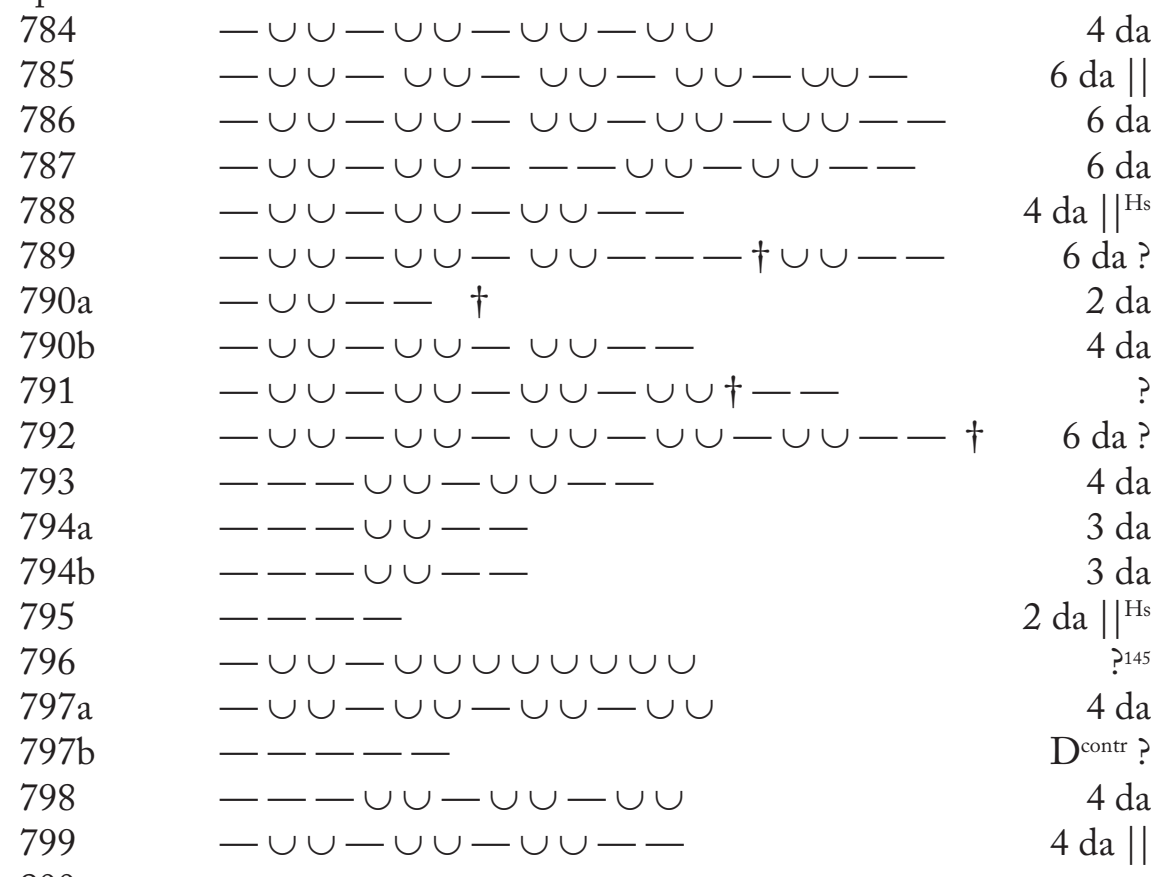

800

$\sim$ antistrophe

801

$-\cup \cup-\cup \cup-\cup \cup-\cup \cup$

802

$-\cup \cup-\cup \cup-\cup \cup-\cup \cup-\cup \cup-$

803

$-\cup \cup-\cup \cup-\cup \cup-\cup \cup-\cup \cup-$

804

$-\cup \cup-\cup \cup---\cup \cup-\cup \cup--$

805

806

$-\cup \cup-\cup \cup-\cup \cup--$

$807 a$

$-\cup \cup-\cup \cup-\cup \cup---\cup \cup--$

$807 \mathrm{~b}$

$-\cup \cup--$

808

$-\cup \cup-\cup \cup-\cup \cup-$

$-\cup \cup-\cup \cup-\cup \cup-\cup \cup-$

$4 \mathrm{da}$
$6 \mathrm{da} \|$
$6 \mathrm{da}$
$6 \mathrm{da}$
$4 \mathrm{da} \|$
$6 \mathrm{da}$
$2 \mathrm{da}$
$4 \mathrm{da}$
$5 \mathrm{da}$

${ }^{145}$ See Diggle (1994: 122). 
$6 \mathrm{da}$

810

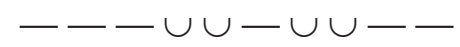

$811 \mathrm{a}$

$811 \mathrm{~b}$

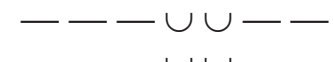

812

813

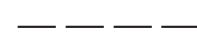

814

815

$-\cup \cup-\cup \cup-\cup \cup-\cup \cup$

816

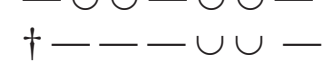

817

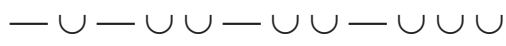

epode

818

819

820

821

822

823

824

825

826

827

828

829

830

831-2

$-\cup \cup-\cup \cup-\cup \cup--\dagger$

$4 \mathrm{da}$

$3 \mathrm{da}$

$3 \mathrm{da}$

2 da $\|$ $4 \mathrm{da}$

$4 \mathrm{da}$

$4 \mathrm{da}$ ?

833

$\cup \cup \cup--\cup \cup-\cup \cup$

$-\cup \cup-\cup \cup-\cup \cup-\cup \cup-\cup \cup-$

$\mathrm{cr}+2 \mathrm{da}$

$6 \mathrm{da}$

$-\cup \cup-\cup \cup-\cup \cup-\cup \cup-\cup \cup--$

$6 \mathrm{da}$

$6 \mathrm{da} \|^{\mathrm{B}}$

$4 \mathrm{da}$

$6 \mathrm{da}$

$6 \mathrm{da}$

2 an

2 an

prm $\|\left.\right|^{\mathrm{H}}$

$4 \mathrm{da}$

$4 \mathrm{da}$

$4 \mathrm{da} \int$

$5 \mathrm{da}$

erasm

Third Stasimon (Ph. 1019-1066)

Strophe

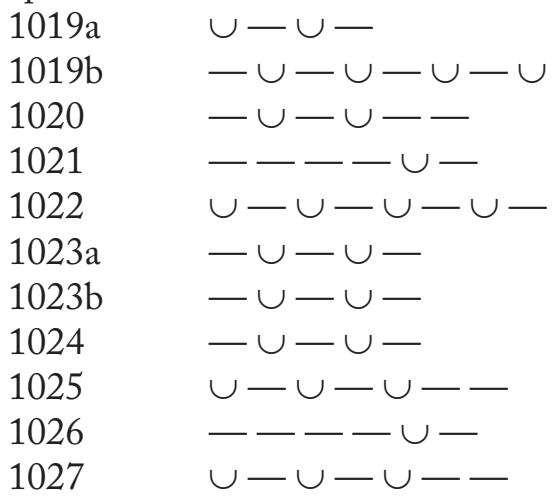

$$
\begin{array}{r}
\text { ia } \\
2 \text { tr } \\
\text { ith } \| \\
\mathrm{mol}+\mathrm{cr} \\
2 \mathrm{ia} \\
\mathrm{h} \delta \\
\mathrm{h} \delta \\
\mathrm{h} \delta \\
\mathrm{ia}+\mathrm{ba} \\
\mathrm{mol}+\mathrm{cr} \\
\mathrm{ia}+\mathrm{ba}
\end{array}
$$




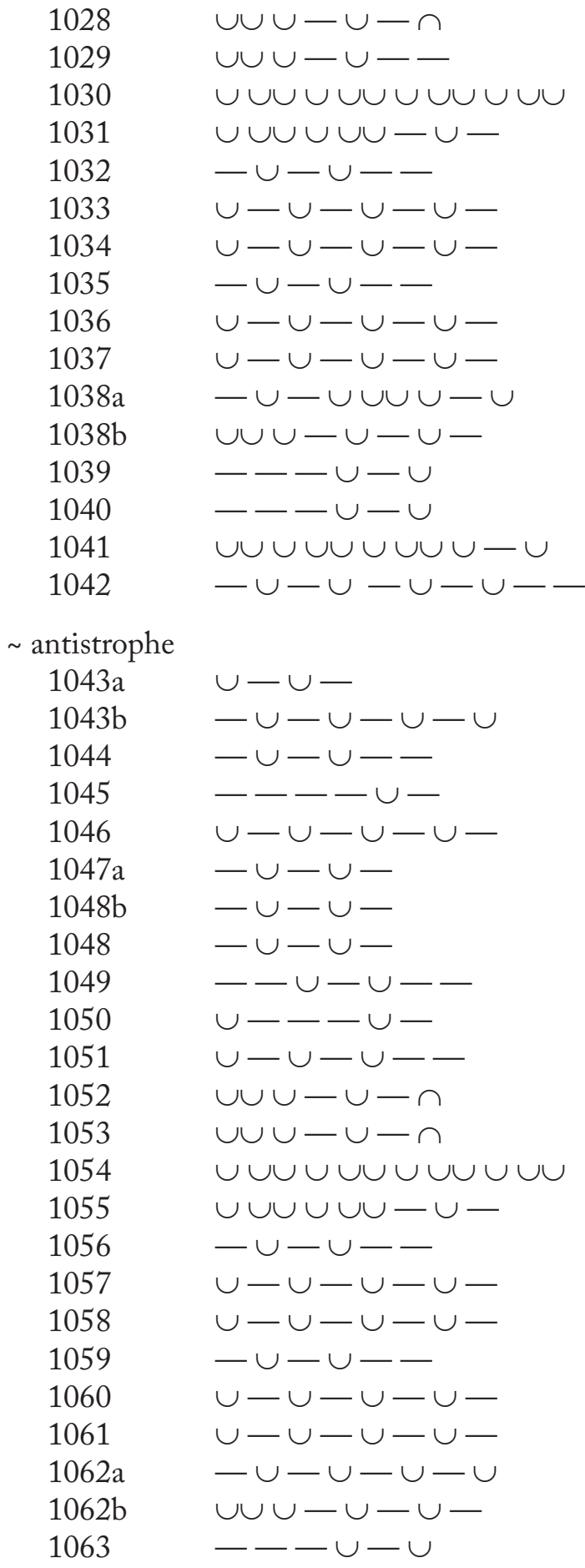

$$
\begin{array}{r}
\text { ith } \|^{\mathrm{B}} \\
\text { ith } \|^{\mathrm{Ba}} \\
2 \mathrm{ia} \\
\mathrm{ia}+\mathrm{cr} \\
\text { ith } \| \\
2 \mathrm{ia} \\
2 \mathrm{ia} \\
\mathrm{ith} \\
2 \mathrm{ia} \\
2 \mathrm{ia} \\
2 \mathrm{tr} \\
\mathrm{lk} \\
\mathrm{sp}+\mathrm{tr} \\
\mathrm{sp}+\mathrm{tr} \\
2 \mathrm{tr} \\
\mathrm{tr}+\mathrm{ith}
\end{array}
$$

$$
\begin{array}{r}
\text { ia } \\
2 \text { tr } \\
\text { ith } \| \\
\mathrm{mol}+\mathrm{cr} \\
2 \mathrm{ia} \\
\mathrm{h} \delta \\
\mathrm{h} \delta \\
\mathrm{h} \delta \\
\mathrm{ia}+\mathrm{ba} \\
\mathrm{ba}+\mathrm{cr} \\
\mathrm{ia}+\mathrm{ba} \\
\mathrm{ith}\|\|^{\mathrm{B}} \\
\mathrm{ith} \|^{\mathrm{Ba}} \\
2 \mathrm{ia} \\
\mathrm{ia}+\mathrm{cr} \\
\mathrm{ith} \| \\
2 \mathrm{ia} \\
2 \mathrm{ia} \\
\mathrm{ith} \\
2 \mathrm{ia} \\
2 \mathrm{ia} \\
2 \mathrm{tr} \\
\mathrm{lk} \\
\mathrm{sp}+\mathrm{tr}
\end{array}
$$




$\begin{array}{llr}1064 & -\smile-\cup-\cup & \mathrm{sp}+\mathrm{tr} \\ 1065 & \cup \cup \cup \cup \cup-\cup-\cup & 2 \mathrm{tr} \\ 1066 & -\cup-\cup-\cup \cup \cup-\leftarrow & \text { tr }+ \text { ith }\end{array}$

\section{Fourth Stasimon (Ph.1284-1307)}

Strophe

\begin{tabular}{|c|c|c|}
\hline 1284 & $----\cup \cup---$ & 2 an \\
\hline 1285 & $\cup \cup-\cup \cup-\cup \cup-\cup \cup-$ & 2 an \\
\hline 1286 & $\cup \cup \cup \cup \cup \cup \cup \cup-$ & $\mathrm{ia}+\mathrm{cr} \int$ \\
\hline 1287 & $\cup----$ & $\delta$ \\
\hline 1288 & $\cup \cup \cup \cup \cup \cup \cup \cup \cup$ & $\mathrm{k}$ \\
\hline 1289 & $\cup \cup \backsim--$ & $\delta$ \\
\hline 1290 & $\cup--\cup-\cup--\cup--$ & $\delta+2 \mathrm{ba} \|^{\mathrm{H}}$ \\
\hline 1291 & $\cup \cup \cup-\cup-\cup \cup \cup-\cup-$ & \\
\hline 1292 & $\cup-\cup-\cup-\cup-$ & $2 \mathrm{ia}$ \\
\hline 1293 & $\cup-\cup-\cup-\cap$ & $\mathrm{ia}+\mathrm{ba} \|^{\mathrm{Bs}}$ \\
\hline $294-5$ & $\cup \cup \cup \cup \cup \cup \cup \cup \cup--$ & \\
\hline
\end{tabular}

$\sim$ antistrophe

1296

1297

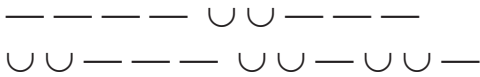

2 an

1298

1299

$\cup \cup \cup \cup \cup \cup-\cup-$

2 an

1300

$\cup--\cup-$

ia + cr $\int$ $\delta$

1301

$\cup \cup \cup \cup \cup \cup \cup \cup \cup \cup$

$1 \mathrm{k}$

1302

$\cup \cup \cup-\cup-$

1303

$\cup--\cup-\cup--\cup-$

$\delta+2 \mathrm{ba}$

$\delta$
ba
$2 \delta$

1304

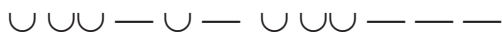

$2 \delta$

2 ia

1305

$\cup-\cup-\cup-\cup-$

$\mathrm{ia}+\mathrm{ba}$

1306-7

$\cup-\cup-\cup-$

$2 \delta$

Antigone's Monody (Ph. 1485-1538)

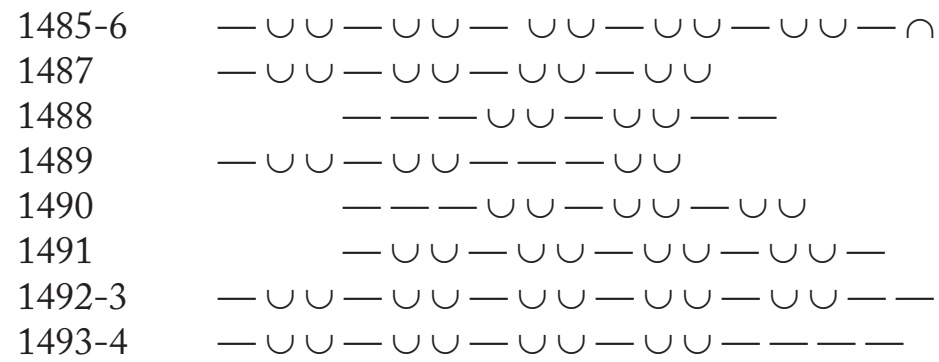

$6 \mathrm{da} \|^{\mathrm{B}}$
$4 \mathrm{da} \int$
$4 \mathrm{da} \|^{\mathrm{H}}$
$4 \mathrm{da} \int$
$4 \mathrm{da}$
$5 \mathrm{da} \wedge$
$6 \mathrm{da} \|^{\mathrm{H}}$
$6 \mathrm{da}$




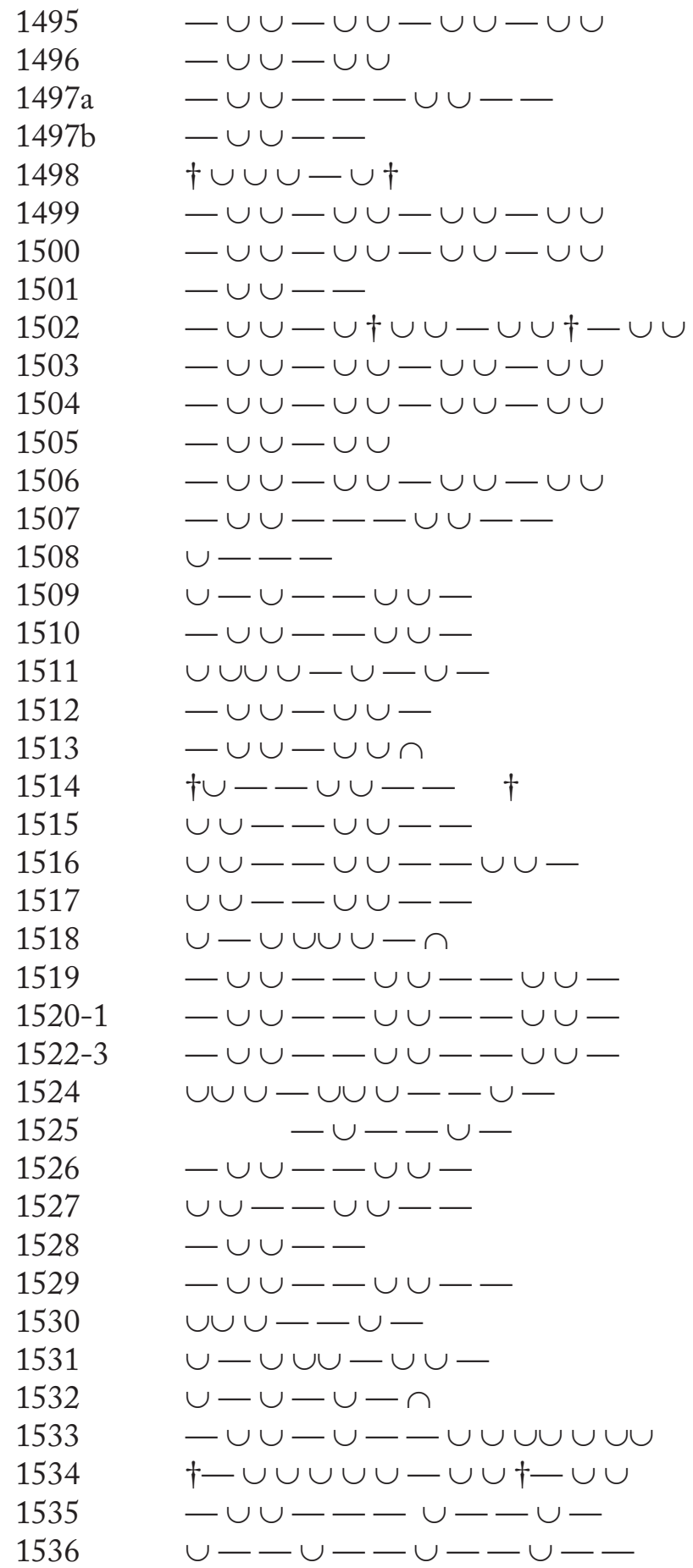


Part II - Scansions

1537
1538

$\cup--\cup-$

reiz $\|\left.\right|^{146}$

\section{Lyric duet ( $P h .1539-1581)$}

OІ $\triangle \mathrm{I} \Pi$ OYC

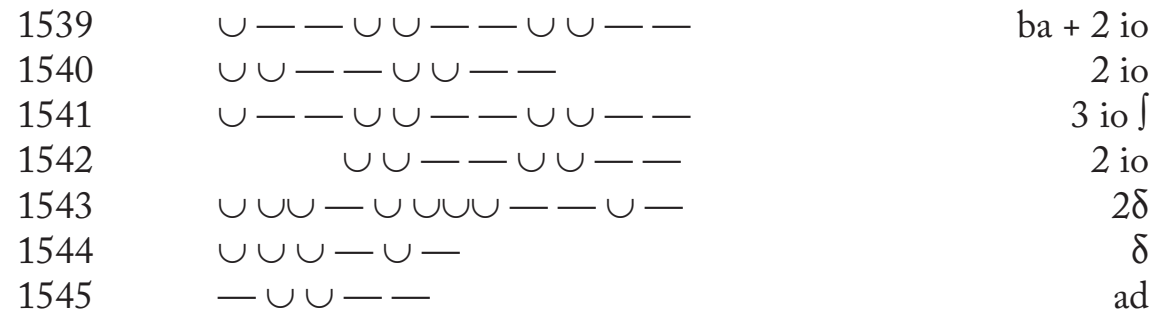

Av.

1546

$-\cup \cup-\cup \cup-\cup \cup--$

2 an $(4 \mathrm{da})^{147}$

1547

$\cup \cup-\cup \cup-\cup \cup--$

1548

$\cup \cup-\cup \cup-\cup \cup--$ prm

1549

$-\cup \cup-\cup \cup-\cup \cup-\cup \cup-\cup \cup--$

$(6 \mathrm{da}) \|^{\mathrm{H}}$

1550

$-\cup \cup--$

$(2 \mathrm{da}) \|^{\mathrm{H}}$

O1.

1551-2 $-\cup \cup-\cup \cup-\cup \cup-\dagger \cup \dagger$

1553

1554

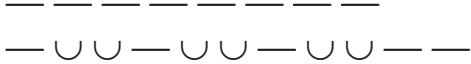

2 an (cf. Ba. 596)

2 an $(4 \mathrm{da}) \|^{\mathrm{H}}$

Av.

1555

1556

$-\cup \cup-\cup \cup-\cup \cup-\cup \cup$

2 an (4da)

1557

$-\cup \cup-\cup \cup-\cup \cup-$

2 an (4da)

1558

$\cup \cup--\longrightarrow$

an

1559

$-\cup \cup-\cup \cup-\cup \cup-\cup \cup-\cup \cup-$

$(6 \mathrm{da})$

1560

$-\cup \cup-$

$(2 \mathrm{da}) \|^{\mathrm{H}}$

1561

$--:: \cup \cup \cup$

2 ia

1562

$-\cup:: \cup \cup-\cup-$

$1 \mathrm{k}$

1563

$-\cup \cup-\cup \cup-\cup \cup-$

$4 \mathrm{da}$

1564

$-\cup \cup-\cup \cup-\cup \cup--$

$4 \mathrm{da}$

1565

$-\cup \cup---\cup \cup--$

$4 \mathrm{da}$

1566

$-\cup \cup-\cup \cup-\cup \cup-\cup \cup$

$4 \mathrm{da}$

$1567 \mathrm{a}$

$-\cup \cup-\cup \cup-\cup \cup-\cup \cup-\cup \cup-\cup \cup$

$6 \mathrm{da}$

$\cup \cup \cup \cup$

$\operatorname{tr}$

${ }^{146}$ See Parker (1968: 267).

${ }^{147}$ See above, p. 46. 


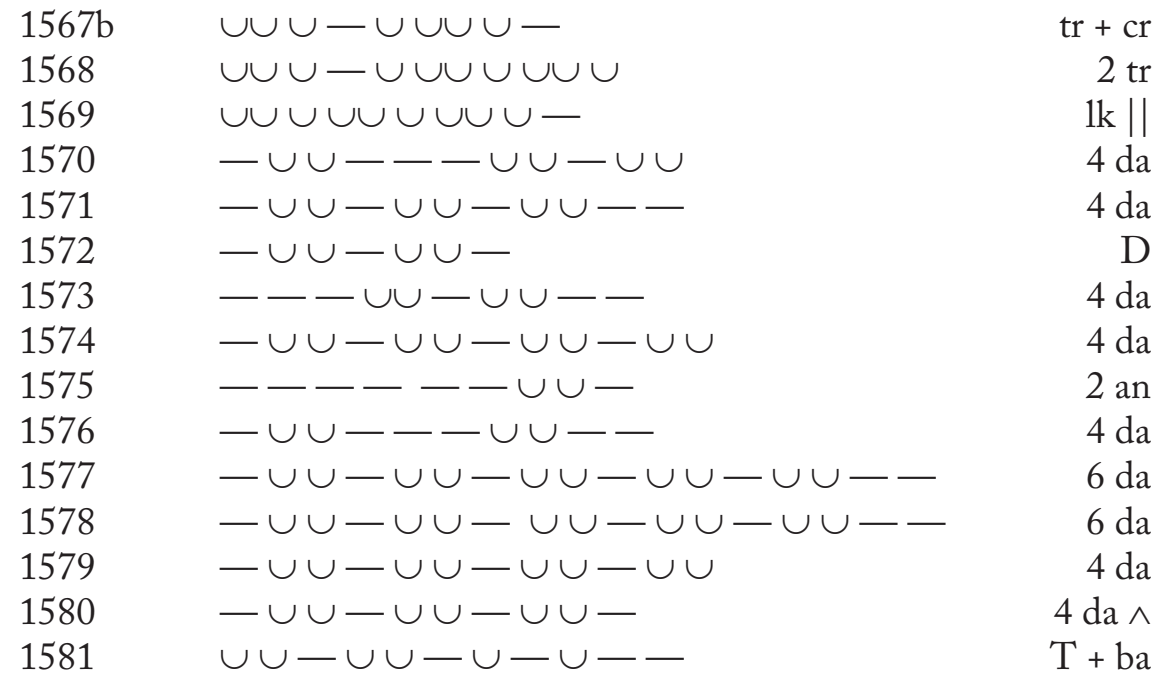

\section{Final lyric scene $(P h .1710-1557)$}

Av.

$1710 \cup-\cup-\cup-\cup \cup \cup \cup \cup \cup \cup-$

3 ia

1711

$\cup-\cup-\cup-\cup-$

2 ia

1712

$\cup-\cup-\cup-\cup-\cup-$

2 ia + ba

Or.

$\begin{array}{ll}1713 & \cup- \\ 1714 & \cup-\cup-\cup-\cup- \\ 1715 & \cup-\cup-\cup-\cup-\end{array}$

e. $\mathrm{m}$.

2 ia

2 ia

Av.

1716

$\cup \cup \cup \cup \cup \cup \cup-\cup-$

2 ia

1717

$\cup-\cup---\cup-\cup-\cup-$

$3 \mathrm{ia}^{148}$

$\mathrm{O}$.

$1718 \quad \cup \cup \cup \cup \cup \cup-\cup-\cup$

$2 \operatorname{tr}$

$1 \mathrm{k}$

Av.

1720

$-\cup-\cup-\cup-$

1721

$-\cup-\cup \cup \cup \cup-$

1722

$-\cup-\cup-\cdots$

$1 \mathrm{k} \mid{ }^{\mathrm{H}}$ ith

${ }^{148}$ Caesura-less trimeter. See Diggle (1991: 138 n. 18; 1994: 360, 475 n. 158). 
O1.

1723

1724

1725

Av.

1726

1727

Or.

1728

1729

1730

1731

Av.

1732

1733

1734

1735

1736

1737

1738

1739

Or.

1740

Av.

1741

1742

1743

1744

1745

1746

O1.

1749

1747

Av.

1748

1750

O1.

1751

1752

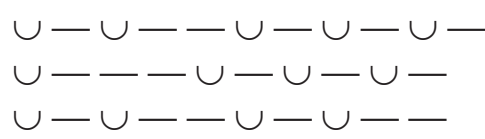

$\mathrm{ia}+\mathrm{cr}+\mathrm{ia}$

$\mathrm{ba}+\mathrm{cr}+\mathrm{ia}$ ia + ith

$\mathrm{ia}+\mathrm{cr}+\mathrm{ia}$ $\mathrm{cr}+2$ ia

$\cup-\cup--\cup-\cup-\cup-$
$-\cup-\cup-\cup-\cup \cup \cup \cup-$

2 ia $\int$

2 ia

$\dagger-\cup-\cup-\dagger$

$\mathrm{ia}+\mathrm{ba}$

$-\backsim \cup \cup \cup \cup-$

$$
\begin{array}{r}
2 \mathrm{tr} \\
\mathrm{tr}+\mathrm{ith} \\
2 \mathrm{tr} \\
2 \mathrm{tr} \\
\mathrm{ith} \\
3 \mathrm{ia} \\
2 \mathrm{ia}+\mathrm{ba} \\
2 \mathrm{ia}
\end{array}
$$

$11 \mathrm{k}$

$1 \mathrm{k}$ ith

3 ia $\mathrm{ia}+\mathrm{cr}+\mathrm{ia}$

3 ia ith

2 ia

2 ia

$\cup-\cup-\cup-\cup-$

$\cup \cup-\cup-\cup-$

$\cup \cup-\cup-\cup-$

2 ia $\int$

2 ia 
Av.

1753

1754-5

1756

1757

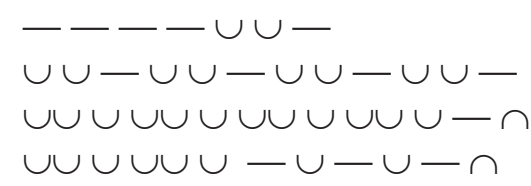

?149

A

tr + ith $\|^{\mathrm{B}}$

tr + ith \|\|$^{B}$

${ }^{149}$ See West (1982: 104). 


\section{Orestes}

Parodos (Or. 141-207)

Strophe $1 \sim$

Xo.

140

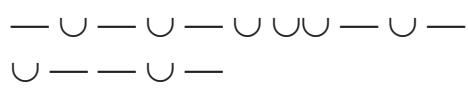

$h \delta+\delta$

141

$\cup--\cup-$

$\mathrm{H} \lambda$.

$142-3$

$\cup \cup \cup-\cup-\cup \cup \cup---$

Xo.

144

$\cup--\cup-$

$\mathrm{H} \lambda$.

145

$\cup---\cup \cup-\cup-$

$\delta+\mathrm{cr}^{150}$

146

$--\cup \cup \cup-\cup-\cdots$

$2 \delta$

Xo.

147

$\cup \cup \cup-\cup-\cup \cup \cup-\cup-$ $2 \delta$

148

149

$\cup-::---$

$\delta$

$150-1$

uuvununuvuuvu $2 \delta$

152

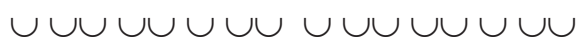

$2 \delta$

$2 \delta$

$\sim$ antistrophe 1

Xo.

153

154

$-\cup-\cup-\cup \cup \cup-\cup-$

h $\delta+\delta$

154

$\cup \cup \cup---$

$\delta$

$\mathrm{H} \lambda$.

$155-6$

$\cup \cup \cup-\cup-\cup \cup \cup--$

$2 \delta$

Xo.

157

$\cup--\cup-$

$\delta$

$\mathrm{H} \lambda$.

158

$\cup--\cup \cup \cup---$

$\delta+\mathrm{mol}$

${ }^{150}$ On the responsion, see Diggle (1994: 201). 
Part II - Scansions

159

$\cup-\cup \cup \cup-\cup \cup \cup-\cup-$

Xo.

160

$\cup \cup \cup---\cup \cup \cup-\cup-$ $2 \delta$

161

$\cup-::--$

162

$\cup \cup \cup \cup \cup \cup \cup \cup \cup \cup \cup \cup \cup \cup$

163-4

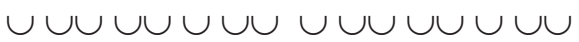

165

$\cup \cup \cup-\cup-\cup--\cup$

Strophe 2

Xo.

166

$\cup--\cup-\cup--\cup-$

$\mathrm{H} \lambda$.

167

$\cup-\cup-\cup-\cap$

168

$-ー \cup \cup ル \cup-$

$\mathrm{ia}+\mathrm{ba} \|^{\mathrm{B}}$
$\delta+\mathrm{cr} \|^{\mathrm{H}}:$

Xo.

169

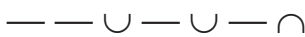

$\mathrm{ia}+\mathrm{ba} \|^{\mathrm{BH}}:$ :

$\mathrm{H} \lambda$.

170

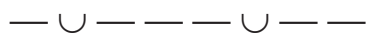

$2 \operatorname{tr}^{151}$

171

$\cup \cup \cup \cup \cup \smile--$

$2 \mathrm{ia}^{152}$

172

$\cup \cup \cup-\cup-$

$\delta \|^{\mathrm{H}}$

Xo.

173

$\cup--$ - : U - -

2 ba

174

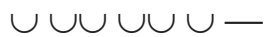

175-6

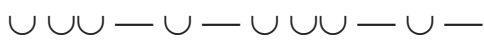

$177-8$

$\cup \cup \cup \cup \cup \cup \cup \cup \smile \cup$

179

$\cup \cup-\cup \cup \cup \cup$

180-1

$\cup \cup \cup-\cup-\cup \cup \cup-\cup-$

$2 \delta\|\|^{\mathrm{Ba}}$

$\delta+\mathrm{cr} \| \mathrm{BHa}$

182

$\cup-\cup \cup-\cup \cup-$

$2 \delta$

183

$\cup \cup-\cup \cup-\cup-\cup$

$\cup \mathrm{D}$

diom

184

$-\cup \cup-\cup \cup-$

$\mathrm{D}$

185

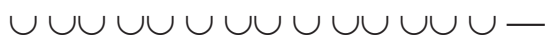

186

$\cup \cup \backsim \cup-\cup-ー \cup-$

$2 \delta$

$\sim$ antistrophe 2

Xo.

187

$\cup--\cup-\cup--\cup-$

${ }^{151}$ For the word-end after long anceps, see Parker (1966: 16).

${ }^{152}$ See above, p. 120 (n.262). 
$\mathrm{H} \lambda$.

188

$\cup-\cup-\cup-\cap$

189

$-\cup-\cup \cup \cup-\cup-$

$\mathrm{ia}+\mathrm{ba} \|^{\mathrm{BH}}$
$\mathrm{h} \delta+\mathrm{cr} \|^{\mathrm{Hs}}:$ :

Xo.

190

$\cup-\cup-\cup-\cap$

$\mathrm{ia}+\mathrm{ba} \|^{\mathrm{BH}}$

$\mathrm{H} \lambda$.

191

192

$-\cup-\cup-\cup-\cdots$

$2 \operatorname{tr}$

193

$\cup \cup \cup \cup \cup \cup \cup-\cup-$

2 ia

$\cup \cup \cup---$

Xo.

194

$\cup-\longrightarrow:: \cup--$

2 ba

195

$\cup \cup \cup \cup \cup \cup-$

$\delta$

196-7 $\cup \cup \cup-\cup-\cup \cup \cup-\cup-$

$2 \delta$

198-9

$\cup \cup \cup \cup \cup \cup \cup \cup \cup \cup \cup-\cup \cap$

$2 \delta \|^{\mathrm{B}}$

200

$\cup \cup \cup \cup \cup \cup \cup \cup \cup \cup \cap$

201-2

$\cup \cup \cup-\cup-\cup \cup \cup-\cup-$

$\delta+\operatorname{cr} \|\left.\right|^{\mathrm{BH}}$

203

$\cup-\cup \cup-\cup \cup-$

$2 \delta$

204

$\cup \cup-\cup \cup-\cup-\cup$

$\cup \mathrm{D}$

205

$-\cup \cup-\cup \cup-$

diom

206

$\cup \cup \dagger$

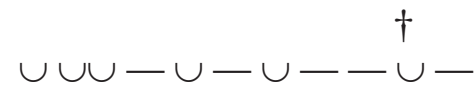

$\mathrm{D}$

$2 \delta$

207

$2 \delta$

First Stasimon (Or.316-347)

Strophe
316
$--\bar{\cup} \cup \cup \cup \cup-$
$\mathrm{sp}$
$\mathrm{cr}+\mathrm{cr}$
317
$\cup \cup \cup-\cup-$
319
$\cup--\cup-\cup \cup \cup \cup \cup \cup-$
$\delta \|^{\mathrm{H}}$
$2 \delta$
320
321
$\cup \cup \cup-\cup-$
$\delta$
322
323
$\cup--\cup-\cup \cup \cup-\cup-$
$2 \delta$
$2 \delta$
$2 \delta \|^{\mathrm{Ha}}$
$\cup \cup \cup-\cup-\cup \cup \cup-\cup-$
$2 \delta$
324
$\cup \cup \cup-\cup-\cup \cup \cup-\cup-$
$2 \delta \int$
$\cup \cup \cup-\cup-\cup \cup \cup-\cup-$
$2 \delta \int$
326
327
328
$\cup----\cup \cup \cup---$
$2 \delta$
329
$\cup-----\cdots \cup$
$\delta$
2 ia $\int$
330
$\cup \cup \cup \cup \cup \cup \cup-\cup-$
$\cup \cup \cup \cup \cup \cup \cup-\cup \cup \cup \cup \cup \cup \cup \cup$
2 ia $+\mathrm{cr}$ 
$\sim$ antistrophe

332

333

334

335

336

337

338

$\cup \cup \cup-\cup \cup \cup-$

$\mathrm{sp}$

$\mathrm{cr}+\mathrm{cr}$

$\cup \cup \cup-\cup-$

$\cup--\cup-\cup \cup \cup-\cup-$

$\delta$

$2 \delta$

$\delta$

$2 \delta$

$\cup--\cup-\cup \cup \cup-\cup-$

$2 \delta$

339

340

$-\cup \cup-\cup--\cup \cup---$

$2 \delta \|^{\mathrm{H}}$

$2 \delta$

341

342

343

344

345

$\cup \cup \cup-\cup-\cup \cup \cup-\cup-$

$2 \delta$

$\cup \cup \cup-\cup-\cup \cup \cup-\cup-$

$2 \delta$

$\cup---\cup \cup \cup--$

$2 \delta \int$

$\cup-----\cup \cup \cup-$

$\cup--\cup-$

$\delta$

2 ia $\int$

346

$\cup \cup \cup \cup \cup-\cup-$

$2 \mathrm{ia}+\mathrm{cr}$

347

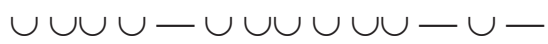

$\cup \cup \cup-\cup-\cup--\cup-$

$2 \delta$

Second Stasimon (Or. 807-843)

Strophe 1

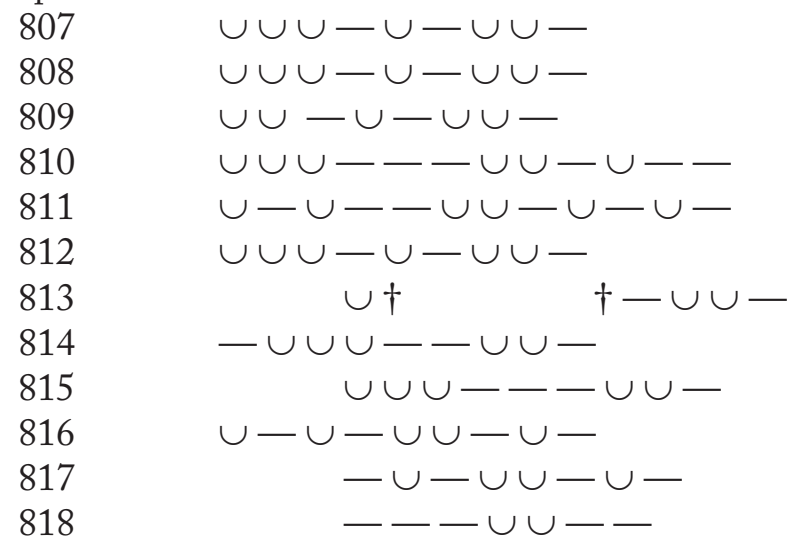

wil

wil wil

wil + ba ia $+\mathrm{ch}+\mathrm{ia}$ wil $\int$

wil

wil

$\cup \mathrm{gl} \int^{153}$

gl $\int$

ph

$\sim$ antistrophe

819

$\cup \cup \cup-\cup-\cup \cup-$

wil

820

$\cup \cup \cup-\cup-\cup \cup-$

wil

821

$\cup \cup \cup-\cup-\cup \cup-$

wil

${ }^{153}$ See above, p. 113. 


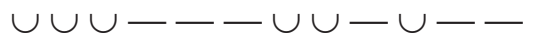

823

824

825

826

827

828

829

830

epode

831

832

833

834

835

836

837

838

839

840

841

842

843

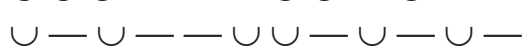

$\cup \cup \cup---\cup \cup-$

$\cup \cup \cup-\cup-\cup \cup-$

$-\cup \cup \cup--\cup \cup-$

$\cup \cup \cup---\cup \cup-$

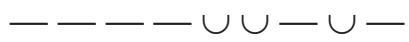

$-\cup-\cup \cup-\cup-$
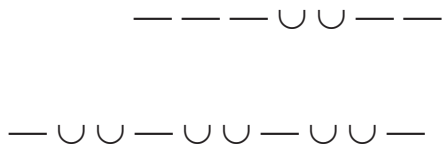

$\cup \cup \cup---\cup \cup-$

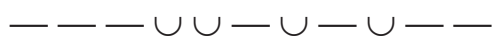

$-\cup--\cup \cup-$

$\cup---\cup \cup-$

$-\cup \cup \cup--\cup \cup-$

$\cup \cup \cup \cup--\cup \cup-$

$\cup \cup-\cup \cup--$

$-\cup \cup--\cup \cup-$

$\cup \cup \cup---\cup \cup-$

$-\cup \cup---\cup \cup-$

$\cup \cup \cup \cup \cup \cup-\cup \cup \cup-$

$-\cup \cup-\cup-$ wil + ba
ia $+\mathrm{ch}+\mathrm{ia}$
wil $\int$
wil
wil $\int$
wil
$-\mathrm{gl} \int$
$\mathrm{gl} \int$
$\mathrm{ph}$

$4 \mathrm{da}^{\text {cat }}$

wil

phal $\|^{\mathrm{H}}$

$\mathrm{cr}+\mathrm{ch}$

$\mathrm{ba}+\mathrm{ch}$

wil ia + ch reiz ||

$2 \mathrm{ch}$

wil

$4 \mathrm{da}^{\text {cat }}$

2 ia $\int_{154}$

ar

\section{Third Stasimon (Or. 960-981)}

Strophe

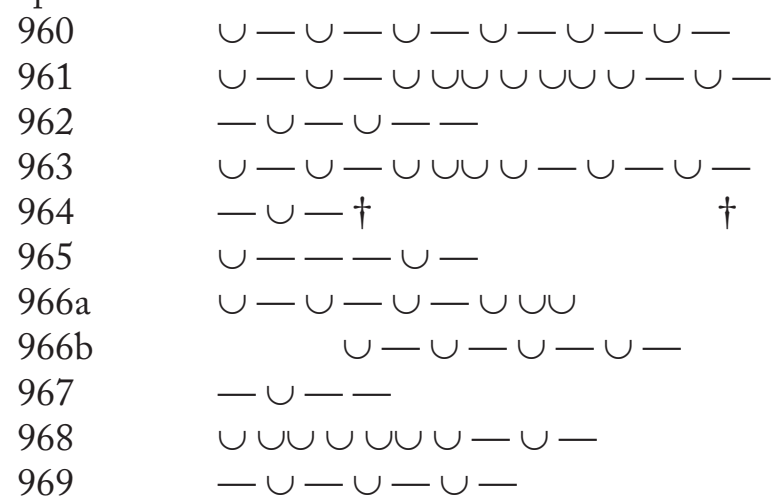

3 ia

3 ia ith $\mid$ $3 \mathrm{ia}$ $\mathrm{ba}+\mathrm{cr}$

2 ia

2 ia $\operatorname{tr} \|{ }^{\mathrm{Ha}}$ 2 ia $1 \mathrm{k}$

${ }^{154}$ See above, p. 119 (n. 259). 
970<smiles></smiles>
ia + ith

$\sim$ antistrophe

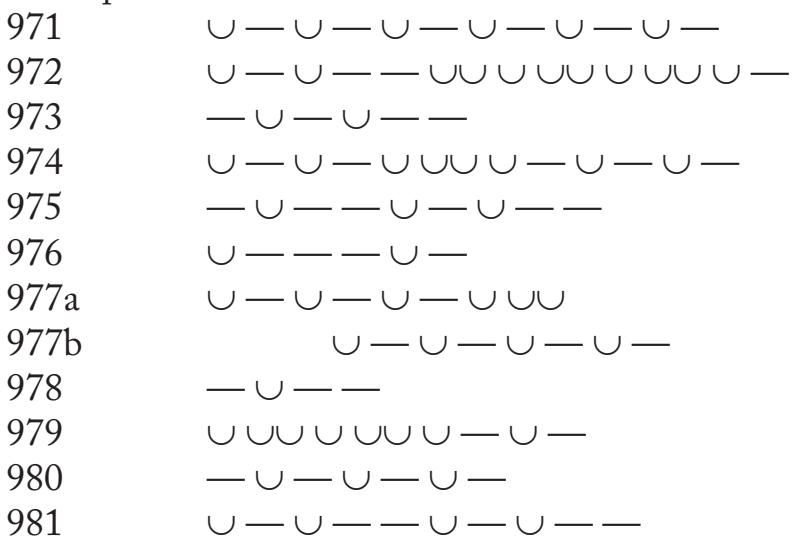

$$
\begin{array}{r}
3 \text { ia } \\
3 \text { ia } \\
\text { ith } \| \\
3 \text { ia } \\
\mathrm{cr}+\mathrm{ith} \| \\
\mathrm{ba}+\mathrm{cr} \\
2 \mathrm{ia} \int \\
2 \mathrm{ia} \\
\mathrm{tr} \| \mathrm{H} \\
2 \mathrm{ia} \\
1 \mathrm{k} \\
\mathrm{ia}+\mathrm{ith}
\end{array}
$$

\begin{tabular}{|c|c|c|}
\hline $982 \mathrm{a}$ & $\cup-\cup--\cup-$ & $\mathrm{ia}+\mathrm{cr}$ \\
\hline $982 b$ & $\cup-\cup-\cup \cup \cup \cup-$ & 2 ia \\
\hline $983 a$ & $---\cup-$ & $\mathrm{sp}+\mathrm{cr}$ \\
\hline $983 b$ & $\cup-\cup \cup \cup \cup-\cup-$ & 2 ia \\
\hline $984 a$ & $\cup \cup---\cap$ & $\mathrm{cr}+\operatorname{mol} \|^{\mathrm{B}}$ \\
\hline $984 b$ & $-\cup-\cup--$ & ith $\|^{\mathrm{H}}$ \\
\hline 985 & $\cup---\cup \cup \cup \cup--$ & $\mathrm{ba}+\mathrm{cr}+\mathrm{ba}$ \\
\hline 986 & $\cup-\cup \cup \cup \cup-\cup-$ & 2 ia $\|^{\mathrm{H}}$ \\
\hline 987 & $\cup \cup \cup \cup \cup \cup \cup \cup \cup \cup \cup \cup \cup-\cup-$ & \\
\hline 988 & $-\cup-\cup--$ & ith \\
\hline 989 & $\cup---\cup-\cup--$ & $\mathrm{ba}+\mathrm{cr}+\mathrm{ba}$ \\
\hline 990 & $\cup-\cup-\cup-\cup-$ & 2 \\
\hline $991 \mathrm{a}$ & $\cup-\cup \cup \cup \cup \cup \cup \cup \cup$ & 2 ia $\int$ \\
\hline $991 b$ & $\cup-\cup-\cup-\cup-$ & 2 ia \\
\hline 992 & $\cup-\cup-\cup--$ & $\mathrm{ia}+\mathrm{ba}$ \\
\hline 993 & $-\cup-\cup--\cup-\cup-$ & $\mathrm{h} \delta+\delta$ \\
\hline 994 & $-\cup-\cup-$ & \\
\hline 995 & $-\cup \cup \cup \cup--$ & $\mathrm{ia}+\mathrm{ba}$ \\
\hline 996 & $\cup-\cup-\cup-\cup-$ & 2 ia \\
\hline 997 & $-\cup-\cup-\cup-$ & $\mathrm{k}$ \\
\hline [998] & $\cup-\cup-\cup-\cup-\cup-\cup-$ & \\
\hline $999 a$ & $\cup-\cup-\cup-\cup \cup \cup$ & 2 ia $\int$ \\
\hline & $\dagger$ & ? \\
\hline & $\dagger$ & \\
\hline
\end{tabular}

\section{Electra's Monody (Or. 982-1011)}




\begin{tabular}{|c|c|c|}
\hline 1001 & $\cup \cup-\cup-\cup-\cup$ & $2 \operatorname{tr}$ \\
\hline 1002 & $-\cup-\cup \cup \cup \cup-\cup$ & \\
\hline 1003 & $-\cup-\cup-\cup-\cup$ & \\
\hline $1004 a$ & $\dagger$ & $1 \mathrm{k}$ \\
\hline $1004 b$ & $\dagger$ & reiz? $\|$ \\
\hline 1005 & $-\cup \cup-\cup \cup-\cup \cup-\cup \cup$ & \\
\hline 1006 & $-\cup \cup---\cup \cup--$ & 4 \\
\hline 1007 & $\dagger \quad t$ & $4 \mathrm{da}$ ? \\
\hline 1008 & $-\cup \cup-\cup \cup-\cup \cup--$ & \\
\hline 1009 & $-\cup \cup-\cup \cup-\cup \cup-\cup \cup$ & $4 \mathrm{~d}$ \\
\hline 1010 & $-\cup \cup-\cup \cup-\cup \cup-\cup \cup$ & \\
\hline & $-\cup \cup-\cup \cup-\cup \cup-\cup \cup$ & \\
\hline & $\cup-\cup \cup \cup \cup--$ & $\delta+$ \\
\hline
\end{tabular}

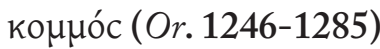

Strophe

$\mathrm{H} \lambda$.

$$
\begin{array}{ll}
1246 & \cup-\cup \cup-\cup \cup- \\
1247 & \cup-\cup \cup \cup \cup-\cup \cup \cup---
\end{array}
$$
$\mathrm{k} \delta+\delta$

Xo.

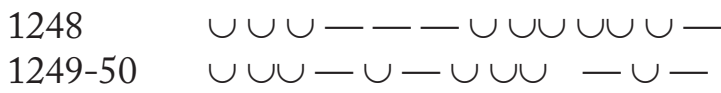
$\mathrm{H} \lambda$.

1251

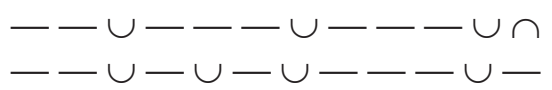

3 ia

3 ia

Xo.

1253

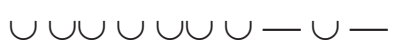

2 ia

1254

$\cup \cup \cup-\cup-$

$\mathrm{H} \lambda$.

1255

$\cup \cup \cup-\cup-\cup \cup \cup-\cup-$

$2 \delta$

1256

$\cup-\cup \cup-\cup \cup-\cup$

erasm

1257

$-\cup \cup-\cup \cup--$

ibyc chol

Xo.

$1258 \quad--\cup---\cup-\cup-\cup-$
$1259 \quad--\cup---\cup-\cup-\cup-$
$1260 \quad--\cup---\cup-\cup-\cup-$

3 ia

3 ia

3 ia

$\mathrm{H} \lambda$.

1261-2 $\cup \cup \cup-\cup-\cup \cup \cup-\cup-$ 
Part II - Scansions

Xo.

1263-4 $\cup-\cup-\cup-\cup \cup-\cup \cup-$

$1265 \cup \cup \cup-\cup-$

$\cup \mathrm{e} \cup \mathrm{D}$

$\delta$

$\sim$ antistrophe

$\mathrm{H} \lambda$.

1266

$\cup-\cup \cup-\cup \cup-$

$\cup \mathrm{D}$

1267

$\cup-\cup \cup \cup \cup--\cup \cup-\cup-$

$k \delta+\delta$

Xo.

1268-9

1270

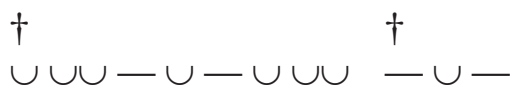

$\mathrm{H} \lambda$.

1271

$\cup-\cup-\cup-\cup-\cup-\cup-$

3 ia

1272

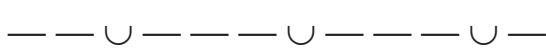

3 ia

Xo.

1273

$\cup \cup \cup \cup \cup-\cup-$

2 ia

1274

$\cup \cup \cup-\cup-$

$\delta$

$\mathrm{H} \lambda$.

1275

$\cup \cup \cup-\cup-\cup \cup \cup-\cup-$

$2 \delta$

1276

$\cup-\cup \cup-\cup \cup-\cup$

erasm

1277

$-\cup \cup-\cup \cup--$

ibyc $^{\text {chol }}$

Xo.

$1278 \cup \cup \cup---\cup-\cup-\cup-$

$1279-\leftarrow \cup--\cup \cup \cup-\cup-\cup$

$1280 \cup-\cup--\leftarrow \cup-\cup-\cup-$

3 ia $\| \mathrm{H}$

3 ia $\|^{\mathrm{H}}$

3 ia

$\mathrm{H} \lambda$.

1281-2 $\cup \cup \cup-\cup-\cup \cup \cup-\cup-$

$2 \delta$

Xo.

1283-4 $\cup-\cup-\cup-\cup \cup-\cup \cup-$

1285

$\cup \cup \cup--$

$\delta$

с $\propto ү \eta ́$ scene (Or. 1286-1310)

$\mathrm{H} \lambda$.

$\begin{array}{ll}1286 & --\cup---\cup-\cup-\cup- \\ 1287 & --\cup-\cup-\cup---\cup-\end{array}$

3 ia

3 ia

Xo.

1288-9

$\cup \cup \cup---\cup \cup \cup--$

1290-1

$\cup \cup \cup-\cup-\cup \cup \cup---$ 
$\mathrm{H} \lambda$.

$1292 \quad--\cup-\cup-\cup-\cup-\cup-\quad 3$ ia

$1293--\cup-\cup-\cup-\cup-\cup \cap \quad 3$ ia

Xo.

1294-5 $\cup-ー \cup--\cup--\cup--\quad 4$ ba

E入. $(\tilde{\varepsilon} c \omega \theta \varepsilon v)$

$1296 \quad \cup-\cup-\cup-\cup-\cup-\cup-$

3 ia

$\mathrm{H} \lambda$.

$1297 \quad--\cup---\cup-\cup-\cup-$
$1298-\cup \cup \cup-\cup-\cup-\cup-\cup$

3 ia

3 ia

Xo.

$1299-\cup \cup-\cup \cup-\cup \cup-\cup \cup$

$4 \mathrm{da}$

$1300-\cup \cup-\cup \cup-\cup \cup-\cup-$

prax

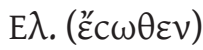

1301

$\cup \cup-\cup--\cup \cup \cup---\cup-$

3 ia

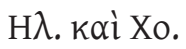

1302

$\cup-\cup \cup-\cup \cup-\cup$

1303

$-\cup \cup-\cup \cup-\cup \cup-\cup$

erasm

1304

$-\cup \cup-\cup \cup-$

ddd $\cup^{155}$

1305

- $\cup \cup \cup \cup \cup \cup \cup \cup \cup-\ldots$

$\mathrm{D}$

$2 \delta$

1306

$\cup \cup \cup-\cdots$

1307

$\cup \cup \cup \cup \cup \cup \cup \cup \cup \cup-$

$\delta$

1308-9

$\cup \cup \cup \cup \cup \cup \cup \cup \cup \cup-\cup-$

2 ia

$2 \delta$

1310

$\cup \cup \cup-\cup-\cup-\cdots-$

$2 \delta$

Strophic pair (Or. 1353-65 1537-49)

Strophe ( 1537-1549)

Xo.

$1353 \mathrm{a}$

$\cup \cup \cup-\cup-$

$1353 \mathrm{~b}$

$\cup \cup \cup-\cup-\cup--\cup-$

$\delta$

1354

$\cup \cup \cup-\cup-\cup--\cup-$

$2 \delta$

1355

$--\cup---\cup-\cup-\cup-$

3 ia

1356

$\cup-\cup---\cup-\cup-\cup-$

3 ia

1357

$\cup \cup \cup-\cup-\cup \cup \cup-\cup-$

$2 \delta$

1358

$\cup--\cup-\cup--\cup \cap$

$2 \delta \|\left.\right|^{\mathrm{B}}$

${ }^{155}$ See above, p. 74. 
1359

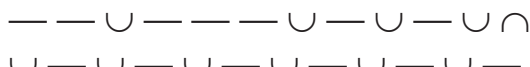

$\cup-\cup-\cup-\cup-\cup-\cup-$

$\cup \cup-\cup-\cup-$

$1 \mathrm{k}$

1362

$\cup \cup \cup \cup \cup-$

1363

$\cup \cup-\cup \cup-\cup \cup-\cup \cup-\cup$

1364

$\cup \cup \cup \cup \cup \cup \cup \cup--$

1365

$\cup \cup \cup-\cup-\cup--\cup-$

Phrygian's Monody (Or.1369-1502)
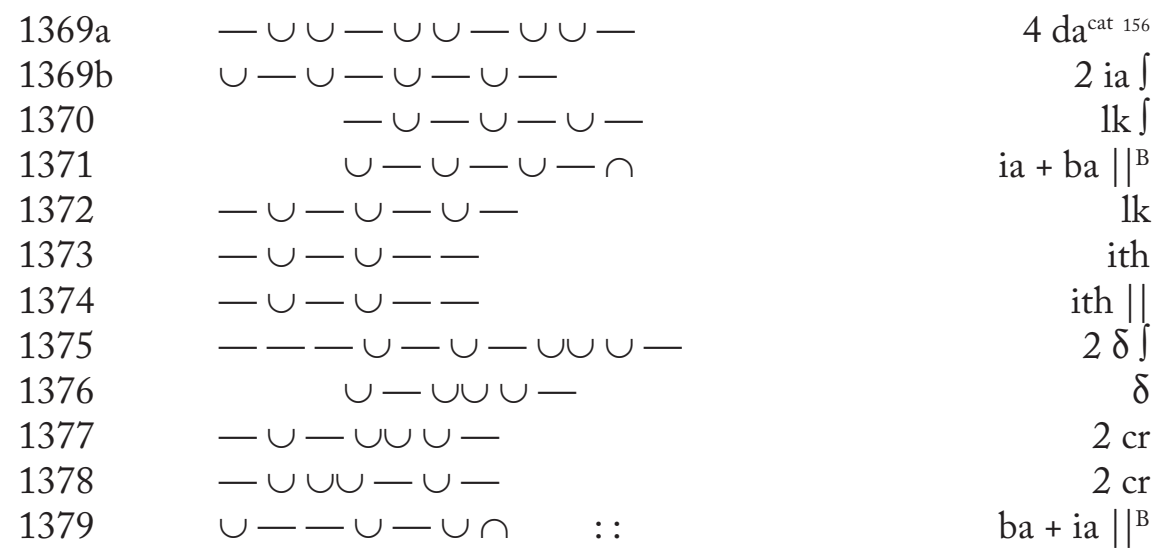

Xo.

1380

3 ia $\Phi \rho$.

1381

1382

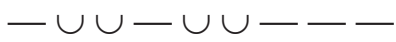

$4 \mathrm{da}^{\mathrm{cat}}$

1383

$-\cup \cup \cup \cup \cup-\cup \cup \cup-\cup-$

[1384]

$\cup \cup \cup-\cup--\cup-\cup-$

$\delta+h \delta \int$

1385

$-\cup-\cup-\dagger$

1386

1387

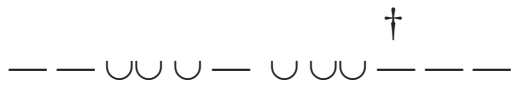

1388

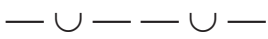

1389 a

$1389 \mathrm{~b}$

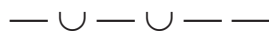

$2 \mathrm{cr}$

ith

cr $\|{ }^{\mathrm{H}}$

1390

$\cup \cup-$

2 ia

1391

$\cup-\cup-\cup-\cup-$

1392

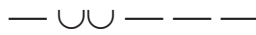

1395

$\cup \cup-\cup \cup-\cup \cup-\cup \cup$

$-\cup \cup-\cup \cup---$

$A \cup-\|$

${ }^{156}$ For this colon thus interpreted, see Diggle (1994: 386). 

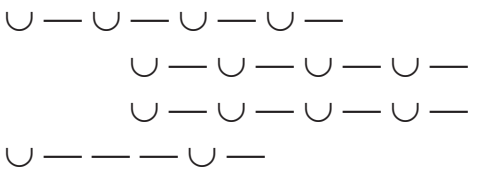

$\cup-\cup \cup \cup-\cup-$

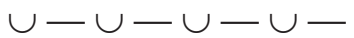

$\cup \cup \cup \cup \cup \cup \cup-$

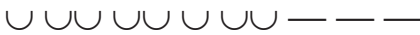

$\cup \cup \cup \cup \cup \cup \cup \cup$

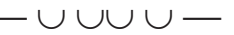

$\cup--\cup$
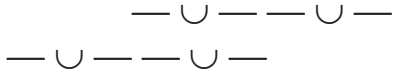

$-\cup--\cup$

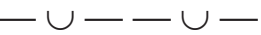

$-\cup--\cup-$
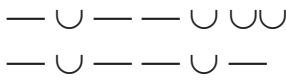

$\cup \cup-\cup \cup-\cup \cup-\cup \cup$

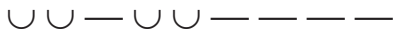

$\cup \cup-\cup \cup---\cup \cup-$

$\cup \cup-\cup \cup-\cup \cup--$ 


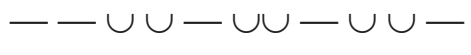

1435

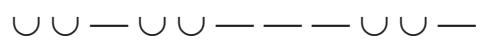

1436-7

1438

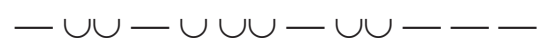

1439

$\cup--\cup-$

$\cup--\cup--\cup-$

$\cup--\cup-\leftarrow \cup-\leftarrow-$

1441

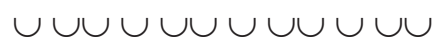

1442

$\cup---\cup-$

1443

$\cup--\cup-\cup-$

1444

1445

$\cup-\cup-\cup-\cup-$

$1446 \mathrm{a}$

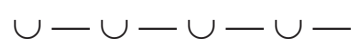

$1446 \mathrm{~b}$

1447

$1448 \mathrm{a}$

$1448 \mathrm{~b}$

1449

1450

1451

1452

$\cup \cup \cup-\cup-\cup-$

$1454 \mathrm{a}$

$1454 \mathrm{~b}$

1455

1456

$1457 \mathrm{a}$

$1457 \mathrm{~b}$

1458

$1459 \mathrm{a}$

$1459 \mathrm{~b}$

1460

1461

1462

1463

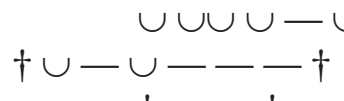

$\dagger \quad+$

$\cup--\cup-$
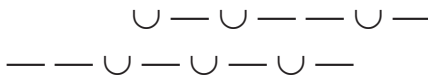

$\cup-\cup-\cup-\cup-$

$\cup-\smile \cup-\cup-$

$\cup-\cup---$

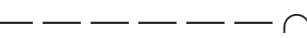

$-\cup \cup-\cup \cup---$

$\cup \cup-\cup \cup-\cup \cup-\cup \cup-$

$\cup \cup-\cup \cup-\cup \cup-\cup-\cup-$

$1464 \mathrm{a}$
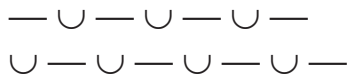

$1464 \mathrm{~b}$

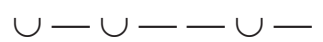

$\cup-\cup-\cup$

2 an

2 an

$2 \delta$

$2 \mathrm{ba}$

3 ba

$4 \mathrm{ba}$

2 ia $\mathrm{ba}+\mathrm{cr} \|$ $\mathrm{ba}+\mathrm{cr} \|$

2 ia

2 ia $\int$

2 ia

$\mathrm{ia}+\mathrm{sp}$

$\mathrm{ba}+\mathrm{cr} \int$

$\mathrm{ia}+\mathrm{cr}$

2 ia

2 ia

$\mathrm{ba}+\mathrm{cr}$

$\mathrm{ia}+\mathrm{sp}$

prm \|\|$^{\mathrm{B}}$

prm

2 an

enop ${ }^{157}$

$1 \mathrm{k}$

2 ia $\int$

$\mathrm{ia}+\mathrm{cr} \int$

$\mathrm{k} \delta$

$\mathrm{ba}+\mathrm{ia} \|^{\mathrm{H}}$

$1 \mathrm{k}$

2 ia $\int$

2 ia + cr $\|$

2 ia

$\mathrm{ba}+\mathrm{cr}$

$\mathrm{ba}+\mathrm{cr} \|^{\mathrm{B}}$

$5 \mathrm{da}^{\text {cat }} \| 158$

1465

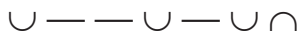

$-\cup \cup-\cup ル \cup \cup---$

${ }^{157}$ This colon is found elsewhere only at Herc. 883b.

${ }^{158} \mathrm{On}$ this colon thus interpreted see Diggle 1994: 390. 


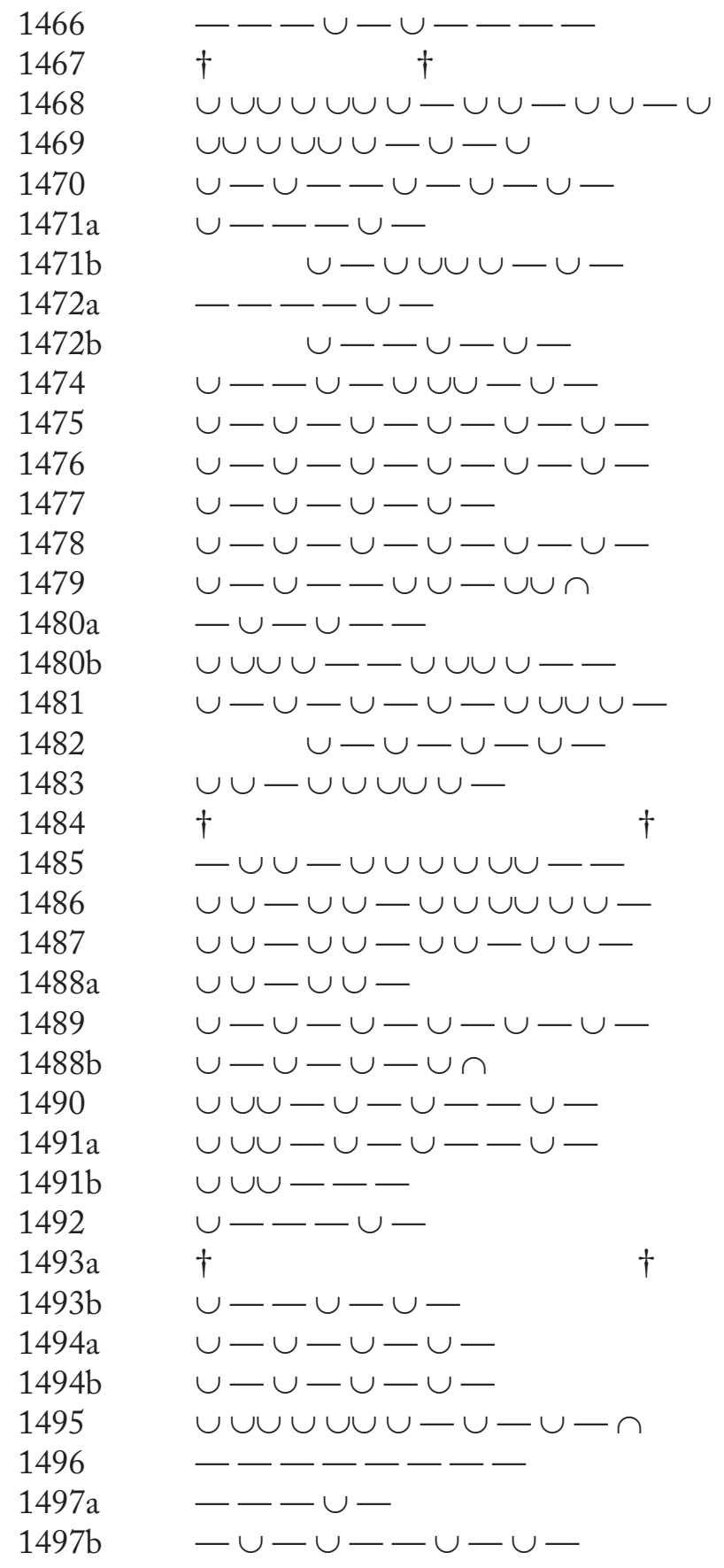

${ }^{159}$ See Parker (1990: 333). 
Part II - Scansions

1498

$\cup-\cup-\cup-\cup-\cup-\cup-$

3 ia

1499

$\cup-\cup-\cup-\cup \cap$

1500

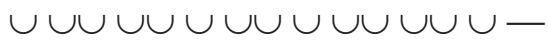

2 ia \|\|$^{\mathrm{B}}$

1501

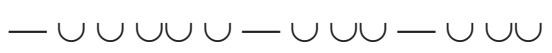

$2 \delta$

1502

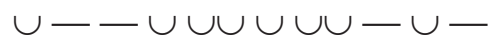

$2 \delta \int$

$2 \delta$

$\sim$ antistrophe $(\sim 1353-1365)$

Xo.

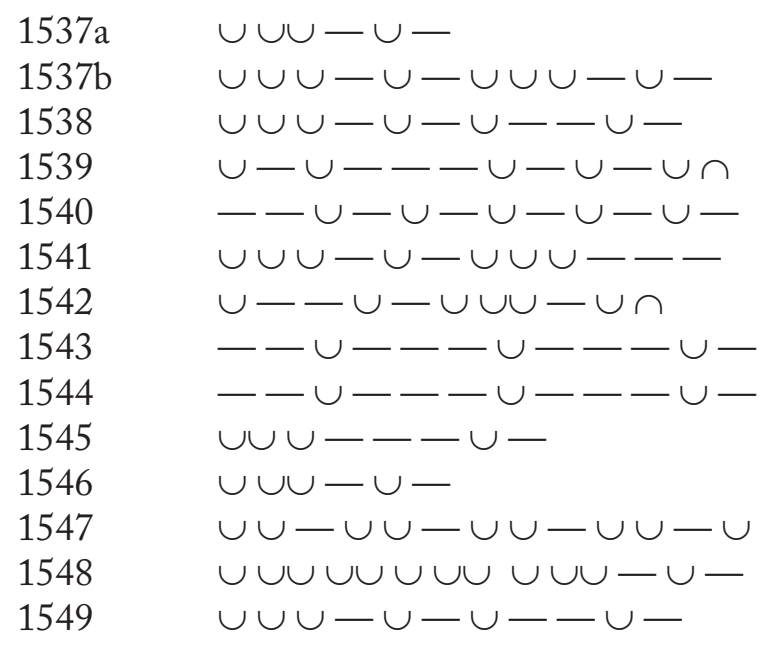

$\delta \|^{\mathrm{H}}$
$2 \delta$
$2 \delta$
$3 \mathrm{ia} \|$
$3 \mathrm{ia} \|\left.\right|^{\mathrm{H}}$
$2 \delta$
$2 \delta \|^{\mathrm{B}}$
$3 \mathrm{ia}$
$3 \mathrm{ia}$
$1 \mathrm{k}^{160}$
$\delta$
$\mathrm{A} \cup$
$2 \delta$
$2 \delta$

${ }^{160}$ See Diggle (1994: 341). 


\section{BACCHAE}

\section{Parodos (Ba. 64-169)}

64

$\cup \cup-\cup \cup-$

2 io $^{\text {cat }}$

65

$\cup \cup--\cup \cup--\cup \cup-$

3 io

66

$\cup \cup-\cup \cup-$

2 io ${ }^{\text {cat }}$

$67 \mathrm{a}$

$\cup \cup--\cup \cup-$

2 io $\int$

$67 \mathrm{~b}$

$\cup \cup--\cup \cup-$

68

$\cup \cup-\cup \cup-$

2 io $^{\text {cat }}$

2 io $^{\text {cat }}$

69

$\cup \cup--\cup \cup-$

2 io

70

$\cup \cup--\cup \cup--\cup \cup-$

3 io

71

$\cup \cup--\cup \cup--$

2 io

72

$\cup \cup-\cup \cup-$

2 io $^{\text {cat }}$

Strophe 1

73

73-4

$-\cup \cup-\cup--$

74

75

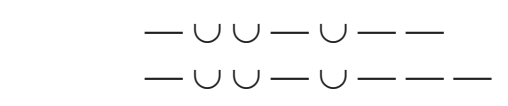

$-\cup \cup-\cup--$

76

77

78

79

80

81

82

83

84

$-\cup \cup-\cup--$

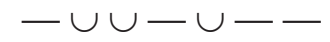

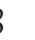

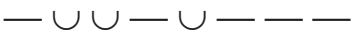

85

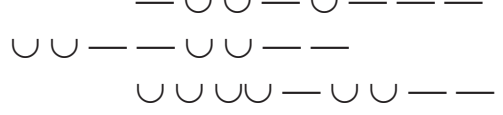

$\cup \cup--\cup \cup--$

86-7

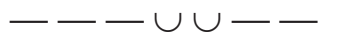

$\cup \cup--\cup \cup-$

88

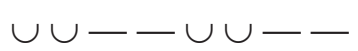

$\cup \cup--\cup \cup--$

$\cup \cup--\cup \cup-$

$\cup \cup--\cup \cup--\cup \cup-$

$\cup \cup-\cup---\cup \cup \cap$

$\operatorname{ar} \int$
$\operatorname{ar} \int$
$\operatorname{ar}-\int$
$\operatorname{ar} \int$
$\operatorname{ar} \int$
2 io $\int$
2 io
2 io
2 io
2 io
2 io
2 io
3 io $\int$
3 io ${ }^{\text {cat }}$

$\sim$ antistrophe 1

89

89-90

$-\cup \cup-\cup-$

90

$-\cup \cup-\cup-$

$\operatorname{ar} \int$

$\operatorname{ar} \int$

91

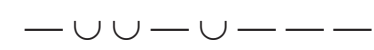

$-\cup \cup-\cup--$

$\operatorname{ar}-$ 
Part II - Scansions

92
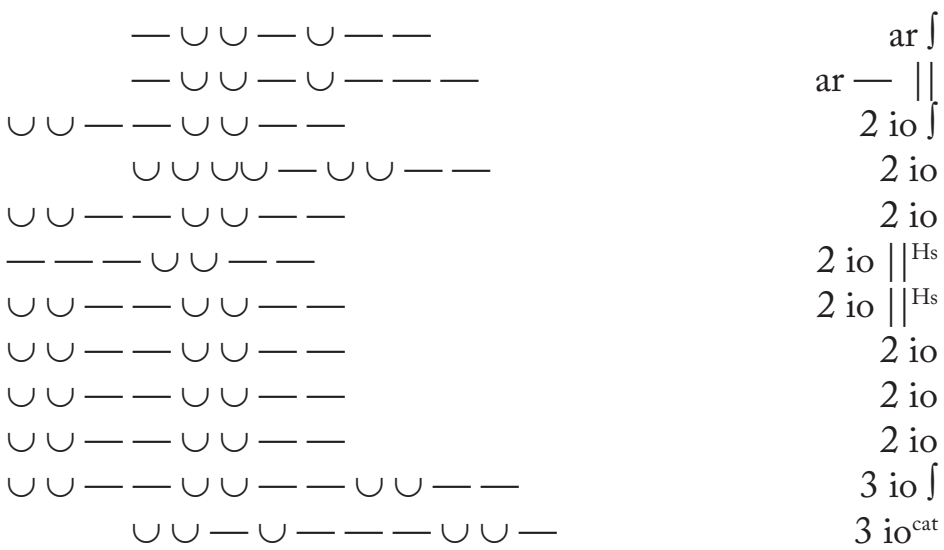

Strophe 2

105

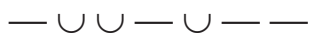

$\operatorname{ar} \int 161$

106

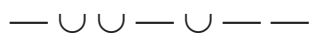

107

$\cup \cup \cup \cup \cup \cup-$

$\mathrm{ia}+\mathrm{ba}^{162}{ }^{\mathrm{ar}}$

108

$-\cup \cup-\cup--$

ar

109

$-\cup \cup-\cup-\cup \cup \cup$

$c h+i a$

110

111

112

113

$-\cup \cup-\cup--$

ar

gl

aeolic colon ${ }^{163}$

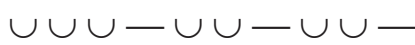

3 io

114

115

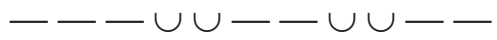

3 io

116

$\cup \cup--\cup \cup--\cup \cup-$

aeolic colon

$\cup \cup \cup-\cup \cup-\cup \cup-$

$4 \mathrm{da} \wedge$

117

$-\cup \cup-\cup \cup-\cup \cup-$

$2 \mathrm{da}$

118

$-\cup \cup-\cup \cup$

gl

119

$\cup-\leftarrow \cup \cup \cup-$

ph

$\sim$ antistrophe 2

120

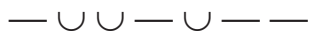

$\operatorname{ar} \int$

121

122

$-\cup \cup-\cup-$

123

124

$\circlearrowleft \cup \cup \cup \cup-$

$\mathrm{ia}+\mathrm{ba} \|^{\mathrm{Ha}}$

ar
ar

ch + ia

125

$-\cup \cup-\cup-\cup \cup \cup$

ar

126

$-\cup \cup-\cup--$

gl

${ }^{161}$ See above, p. 106.

${ }^{162}$ See Diggle (1994: 470).

${ }^{163}$ See Parker (1997: 199 and 450), who favours the label 'aeolic dactyls'. 
aeolic colon
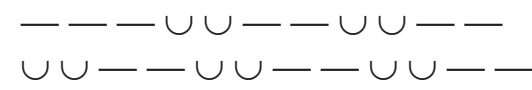

epode

135

136

137

138

139

140

141

142

143

144

145

146

147

$148 \mathrm{a}$

$148 \mathrm{~b}$

149

150

151

152

153

154

155

156

$157-8$

159

160

161-2

163-4

165-6

167-9

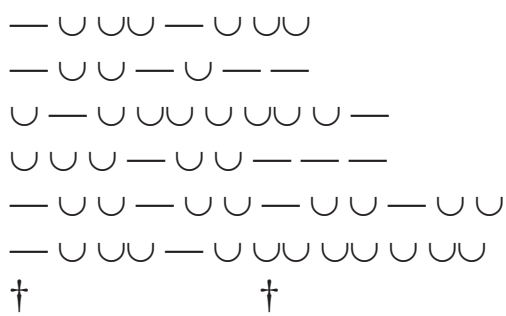

$2 \mathrm{cr}$

ar

2 ia

g1

$4 \mathrm{da}$

$3 \mathrm{cr}$ ?

e. $\mathrm{m}$

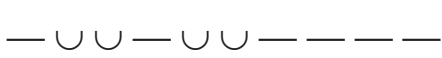

$4 \mathrm{da}$

$-\cup \cup---\cup \cap$

$\cup \cup--\cup \cup--$

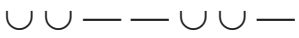

$---\cup \cup--$

$---\cup \cup--$

$\cup--\cup--$

$\cup--\cup \cup-$

$\cup \cup-\cup \cup--$

$\cup \cup-\cup \cup \cup \cup--\cup \cup-\frac{-}{\dagger}$

$-\cup \cup--$

$-\cup \cup-$

$\mathrm{ch}+$ ia $\|^{\mathrm{B}}$

2 io $\int$

2 io

2 io

2 io

2 ba

$\wedge 2$ io

2 io $\wedge$

3 io

ad $\|^{\mathrm{H}}$

ad ||

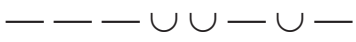

$-\cup \cup-\cup \cup-\cdots$

$\cup \cup \cup-\cup \cup-\cup-$

$-\cup \cup \cup-\cup \cup \cup-\cup \cup-\cup \cup$

$-\cup \cup-\cup \cup-\cup \cup-\cup \cup$

$-\cup \cup U \cup \cup$

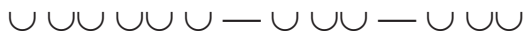

$\mathrm{D}-$

$\mathrm{g} 1$

$\mathrm{cr}+3 \mathrm{da}$ ?

$4 \mathrm{da}$

$2 \mathrm{cr}$

$2 \delta$

$4 \mathrm{da} \int$

$4 \mathrm{da}$

$6 \mathrm{da}$ 
First Stasimon (Ba.370-433)

Strophe 1

370

371

372

373

374

375

376

377

378

379

380

381

382

383

384

385

$\sim$ antistrophe 1

386

387

388

389

390

391

392

393

394

395

396

397

398

399

400

401

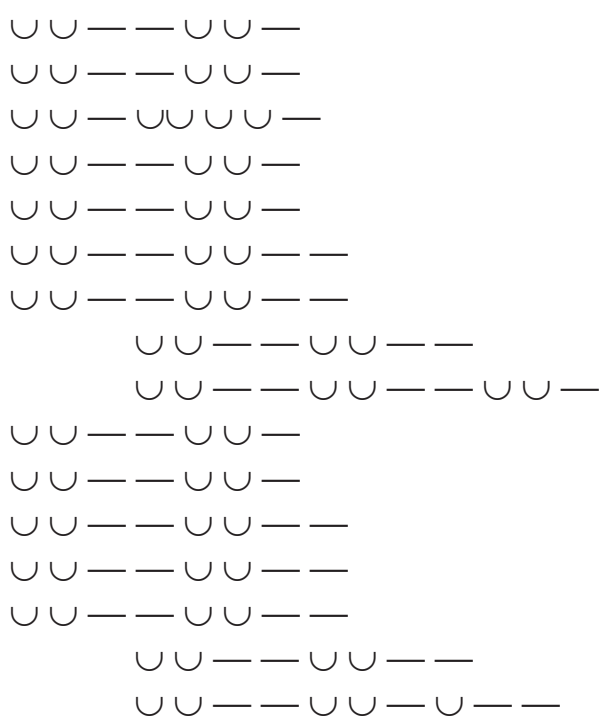

$\cup \cup--\cup \cup-$

$\cup \cup--\cup \cup-$

$\cup \cup--\cup \cup-$

$\cup \cup--\cup \cup-$

$\cup \cup--\cup \cup-$

$\cup \cup--\cup \cup-$

$\cup \cup--\cup \cup-$

$\cup \cup--\cup \cup--$

$\cup \cup--\cup \cup--\cup \cup-$

$\cup \cup-\leftarrow \cup \cup$

$\cup \cup--\cup \cup-$

$\cup \cup--\cup \cup--$

$\cup \cup-\cup U \cup \cup--$

$\cup \cup--\cup \cup-$

$\cup \cup--\cup \cup--$

$\cup \cup--\cup \cup-\cup-$
2 io $^{\text {cat }}$

2 io $^{\text {cat }}$

2 io $^{\text {cat }} \|^{\mathrm{Ha}}$

2 io $^{\text {cat }}$

2 io $^{\text {cat }}$

2 io

2 io $\int$

2 io $\int$

3 io $^{\text {cat }}$

2 io $^{\text {cat }}$

2 io $^{\text {cat }}$

2 io

2 io

2 io $\int$

2 io $\int$

3 io $^{\text {cat }}$

2 io $^{\text {cat }}$

2 io $^{\text {cat }}$

2 io $^{\text {cat }} \|^{\mathrm{H}}$

2 io $^{\text {cat }}$

2 io $^{\text {cat }}$

2 io

2 io

2 io $\int$

3 io $^{\text {cat }}$

2 io $^{\text {cat }}$

2 io $^{\text {cat }}$

2 io

2 io

2 io

2 io

3 io ${ }^{\text {cat }}$

ph $\mid$

ph II gl I

ph ||

g1 
407

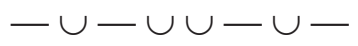

408

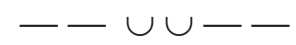

409

410

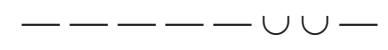

411

412

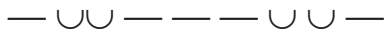

413

$\cup-\cup \cup \cup \cup \cup \cup \cup \cup \cup$

414-5

$\cup--\cup \cup-\cap$

416

$\cup-\cup \cup \cup \cup-\cup \cup \cup \cup-\cup-$

gl

ph $\|{ }^{\mathrm{H}}$

wil

wil

ph $\mid{ }^{\mathrm{H}}$

2 ia ph $\|^{\mathrm{B}}$

3 ia $\int$

ar

$\sim$ antistrophe 2

417

$\cup--\cup \cup--$

418

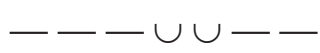

419

$\cup--\cup \cup-\cup-$

420

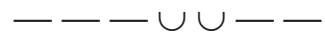

421

422

$\cup--\cup \cup-\cup-$

423

$-\cup-\cup \cup-\cup-$

424

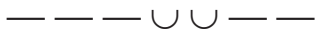

425

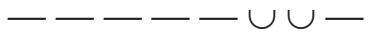

ph | $\mathrm{ph}$ glf $\mathrm{ph}$ g1 $\stackrel{\mathrm{g} 1}{\mathrm{H}}$ wil wil

426

$427-8$

429

$\cup \cup \cup--\cup \cup-$ ph $\|^{\mathrm{H}}$

$$
\dagger
$$

430-1

$\cup--\cup \cup--\dagger$

432-3

$\cup-\cup \cup \cup \cup-\cup \cup \cup \cup \cup \cup \cup-$

\section{Second Stasimon (Ba.519-575)}

Strophe 1

519

$\cup \cup--\cup \cup-$

2 io $^{\text {cat }}$

520

$\cup \cup--\cup \cup-\cdots$

2 io

521

$\cup \cup--\cup \cup--$

2 io

522

$\cup \cup-\cup \cup \cup \cup \cap$

523

$\cup \cup--\cup \cup--\cup \cup-$

524-5

$\cup \cup--\cup \cup-\cup \cup \cup \cup--$

526

$\cup \cup-\cup-\cup-\cdots$

527

$\cup \cup-\cup-\cup-\cdots$

528

529

530

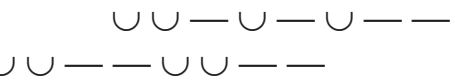

$\cup \cup--\cup \cup-$

2 io ${ }^{\text {cat }} \mid \|^{\mathrm{B}}$

3 io

3 io

anacr $\int$

anacr $\|$

2 io

2 io

anacr

531

$\cup \cup-\cup-\cup-\cdots$

anacr

532

$\cup \cup-\cup-\cup--$

anacr 
Part II - Scansions

533

$\cup \cup--\cup \cup--$

2 io

534

$\cup \cup--\cup \cup--$

2 io

535

$\cup \cup--\cup \cup-\cdots$

2 io

536

$\cup \cup-\backsim \cup \cup \cup-$

3 io $^{\text {cat }}$

$\sim$ antistrophe 1

[537]

538

$\cup \cup--\cup \cup-$

2 io $^{\text {cat }}$

539

$\cup \cup--\cup \cup--$

2 io

540

$\cup \cup--\cup \cup-$

541

$\cup \cup--\cup \cup \cap$

2 io

542

$\cup \cup--\cup \cup--\cup \cup-$

543-4

$\cup \cup--\cup \cup-\cup \cup \cup \cup-$

545

546

547

548

549

550

$\cup \cup-\cup-\cup-\cdots$

$\cup \cup-\cup-\cup--$

551

552

553

554

555

$\cup \cup--\cup \cup-\longrightarrow$

$\cup \cup--\cup \cup--$

2 io $^{\text {cat }}||^{\mathrm{B}}$

3 io

3 io

anacr

anacr |

2 io

2 io

anacr

anacr

anacr

2 io

2 io

2 io

3 io $^{\text {cat }}$

epode

556

557

558

559

560

561-2

$\cup \cup--\cup \cup--$

$\cup \cup--\cup$

2 io

2 io $^{\text {cat }}$

2 io

2 io $^{\text {cat }}$

3 io

3 io

2 io

563

564

$\cup \cup--\cup \cup--$

2 io $\|$

2 io $^{\text {cat }}$

2 io

$566 \quad \cup \cup--\cup \cup-$

2 io $\int$

567

$\cup \cup--\cup \cup--$

2 io $^{\text {cat }}$

569

$\cup \cup--\cup \cup-$

2 io $\int$

570

$\cup \cup--\cup \cup--$

2 io 
571-2

573

574

575

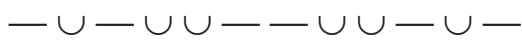

$-\cup \cup-\cup \cup \cup \cup U$

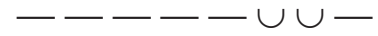

$---\cup \cup--$ 'asclepiad' 164 $\mathrm{ch}+\mathrm{ia}^{165}$ wil ph

\section{Lyric scene ( $B a .576-603)$}

$\Delta \mathrm{l}$.

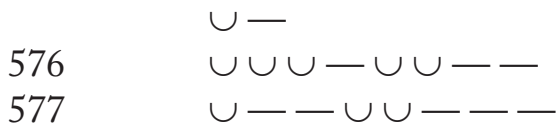

e. m.

ph

g1

Xo.

578

$\circlearrowleft \cup-\cup \cup \cup \cup$

$1 \mathrm{k}$

579

$\cup \cup \cup \cup-\cup-$

$\Delta \mathrm{l}$.

580

$\cup \cup \cup-\cup \cup-$

581

$\cup \cup \cup-\cup \cup-$

$\mathrm{ph} \| \mathrm{H}$ ph

Xo.

582

$\cup \cup--\cup \cup-\cup U$

$\mathrm{cr}+2 \mathrm{da}$

583

$\circlearrowleft \cup-\cup \cup$

584

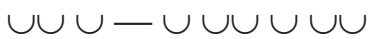

2 cr (cf. 590)

$1 \mathrm{k} \|$

$\Delta 1$.

585

$-\cup \cup-\cup \cup-\cup \cup-\cup \cup$

$4 \mathrm{da}$

Xo.

586

587

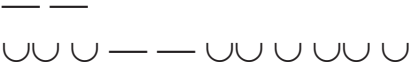

$2 \operatorname{tr} \int$

588 $-\cup-\cup-\cup \cap$

589

590

$\cup \cup-\cup \cup \cup \cup$ $1 \mathrm{k} \|{ }^{\mathrm{B}}$

$1 \mathrm{k} \|$

$2 \mathrm{cr}$

$591-\cup \cup-\cup \cup-\cup \cup-\cup \cup$ $4 \mathrm{da}$

592

$\cup \cup \cup \cup \cup \cup \cup \cup \cup \cup \cup$

$2 \operatorname{tr} \int$

593

$-\cup-\cup-\cup-$

$1 \mathrm{k} \|{ }^{\mathrm{H}}$

$\Delta \mathrm{l}$.

595

$-\cup \cup-\cup \cup-\cup \cup-\cup \cup$

$4 \mathrm{da}$

Xo.

596

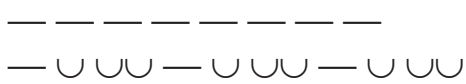

$4 \mathrm{da}$

597

${ }^{164}$ So Seaford (comm. Ba., p. 194).

165 See Diggle (1995: 40). 
Part II - Scansions

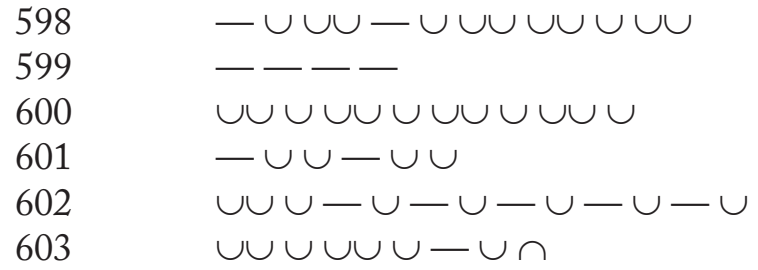

$3 \mathrm{cr}$ $2 \mathrm{sp}$ 2 tr $2 \mathrm{da}$ $3 \operatorname{tr}$ $1 \mathrm{k} \|$

Third Stasimon (Ba.862-912)

Strophe 1

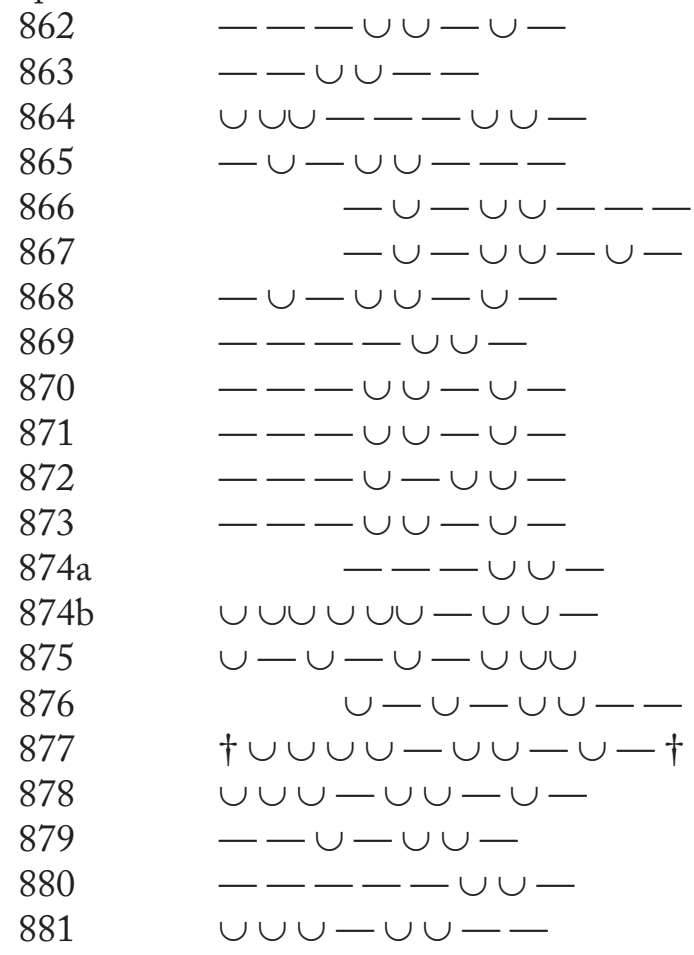

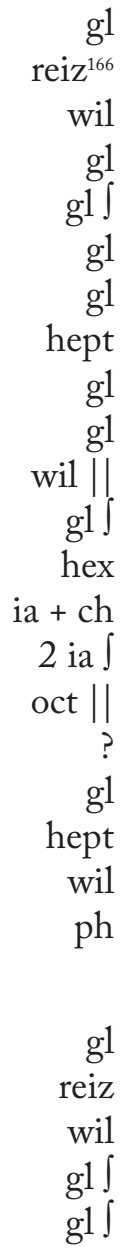

antistrophe 1

882

883

884

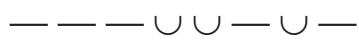

885

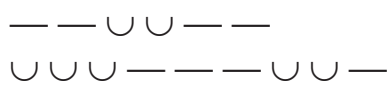

886

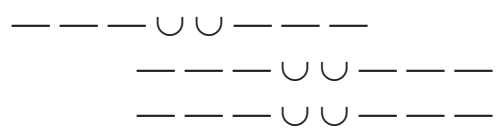
887

${ }^{166}$ See above, p. 107. 


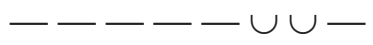

epode

902

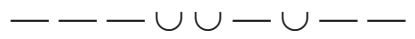

903

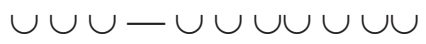

904

905

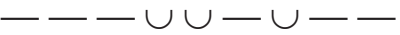

906

$\cup \cup \cup \cup \cup \cup \cup \cup \cup$

907

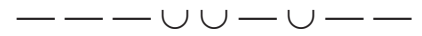

908

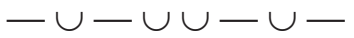

909

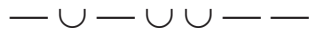

910

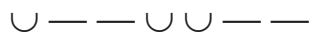

911

$\cup--\cup \cup--$

912

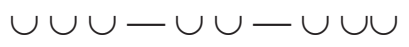

$\operatorname{hipp}^{167}$ gl168

hipp 2 ia hipp || gl ph ph ph ||

\section{Fourth Stasimon (Ba.977-1023)}

Strophe 1

977

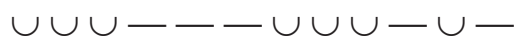

978

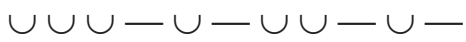

979

$\cup-\backsim \cup \cup$

980

$\cup \cup \cup-\cup-\cup--\cup-$ 


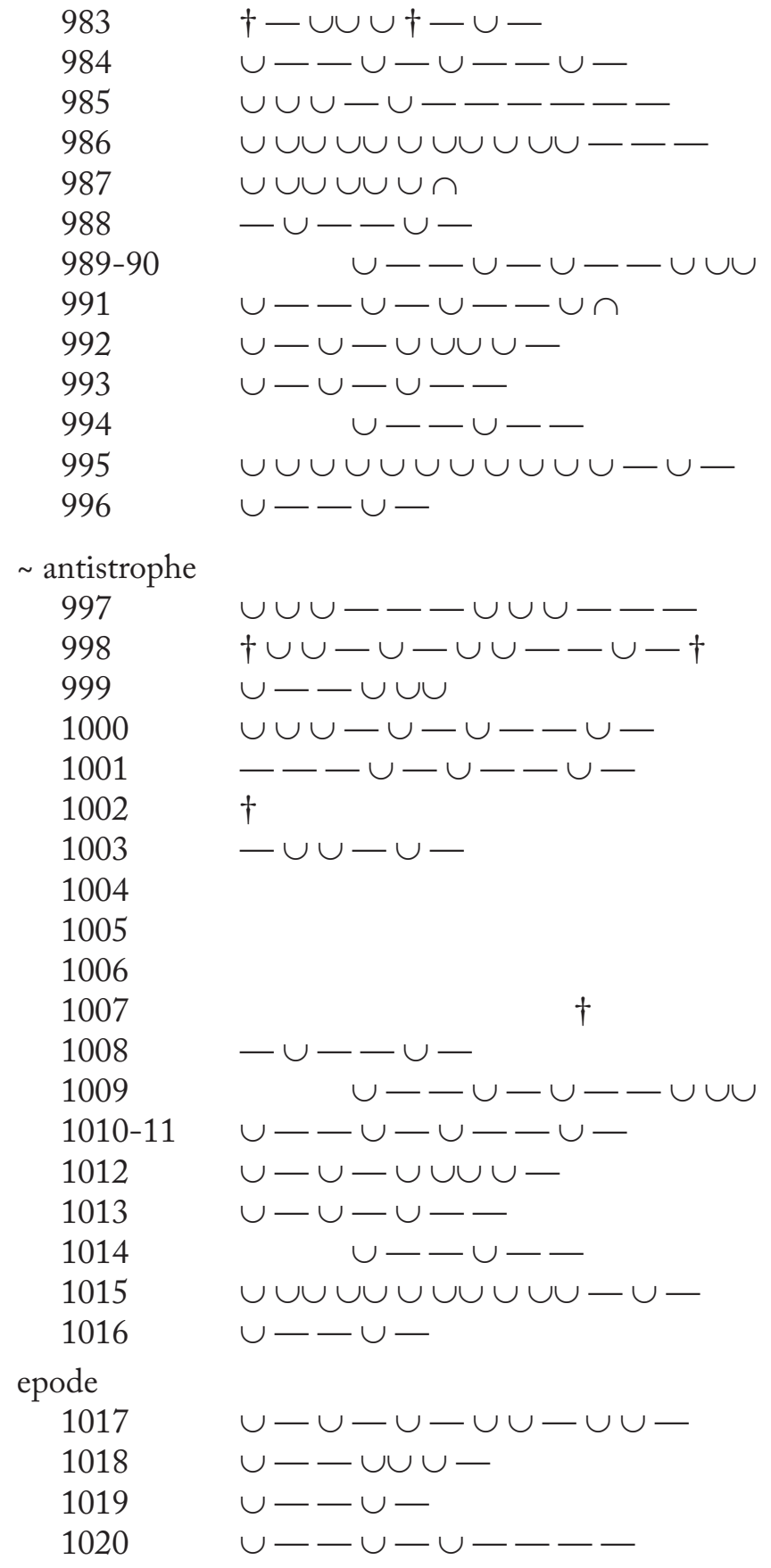

$\mathrm{k} \delta$ ?

$2 \delta$

$2 \delta$

$2 \delta$

$\delta \|^{\mathrm{B}}$

$2 \mathrm{cr}$

$2 \delta$

$2 \delta \|^{\mathrm{B}}$

2 ia

ia + ba $\int^{169}$

2 ba

$2 \delta$

$\delta$

$2 \delta$

?

$\delta$

$2 \delta$

$2 \delta$

?

?

?

?

?

2 cr $\int$

$2 \delta$

$2 \delta \|$

2 ia ia + ba $\int$

$2 \mathrm{ba}$

$2 \delta$

$\delta$

$\cup$ e $\cup \mathrm{D}$

$\mathrm{ba}+\mathrm{cr}$

$\delta \|$

$2 \delta$

${ }^{169}$ See above, p. 121 (n. 268). 
Ba. 1034-1038

Xo.

1034

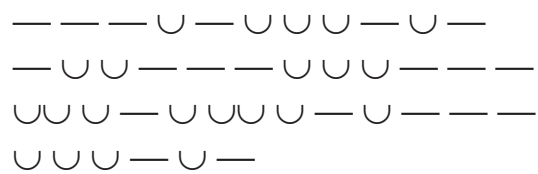

Ba. 1153-1164

Xo.

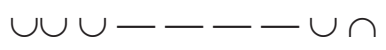

1155

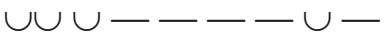

$\mathrm{cr}+\delta \|^{\mathrm{B}}$ $\mathrm{cr}+\mathrm{d}$

1156

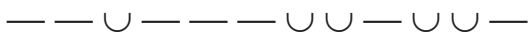

- e - D $\|^{\mathrm{H}}$

1157

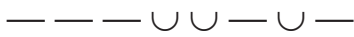

\section{Lyric scene (Ba.1168-1199)}

Strophe

Aү.

$1168 \quad \cup \cup \cup-\longrightarrow-:: \cup \cup \cup-\cup-$

Aү. 
Part II - Scansions

Xo.

1172

$\cup--\cup-\cup---\cap$

$2 \delta \|:$ :

Aү.

1173

$\cup-\cup-\cup-\cup$

2 ia

1174

$<\quad>\cup \cup-\cup$

1175

$-\cup-\cup \cap$

h $\delta \|$

Xo.

1176

$\cup \cup \cup-\cup-$

$\delta$

Aү.

1177

$\cup-\leftarrow:: \cup-\longrightarrow$

$2 \mathrm{ba}$

Aү.

1178

$\cup \cup \cup-\cup-$

Xo.

$\begin{array}{ll}1179 & \cup-\cup-\cup:: \cup \cup-\cup \cup- \\ 1180 & \cup-\cup-\leftarrow-\cup \cup-\cup \cup-\end{array}$

$\cup$ e $\cup \mathrm{D}$

$\cup$ e $\cup \mathrm{D}$

Xo.

1181

$\cup--:: \cup--$

$2 \mathrm{ba}$

Xo.

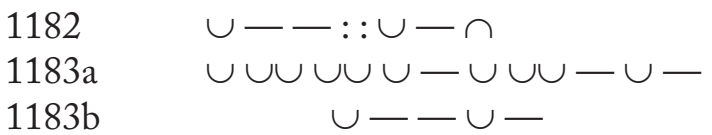

$\sim$ antistrophe

Aү.

1184

$\cup \cup \cup---:: \cup \cup \cup-\cup-$

Aү.

1185

$\cup \cup \cup-\cup-$

$\delta \int$

1186

$\cup \cup \cup \cup \cup \cup \cup \cup \cup \cup \cup$

2 ia

1187

$\cup \cup \cup--$

Xo.

1188<smiles>[V]=[V]=[Hg]</smiles>

$2 \delta \|^{\mathrm{H}}:$ :

Aү.

1189

$\cup-\cup-\cup-\cup-$

2 ia

1190

$\cup-\cup-\cup \cup-\cup \cup-\cup$

1191

$-\cup-\cup \cap$

enop $^{171}$

h $\delta \|^{B}$

Xo.

1192

$\cup \cup \cup-\cup-$

${ }^{171}$ Cf. Med. 207, Ph. 128 and above, p. 78. 
Aү.

1193

$\cup--:: \cup-\longrightarrow$

$2 \mathrm{ba}$

Aү.

1194

$\cup \cup \cup---$

Xo.

1195

$--\cup--::-\cup \cup-\cup \cup-$

$-\mathrm{e}-\mathrm{D}$

1196

$\cup-\cup---\cup \cup-\cup \cup-$

$\cup \mathrm{e}-\mathrm{D}$

Xo.

1197

$\cup--:: \cup--$

$2 \mathrm{ba}$

Xo.

1198

$\cup--:: \cup-\cap$

2 ba $\|^{\mathrm{B}}$

$1199 \mathrm{a}$

$\cup \cup \cup \cup \cup \cup-\cup \cup \cup-\cup-$

$2 \delta$

$1199 b$

$\cup--\cup-$ $\delta$ 


\section{IpHigenia in Aulide}

Agamemnon's lyric anapaests ( $L A$ 115-137)

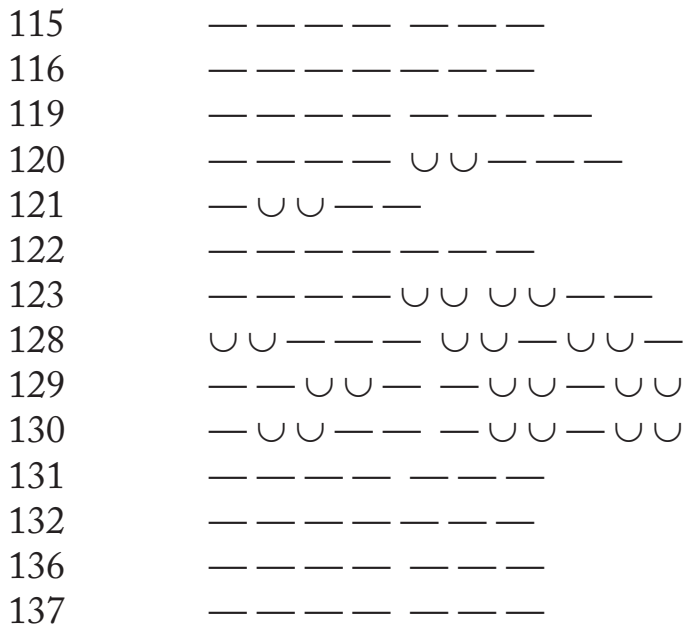

Parodos (LA 164-302)

Strophe 1

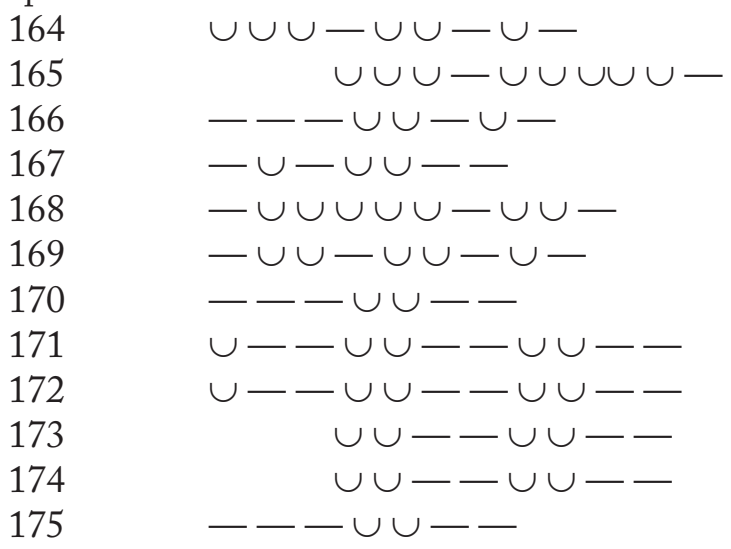

${ }^{172}$ See Itsumi (1982: 63, 68).

${ }^{173}$ See above, p. 95. 


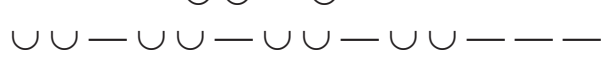

178

$\cup \cup-\cup \cup-\cup-$

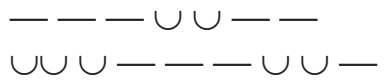

$\sim$ antistrophe 1

185

186

187

188

189

190

191

192

193

194

195

196

197

198

199

200

201

202

203

204

205 $\cup \cup \cup-\cup \cup-\cup-$

$\cup \cup \cup-\cup \cup \cup U \cup-$

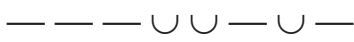

$-\cup-\cup \cup-$

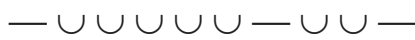

$-\cup \cup-\cup \cup-\cup-$

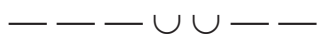

$\cup--\cup \cup--\cup \cup-$

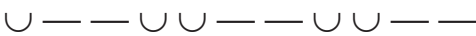

$\cup \cup-\leftarrow \cup \cup-$
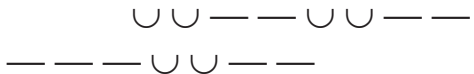

$-\cup \cup-\cup-$

$\cup \cup-\cup \cup-\cup \cup-\cup \cup--$

$\cup \cup-\cup \cup-\cup-$

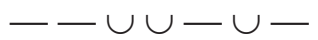

$\cup \cup \cup-\cup \cup-\cup \cup$

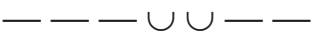

$\circlearrowleft \cup---\cup \cup$

$--\cup \cup \cup \cup$

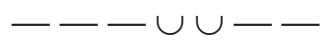

epode

206

207

208
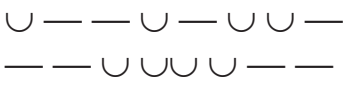

$\cup-\cup-\cup \cup-$ gl $\int$

gl

$\mathrm{ph} \| \mathrm{H}$

gl

?

ibyc

ph $\|$

3 io

3 io

2 io $\int$

2 io

ph $\int$

dod

$\mathrm{A}+\mathrm{sp}$

tel

gl

ph ||

wil

gl f

ph

wil $^{174}$

ia + ba $^{175}$

hept

${ }^{174}$ Interpretation of this colon hinges on the metrical shape of the word icóvepov. LSJ indicate that the alpha is short, but Günther (p.62) admits the possibility that it may be scanned as long. The iota of 'ícoc is short, as the accent confirms, but in compounds (e.g. ícó $\theta \varepsilon \circ$ ) it is long.

175 See Diggle (1994: 471). 

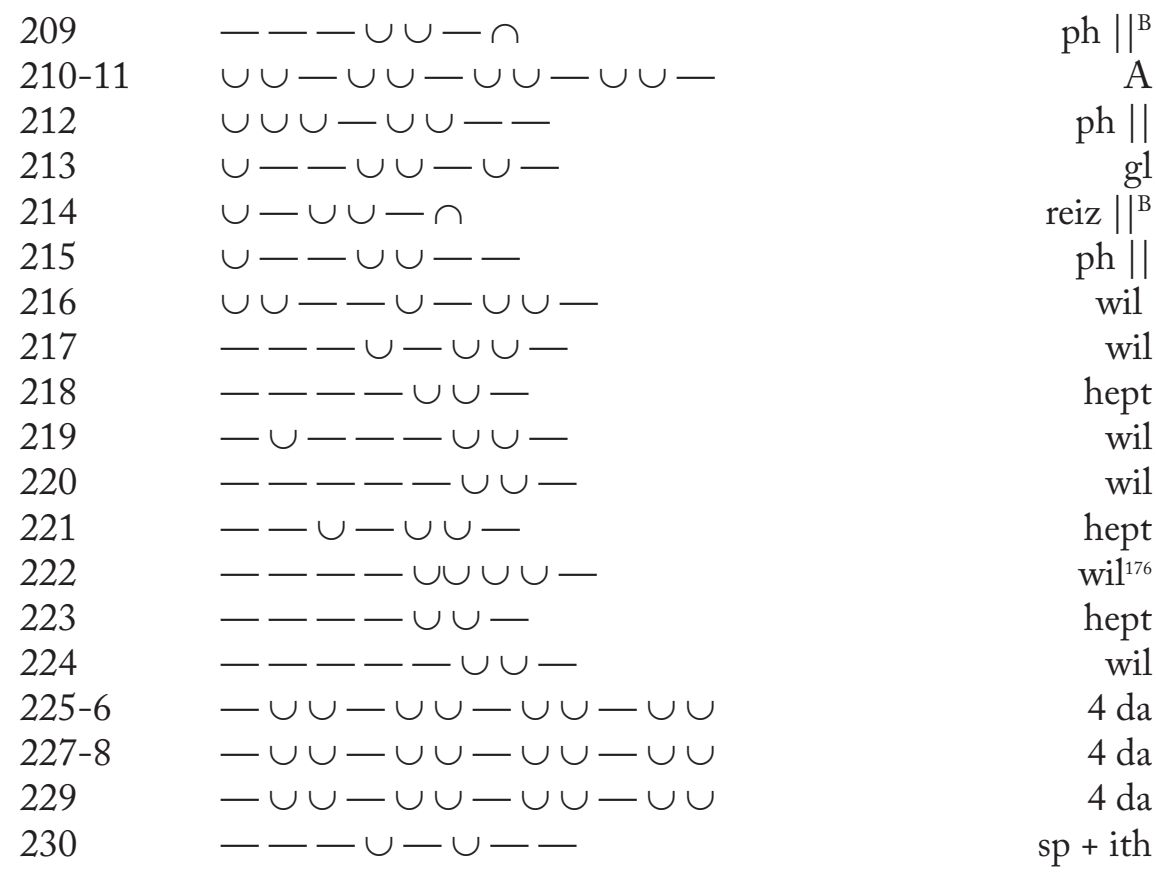

Strophe 2

231

232

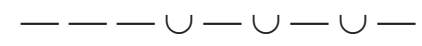

233

$-\cup-\cup-\cup-$

234

235

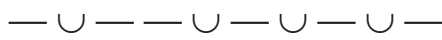

236

237

238

239

240

241

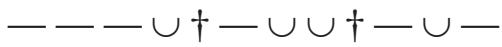

$-\cup-\cup$ h⿱亠凶禸

$\mathrm{sp}+\mathrm{lk}$ $\mathrm{lk} \| \mathrm{Ba}$ $\mathrm{cr}+\mathrm{lk}$

$-\cup-\cup-\cup-$

$1 \mathrm{k}$

$\mathrm{sp}+\mathrm{lk}$

$\mathrm{sp}+\mathrm{lk}$ $\mathrm{cr}+\mathrm{lk} \int$

$1 \mathrm{k} \mid{ }^{\mathrm{Ba}}$ $\mathrm{sp}+\mathrm{lk}$

$\sim$ antistrophe 2

242

243

? $--\cup-\cup-\cup-$

$---\cup-\cup-\cup-$

$-\cup--\cup-\cup-\cup-$
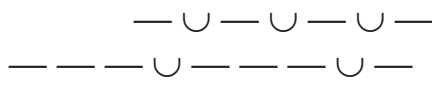

$\mathrm{sp}+\mathrm{lk}$

$1 \mathrm{k} \|^{\mathrm{B}}$

244

245

246

$---\cup-\cup-\cup-$

$-\cup-\cup-\cup \cap$

$\mathrm{cr}+\mathrm{lk}$

$\mathrm{sp}+\mathrm{lk}$

ho

247

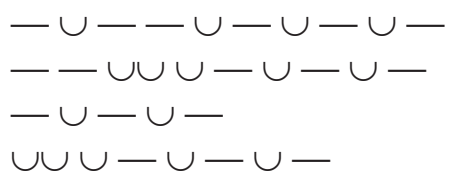

$1 \mathrm{k}$

${ }^{176}$ The resolution in the first long of the choriamb is suspect: see above, p. 95 . 
Part II - Scansions

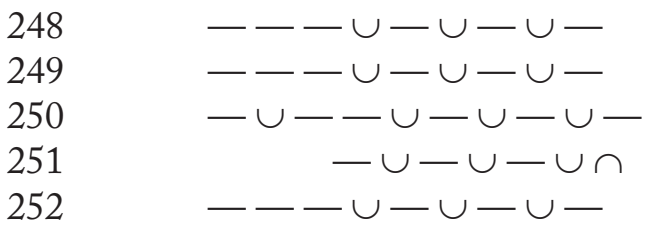

$\mathrm{sp}+1 \mathrm{k}$

$\mathrm{sp}+\mathrm{lk}$

$\mathrm{cr}+1 \mathrm{k}\rfloor$

$1 \mathrm{k} \|{ }^{\mathrm{B}}$

$\mathrm{sp}+\mathrm{lk}$

Strophe 3

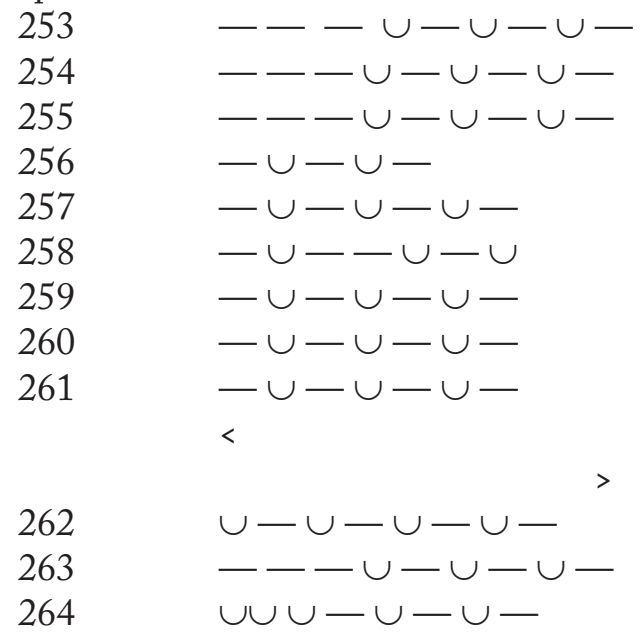

$\mathrm{sp}+\mathrm{lk}$

$\mathrm{sp}+\mathrm{lk}$

$\mathrm{sp}+\mathrm{lk}$

h $\delta$

$1 \mathrm{k}$

$\mathrm{cr}+\operatorname{tr}$

$1 \mathrm{k}$

$1 \mathrm{k} \|^{\mathrm{Ha}}$

$1 \mathrm{k}$

$2 \mathrm{ia}$
$\mathrm{sp}+\mathrm{lk}$
$\mathrm{lk}$

$\sim$ antistrophe 3

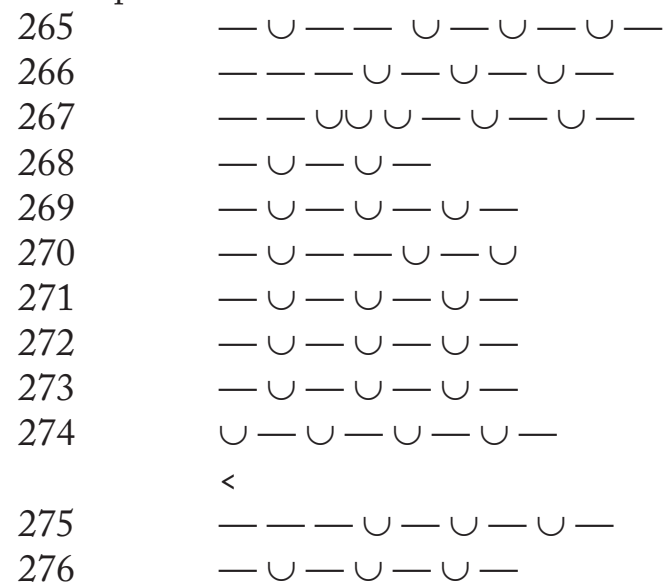

$\mathrm{cr}+\mathrm{lk}$ $\mathrm{sp}+\mathrm{lk}$ $\mathrm{sp}+\mathrm{lk}$

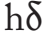
$1 \mathrm{k}$ $\mathrm{cr}+\operatorname{tr}$ $1 \mathrm{k}$ $1 \mathrm{k} \|{ }^{\mathrm{H}}$ $1 \mathrm{k}$ 2 ia $\mathrm{sp}+\mathrm{lk}$ $1 \mathrm{k}$

Second epode

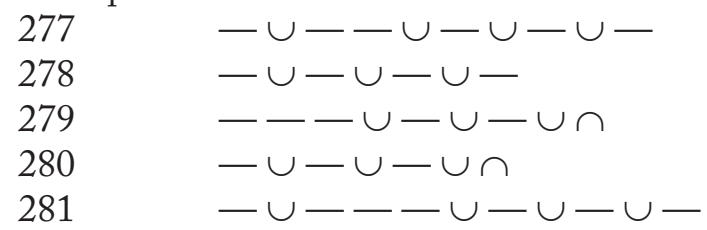




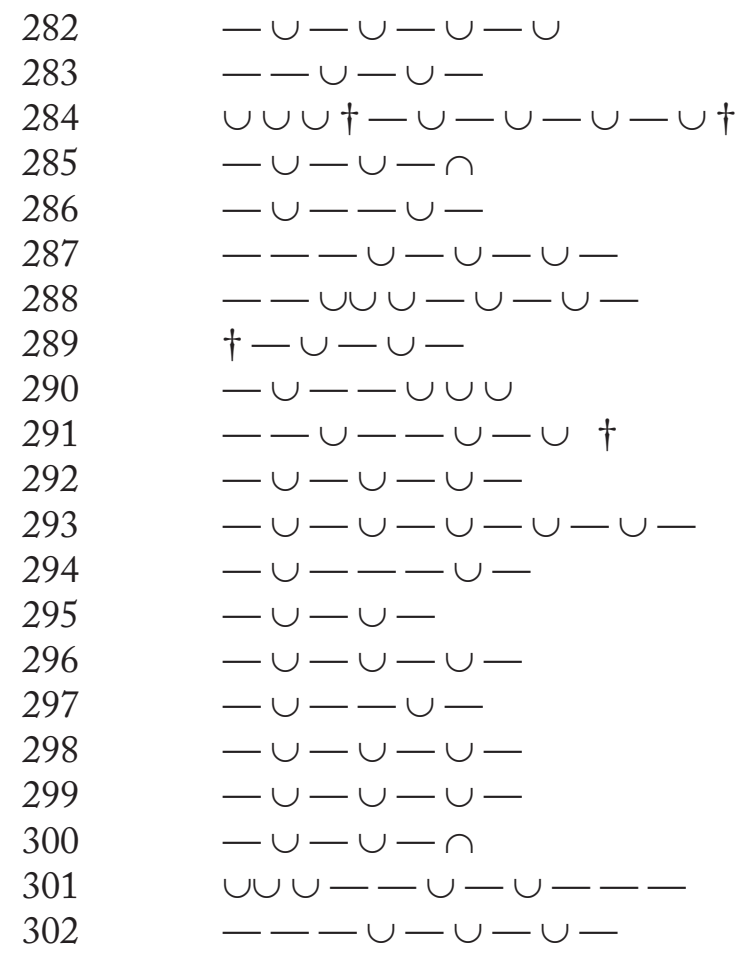

\section{First Stasimon (LA 543-589)}

Strophe

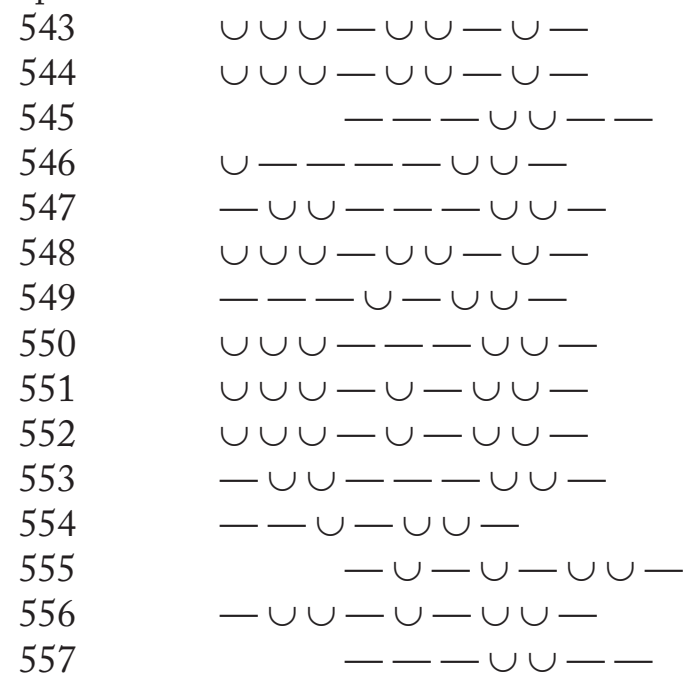


Part II - Scansions

$\sim$ antistrophe

558

559

$\cup \cup \cup-\cup \cup-\cup-$

560

$\cup \cup \cup-\cup \cup-\cup-$

561

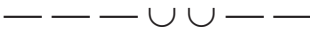

562

$\cup----\cup \cup-$

563

$\cup \cup \cup---\cup \cup-$

gld

ph |

wil

wil

564

$\cup \cup \cup---\cup \cup-$

wil

565

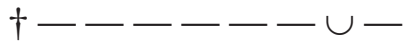

?

wil?

566

$\cup \cup \cup-?--\cup \cup-\dagger$

wil

567

$\cup \cup \cup-\cup-\cup \cup-$

568

$\cup \cup \cup-\cup-\cup \cup-$

wil

569

$\cup \cup \cup---\cup \cup-$

570

$\cup-\cup-\cup \cup-$

wil

hept $\int$

wil

571

572

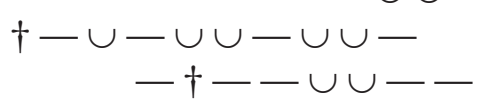

?

ph

epode

573

574

575

576

577

578

579

$\uparrow \cup \cup \cup-\cup \cup-\cup \cup \cup \dagger$

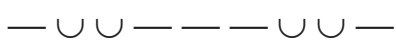

580
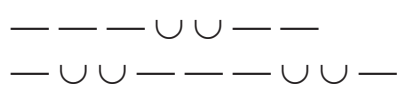

581

582

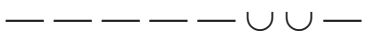

$\cup-\cup-\dagger \cup-\dagger$

$---\cup \cup-\cup \cup \cup$

$\dagger \cup \cup \cup \cup \cup \cup \cup \dagger \cup-$

gl
wil
ph $\|$
wil
wil
?
g1
lk?
ph $\|^{\mathrm{H}}$
$\mathrm{T} \int$
wil

583

$-\cup-\cup \cup--$

$\cup \cup-\cup \cup-\cup-$

584

$-\cup---\cup \cup-$

hept

585

$\cup---\cup \cup-$

erasm

586

$\cup-\cup \cup-\cup \cup-\cup$

ith ||

587

$-\cup-\cup-\cdots$

588

$\cup \cup \cup \cup \cup \cup$

tr

$4 \mathrm{da}^{\mathrm{cat}}$

589

$-\cup \cup-\cup \cup-\cup \cup-$

$+----\cup \cap \dagger$

?

Second Stasimon (IA751-800)

Strophe

751

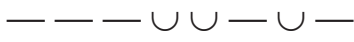

gl

752

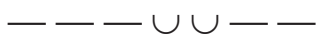

$\mathrm{ph}$

753 

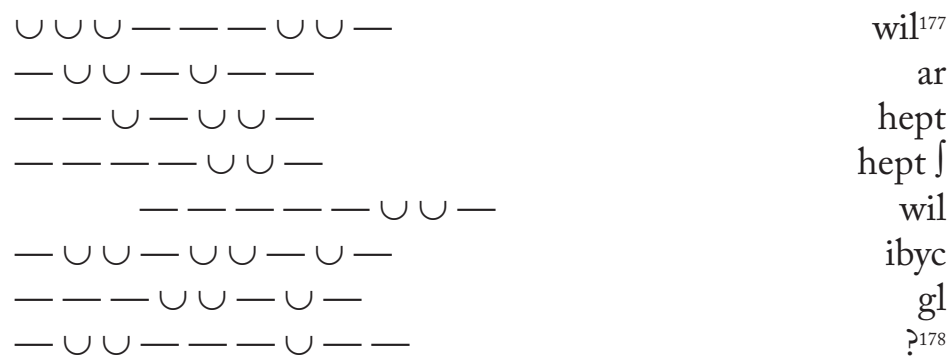

$\sim$ antistrophe

762

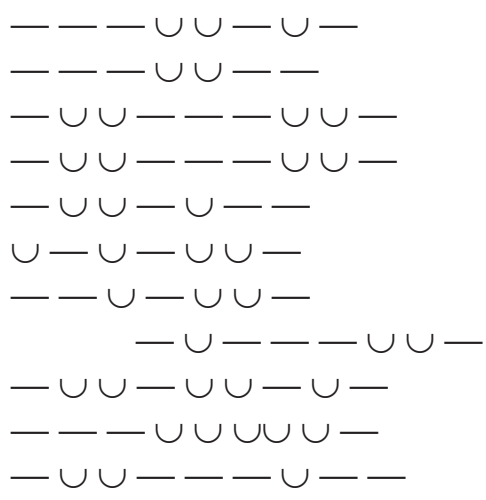

g1
ph
wil
wil
ar
hept
hept $\int$
wil
ibyc
gl
?

763

764

765

766

767

768

769

770

771

772

epode

773

774

775

776

777

778

779

780

781

782

783

784-5

786

787

788
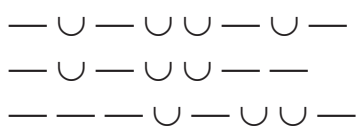

$-\cup \cup-\cup \cup-\dagger-\cdots$

$\cup-\cup--\dagger$

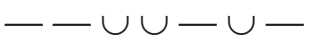

$--\cup-\cup \cup-$

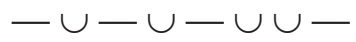

$-\cup \cup \cup \cup-\cup$

$\cup \cup-\cup \cup-$

ph

wil

wil

ar

hept hept $\int$

wil

ibyc

g1

789

$\cup-\cup \cup-\cap$
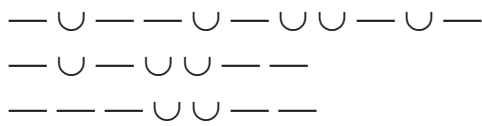

$\cup--\cup-\cup \cup$

gl

ph

wil $4 \mathrm{da} \wedge$ ?

tel || hept $\int$ wil $\|{ }^{\mathrm{H}}$ g1

reiz reiz ||$^{\mathrm{B}}$ $\mathrm{cr}+\mathrm{gl}$ $\mathrm{ph} \|{ }^{\mathrm{H}}$ ph wil reiz

${ }^{177}$ On the odd responsion, see Itsumi (1984: 72 n. 17).

${ }^{178}$ On this colon, see Diggle (1994: 505-6) and above, pp. 99-100. 
$794 \cup \cup \cup-\cup-\cup \cup-\cup-\cup \cap$

\section{Third Stasimon (IA 1036-1097)}

\section{Strophe}

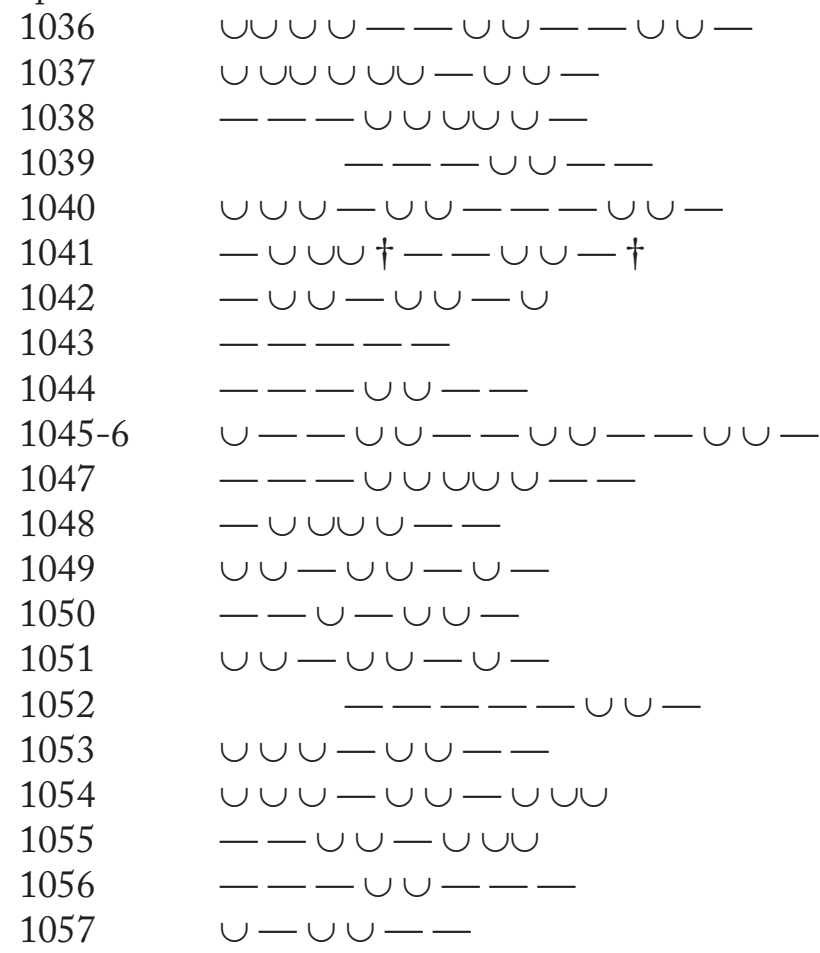

$3 \mathrm{ch}$ ia + ch

$1041-\cup \cup \cup \cup \dagger--\cup \cup-\dagger$

$\mathrm{D} \cup$

pentamakron

$$
\text { ph } \|^{\text {Ba }}
$$

hex $+2 \mathrm{ch}$

$$
\begin{array}{r}
\text { hipp } \\
\text { ith } \\
\mathrm{T} \\
\text { hept } \\
\mathrm{T} \int \\
\text { wil } \\
\text { ph Il } \\
\text { gl } \\
\text { tel } \\
\text { gl } \\
\text { reiz } \\
\\
3 \mathrm{ch} \\
\text { ia }+\mathrm{ch}
\end{array}
$$

$\sim$ antistrophe

1058

$\cup \cup \cup \cup--\cup \cup--\cup \cup-$

1059

$\cup \cup \cup \cup \cup \cup-\cup \cup-$ 


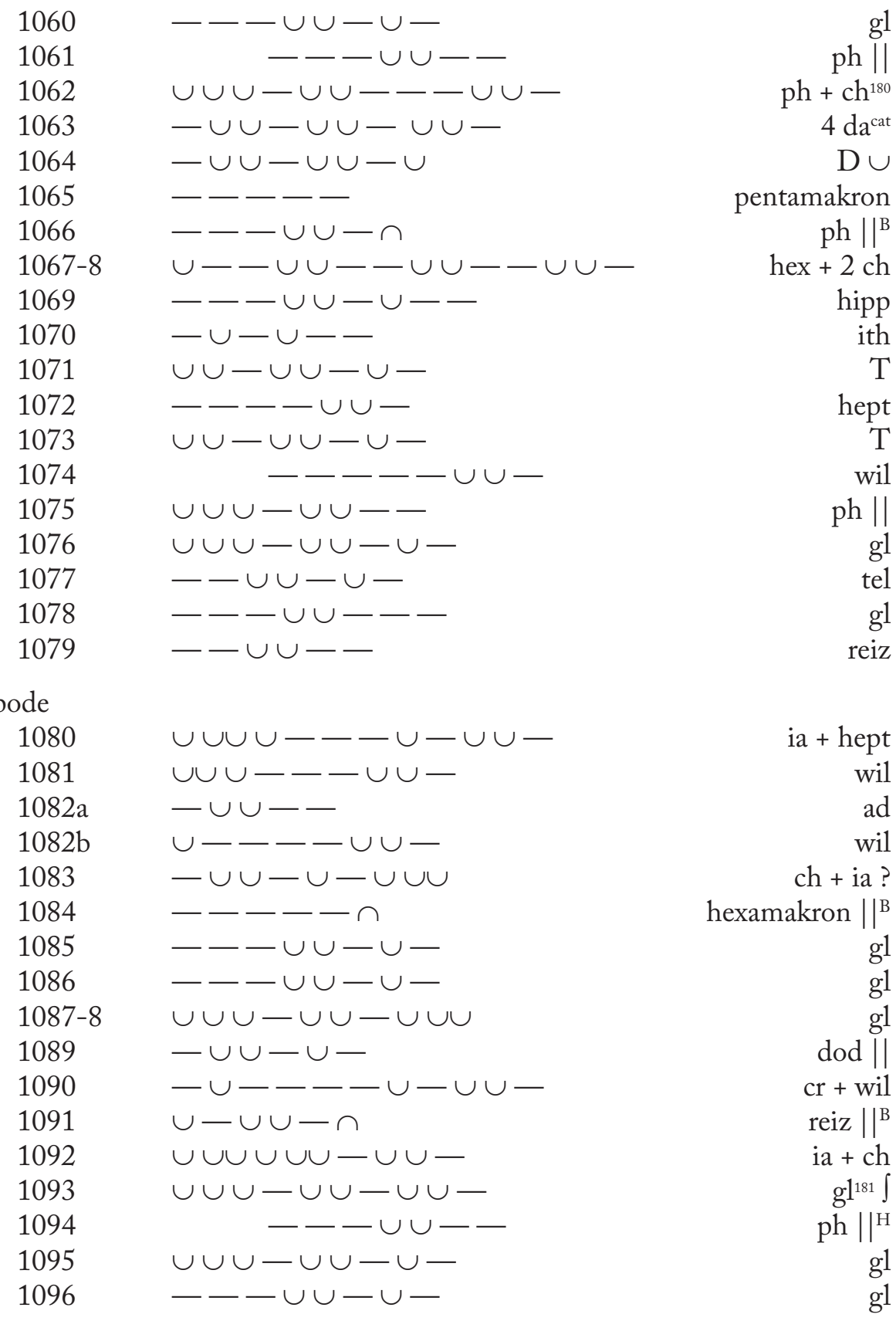

${ }^{180}$ The invocation (cf. above, p. 25) would suggest period-end, but the break in the strophe is awkward.

${ }^{181}$ Cf. Ba. 112 127, 115 130. 
1097

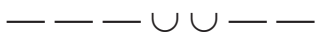

ph

Iphigenia's Monody (LA 1283-1335) ${ }^{182}$

1283

$\cup-\cup-$

1284

1285

$\cup \cup-\cup-\cup \cap$

$1 \mathrm{k} \|^{\mathrm{B}}$

1286

$-ー \cup ル \cup \cup U$

1287

$\cup \cup \cup \cup \cup \cup \cup \cup \cup \cup$

1288

$-\cup \cup \cup-\cup-$

1289

$\cup \cup-\cup \cup \cup \cup$

1290

1291

1292

$\cup \cup--\cup-$

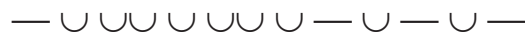

1293

1294

1295

1296

1297

1298-9

1300

1301-2

1303

1304

1305

1306

1307

1308

1309

1310

1311

1312

1313

1314

1315

1316

1317

1318

1319

$-\cup-\cup-\cup-\cup$

$-\cup-\cup-\cup-\cup$

$-\cup \cup-\cup \cup-\cup \cup-$

$\mathrm{pa}+\mathrm{cr} \| \mathrm{H}$

$4 \mathrm{da}^{183}$

$2 \mathrm{sp}$

$\mathrm{sp}+\mathrm{da}+\mathrm{sp}$ ? $^{184}$

$\mathrm{D}$ ?

$4 \mathrm{cr}$

$\operatorname{tr}+2 \mathrm{cr}$ ?

$\dagger$

2 tr

$1 \mathrm{k}$

$\mathrm{cr}+\mathrm{tr}$

$2 \mathrm{cr}$

$2 \mathrm{tr}$

$2 \operatorname{tr} \int$ 183 .

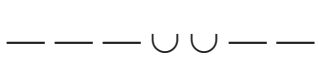

$-\cup \cup-\cup \cup ー \cup-ー \cup U$$$
-\cup \cup \cup \cup \cup \cup-\cup-
$$$$
\dagger
$$$$
-\cup \cup \cup-\cup-\cup
$$

$2 \operatorname{tr}$ $\mathrm{cr}+\operatorname{tr} \|$ B?

$\mathrm{pa}+\operatorname{tr}$

$\mathrm{pa}+\mathrm{cr}$

$2 \mathrm{tr}$

2 tr $2 \operatorname{tr} \int$

$\cup \cup \cup-\cup-\cup \cup \cup \cup$

$1 \mathrm{k}$
$1 \mathrm{k} \|^{\mathrm{B}}$
$2 \mathrm{tr}$
$2 \mathrm{pa}$
$2 \mathrm{tr}$
$1 \mathrm{k}$
$2 \mathrm{ia}$
$2 \mathrm{ia}$
$3 \mathrm{ia} \|$
2 an

${ }^{182}$ See above, pp. 55-7.

${ }^{183}$ See above, pp. 68-9.

${ }^{184}$ Parker analyses as 'anapaestic tripody' (1997: 516). 
1320

1321

1322

1323

1324

1325

1326

1327

1328

1329

1330

1331-2

1333

$1334 \mathrm{a}$

$1334 \mathrm{~b}$

1335
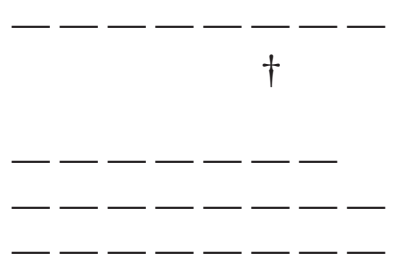

$-\cup \cup-$

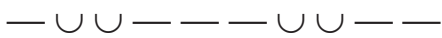

$\dagger$

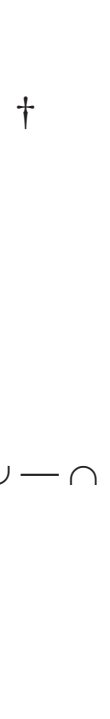

2 an

(prm?)

(prm?)

prm

2 an

2 an

an

2 an

2 an

an

$6 \mathrm{da}$

$4 \mathrm{da}$

$\mathrm{cr}+\mathrm{sp}$

e. $m$.

2 tr

$\mathrm{tr}+\mathrm{lk}$

\section{Iphigenia's second Monody (IA1475-1531)}

IФ.

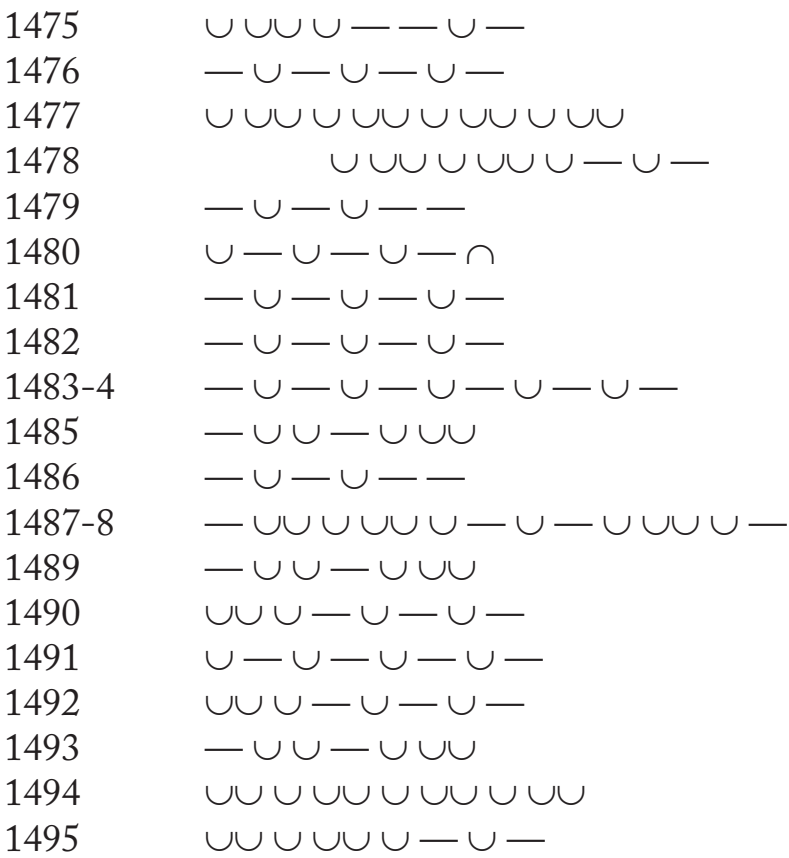

${ }^{185}$ Cf. Diggle (1994: 411). 
Part II - Scansions

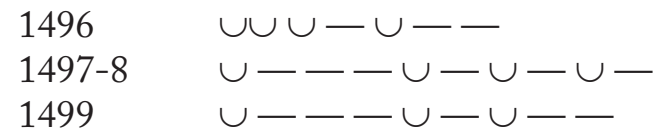

$$
\begin{array}{r}
\text { ith } \| \\
\mathrm{ba}+1 \mathrm{k} \\
\mathrm{ba}+\mathrm{ith} \|
\end{array}
$$

Xo.

$\begin{array}{ll}1500 & \cup-\cup-\cup-\cup- \\ 1501 & \cup-\cup-\cup-\cup-\end{array}$

IФ.

$\begin{array}{ll}1502 & \cup-\cup-\cup \cup \cup \cup- \\ 1503 & \cup-\cup-\cup-\cup-\end{array}$

2 ia

2 ia

Xo.

$1504 \cup-\cup-\cup-\cup-$

2 ia $\|$

IФ.

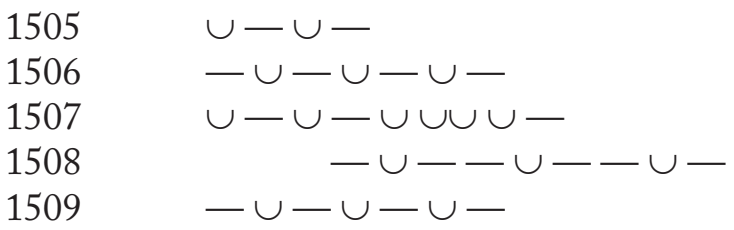

${ }^{\text {ia }}$
$2 \mathrm{ia}$
$3 \mathrm{cr}$
$1 \mathrm{k} \|$

Xo.

$1510 \mathrm{a}$

$\cup-\cup-$

$1510 \mathrm{~b}$

$\cup-\cup--\cup-$

1511

$-\cup-\cup-\cup-$

1512

1513

$--\cup \cup \cup \cup \cup-$

1514

1515

$\cup-\cup--\cup-\cup-$

1516

1517

$-\cup-\cup-\cup-$

$\cup \cup-\cup-\cup-$

1518

$\dagger \cup-\cup-\cup-\cup-\cup-\cup-$

1519

$\cup-\cup-\cup---$

1520

$\cup-\leftarrow \cup-\cup \cup-\cup-\cup \dagger$

$\cup-\cup--\cup-$

1521

$-\cup-\cup-\cup-$

1522

$-\cup-\cup-\cup-$

1523

1524

1525

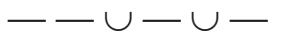

$\cup-\cup-\cup-\cup-\cup-\cup-$

1526

$-\cup \cup \cup \cup \cup-\cup-\cup-\cup-$

1527

$\cup-\cup-\cup-\cup-$

ia

$\mathrm{ia}+\mathrm{cr}$

$1 \mathrm{k}$

2 ia

ia + ith

2 ia

$1 \mathrm{k}$

3 ia

?

$\mathrm{ia}+\mathrm{cr}$

$1 \mathrm{k} \|$

$1 \mathrm{k}$

$\mathrm{pa}+\mathrm{cr}$

3 ia $\|^{\mathrm{H}}$

3 ia

2 ia

$\mathrm{cr}+\mathrm{ia}=\mathrm{lk}^{186}$

1528

$-\cup---\cup-$

?

${ }^{186}$ See Diggle (1994: 341). 
Iphigenia in Aulide

1529

$-\cup \cup-\cup \cup-\cup \cup-$

1530

$\cup-\cup \cup \cup \cup-\dagger$

1531

$\cup \cup-\backsim \cup-\cup--$

cr + ith || 


\section{RHesus}

\section{Parodos (Rh.23-51)}

Strophe
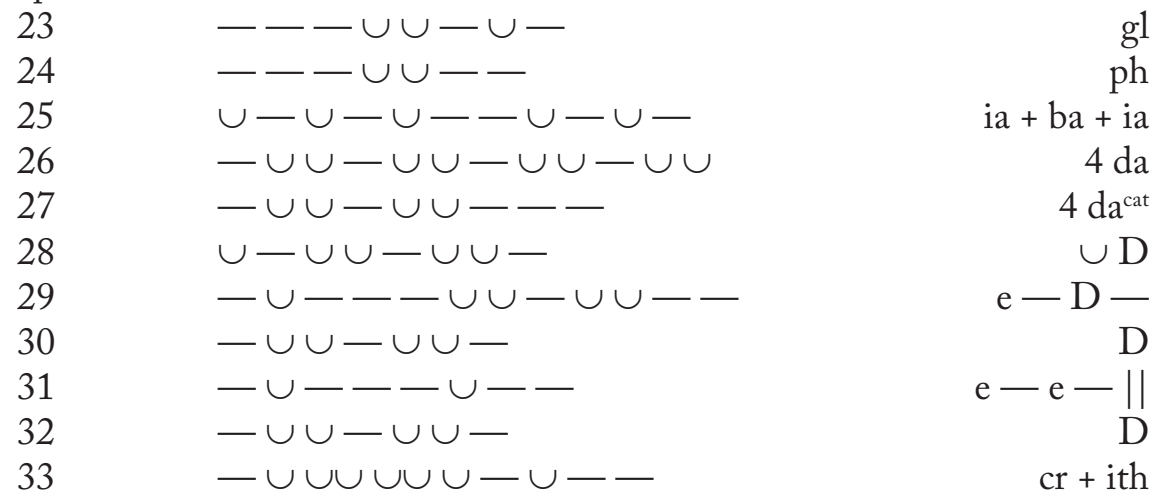

$\sim$ antistrophe

41

42

43

44

45

46

47

48

49

50

51
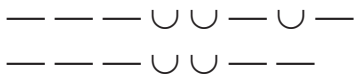

$\cup-\cup-\cup-\backsim-\cup-$

$-\cup \cup-\cup \cup-\cup \cup-\cup \cup$

$-\cup \cup-\cup \cup--$

$\cup-\cup \cup-\cup \cup-$

$-\cup---\cup \cup-\cup \cup-$

$-\cup \cup-\cup \cup$

$-\cup--\backsim-\cap$

$-\cup \cup-\cup \cup$

$-\cup \cup \cup \cup \cup \cup$ $g 1$
ph
$\mathrm{ia}+\mathrm{ba}+\mathrm{ia}$ $4 \mathrm{da}$ $4 \mathrm{da}^{\text {cat }}$ $\cup \mathrm{D}$ $\mathrm{e}-\mathrm{D}-$ $\mathrm{D}$ $\mathrm{e}-\mathrm{e}-\|^{\mathrm{B}}$ $\mathrm{D}$ cr + ith

\section{Rh. 131-201}

Strophe

131

$\cup \cup \cup-\cup \cup \cup \cup \cup \cup-\cup-$ $2 \delta$

132

$\cup \cup \cup-\cup-\cup--\cup-$ 
Part II - Scansions

135

$\cup \cup \cup \cup \cup-\cup-$

2 ia

136

$\cup \cup ル \cup-$

$\delta \int$

137

$\cup-\cup-\leftarrow \cup$

$\mathrm{ia}+\mathrm{cr}$

$\sim$ antistrophe

195

$\cup \cup-\cup U \cup \cup \cup \cup \cup-$

$2 \delta$

196

$\cup \cup \cup \cup-\cup-\backsim-$

197

$\cup \cup \backsim \cup \cup \cup \cup-$

$\cup--\cup-$

$2 \delta$

198

199

$\cup \cup \cup \cup \cup-\cup-$

$2 \delta$ J

$\delta$

2 ia

200

$\cup \cup \cup-\cup-$

$\delta$

201

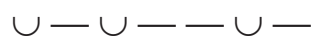

$\mathrm{ia}+\mathrm{cr}$

Rh. 224-263

Strophe 1

224

225

$--\cup--\cup \cup-\cup \cup-$

ia $+D$

226

$-\cup-\cup--$

ith

227

$\cup-\cup--\leftarrow \cup \cup-\cup \cup-$

$\cup \mathrm{e}-\mathrm{D}-\mathrm{f}$

228-9

$-\cup \cup-\cup \cup-$

$\mathrm{D}$

230

$-\cup--\leftarrow \cup \cup-\cup \cup-$

$\mathrm{e}-\mathrm{D}-$

$-\cup---\cup \cup-\cup \cup-$

$\mathrm{e}-\mathrm{D}$

231

$-\longleftarrow \cup \cup-\cup \cup-$

$-\mathrm{D}$

232

$--\cup-\cup--$

$\mathrm{ia}+\mathrm{ba}$

$\sim$ antistrophe 1

233

$\cup-\cup--\cup \cup-\cup \cup-$ $\mathrm{ia}+\mathrm{D}$

234

$-\cup-\cup--$

235

$\cup-\cup---\cup \cup-\cup \cup--$

$v e-D-\int^{i t h}$

236 $-\cup \cup-\cup \cup$

237-8

$-\cup---\cup \cup-\cup \cup--$

239

$-\cup---\cup \cup-\cup \cup-$

240

$-\longleftarrow \cup \cup-\cup \cup$

241

$-\backsim \cup-\cup-$

$\mathrm{D}$

$\mathrm{e}-\mathrm{D}-$

$\mathrm{e}-\mathrm{D}$

$-\mathrm{D}$

$\mathrm{ia}+\mathrm{ba}$

Strophe 2

242-3

$\cup-\cup--\cup \cup-\cup-\cup-$

244

$-\cup \cup-\cup \cup-\cup \cup-$

$i a+c h+i a$ $4 \mathrm{da}^{\text {cat }}$

245

$-\cup \cup-\cup \cup--$

$\mathrm{D}-$

246-7

$-\cup \cup-\cup \cup-\cup-\cup \cup-\cup \cup-$

248

$-\cup--$

$\mathrm{D} \cup \mathrm{D}$

$\mathrm{e}-$ 
$\cup \cup-\cup \cup-\cup-\cup-\cup \cap$

$\operatorname{diom}+\operatorname{cr}^{187}$

$\cup \cup \cup \cup \cup-$

$\sim$ antistrophe 2

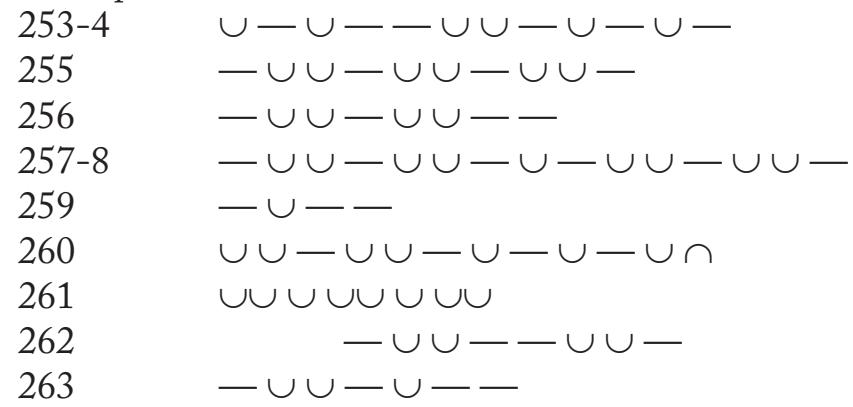

$\mathrm{ia}+\mathrm{ch}+\mathrm{ia}$ $4 \mathrm{da}^{\text {cat }}$ $\mathrm{D}-$ $\mathrm{D} \cup \mathrm{D}$ e diom $+\mathrm{cr}$ $\mathrm{h} \delta \int$ $2 \mathrm{ch}$ ar

\section{Rh. 342-379}

Strophe 1

342

343

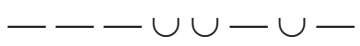

344

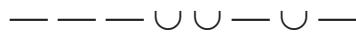

345

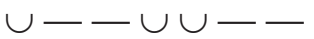

346

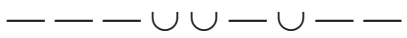

hipp ph $\|^{\mathrm{HBa}}$

347

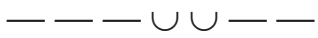

ia + ar

348

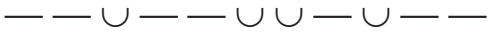

$-\mathrm{D}$

349

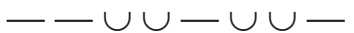

$e-D$ J

350

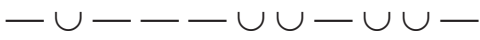

ar

$\sim$ antistrophe 1

351

352

353

354

355

356

357

358

359

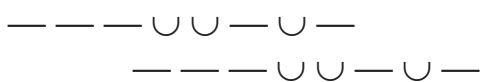

${ }^{187}$ Cf. IT 1271. See above, p. 75. 
Strophe 2

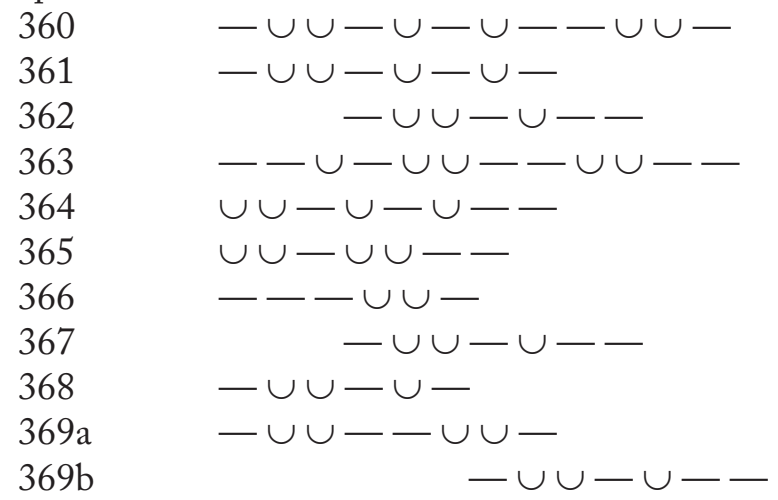

$$
\begin{array}{r}
c h+i a+c h \\
c h+i a \int \\
\text { ar } \\
\text { ia }+2 \text { io } \\
\text { anacr } \\
\text { io } \wedge+\text { io } \\
\text { hex } \\
\text { ar } \|^{\mathrm{Ha}} \\
\text { dod } \\
2 \mathrm{ch} \int \\
\text { ar }
\end{array}
$$

$\sim$ antistrophe 2

370

371

372

373

374

375

376

377

378

$379 \mathrm{a}$

$379 \mathrm{~b}$

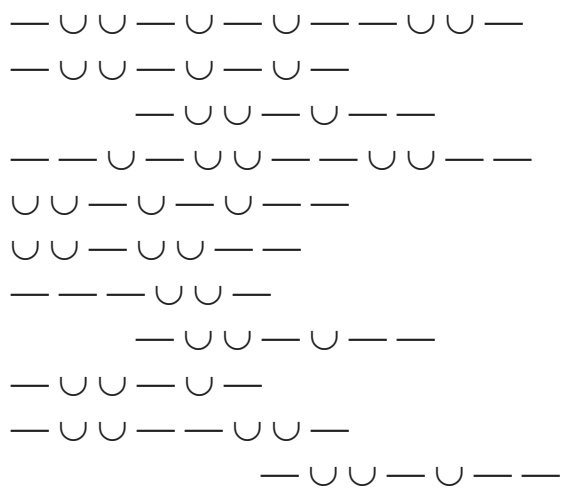

$R h .455-466 \sim 820-831$

Strophe

455

$\cup-\cup-$

456

$\cup \cup \cup-\cup-\cup \cup \cup-\cup-$

$2 \delta$

457

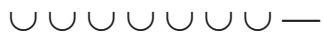

458

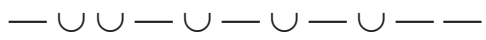

$\mathrm{d} \cup$ ith

459

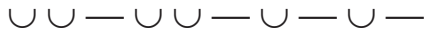

cyren $\|{ }^{\mathrm{H}}$

460

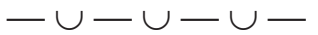

$1 \mathrm{k}$

461-2

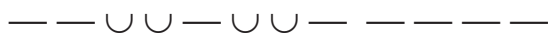

$-\mathrm{D}+2 \mathrm{sp}\|\|^{\mathrm{H}}$

$\cup \cup-\cup \cup-\cup-\cup-\cap$

463

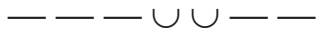

464

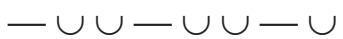

$\mathrm{T}+\mathrm{ba}$
$\mathrm{D}^{\mathrm{contr}}-\|^{\mathrm{Hs}}$
$\mathrm{D} \cup$

${ }^{188}$ See Willink (2010: 573-4) and Liapis (comm. Rh.pp. 194-5). 


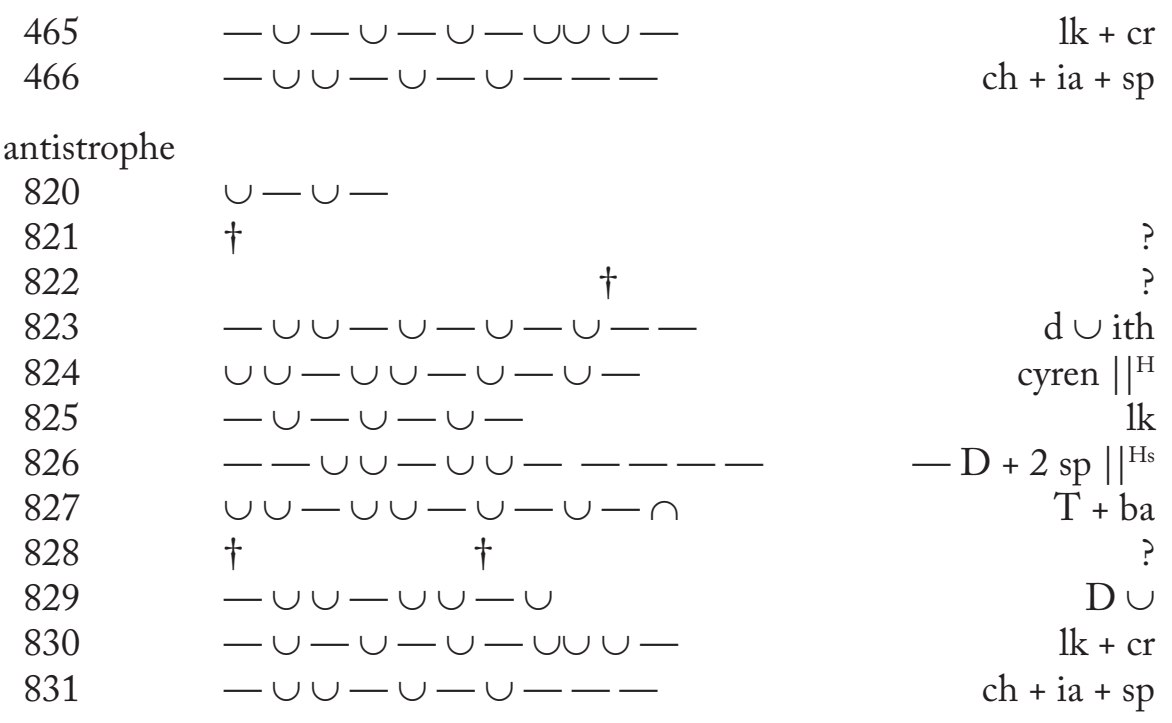

\section{Rh. 527-555}

Strophe

527-8

529

530

531

532

533

534

535

536-7

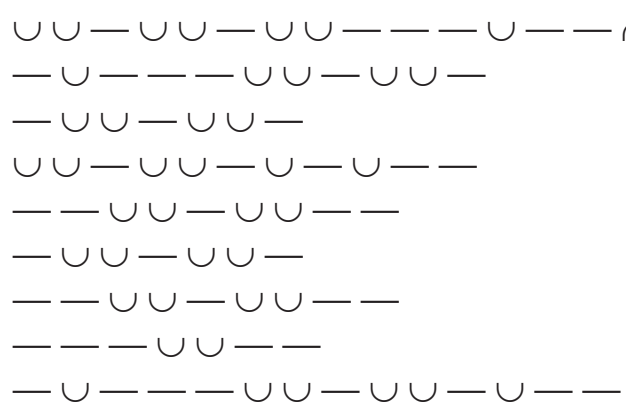

$\cup \cup \mathrm{D}-\mathrm{e} \mathrm{sp}^{\mathrm{B}}$ $\mathrm{e}-\mathrm{D}$

$\cup-\cup-$

1

$-\cup \cup-\cup-\cup-\cup-$

$\mathrm{d} \cup$ ith $1 \mathrm{k}$ 
Part II - Scansions

\section{Rh. 675-689}

Xo.

$675 \mathrm{a}$

675b

$$
2 \mathrm{tr}
$$

676

$\cup-$

ba

677

$-\cup-\cup-$

ith

680

$-\cup-\cup-$

ho

681

$678-9$

$-\cup--\cup-\cup$

$\mathrm{cr}+\mathrm{tr}$

682

$-\cup-\cup-\cup---\cup---\cup-$

4 tr $^{\mathrm{cat}}$

$\cup \cup-\cup \cup \cup \cup \cup \cup$

$3 \mathrm{cr}$

$0 \delta$.

683

$-\cup-\cup-:: \cup---\cup-\cup-\cup-$

$4 \operatorname{tr} \wedge$

684

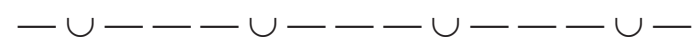

$4 \operatorname{tr}^{\mathrm{cat}}$

$0 \delta$.

685

686

687

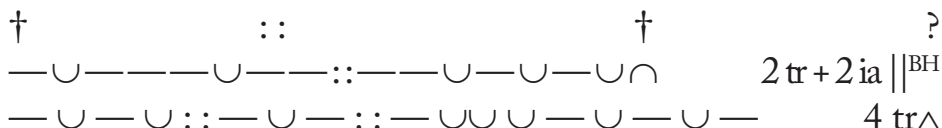

Xo.

688

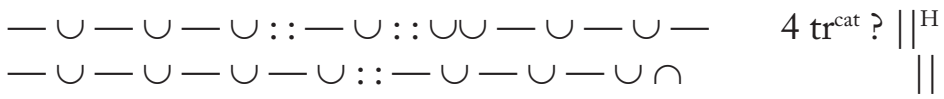

Xo.

689

$-\cup-\cup-\cup---\cup-\cup-\cup \cap$

$4 \operatorname{tr}^{\mathrm{cat}}$

690

$-\cup-\cup-\cup---\cup---\cup-$

$R h .692-727$

Strophe

692

$\cup-\backsim \cup$

$\delta$

693

$\cup \cup \cup \cup \cup-\cup-$

2 ia

694

$\cup \cup \cup-\cup-$

$\delta$

695

$\cup--\cup--$

2 ba

696

$\cup \cup \cup-\cup-$

$\delta$

697

698

699

700

$--\cup---\cup-\cdots \cup \cup$

3 ia $\|\left.\right|^{\mathrm{B}}$

$\cup \cup \cup-\cup--\cup \cup-\cup-$

$2 \delta$

$-\cup \cup-$

701

$\cup \cup \cup-\cup-\cup \cup \cup-\cup-$

$2 \delta$

702

$--\cup--\cup \cup \cup---\cup-$

3 ia

$\cup-\cup---\cup-$

2 ia

703

$-\cup \cup-\cup-\cup \cup \cup-\cup-$

$2 \delta$ 
704

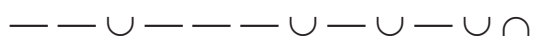

3 ia

705

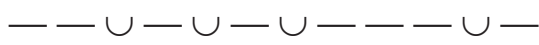

3 ia

706

$\cup--\cup-\cdots$

$2 \mathrm{ba}$

707

$\cup--\cup--$

708

$\cup--\cup--\cup-\cdots$

$2 \mathrm{ba}$

709

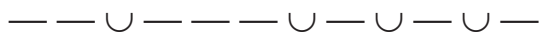

3 ba

3 ia

$\sim$ antistrophe

710

$\cup--\cup-$

711

$\cup \cup \cup \cup \cup \cup \cup-\cup-$

712

$\cup \cup \cup-\cup-$

713

$\cup--\cup-$

714

$\cup \cup-\cup-$

715

$\cup-\cup---\cup-\cdots \cup-$

716

$\cup \cup \cup-\cup-\cup \cup \cup-\cup-$

717

718

$-\cup \cup-$

$\cup \cup \cup \cup-\cup \cup \cup-\cup-$

719

720

$\cup-\cup-\cup-\cup-\cup-\cup-$

$\cup-\cup-\cup-\cup-$

721

$\cup \cup \cup-\cup-\cup \cup \backsim \cup$

722

723

724

725

726

727

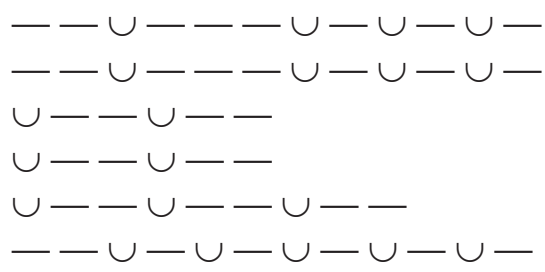

3 ia

3 ia

$2 \mathrm{ba}$

2 ba

$3 \mathrm{ba}$

3 ia

Muse's Monody $(R h .895-914)^{189}$

Strophe

MOYCA

895

$\cup-\cup \cup-\cup \cup-$

$\cup \mathrm{D}$

896

$\cup-\cup \cup-\cup \cup-$

$\cup \mathrm{D}$

897

$-\cup-\cup--$

ith

898

$\cup-\cup \cup-\cup \cup--$

erasm||

899

$---\cup \cup-\cup \cup-$

900

$\cup \cup-\cup \cup-\cup-\cup--$

${ }^{190}$ Cf. above, p. 73. 
Part II - Scansions

901

902

903

$\sim$ antistrophe

906

907

908

909

910

911

912

913

914 $\cup \cup-\cup \cup-\cup-\cup-$

$-\cup \cup-\cup \cup-\cup \cup-$

$\cup \cup-\cup \cup-\cup \cup-$
$\mathrm{T}+\mathrm{ba}$

$4 \mathrm{da} \wedge$

enop prm

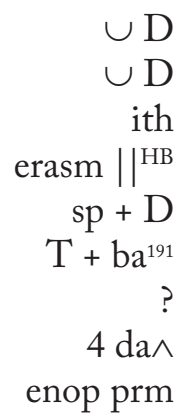

${ }^{191}$ See above, p. 27 with n. 23. 


\section{Phaethon}

Parodos (Phaeth. 63-101)

Strophe 1
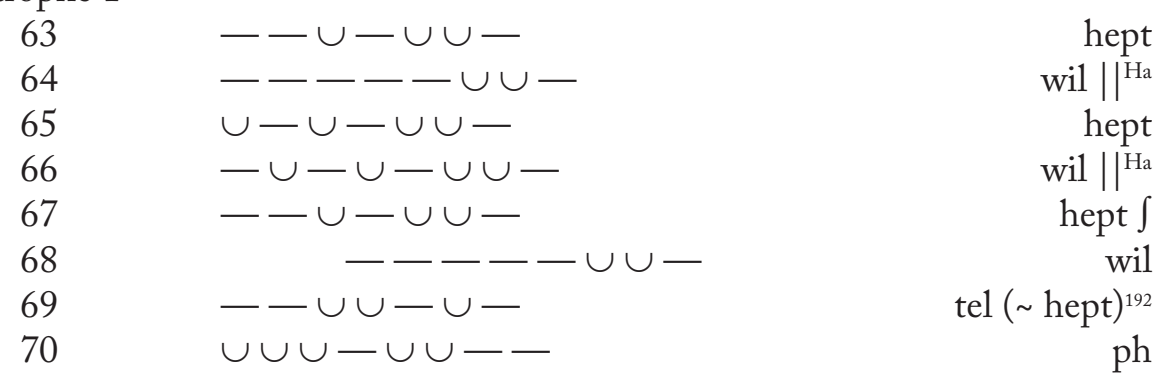

$\sim$ antistrophe 1

71

72

73

74

75

76

77

78

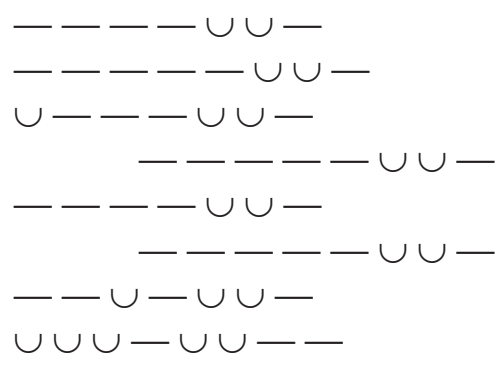

Strophe 2

79

80

81

82

83

84

85

$\cup \cup-\cup \cup-\cup \cup-\cup \cup-$

$$
\cup \cup-----\cup \cup-
$$$$
\cup \cup-\cup \cup-\cup \cup-\cup \cup
$$

86

hept wil $\|{ }^{\mathrm{H}}$ hept wil $\|\left.\right|^{\mathrm{H}}$ hept $\int$ wil hept ( tel) ph

$$
\begin{array}{r}
2 \text { an } \\
2 \text { an } \\
2 \text { an }\|\|^{\mathrm{H}} \\
\text { prm } \|{ }^{\mathrm{H}} \\
\text { prm ? } \\
\mathrm{D}^{\text {contr }} \\
2 \text { an } \\
2 \text { ia }+ \text { ba }
\end{array}
$$

${ }^{192}$ See above, p. 110. 
$\sim$ antistrophe 2

87

88

89

90

91

92

93

94

epode

95

96

97

98

99

100

101 $\cup \cup-\cup \cup-\cup \cup-\cup \cup-$

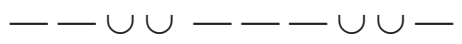

$\cup \cup-\cup \cup-\cup \cup-\cup \cup-$

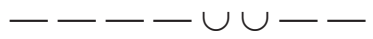

$--\cup \cup-\cup \cup-\longrightarrow$

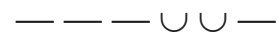

$\cup \cup-\cup \cup-\cup \cup-\cup \cup-$

$\cup-\cup-\cup \cup \cup \cup-\cup--$

$\cup-\cup-\cup \cup \cup \cup-\cup-\cup-$

$\cup-\cup--\cup-$

$-\cup \cup-\cup \cup-\cup \cup-\cup \cup-$

$\cup-\cup--\cup-$

$\cup \cup \cup-\cup \cup \cup \cup-\cup$

$\cup \cup-\cup-\cup-$

$\cup-\cup--\cup-\cup--$
2 an

2 an

2 an $\|$

prm $\|$

prm

$\mathrm{D}^{\text {contr }}$

2 an

2 ia $+b a$

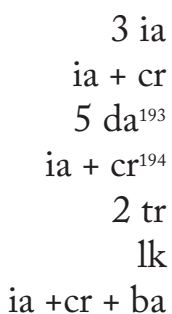

3 ia $\mathrm{a}+\mathrm{cr}$ $5 \mathrm{da}^{193}$ $+\mathrm{cr}^{194}$ $2 \operatorname{tr}$ $1 \mathrm{k}$ $\mathrm{ia}+\mathrm{cr}+\mathrm{ba}$

\section{Wedding song (Phaeth. 227-244)}

Strophe

\section{ПAP ENOI}

227

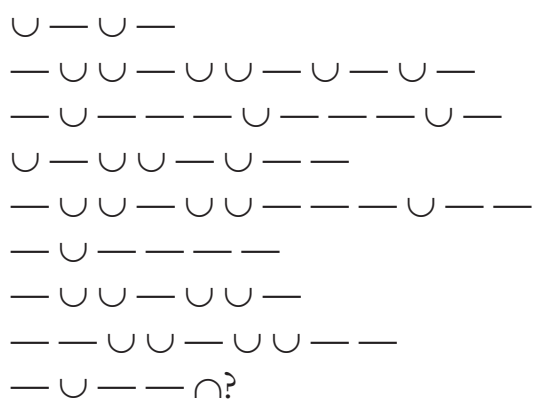

$$
\begin{array}{r}
\text { ia } \\
\mathrm{D} \cup \mathrm{e} \|^{\mathrm{Ha}} \\
\mathrm{e}-\mathrm{e}-\mathrm{e} \\
\mathrm{hag}\|\|^{\mathrm{Ha}} \\
-\mathrm{e}-\|^{\mathrm{Ba}} \\
\mathrm{e}-\mathrm{e}^{\text {syncp }} \\
\mathrm{D} \\
\mathrm{erasm} \\
\mathrm{cr}+\mathrm{sp}
\end{array}
$$

228

229

230

231

232

233

234

235

$\sim$ antistrophe

236

237

238

239

240

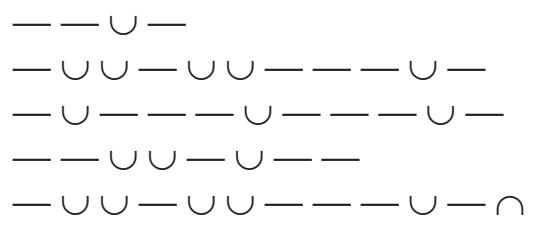


241

242

243

244

Xo.

270

271

272

273

274

275

276

277

278

279

280

281

282

283

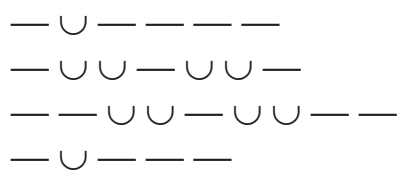

$\mathrm{e}-\mathrm{e}^{\mathrm{syncp}}$

D

erasm

$\mathrm{cr}+\mathrm{sp}$

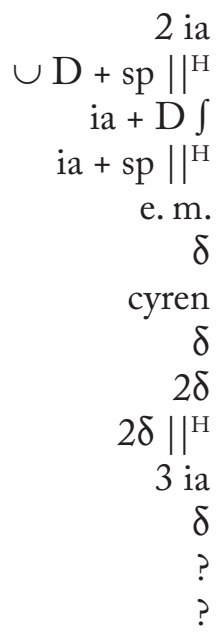




\section{HyPSiPYLE}

\section{$\operatorname{Tr} G F S$}

24

25

26

27

28

29

30

31

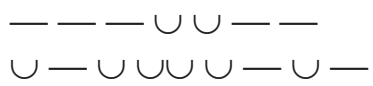

$-\cup \cup---\cup \cup-\cup \cup$

$-\cup \cup-\cup \cup-\cup \cup-\cup \cup$

$-\cup \cup-\cup \cup-\cup \cup-\cup \cup$

$-\cup \cup-\cup \cup-\cup \cup-\cup \cup$

$-\cup \cup-\cup \cup-$

UU- U- $\mathrm{ph}$

2 ia

$4 \mathrm{da}$

$4 \mathrm{da}$

$4 \mathrm{da}$

$4 \mathrm{da}$

$\mathrm{D}$

ith

(XOPOC)

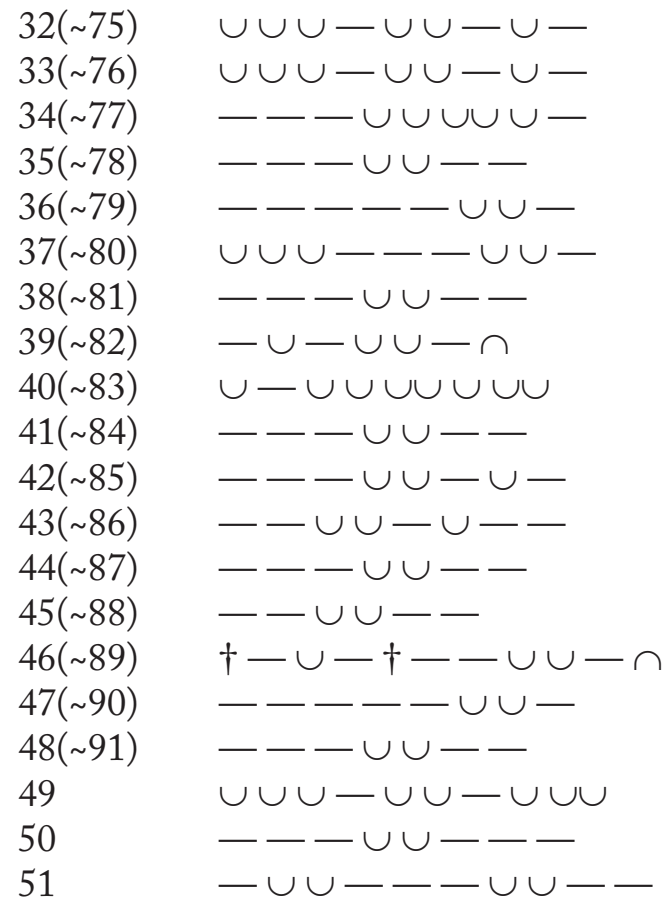

g1

g1

$\mathrm{gl}$

ph $\|{ }^{\mathrm{H}}$

wil

wil

ph $\|^{\mathrm{B}}$ tel ? ${ }^{195}$

ph

$\mathrm{gl}$

hag

ph

reiz wil - $\|^{\mathrm{B}}$ ?

wil

ph

g1

$4 \mathrm{da}$ ?

$4 \mathrm{da}$ ?

195 See above, pp. 96-7. 


\section{Hypsipyle's Monody}

61

62

63

64

65

66

67

68

69

70

71

72

73

74 $\cup-\cup \cup---$

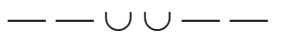

$\cup--\cup \cup--$

$\cup \cup--\cup \cup-$

$--\cup-\cup \cup-$

$\cup \cup \cup \cup \cup-\cup$

$-\cup \cup-\cup \cup-$

$-\cup \cup-\cup \cup$

$\cup \cup-\cup \cup-\cup \cup-\cup \cup-$

$\cup \cup-\cup \cup-$

$\cup \cup-\cup \cup-\cup \cup-\cup \cup-$

$\cup \cup-\cup \cup-\cup \cup-\cup \cup$

$\cup \cup-\cup \cup$

$\cup \cup \cup \cup-$

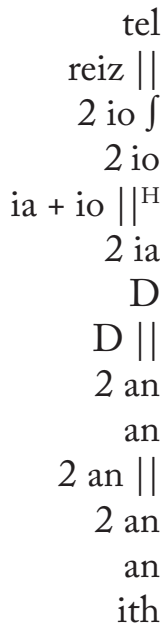

Xo.

75

$\cup \cup \cup-\cup \cup-\cup-$

76

$\cup \cup \cup-\cup \cup-\cup-$

77

$\cup-\longleftarrow \cup \cup-\cup$

78

79

80

81

82

83

84

85

86

87

88

89
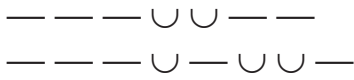

$\cup \cup \cup---\cup \cup-$

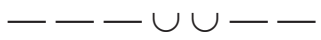

$-\cup-\cup \cup-$

$-\longleftarrow \cup \cup-\cup-$

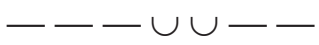

$---\cup \cup-\cup$

105

106

107

108

109

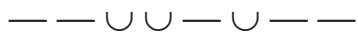

$---\cup \cup--$

$\cup-\cup \cup-$

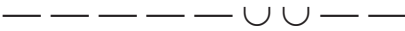

110 $\cup--\cup \cup--\cup \cup-$

$\cup \cup-\backsim \cup \cup-$

$\cup \cup \cup \cup \cup \cup \cup$

$\cup \cup-\cup \cup-: \cup \cup-\cup \cup-$

$\cup \cup-\cup \cup-: \cup \cup-\cup \cup-$

$\cup \cup-\cup \cup$ tel

iz

2 io

2 ia

$\mathrm{D}$

an

an

an

an

ith

g1

g1

g1

ph

wil

wil

ph

ph

tel

ph

g1

hag

ph

reiz

wil - ?

3 io

3 io

$2 \mathrm{ia}^{196}$

2 an

2 an

an

${ }^{196}$ Bond (p. 63) analyses ' 2 tr', but iambics prevent split resolution. 
Fr. 754 Kannicht

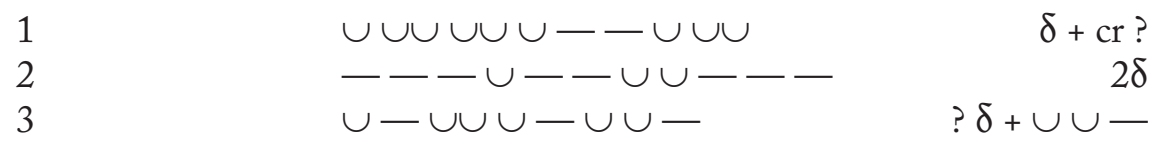

\section{$\operatorname{Tr} G F S$}

244

245

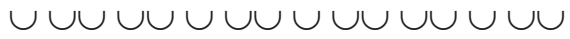

246

$\cup \cup \cup \cup \cup \cup \cup \cup \cup--\cup-$

$2 \delta$

$\mathrm{h} \delta+\mathrm{cr}$ ?

' $\Psi$.

256

$-\cup-\cup--\cup-$

$\mathrm{ia}+\delta$

$2 \delta$

258

$--\cup-\cup \cup \cup \cup \cup$

$2 \delta$

260

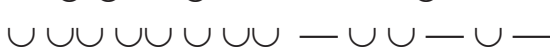

$2 \delta$

261

$\cup \cup \backsim \cup \cup \cup \cup-$

A

262

$\cup \cup-\cup \cup-\cup \cup---$

$\delta$

264

$\cup \cup \cup-\cup-$

$\delta$

265

266

$-ー \cup \cup \cup$

$A \cup-$

$\cup \cup-\cup \cup-\cup \cup-\cup \cup-\cup$

268

269

$\cup---$

$\delta$

$2 \mathrm{sp}$

270

$-\cup \cup-\cup \cup$

$\mathrm{D}$

271

272

273

$\cup \cup-\cup \cup-\cup-\cup$

diom

$\mathrm{D}-\|^{\mathrm{B}}$ ibyc

$-\cup \cup-\cup \cup-\cup-$

EŰv.

274

275

276

277

279

281

282

284

285

$\cup \cup \cup-\cup-$

$-\mathrm{e}-\mathrm{D}-\|_{\mathrm{D}}^{\mathrm{B}}$ cyren

2 ia cyren $^{\text {chol }}$

$\cup \cup-\cup \cup-\cup--$

$2 \delta$

$--\cup \cup \cup-\cup \cup \cup-\cup$

$\delta$ $\mathrm{ia}+\delta$ ?

$\dagger \cup \cup \cup \cup \cup \cup \cup \cup \cup-\cup-\dagger$

2 ia

$?+\delta$

288

$\cup \cup \cup \cup \cup \cup \cup-\cup-$

$\delta$ 
Part II - Scansions

Fr. 8/9 p. 33 Bond = Fr. 753 Kannicht

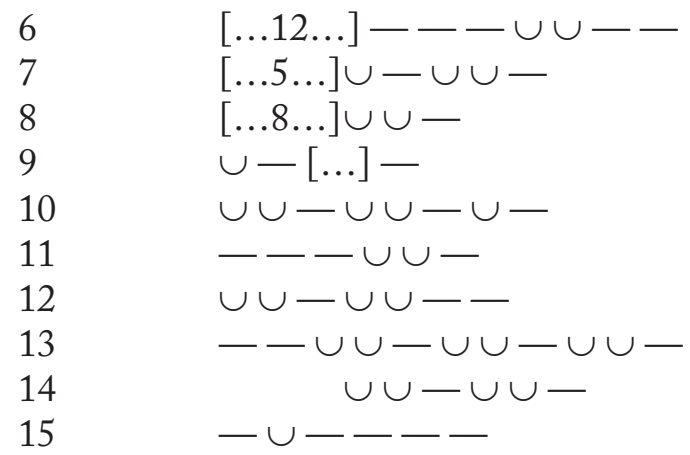

$$
\begin{array}{r}
\text { T (tel) } \\
\text { hex } \\
\text { reiz } \\
2 \text { an } \int \\
\text { an } \\
\text { cr }+ \text { mol }
\end{array}
$$




\section{Cresphontes}

Fr. III $(\operatorname{Tr} G F S)=$ Fr. 453 Kannicht

Strophe
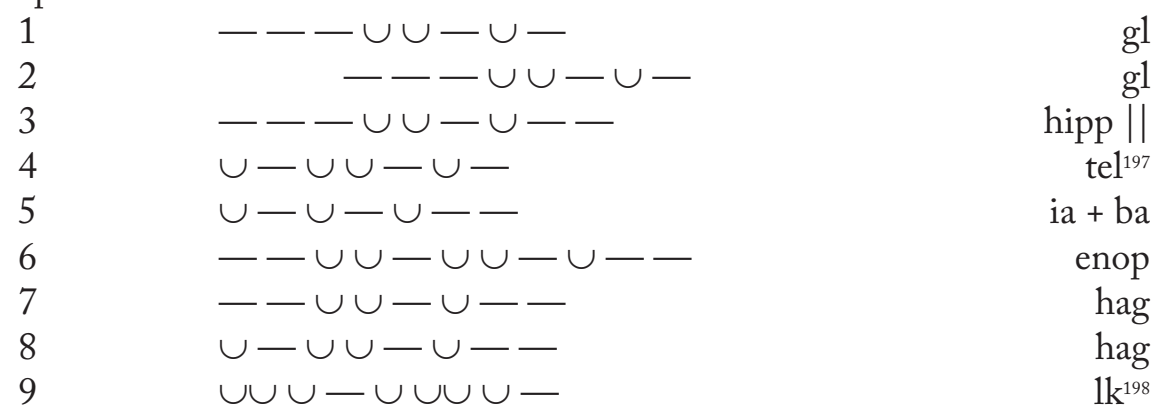

$\sim$ antistrophe

10

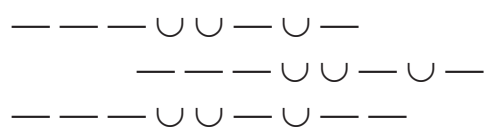

$\mathrm{glf}$
$\mathrm{gl}$
$\operatorname{hipp} \|$

${ }^{197}$ With Kannicht's text, 'ia + cr'.

${ }^{198}$ Cf. Telephus II.5. See Diggle (1994: 388 n. 86). 


\section{Erechtheus}

\section{Fr. III $(\operatorname{Tr} G F S)=$ Fr. 369 Kannicht}

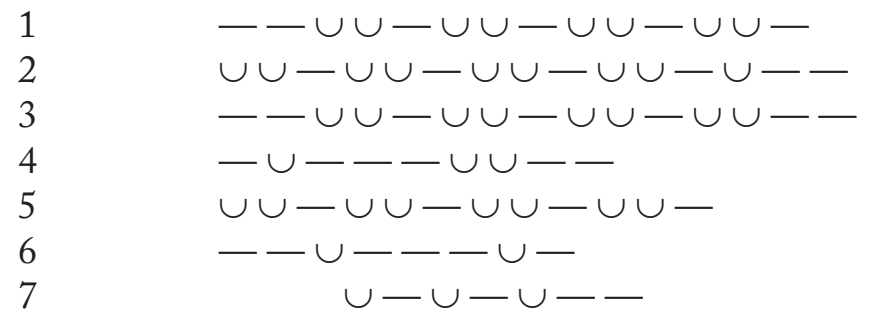

$$
\begin{array}{r}
\mathrm{sp}+\mathrm{A} \\
\mathrm{A}+\mathrm{ba} \\
\mathrm{enop} \\
\mathrm{e}-\mathrm{d}-\frac{\mathrm{A}}{} \\
-\mathrm{e}-\mathrm{e} \int \\
\mathrm{ia}+\mathrm{ba}
\end{array}
$$




\section{Telephus}

Fr. II $(T r G F S)=$ Fr. 727c Kannicht

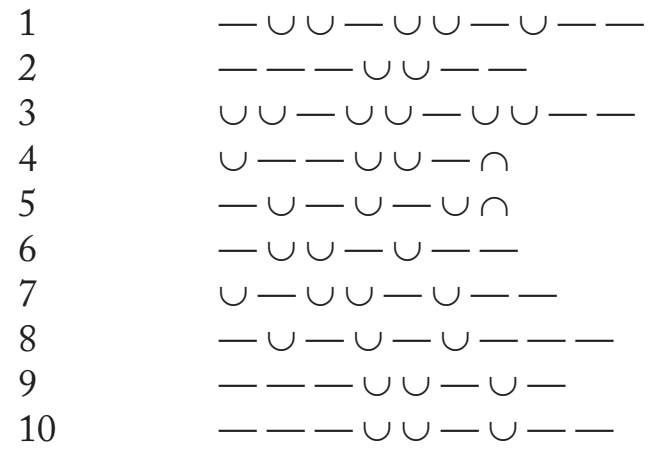

decasyll

ph

prm

ph $\|\left.\right|^{\mathrm{B}}$

lk $\|^{\mathrm{B}}$

ar

hag

$1 \mathrm{k}+\mathrm{sp}$

g1

hipp 


\section{Bibliography}

\section{Editions}

An asterisk $\left(^{*}\right)$ marks the edition to which I refer (unless otherwise stated) in listing or describing metrical phenomena pertaining to the poet in question.

\section{Aeschylus}

D. L. Page, Oxford, 1972.

*M. L. West, Stuttgart \& Leipzig, 1998.

\section{Aristophanes}

*N. G. Wilson, Oxford, 2007.

\section{Bacchylides}

*H. Maehler, Leipzig, 1970.

H. Maehler, Leiden, 1982-1997.

H. Maehler, Cambridge, 2004.

\section{Euripides}

G. Murray, Oxford, 1902-1913.

*J. Diggle, Oxford, 1981-1984.

D. Kovacs, Cambridge (Mass.), 1994-2002.

\section{Pindar}

*B. Snell, rev. H, Maehler, Leipzig, 1987.

\section{Sophocles}

R. D. Dawe, Stuttgart \& Leipzig, ${ }^{3} 1996$.

*H. Lloyd-Jones \& N. G. Wilson, Oxford, 1990. 


\section{EDITIONS OF INDIVIDUAL PLAYS}

Aeschylus

Persae

A. F. Garvie, Oxford, 2009.

Septem contra Thebas

G. O. Hutchinson, Oxford, 1983.

Agamemnon

E. Fraenkel, Oxford, 1950.

Choephori

A. F. Garvie, Oxford, 1988.

Eumenides

A. H. Sommerstein, Cambridge, 1989.

Prometheus

M. Griffith, Cambridge, 1983.

\section{Aristophanes}

Acharnians

S. D. Olson, Oxford, 2004.

Clouds

K. J. Dover, Oxford, 1968.

Peace

S. D. Olson, Oxford, 2003.

Birds

N. Dunbar, Oxford, 1997.

Thesmophoriazusae

C. Austin \& S. D. Olson, Oxford, 2004.

Frogs

K. J. Dover, Oxford, 1993. 


\section{Euripides}

Alcestis

A. M. Dale, Oxford, 1954.

L. P. E. Parker, Oxford, 2007.

Medea

D. L. PAge, Oxford, 1938.

D. J. Mastronarde, Cambridge, 2002.

Heraclidae

J. Wilkins, Oxford, 1993.

Hippolytus

W. S. Barrett, Oxford, 1965.

Andromache

P. T. Stevens, Oxford, 1971.

Hecuba

K. Matthiessen, Berlin, 2010.

Supplices

C. Collard, Groningen, 1975.

Electra

J. D. Denniston, Oxford, 1939.

Heracles

U. von Wilamowitz-Moellendorff, Berlin, ${ }^{2} 1895$.

G. W. Bond, Oxford, 1981.

Iphigenia in Tauris

M. Platnauer, Oxford, 1939.

D. Sansone, Leipzig, 1981.

P. Kyriakou, Berlin, 2006. 
Ion

A. S. Owen, Oxford, 1939.

U. von Wilamowitz-Moellendorff, Zürich, 1969 (= 1926).

Helen

A. M. Dale, Oxford, 1967.

R. Kannicht, Heidelberg, 1969.

W. Allan, Cambridge, 2008.

Phoenissae

D. J. Mastronarde, Cambridge, 1994.

Orestes

M. L. West, Warminster, 1987.

C. W. Willink, Oxford, 1989 (with Addendis Addenda).

Bacchae

E. R. Dodds, Oxford, ${ }^{2} 1960$.

R. SEAFord, Warminster, 1996.

Iphigenia at Aulis

F. Jouan, Paris, 1983.

H. C. Günther, Leipzig, 1988.

W. Stockert, Wien, 1992.

F. Turato, Venezia, 2001.

Rhesus

V. Liapis, Oxford, 2012.

Cyclops

R. A. S. Seaford, Oxford, 1984.

Sophocles

Ajax

P. J. Finglass, Cambridge, 2011. 
Electra

P. J. Finglass, Cambridge, 2007.

Oedipus Rex

R. D. DAwE, Cambridge, 2006 (revised edition).

Trachiniae

M. Davies, Oxford, 1991.

Antigone

M. Griffith, Cambridge, 1999.

\section{Fragments}

C. A. Austin, Nova Fragmenta Euripidea in Papyris Reperta, Berlin 1968.

G. W. Bond, Euripides, Hypsipyle, Oxford, 1963.

C. Collard \& M. Cropp, Euripides, Fragments, 2 vols, Cambridge (Mass.), 2008-2009.

W. E. H. Cockle, Euripides, Hypsipyle, Roma, 1987.

J. Diggle, Euripides, Phaethon, Cambridge, 1970.

*J. Diggle, Tragicorum Graecorum Fragmenta Selecta, Oxford, 1998.

R. Kannicht, Tragicorum Graecorum Fragmenta, Vol. 5: Euripides, Göttingen, 2004 (2 vols).

H. Lloyd-Jones, Sophocles, Fragments, Cambridge (Mass.), 1996.

A. NAuck, Tragicorum Graecorum Fragmenta, Hildesheim, 1964 (reprint).

S. Radt, Tragicorum Graecorum Fragmenta, Vol. 4: Sophocles, Göttingen, 1977.

\section{General:}

W. S. Barrett (2007), Greek Lyric, Tragedy E Textual Criticism: Collected Papers, Oxford.

L. Battezzato (2008), "Colometria antica e pratica editoriale moderna", QUCC 89, 133-154.

(2009a), "The Fragmentum Grenfellianum: Metrical Analysis, Ancient Punctuation and the Sense of an Ending" in J. R. C. Cousland and J. R. 
Hume, The Play of Texts and Fragments: Essays in honour of Martin Cropp, Leiden, 403-420.

(2009b), "Techniques of Reading and Textual Layout in Ancient Greek Texts", PCPS 55, 1-23.

C. M. Bowra (1964), Pindar, Oxford.

W. Breitenbach (1934), Untersuchungen zur Sprache der euripideischen Lyrik, Tübingen.

F. Budelmann (2009), The Cambridge Companion to Greek Lyric, Cambridge.

J. Buijs (1985), "Studies in the Lyric Metres of Greek Tragedy", Mnemosyne $38,62-92$.

(1986), "Studies in the Lyric Metres of Greek Tragedy", Mnemosyne $39,42-73$.

C. Collard (1989-1990), “The Stasimon, Euripides, Hecuba 905-52”, Sacris Erudiri 31, 85-98.

G. Сомотті (1977), "Words, Verse and Music in Euripides' Iphigenia in Aulis", Museum Philologicum Londinense 2, 69-84.

N. C. Conomis (1964), “The Dochmiacs of Greek Drama”, Hermes 92, 23-50.

M. Cropp (1997), “Euripides, Phoenissae 1567-1578”, CQ 47, 570-574.

A. M. Dale (1936), "Lyric Clausulae in Sophocles" in Greek Poetry and Life: Essays presented to Gilbert Murray, Oxford, 181-205.

- (21968), The Lyric Metres of Greek Drama, Cambridge.

- (1969), Collected Papers, Cambridge.

(1971), Metrical Analyses of Tragic Choruses, I: Dactylo-epitrite, BICS Suppl. 21.1 (1971).

(1981), Metrical Analyses of Tragic Choruses, II: Aeolo-Choriambic, BICS Suppl. 21.2

- (1983), Metrical Analyses of Tragic Choruses III: Dochmiac-IambicDactylic-Ionic, BICS Suppl.21.3.

C. Danesin (1998), "Gliconei in responsione in Euripide”, MD 40, 145-204.

R. D. Dawe (1973), Studies on the Text of Sophocles, Leiden, vol. I.

(1973a), Studies on the Text of Sophocles, Leiden, vol. II.

(1978), Studies on the Text of Sophocles, Leiden, vol. III. 
M. De Poli (2006), "Giambo e anapesto tra metrica e ritmica. Fenomeni di superallungamento in Euripide?”, Eikasmos 17,121-129.

(2011), Le Monodie di Euripide: Note di critica testuale, Padova.

J. D. Denniston (1936), "Lyric Iambics in Greek Drama" in Greek Poetry and Life: Essays presented to Gilbert Murray, Oxford, 121-144.

V. Di Benedetto (1961), "Responsione strofica e distribuzione delle battute in Euripide”, Hermes 89, 298-321.

J. Diggle (1981), Studies on the Text of Euripides, Oxford.

(1990), LCM 15.5, 74-79 (review of Cole, Epiploke).

(1991), The Textual Tradition of Euripides' Orestes, Oxford.

(1994), Euripidea: Collected Essays, Oxford.

- (1994a), CR 44, 324-325 (review of Sicking, Griechische Verslehre).

- (1995), “Notes on Euripides, Hypsipyle”, Eikasmos 6, 39-44.

(1995-6), "Notes on fragments of Aeschylus" Museum Criticum 30-1, 99-104.

(1996), "P. Petrie 1. 1-2: Euripides, Antiope (fr. 223 (Nauck) Kannicht, XLVIII Kambitsis)”, PCPS 42, 106-126.

___ (1996a), "Epilegomena Phaethontea" AC 65, 189-199.

- (1996b), "Sophocles, Ichneutae (fr. 314 Radt), ZPE 112, 3-17.

(1997), “Notes on fragments of Euripides”, CQ 47, 98-108.

M. FAntuzzi (2007), "La mousa del lamento in Euripide, e il lamento della Musa nel Reso ascritto a Euripide”, Eikasmos 18, 173-199.

R. Ferrari (1990), “Osservazioni sulla parodo dell' Ifigenia in Aulide di Euripide (vv. 231-302)”, Eikasmos 1, 101-109.

P. J. Finglass (2007), Pindar, Pythian 11, Cambridge.

- (2009), "Interpolation and Responsion in Sophocles' Ajax”, CQ 59, 335-352.

S. Frade (2006), A Poética do Ciclo Coral de Fenícias: uma visita à oficina lírica de Eurípides, Lisboa (dissertação de mestrado).

E. Fraenkel (1964), Kleine Beiträge zur klassischen Philologie I, Roma.

(1965), review of Ritchie, Authenticity: Gnomon 37, 228-241.

A. Fries (2010), "The Poetic Technique of [Euripides]: the case of Rhesus 118”, CQ 60, 345-351. 
B. Gentili \& F. Perusino (1999), La colometria antica dei testi poetici greci, Pisa-Roma.

M. Griffith (1977), On the Authenticity of the Prometheus Bound, Cambridge.

W. B. Henry (2003), "Contracted Biceps in Pindar”, ZPE 143, 11-16.

D. E. Hill (1974), "Quaestio Prosodiae”, Glotta 52, 218-231.

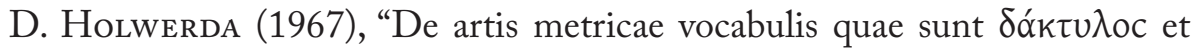

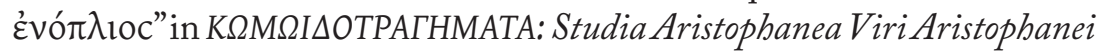
W. J. W. Koster in honorem, Amsterdam, 51-58.

J. Holzhausen (1995), “Textprobleme in der 'Helena' des Euripides”, Philologus 139, 181-203.

M. Hose (1990), Studien zum Chor bei Euripides I, Stuttgart.

- (1991), Studien zum Chor bei Euripides II, Stuttgart.

G. O. Hutchinson (2001), Greek Lyric Poetry: A Commentary on Selected Larger Pieces, Oxford.

M. Imнof (1970), “Euripides' Ion und Sophokles' Oedipus auf Kolonos”, $M H$ $27,62-89$.

J. Irigoin (1953), Recherches sur les mètres de la lyrique chorale grecque. La structure $d u$ vers, Paris.

K. Itsumi (1982), “The 'Choriambic Dimeter' of Euripides”, CQ 32, 59-74.

___ (1984), "The Glyconic in Tragedy", CQ 34, 66-82.

(1991-1993), “Enoplian in Tragedy”, BICS 38, 243-261.

(2007), "What's in a Line? Papyrus formats and Hephaestionic Formulae", in P.J. Finglass, C. Collard \& N.J. Richardson (ed.), Hesperos: Studies in Ancient Greek Poetry Presented to M. L. West on his Seventieth Birthday, Oxford, 306-325.

- (2009), Pindaric Metre: The 'Other Half', Oxford.

D. Korzeniews ki (21989), Griechische Metrik, Darmstadt.

D. Kovacs (1994), Euripidea, Leiden.

(1996), Euripidea Altera, Leiden.

(2003), “Toward a reconstruction of Iphigenia Aulidensis”, JHS 123, 77-103.

(2003a), Euripidea Tertia, Leiden. 
V. Liapis (2009), “Rhesus revisited: the case for a fourth-century Macedonian context”, JHS 129, 71-88.

J. B. Lidov (1989), “Alternating rhythm in archaic Greek poetry”, TAPA 119, 63-85.

(2010), "Metre, Colon and Rhythm: Simonides (PMG 542) and Pindar between Archaic and Classical", CP 105, 25-53.

H. Lloyd-jones \& N. G. Wilson (1990), Sophoclea: Studies on the Text of Sophocles, Oxford.

- (1997), Sophocles: Second Thoughts, Göttingen.

M. J. Lossau (1995), “ “Äolisches’ in Euripides'Medea”, Philologus 139, 483-490.

F. Lourenço (2000), "An Interpolated Song in Euripides? Helen 229-52", JHS 120, 132-138.

- (2000a), “Two Notes on Euripides' Helen (186; 1472)”, CQ 50, 601603.

—_ (2000b), “Metrical Notes on 'Andromeda's Lament' in Thesmophoriazusae", Euphrosyne 28, 321-324.

P. MaAs (1962), Greek Metre (tr. H. Lloyd-Jones), Oxford.

M. C. Martinelli (1995), Gli strumenti del poeta: elementi di metrica greca, Bologna.

P. Masqueray (1895), Théorie des formes lyriques de la tragédie grecque, Paris.

D.J.Mastronarde \&J.M.Bremer (1982), The Textual Tradition of Euripides' Phoinissai, California.

D.J. Mastronarde (2010), The Art of Euripides: Dramatic Technique and Social Context, Cambridge.

C. Morais (1995), "Uma catábase agonístico-burlesca com contraposição rítmica (Ar. Ra. 208-268)”, Humanitas 47, 307-325.

H. W. Nordheimer (1980), Die Chorlieder des Euripides in ibrer dramatischen Funktion, Frankfurt.

R. PAdel (1974), "Imagery of the elsewhere: two choral odes of Euripides", CQ 24, 227-241.

D. L. Page (1955), Sappho and Alcaeus, Oxford.

L. P. E. Parker (1958), "Some Recent Researches on the Versification of Pindar and Bacchylides”, BICS 5, 13-24. 
(1958a), "Some Observations on the Incidence of Word-End in Anapaestic Paroemiacs and its Application to Textual Questions", $C Q$ 8, 82-89.

___ (1966), “Porson's Law Extended”, CQ 16, 1-26.

(1968), "Split Resolution in Greek Dramatic Lyric”, CQ 18, 241-269.

(1976), “Catalexis”, CQ 26, 14-28.

- (1988), "Eupolis the Unruly”, PCPS 214, 115-122.

- (1990), "Trochee to Iamb, Iamb to Trochee”, in E. Craik (ed.), 'Owls to Athens': Essays on Classical Subjects for Sir Kenneth Dover, Oxford, 331348.

(1997), The Songs of Aristophanes, Oxford.

(2001), "Consilio et Ratio? Papyrus A of Bacchylides and Alexandrian metrical scholarship”, CQ 51, 23-52.

(2007), “Dionysius' Ear', in P. J. FINGLASS, C. COLLARD \& N. J. Richardson (ed.), Hesperos: Studies in Ancient Greek Poetry Presented to M. L. West on his Seventieth Birthday, Oxford, 297-305.

M. Patin ( $\left.{ }^{4} 1873\right)$, Études sur les tragiques grecs, Tome I, Paris.

A. Pickard-cambridge (21968), The Dramatic Festivals of Athens, second edition revised by J. Gould and D. M. Lewis, Oxford.

R. Pretagostini (1972), "Lecizio e sequenze giambiche o trochaiche", $R I F C$ 100, 257-273.

L. Prauscello (2006), Singing Alexandria: Music between Practice and Textual Transmission, Leiden.

M. O. Pulquério (1967-1968), "Características Métricas das Monódias de Eurípides”, Humanitas 19-20, 87-168.

W. Ritchie (1964), The Authenticity of the Rhesus of Euripides, Cambridge.

M. H. Rocha Pereira (1961), Sobre a Autenticidade do Fragmento 44 Diehl de Anacreonte, Coimbra.

L. E. Rossi (1963), “Anceps: Vocale, sillaba, elemento”, $R F$ 91, 52-71.

I. Rutherford (2001), Pindar's Paeans: A Reading of the Fragments with a Survey of the Genre, Oxford.

R. Schmiel (1970), “The Recognition Duo in Euripides' Helen”, Hermes 100, 274-294. 
O. Schroeder (1910, $\left.{ }^{2} 1928\right)$, Euripidis Cantica, fragmento Grenfelliano adiecto, Leipzig.

J. F. A. Seidler (1811-12), De Versibus Dochmiacis Tragicorum Graecorum, Leipzig.

C. M. J. Sicking (1993), Griechische Verslehre, München.

G. M. Sifakis (1967), Studies in the History of Hellenistic Drama, London.

M. F. Silva (2005), Ensaios sobre Eurípides, Lisboa.

B. SNell ( $\left.{ }^{4} 1982\right)$, Griechische Metrik, Göttingen.

T. C. W. Stinton (1990), Collected Papers on Greek Tragedy, Oxford.

W. Stockert (1982), "Zum Schlussteil der Parodos der euripideischen Iphigenie in Aulis", Prometheus 8, 21-30.

L. A. Swift (2010), The Hidden Chorus: Echoes of Genre in Tragic Lyric, Oxford.

J. A. Symonds (31920), Studies of the Greek Poets, London.

A. Tessier (1975), "Per un inventario di docmi ripetitivi in Euripide", Bolletino dell'Istituto di Filologia Greca, Padova 2, 130-143.

M. L. West (1977), “Tragica I”, BICS 24, 89-103.

(1981), “Tragica V”, BICS 28, 61-78.

(1982), Greek Metre, Oxford.

(1982a), “Three Topics in Greek Metre”, CQ 32, 281-297.

(1990): review of D. J. Mastronarde (ed.), Euripides: Phoenissae, Leipzig, 1988 in CP 85, 311-317.

- (1992), Ancient Greek Music, Oxford.

U. von Wilamowitz-Moellendorff (1921), Griechische Verskunst, Berlin.

C. W. Willink (2010), Collected Papers on Greek Tragedy, ed. by W. B. Henry, Leiden.

N. G. Wilson (2007), Aristophanea: Studies on the Text of Aristophanes, Oxford.

R. E. Wycherley (1946), “Aristophanes and Euripides”, GERR 15, 98-107.

G. Zuntz (1965), An Inquiry into the Transmission of the Plays of Euripides, Cambridge. (1984), Drei Kapitel zur griechischen Metrik, Wien. 


\section{INDEX LOCORVM}

Euripidean plays are listed as in the three volumes of the OCT (Cyclops followed by tragedies listed chronologically; then fragmentary plays, listed alphabetically). Works of other authors are listed alphabetically.

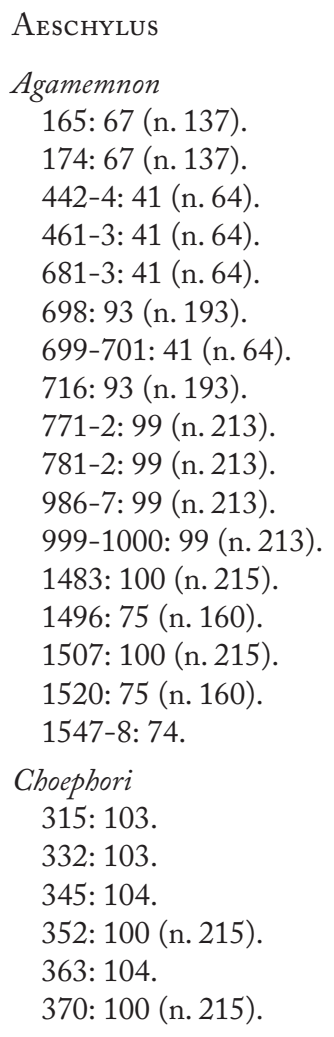

385: 75 (n. 160).

399: 75 (n. 160).

466: 104.

469-70: 99 (n. 213).

471: 104.

474-5: 99 (n. 213).

607: 41 (n. 64).

617: 41 (n. 64).

\section{Eumenides}

494: 41 (n. 64).

496: 35 (n. 44).

497: 41 (n. 64).

503: 41 (n. 64).

505: 35 (n. 44).

506: 41 (n. 64).

515: 41 (n. 64).

524: 41 (n. 64).

782: 41 (n. 64).

812: 41 (n. 64).

996: 74 .

1014: 74.

Persae

556-7: 99 (n. 213).

566-7: 99 (n. 213).

638: 35 (n. 44).

645: 35 (n. 44).

651: 75 (n. 160). 


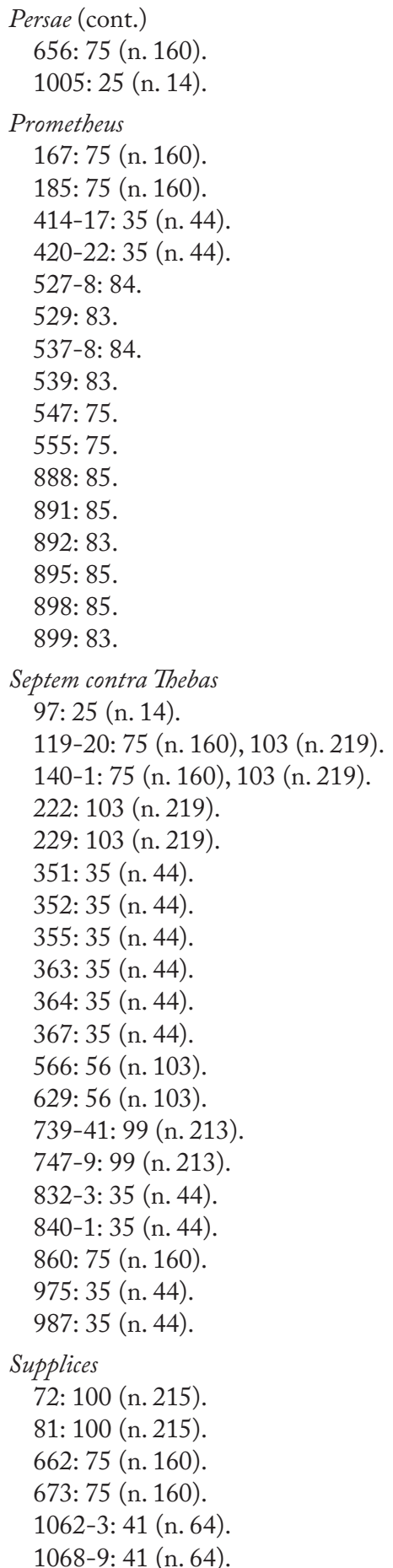

\section{Alcaeus \\ PLF 338, 1: 104.}

\section{Alcman}

Fr. 1, 57 (PMGF 1): 100.

\section{Anacreon}

Fr. 419 (PMG): 36 (n. 49).

\section{Archilochus}

Fr. 168 (West): 73.

\section{Aristophanes \\ Acharnenses \\ 361: 53 (n. 93). \\ Aues}

1372: 95 (n. 198).

1412: 76 (n. 162).

1415: 76 (n. 162).

Ecclesiazusae

576: 83.

579: 82 .

Equites

589-90: 113 (n. 245).

599-60: 113 (n. 245).

1266: 84 .

1267: 83 .

1268: 83 .

1269: 84 .

1270: 83 .

1292: 84 .

1294: 83.

1296: 83.

Lysistrata

1288: 103.

Nubes

275: 25 (n. 14)

298: 25 (n. 14).

315: 65 .

465: 83.

466: 82.

470-1: 82.

472-3: 82 .

474-5: 82.

615: 71 (n. 146). 


\section{Pax}

389: 95 (n. 199).

588: 95 (n. 199).

775: 82.

780: 84 .

784: 82.

795: 82.

805: 82.

Ranae

219: 82.

676: 82 .

708: 82.

1208 ff: 40.

1251: 93 (n. 193).

1317: 93 (n. 193).

1327: 93 (n. 193).

Thesmophoriazusae

130 ff: 87 (n. 182).

330: 82.

914-5: 32 .

1136: 103 (+ n. 221).

1137-8: 103.

1148: 103.

1149: 103 (+ n. 221).

1150: 103.

1156: 103.

Vespae

278: 83.

275: 83 (+ n. 172).

277: 83 (+ n. 173).

279: 82, 83.

283: 83 (+ n. 172).

284: 83 .

285: 83 (+ n. 173).

287: 82 .

289: 83.

PCG 9: 105.

Aristotle

Poetics

1149b: 31.

1449b: 36 .

1459b: 65 .

Rhetoric

3.8.1408b: 36 (n. 48).

\section{BAcChylides}

5 (s): 82 .

13 (str.): 83 .

14 (str.): 84.

\section{Demetrius}

De elocutione

164: 32 (n. 36).

166: 32 (n. 36).

\section{Euripides}

Cyclops

41: 109 (n. 235).

41-81: 48 (n. 82).

42: 110 (n. 237).

43: 109 (n. 235).

44: 110 (n. 238).

45: 109 (n. 235).

46: 109.

47: 109 (n. 235).

48: 109 (n. 234, n. 235).

49: $24,48$.

50: 49.

51: 45 (n. 74), 50.

52: 75 .

54: 110 .

55: 109 (n. 235).

56: 110 (n. 237).

57: 109 (n. 235).

58: 110 .

59: 109 (n. 235).

61: 109 .

62: 109 (n. 234, n. 235).

64: 110 (+ n. 238).

65: 102.

66: 110 (+ n. 238).

67: 109 (n. 235).

69: 92 (n. 191).

68: 110 (n. 237).

70: 109 (n. 235).

71: 109 (n. 235).

72: 22, 110 (+ n. 237).

73: 22.

76: 110 .

77: 121.

78-9: 49.

80: 49. 


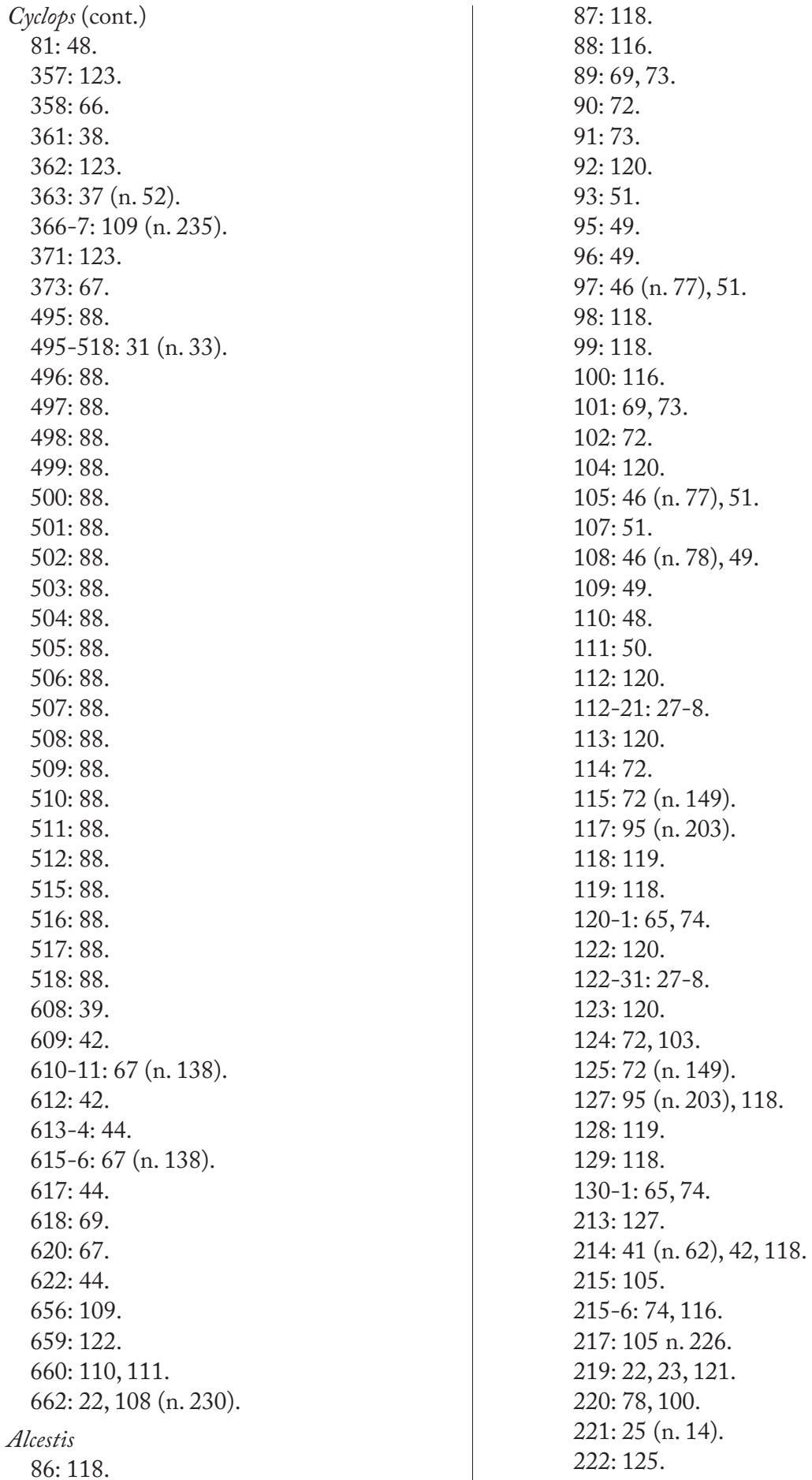


224: 74 .

225: 75 .

227: 41 (n. 62), 43.

228: 105 .

228-9: 74, 116.

229: 105 (n. 226).

231: 22, 23, 121.

232: $78,100$.

234: 125 .

236: 74 .

237: 75 .

245: 105 (+ n. 226), 106 (n. 228, n. 229).

248: 103.

249: 105 (+ n. 226), 106 (n. 228, n. 229).

252: 78 .

253: 29, 78, 100.

254 (+ n. 259).

255: 121 .

256: 105 (n. 226), 106 (n. 228), 113.

259: 78 .

260: 29, 78, 100.

261: 118 .

262: 121.

263: 105 (n. 226), 106 (n. 228), 113.

266: 29 (n. 28), 120.

267: 42.

268: 115 (n. 248).

269: 30 (n. 29).

270: $24,111$.

272: 125.

393: 56 (n. 103), 60 (n. 114), 63.

393-403: 30 (n. 31).

394: 118.

395: 60 (n. 115).

396-7: 77.

399: 60 (n. 115).

400: 76.

401: 121.

403: 105 (n. 226), 106 (n. 228).

406: 56 (n. 103), 60 (n. 115), 63.

406-15: 30 (n. 31).

407: 118 .

408: 60 (n. 115).

409-10: 77.

411: 23.

412: 76.

413: 27, 121.

414: 74 .

415: 23, 105 (n. 226), 106 (n. 228).
435: 72 (n. 149).

436: 73 .

437: 76 (n. 162).

438: 73.

439: 72 .

440: 72 (n. 149).

441: 120.

442: 76 (n. 162).

443: 79.

444: 105 (n. 226), 106 (n. 228).

445: 72 (n. 149).

446: 73.

448: 73.

447: 76 (n. 162).

449: 72.

450: 72 (n. 149).

451: 120 .

452: 76 (n. 162).

453: 79.

454: 105 (n. 226), 106 (n. 228).

455: 105 (n. 226).

455-461: 25.

456: 96 (n. 205).

457: 75.

459: 127.

460: 76 (n. 162).

461: 78 .

462: 67.

463: 67 (n. 138).

464: 29, 65, 67 (n. 138).

465: 29 (n. 26), 120.

466: 105 (n. 226).

467: 96 (n. 205).

468: 75.

469: 127 .

470: 76 (n. 162).

471: 77, 87.

472: 67.

473: 67 (n. 138).

474: 29, 65, 67 (n. 138).

475: 29 (n. 26), 120.

568-9: 25 (n. 14), 74, 81, 86.

570-1: 83.

572: 120 .

573: 84.

574: 120 .

575: 92 (n. 191).

576: 112 .

576-9: 81. 
Alcestis (cont.)

577: 95 (n. 203).

578-9: 23, 74, 86.

579: 24.

580-1: 83 .

582: 120 .

583: 84.

584: 23 (n. 9), 120.

585: 92 (n. 191).

586: 112 .

587: 95 (n. 203).

588: 72 .

589: 83.

590: 83.

591: 67 (n. 138).

592: 23 (n. 9), 105 (n. 226).

595: 83, 100.

597: 72 .

598: 83.

599: 83.

600: 67 (n. 138).

601: 105 (n. 226).

604: 83, 100.

872: 125 .

873: 59, 60 (n. 114).

874: 22, 60 (n. 115).

875: 118 .

876: 85 .

877: 59, 60 (n. 114).

889: 125 .

890: 59, 60 (n. 114).

891: 22, 59, 60 (n. 115).

892: 22, 118.

893: 85.

894: 59, 60 (n. 114).

903: 117.

903-5: 26.

904: 69.

905: 121.

907-8: 119 .

909: 76.

910: 108 (n. 230).

911: 105, 106 (n. 228).

926: 117.

927: 69 .

928: 121

930-1: 119.

932: 76.

933: 108 (n. 230).
934: 105, 106 (n. 228).

962: 96 (n. 205).

963: 92 (n. 191).

964: 92 (n. 190).

965: 96 (n. 204).

966: 92 (n. 191).

967: 95 (n. 203).

968: 95 (n. 203).

969: 92 (n. 191).

970: 22, 105 (n. 226).

971: 93, 104.

972: 105 (n. 226), 106 (n. 228).

973: 96 (n. 205).

974: 92 (n. 190).

975: 92 (n. 191).

976: 95 (n. 203).

977: 92 (n. 190).

978: 95 (n. 203).

979: 95 (n. 203).

980: 92 (n. 191).

981: 22, 105 (n. 226).

982: 93, 104.

983: 105 (n. 226), 106 (n. 228).

984-5: 115.

986-7: 113.

988: 92 (+ n. 190).

989: 96 (n. 207), 97.

990: 110.

991: 100 .

992: 100

993: 100 .

994: 99 (n. 214).

995-6: 115.

997-8: 113.

999: 92 (+ n. 190).

1000: 96 (n. 207), 97.

1001: 111.

1000-5: 101.

1002: 100 .

1003: 100 .

1004: 100 .

1005: 99 (n. 214).

Medea

96: 49.

96-7: 31 (n. 35).

$97(+$ n. 86).

111: 46 (n. 78), 49.

111-4: 31 (n. 35).

112: 49. 
113: 49.

114: 50.

131: 46 (n. 78), 49.

132: 45 (n. 74), 50, 65 (n. 134).

133: 22, 45 (n. 74).

134-5: 67 (n. 138).

135: 76 .

136: 67 (n. 138).

137: 65,69 .

138: 99.

144: 49.

144-7: 31 (n. 35).

146: 50 .

147: $22,50$.

148: 49.

149: 50 .

150: 48.

151: 78, 100.

151-3: 102 .

152: 78, 100.

153: $78,100$.

154: 108 (n. 230).

155-6: 112.

157: 78, 100.

158: 78, 100.

159: 114 .

160: 49.

160-7: 31 (n. 35).

161: 49.

162: 50 .

163: 49.

164: 49.

165: 49.

166: 49.

167: 50 .

173: 49.

174: 50.

175: 48.

176: 78, 100.

177: 78, 100.

178: 78, 100.

179: 108 (n. 231).

180: 112 .

181: 78, 100.

182: 78, 100.

183: 114 .

205: 128.

206: 29 (n. 28), 119.

207: 78.
208: 37.

209: 84.

210: 72 (n. 149).

211: 119 .

212: 95 (n. 203).

410: 83.

411: 83.

412-3: 82.

415-6: 84.

417-8: 83.

419-20: 85.

421-2: 83.

423: 83.

424: 82.

426-7: 84.

427: 22.

428-9: 83.

430-1: 85.

432: 112 .

433-4: 74.

435: 96.

436: 96 (n. 207), 97.

437: 92 (n. 190, n. 191).

439: 112 .

438: 96 (n. 204).

440-1: 74.

442: 96 (n. 207).

443: 96 (n. 207), 97.

444: 92 (n. 190).

445: 96 (n. 204).

627-8: 83 .

629-30: 82 .

631-2: 84 .

633-4: 84.

635: 85.

636-7: 83 .

638-9: 82.

640-1: 84.

642-3: 84.

644: 85.

645: 115 (n. 248).

646: 105 (n. 226).

647-8: 79.

648: 27 (n. 22).

649: 29, 63.

650: 76 (n. 162).

651: 109 .

653: 99.

654: 115 (n. 248). 
Medea (cont.)

655: 105 (n. 226).

656-7: 79 .

658: $29,63$.

659: 76 (n. 162).

660: 109 .

662: 99.

781: 84.

824: 82 .

825: 83.

826-7: 84 .

828-9: 82.

830-1: 84.

832-3: 82.

834: 72, 73, 99 (n. 214).

835: 83.

836-7: 83.

838-9: 84.

840: 72 (+ n. 151), 82.

841-2: 84 .

843-4: 82.

845: 72, 73 (+ n. 153), 99 (n. 214).

846: 72 .

847: 105.

848: 120.

849: $78,100$.

850: 78, 100.

851: 96.

852: 29 (n. 26), 78, 100.

853: 78, 100.

854: 96 (n. 207).

855: 108 .

856: 72 .

857: 105.

858: 120 .

859: 78, 100.

860: 22, 78, 100.

861: 96.

862: 29 (n. 26), 78, 100.

863: 78, 100.

864: 96 (n. 207).

865: 108 .

976: 83.

977: 84 .

979: 83.

980-1: 72, 82.

983: 83.

985: 84.

986: 83 .
987-8: 72, 82.

990-1: 79 .

992: 120.

993: 77.

994: 72.

996-7: 79 .

998: 120.

999: 77.

1000: 72 .

1251: 59, 60 (n. 114).

1251-60: 30 (n. 30).

1252: 29 (n. 28), 61.

1253: 60 (n. 114), 60 (n. 115).

1254: 60 (n. 114).

1255: 59, 61 .

1256: 60 (n. 114), 62.

1257: 60 (n. 115).

1258: 60 (n. 115), 62.

1259: 60 (n. 114).

1260: 59, 62 .

1261: 59, 60 (n. 114).

1261-70: 30 (n. 30).

1262: 29 (n. 28), 61.

1263: 60 (n. 114), 60 (n. 115).

1264: 60 (n. 114).

1265: 59, 61 .

1266: 59 (n. 110), 60 (n. 114), 62.

1267: 60 (n. 115).

1268: 60 (n. 115).

1269: 60 (n. 114), 60 (n. 115).

1270: 59, 60 (n. 115), 62.

1273: 60 (n. 114).

1273-81: 30 (n. 30).

1274: 25 (n. 14), 60 (n. 115).

1275: 60 (n. 114).

1276: 60 (n. 114).

1279: 60 (n. 114), 60 (n. 115).

1280: 60 (n. 114).

1281: 26, 29 (n. 28), 119.

1282: 60 (n. 114).

1282-92: 30 (n. 30).

1283: 60 (n. 114), 60 (n. 115).

1286: 29 (n. 26), 60 (n. 114).

1287: 60 (n. 114).

1288: 22 .

1290: 60 (n. 114), 60 (n. 115), 107.

1291: 60 (n. 114).

1292: 60 (n. 114), 119. 


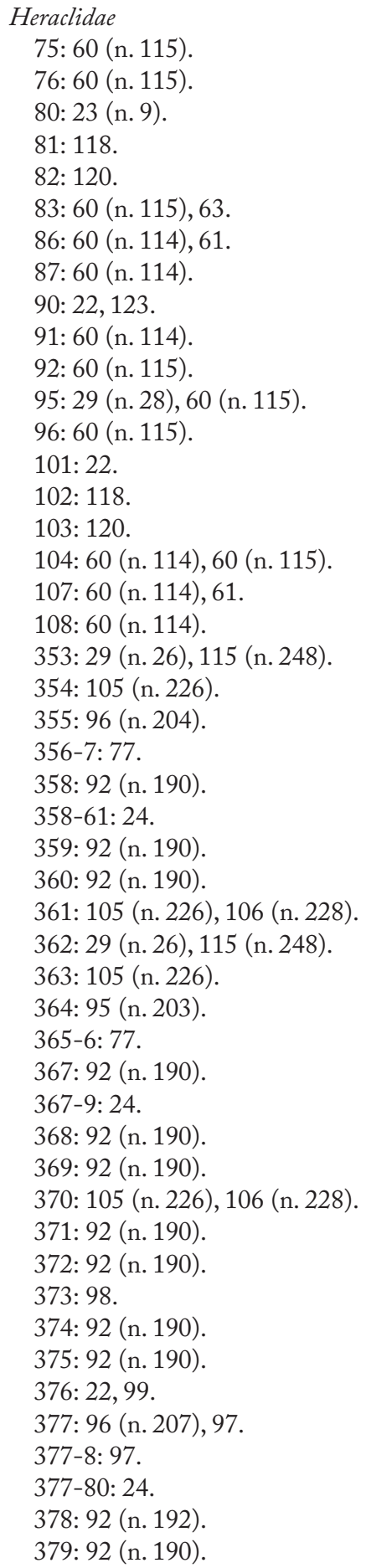

380: 105 (n. 226), 106 (n. 228).

608: 22, 24, 66.

609: 108 .

610: 67 (n. 138).

611: 67, 68 .

612: 67 (n. 138), 108.

613: 67.

615: 67 (n. 138).

615-7: 24.

616: 67 (n. 138).

617: 72.

619: 66.

620: 108 .

622: 67, 68 .

623: 108 .

624: 65, 67.

625: 67.

626: 67 (n. 138).

626-8: 24.

627: 67 (n. 138).

628: 72 .

748: 92 (n. 190).

748-50: 25 (n. 14).

749: 92 (n. 190).

750: 98.

752: 92 (n. 192).

753: 92 (n. 190).

754: 108 (n. 230).

755: 92 (n. 190).

756: 92 (n. 190).

757: 98.

758: 111.

759: 92 (n. 190).

760: 92 (n. 190).

761: 98.

763: 92 (n. 192).

764: 92 (n. 190).

765: 108 (n. 231).

766: 92 (n. 190).

767: 92 (n. 190).

768: 98.

769: 111.

770: 92 (n. 190).

771: 92 (n. 190).

772: 92 (n. 190).

773: 125 .

774: 72.

775: 77.

776: 125 . 
Heraclidae (cont.)

777: 93.

778: 92 (n. 190).

779: 92 (n. 190).

780: 125 .

781: 72.

782: 77.

782-3: 26 (n. 15).

783: 125 .

892: 123.

893: 105 (n. 225).

894: 112.

895: 92 (n. 190).

896: 100.

897: 29 (n. 26), 105 (n. 226).

898-9: 112.

900: 96 (n. 204).

901: 123.

901-2: 26 (n. 15).

902: 105 (n. 226).

903: 112.

904: 92 (n. 190).

905: 100 .

906: 29 (n. 26), 105 (n. 226).

907-8: 112.

909: 96 (n. 204).

910: 116.

910-14: 24.

911: 92 (n. 191).

912: 92 (n. 190).

913: 92 (n. 191).

914: 100.

915: 96 (n. 207), 97.

916: 99.

917: 105.

917-8: 106.

918: 99 (n. 214).

919: 116.

919-23: 24.

920: 92 (n. 190).

921: 92 (n. 191).

922: 92 (n. 190).

923: 100 .

924: 96 (n. 207), 97.

925: 99.

926: 105.

926-7: 106.

927: 99 (n. 214).

\section{Hippolytus}

58: 22, 102 (+ n. 218).

59: 72 (n. 149).

60: 22,72 .

61: 29 (n. 28), 115.

62: 108 .

63: 92 (n. 191).

64-5: 92 (n. 190).

66: 92 (n. 190).

67: 42.

68: 92 (n. 190).

69: 99 (n. 214).

70: 72 .

71-2: 102 .

121: 82.

122: 111.

123-4: 99 (n. 214).

125: 78.

128: 112 .

130: 112 .

131: 82.

132: 111.

133-4: 99 (n. 214).

135: 78.

138: 112 .

140: 112 .

141: 25 (n. 14), 94.

142: 109.

143: 95 (n. 203).

144: 102.

146: 109.

147: 113.

148: 110 (n. 237).

149: 109.

150: 94.

151: 92 (n. 191), 94.

152: 109.

153: 95 (n. 203).

154: 102.

155: 110 (n. 238).

156: 109 (n. 235).

157: 113 .

158: 110 (n. 237).

159: 109 .

160: 94 .

161: 125.

163: 73.

164: 69, 73.

165: 77. 
166: 77.

167: 73 .

169: 120 .

208: 50.

208-11: 31 (n. 35).

209: 49.

210: 49 .

211: 50 .

215: 49.

215-22: 31 (n. 35).

216: 49.

217: 48.

218: 49.

219: 50 .

220: 49.

221: 49 .

222: 48.

228: 50 .

228-31: 31 (n. 35).

229: 49.

230: 49.

230-1: 45.

231: 49.

362: 24, 25 (n. 14), 60 (n. 114), 122.

363: 61 .

364: 60 (n. 114).

365: 53 (n. 92), 60 (n. 115), 63.

366: 59, 60 (n. 114).

367: 59, 60 (n. 114).

368: 22, 123.

369: 59 (n. 110), 60 (n. 115), 62.

370: 60 (n. 114).

371: 123.

372: 60 (n. 114), 60 (n. 115).

525: 113 .

526: 87,112 .

527: 87,112 .

528: 87, 112.

529: 108 (n. 230).

530-1: 114.

530-4: 42.

532-3: 114.

534: 108 (n. 231).

535: 113.

536: 87,112 .

537: 87, 112 .

538: 87, 112 .

539: 108 (n. 230).

540-1: 114.
540-4: 42.

542-3: 114.

544: 108 (n. 230).

545: 111.

546: 96 (n. 204).

547-8: 113.

549: 110 (n. 238).

550: 93 (n. 193).

551: 92 (n. 191).

552: 78.

553: 112 .

554: 108 (n. 230).

555: 111.

556: 96 (n. 204).

557-8: 113.

559: 110 (n. 238).

560: 93 (n. 193).

561: 92 (n. 190).

562: 78 .

563: 112 .

564: 108 (n. 230).

569: 60 (n. 114).

571: 63.

572: 22, 60 (n. 115).

573: 60 (n. 114), 60 (n. 115).

574: 60 (n. 115).

577: 60 (n. 115).

578: 60 (n. 114).

579: 60 (n. 114).

580: 29 (n. 28), 61.

581: 22, 60 (n. 115).

584: 60 (n. 114).

585: 60 (n. 114).

586: 60 (n. 114).

587: 61 .

588: 60 (n. 115).

591: 62 .

592: 60 (n. 115).

593: 60 (n. 114).

595: 119.

669: 60 (n. 114), 122.

670: 60 (n. 114), 60 (n. 115).

671: 60 (n. 114).

672: 60 (n. 115), 63.

673: 59, 60 (n. 114).

674: 59, 60 (n. 114).

675: 123 .

676: 60 (n. 115), 63.

677: 60 (n. 114). 
Hippolytus (cont.)

678: 123.

679: 60 (n. 114), 60 (n. 115).

732: 89.

732-4: 87.

733: 88.

735: 92 (n. 190).

734: 88.

737: 92 (n. 190).

736: 96 (n. 204).

738: 92 (n. 191).

739: 96 (n. 204).

740: 112 .

741: 94.

742: 88.

742-4: 87.

743: 88.

744: 88.

745: 92 (n. 190).

746: 95 (n. 203).

747: 92 (n. 191).

748: 92 (n. 190).

749: 95 (n. 203).

750: 112.

751: 94.

752: 92 (n. 190).

753: 92 (n. 191).

754: 92 (n. 191).

755-6: 79.

757: 22, 75 (+ n. 157).

758-9: 82.

760-1: 83.

762: 83.

763: 85.

764: 92 (n. 190).

765: 92 (n. 190).

767-8: 79.

769: 22, 75 (+ n. 157).

770-1: 82 .

772-3: 83.

774: 83.

775: 22,85 .

811: 60 (n. 115).

812: 60 (n. 115).

813: 117, 123.

814: 60 (n. 114), 60 (n. 115).

815: 60 (n. 114), 61.

816: 60 (n. 114), 60 (n. 115).

817: 60 (n. 115), 62.
818: 60 (n. 114).

821: 60 (n. 115).

822: 60 (n. 114), 60 (n. 115).

826: 60 (n. 115).

827: 60 (n. 114), 60 (n. 115).

830: 29 (n. 28), 57, 61.

831: 60 (n. 115), 61.

832: 60 (n. 114), 62.

833: 60 (n. 114).

836: 60 (n. 115).

837: 60 (n. 114).

840: 60 (n. 115).

841: 60 (n. 114), 61.

845: 60 (n. 114), 60 (n. 115).

848: 29 (n. 28), 57, 60 (n. 115), 61.

849: 59, 60 (n. 114), 62.

850: 60 (n. 114), 61.

851: 60 (n. 114).

852: 60 (n. 115), 63.

853: 60 (n. 115), 61.

854: 60 (n. 114).

855: 60 (n. 114), 60 (n. 115).

866: 59, 60 (n. 115).

867: 60 (n. 114).

869: 60 (n. 114), 60 (n. 115).

870: 59 (n. 110), 60 (n. 114), 61.

877: 126.

878: 124.

879: 63.

880: 62 .

882: 60 (n. 115).

883: 60 (n. 114), 61.

884: 60 (n. 115).

1091: 59.

1102-3: 66.

1104-5: 81, 86 (+ n. 181).

1106-7: 66.

1111-2: 66.

1113-4: 81, 86 (+ n. 181).

1115-6: 66.

1120: 29 (n. 26).

1120-1: 66.

1121: 24.

1124: 67, 68 .

1125: $21,22$.

1126: 67, 68 .

1128-9: 67, 68.

1130: 121.

1131: 29 (n. 26). 
1131-2: 66.

1135: 67, 68.

1136: 22.

1137: 67, 68 .

1139-40: 67, 68.

1141: 121.

1142: 118.

1143: 120.

1144: 23, 25 (n. 14), 127.

1145: 122.

1146: 22, 120.

1147: 117.

1148: 82 .

1148-50: 42.

1149: 43.

1267: 62 .

1268: 59, 60 (n. 114), 62.

1270: 72.

1271: 62 .

1272: 60 (n. 114), 63.

1273: 62 .

1274: 84.

1275: 62.

1276: 60 (n. 115).

1278: 60 (n. 115).

1279: 60 (n. 114), 61.

1280-1: 84.

1282: 75.

1370-8: 47.

1370: 48.

1371: 46 (n. 78), 50.

1372: 48.

1373: 50.

1374: 46 (n. 77).

1374-5: 47.

1376: 49.

1377: 22, 48.

1378: 49.

1379: 118 .

1379-88: 47.

1380: 122 .

1381: 48, 122.

1382: 119.

1383: 118 .

1385: 26 (n. 15), 42, 106 (n. 227), 122.

1386: 41 (n. 62), 42, 43.

1388: 22, 120, 121.

\section{Andromache}

103-16: 69, 72 (n. 151).
103: 66.

105: 22, 66.

107: 66.

108: 23.

109: 66.

111: 22,66 .

113: 66.

115: 22, 66 .

117: 66 .

118: 120 .

119: 29 (n. 27), 66.

120: 120 .

121: 126.

122: 66.

123: 120 .

124-5: 79 .

124: 77.

125: 120 .

126: 66.

127: 120.

128: 29 (n. 27), 66.

129: 120 .

130: 126.

131: 66.

132: 120.

133: 77.

133-4: 79.

134: 120 .

135: 66.

136: 42.

138: 127.

139: 123 .

140: 121.

141: 66.

142: 41, 42.

144: 127.

145: 123.

146: 121.

274: 66 (+ n. 136).

275: 122 .

276: 41 (n. 62), 42.

277: 118 .

278: 23, 120.

278-9: 66 (n. 136).

279: 77.

282: 126.

283-4: 66.

285: 122 .

286: 41 (n. 62), 42. 
Andromache (cont.)

287: 119.

288: 120 .

289: 77.

292: 126.

293: 67 (n. 138).

294: 42.

295: 29 (n. 27), 126.

296: 77.

297: 118 .

298: 77.

299: 22, 123.

300: 128.

301: 67 (n. 138).

302: 42.

303: 29 (n. 27), 126.

304: 77.

306: 77.

307: 22 .

308: 128.

449: 109.

464-5: 124.

466: 118.

469: 126.

470: 126.

471-2: 124 .

474: 118 .

475: 125.

476: 126.

477-8: 126.

479: 123.

480: 77.

481: 124 .

482: 69.

483: 119.

484: 41 (n. 64), 42 (n. 68), 43 (n. 70).

485: 22, 120.

486: 123.

487-8: 77.

489: 124 .

490: 23, 65, 69 .

491: 29 (n. 28), 119.

492: 41 (n. 64), 42 (n. 68), 43 (n. 70).

493: 120 .

501: 92 (n. 191).

502: 92 (n. 191).

503: 96 (n. 205).

504: 92 (n. 190).

505: 96 (n. 206).
506: 92 (n. 191), 107.

507: 92 (n. 190).

508: 96 (n. 206).

510: 92 (n. 190).

511: 92 (n. 190).

512: 22, 27, 99.

513: 92 (n. 190).

514: 96 (n. 204).

523: 92 (n. 191).

524: 92 (n. 191).

525: 95 (n. 203).

526: 92 (n. 190).

527: 96 (n. 206).

528: 92 (n. 190).

530: 92 (n. 190).

531: 96 (n. 206).

532: 92 (n. 191).

533: 92 (n. 190).

534: 22, 27, 99.

535: 92 (n. 190).

536: 96 (n. 204).

766-7: 84.

768-9: 84.

770: 84.

771: 72.

772-3: 83.

775-6: 84 .

774: 72, 82 .

777: 120 .

778-9: 84.

780: 84.

781: 22 .

782: 72.

783-4: 83.

785-6: 72, 82 (+ n. 170).

787-8: 84 .

789: 120 .

790: 72 (n. 149).

791: 84.

792: 83.

793-4: 82.

796: 72.

797: 83.

798-9: 125.

800: 109 (n. 235).

801: 95 (n. 203).

826: 73 .

827: 77, 103.

830: 73 . 
831: 77, 103.

833: 60 (n. 114).

834: 67 (n. 138).

834-5: 26.

835: 22,63 .

837: 60 (n. 114), 60 (n. 115).

838: 67.

839: 63.

841: $24,74$.

842: 61.

843: 63.

844: 63.

846: 117.

847: 121.

848: 121.

849: 59 (n. 110), 60 (n. 114), 62.

850: 60 (n. 114), 60 (n. 115).

853: 29 (n. 28), 61.

854: 60 (n. 115).

855: 60 (n. 115), 63.

856: 118 .

857: 75 .

858: 62.

859: 60 (n. 115).

860: 59 (n. 110), 60 (n. 115).

861: 108.

862: 75.

863: 67.

864: 105 (n. 226).

865: 62, 104.

1010: 84.

1011-2: 83.

1013: 72 (n. 149).

1014: 75 .

1015: 72 .

1016: 68 .

1017: 122 .

1018: 120 .

1019: 84.

1020-1: 83.

1022: 72 (n. 149).

1023: 75.

1024: 72 .

1025: 68.

1026: 122 .

1027: 120 .

1029: 84.

1030: 120 .

1031: 126.
1032: 125 .

1033-4: 78, 81.

1035: 83.

1036: 126.

1038-9: 84.

1040: 120.

1041: 126 .

1042: 125 .

1043-4: 78, 81.

1045: 83.

1046: 126.

1173: 67 (n. 138).

1174: 29 (n. 26), 67, 68.

1176: 67 (n. 138).

1177-8: 66.

1181: 67 (n. 138).

1182: 67, 68 .

1183: 68 (n. 140).

1186: 67 (n. 138).

1187: 29 (n. 26), 67, 68.

1189: 67 (n. 138).

1190: 66.

1193: 67.

1194: 67 (n. 138).

1195: 67, 68 .

1196: 68 (n. 140).

1197-8: 124.

1199: 126.

1200-1: 125.

1202-3: 126.

1204: 124 .

1205: 127.

1207: 118 .

1208: 123.

1209: 42.

1210: 41 (n. 62), 42.

1211: 124.

1212: 125 .

1213-4: 124.

1215: 126.

1216: 124 .

1217: 126 .

1219: 22, 127.

1220: 118.

1221: 123.

1222: 42.

1223: 22, 41 (n. 62), 42.

1224: 124.

1225: 22, 125. 
Hecuba

68: 46 (n. 78), 49.

69: 46 (n. 77), 50.

70: 69 .

71: 49 .

72: 22, 46 (n. 77), 50.

79: 49 .

80: 49 .

81: 49.

82: 51.

83: $22,48$.

84: 49 .

85: 49 .

86: 48.

87: 49 .

88: 50 .

89: 46 (n. 77), 51.

154: 49.

154-61: 47.

155: 50.

156: 46 (n. 77), 47, 50.

157: 50 .

158: 50 .

159: 49.

159-61: 46 (n. 78).

160: 50.

161: 48 .

162: 50 .

163: 50 .

164: 23, 51 .

165: 62.

166: 69.

167: 66 .

167-9: 65 .

169: 64 .

170: 46 (n. 77), 50.

170-96: 36 (n. 50).

171: 51 .

172: 50 .

175: 117 (+ n. 254).

177: 50 .

178: 46 (n. 77), 50.

179: 46 (n. 77), 51.

180: 48.

181: 49.

182: 62 .

183: 51.

184: 46 (n. 77), 51.

185: 60 (n. 115).
186: 50 .

187: 48.

188: 46 (n. 77), 51.

189: 50 .

190: 62 .

191: 51.

192: 50 .

193: 48.

194: 46 (n. 77), 50.

195: 46 (n. 77), 50.

196: 51.

197: 46 (n. 78), 50.

198: 50 .

199: 50 .

202: 49.

203: 46 (n. 77), 47 (n. 80), 50.

204: 48.

205: 50.

206: 46 (n. 77), 47 (n. 80), 50.

207: 62 .

208: 69 .

209: 66 .

209-10: 65 .

210: 64.

444: 24, 25 (n. 14), 95 (n. 203).

445: 92 (n. 191).

446: 111.

447: 92 (n. 191).

448: 92 (n. 190).

450: 72 (n. 149).

451: 96 (n. 207), 97.

452: 93.

453-4: 111.

455: 95 (n. 203).

456: 92 (n. 190).

457: 111.

458: 92 (n. 191).

459: 92 (n. 190).

460: 109 (n. 235).

461: 72 (n. 149).

462: 96 (n. 207), 97.

463: 92 (n. 191).

464-5: 111.

466: 96 (n. 207).

467: 96 (n. 207), 97.

468: 92 (n. 190).

469: 105.

470: 92 (n. 190).

472: 109 (n. 234, n. 235). 
471: 92 (n. 190).

473: 94.

474: 111.

475: 96 (n. 207).

476: 95, 96 (n. 207), 97.

477: 92 (n. 190).

478: 105.

479: 92 (n. 191).

480: 92 (n. 190).

481: 109 (+ n. 234).

482: 94.

483: 111.

621-2: 124.

629: 122 .

630: 126 .

631: 98, 99 (n. 214).

632: 109 .

633-4: 125 .

635: 97 (n. 209).

636: 109 .

637: 104, 113.

638: 122 .

639: 126.

640: 98, 99 (n. 214).

641: 109.

642-3: 125.

644: 97 (n. 209).

645: 109 (n. 235).

646: 104, 113.

647-8: 85 .

649-50: 85 .

653-4: 76.

655: 79.

666-7: 125.

684: 22, 59 (n. 110), 61.

685: 118 .

686: $23,118$.

687: 62 .

689: 123.

690: 60 (n. 115), 61.

691: 60 (n. 115), 62.

692: 63.

694: 63.

695: 63.

696: 63.

697: 59 (n. 110), 62.

699: 23, 123.

700: 62.

703: 119.
704: 60 (n. 114), 63.

705: 22, 60 (n. 115).

706: 41 (n. 62), 42.

707: 59 (+ n. 110), 62 .

709: 60 (n. 115).

710: 62 .

711: 60 (n. 115), 63.

905: 76, 97 (n. 209).

906-7: 84.

908: 84.

909: 76.

910: 98 (n. 209).

911: 92 (n. 190).

912: 99 (n. 214).

912-3: 99 (+ n.213), 107.

913: 99.

914: 76, 97 (n. 209).

915-6: 84.

917: 84.

918: 76.

919: 98 (n. 209).

920: 92 (n. 190).

921: 99 (n. 214).

921-2: 99 (+ n. 213), 107.

922: 22, 99 (n. 214).

923: 119.

924: 118.

925-6: 79 .

927: 76 (n. 162).

928: 119.

930: $79,83$.

931: 72 (n. 149).

932: 121.

933: 119.

934: 118.

935-6: 79 .

937: 76 (n. 162).

938: 119 .

940: 79, 83.

941: 72 (n. 149).

942: 121.

943-4: 84.

945: 72 (n. 149).

946: 121.

947: 22, 116.

948: 84.

949: 121.

950-1: 125.

952: $22,75$. 


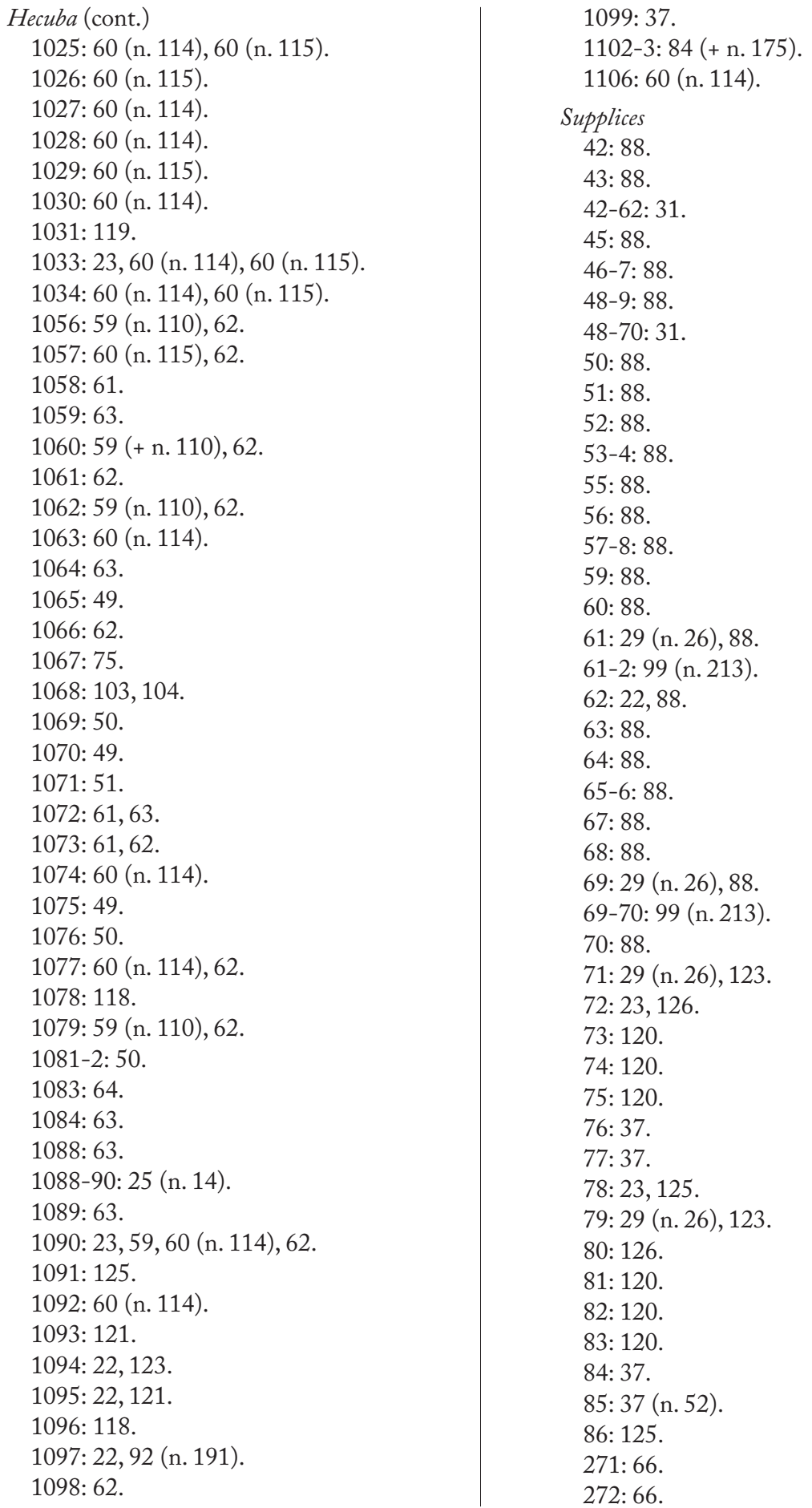


273: 66.

274: 66 .

277: 66 .

278-9: 66 .

281: 67,68 .

282: 66.

283: 66.

284: 66.

285: 66.

365: 125 .

366: 22, 23, 41 (n. 62), 42 (n. 68), 43.

367: 119 .

368: 23, 36 (n. 51), 41, 43.

369: 125 .

370: 23, 41 (n. 62), 42 (n. 68), 43.

371: 118 .

372: 36 (n. 51), 41, 43.

373: 124 .

374: 126 .

375: 124.

376: 127.

377: 124.

378: 126.

379: 22, 23, 124.

380: 127.

598: 79.

599: 74.

600: 126 .

601: 126 .

602: 124 .

603: 126 .

604: 126.

605: 124.

606-7: 126.

607: 22 .

608: 79.

609: 74 .

610: 126 .

611: 126.

612: 124 .

613: 126.

614: 124 .

615: 123 .

616-7: 126.

618: 124 .

619: 128 .

620: 126.

621: 119 .

622: 122, 123.
623: 42 (n. 68), 43.

624: 43.

625: 22, 120.

626: 124.

627: 128 .

628: 126.

629: 119.

630: 122, 123.

631: 42 (n. 68), 43.

632: 43.

633: 120 .

778: 76, 98 (n. 209).

779: 120.

780: 42.

781: 121.

782: 126.

783: 123.

784: 42.

785: 125.

786: 76, 98 (n. 209).

787: 120 .

788: 42.

789: 121.

790: 126.

791: 123.

792: 42.

793: 125.

798: 120 .

799: 42.

800: 126 .

801: 121.

802: 118 .

803: 118 .

804: 22, 59, 60 (n. 114).

808: 22, 66 .

809: 118.

810: 22, 120.

811: 121.

812: 42.

813: 126.

814: 121.

815: 118.

816: 118 .

817: 59, 60 (n. 114).

821: 22, 66 .

822: 118 .

823: 120 .

824: 126 .

826: 124. 
Supplices (cont.)

827: 22, 118.

829: 120.

830: 120.

831-2: 124 .

833: 120 .

834: 22, 120.

835: 126.

836: 128 .

890: 67.

919: 29 (n. 28).

920: 126.

921: 122 .

923: 123

924: 22

955: 92 (n. 191).

956: 92 (n. 190).

957: 112 .

958: 110 (n. 238).

959: 109 (n. 235).

960: 111.

961: 109 (n. 235).

962: 111

963: 92 (n. 191).

964: 92 (n. 191).

965: 112.

966: 110 (n. 238).

967: 109 (n. 235).

970: 22, 111.

971: 93 (+ n. 193).

971-2: 91 (n. 188).

972: 96 (n. 206).

973: 92 (n. 190).

974: 92 (n. 190), 115.

976: 109 (n. 234).

977: 115.

978: 29 (n. 28).

979: 95 (n. 203).

990: 122

992: 22, 92 (+ n. 192).

996: 96 (n. 204).

998: 109

999: 109 (+ n. 234).

1000: 29 (n. 26), 92 (n. 191).

1001: 109 (n. 235).

1002: 22, 29 (n. 27), 122.

1003: 22, 96 (n. 205).

1004: 95, 95 (n. 203).

1005: 115 .
1006: 109 (n. 235).

1007: 109 (n. 235).

1008: 95 (n. 203).

1012: 122.

1014: 22, 92 (+ n. 192).

1019: 96 (n. 204).

1021: 110.

1022: 109 (+ n. 234).

1023: 29 (n. 26).

1024: 109 .

1025: 22, 29 (n. 27), 122.

1026: 96 (n. 205).

1029: 109 (n. 235).

1030: 22, 95 (n. 203).

1072: 60 (n. 114).

1074: 61 .

1075: 60 (n. 114).

1078: 56 (n. 103), 60 (n. 115), 63.

1079: 60 (n. 114), 63.

1123: 117.

1124: 123 .

1125: 22, 123.

1126: 128 .

1127: 43.

1128: 42.

1129: 124 .

1130: 128 .

1131: 117, 123.

1132: 123.

1133: 23, 128.

1134: 43.

1135: 42.

1136: 124 .

1137: 128 .

1139: 125 .

1140: 118.

1141: 126.

1143: 124 .

1144: 128.

1147: 118 .

1146: 125 .

1148: $22,126$.

1149: 126.

1150: 124 .

1151: 128.

1152: 124.

1153: 124.

1154: 118.

1155: 119. 
1156: 119.

1157: 126.

1158: 124.

1160: 118 .

1161: 119 .

1162: 119 .

1163: 126.

\section{Electra}

112: 45 (n. 74), 50.

113: 22, 45 (n. 74), 50.

115: 93 (n. 193).

116: 94.

117: 92 (n. 190).

118: 92 (n. 192).

119: 96 (n. 203).

120: 96 (n. 207), 97.

121: 104.

122: 92 (n. 191).

122 ff: 48 (n. 82).

123: 92 (n. 190).

124: 22, 96 (n. 203).

125: 93 (+ n. 193).

127: 45 (n. 74), 50.

128: 22, 45 (n. 74), 50.

130: 93 (n. 193).

131: 94.

132: 92 (n. 190).

133: 92 (n. 192).

134: 96 (n. 203).

135: 96 (n. 207), 97.

136: 104.

137: 92 (n. 190).

138: 92 (n. 190).

139: 96 (n. 203).

140: 67 (n. 138).

141: 69.

142: 108 (n. 231).

144: 98 (n. 209).

145: 96 (n. 204).

146: 92 (n. 191).

147: 93 (n. 193).

148: 93 (n. 193).

149: 96 (n. 206).

150: 111 (+ n. 239).

151: 103.

152: 93 (n. 193).

153: 41 (n. 62), 42, 43.

154: 93 (n. 193).

155: 103.
157: 67 (n. 138).

158: 69.

159: 108 (n. 231).

160: 92 (n. 192).

162: 96 (n. 204).

164: 93 (n. 193).

166: 96 (n. 206).

167: 77.

168: 75.

169: 109 (n. 233), 112.

170: 109 .

171: 92 (n. 191).

172: 109 (n. 235).

175: 92 (n. 191).

176: 92 (n. 191).

177: 96 (n. 203).

179: 96 (n. 203).

180: 109 (n. 235).

181-2: 126.

183: 96 (n. 203).

184: 92 (n. 190).

185: 92 (n. 190).

186: 92 (n. 191).

187: 96 (n. 203).

188: 109 (n. 235).

189: 22, 96 (n. 203).

190: 77.

192: 109 (n. 233), 112.

193: 109.

194: 92 (n. 191).

195: 109 (n. 235).

198: 92 (n. 190).

199: 92 (n. 190).

200: 96 (n. 203).

201: 109.

202: 96 (n. 203).

203: 109 (n. 235).

204-5: 126.

206: 96 (n. 203).

207: 109 (n. 235).

208: 109 (n. 235).

209: 109 .

210: 96 (n. 203).

211: 109 (n. 235).

212: 96 (n. 203).

432: 112.

433: 109 (n. 235).

434: 112.

435: 93 (n. 193). 
Electra (cont.)

436: 92 (n. 190).

437: 111.

439: 94.

440: 93 (n. 193).

441: 96 (n. 206).

442: 112.

443: 109 (n. 235).

444: 112 .

445: 93 (+ n. 193).

446: 92 (n. 190).

447: 111.

449: 94.

450: 93 (n. 193).

451: 96 (n. 206).

454: 96 (n. 203).

455: 92 (n. 190).

458: 93 (+ n. 193).

460-1: 89.

465: 22.

466: 96 (n. 203).

467: 92 (n. 190).

452: 67.

459: 73 (+ n. 154).

462: 88 .

464: 67.

470: 93 (n. 193).

471: 73 (+ n. 154).

472-3: 89.

474: 88.

475: 22.

475-6: 66 .

479: 119 .

480: 22, 41 (n. 62), 43.

480-1: 26.

481: 121 (+ n. 267).

483: 72 .

484: 92 (+ n. 190).

485: 121 (+ n. 266).

486: 75.

585: 29 (n. 28), 60 (n. 115), 61.

586: 74.

587: 60 (n. 114).

588: 74 .

589: 60 (n. 114).

590: 77.

590-5: 54-5.

591: 61 .

593: 60 (n. 115).
592: 61.

594: 60 (n. 114).

595: 60 (n. 114).

643: 99 (n. 214).

675: 99 (n. 214).

700: 98.

701: 103, 104.

702: 109 (n. 235).

703: 109 .

704: 111.

706: 92 (n. 192).

707: 92 (n. 190).

708: 98 (n. 209).

709: 93.

710: 105 (n. 226).

714: 98.

715: 103, 104.

716: 109 (n. 235).

717: 109 (n. 235).

718: 110 (n. 237).

720: 92 (n. 192).

721: 92 (n. 190).

722: 98 (n. 209).

723: 93.

724: 105 (n. 226).

725: 72 (n. 149).

726: 115 .

727: 98 (n. 209).

728: 92 (n. 190).

729: 29 (n. 26), 109.

730: 58, 100, 101.

731: 100, 102.

732: 93, 96, 97.

733: 75.

734: 102.

735: 110 (n. 238).

736: 112 .

737: 98 (n. 209).

738: 92 (n. 190).

739: 29 (n. 26), 109 (n. 235).

740: 58, 100, 101.

741: 100, 102.

742: 96 (n. 207), 97.

743: 75.

744: 102.

745: 110 (n. 237).

746: 112.

834: 73.

860: 82 . 
861: 84.

862-3: 83.

864: 79.

865: 127.

874: 82.

875: 84.

876-7: 83 .

878: $73,79$.

879: 127.

1147: 60 (n. 114), 60 (n. 115).

1148: 60 (n. 114), 63.

1149: 119.

1150: 60 (n. 114).

1151: 60 (n. 114), 60 (n. 115).

1152: 60 (n. 114), 61.

1153: 61.

1154: 120 .

1155: 60 (n. 114), 60 (n. 115).

1156: 60 (n. 115).

1157: 120 .

1158: 60 (n. 114), 60 (n. 115).

1160: 60 (n. 115), 63.

1161: 61.

1162: 22, 120.

1163: 60 (n. 114).

1164: 22, 60 (n. 115), 61.

1177: 127.

1178: 119 .

1179: 29 (n. 28), 119.

1181: 118 .

1182: 123.

1183: 124 .

1184: 120.

1187: 118.

1188: 118.

1189: 126 .

1190: 127.

1191: 29 (n. 28), 118.

1192: 119.

1193: 115 (n. 250).

1194: 118.

1195: 42.

1196: 118.

1197: 23, 120.

1198: 123.

1199: 124.

1200: 120.

1201: 118.

1202: 121
1203: 118.

1204: 118.

1205: 22, 126.

1206: 123.

1207: 22, 125.

1208: 122 .

1209: 29 (n. 28), 124.

1210: 118.

1211: 118.

1212: 29 (n. 26), 120.

1213-4: 123.

1215: 125 .

1216: 122 .

1217: 124.

1218: 118.

1219: 118 .

1220: 29 (n. 26), 120.

1221: 124 .

1222: 42.

1223: 118 .

1224: 118 .

1225: 118 .

1226: 22,75 .

1228: 42.

1229: 118 .

1230: 118 .

1231: 118 .

1232: 22, 75.

Heracles

107: 119

108: 121

109: 118 .

110: 118 .

111: 23, 121.

113: 121.

114: 118 .

115: 29 (n. 28), 119.

116: 119 .

117: 118 .

118: 120 .

120: 121 .

125: 121.

126: 119 .

127: 118

128: 29 (n. 28), 119.

129: 118.

130: 120 .

131: 29 (n. 28), 38.

132: 38,42 . 
Heracles (cont.)

134: 23, 42.

135: 122 .

136: 73.

137: 120 .

348: 92 (n. 191).

348-9: 91 (n. 188).

349: 96 (n. 203).

350: 109 (n. 235).

351: 109 (n. 234).

352: 115.

353: 105 (n. 226), 122.

354: 22, 100.

355: 92 (n. 190).

356: 92 (n. 191).

357: 92 (n. 190).

358: 22, 96 (n. 204).

359: 23, 24, 96 (n. 203).

359-63: 25 (n. 12).

360: 96 (n. 203).

361: 96 (n. 203).

362: 92 (n. 190).

363: 96 (n. 203).

364: 92 (n. 191).

364-5: 91 (n. 188).

365: 96 (n. 203).

366: 109 (n. 235).

367: 109 (n. 234).

368: 115.

369: 105 (n. 226), 122.

370: 100.

371: 92 (n. 190).

372: 92 (n. 190).

373: 92 (n. 190).

374: 96 (n. 203).

375-9: 25 (n. 12).

376: 96 (n. 203).

377: 96 (n. 203).

378: 92 (n. 190).

379: 96 (n. 203).

380: 72 .

381: 77, 103.

382: 65 (+ n. 133).

383: 22, 23, 121.

384: 37 (n. 52).

385: 122 .

386: 41, 42 .

387: 120 .

388: 126 .
389: 96 (n. 204).

389-93: 25 (n. 12).

390: 96 (n. 205).

391: 96 (n. 203).

392: 92 (n. 190).

393: 22, 96 (n. 203).

394: 72.

395: 77, 103.

396: 65 (+ n. 133).

397: 22, 23, 121.

398: 37 (n. 52).

399: 122.

400: 41, 42.

402: 126 .

403: 96 (n. 204).

403-7: 25 (n. 12).

404: 96 (n. 205).

405: 96 (n. 203).

406: 92 (n. 190).

407: 96 (n. 203).

408: 126.

409: 29 (n. 27), 119.

410: 126.

411: 120 .

412: 41 (n. 62), 43.

415: 119.

416: 119 .

417: 118.

418: 120 .

419: 96 (n. 204).

419-24: 25 (n. 12).

420: 96 (n. 206).

421: 96 (n. 203).

422: 96 (n. 206).

423: 92 (n. 191).

424: 96 (n. 204).

425: 126.

426: 29 (n. 27), 119.

427: 126 .

428: 120 .

429: 43.

430: 120.

431: 42.

432: 118.

433: 119.

434: 118 .

435: 23, 120.

436: 96 (n. 204).

436-41: 25 (n. 12). 
437: 96 (n. 206).

438: 96 (n. 203).

439: 96 (n. 206).

440: 92 (n. 190).

441: 96 (n. 203).

637: 115 (n. 248).

638: 105 (n. 226).

639: 115 .

642: 93, 99.

643: 92 (n. 190).

644: 100, 102.

645: 102.

646: 110 (n. 236, n. 237).

647: 102.

648: 110 (n. 236, n. 237).

649: 93 (n. 193).

650: 92 (n. 191).

651: 92 (n. 190).

652: 92 (n. 190).

653: 92 (n. 190).

654: 96 (n. 204).

655: 115 (n. 248).

656: 105 (n. 226).

657: 115 .

660: $23,99$.

661: 92 (n. 190).

662: 100 .

663: 22, 102.

664: 110 (n. 236, n. 238).

665: 102.

666: 110 (n. 236, n. 237).

667: 93 (n. 193).

668: 92 (n. 190).

669: 92 (n. 190).

670: 92 (n. 190).

671: 92 (n. 190).

672: 96 (n. 203).

673: 115.

674: 109 (n. 235).

675: 109 (n. 234, n. 235).

676: 92 (n. 190).

677: 99 (n. 214).

678: 24 (n. 11), 88.

679: 88.

680: 88.

681: 96 (n. 204).

682: 110 .

683: 110 .

684: 22, 96 (n. 203).
685: 96 (n. 207).

686: 96 (n. 203).

687: 115 .

688: 109 (n. 235).

689: 22, 109 (n. 234, n. 235).

690: 109 (n. 235).

691: 99 (n. 214).

692: 88.

693: 88.

694: 88.

695: 96 (n. 204).

696: 109.

697: 109.

698: 96 (n. 203).

699: 96 (n. 207).

700: 96 (n. 203).

735: 60 (n. 115).

736: 60 (n. 115).

737: 63 .

738: 60 (n. 114).

739: 60 (n. 114).

742: 59.

743: 60 (n. 115).

744: 117.

745: 60 (n. 115), 61.

746: 60 (n. 114).

750: 60 (n. 115).

751: 60 (n. 115).

752: 63.

753: 60 (n. 114).

757: 59, 61, 117.

759: 60 (n. 114).

763: 29 (n. 27), 116, 117.

764: 22, 105 (n. 226).

765: 115 (n. 249).

766: 115 (n. 249).

768-9: 124.

770: 124.

771: 126.

772: 29 (n. 27), 116, 117.

774: 115 (n. 249).

773: 105 (n. 226).

775: 115 (n. 249).

776: 29 (n. 28), 121.

778-9: 124.

780: 22, 126.

781: 92 (n. 190).

782: 92 (n. 190).

783: 96 (n. 206). 
Heracles (cont.)

784: 109 (n. 235).

785: 92 (n. 190).

786-7: 115 .

788: 110 (n. 238).

789: 22, 96 (n. 203).

790: 109

790-1: 25 (n. 14).

791: 22, 110, 112 .

792: 109 (+ n. 234).

793: 121.

794: 93, 100, 102 (+ n. 217).

795: 102 .

796: 102.

797: 108 (n. 230).

798: 92 (n. 190).

799: 92 (n. 190).

800: 96 (n. 206).

801: 109 (n. 235).

802: 92 (n. 190).

803-4: 115.

805: 110 (n. 238).

806: 96 (n. 203).

807: 109 .

808: 110,112 .

809: 23, 109 (+ n. 234).

810: 121 .

811: 100.

812: 102.

813: 102 .

814: 108 (n. 231).

875: 60 (n. 115).

875-921: 30 (n. 31).

876: 60 (n. 114), 60 (n. 115).

877: 60 (n. 114), 60 (n. 115).

878: 60 (n. 115), 63.

879: 122

880: 23, 123.

881: 22, 105 (n. 226).

882: 96 (n. 204).

883: 77, 78 .

884: 60 (n. 115), 63.

885: 60 (n. 114), 60 (n. 115).

886: 60 (n. 114), 61, 63.

887: 22, 62, 63, 78, 102.

889: 85 .

890: 68.

891: 117.

892: 85.
893: 77

894: 22, 123.

895: 59, 63.

896-7: 79 .

898: 123 .

900: 60 (n. 114), 60 (n. 115).

901: 60 (n. 115).

902: 60 (n. 115).

903: 63

904: 117

907-8: 79

909: 123

912: 60 (n. 115).

913: 121.

915: 59, 60 (n. 115).

917: 59 (n. 110), 61, 62.

918: 63.

919: 29 (n. 28), 61.

921: 60 (n. 114).

1030: 77

1016: 60 (n. 115).

1016-88: 30 (n. 31).

1017: 22, 77 .

1018: 59 (n. 110), 62.

1019: 61.

1020: 59, 61 .

1021: 63 .

1022: 61, 63 .

1023: 62 .

1024: 59, 62 .

1025: 22, 121.

1026: 59 (n. 110), 61, 62.

1027: 59, 62 .

1029: 73.

1030: 103 .

1032: 73

1033: 77, 104.

1034: 124.

1035: 60 (n. 115).

1036: 22, 121.

1037: 77, 104.

1038: 73 .

1042: 60 (n. 114), 61.

1043: 60 (n. 115).

1044: 60 (n. 114).

1045: 60 (n. 114), 60 (n. 115).

1046: 60 (n. 114), 60 (n. 115).

1049: 108 (n. 231).

1049-51: 107. 
1050: 108 (n. 231).

1051: 108 (n. 231).

1052: 58, 59 (n. 111), 61, 63.

1053: 118.

1054: 23, 120.

1055-6: 79.

1057: 61.

1058: 63

1060: 60 (n. 115), 62.

1061: 61, 62.

1062: 29 (n. 28), 61, 63.

1063: 63.

1064: 121.

1065: 121.

1066: 121.

1067: 121 .

1069: 22.

1070: 61, 63, 79.

1071: 61 .

1072: 60 (n. 115).

1073: 119.

1074: 118.

1075: $22,84$.

1076: 72 .

1077: 72, 108.

1078: 60 (n. 115), 62.

1079: 60 (n. 115), 63.

1080: 76 (n. 162).

1081-2: 124 .

1083: 73.

1084: 22, 72 (n. 149).

1085: 56, 59 (n. 110), 60 (n. 115), 62.

1086: 61, 63 .

1178: 59 (n. 110), 62.

1178-1213: 30 (n. 31).

1180: 29 (n. 28), 60 (n. 115), 61.

1182: 60 (n. 115).

1183: 60 (n. 114).

1184: 29 (n. 28), 57, 60 (n. 115), 61.

1185: 86, 104.

1186: 86, 104.

1187: 85, 104.

1188: 74 .

1190: 61 .

1191: 61.

1192: 61 .

1193: 61.

1194: 60 (n. 114), 63.

1197: 77 .
1199: 72.

1200: 72 .

1201: 22, 72 (n. 149).

1203: 59, 60 (n. 115).

1204: 61, 62 .

1205-6: 77.

1207: 77 .

1208-9: 77.

1210: 60 (n. 114), 60 (n. 115).

1211: 60 (n. 114), 60 (n. 115).

1212: 60 (n. 115), 61.

1213: 22, 60 (n. 114), 60 (n. 115).

Troades

102: 46 (n. 78).

122: 51 .

122-52: 31, 36 (n. 50).

123: 50 .

124: 93 (n. 193), 94.

124-5: 48 (n. 82).

125: 93 (n. 193), 94.

126: 46 (n. 77), 51.

127: 46 (n. 77), 50.

130: 51.

131: 49.

132: 50.

133: $22,51$.

134: 48.

135: 50.

137: 46 (n. 77), 51.

138: 50.

139: 49.

140: 48.

141: 51.

142: 46 (n. 77), 51.

143: 46 (n. 77), 48, 50.

145: 49.

146: 50 .

149: 48.

150: 49.

151: 49.

152: 46 (n. 77), 51.

153: 49.

154: 49.

155: 49.

156: 49.

158: 22, 46 (n. 77), 51.

159: 49.

160: 46 (n. 77), 51.

161: 50 . 


\section{Troades (cont.)}

162: 50.

163: 46 (n. 77), 51.

164: 48, 117.

165: 49.

166: 46 (n. 77), 49.

167: 22, 46 (n. 77), 51.

168: 48.

168-72: 46.

169: 46 (n. 77), 50.

170: 48.

171: 46 (n. 77), 51.

172: 48, 50, 117.

173: 50 .

174: 50 .

175: 22,51 .

176: 49.

177: 49 .

178: 49.

180: 49.

181: 46 (n. 77), 51.

182: 46 (n. 77), 49.

183: 46 (n. 77), 51.

184: 50 .

185: 50 .

186: 46 (n. 77), 51, 117.

187: 48,50 .

188: 50.

189: 51.

190: 48.

191: 46 (n. 77), 50.

192: 48, 51.

193: 22, 48, 50, 117.

194: 49.

195: 46 (n. 77), 50.

196: 51.

197: 50 .

198: 50.

199: 50.

200: 46 (n. 77), 51.

201: 49.

202: 49.

203: 46 (n. 77), 50.

204: 46 (n. 77), 50.

205: 50 .

206: 49 .

207: 51.

208-9: 51.

210: 46 (n. 77), 50.
211: 50 .

212: 50 .

213: 51 .

214: 50 .

215: 46 (n. 77), 50.

216: 50 .

217: 46 (n. 77), 51.

218: 49.

219: 50 .

220: 46 (n. 77), 50.

221: 46 (n. 77), 50.

222: 49.

223: 50 .

224: 46 (n. 77), 51.

226: 50 .

227: 50 .

228: 50 .

229: 46 (n. 77), 51.

239: 60 (n. 115).

241: 117.

242: 60 (n. 114), 62.

244: 60 (n. 115), 61.

245: 62.

247: 117 .

248: 61, 62.

250: 74 .

251: 62 .

253: 58, 62.

254: 60 (n. 114), 62.

256: 72 .

257: 72.

258: 77, 104.

260: 57, 61 .

265: 62 .

266: 73 .

267: 77, 104.

269: 117.

270: 77, 104.

273: 60 (n. 115), 62.

275: 79 .

276: 60 (n. 114), 62.

279: 22, 24, 118.

280: 128 .

282: 75 .

283: 63 .

284: 60 (n. 115).

285: 126.

286: 73.

287: 63. 
288: 60 (n. 115), 61.

291: 63, 118.

308: 29 (n. 28), 56, 60 (n. 115), 61.

309: 54 (n. 98), 117.

310: 55 (n. 101), 57, 59 (n. 110), 62.

311: 64 .

312: 60 (n. 115), 63.

313: 118.

314: 33 (n. 39), 92 (n. 192).

316-7: 124.

318: 118 .

319: 120 .

320: 120.

321: 122.

322: 33 (n. 39), 92 (n. 192).

323: 33 (n. 39), 92 (n. 192).

324: 96 (n. 204), 117.

325: 22, 24, 56, 61, 62.

326: 54 (n. 98), 117.

327: 57, 59 (n. 110), 60 (n. 115), 62.

328: 64 .

329: 60 (n. 115), 63.

330: 118 .

331: 33 (n. 39), 92 (n. 192).

332: 126.

333: 124.

334: 118.

335: 120 .

336: 120 .

338: 33 (n. 39), 92 (n. 192).

339: 33 (n. 39), 92 (n. 192).

340: 22, 96 (n. 204), 117.

511: 72 (n. 149).

513-4: 82.

515: 85.

516: 77.

517-8: 72, 85.

518: 23.

519: 119 .

520: 119 .

521: 121.

522: 120 .

523: 119 .

524: 118.

525: 119 .

526: 119 .

527: 118 .

528: 118 .

529: 121.
530: 120.

531: 72 (n. 149).

533-4: 82.

535: 85.

536: 77.

537-8: 72, 85 .

539: 119 .

540: 119 .

541: 121.

542: 120 .

543: 118 .

544: 118.

545: 119 .

546: 118 .

547: 118 .

548: 118 .

549: 121.

551: 118.

552-3: 118.

554: 118.

555: 120 .

556: 118.

557: 22, 119.

558: 118.

559: 118 .

560: 122 .

561: 122 .

562: 122 .

563: 122 .

564: 21, 122.

565: 29 (n. 28), 119.

566: 72 (n. 149).

567: 121.

577: 22, 24, 126.

578: 126.

579: 123 .

580: 122, 123.

581: 120.

582: 126 .

583: 126 .

584: 123.

585: 122, 123.

586: 120 .

587: 122 .

588: 122 .

589: 72 (n. 149).

590: 120 .

591: 122 .

592: 122. 
Troades (cont.)

593: 72 (n. 149).

594: 120 .

595: 66.

596: 66 .

597: 66.

598: 66.

599: 66.

600: 66.

601: 66 .

602: 66.

603: 66 .

606: 66 .

799: 82.

800: 83.

801: 82 .

802: 82 .

803: 66.

804: 85 .

805: 84 .

806: 67.

809: 82 .

810: 83.

811: 82 .

812: 82.

813-4: 66 .

815: 85.

816: 22,84 .

817: 67.

818-9: 74.

820-1: 84 (+ n. 174).

822: 72 (n. 149).

823-4: 82.

825-6: 65, 67 (n. 138).

827-8: 72 (n. 149).

829: 120 .

843-4: 82.

830: 41, 42.

831: 37 (n. 54).

832: 37.

833: 75.

834: 72 (n. 149).

835: 119.

836: 119.

837-8: 79.

838: 67 (n. 137).

839: 120.

841: 23.

842: 72 (n. 149).
844: 22.

845: 67 (n. 138).

846-7: 72 (n. 149).

848: 120 .

849: 41, 43.

850: 37.

851: 37.

852-3: 75 .

854: 72 (n. 149).

855: 119 .

856: 119 .

857-8: 79 .

858: 67 (n. 137).

859: 120 .

1060: 92 (n. 190).

1061: 92 (n. 190).

1062: 96 (n. 203).

1063: 92 (n. 190).

1064: 92 (n. 190).

1065: 93, 96.

1067: 119 .

1068: 119 .

1070: 74 .

1071: 92 (n. 190).

1072: 92 (n. 190).

1073: 96 (n. 204).

1074: 92 (n. 190).

1075: 92 (n. 192).

1076: 96 (n. 203).

1078: 119.

1079: 119.

1080: 74 .

1082: 72 (n. 149).

1083: 121.

1084-5: 124.

1085: 23.

1087: 127.

1088: 125 .

1089: 118 .

1093: 41 (n. 62), 42, 43.

1094: 72 (n. 149).

1095: 72 (n. 149).

1096: 72 (n. 149).

1097: 72 (n. 149).

1098: 72 (n. 149).

1099: 121.

1100: 72 (n. 149).

1101: 121.

1102-3: 124. 
1105: 22, 127.

1106: 125 .

1107: 118.

1111: 41 (n. 62), 42, 43.

1112: 72 (n. 149).

1113: 72 (n. 149).

1114: 72 (n. 149).

1115: 72 (n. 149).

1116: 72 (n. 149).

1117: 22, 29 (n. 28), 121.

1217: 29 (n. 28), 60 (n. 114), 60 (n. 115), 61.

1226: 117.

1227: $42,43$.

1229: 121.

1230: 121.

1231: 60 (n. 114), 61.

1235: 22, 121.

1236: 23, 60 (n. 114).

1238: 23, 25 (n. 14), 121.

1287: 117 .

1288: 29 (n. 28), 119.

1290: 125.

1291: 119 .

1292-3: 125.

1294: 117.

1298: 118.

1299: 125.

1303: 30 (n. 28), 125.

1304: 126.

1305: 22, 124.

1306: 126.

1307: 126.

1308: 37 (n. 52).

1309: 120.

1311: 124.

1312: 119.

1313: 30 (n. 28), 119.

1314: 118.

1315: 119.

1316: 125 .

1318: 30 (n. 28), 125.

1319: 126.

1320: 22, 124.

1321: 126.

1322: 126 .

1323: 37 (n. 52).

1324: 120 .

1326: 124 .
1328-9: 119.

1331: 119 .

1332: 125 .

Iphigenia in Tauris

123: 48.

124: 50 .

125: 45 (n. 74), 46 (n. 77), 50.

126: 59 (n. 110), 62.

127: 62 .

128: 51.

129: 46 (n. 77), 51.

130: 49.

131: 46 (n. 77), 51.

132: 46 (n. 77), 50.

133-4: 46 (n. 77), 50.

135: 51.

136: 46 (n. 77), 51.

137: 49.

138: 49.

139: 50.

140: 46 (n. 77), 50.

141: 49.

143: 48.

144: 51.

146: 45 (n. 74), 50.

147: 22,51 .

148: 46 (n. 77), 50.

149: 46 (n. 77), 49.

151: 48.

152: 46 (n. 77), 51.

153: 48.

154: 51.

155: 46 (n. 77), 51.

156: 46 (n. 77), 51.

157: 48.

158: 49.

159: 49.

160: 46 (n. 77), 50.

161: 46 (n. 77), 50.

162: 46 (n. 77).

163-4: 46 (n. 77), 51.

165: 46 (n. 77), 51.

166: 46 (n. 77), 50.

167: 51 .

168-9: 51.

169: 45 (n. 73).

170: 49.

171: 49.

172: 50 . 
Iphigenia in Tauris (cont.)

173-4: 50 .

175: 49.

176: 49.

177: 51.

178-9: 50.

180: 49.

181: 46 (n. 77), 50.

182: 50 .

183-4: 50.

186: 46 (n. 77), 50.

187: 46 (n. 77), 50.

191: 46 (n. 77), 51.

192: 50.

193: 45 (n. 74), 50.

196: 50.

198-9: 46 (n. 77), 50.

200: 50 .

201: 46 (n. 77), 50.

202: 46,48 .

203: 51 .

205: 46 (n. 77), 50.

207: 51 .

208: 50 .

206: 50 .

209: 49.

210: 46 (n. 77), 51.

211: 50 .

212: 46 (n. 77), 51.

214: 51 .

215: 50 .

216: 51.

217: 50 .

218: 50 .

219: 51.

220: 30 (n. 28), 119.

221: 50 .

222: 50 .

223: 49.

224: 50 .

227: 46 (n. 77), 50.

228: 46 (n. 77), 50.

229: 50 .

230: 46 (n. 77), 50.

231: 22, 45 (n. 74), 48, 49.

232-3: 119 .

234: 50 .

235: 46 (n. 77), 51.

392-3: 76.
396: 76.

397: 96 (n. 203).

398-9: 124.

400: 121.

401: 78, 100.

404: 123.

405: 92 (n. 190).

406: 22, 96 (n. 203).

402-3: 79.

407-8: 76.

410: 125 .

411: 76.

412: 96 (n. 203).

415: 121.

416: 78, 100.

417-8: 79.

419: 123.

420: 92 (n. 190).

421: 96 (n. 203).

422: 92 (n. 190).

425: 93 (n. 195), 127.

426: 23, 105 (n. 226).

429: 110 (n. 238).

430: 110 (n. 238).

431: 102 .

432: 110 (n. 237).

433: 111 .

434: 110 (n. 238).

435: 115 (n. 248).

436: 109 (n. 235).

437: 109.

438: 96 (n. 203).

439: 109 (n. 235).

440: 96 (n. 207).

441: 111.

442: 93 (n. 195), 127.

443: 105 (n. 226).

444: 109.

445: 110 (n. 237).

446: 110 (n. 237).

447: 110 (n. 237).

448: 102.

449: 110 (n. 237).

450: 111.

451: 110 (n. 237).

452: 115 (n. 248).

453: 109 .

454: 109 (n. 235).

455: 96 (n. 203). 
644: 60 (n. 114), 60 (n. 115).

645: 120 .

647: 22, 61, 63.

648: 60 (n. 115).

649: 60 (n. 115).

651: 59 (+ n. 110), 62 .

652: 59, 63.

654: 61.

655: 30 (n. 28), 61.

656: 60 (n. 115).

657: 60 (n. 114).

827: 123.

827-9: 58.

830: 62 .

831: 59 (n. 110).

832: 61.

833: 124.

835: 60 (n. 115).

836: 60 (n. 115).

837-8: 123.

839: 120 .

840: 60 (n. 114), 61.

842: 60 (n. 115).

843: 22, 123.

844: 62 .

845: 123.

846: 60 (n. 114).

847: 60 (n. 115).

848: 77.

852: 61.

853: 62.

854: 60 (n. 114), 60 (n. 115).

856: 60 (n. 115).

857: 62 .

858: 62 .

859: 60 (n. 115).

860: 60 (n. 115).

861: 59 (n. 110), 61.

862: 63.

864: 119 .

865: 43.

867: 23, 41 (n. 62), 42.

868: 59 (n. 110).

870: 56, 62 .

871: 61.

872: 60 (n. 115).

873: 60 (n. 114).

875: 37.

876: 77.
877: 61.

878: 63.

879: 63 .

880: 77.

881: 117.

882: 59 (n. 110), 62.

883: 63.

884: 22, 76 (n. 162).

885: 62 .

886-7: 77.

888-9: 82.

890: 60 (n. 115).

891: 62.

892: 63.

894: 22, 25 (n. 14).

895: 77.

898: 60 (n. 114).

899: 22, 60 (n. 114).

1089: 92 (n. 191).

1089 ff: 32.

1090: 92 (n. 190).

1091: 96 (n. 206).

1092: 103, 104, 109 (n. 233).

1093: 93 (n. 193), 112.

1094: 92 (n. 192).

1095: 96 (n. 203).

1097: 109.

1098: 103.

1099: 109.

1100: 110 (n. 237).

1101: 93, 109 (n. 233).

1102: 109 (n. 235).

1103: 109 (n. 235).

1104: 93 (n. 193).

1105: 96 (n. 203).

1106: 92 (n. 190), 93.

1106 ff: 32.

1107: 92 (n. 191).

1108: 96 (n. 206).

1109: 104, 109 (n. 233).

1110: 93 (n. 192), 112.

1111: 92 (n. 192).

1112: 22, 96 (n. 203).

1113: 92 (n. 191).

1115: 103.

1116: 109 (n. 235).

1117: 110 (n. 238)

1118: 109 (+ n. 233).

1119: 109 (n. 235). 
Iphigenia in Tauris (cont.)

1120: 110.

1121: 93 (n. 193).

1122: 96 (n. 203).

1123: 94.

1124: 99 (n. 214).

1125: 109.

1126: 109.

1127: 96 (n. 207), 97.

1128: 109.

1129: 93 (n. 193), 104.

1131: 109.

1132: 22.

1137: 120 .

1138: 94.

1139: 99 (n. 214).

1140: 109.

1141: 109 (n. 235).

1142: 22, 96 (n. 207).

1144: 104.

1147: 96 (n. 207).

1234: 23, 24, 120.

1234-58: 36.

1235: 71.

1237: 67, 68 .

1238-9: 68.

1239: $22,23$.

1240: 78 .

1241: 113.

1242: 109 (n. 235).

1243: 109 (n. 235).

1244: 109 (+ n. 234).

1245: 75 .

1246-7: 75 .

1250: 119 .

1251: 76 (n. 162).

1255: 128.

1256-7: 77.

1258: 120 .

1259: 120 .

1259-83: 36.

1262: 67, 68 .

1263-4: 68.

1264: 22, 23.

1265: 78 .

1266: 113

1267: 109 .

1268: 109.

1269: 109 (+ n. 234).
1270: 75 .

1271: 75 (+ n. 158).

1274: 119.

1275: 76 (n. 162).

1280: 128 .

1281-2: 77.

1283: 120 .

Ion

112: 110.

$112 \mathrm{ff:} 32$.

113: 92 (n. 190).

114: 109 (n. 235).

115: 108 (n. 230).

116: 110 (n. 236, n. 237).

117: 109 .

119: 96 (n. 203).

120: 92 (n. 190).

121: 92 (n. 190).

122-3: 124.

124: 96 (n. 203).

125: 122 .

126: 122 .

127: 122 .

128: 110 .

$128 \mathrm{ff:} 32$.

129: 92 (n. 191).

130: 109 (n. 235).

131: 108 (n. 230).

132: 110 (n. 236, n. 237).

133: 109 (n. 235).

134: 111 .

135: 96 (n. 203).

136: 92 (n. 190).

137: 92 (n. 190).

138-9: 125 .

139: 30 (n. 28).

140: 22, 96 (n. 203).

141: 122 .

$141 \mathrm{ff:} 32$.

142: 122 .

143: 122 .

144: 45, 51 .

145: 48 .

146: 46 (n. 77), 51.

147: 48

149: 121 .

150: 121.

151: 46 (n. 77), 51.

152: 51 . 
153: 45 (n. 74), 50.

154: 50 .

155: 46 (n. 77), 51.

156: 46 (n. 77), 51.

157: 46 (n. 77), 51.

158: 46 (n. 77), 50.

159: 46 (n. 77), 50.

160: 48.

161: 49.

162: 49.

163: 48.

164: 46 (n. 77), 50.

165: 46 (n. 77), 50.

166: 48.

167: 23, 45 (+ n. 74), 49.

168: 51 .

169: 46 (n. 77), 51.

170: 49.

171: 51 .

171-5: 45.

172: 46 (n. 77), 51.

173: 46 (n. 77), 51.

174: 46 (n. 77), 51.

175: 51.

176: 48.

177: 49.

179: 51.

180: 46 (n. 77).

181: 46 (n. 77), 50.

182: 46 (n. 77), 50.

183: 51.

184: 92 (n. 190).

184-7: 24.

185: 92 (n. 190).

186: 92 (n. 191).

187: 96 (n. 204).

188: 92 (n. 190, n. 191).

189: 96 (n. 203).

190: 122, 123.

191: 100.

192: 102.

193: 108 (n. 231).

194: 92 (n. 192).

194 ff: 32.

195: 92 (n. 190).

196: 92 (n. 191).

197: 96 (n. 204).

198: 92 (n. 190).

199: 92 (n. 190).
200: 96 (n. 205).

201: 122, 123.

202: 100, 102.

203: 102.

204: 108 (n. 231).

205: 92 (n. 190).

206: 94.

207: 102.

209: 109.

210: 109 (n. 235).

211: 96 (n. 203).

212: 119.

213: 22, 121.

214: 122 .

215: 119 .

216: 119 .

217: 121.

219: 92 (n. 192).

220: 92 (n. 191).

221: 102.

223: 92 (n. 190).

225: 96 (n. 203).

230: 119 .

231: 22, 59 (n. 110), 121.

233: 119, 122.

235: 119, 121.

236: 126 .

453: 111.

454: 96 (n. 205).

456: 110 (n. 238).

458: 22, 98.

459: 109 .

460: 98 .

461: 96 (n. 207), 97.

462: 96, 97.

463: 93 (+ n. 193).

464: 108 (n. 230).

465: 109.

468: 76, 98 (n. 209).

469: 76, 98 (n. 209).

470: 77.

471: 108 (n. 230).

473: 110 (n. 237).

474: 96 (n. 205).

476: 110 (n. 238).

477: 77.

478: $22,98$.

479: 109 .

480: 98. 


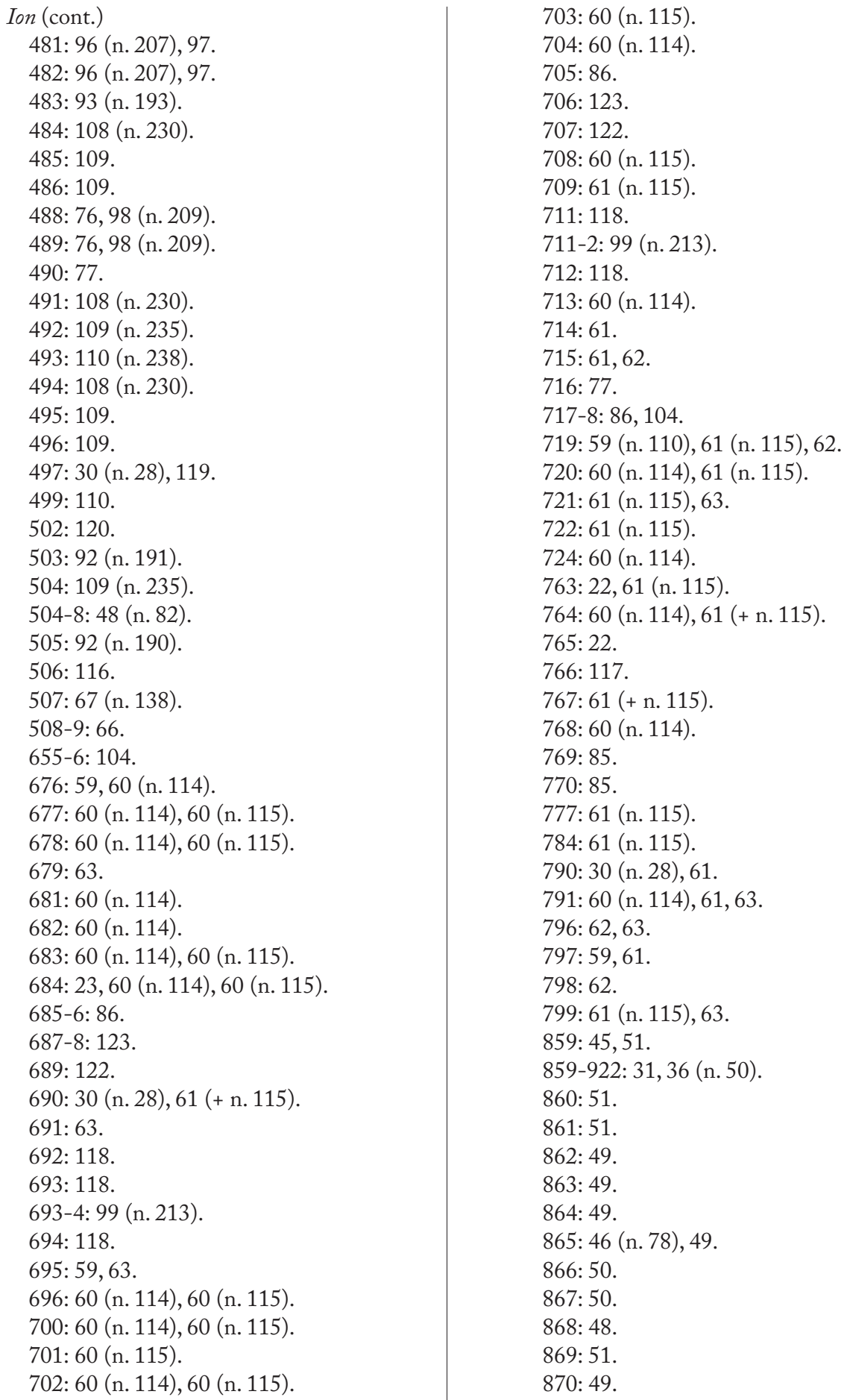


871: 49.

872: 49.

873: 48.

874: 49.

875: 49.

876: 49.

877: 50.

878: 46 (n. 78), 50.

879: 48.

880: 51.

881: 46 (n. 77), 50.

882: 49.

883: 46 (n. 77), 49.

884: 50.

885: 51.

887: 46 (n. 77), 51.

888: 51.

889: 30 (n. 28), 119.

891: 51.

892: 46 (n. 77), 51.

893: 46 (n. 77), 50.

894: 61 (n. 115).

895: 62.

896: 63.

897: 46 (n. 77), 51.

898: 46 (n. 77), 51.

899: 51.

900: 49.

901: 22, 51.

902: 51.

903: 46 (n. 77), 51.

904: 48.

905: $50(+$ n. 85).

906: $62(+$ n. 124).

907: 25 (n. 14), 46 (n. 77), 51.

908: 59 (n. 110), 62 (+ n. 124).

910: 46 (n. 77), 50.

911: 51.

912: 50 (+ n. 86, n. 87).

913: 51.

914: 48.

915: 51.

917: 46 (n. 77), 50.

918: 49.

919: 46 (n. 77), 50.

920: 49.

921: 49.

922: 46 (n. 77), 51.

1048: 82.
1049: 75.

1050: 111.

1051: 111 .

1052-3: 112.

1055: 111.

1054: 115 .

1056: 110 (n. 238).

1057: 110.

1058: 105.

1058-9: 106 (n. 229).

1059: 105 (n. 226).

1060: 112 .

1061: 82.

1062: 75 .

1063: 111.

1063-4: 95 (n. 202).

1064: 111 .

1065-6: 112.

1067: 30 (n. 28), 115.

1068: 111.

1069: 110 (n. 238).

1070: 110 (n. 238).

1071: 105.

1071-2: 106 (n. 229).

1072: 105 (n. 226).

1073: 111.

1074: 115.

1075: 74.

1076: 118.

1077: 119 .

1078: 75.

1079: 120 .

1080: 96 (n. 205).

1081: 110 (n. 237).

1084: 110.

1085: 92 (n. 190).

1086: 108 (n. 230).

1087: 111.

1088: 92 (n. 190).

1089: 96 (n. 205).

1090: 115.

1091: 74.

1092: 119.

1093: 119 .

1094: 75.

1095: 30 (n. 28), 120.

1096: 96 (n. 205).

1097: 110 (n. 237).

1101: 92 (n. 190). 
Ion (cont.)

1102: 108 (n. 230).

1103: 110 (n. 237).

1104: 92 (n. 190).

1105: 96 (n. 205).

1110: 110 (n. 237).

1229: 109 (n. 235).

1230: 96 (n. 206).

1231: 30 (n. 28), 121.

1235: 93 (n. 193).

1236: 92 (n. 191).

1237: 111.

1238: 93 (n. 193).

1239: 111.

1240: 87.

1241: 87.

1242: 109 (n. 235).

1243: 96 (n. 203).

1441: 85 .

1442: 77.

1445: 62, 63, 79 (+ n. 167).

1446-7: 128.

1448: 74.

1449: 122 .

1452: 61 (n. 115).

1453: 61 (n. 115).

1454: 61 (n. 115).

1455: 60 (n. 114), 61.

1458: 76 (n. 162).

1459: 125 .

1460: 59 (n. 110), 61 (n. 115), 62.

1461: 60 (n. 114), 61 (n. 115).

1463: 125 .

1464: 125 .

1465: 122.

1466: 77.

1467: 60 (n. 114), 62.

1470: 117 .

1471: 60 (n. 114), 61 (n. 115).

1474: 59 (n. 110), 62.

1476: 22, 41 (n. 62), 42, 43.

1478: 72, 82, 85 (n. 179).

1479: 72 (n. 149).

1480: 76, 98 (n. 209).

1482: 76, 98 (n. 209).

1483: 121.

1484: 76, 77, 104.

1486: 76, 98 (n. 209).

1487: 59, 61, 62.
1490: 63.

1491: 61 (n. 115).

1492: 125 .

1493: 125 .

1495: 61.

1496: 60 (n. 114).

1497: 62.

1499: 61 (n. 115), 63.

1502: 63 .

1503: 61.

1504: 82 .

1505-6: 82 .

1507: 22, 118.

1508: 77.

1509: 75.

Helena

165: 66.

166: 68 (n. 139).

167: 43.

167-78: 35.

167-228: 118 (n. 258).

168: 42.

171: 43, 118 (n. 258).

172: 37 .

172-3: 29.

173: 37.

174: 38.

175: $29,37$.

176: 37.

177: 29, 38 .

178: 42 (n. 68), 43.

179: 43.

179-90: 35.

180: 29, 43.

183: $22,43$.

184: 37.

184-5: 29.

185: 37.

186: 38.

187: 29, 37.

189: $29,37$.

190: 43.

191: 44.

191-210: 35.

192: 38.

194-5: 30 (n. 28), 44.

200: 38 .

201: 30 (n. 28), 38.

205: 37 (n. 52). 
206: 38 .

207: 30 (n. 28), 38.

208: 37.

209: 38.

210: 22.

211: 44.

211-2: 25 (n. 14).

211-28: 35 .

212: 38 .

214: 30 (n. 28), 44.

219: 38.

220: 38.

221: 24 (n. 10).

224: 37 (n. 52).

225: 38 .

226: 37, 38.

227: 30 (n. 28), 38.

229-52: 35.

230: 23.

231: 39 .

233: 119.

234: 30 (n. 28), 118.

235-7: 41.

243: 23, 118.

246: 118, 122.

252: 22,39 .

330: 118 .

332: 121.

334: 118.

335: 120 (+ n. 265).

336: 119 .

339: 118 .

358: 39.

330-74: 35.

340: 119 .

341: 37.

342-3: 43.

347: 119 .

348: 119.

349: 37.

350: 38 .

351: 38.

353: 38.

354: 37 (n. 52).

355: 38.

357: 37 (n. 52), 122.

360: 43.

361: 119 .

362: 121.
363: 126.

364: 38 .

365: 38.

367: 37.

368: 37.

369: 22,38 .

370: 120.

371: 37.

372: 37 .

374: 126.

375: 67 (n. 138).

376: 65 .

377: 67 (n. 138).

378: 68.

379: 67.

380: 67, 68 .

381: 67 (n. 138).

382: 66.

383: 67 (n. 138).

384: 66.

385: 120 .

515: 126.

516: 22, 128.

517: 105.

518: 92 (n. 191).

519: 96 (n. 206).

520: 115.

521: 115.

522: 96 (n. 203).

523: 111.

524: 92 (n. 192).

525: 92 (n. 191).

526: 115.

527: 96 (n. 203).

625-97: 31 (n. 32).

627: 61 (n. 115).

628: 53 (n. 90), 61 (+ n. 115).

629: 61 (n. 115).

632: 125 .

633: 125 .

634: 61 (+ n. 115).

635: 59 (n. 110), 62.

636: 125 .

638: 59 (n. 110), 62, 63.

639-40: 78.

641: 123.

642: 122 .

644: 22, 25 (n. 14), 78.

644-5: 26. 
Helena (cont.)

645: 60 (n. 114), 61 (n. 115).

648: 53 (n. 90), 117.

649: 61 (n. 115), 63.

650: 30 (n. 28), 61.

651: 61 (n. 115), 63.

654: 61 (+ n. 115).

655: 61 (n. 115).

657: 75.

659: 60 (n. 114), 63.

661: 59, 63 .

662: 59, 61 (n. 115).

664: 53 (n. 90), 72 (n. 149), 73.

666: 59 (n. 110), 62.

667: 61 (n. 115), 63.

668: 61 (n. 115).

670: 61, 63.

671: 63 .

673: 61 (n. 115), 63.

674: 61 (n. 115).

676: 53 (n. 90), 62.

677: 53 (n. 90), 60 (n. 114), 63.

678: 61 (n. 115).

680: 75 .

681: 75 .

682: 62,63 .

684: 30 (n. 28), 57, 61.

685: 60 (n. 114).

686: 85 .

687: 77.

689: 30 (n. 28), 61 (+ n. 115).

692: 77.

693: 72 (n. 149).

694: 57, 58, 61 .

694-7: 32 .

695: 61.

696: 30 (n. 28), 53 (n. 90), 61 (+ n. 115).

697: 60 (n. 114).

1107: 79 .

1108: $118(+$ n. 258).

1109: 22, 108 (n. 230), 111.

1110: 78, 93, 100, 102.

1111: 84 (+ n. 176).

1112: 121

1113: 98 (n. 209).

1114: 96.

1115: 93.

1116: 96 (n. 205).

1117: 30 (n. 28), 124.
1118: 30 (n. 28), 124.

1119: 76, 93, 98 (+ n. 209).

1120: 77.

1121: 121.

1122: 79 .

1123: 118 (+ n. 258).

1124: 22, 108 (n. 230), 111.

1125: 78, 93, 100, 102.

1126: 84.

1127: 121

1128: 98 (n. 209).

1129: 96.

1130: 93.

1131: 23, 96 (n. 203).

1132: 124

1133: 30 (n. 28), 124.

1134: 76, 98 (n. 209).

1135: 77.

1136: 121 .

1137: 79.

1138: 118 (+ n. 258).

1139-40: 82.

1141-2: 82 .

1143: 118 (+ n. 258).

1144: 79.

1145: 118 (+ n. 258).

1146: 72 (n. 149).

1147: 126.

1148: 30 (n. 28), 124.

1151: 79 .

1152: 118 (+ n. 258).

1153-4: 82.

1155-6: 82 .

1157: 118 (+ n. 258).

1159: 118 (+ n. 258).

1160: 72 (n. 149).

1161: 126.

1163: 30 (n. 28).

1301: 93.

$1301 \mathrm{ff:} 32,36$.

1302: 92 (n. 190).

1303: 111.

1304: 109 (+ n. 234).

1305: 109 .

1306: 109.

1308: 119.

1309: 119 .

1310: 110 (n. 238).

1311: 110 (n. 238). 
1312: 109 (n. 235).

1315: 109 (n. 235).

1316: 23, 109 (n. 234, n. 235).

1317: 109 (n. 235).

1318: 96 (n. 203).

1319: 93.

1319 ff: 32.

1320: 109 .

1322: 109 (+ n. 234).

1323: 109 .

1324: 109 (n. 235).

1326: 119 .

1327: 30 (n. 28), 119.

1328: 110 (n. 237).

1329: 109 (n. 235).

1330: 109 (n. 235).

1331: 109 (n. 235).

1332: 98 (+ n. 209).

1333: 109 .

1334: 109 (n. 234, n. 235).

1335: 109 (n. 235).

1336: 96 (n. 203), 109 (n. 235).

1337: 115 .

1338: 115 .

1339: 110 (n. 237).

1340: 115.

1341: 23, 25 (n. 14), 102 (n. 218), 115.

1342: 98 (n. 209).

1343: 110 (n. 237).

1345: 110 (n. 237).

1346: 110 (n. 237).

1347: 30 (n. 28), 115.

1348: 93.

1349: 93.

1350: 105 .

1351: 108 (n. 231).

1351-2: 99 (n. 213), 107.

1352: 108 (n. 230).

1355: 110 (n. 238).

1356: 115.

1357: 115 .

1358: 98 (n. 209).

1359: 110 (n. 238).

1361: 110 (n. 238).

1362: 110 (n. 237).

1363: 30 (n. 28), 115.

1364: 93.

1365: 92 (n. 190).

1367-8: 99 (n. 213).
1451: 107, 115.

1451 ff: 32 .

1452: 112.

1453: 105 .

1454: 115.

1455: 111.

1455 ff. 32.

1456: 109 (n. 234), 110.

1457: 115 .

1458: 96 (n. 205).

1459: 93 (+ n. 193).

1460: 109.

1461: 93 (n. 193).

1463: 110 (n. 238).

1464: 112.

1465: 115 .

1466: 112 .

1467: 105 .

1468: 115 .

1469: 111 .

1470: 109 (n. 234), 110.

1471: 115 .

1472: 96 (n. 205).

1473: 109.

1474: 92 (n. 190).

1475: 93 (n. 193).

1477: 112 .

1478: 73 .

1479: 23,72 .

1480: 72

1481: 92 (n. 190), 109 (n. 233).

1482: 109 (n. 235).

1483: 110 (n. 238).

1484: 42 (n. 66), 72 (n. 149).

1485: 42 (+ n. 68), 43 .

1486: 121 .

1487: 92 (n. 190).

1488: 92 (+ n. 191).

1489: 93.

1490: 109 (+ n. 234).

1491: 110 (n. 237).

1492: 109.

1494: 96 (+ n. 206).

1495: 73.

1496: 72.

1497: 25 (n. 14), 72.

1498: 109 (+ n. 233).

1499: 109.

1500: 110 (n. 238). 
Helena (cont.)

1501: 42 (n. 66), 72 (n. 149).

1502: $42,43$.

1503: 30 (n. 28), 121.

1504: 109 (n. 235).

1505: 92 (+ n. 190).

1506: 92 (n. 190).

1507: 109 (+ n. 234).

1508: 110 (n. 237).

1509: 109 (n. 235).

1510: 92 (n. 190).

1511: 96 (+ n. 203).

Phoenissae

103: 57, 60 (n. 114), 61.

104: 59 (n. 110), 62.

109: 61 .

110: 77.

111: 63

115: 61 (n. 115).

116: 62 .

119: 72.

119-122: 42.

120: 43.

121-2: 86, 104.

127: 59, 61 (n. 115).

127-30: 78 (n. 165).

128: 23, 78 (+ n. 165).

128-30: 42 .

129: 42.

130: 86, 104.

135: 67 (n. 138).

136: 69 .

137: 61 (n. 115).

138: 123 .

147: 42.

145: 123 .

146: 77.

148: 22, 123.

149: 61 (n. 115).

151: 67 (n. 138).

152: 22,66 .

153: 63.

156: 59 (n. 110), 62, 63.

157: 63 .

158: 22, 124.

164: 78 .

165: $61(+$ n. 115).

166: 60 (n. 114).

167: 30 (n. 28), 61.
168: 22, 26 (n. 15), 123.

169: 60 (n. 114), 61 (n. 115).

182: 61 (n. 115), 63.

183: 62,64 .

184: 77.

185: 118 .

190: 67.

191: 23, 67, 68.

191-2: 26 (n. 15).

192: 69.

202: 93 (n. 193).

$202 \mathrm{ff:} 33$.

203: 92 (n. 191).

204: 96 (n. 203).

205: 110 (n. 237).

206: 93 (+ n. 193).

207: 96 (n. 203).

208: 93 (+ n. 193).

209: 92 (n. 190).

210: 109 .

211: 93 (n. 193).

212: 92 (n. 190).

213: 22, 96 (n. 203).

214: 93 (n. 193).

214 ff: 33.

215: 92 (n. 190).

216: 96 (n. 203).

217: 110 (n. 238).

218: 93 (n. 193).

219: 96 (n. 203).

220: 93 (n. 193).

220-4: 91.

221: 93.

222: 93 (n. 193).

223: 93 (n. 193).

224: 92 (n. 190).

225: 96 (n. 203).

226: 92 (n. 190).

226-8: 26 (n. 14).

227: 93 (+ n. 193).

228: 96 (n. 203).

229: 109 .

230: 22, 96 (n. 203).

231: 109 (n. 235).

232: 93 (n. 193).

233: 92 (n. 190).

234: 93 (+ n. 193).

235: 92 (n. 190).

236: 115 . 
237: 93 (+ n. 193).

238: 22.

239-42: 33.

239-49: 35 .

247: 37.

248: 44.

250: 23, 24 (n. 10).

250-60: 35 .

258: 37.

259: 44.

293: 56 (n. 103), 61 (n. 115), 63.

294: 119.

295: 127.

296: 30 (n. 28), 61.

297: 62 .

298: 126.

299: 60 (n. 114), 61.

300: 59, 60 (n. 114).

301: 22.

303: 22.

304: 118.

305: 118.

306: 118 .

307: 118.

308: 119 .

309: 59, 62, 63.

310: 118.

311: 123.

312: 121.

313: 22, 121.

314: 43.

315: 22, 121.

317: 23, 26 (n. 15), 41 (n. 62), 42.

318: 60 (n. 114), 61 (n. 115).

319: 61 (n. 115), 63.

320: 122 .

321: 122.

322: 61 (n. 115).

323: 60 (n. 114), 61 (n. 115).

325: 60 (n. 114).

326: 61 (n. 115).

327: 123 .

328: 60 (n. 114).

329: 60 (n. 114).

331: 122 .

332: 118.

333: 118.

334: 122 .

335: 60 (n. 114), 61 (n. 115).
336: 61 (n. 115).

337: 118.

338: 22, 42, 120.

339: 118 .

340: 118.

341: 118.

342: 118.

343: 121.

344: 60 (n. 114), 61 (n. 115).

345: 61 (n. 115).

346: 62 .

347: 61 (n. 115), 62.

348: 62, 63.

349: 59 (n. 110), 61 (n. 115), 62.

350: 73.

351: 67 (n. 138).

352: 67 (n. 138).

353: 72 (n. 149).

354: 61 (n. 115).

638-56: 35.

640: 37.

641: 37.

645: 37.

652: 119 .

653: 118 .

654: 123.

655: 37 (n. 52), 40.

657-75: 35 .

659: 37.

660: 37.

664: 37.

667: 26 (n. 15).

668: 37 (n. 52).

671: 119 .

672: 118 .

673: 123 .

674: 37 (n. 52), 40.

676: 23, 24 (n. 9), 24 (n. 10).

676-89: 35 .

677: 22,38 .

678: 37.

685: 38.

686: 125 .

687: 118 .

688: 118 .

784: 67 (n. 138).

785: 66.

786: 66.

787: 66. 
Phoenissae (cont.)

788: 67, 68.

789: 66.

790: 67, 68, 69.

791: 67.

792: 66.

793: 68.

793-4: 65.

794-5: 67.

796: 65.

797: 67 (n. 138), 72.

798: 67.

798-9: 99 (n. 213).

799: 67, 68.

801: 67 (n. 138).

801-2: 26 (n. 14).

802: 66.

803: 66.

804: 66 .

$805: 67,68$.

806: 66 .

807: 67, 68, 69 .

808: 67.

809: 66.

810: 68.

810-11: 65.

811-12: 67.

813: 67 (n. 138).

814: 67 (n. 138).

815: 72.

816: 99 (n. 213).

817: 67, 68 .

818: 69.

819: 66.

820: 66.

821: 23,66 .

822: 67,68 .

823: 66.

824: 66.

825: 49.

826: 46 (n. 77), 49.

827: 45 (n. 73), 50.

828: 67,68 .

829: 67.

830: 67 (n. 138).

831-2: 67.

833: 73.

864: 36.

1019: 37 (n. 52), 117.
1020: 120.

1021: 123.

1022: 118.

1025: 121.

1026: 122, 123.

1027: 121.

1028: 22, 120.

1029: 120 .

1030: 30 (n. 28), 119.

1031: 30 (n. 28), 121.

1032: 120.

1033: 118.

1034: 118.

1035: 120 .

1036: 118.

1037: 118.

1038: 37,42 .

1039: 38 .

1040: 38 .

1041: 30 (n. 28), 38.

1042: 44 (+ n. 72).

1043: 37 (n. 52), 117.

1044: 120.

1045: 123.

1046: 118.

1049: 121.

1050: 122, 123.

1051: 121.

1052: 22, 120.

1053: 22, 120.

1054: 30 (n. 28), 119.

1055: 121.

1056: 120 .

1057: 118.

1058: 118.

1059: 120 .

1060: 118.

1061: 118.

1062: 37 (n. 52), 42.

1063: 38 .

1064: 38 .

1065: 37.

1066: 44.

1284: 50 .

1284-5: 46 (n. 78).

1285: 49.

1286: 30 (n. 28), 121.

1287: 63 .

1288: 30 (n. 28), 42, 43. 
1289: 63.

1290: 25 (n. 14), 59, 60 (n. 114).

1291: 61 (n. 115).

1292: 118.

1293: 22, 25 (n. 14), 121.

1294: 61.

1295: 63.

1296: 50 .

1297: 49.

1298: 30 (n. 28), 121.

1299: 61 (n. 115).

1300: 42, 43.

1301: 61 (n. 115).

1302: 59, 60 (n. 114).

1303: 61 (n. 115), 63.

1304: 118 .

1305: 121 .

1306: 61, 63.

1485: 23, 24, 66.

1487: 67 (n. 138).

1488: 67,68 .

1489: 67.

1490: 67.

1491: 67.

1492-3: 66 (+ n. 136).

1493: 68 (n. 139).

1495: 67 (n. 138).

1497: 67, 68, 69.

1496: 69 .

1499: 67 (n. 138).

1500: 67 (n. 138).

1501: 69 .

1503: 67 (n. 138).

1504: 67 (n. 138).

1505: 69.

1506: 67,68 .

1507: 67, 68 .

1509: 115 .

1510: 115 (n. 248).

1511: 118.

1512: 72 (n. 149).

1513: 72 (n. 149).

1515: 87.

1516: 88 .

1517: 87.

1518: 23, 121.

1519-23: 115.

1525: 122 .

1526: 115 (n. 248).
1528: 108 .

1529: 115 (n. 248).

1530: 122 .

1531: 115.

1532: 22, 25 (n. 14), 102 (n. 218), 121.

1533: 56, 62.

1535: 60 (n. 114), 62.

1536: 128 .

1537: 60 (n. 114).

1537-8: 58.

1538: 58 .

1539: 89 .

1540: 87.

1543: 60 (n. 114), 61.

1544: 61 (n. 115).

1545: 108.

1546: 46 (n. 76), 68.

1546-59: 46.

1547: 50 .

1547-8: 46 (n. 76).

1548: 50 .

1549: 66

1549-50: 46 (n. 76).

1550: 25 (n. 14), 69.

1553: 50 .

1554: 49, 68 .

1555: 49.

1556: 49, 68 .

1557: 46 (n. 76), 48.

1558: 66 (+ n. 136).

1558-9: 46 (n. 76).

1559: 25 (n. 14).

1560: 119.

1561: 42, 43.

1562: 67.

1562-4: 68 .

1563: 67.

1564: 67.

1565: 67 (n. 138).

1566: 66.

1567: 36 (n. 51), 42 (n. 68), 43.

1567-78: 69 (n. 142).

1568: 30 (n. 28), 38.

1569: 30 (n. 28), 42 (+ n. 68), 43.

1570: 67.

1571: 67, 68 .

1572: 72 (n. 149).

1573: 69.

1574: 67 (n. 138). 
Phoenissae (cont.)

1575: 50.

1576: 67.

1577: 66 (+ n. 136).

1578: 66, 67.

1579: 67 (n. 138).

1580: 69 .

1581: 76 (n. 162).

1710: 124 .

1711: 118.

1712: 125 .

1714: 118 .

1715: 118 .

1716: 119 .

1717: 124 .

1718: 37.

1719: 41, 43.

1720: 42 .

1721: 41, 43.

1723: 126.

1724: 126 .

1725: 126.

1726: 126 .

1728: 119 .

1729: 119.

1731: 121.

1732: 37.

1733: 44 (+ n. 72).

1734: 30 (n. 28).

1735: 30 (n. 28), 37.

1737: 124 .

1738: 125 .

1739: 118 .

1740: 42.

1741: 42

1744: 126.

1745: 124 .

1747: 118 .

1748: 43.

1749: 118.

1750: 41 (n. 62), 43.

1751: 119.

1752: 30 (n. 28), 119.

1753: 110 (n. 237).

1754-5: 77.

1756: 22, 30 (n. 28), 44 (+ n. 72).

1757: 22, 44 (+ n. 72$)$.

Orestes

140: 61 (n. 115), 63.
141: 53-4, 60 (n. 114).

142: 61 (n. 115).

143: 63 .

144: 61 (n. 115).

145: 59, 62 (+ n. 125).

146: 62, 63 .

147: 61 (n. 115).

148: 63.

149: 30 (n. 28), 61.

150: 61.

151: 61 .

152: 61 (n. 115).

153: 61 (n. 115), 63.

154: 53-4, 61 (n. 115).

155: 61 (n. 115).

156: 63.

157: 61 (n. 115).

158: 59, 62 .

159: 61 (+ n. 115).

160: 61 (n. 115), 63.

161: 63 .

162: 30 (n. 28), 61.

163: 61.

164: 61 .

165: 61 (n. 115).

166: 60 (n. 114).

167: 22, 26 (n. 15), 121.

168: 59, 62 .

169: 22, 23, 121 .

170: 37 (n. 54).

171: 120 .

172: 61 (n. 115).

173: 122 .

174: 30 (n. 28), 61.

175: 61 (n. 115).

176: 61 (n. 115).

177: 61 .

178: 61 (n. 115).

179: 22, 23, 59, 61 .

180: 61 (n. 115).

181: 61 (n. 115).

182: 72 .

183: 75.

184: 72 (n. 149).

185: 30 (n. 28), 57, 61.

186: 60 (n. 114), 61 (n. 115).

187: 60 (n. 114).

188: $22,121$.

189: 59, 63. 
190: 23, 121.

191: 37.

192: 119.

193: 63.

194: 122.

195: 30 (n. 28), 61.

196: 61 (n. 115).

197: 61 (n. 115).

198: 61.

199: 61 (n. 115).

200: 22, 23, 59, 61 .

201: 61 (n. 115).

202: 61 (n. 115).

203: 72 .

204: 75.

205: 72 (n. 149).

207: 60 (n. 114), 61 (n. 115).

313: 122 .

316: 117.

317-8: 25 (n. 14).

318: 61 (n. 115).

319: 60 (n. 114), 61.

320: 61 (n. 115).

321: 60 (n. 114), 61 (n. 115).

322: 61 (+ n. 115).

323: 61 (n. 115).

324: 61 (n. 115).

325: 61 (n. 115).

326: 63 .

327: $61,63$.

328: 63.

329: 119.

330: 30 (n. 28).

331: 60 (n. 114), 61 (n. 115).

332: 117.

333: 122.

334: 61 (n. 115).

335: 60 (n. 114), 61.

336: 63.

337: 60 (n. 114), 61 (n. 115).

338: 59 (n. 110), 62.

339: 61 (n. 115).

340: 61 (n. 115).

341: 61 (n. 115).

342: 63.

343: 62, 63.

344: 60 (n. 114).

345: 119.

347: 60 (n. 114), 61 (n. 115).
807: 109 .

808: 109 .

809: 109 .

810: 112 .

811: 126.

812: 109 .

814: 110 .

816: 113 .

817: 92 (n. 191).

818: 96 (n. 203).

819: 109 .

820: 109 .

821: 109 .

822: 112 .

823: 126 .

824: 109 .

825: 109 .

827: 110 .

828: 113.

829: 92 (n. 191).

830: 96 (n. 203).

831: 69.

832: 109 .

833: 111.

834: 115.

835: 116.

836: 110 .

837: 115 .

838: 98.

839: 115 (n. 248).

840: 109 .

841: 69 .

842: 30 (n. 28), 120.

843: 105 (n. 226), 106 (n. 228).

960: 123 .

961: 124 .

963: 124.

964: 36.

965: 122 .

966: 118, 119.

967: 36 (n. 51).

968: 30 (n. 28), 119.

969: 42.

970: 126.

971: 123.

972: 124.

974: 124.

975: 127.

976: 122 . 
Orestes (cont.)

977: 118, 119.

978: 36 (n. 51).

979: 30 (n. 28), 119.

980: 42.

981: 126.

982: 119, 120.

983: 119, 123.

984: 22, 120, 122.

986: 119 .

987: 30 (n. 28), 124.

988: 120 .

989: 126.

990: 118 .

991: 118, 119.

992: 121.

993: 63.

994: 63.

995: 121.

996: 118.

997: 42.

999: 119.

1001: 37.

1002: 37.

1003: 37 (n. 52).

1004: 42.

1005: 67 (n. 138).

1006: 67, 68 .

1008: 67, 68 .

1009: 67.

1010: 67 (n. 138).

1011: 59, 61, 67 (n. 138).

1246: 72.

1247: 63, 64.

1248: 61, 63.

1250: 61 (n. 115).

1251: 124 .

1252: 123 .

1253: 119 .

1254: 61 (n. 115).

1255: 61 (n. 115).

1256: 73.

1257: 77.

1261: 61 (n. 115).

1262: 61 (n. 115).

1265: 61 (n. 115).

1266: 72.

1267: 62, 64 .

1257: 104 .
1270: 61 (n. 115).

1271: 123 .

1272: 124 .

1273: 119 .

1274: 61 (n. 115).

1275: 61 (n. 115).

1276: 73 .

1277: 77, 104.

1278: 124 .

1281: 61 (n. 115).

1282: 61 (n. 115).

1285: 63 .

1288: 63 .

1289: 63 .

1290: 61 (n. 115).

1291: 63.

1294-5: 128.

1299: 67 (n. 138).

1300: 74 .

1302: 73 .

1303: 74 .

1304: 72 (n. 149).

1305: 56, 59 (n. 110), 62, 63.

1306: 63.

1307: 119 .

1308: 30 (n. 28), 61.

1309: 61 (n. 115).

1310: 61 (n. 115), 63.

1342: 60 (n. 114).

1353: 61 (n. 115).

1354: 60 (n. 114).

1355: 123.

1356: 124 .

1357: 61 (n. 115).

1358: 22, 60 (n. 114).

1359: $22,123$.

1360: 123.

1361: 42, 43.

1362: 61.

1363: 77.

1364: 61, 63.

1365: 60 (n. 114), 61 (n. 115).

1369: 69, 74, 118.

1370: 41 (n. 64), 42.

1371: 22, 121.

1372: 42.

1373: 120.

1374: 120.

1375: 61. 
1376: 61.

1377: 122 .

1378: 122.

1379: 22, 122.

1381: 69, 77, 104.

1382: 56 (n. 103), 61 (n. 115), 63.

1383: 59, 61 (n. 115), 62.

1387: 62, 63 .

1388: 122 .

1389: 117, 120.

1391: 62.

1392: 77.

1395: 67, 69.

1396: 22.

1397: 48, 50.

1398: 49, 77.

1399: 121.

1400: 63, 118.

1401: 121.

1402: 42, 60 (n. 114).

1403: 49.

1404: 49.

1405: 50.

1406: 49.

1407: 122, 123.

1408: 42.

1409: 118.

1410: 118.

1411: 118.

1412: 119, 122.

1413: 118.

1414: 119.

1415: 30 (n. 28), 59, 61.

1416: 30 (n. 28), 119.

1417: 63.

1418: 122 .

1419: 122.

1420: 122.

1421: 122.

1422: 122.

1423: 122.

1424: 122.

1426: 47 (n. 78).

1427: 46 (n. 77), 50.

1428: 49.

1429: 50 .

1431: 69.

1432: 120.

1433: 122 .
1434: 49.

1434-5: 47.

1435: 49.

1438: 122.

1439: 127.

1440: 128.

1441: 119 .

1442: 122.

1443: 122 .

1444: 118 .

1445: 118 .

1446: 118 .

1448: $120,122$.

1449: 118.

1450: 118.

1451: 122 .

1452: 121 .

1454: 23, 25 (n. 14), 45 (n. 73$), 46$ (n. 77), 50 .

1455: 49.

1456: 78

1457: 42, 118.

1458: 120 .

1459: $64,122$.

1460: 42 .

1461: 118.

1463: 118.

1464: $22,122$.

1465: 67.

1466: 61, 63.

1468: 79, 122.

1469: 30 (n. 28), 43.

1470: 126.

1471: 119, 122.

1472: 122, 123.

1475: 123.

1476: 123 .

1477: 118 .

1478: 123.

1479: 23, 79.

1480: 120, 126.

1481: 124 .

1482: 118.

1483: 98.

1484: 51.

1485: 48, 49.

1486: 48, 49.

1487: 49.

1488: 22, 48, 118. 
Orestes (cont.)

1489: 123.

1489-90: 27.

1490: 61 (n. 115), 62.

1491: 60 (n. 114), 61 (n. 115), 63.

1492: 122.

1493: 122.

1494: 118.

1495: $23,125$.

1496: 67.

1497: 61, 63.

1498: 123.

1499: $22,118$.

1500: $57,61$.

1501: 61, 62 .

1502: 61 (+ n. 115).

1537: 24, 25 (n. 14), 61 (n. 115).

1541: 61 (n. 115), 63.

1542: 23, 61 (n. 115).

1543: 124.

1544: 124.

1545: 42, 43.

1546: 61 (n. 115).

1547: 77.

1548: 61 (+ n. 115).

1549: 60 (n. 114), 61 (n. 115).

Bacchae

64: 88.

65: 88.

66: 88 .

67: 87,88

68: 88 .

69: 87.

70: 88.

$71: 87$.

72: 88 .

78: 87.

79: 87,88 .

80: 87.

$81: 87,88$.

82: 87.

83: 88.

84: 29 (n. 26), 88.

85: 88.

86-7: 88.

88: 22,88 .

94: 87.

95: 87,88 .

96: 87.
97: $87,88$.

98: 87.

99: 88.

100: 29 (n. 26), 88.

101: 88 .

102-3: 88 .

104: 88 .

105: 58, 101, 105 (n. 226), 106.

106: 105 (n. 226).

107: 30 (n. 28), 121.

108: 105 (n. 226).

109: 116.

110: 105 (n. 226).

111: 92 (n. 190).

112: 94

113: 87,88 .

114: 88 .

115: 94.

116: 69 .

117: 69 .

118: 92 (n. 192).

119: 28 (n. 24), 96 (n. 203).

120: 58, 101, 105 (n. 226), 106.

120-2: 26 (n. 14).

121: 105 (n. 226).

122: 121 .

123: 93, 105.

124: 116 .

125: 105 (n. 226).

126: 92 (n. 190).

127: 94.

128: 87,88 .

129: 88 .

130: 94.

131: 69 .

132: 69.

133: 92 (n. 192).

134: 28 (n. 24), 96 (n. 203).

135: 122 .

136: 105 (n. 226).

137: 30 (n. 28), 119.

138: 93 (n. 193), 94.

139: 67 (n. 138).

142: 67,69 .

143: 22, 116.

144: 88 .

145: 88 .

146: 87,88 .

146-7: 28 (n. 24), 96 (n. 203). 
147: 87, 88.

148: 122 .

149: 88.

150: $87,88$.

152: 25 (n. 14), 102 (n. 218).

152-3: 108.

154: 92 (n. 190).

156: 93 (n. 193).

159: 67 (n. 138).

160: 122 .

161: 30 (n. 28), 61.

162: 61.

163-4: 67 (n. 138).

165-6: 67 (n. 138).

167-9: 66 .

370: 88.

371: 88.

372: 87 (+ n. 184), 88 .

373: 88.

374: 88 .

375: 88.

376: 88.

377: 88.

378: 88.

379: 88.

380: 88.

381: 88.

382: 87 (n. 184), 88.

383: 88.

384: 88.

385: 88.

386: 88.

387: 88.

388: 87 (n. 184), 88.

389: 88 .

390: 88.

391: 88.

392: 88.

393: 88.

394: 88.

395: 88.

396: 88.

397: 88.

398: 87 (+ n. 184), 88 .

399: 88.

400: 80.

401: 88.

402: 96 (n. 205).

402-5: 25 (n. 13).
403: 96 (n. 203).

404: 92 (n. 192).

405: 96 (n. 203).

406: 92 (n. 192).

407: 92 (n. 191).

408: 96 (n. 203).

409: 109 (n. 235).

410: 109.

411: 96 (n. 203).

412: 30 (n. 28), 119.

413: 96 (n. 205).

412-6: 28 (n. 24).

413: 22, 25 (n. 14).

414-5: 124.

416: 105 (n. 226), 106 (n. 228).

417: 96 (n. 205).

418: 96 (n. 203).

419: 92 (n. 192).

420: 96 (n. 203).

421: 92 (n. 192).

422: 92 (n. 191).

423: 96 (n. 203).

424: 109 (n. 235).

425: 109.

426: 96 (n. 203).

427-33: 28 (n. 24).

429: 96 (n. 205).

430-1: 125.

432-3: 105 (n. 226), 106 (n. 228).

519: 88 .

520: 88.

521: 88 .

522: 23, 87 (n. 184), 88.

523: 88.

524-5: 87 (n. 184), 88.

526: 88 .

527: 88.

528: 88 .

529: 88.

530: 88 .

531: 88 .

532: 88.

533: 88 .

534: 88.

535: 88 .

536: 88 .

538: 88.

539: 88.

540: 88. 
Bacchae (cont.)

541: 23, 87 (n. 184), 88.

542: 88 .

543-4: 87 (n. 184), 88.

545: 88 .

546: 88.

547: 88 .

548: 88 .

549: 88.

550: 88 .

551: 88 .

552: 88.

553: 88 .

554: 88 .

555: 88 .

556: 88 .

557: 88 .

558: 88.

559: 88 .

560: 88 .

561-2: 88 .

563: 88 .

564: 88.

565: 88.

566: 88 .

567: 88 .

568: 88 .

569: 88.

570: 88.

571-2: 88 .

573: 116.

575: 28 (n. 24), 96 (n. 203).

576: 28 (n. 24), 96 (n. 206).

577: 94.

578: 40, 42 (n. 68), 43.

579: 41, 43.

580: 96 (n. 206).

580-1: 28 (n. 24).

581: 96 (n. 206).

582: 69 .

584: 40, 41, 42 (n. 68), 43.

585: 40, 65, 67 (n. 138).

588: 22, 41, 42.

589: 40, 41, 42 (n. 68), 43.

590: 122 .

591: 67 (n. 138).

592: 37.

593: 41, 42.

594: 67 (n. 138).
595: 67 (n. 138).

596: 67,69 .

599: 123.

600: 30 (n. 28), 37.

601: 69 .

602: 43.

603: 23, 41, 43.

862: 92 (n. 190).

863: 108 (n. 230).

863-83: 107.

864: 109.

865: 94.

866: 94.

867: 92 (n. 191).

868: 92 (n. 191).

869: 110 (n. 237).

870: 92 (n. 190).

871: 92 (n. 190).

872: 109 (n. 234).

873: 92 (n. 190).

874: 111, 115.

875: 119.

876: 102 .

877: 113 (n. 244).

878: 93 (n. 193).

879: 110 (n. 238).

880: 109 (n. 234, n. 235).

881: 28 (n. 24), 96 (n. 206).

883: 108 (n. 230).

884: 109 .

882: 92 (n. 190).

885: 94.

886: 94.

887: 94 (+ n. 196).

888: 92 (n. 190).

889: 110 (n. 238).

890: 92 (n. 190).

891: 92 (n. 190).

892: 109 (n. 234, n. 235).

893: 92 (n. 190).

894: 111, 115.

895: 119 .

896: 102 .

897: 113 (n. 244).

898: 93 (n. 193).

899: 110 (n. 238).

900: 109 (n. 234, n. 235).

901: 28 (n. 24), 96 (n. 206).

902: 99 (n. 214). 
902-6: 99.

903: 30 (n. 28), 92, 93 (+ n. 193).

904: 99 (n. 214).

905: 30 (n. 28), 119.

906: 99 (n. 214).

907: 92 (n. 191).

908: 28 (n. 24), 96 (n. 204).

909: 28 (n. 24), 96 (n. 205).

910: 28 (n. 24), 96 (n. 205).

911: 93 (+ n. 193).

912: 28 (n. 24), 96 (n. 203).

933: 58, 101 (n. 216), 106 (n. 227).

977: 61 (n. 115), 63.

978: 61 (n. 115).

979: 61.

980: 61 (n. 115).

981: 60 (n. 114), 61.

982: 61,62 .

983: 54 (n. 98).

984: 60 (n. 114).

985: 61 (n. 115), 62.

986: 61, 63.

987: 22,61 .

988: 122 .

989: 60 (n. 114).

990: 61.

991: 60 (n. 114).

992: 119.

993: 121.

994: 122.

995: 30 (n. 28), 61 (+ n. 115).

996: 60 (n. 114).

997: 63.

999: 61.

1000: 61 (n. 115).

1001: 60 (n. 114), 61.

1003: 54 (n. 98).

1008: 122.

1009: 60 (n. 114), 61.

1010: 60 (n. 114).

1011: 60 (n. 114).

1012: 119 .

1013: 58, 106 (n. 227), 121.

1014: 122 .

1015: 61 (+ n. 115).

1016: 60 (n. 114).

1017: 85.

1018: 122.

1019: 60 (n. 114).
1020: 60 (n. 114), 63.

1021: 60 (n. 114), 61.

1022: 119 .

1023: 60 (n. 114).

1034: 61 (+ n. 115).

1035: 62 .

1038: 61 (n. 115).

1153: 22, 24, 59, 61.

1154: 59, 61 .

1155: 85 .

1158: 63 .

1160: 62 .

1161: 22, 123.

1162: 59 (n. 110), 62.

1168: 59 (n. 111), 61 (n. 115), 63.

1169: 61 (n. 115).

1170: 119 .

1171: 63 .

1172: 22, 60 (n. 114).

1173: 118 .

1175: 22, 63.

1176: 61 (n. 115).

1177: 122 .

1178: 61 (n. 115).

1179: 85 .

1180: 85 .

1181: 122 .

1182: 22, 29 (n. 27), 122.

1183: 60 (n. 114), 61 (+ n. 115).

1184: 63 .

1185: 61 (n. 115).

1186: 119 .

1187: 63 .

1188: 60 (n. 114).

1189: 118 .

1190: 78 .

1191: 23, 63 .

1192: 61 (n. 115).

1193: 122 .

1194: 63.

1196: 85 .

1197: 122 .

1198: 22, 29 (n. 27), 122.

1199: 30 (n. 28), 60 (n. 114), 61 (+ n. 115).

Iphigenia Aulidensis

1-48: 34 (n. 43).

49-114: 34 (n. 43).

115: 51.

115-63: 34 (n. 43). 
Iphigenia Aulidensis (cont.)

116: 46 (n. 77), 51.

119: 50 .

120: 50 .

121: 48.

122: 46 (n. 77), 51.

123: 51 .

128: 49.

129: 50 .

130: 49.

129-30: 47 (n. 78$).$

131: 51.

132: 46 (n. 77), 51.

136: 51 .

137: 51.

164: 93 (n. 193).

164-230: 34 (n. 43).

165: 93 (+ n. 193).

166: 92 (n. 190).

167: 28 (n. 24), 96 (n. 204).

168: 110 .

169: 103.

170: 28 (n. 24), 96 (n. 203).

171: 89 .

171-4: 87.

172: 89 .

173: 88 .

174: 88 .

175: 28 (n. 24), 96 (n. 203).

175-6: 95.

176: 105 (+ n. 224).

177: 77.

178: 98 (+ n. 209).

179: 96 (n. 207).

180: 93 (+ n. 193).

181: 28 (n. 24), 96 (n. 203).

182: 109 .

183: 93.

184: 28 (n. 24), 96 (n. 203).

185: 93 (n. 193).

186: 93 (+ n. 193).

187: 92 (n. 190).

188: 28 (n. 24), 96 (n. 204).

189: 110 .

190: 103.

191: 28 (n. 24), 96 (n. 203).

192: 89.

192-5: 87.

193: 89.
194: 88.

195: 88.

196: 28 (n. 24), 96 (n. 203).

196-7: 94.

197: 105 (+ n. 224).

198: 77.

199: 75, 98 (+ n. 209).

200: 96 (n. 207).

201: 93 (+ n. 193).

202: 28 (n. 24), 96 (n. 203).

203: 109.

204: 93.

205: 28 (n. 24), 96 (n. 203).

207: 121 .

208: 110 .

209: 22, 96 (n. 203).

209-15: 28 (n. 24).

210-11: 77.

212: 96 (n. 206).

213: 92 (n. 192).

214: 22, 108 (n. 231).

215: 96 (n. 205).

216: 110 .

217: 109.

218: 110 (n. 237).

219: 109.

220: 109 (n. 235).

221: 110 (n. 238).

222: 110 .

223: 110 (n. 237).

224: 109 (n. 235).

225-6: 67 (n. 138).

227-8: 67 (n. 138).

229: 67 (n. 138).

231: 44.

231-41: 35 .

231-302: 34 (n. 43).

232: 42 .

233: 40, 44 .

236: 42.

237: 44.

238: 44.

240: 42.

241: 44.

242: 44.

242-52: 35 .

243: 23,42 .

244: 40, 44.

245: 44. 
247: 43.

248: 44.

249: 44.

251: $22,42$.

252: 44.

253: 44.

253-64: 35.

254: 44.

255: 44.

257: 42.

259: 42.

260: 42.

261: 42.

262: 118.

263: 44.

264: 43.

265-76: 35 .

266: 44.

267: 44.

269: 42.

271: 42.

272: 42.

273: 42.

274: 118 .

275: 44.

276: 42.

277: 44.

277-302: 35 .

278: 42.

279: 23, 44.

280: 23, 25 (n. 14), 42.

281: 43 (+ n. 71).

282: $22,37$.

283: 38 .

285: 22, 120 .

286: 122 .

287: 44.

288: 44.

293: 43.

294: 43.

296: 42.

297: 122.

298: 42.

299: 42.

300: 22, 120.

301: 44.

302: 44.

302-65: 34 (n. 43).

366-75: 34 (n. 43).
376-403: 34 (n. 43). 404-12: 34 (n. 43). 413-39: 34 (n. 43). 440-1: 34 (n. 43). 442-64: 34 (n. 43). 465-70: 34 (n. 43). 471-507: 34 (n. 43). 508-10: 34 (n. 43). 511-19: 34 (n. 43). 520-1: 34 (n. 43). 522-35: 34 (n. 43). 536-42: 34 (n. 43). 543: 93 (n. 193). 543-89: 34 (n. 43). 544: 93 (n. 193). 545: 96 (n. 203). 547: 109.

548: 93 (n. 193). 549: 109 . 550: 109 . 551: 109 . 552: 109 . 553: 109 .

554: 110 (n. 238). 555: 109 . 556: 110 . 557: 96 (n. 203). 558: 93 (n. 193). 559: 93 (n. 193). 560: 96 (n. 203). 562: 109 . 563: 109 . 566: 109. 567: 109 . 568: 109. 569: 110 .

570: 109 (n. 235). 572: 96 (n. 203). 573: 93 (n. 193). 574: 109. 575: 96 (n. 203). 576: 109. 577: 109 (n. 235). 581: 96 (n. 204). 582: 98 (n. 209). 583: 109 . 584: 111. 585: 73. 587: 36 (n. 51). 
Iphigenia Aulidensis (cont.)

588: 69.

589: 22 .

590-7: 34 (n. 43).

598-606: 34 (n. 43).

607-30: 34 (n. 43).

631-2: 34 (n. 43).

633-4: 34 (n. 43).

635: 34 (n. 43).

638-51: 34 (n. 43).

653-64: 34 (n. 43).

656: 109 .

666-73: 34 (n. 43).

674-5: 34 (n. 43).

675-80: 34 (n. 43).

681-93: 34 (n. 43).

694: 34 (n. 43).

695-719: 34 (n. 43).

720-2: 34 (n. 43).

723-6: 34 (n. 43).

727-38: 34 (n. 43).

739: 34 (n. 43).

740-50: 34 (n. 43).

751: 92 (n. 190).

751-2: 91 (n. 188).

751-800: 34 (n. 43).

752: 96 (n. 203).

753: 109.

754: 109.

755: 105 (n. 226).

756: 110 (n. 236, n. 238).

757: 110 (n. 237).

758: 109 (n. 235).

759: 103.

760: 92 (n. 190).

761: 99.

762: 92 (n. 190).

762-3: 91 (n. 188).

763: 96 (n. 203).

764: 109 .

765: 109 .

766: 105 (n. 226).

767: 110 (+ n. 236).

768: 110 (n. 238).

769: 109 .

770: 103

771: 93.

772: 99.

773: 92 (n. 191).
774: 96 (n. 204).

775: 109 .

776: 69 .

778: 96 (n. 207), 97.

779: 110 (n. 238).

780: 109 (+ n. 234).

781: 95 .

782: 98

783: 108 (n. 231).

784-5: 112 .

786: 96 (n. 204).

787: 96 (n. 203).

788: 109 .

789: 108 (+ n. 230).

790: 94.

791: 93 (n. 193).

795: 93, 96.

794: 22.

797: 109 .

798: 110 (n. 237).

799: 96 (n. 207).

800: 99 (n. 214).

801-18: 34 (n. 43).

819-98: 34 (n. 43).

899: 34 (n. 43).

900-8: 34 (n. 43).

909-14: 34 (n. 43).

915-6: 34 (n. 43).

917-8: 34 (n. 43).

919-1035: 34 (n. 43).

1036: 115.

1036-79: 34 (n. 43).

1037: 115 .

1038: 93.

1039: 96 (n. 203).

1040: 113.

1042: 72 .

1044: 96 (n. 203).

1045-6: 113.

1047: 93, 99.

1049: 98 (n. 209).

1050: 110 (n. 238).

1051: 98 (n. 209).

1052: 109 (n. 235).

1053: 96 (n. 206).

1054: 93 (n. 193).

1055: 96.

1056: 94 .

1057: 108 (n. 231). 
1058: 115.

1059: 115.

1060: 92 (n. 190).

1062: 113.

1064: 72.

1066: 22, 96 (n. 203).

1067-8: 113.

1069: 99 (n. 214).

1071: 98 (n. 209).

1072: 110 (n. 237).

1073: 98 (n. 209).

1074: 109 (n. 235).

1075: 96 (n. 206).

1076: 93 (n. 193).

1077: 96 (n. 207).

1078: 94.

1079: 108 (n. 230).

1080: 113 .

1080-97: 34 (n. 43).

1081: 109 .

1082: 108.

1083: 116.

1084: 22.

1085: 92 (n. 190).

1086: 92 (n. 190).

1087-8: 93 (n. 193).

1089: 104.

1091: 22, 108 (n. 231).

1092: 115.

1093: 94.

1094: 96 (n. 203).

1095: 93 (n. 193).

1096: 92 (n. 190).

1097: 96 (n. 203).

1098-1119: 34 (n. 43).

1120-3: 34 (n. 43).

1124-6: 34 (n. 43).

1127-9: 34 (n. 43).

1130-3: 34 (n. 43).

1134-69: 34 (n. 43).

1170-2: 34 (n. 43).

1173-84: 34 (n. 43).

1185: 34 (n. 43).

1186-1240: 34 (n. 43).

1241-52: 34 (n. 43).

1253-69: 34 (n. 43).

1270: 34 (n. 43).

1271-75: 34 (n. 43).

1276-82: 34 (n. 43).
1283: 117.

1283-1335: 36.

1283-1337: 34 (n. 43).

1284: 23, 24, 25 (n. 14).

1284-90: 55-7.

1285: 30 (n. 28), 38.

1286: 30 (n. 28), 37.

1288: 40.

1289: 122 .

1290: 44, 56.

1291: 37 (n. 52).

1292: 37 (n. 52).

1293: 38.

1294: 67, 69.

1294-5: 68.

1295: 69.

1297: 72 (n. 149).

1300: 39 (n. 57), 44.

1301: 37 (n. 53).

1303: 37.

1304: 40.

1305: 38.

1306: 38.

1307: 37.

1308: 37.

1309: 37.

1311: 22 .

1312: 37.

1314: 37.

1315: 41.

1316: 119 .

1317: 118 .

1318: 125 .

1319: 50.

1320: 46 (n. 77), 50.

1323: 51.

1324: 50.

1325: 50 .

1326: 48.

1327: 49 .

1327-9: 47 (n. 78).

1328: 50 .

1329: 48.

1330: 22, 66.

1331-2: 67 (n. 138).

1334: 37.

1335: 43

1338-1403: 34 (n. 43).

1404-6: 34 (n. 43). 


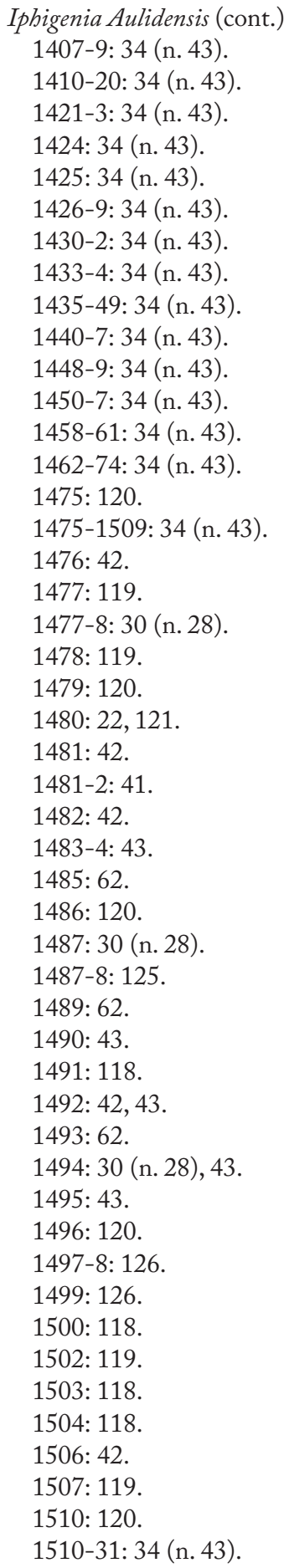

1511: 42.

1512: 119.

1513: 126.

1514: 118.

1515: 43.

1519: 120.

1520: 42.

1521: 42.

1522: 38 .

1523: 123 .

1524: 124 .

1525: 118 .

1526: 43.

1531: 127.

1532-77: 34 (n. 43).

1578-1629: 34 (n. 43).

Rhesus

23: 92 (n. 190).

23-4: 91 (n. 188).

24: 96 (n. 203).

25: 125 .

26: 67 (n. 138).

27: 69 .

28: 72 .

29: 84 .

31: 83.

32: 72 (n. 149).

33: 127.

41: 92 (n. 190).

41-2: 91 (n. 188).

42: 96 (n. 203).

43: 125 .

44: 67 (n. 138).

45: 69.

46: 72 .

47: 83.

49: $22,83$.

50: 72 (n. 149).

51: 127.

131: 61 (+ n. 115).

132: 60 (n. 114), 61 (n. 115).

133: 61 (n. 115).

134: 29 (n. 27), 60 (n. 114).

135: 119.

136: 61 (n. 115).

137: 29 (n. 27), 120.

195: 61 (+ n. 115).

196: 60 (n. 114), 61 (n. 115).

197: 61 (n. 115). 
198: 29 (n. 27), 60 (n. 114).

199: 119 .

200: 61 (n. 115).

201: 29 (n. 27), 120.

224: 79.

226: 84.

227: 72 (n. 149).

230: 84.

231: 72 .

232: 121.

233: 79.

235: 84.

236: 72 (n. 149).

237-8: 84 .

240: 72.

241: 121 .

242-3: 126.

244: 69 .

245: 72 .

246-7: 82 .

248: 83.

249: 23, 75 .

250: 63.

251: 115 (n. 248).

252: 105 (n. 226), 106 (n. 228).

253-4: 126.

255: 69 .

256: 72 .

257-8: 82 .

259: 83.

260: 22,75 .

261: 63 .

262: 115 (n. 248).

263: 105 (n. 226), 106 (n. 228).

342: 92 (n. 190).

343: 92 (n. 190).

344: 96 (n. 205).

345: 99 (n. 214).

346: 25 (n. 14), 96 (n. 203).

347: 112 .

348: 72 .

349: 83.

350: 105 (n. 226), 106 (n. 228).

351: 92 (n. 190).

352: 92 (n. 190).

353: 96 (n. 203).

354: 99 (n. 214).

355: 23, 96 (n. 205).

356: 112 .
357: 72.

359: 105 (n. 226), 106 (n. 228).

360: 128.

361: 116.

362: 105 (n. 226).

363: 89.

364: 88.

365: 88.

366: 111 .

367: 105 (n. 226).

368: 105.

369: 105 (n. 226), 106 (n. 228), 115 (n. 248).

370: 128.

371: 116

372: 105 (n. 226).

373: 89.

374: 88 .

375: 88.

376: 111.

377: 105 (n. 226).

378: 105 .

379: 105 (n. 226), 106 (n. 228), 115 (n. 248).

457: 85 .

458: $74,83$.

459: 42.

460: 29 (n. 27), 79.

461-2: 76 (n. 162).

462: 22.

464: 72.

465: 127.

527: 81.

528: 22, 24.

529: 83.

530: 72 (n. 149).

531: 76 (n. 162).

532: 73.

533: 72 (n. 149).

534: 73.

535: 96 (n. 203).

536-7: 86 .

546: 81.

548: 83.

549: 72 (n. 149).

550: 76 (n. 162).

551: 73 .

552: 72 (n. 149).

553: 73 . 


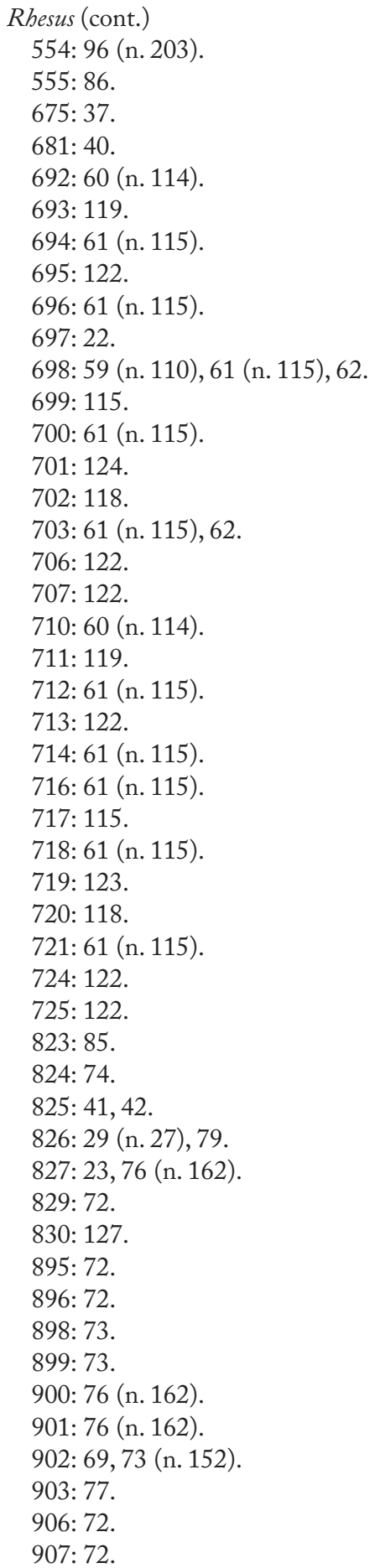

909: 22, 73.

910: 73.

911: 27 (n. 23), 76 (n. 162).

913: 69, 73 (n. 152).

914: 77.

Fragments

Cresphontes

(Austin)

Fr. 71, 9: 93, 98 (+ n. 212).

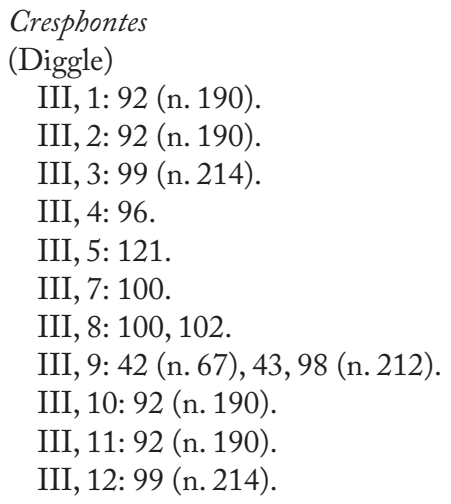

\section{Erechtheus}

III, 1: 77.

III, 2: $77(+$ n. 163).

III, 3: 79.

III, 4: 83 .

III, 5: 77 .

III, 6: 84 .

III, 7: 121.

IV, 3: 124 .

\section{Hypsipyle}

(Bond)

Fr. I ii, 4: 95 (n. 201).

Fr. I iii, 8: 96 (n. 206).

Fr. 8/9, 10: 98 (n. 209).

Fr. 8/9, 13-4: 47 (n. 81).

Fr. 64, 91: 25 (n. 14).

Fr. 64, 104: 43 (n. 69).

Fr. 754, 2: 59, 61.

\author{
Hypsipyle \\ (Diggle) \\ 21: 109 (n. 233). \\ 22: 109 (n. 233). \\ 24: 96 (n. 203). \\ 25: 119 .
}


26: 67.

27: 67 (n. 138).

28: 67 (n. 138).

29: 67 (n. 138).

30: 72 (n. 149).

31: 120 .

32: 93 (n. 193).

33: 93 (n. 193).

34: 93.

35: 96 (n. 203).

36: 109 (n. 235).

37: 109.

38: 96 (n. 203).

39: 22, 96 (n. 204).

40: 93, 96-7, 98 (n. 211).

41: 96 (n. 203).

42: 92 (n. 190).

43: 100.

44: 96 (n. 203).

45: 108 (n. 230).

46: 22.

47: 109 (n. 235).

48: 96 (n. 203).

49: 93 (+ n. 193).

61: 95 (n. 201), 96.

62: 108 (n. 230).

63: 88, 109 (n. 233).

63-5: 109 (n. 233).

64: 88, 109 (n. 233).

65: 89, 96 (n. 206).

66: 30 (n. 28), 119.

67: 72 (n. 149).

69: 46 (n. 77), 49.

70: 48.

71: 49.

72: 46 (n. 77), 49.

73: 48.

74: 120.

75: 93 (n. 193).

76: 93 (n. 193).

77: 92 (n. 192).

78: 96 (n. 203).

79: 109.

80: 109.

81: 96 (n. 203).

82: 96 (n. 204).

84: 96 (n. 203).

85: 92 (n. 190).

86: 100 .
87: 96 (n. 203).

88: 108 (n. 231).

92: 30 (n. 28).

107: 30 (n. 28), 119 (+ n. 260).

108: 49.

109: 49.

110: 48.

111: 120 .

148: 88.

244: 61.

245: 60 (n. 114), 61.

246: 63.

256: 61 .

257: 59 (n. 110), 61, 62.

258: 59 (+ n. 110), 61, 62 .

260: 61 (n. 115).

261: 46 (n. 77).

262: 61 (n. 115).

264: 62 .

266: 63 .

269: 72 (n. 149).

270: 75 .

271: 22,72 .

273: 61 (n. 115).

274: 22, 84, 85 (n. 179).

275: 72 (n. 149).

276: 74 .

276-7: 25 (n. 14).

279: 75 .

281: 61 (n. 115), 62.

282: 61 (n. 115).

285: 119 .

288: 61.

288-9: 43 (n. 69).

289: 61.

Hypsipyle

(Kannicht)

Fr. 753c, 16: 76.

Fr. 753c, 18: 76 .

Fr. 753c, 21: 122.

Fr. 754, 1: 61.

Fr. 754, 2: 61, 62.

Fr. 759a, 1612: 25 (n. 14).

\section{Phaethon}

63: 110 (n. 238).

64: 109 (n. 234, n. 235).

65: 110 .

66: 109 . 


\section{Phaethon (cont.)}

67: 110 (n. 238).

68: 109 (n. 234, n. 235).

69: 110 .

70: 96 (n. 206).

71: 110 (n. 237).

72: 109 (n. 235).

73: 111.

74: 109 (n. 234, n. 235).

75: 110 (n. 237).

76: 109 (n. 234, n. 235).

77: 110 (+ n. 238).

78: 96 (n. 206).

79: 46 (n. 77), 49.

80: 46 (n. 77), 49.

81: 46 (n. 77), 49.

82: 45 (n. 73, n. 74), 50.

83: 46 (n. 77), 51.

84: 48.

85: 49.

86: 125.

87: 46 (n. 77), 49.

88: 46 (n. 77), 49.

89: 46 (n. 77), 49.

90: 51.

91: 51 .

92: 48.

93: 49.

94: 125.

95: 124.

96: 120.

97: 67.

98: 120 .

99: 37.

100: $41,43$.

101: 126.

228: 82.

229: 83.

230: 29 (n. 26), 78, 100, 102.

231: 82 .

233: 72 (n. 149).

234: 73 .

235: 123.

237: 82 .

238: 83.

239: 29 (n. 26), 78, 100.

240: 25 (n. 14), 82.

242: 72 (n. 149).

243: 73 .
244: 123.

270: 118.

271: 74 .

272: 79.

273: 121 (+ n. 272).

275: 61 (n. 115).

276: 74 .

277: 60 (n. 114).

278: 60 (n. 114), 61 (n. 115).

279: 61 (n. 115).

280: 123 .

281: 62 .

\section{Telephus}

II, 2: 96 (n. 203).

II, 4: 96 (n. 205).

II, 5: 22, 42 (+ n. 67).

II, 6: 105 (n. 226).

II, 7: 100, 102.

II, 9: 92 (n. 190).

II, 10: 99 (n. 214).

IвусUS

PMGF S151: 100.

PMGF 286, 1-3: 102-3.

PMGF 286, 7: 103.

\section{Pindar}

Olympian Odes

1,1: 91.

3 (str.): 82 .

6 (str.; ep.): 82.

8 (ep. 1; antistr. 1; ep. 2, 3, 4): 82.

10, 2: 113 (n. 244).

10 (str.): 92 (n. 189).

10 (ep. line 2): 94.

11 (str.): 82.

14, 8: 112 (n. 242).

\section{Pythian Odes}

3 (str.; ep.): 82.

5, 7-8: 113 (n. 244).

5 (str. 6): 53 (n. 88).

6, 5: 111 (n. 240).

7 (str. 5): 53 (n. 88).

8, 19: 92 (n. 189).

9 (str.): 82 .

12 (str. 1, 2, 3; 4): 82. 
Nemean Odes

2, 16: 92 (n. 189).

4, 23: 92 (n. 189).

6, 6-7: 112 (n. 241).

6 (ep.): 92 (n. 189).

7 (str.): 99.

7 (ep.): 111 (n. 240).

9 (str.): 82.

10, 7: 75 .

10 (ep.): 82.

11 (str.; ep.): 82.

\section{Isthmian Odes}

1 (str.; antistr. 3): 82 .

2 (str.; ep.): 82.

5 (ep.): 82.

\section{Sappho}

Fr. 31.9-10 (PLF): 27 (n. 20).

\section{Sophocles}

Aias

175: 84.

178: 85.

179: 85 .

180: 85 .

186: 84 .

189: 85.

190: 85.

191: 85 .

196: 100 (n. 215).

199: 95 (n. 200), 99 (n. 213).

231: 94.

254: 94.

394: 24.

414: 24.

596: 99.

598: 100 (n. 215).

606: 35 (n. 45).

607: 35 (n. 45).

609: 99.

611: 100 (n. 215).

620: 35 (n. 45).

621: 35 (n. 45).

627: 104 .

628: 113 (n. 245).

638: 104 .

640: 113 (n. 245).

868: 41 (n. 62).
871: 41 (n. 62).

902: 35 (n. 45).

911: 85.

948: 35 (n. 45).

957: 85.

1191: 112 (n. 241).

1198: 112 (n. 241).

1199: 102.

1206: 100 (n. 215).

1210: 108.

1211: 102.

1218: 100 (n. 215).

1222: 108.

\section{Antigone}

102: 92 (n. 189).

119: 92 (n. 189).

134: 74.

135: 74 .

148: 74 .

149: 74 .

336: 102.

346: 102.

360: 35 (n. 45).

370: 35 (n. 45).

584: 84.

594: 83.

595: 84.

783: 100 (n. 215).

784: 100 (n. 215).

787: 113 (n. 245).

789: 100 (n. 215).

793: 100 (n. 215).

797: 113 (n. 245).

794: 100 (n. 215).

799: 100 (n. 215).

807: 104.

812: 108 .

824: 104.

829: 108.

842: 104.

861: 104.

880: 35 (n. 45).

881: 35 (n. 45).

946: 99 (n. 213).

957: 99 (n. 213).

1139: 41 (n. 62).

1141: 93.

1148: 41 (n. 62).

1150: 93. 
Antigone (cont.)

1289: 63 (n. 132).

Electra

123: 114.

139: 114 (+ n. 247).

208: 41 (n. 62).

228: 41 (n. 62).

472: 113 (n. 245).

486: 100 (n. 215).

488: 113 (n. 245).

502: 100 (n. 215).

855: 41 (n. 62).

866: 41 (n. 62).

1062: 75 (n. 160).

1074: 75 (n. 160).

1069: 75 (n. 160).

1081: 75 (n. 160).

1247: 56 .

1267: 56 .

1284: 35 (n. 45).

1285: 35 (n. 45).

1286: 35 (n. 45).

1413: 82 .

1414: 82.

1433: 82.

1434: 82 .

Oedipus Coloneus

119: 103.

124-7: 91.

128: 104.

132: 92 (n. 189).

151: 103.

156-9: 91.

160: 104.

164: 92 (n. 189).

182: 93 (n. 193).

197: 93 (n. 193).

200: 93 (n. 193).

209: 41 (n. 62).

216: 73 (n. 154).

218: 73 (n. 154).

220: 73 (n. 154).

222: 73 (n. 154).

237: 25 (n. 14).

239: 103.

252: 103.

512: 102 .

514: 100 (n. 215).

515: 100 (n. 215).

516: 100 (n. 215).

523: 102 .

526: 100 (n. 215).

527: 100 (n. 215).

528: 100 (n. 215).

668-80: 33 .

671: 92 (n. 189).

675: 92 (n. 189).

680: 100 (n. 215).

681-93: 33.

684: 92 (n. 189).

688: 92 (n. 189).

693: 100 (n. 215).

1058: 108 .

1073: 108 .

1080: 35 (n. 45).

1081: 35 (n. 45).

1091: 35 (n. 45).

1092: 35 (n. 45).

1218: 92 (n. 189).

1220: 35 (n. 45).

1221: 35 (n. 45).

1222: 35 (n. 45).

1232: 92 (n. 189).

1235: 35 (n. 45).

1236: 35 (n. 45).

1237: 35 (n. 45).

1245: 103.

1563: 41 (n. 62).

1575: 41 (n. 62).

1680: 35 (n. 45).

1681: 35 (n. 45).

1684: 35 (n. 45).

1688: 35 (n. 45).

1707: 35 (n. 45).

1708: 35 (n. 45).

1711: 35 (n. 45).

1715: 35 (n. 45).

1724-36: 36.

1730: 35 (n. 45).

1731: 35 (n. 45).

1732: 35 (n. 45).

1733: 35 (n. 45).

1734: 35 (n. 45).

1735: 35 (n. 45).

1736: 35 (n. 45), 40.

1737-50: 36 .

1743: 35 (n. 45). 
1744: 35 (n. 45). 1745: 35 (n. 45). 1746: 35 (n. 45). 1747: 35 (n. 45). 1748: 35 (n. 45). 1749: 35 (n. 45). 1750: 35 (n. 45), 40.

\section{Oedipus Tyrannus} 199: 41 (n. 62). 212: 41 (n. 62). 332: 27.

469: 77.

661: 56 .

692: 56.

883: 35 (n. 45).

884: 41 (n. 62).

885: 100 (n. 215).

886: 41 (n. 62).

888: 41 (n. 62).

894: 35 (n. 45).

895: 35 (n. 45).

897: 35 (n. 45).

898: 41 (n. 62).

900: 41 (n. 62).

901: 100 (n. 215).

902: 41 (n. 62).

907: 35 (n. 45).

908: 35 (n. 45).

1199: 23 (n. 9).

1200: 23 (n. 9).

1209: 78 .

1218: 78.

1330: 56.

1338: 41 (n. 62).

1358: 41 (n. 62).

\section{Philoctetes}

141: 113.

156: 113.

173: 92 (n. 189).

177: 25 (n. 14), 104.

184: 92 (n. 189).

188: 23 (n. 9), 104.

189: 23 (n. 9).

714: 25 (n. 14), 104.

725: 104.

827: 74.

843: 74.

864: 35 (n. 45).
1090: 104.

1111: 104.

1127: 92 (n. 189).

1129: 92 (n. 189).

1150: 92 (n. 189).

1152: 92 (n. 189).

1171: 41 (n. 62).

1209: 102.

1212: 41 (n. 62).

1216: 110.

1217: 100 (n. 215).

\section{Trachiniae}

97: 83.

106: 83.

133: 41 (n. 63).

222: 41 (n. 62).

223-4: 99 (n. 213).

502: 84.

512: 84.

633: 100 (n. 215).

640: 100 (n. 215).

647: 75 (+ n. 155).

648: 76 (n. 162).

655: 75 (+ n. 155).

656: 76 (n. 162).

826: 35 (n. 45).

827: 35 (n. 45).

828: 35 (n. 45).

836: 35 (n. 45).

837: 35 (n. 45).

838: 35 (n. 45).

842: 121 (n. 268).

844: 92 (n. 189), 93 (n. 193).

855: 92 (n. 189), 93 (n. 193).

879: 35 (n. 45).

894-5: 99 (n. 213).

957: 78, 100 (n. 215).

960: 78, 100 (n. 215).

966: 78, 100 (n. 215).

969: 78, 100 (n. 215). 


\section{INDEX RERVM}

'A': 54, 76-7, 84 (n. 176).

Adonean: 68, 108.

Aeolic: 24, 28 (n. 24), 32, 33, 42 (n. 66, n. 67$), 48,72,75,76,77,78,87,88$, 91-116.

Aeolic base: 92, 93 (+ n. 193), 94-7, 99-100, 111.

Aeolic cola with iambic suffix: 111, 115.

Iambic prefix: 112 .

Choriambic prefix: 76.

Choriambic suffix: 113.

Choriambic expansion: 113.115.

Iambo-choriambic phrases: 115.

Aeolic heptasyllable: 72 (n. 150), $91,110 \mathrm{ff}$.

Aeolic hexasyllable: 48, 95, 108, $111 \mathrm{ff} ., 113,114$.

Alcaic decasyllable: 75-6, 86, 99, 103 (n. 219).

Anaclasis: 10, 91, 100, 102, 106 (n. 227), 109-10.

Anacreontic: 31, 87, 88, 99 (n. 213).

AnAdiplosis: 29, 57 (+ n. 108), 117 (n. 256).
Anapaests: 10, 20, 28 (n. 24), 30, 31, 36, 45 ff., 54, 62 (n. 124), 65 (n. 134), 71, 75 (n. 155), 76, 117 (n. 255).

Absence of metron diaeresis in: 46 (n. 77).

Balancing anaphorae: 46 (n. 78).

Beginning with four shorts: 48 (n. 84).

Dimeters (?): 10, 45.

Resolution in: 47, 48.

Synartesis in: 47.

Anceps: 27, 28 (n. 24), 81, 91, 104, 113, 120 (n. 262).

Link anceps: 71 (+ n. 148), 81.

Long anceps: 36 (n. 51), 37, 39, 43 (n. 69, n. 71), 58, 59 (n. 110, n. 111), 61, 63, 74, 77, 81, 86, 112, 117,118 (n. 258), 119 (n. 259).

Long anceps in responsion with short: 75 (n. 158), 108.

Anceps iuxta anceps: 27, 28 (n. 24), 112 (n. 243).

Resolved anceps: 55-6 (+ n. 104), 81.

Short anceps: 67 (n. 137), 75, 76, 77, 81, 86, 102, 108.

Archebulean: 77.

Archilochean dicolon: 73, 79, 100. 
Aristophanean: 23, 72, 91, 93, 101, $105 \mathrm{ff.}, 112$.

Astropha: 24 (n. 9, n. 10), 26, 37 (n. 55), 48.

BAcchiac: 21, 43 (n. 70), 59, 68 (n. 140), 77 (n. 163), 103, 106 (n. 227), 120 (n. 265), 121 (+ n. 268), 122-3, 128. Resolution in: 21-2, 120 (n. 265), 235 (n. 89).

BREVIS IN LONGO: 21-3, 24, 25, 26, 27, 37, $45,55,56,57,65,67,68,72,75,76$, $78,92,94,95,102,104,105,110$.

BREVIS IVXTA ANCEPS: 65.

Caesura: 66, 71, 117 (+ n. 253), 124 (n. 276).

Catalexis: 35, 45, 47 (n. 79), 66, 67, 69, 76, 91, 95, 98, 108, $113(+\mathrm{n}$. 245), 118 (n. 258), 127 (n. 279). Catalectic opening cola: 24-5.

Catalectic cola in synartesis: 58, 101.

Change of metre: 26, 28, 30, 42, 57, 68-9, 75 (n. 157), 92, 116.

\section{Choerilean: 82.}

Cholosis: 48 (n. 82), 75, 77-8, 92-6, 101,103 (+ n. 219), 104, 111, 114.

Choriamb: 10, 58, 76, 91, 100, 111, 112 (n. 241), 113, 114-6.

Resolution in: 58, 92-3, 95-9, 102, 104-5, 110.

Choriambic dimeter: 10, 108, 115 (+ n. 248).

Clausula: 25, 28 (n. 24), 41, 45, 48, 68 (+ n. 140), 75, 87, 92 (n. 189), 94, 98-100, 101 (n. 216), 103 (+ n. 219), 104-5, 107-8, 110-1, 114, 121 (n. 268), 127 (n. 279).
Colometry: 9-10, 25, 39-40, 43 (n. 69), 45 (n. 74), 47 (n. 81), 54 (+ n. 96), 58, 94, 95 (n. 202), 101, 105 (n. 224), 106, 121 (n. 272).

Contraction: 28 (n. 24), 72-3, 77 (n. 163), 79, 82 (n. 170, n. 171), 87.

Cretic: 26 (n. 17), 38-9, 41, 44, 55 (n. 100), 56, 57 (n. 109), 59, 68-9, 85, 111,120 (+ n. 265), 122-3.

Cyrenaic: 74-5, 105, 116 (n. 251).

DActylic: $20,24,30,31,36,42,46$ (+ n. 76), 65 ff., 71-4, 76, 79, 81, 103 (n. 219, n. 220), 108, 116.

Dactyl followed by hiatus and presumed period-end: 65 .

Spondaic hexameter: 68 (n. 139).

Resolution: 65.

Tetrameter with catalexis: 73 (+ n. 152), 74, 104 (n. 223).

Dactylo-epitrite: $20,30-1,42,71$, 72 (n. 159), 79, 81 ff., 99-101, 118 (n. 258), 127 (n. 279).

Diaeresis: 46-7 (+ n. 80), 54, 68, 87.

Diomedean: 27, 75.

Dochmiacs: $10,20,27,29,30-1,42$, 43 (n. 69), 48, 53 ff., 75 (n. 155), 99 (n. 213), 102, 103 (n. 219), 107, 108, 117 (n. 256), 120 (n. 262).

Dochmiac dimeter (?): 10, 54 .

Dochmiac + hypodochmiac: 56 (n. 103).

Dochmiac 'trimeter': 54 (n. 96).

Hypodochmiac: 54 (n. 98), 56, 62 (n. 122), 63, 78.

Kaibelianus: 54 (n. 98), 64.

Dodrans: 48, 91, 93-4, 97, 104-6, 111-3.

Aeschylus: 104.

Sophocles: 104.

Synartesis: 106 (n. 229). 
Dovetailing (see also under 'Overlap' and 'Synartesis': 24, 26 (n. 18), 41 (n. 64), 43 (n. 70), 94-5, 106, 111.

Elision: 26-7, 95, 99 (n. 213), 107.

EnOPlian: 20, 25, 27, 30-1, 36, 42, 48, 67 (n. 137), 68 (n.141), 71 ff., 81, 857, 96 (n. 203), 98-104, 107-8, 116.

Enoplian dochmiacs: 20, 30 (n. 31), 31, 102, 103 (n. 219), 107.

ENOPLIAN PAROEMIAC: 77, 81, 86.

Glyconic: 10, 42, 48 (n. 82), 78, 91 ff., 95-9, 101, 103-4, 108, 111.

Cholosis: 93-4.

Hymeneal glyconics: 33 (n. 39).

Period-closing phrase in Euripides: 92. Pindar: 92 (n. 189).

Sophocles: 92 (n. 189).

Resolution:

First long of the choriamb: 93 (n. 194), 95.

Second long of the choriamb: 92-3.

Final syllable: 93.

Tribrach base: 92-3.

Aristophanes: 93 (n. 193).

Sophocles: 93 (n. 193).

Hagesichorean: 29, 78, 91 (n. 186), 93, 98, 100 ff., 102, 106.

Aeschylus and Sophocles: 100 (n. 215).

Gleitender Übergang: 101.

Hemiepes: 28 (n. 24), 42, 68, 71-2, 73, 79, 81, 82 (n. 170, n. 171).

Hiatus: 20, 23-5, 27 (+ n. 23), 45 (n. 73, n. 74), 48, 57, 65, 68, 94 (n. 197), 97, 104, 105 (n. 225), 110.

Hipponactean: 73 (n. 153), 91 (+ n. 186), 93-4, 97-100, 106.

Twin clausula: 99 (n. 213).
IAмBic: 20, 28 (n. 24), 31, 35 (n. 46), 39-42, 43 (n. 69), 47, 53-4, 55 (n. 100, n. 101), 57 (n. 109), 59, 66, 68, 74, 77, 84 (n. 174), 85, 87, 89 (+ n. 185), 99 (n. 213), 100, 106 (n. 227), 110 (n. 237), 111-2, 114, 115 (+ n. 249, n. 250), 116, $117 \mathrm{ff}$.

'Impure' iambics: 60, 120 (n. 262).

Resolution before long anceps: 119 (n. 259).

Trimeters without caesura: 117 (n. 253), 124 (n. 276).

IвyCEAn: 28 (n. 24), 73, 76-7, 85, 98, $102-4$.

Invocations: 25-6, 97, 106.

Ionic: 20, 28 (n. 24), 31, 33, 68 (n. 140), 87-9, 96 (n. 203), 99 (n. 213), 108, 109 (n. 233), 113.

Catalexis: 28 (n. 24).

ITHYPHALLIC: 23 (n. 9), 27-8, 44, 62, 67 (n. 137), 103, $120(+263)$.

LeCYTHION: 35 (n. 46), 39 (+ n. 59), 404, 78 (n. 165), 98 (n. 212), 117, 121 (n. 266, n. 267).

As gleitender Übergang: 41-2.

Iambic lecythia not catalectic: 118 (n. 258).

Resolution in penultimate long: 42 (n. 68).

Word-overlap avoided in Sophocles and Euripides: 39 (n. 59), 41 (+ n. 64), 43 (n. 70).

'Mirror effects' in Responding STANZAS: 29 (+ n. 26, n. 27).

Modulation: 26, 30 (n. 29), 35, 101.

Molossus: 38, 44, 59, 62 (n. 122), 75 (n. 155), 122-3.

Monody: 30 (n. 31), 31, 36 (+ n. 50), $37,40,47,53,57,69,73$ (n. 152), 
103 (n. 222), 115.

Overlap (see also under 'Dovetailing' and 'Synartesis'): 10, 26, 41, 47, 57, 95, 101 (+ n. 216), 106.

Palimbacchiac: 38, 127 (n. 279).

Paroemiac: 45-6, 50, 62 (n. 124), 75, 108.

Pause: 23 (+ n. 9), 25-6, 57, 68, 75 (n. 157), 92, 101, 104.

Pendent aeolic octosyllable: 102.

Period: 20-8, 41, 45-6, 57, 65, 68, 73 (n. 152), 74-6, 92, 94-5, 97-8, 99 (n. 213), 101-2, 104, 106-8, 110, 112, 114, 121 (n. 268).

Period-end: 21-6, 28, 45, 65, 68, 92 , 104, 106-7.

Elision at (?): 26-7.

Phalaecian: 111-2.

Pherecratean: 28 (n. 24), 91, 93 (+ n. 193), 94, 95 ff., 99 (+ n. 213), 105, $107,113$.

Phrasing: 20-1, 23, 26-9, 37 (n. 55), 76, 106-7.

Asymmetrical phrasing in responding stanzas: $27-9$.

Polyschematist: 10.

Praxillean: 27, 65, 74, 81, 86.

Priapean: 21 (n. 5), 28 (n. 24), 91, 100.

Reizianum: 58, 76, 91, 93, 98, 101, 107-8.

Resolution: 31-2, 35, 42, 47-8, 58, $65,85,87$ (+ n. 184), 92-3, 95-9, 102, 103 (n. 221), 104-5, 110-1, 124-5.

Resolution before long anceps: 37 (n. 53), 119 (n. 259).
Resolution before syncopation: 117 (n. 253).

Split resolution: 43 (n. 70), 58, 98 (n. 212), 117, 119 (n. 260), 121 (n. 266, n. 267).

Responsion: 29 (n. 27), 83 (n. 172), 96, 104, 109 (n. 233).

Asymmetrical responsion: 66, 77, 87 (n.184), 97, 103 (n. 219), 108, 109 (n. 233), 110.

Irregular responsion: 53 (n. 94), 54 (n. 98), 57, 72, 75, 81, 94 (n. 196), 96, 98, 101, 103 (n. 219), 114.

SpondeE: 38, 44, 59, 65, 68-9, 72, 75, $85,113,121,123$.

Stanza: 20, 23-4, 26-9, 39, 48 (n. 82), 68, 75, 87 (n. 184), 91, 98, 99 (+ n. 213), 100-1, 102-4, 106, 114, 116.

Synapheia: 26, 101.

Synartesis (see also under 'Dovetailing' and 'Overlap'): 26, 39 (n. 59), 41 (+ n. 64), 47, 58, 65 (n. 133), 73, 76, 91, 95, 97-8, 101 (n. 216), 103-4, 106 (n. 227, n. 229), 109-10, 113, 121 (n. 268).

Syncopation: 33, 35 (+ n. 46), 36, 38 40, 47, 53 (n. 94), 57 (n. 109), 59, $60,66,88,111,115,117$ (+ n. 253), 120,125 .

Synizesis: 84 (n. 175).

'T': 76, 97-8.

Telesillean: 76, 91, 93, 96-8, 104, 105 (n. 224), 110, 113.

TRIBRACH-SHAPED WORDS: 29-30 (+ n. 28).

Trochaeo-Iambic: 44 (n. 72). 
Trochaic: 20, 27, 29, 31, 33, 35 ff., 568, 66, 76 (n. 162), 118 (n. 258).

Twin clausula: 99 (+ n. 213), 107.

Wilamowitzian: 10, 91, 94 (n. 196), 108 ff., 110-1, 115.

Responsion with glyconic: 108-9 (n. 233).

WORD-BREAK: 112, 114.

WORD-END AFTER LONG ANCEPS: 37 (n. 54), 43 (n. 69, n. 71), 58-9, 117.

WORD-END BETWEEN TROCHAIC AND IAM BIC: 57 (n. 109). 


\section{Volumes published in the Humanitas Supplementum Collection}

1. Francisco de Oliveira, Cláudia Teixeira e Paula Barata Dias: Espaços e Paisagens. Antiguidade Clássica e Heranças Contemporâneas. Vol. 1 - Linguas e Literaturas. Grécia e Roma (Coimbra, Classica Digitalia/CECH, 2009).

2. Francisco de Oliveira, Cláudia Teixeira e Paula Barata Dias: Espaços e Paisagens. Antiguidade Clássica e Heranças Contemporâneas. Vol. 2 - Linguas e Literaturas. Idade Média. Renascimento. Recepção (Coimbra, Classica Digitalia/CECH, 2009).

3. Francisco de Oliveira, Jorge de Oliveira e Manuel Patrício: Espaços e Paisagens. Antiguidade Clássica e Heranças Contemporâneas. Vol.3 - História, Arqueologia e Arte (Coimbra, Classica Digitalia/CECH, 2010).

4. Maria Helena da Rocha Pereira, José Ribeiro Ferreira e Francisco de Oliveira (Coords.): Horácio e a sua perenidade (Coimbra, Classica Digitalia/CECH, 2009).

5. José Luís Lopes Brandão: Máscaras dos Césares. Teatro e moralidade nas Vidas suetonianas (Coimbra, Classica Digitalia/CECH, 2009).

6. José Ribeiro Ferreira, Delfim Leão, Manuel Tröster and Paula Barata Dias (eds): Symposion and Philanthropia in Plutarch (Coimbra, Classica Digitalia/CECH, 2009).

7. Gabriele Cornelli (Org.): Representações da Cidade Antiga. Categorias históricas e discursos filosóficos (Coimbra, Classica Digitalia/CECH/Grupo Archai, 2010).

8. Maria Cristina de Sousa Pimentel e Nuno Simões Rodrigues (Coords.): Sociedade, poder e cultura no tempo de Ovídio (Coimbra, Classica Digitalia/ $\mathrm{CECH} / \mathrm{CEC} / \mathrm{CH}, 2010)$.

9. Françoise Frazier et Delfim F. Leão (eds.): Tychè et pronoia. La marche du monde selon Plutarque (Coimbra, Classica Digitalia/CECH, École Doctorale 395, ArScAn-THEMAM, 2010).

10. Juan Carlos Iglesias-Zoido, El legado de Tucídides en la cultura occidental (Coimbra, Classica Digitalia/CECH, ARENGA, 2011).

11. Gabriele Cornelli, O pitagorismo como categoria historiográfica (Coimbra, Classica Digitalia/CECH, 2011).

12. Frederico Lourenço, The Lyric Metres of Euripidean Drama (Coimbra, Classica Digitalia/CECH, 2011). 
This is the first complete survey to appear in more than a hundred years (and the first ever to be published in English) of Euripides' metrical practice in the songs of all his extant plays and longer lyric fragments. All interpretations and scansions of Euripides' lyrics offered in this book are based on James Diggle's Oxford Classical Text.

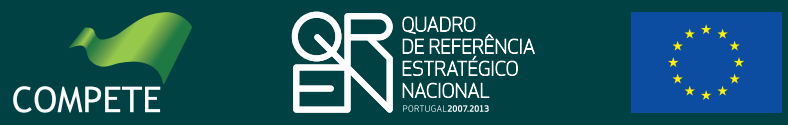

